\title{
Architectural Variability in the Caddo Area of Eastern Texas
}

T. Clay Schultz

Follow this and additional works at: https://scholarworks.sfasu.edu/ita

Part of the American Material Culture Commons, Archaeological Anthropology Commons, Environmental Studies Commons, Other American Studies Commons, Other Arts and Humanities Commons, Other History of Art, Architecture, and Archaeology Commons, and the United States History Commons

Tell us how this article helped you.

This Article is brought to you for free and open access by the Center for Regional Heritage Research at SFA ScholarWorks. It has been accepted for inclusion in Index of Texas Archaeology: Open Access Gray Literature from the Lone Star State by an authorized editor of SFA ScholarWorks. For more information, please contact cdsscholarworks@sfasu.edu. 


\section{Architectural Variability in the Caddo Area of Eastern Texas}

Creative Commons License

(c) (i) (8)

This work is licensed under a Creative Commons Attribution-NonCommercial 4.0 International License 
Architectural Variability in the Caddo Area of Eastern Texas

\author{
T. Clay Schultz
}

Special Publication No. 16

Friends of Northeast Texas Archaeology 


\begin{abstract}
This dissertation focuses on the nature of architectural space in the Caddo area of eastern Texas, in the southwestern portion of the Caddo archaeological area. The early European accounts and the archaeological record indicate there was a wide range in size, shape, form, and use of architectural space in the Caddo area. Buildings have a variety of structural attributes and may be found isolated or associated with plazas or earthen mounds. This dissertation is a detailed examination of this architectural diversity. The sites included in this study range from large multi-mound centers that have seen largescale and long-term research, such as the George C. Davis site, to smaller hamlets and farmsteads. This study includes 265 structures from 31 sites located throughout the Pineywoods, Post Oak Savanna and Blackland Prairie of eastern Texas.

This dissertation provides an examination of the structuring of architectural space by Caddo groups living in eastern Texas. Through a detailed examination of documentary, archaeological, and geophysical data, this research examines the nature of the Caddo built environment; how Caddo cultural space was created, maintained, and altered, and how this relates to broader Caddo society. The purpose of this dissertation is to provide descriptions and comparisons of Caddo architecture from eastern Texas to address three interrelated themes: cultural significance of architectural space to the Caddo, physical form of structures and construction attributes, and variation and change.
\end{abstract}




\section{Acknowledgements}

I would like to express my gratitude to my dissertation committee, Maria Wade, Darrell Creel, James Denbow, F. Kent Reilly, and committee chair Samuel Wilson, for their guidance and patience throughout this process. In addition, many folks provided guidance, data, reports, or suggestions along the way including Tim Perttula, Mark Parsons, Mark Walters, Dale Hudler, Jim Bruseth, David Kelly, Ross Fields, Bo Nelson, and many others. I would especially like to thank Timothy K. Perttula for his feedback and thoughts over the years and his review of the draft. Many thanks to my good friends Chester P. Walker and Paul Shawn Marceaux, who, along with Tim, I have joined at occasional Caddo lunches in Austin to discuss Caddo archaeology and research. My thanks goes out to my other good friends, family, and co-workers with whom I have discussed thoughts, ideas, problems and concerns related to this research, academia, professional archaeology, and life in general over the years. To anyone that I have not mentioned specifically but who provided feedback, thoughts, suggestions, data, criticisms, etc., please know that you have by gratitude and appreciation.

My wife Eleanore Whitworth has been invaluable as a partner and has shown incredible patience while I pursued this goal. I wish to express to her my sincerest and heartfelt gratitude. 


\section{Table of Contents}

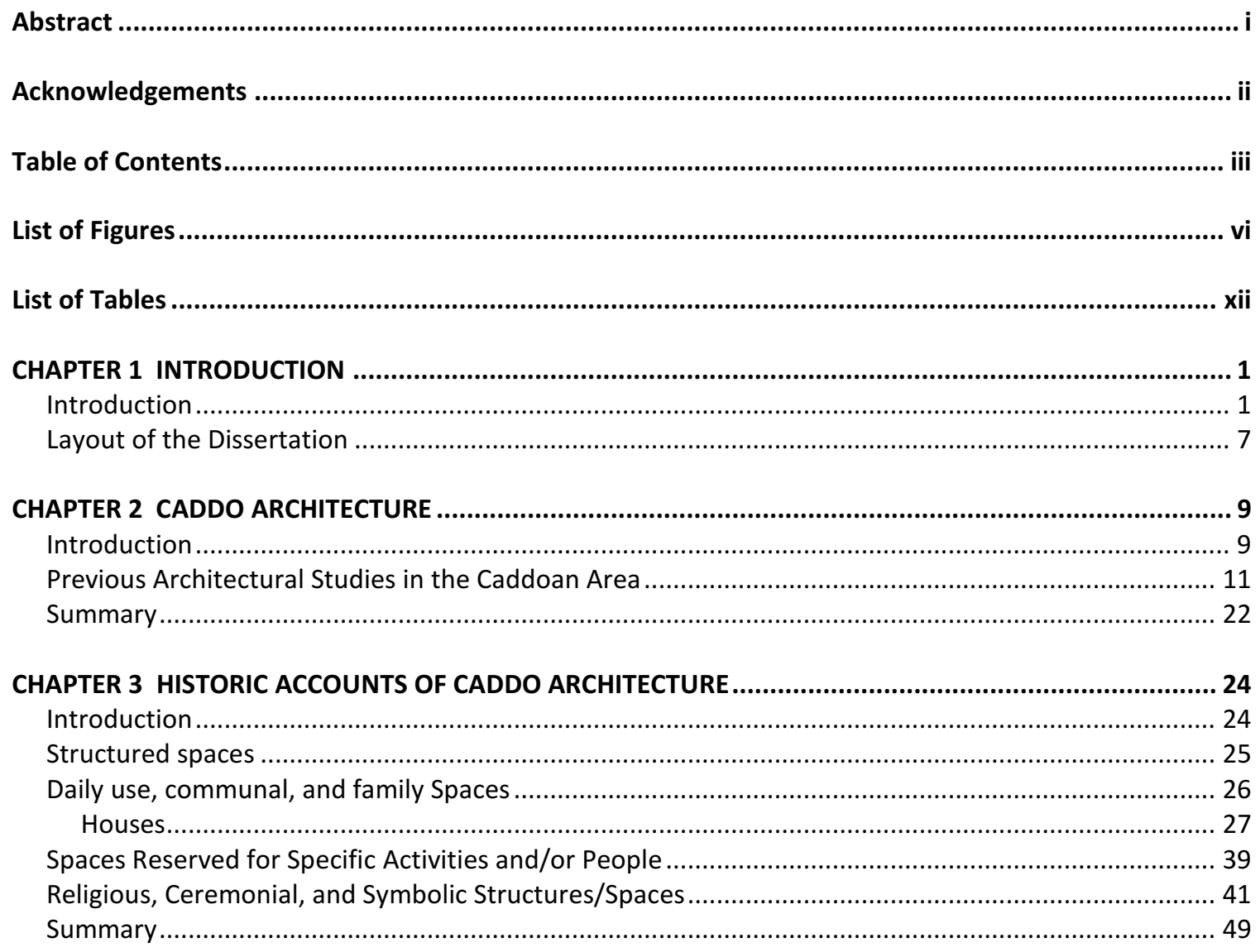

CHAPTER 4 ARCHITECTURE FROM THE GEORGE C. DAVIS SITE ....................................................51

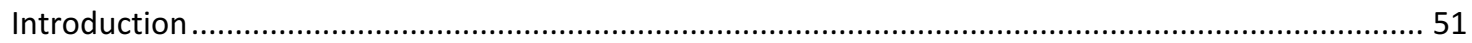

Previously Excavated Structures from The George C. Davis Site .................................................... 54

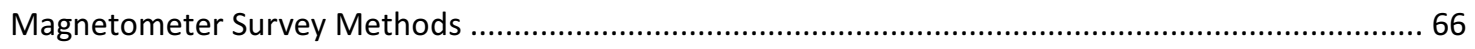

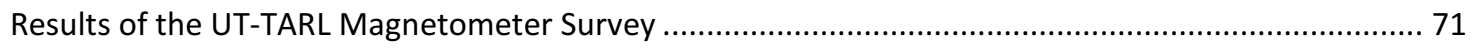

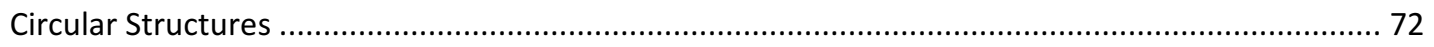

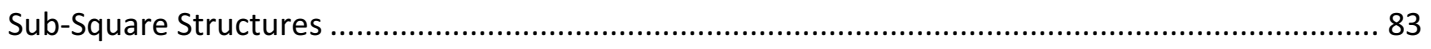

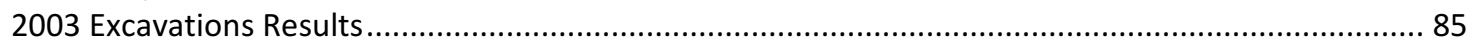

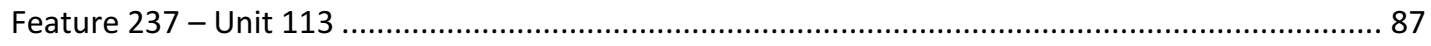

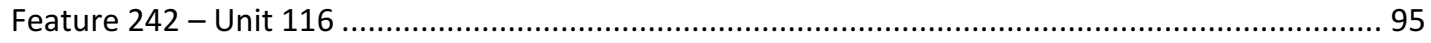

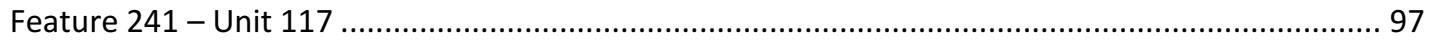

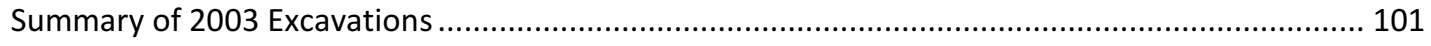

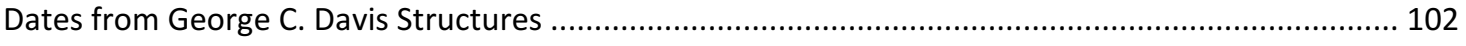

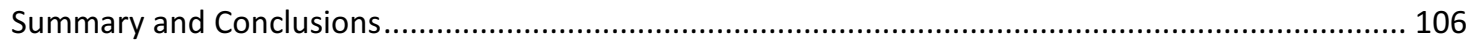

CHAPTER 5 STRUCTURES ASSOCIATED WITH CADDO MOUNDS .................................................. 108 


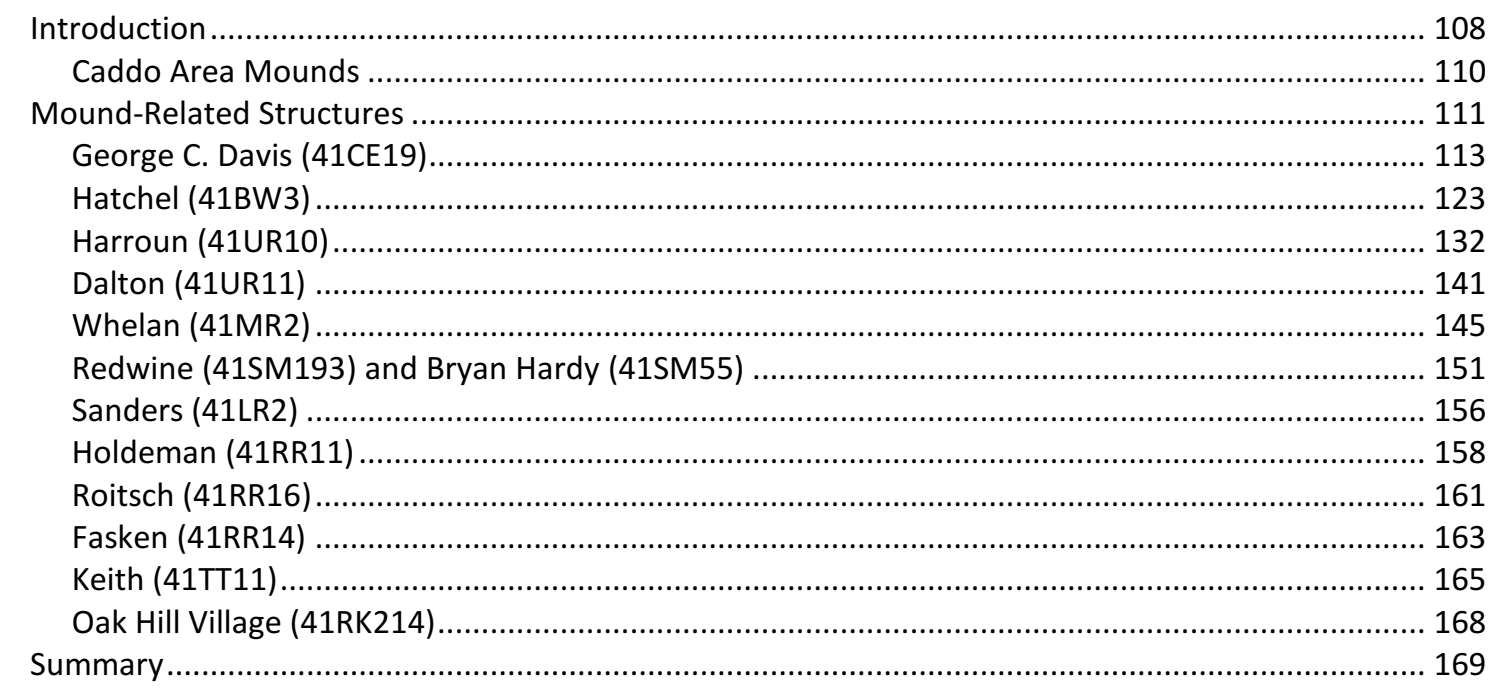

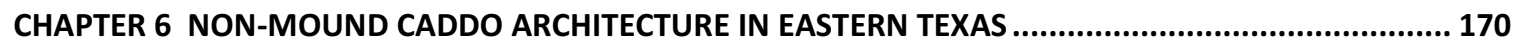

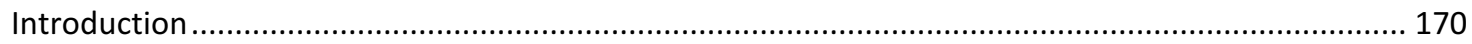

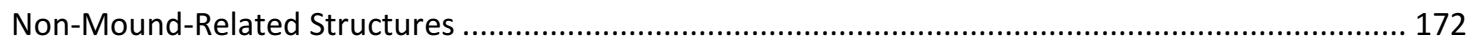

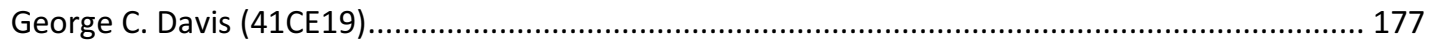

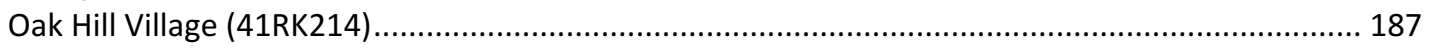

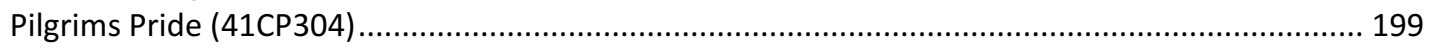

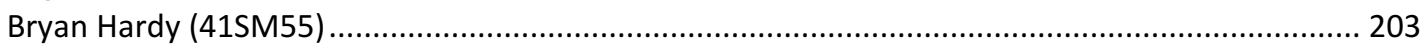

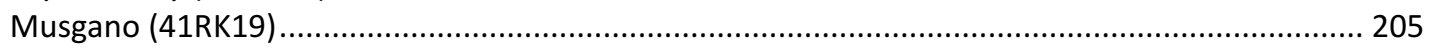

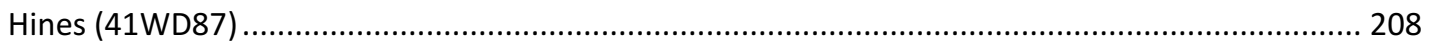

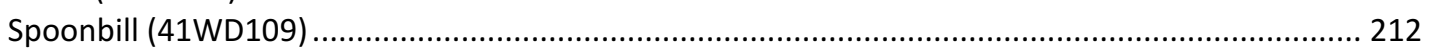

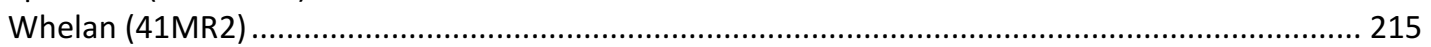

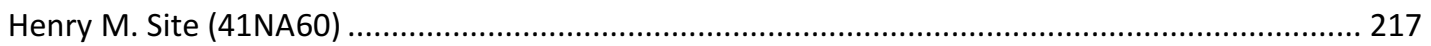

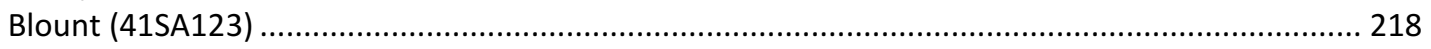

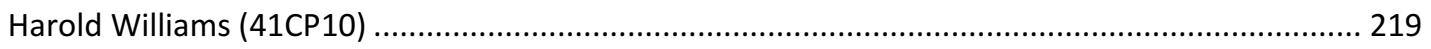

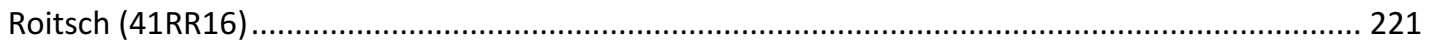

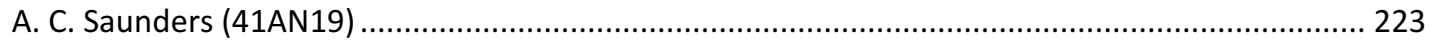

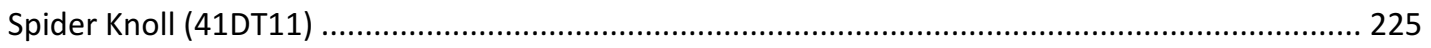

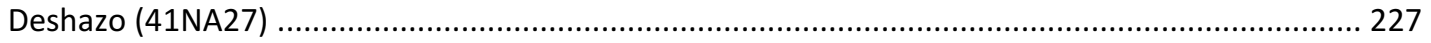

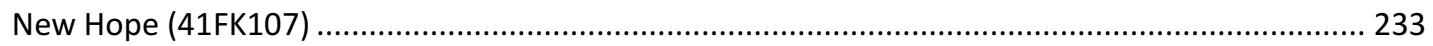

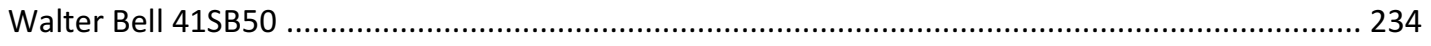

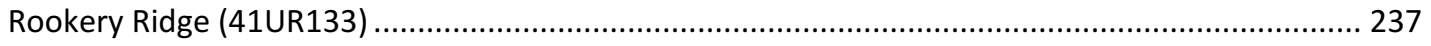

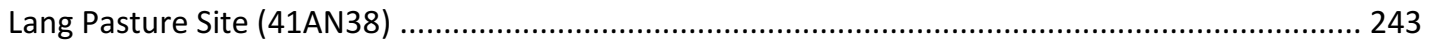

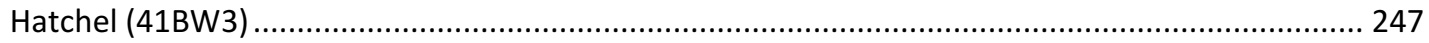

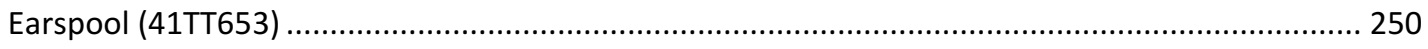

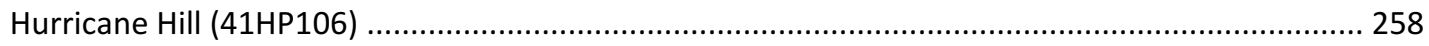

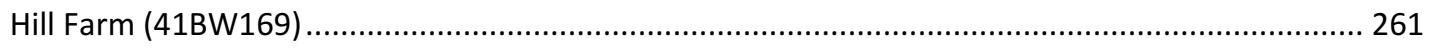

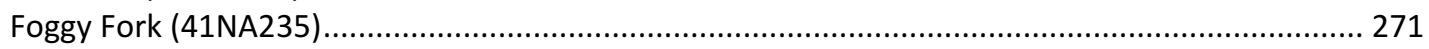

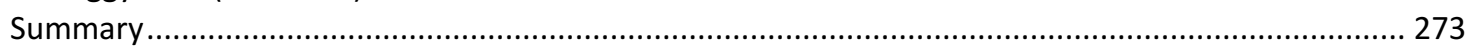

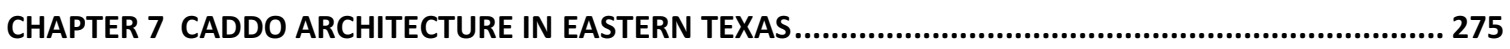

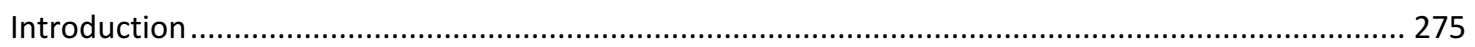

iv 


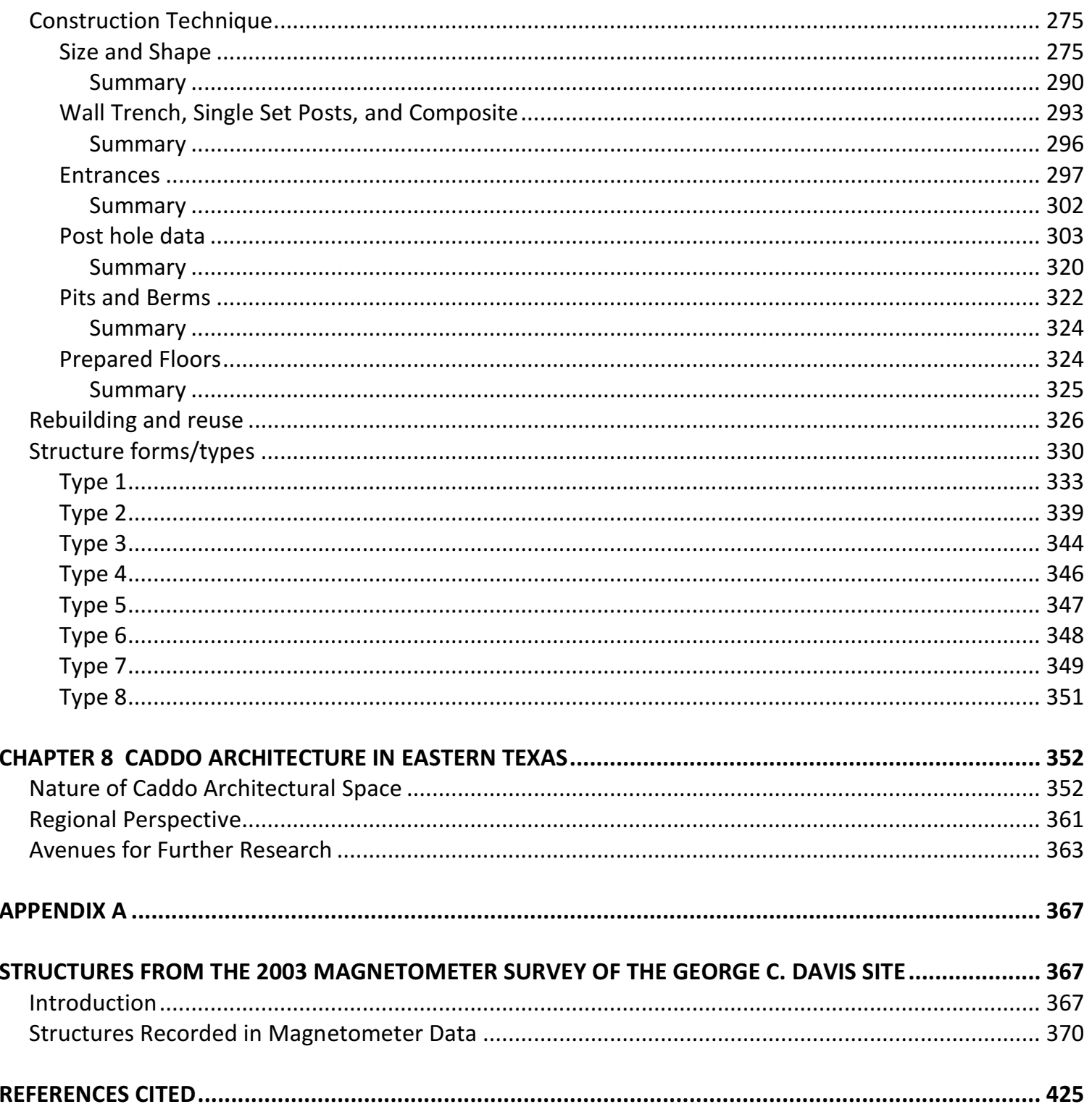




\section{List of Figures}

FIGURE 1. APPROXIMATE EXTENT OF THE CADDOAN ARCHAEOLOGICAL AREA (PERTTULA AND BRUSETH 1998:1 AND FIGURE 1-1). REPRODUCED COURTESY OF THE TEXAS ARCHAEOLOGICAL RESEARCH LABORATORY (TARL).

FIGURE 2. GRASS COVERED BUILDING FROM HARRINGTON (1920:250 AND FIGURE 40)........................ 12

FIGURE 3: WALLED BUILDING FROM HARRINGTON (1920:250, FIGURE 41). ......................................... 13

FIGURE 4. PORTION OF THE SOULE PHOTOGRAPH ENTITLED "CHIEF LONG HAT'S CAMP."....................... 28

FIGURE 5. HOUSE AND ARBOR FROM SOULE PHOTOGRAPH ENTITLED “CHIEF LONG HAT'S CAMP." ........ 28

FIGURE 6. MAP FROM THE 1691-1692 EXPEDITION LED BY DOMINGO TERÁN DE LOS RIOS...................... 30

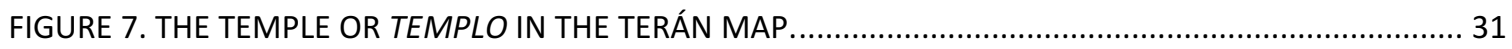

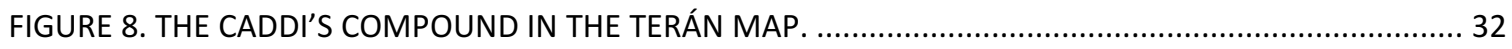

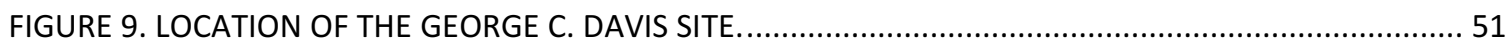

FIGURE 10. MAP OF PREVIOUS EXCAVATIONS AT THE GEORGE C. DAVIS SITE (STORY 1997). REPRODUCED COURTESY OF THE TEXAS ARCHEOLOGICAL SOCIETY.............................................................. 53

FIGURE 11. AREA OF OVERLAPPING STRUCTURES ADJACENT TO MOUND A (STORY 1998:29, FIGURE 2-14).

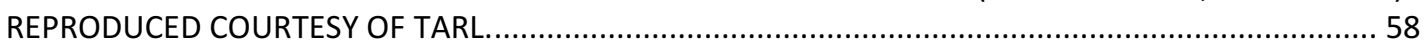

FIGURE 12. PLAN OF FEATURE 35, “THE MAZE” (STORY 1998:35, FIGURE 2-20). REPRODUCED COURTESY

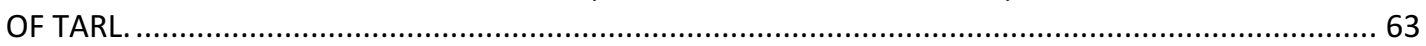

FIGURE 13. EXAMPLE OF GEORGE C. DAVIS STRUCTURE WITH EXTENDED ENTRANCE (FEATURE 9) (STORY

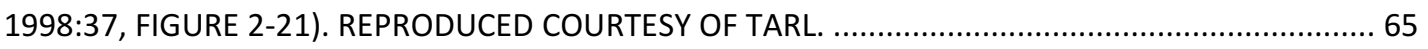

FIGURE 14. FEATURE 45, A STRUCTURE WITH AN EXTERIOR PARTITION (STORY 1998:33, FIGURE 2-18)... 66

FIGURE 15. OVERLAY OF THE GEORGE C. DAVIS SITE MAGNETOMETER SURVEY AREA ON THE AERIAL PHOTOGRAPH OF THE SITE AREA.

FIGURE 16: EXAMPLE OF CIRCULAR STRUCTURE FROM THE GEORGE C. DAVIS SITE MAGNETOMETER DATA (FEATURE 179).

FIGURE 17. EXAMPLE OF A PROBABLE BURNED CIRCULAR STRUCTURE FROM THE GEORGE C. DAVIS SITE

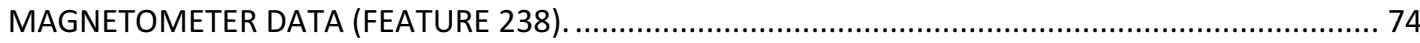

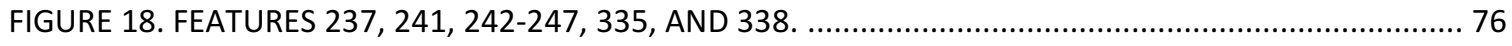

FIGURE 19. FEATURE 125 (STORY 1998:38, FIGURE 2-22). REPRODUCED COURTESY OF TARL.................. 77

FIGURE 20. FEATURES 31, 37, AND 38 (STORY 1998:32, FIGURE 2-17). REPRODUCED COURTESY OF TARL.

FIGURE 21. SMALL CIRCULAR STRUCTURES FROM THE GEORGE C. DAVIS SITE MAGNETOMETER DATA,

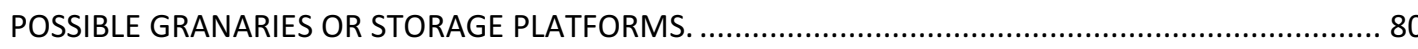

FIGURE 22: EXAMPLE OF CIRCULAR STRUCTURE WITH PROBABLE CENTRAL HEARTH............................. 82

FIGURE 23. CIRCULAR STRUCTURES WITH POSSIBLE EXTENDED ENTRANCES FROM THE GEORGE C. DAVIS

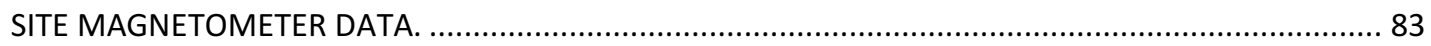

FIGURE 24. EXAMPLES OF SUB-SQUARE STRUCTURES, FEATURES 252 AND 281 ................................... 84

FIGURE 25. SHADED RELIEF MAP OF MAGNETOMETER DATA WITH TARGETED FEATURES........................ 86

FIGURE 26. FEATURES 237, 241, AND 242. STRUCTURES PARTIALLY EXCAVATED IN 2003...................... 87

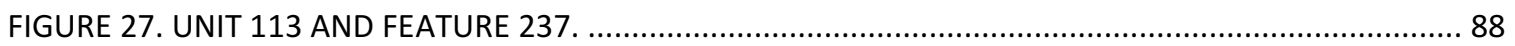

FIGURE 28. PLAN VIEW OF UNIT 113 AND FEATURES 237.1, 237.4, AND 237.6................................... 90

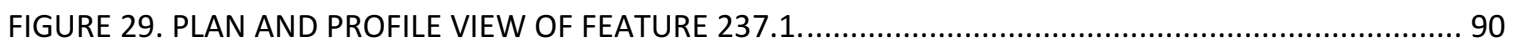

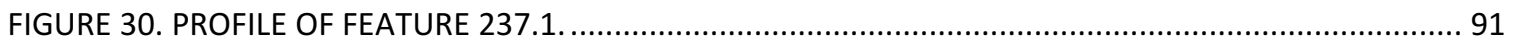

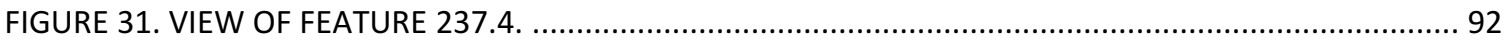


FIGURE 32. FEATURE 237.4.

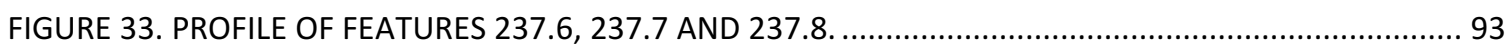

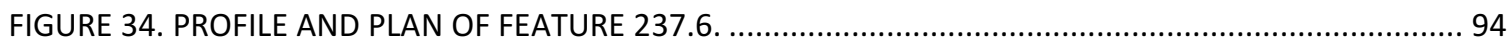

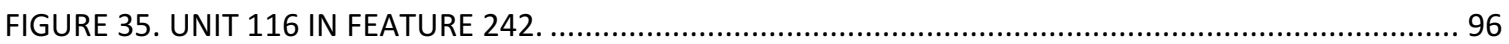

FIGURE 36. FEATURES 242.2 (INNER HEARTH) AND 242.3 (OUTER HEARTH)........................................97

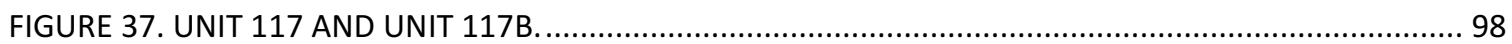

FIGURE 38. FEATURES 241.2 (THE HEARTH IS IN THE NORTHWEST CORNER)..................................... 98

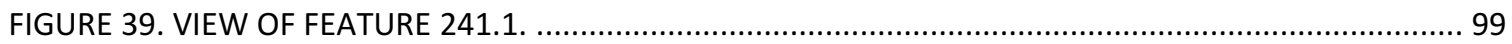

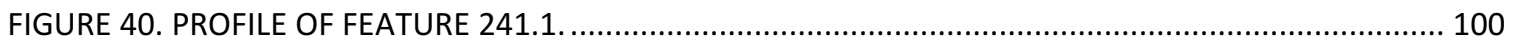

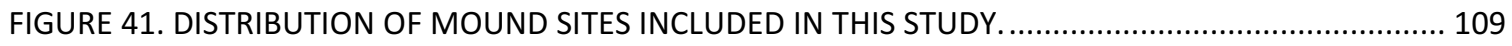

FIGURE 42. STRUCTURES 321 AND 322 FROM THE GEORGE C. DAVIS SITE....................................... 121

FIGURE 43. FEATURE 25 FROM THE HATCHEL SITE. REPRODUCED COURTESY OF TARL. ...................... 124

FIGURE 44. HARROUN MOUNDS B, C AND D PROFILES (JELKS AND TUNNELL 1959: FIGURES 3 AND 7). REPRODUCED COURTESY OF THE UNIVERSITY OF TEXAS DEPARTMENT OF ANTHROPOLOGY........ 133

FIGURE 45. HARROUN STRUCTURES 1 AND 2 (JELKS AND TUNNELL 1959:29: FIGURE 8). REPRODUCED COURTESY OF TARL.

FIGURE 46. HARROUN STRUCTURE 3 (JELKS AND TUNNELL 1959:FIGURE 3). REPRODUCED COURTESY OF TARL.

FIGURE 47. HARROUN STRUCTURE 4 (JELKS AND TUNNELL 1959:36:FIGURE 10). REPRODUCED COURTESY

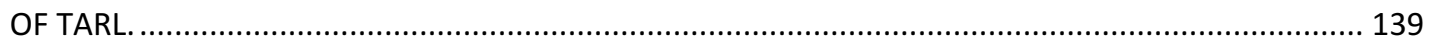

FIGURE 48. DALTON STRUCTURES A AND B. REPRODUCED COURTESY OF TARL............................... 142

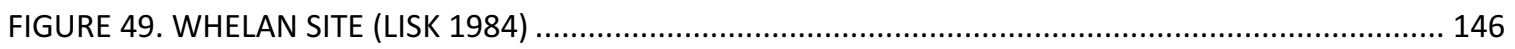

FIGURE 50. PLAN OF STRUCTURE UNDER THE REDWINE SITE MOUND (WALTERS AND HASKINS 1998:24 AND FIGURE 9). REPRODUCED COURTESY OF THE FRIENDS OF NORTHEAST TEXAS ARCHAEOLOGY.

FIGURE 51. PLAN MAP OF THE HOUSE 1 FROM THE BRYAN HARDY SITE (ADAPTED FROM WALTERS AND HASKINS 2000:5 AND FIGURE 3).

FIGURE 52. PLAN MAP OF THE HOLDEMAN MOUND STRUCTURE (ADAPTED FROM PERINO 1995). REPRODUCED COURTESY OF THE FRIENDS OF NORTHEAST TEXAS ARCHAEOLOGY.

FIGURE 53. STRUCTURE FROM THE EAST MOUND AT THE ROITSCH SITE (PERTTULA ET AL. 2001:171, FIGURE 3). REPRODUCED COURTESY OF THE TEXAS ARCHEOLOGICAL SOCIETY..... 159 RE 54. STRUCTURE FROM THE FASKEN MOUND (PERTTULA ET AL. 2001: 228, FIGURE 45). REPRODUCED COURTESY OF THE TEXAS ARCHEOLOGICAL SOCIETY......................................... 165

FIGURE 55. STRUCTURE 2 FROM THE KEITH MOUND. ............................................................... 167

FIGURE 56: DISTRIBUTION OF SITES WITH NON-MOUND STRUCTURES INCLUDED IN THIS STUDY......... 171

FIGURE 57. PLAN OF THE OAK HILL VILLAGE SITE (ROGERS AND PERTTULA 2004:FIGURE 6). ................ 189

FIGURE 58. POSSIBLE GRANARIES FROM THE OAK HILL VILLAGE SITE. (ROGERS AND PERTTULA 2004:FIGURE 16)

FIGURE 59. STRUCTURES 2 (LEFT) AND 18 FROM THE OAK HILL VILLAGE SITE (ADAPTED FROM ROGERS AND PERTTULA 2004:FIGURES 19 AND 20) ................................................................. 197

FIGURE 60. STRUCTURE 1 FROM THE PILGRIM'S PRIDE SITE (PERTTULA 2005:70, FIGURE 4-13)............200

FIGURE 61. STRUCTURE 2 FROM THE PILGRIM'S PRIDE SITE (PERTTULA 2005:80, FIGURE 4-25). ............ 202

FIGURE 62. PLAN MAP OF STRUCTURES 2 \& 3 FROM THE BRYAN HARDY SITE (WALTERS AND HASKINS 2000:7 AND FIGURE 5). REPRODUCED COURTESY OF THE FRIENDS OF NORTHEAST TEXAS ARCHAEOLOGY.

FIGURE 63. THE MUSGANO SITE FEATURES AND STRUCTURE REPRODUCED COURTESY OF TARL. ......... 205

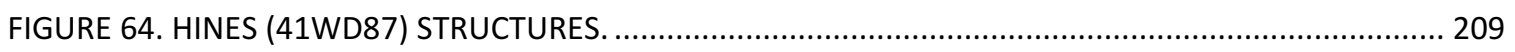


FIGURE 65. CADDO STRUCTURE FROM THE SPOONBILL SITE (BRUSETH AND PERTTULA 1981:FIGURE 3-

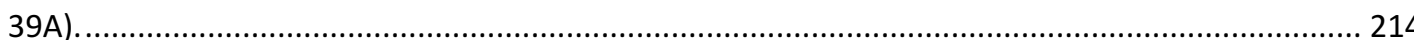

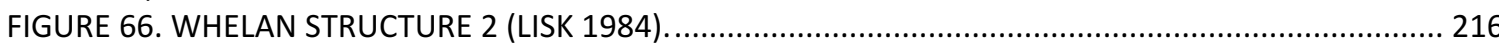

FIGURE 67. FEATURE 7 FROM THE HAROLD WILLIAMS SITE (41CP10) (TURNER AND SMITH 2002:38 AND FIGURE 24). REPRODUCED COURTESY OF THE TEXAS ARCHEOLOGICAL SOCIETY............................. 221

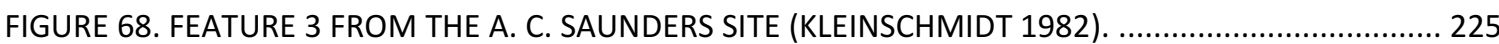

FIGURE 69. STRUCTURES 1-3 FROM THE DESHAZO SITE (GOOD 1982:54, FIGURE 17) ........................... 228 FIGURE 70. NEW HOPE SITE (41FK107) (NELSON AND PERTTULA 2006:30). REPRODUCED COURTESY OF

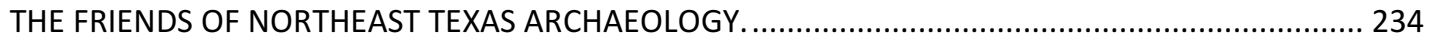

FIGURE 71. SITE MAP OF THE WALTER BELL SITE (JELKS 1965:312 AND FIGURE 20).............................. 235

FIGURE 72. STRUCTURE 2 AT THE WALTER BELL SITE (JELKS 1965:314 AND FIGURE 22). ........................ 236

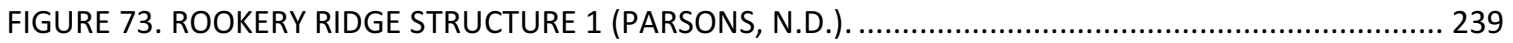

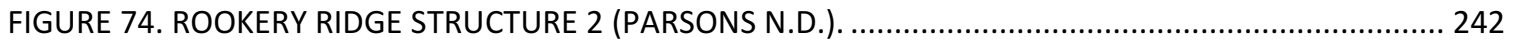

FIGURE 75. PLAN OF THE STRUCTURES FROM THE EARSPOOL SITE (FROM GALAN 1998 ....................... 251

FIGURE 76. STRUCTURES A (LEFT) AND B (RIGHT) FROM THE HURRICANE HILL SITE (PERTTULA 1999, FIGURES 6-21 AND 6-22). REPRODUCED COURTESY OF THE FRIENDS OF NORTHEAST TEXAS

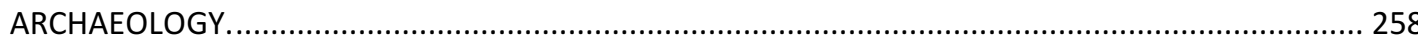

FIGURE 77. HURRICANE HILL STRUCTURE D (PERTTULA 1999). REPRODUCED COURTESY OF THE FRIENDS

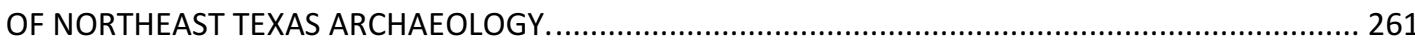

FIGURE 78. PLAN OF AREA A COLLECTION BLOCKS (WALKER 2009:FIGURE 5-4) .................................... 265

FIGURE 79. INTERPRETATIONS OF AREA A FEATURES IN THE REMOTE SENSING DATA (WALKER

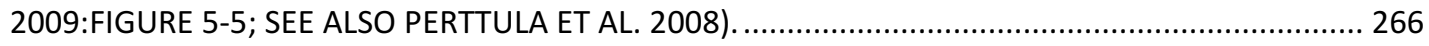

FIGURE 80. PLAN OF AREA B COLLECTION BLOCKS (WALKER 2009:FIGURE 5-6).................................... 267

FIGURE 81. INTERPRETATIONS OF AREA B FEATURES IN THE REMOTE SENSING DATA (WALKER

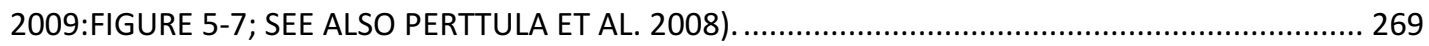

FIGURE 82. GEOPHYSICAL SIGNATURES OF VARIOUS TYPES OF HOUSES AT THE HILL FARM SITE (WALKER 2009:FIGURE 5-3)

FIGURE 83. DETAIL OF THE 1691 TERÁN MAP SHOWING THE AREA INTERPRETED BY PERTTULA ET AL. (2008:FIGURE 14) AS THE APPROXIMATE LOCATION OF THE HILL FARM SITE HOUSEHOLD COMPOUNDS

FIGURE 84. STRUCTURE 1 FROM THE FOGGY FORK SITE (41NA235) (PERTTULA 2008:133). .................... 272

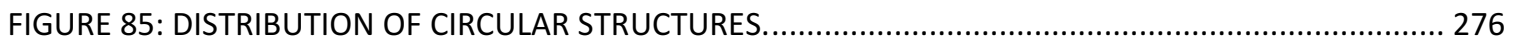

FIGURE 86. FEATURES 238 AND 7 FROM THE GEORGE C. DAVIS SITE............................................... 277

FIGURE 87. HISTOGRAM SHOWING APPROXIMATE INTERIOR AREA OF THE NON-MOUND CIRCULAR

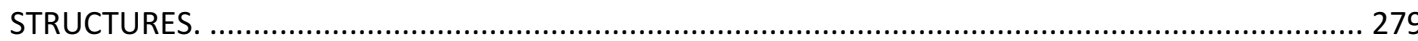

FIGURE 88. HISTOGRAM SHOWING APPROXIMATE INTERIOR AREA OF THE MOUND-RELATED CIRCULAR

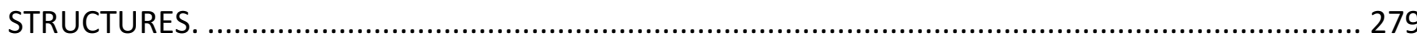

FIGURE 89. THE INTERIOR AREA OF MAGNETOMETER STRUCTURES FROM THE GEORGE C. DAVIS AND HILL

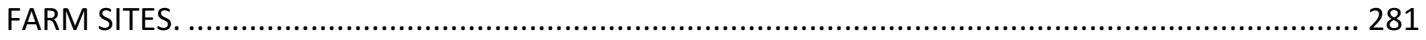

FIGURE 90. THE INTERIOR AREA OF CIRCULAR NON-MOUND MAGNETOMETER STRUCTURES COMPARED

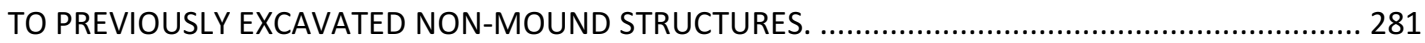

FIGURE 91. COMPARISON OF MOUND AND NON-MOUND STRUCTURE AREAS..................................... 282

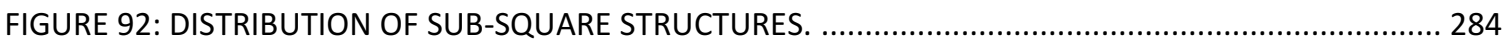

FIGURE 93. POSSIBLE SUB SQUARE TO RECTANGULAR NON-MOUND STRUCTURES IN THE GEORGE C.

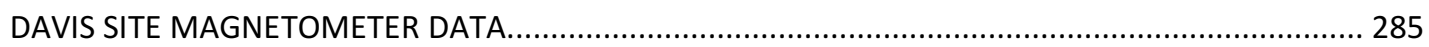
FIGURE 94. COMPARISON OF INTERNAL AREA IN MOUND AND NON-MOUND SUB-SQUARE STRUCTURES.

286

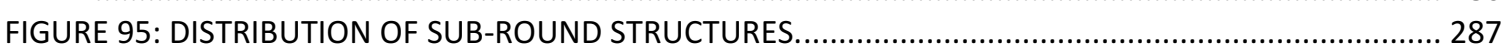


FIGURE 96: DISTRIBUTION OF RECTANGULAR STRUCTURES.

FIGURE 97: HISTOGRAM COMPARING INTERIOR AREAS OF MOUND AND NON-MOUND RELATED STRUCTURES BY SHAPE.

FIGURE 98. COMPOSITE WALL TRENCH AND SINGLE-SET POST MOUND STRUCTURES FROM THE GEORGE

C. DAVIS SITE, FEATURE 43, 44 AND 45 (SPOCK 1977).

FIGURE 99: ENTRANCE TRENCHES FROM THE HOLDEMAN (PERINO 1995) AND BRYAN HARDY (WALTERS AND HASKINS 2000) SITES.

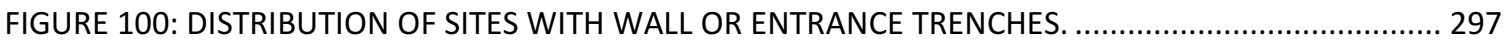

FIGURE 101: DISTRIBUTION OF SITES WITH EXTENDED ENTRANCES.

FIGURE 102. COMPARISON OF SPACING BETWEEN EXTERIOR WALL POST HOLES BY STRUCTURE SHAPE FOR NON-MOUND STRUCTURES.

FIGURE 103. SCATTERPLOT OF WALL POST HOLE SPACING AND STRUCTURE AREA FOR NON-MOUND STRUCTURES.

FIGURE 104. COMPARISON OF SPACING BETWEEN EXTERIOR WALL POST HOLES BY STRUCTURE SHAPE FOR MOUND-RELATED STRUCTURES.

FIGURE 105. COMPARISON OF MEAN DISTANCE FROM WALL POST HOLES TO THE CENTER OF THE STRUCTURE BY STRUCTURE SHAPE FOR NON-MOUND STRUCTURES 308

FIGURE 106. COMPARISON OF MEAN DISTANCE FROM WALL POST HOLES TO CENTER OF STRUCTURE BY STRUCTURE SHAPE FOR MOUND-RELATED STRUCTURES.

FIGURE 107. RATIO OF AVERAGE DISTANCE BETWEEN WALL POST HOLES AND FROM WALL POST HOLES TO CENTER OF STRUCTURE BY STRUCTURE SHAPE FOR NON-MOUND STRUCTURES.

FIGURE 108. RATIO OF AVERAGE DISTANCE BETWEEN WALL POST HOLES AND FROM WALL POST HOLES TO CENTER OF STRUCTURE BY STRUCTURE SHAPE FOR MOUND-RELATED STRUCTURES.

FIGURE 109. SCATTERPLOT OF WALL POST HOLE SPACING AND DISTANCE FROM WALL TO CENTER OF STRUCTURE FOR NON-MOUND STRUCTURES.

FIGURE 110. SCATTERPLOT OF WALL POST HOLE SPACING AND DISTANCE FROM WALL TO CENTER OF STRUCTURE FOR MOUND-RELATED STRUCTURES.

FIGURE 111. THE RATIO OF AVERAGE DISTANCE BETWEEN EXTERIOR POST HOLES AND FROM THE EXTERIOR POST HOLES TO THE CENTER OF THE STRUCTURE FOR STRUCTURES IN THIS STUDY. .... 313

FIGURE 112. THE RATIO OF AVERAGE DISTANCE BETWEEN EXTERIOR POST HOLES AND FROM THE EXTERIOR POST HOLES TO THE CENTER OF THE STRUCTURE - COMPARING MOUND AND NONMOUND STRUCTURES IN THIS STUDY......

FIGURE 113. MEAN WALL POST HOLE DIAMETER BY STRUCTURE SHAPE FOR NON-MOUND STRUCTURES.

FIGURE 114. MEAN WALL POST HOLE DEPTH BY STRUCTURE SHAPE FOR NON-MOUND STRUCTURES... 316

FIGURE 115. SCATTERPLOT OF WALL POST HOLE SPACING AND MEAN WALL POST HOLE DIAMETER FOR NON-MOUND STRUCTURES.

FIGURE 116. SCATTERPLOT OF WALL POST HOLE SPACING AND MEAN WALL POST HOLE DEPTH FOR NONMOUND STRUCTURES.

FIGURE 117. MEAN WALL POST HOLE DIAMETER BY STRUCTURE SHAPE FOR MOUND-RELATED STRUCTURES. 318

FIGURE 118. MEAN WALL POST HOLE DEPTH BY STRUCTURE SHAPE FOR MOUND-RELATED STRUCTURES. 318

FIGURE 119. SCATTERPLOT OF WALL POST HOLE SPACING AND MEAN WALL POST HOLE DIAMETER FOR MOUND STRUCTURES.

FIGURE 120. SCATTERPLOT OF WALL POST HOLE SPACING AND MEAN WALL POST HOLE DEPTH FOR

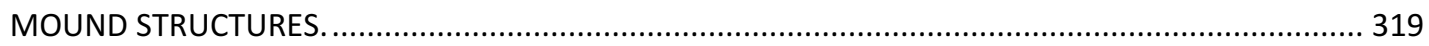

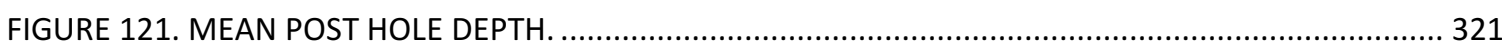


FIGURE 122. WALKER'S (2009:FIGURE 4.8) STRUCTURE TYPES FROM THE DAVIS SITE MAGNETOMETER DATA. 1, WALKER'S TYPE 1 STRUCTURES, 2, TYPE 2 STRUCTURES, 3, TYPE 3 STRUCTURES, AND 4, FIRE HEARTHS.

FIGURE 123. WALKER'S STRUCTURE TYPES FROM THE HILL FARM SITE MAGNETOMETER DATA (WALKER 2009:FIGURE 5-3)

FIGURE 124: FEATURES 237, 241, 242-247, 335, AND 338 FROM THE GEORGE C. DAVIS SITE. ............... 335

FIGURE 125: COMPARISON OF TYPE 1 STRUCTURES FROM THE GEORGE C. DAVIS SITE (WALKER 2009:FIGURE 4.10).

FIGURE 126: TYPE 1 STRUCTURE FROM THE OAK HILL VILLAGE SITE.

FIGURE 127. TYPE 1 MOUND STRUCTURES: A, GEORGE G. DAVIS, FEATURE 42; B, GEORGE C. DAVIS, FEATURES 31, 37-38; C, HARROUN, MOUND B, HOUSE NO. 3; D, BRYAN HARDY......................... 338

FIGURE 128. DISTRIBUTION OF TYPE 2 STRUCTURES BY INTERIOR AREA. ............................................ 340

FIGURE 129. DISTRIBUTION OF TYPE 2 MOUND AND NON-MOUND STRUCTURES BY INTERIOR AREA.... 343

FIGURE 130. DISTRIBUTION OF TYPE 2 MOUND AND NON-MOUND STRUCTURES BY INTERIOR AREA, WITHOUT THOSE STRUCTURES RECORDED THROUGH MAGNETOMETER SURVEYS AT GEORGE C. DAVIS AND HILL FARM.

FIGURE 131. TYPE 2 MOUND STRUCTURES ASSOCIATED WITH PARTITIONS.

FIGURE 132: STRUCTURES RECORDED AS PART OF THE TARL/UT MAGNETOMETER SURVEY OF THE GEORGE C. DAVIS SITE.

FIGURE 133: FEATURE 179

FIGURE 134: FEATURE 237

FIGURE 135: FEATURE 241

FIGURE 136: FEATURE 242

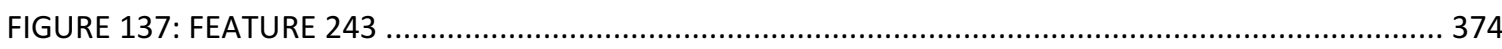

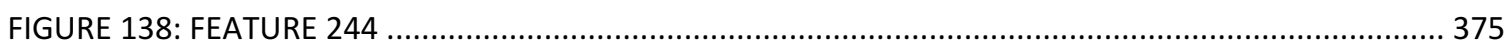

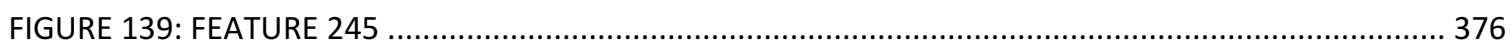

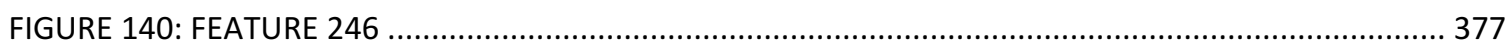

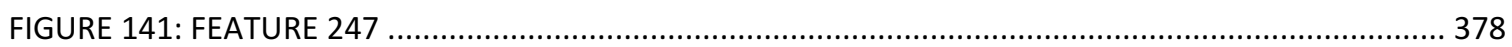

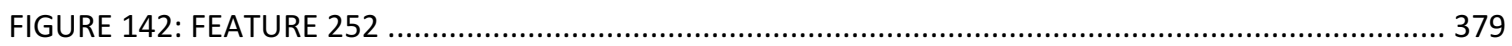

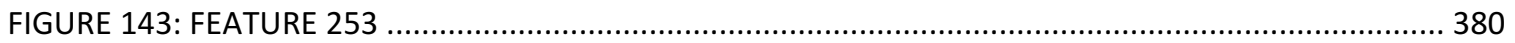

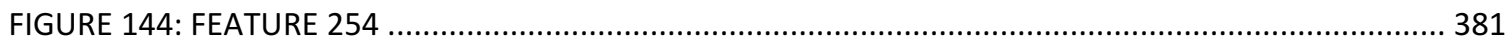

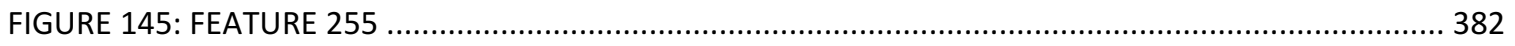

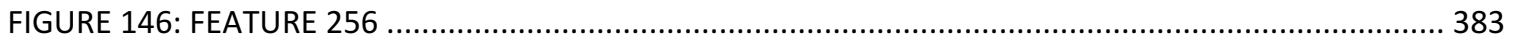

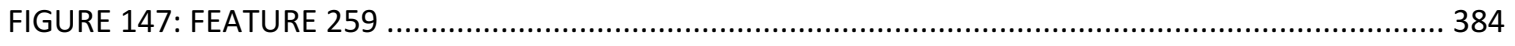

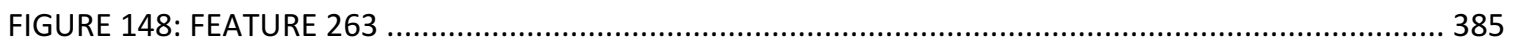

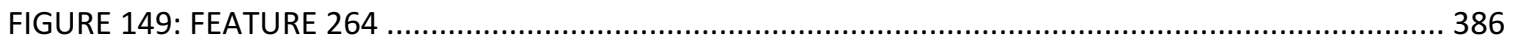

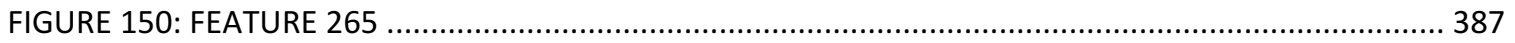

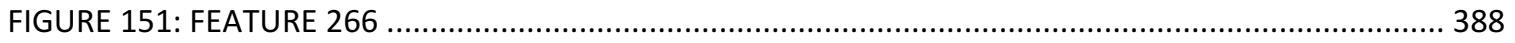

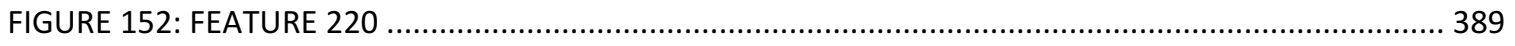

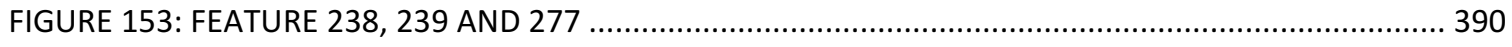

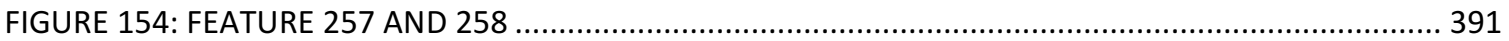

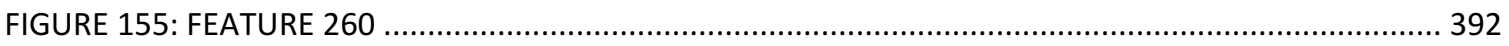

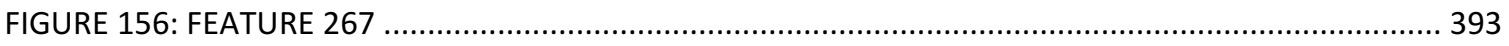

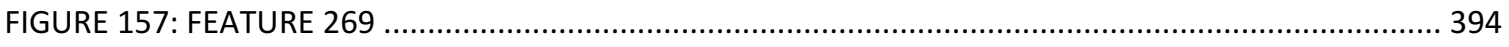

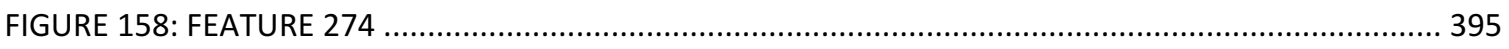

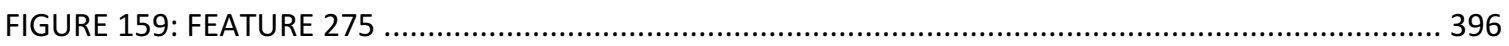

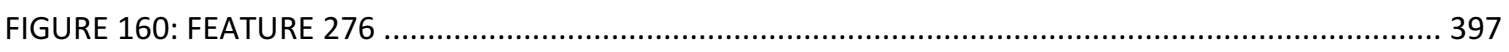

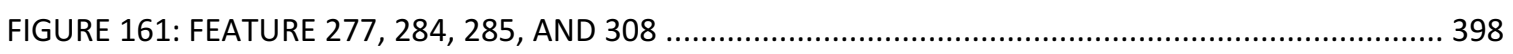




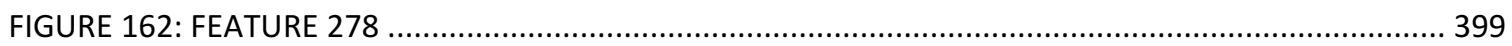

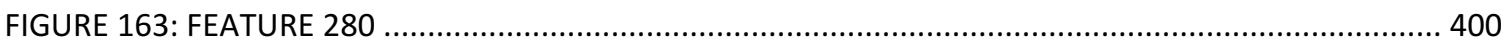

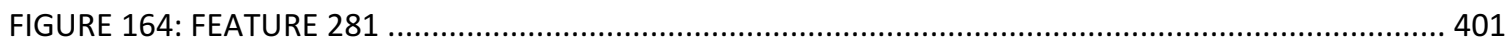

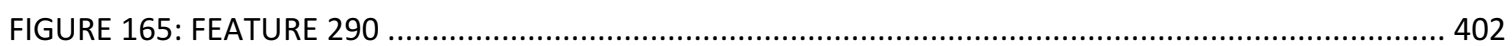

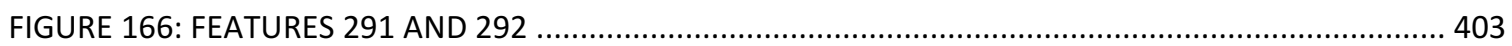

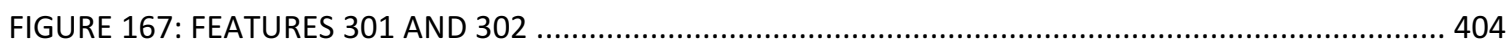

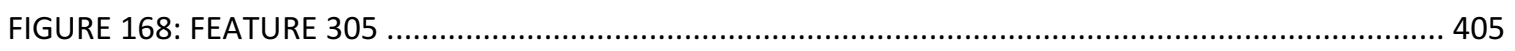

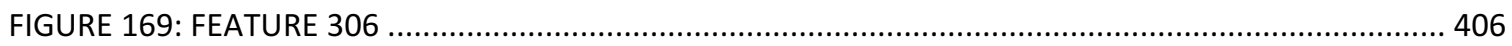

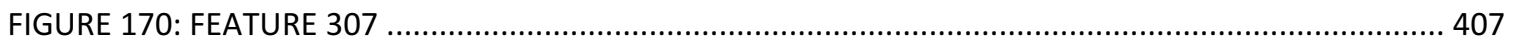

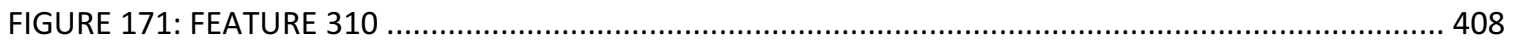

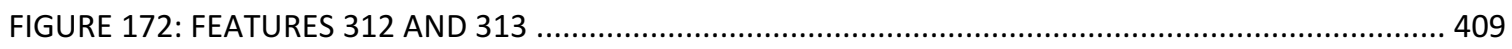

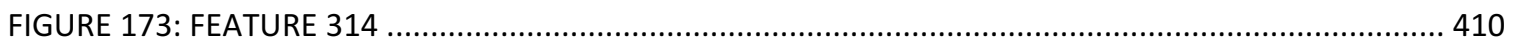

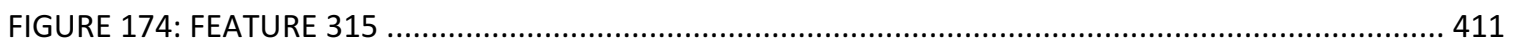

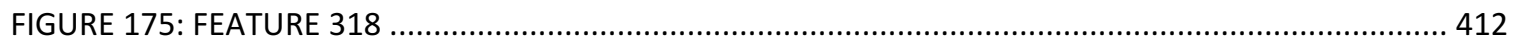

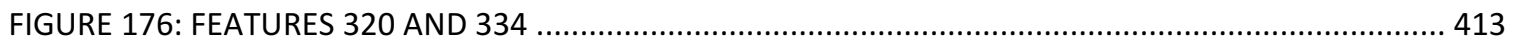

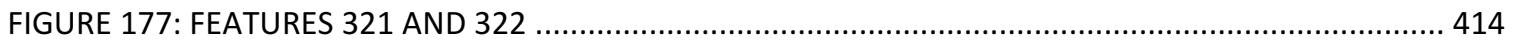

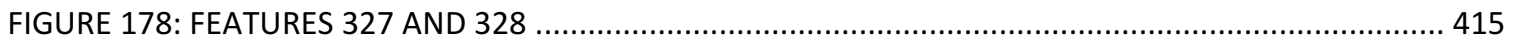

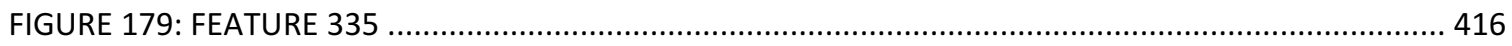

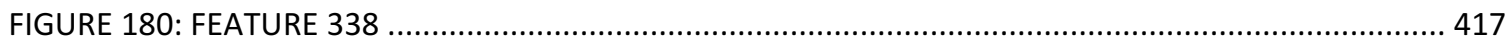

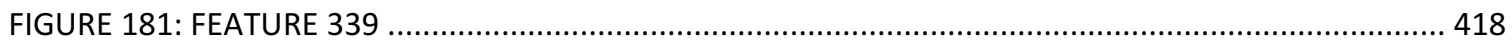

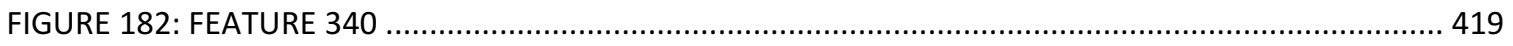

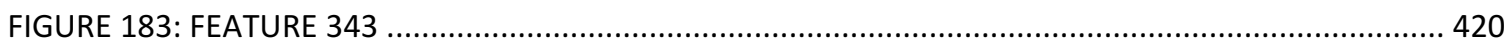

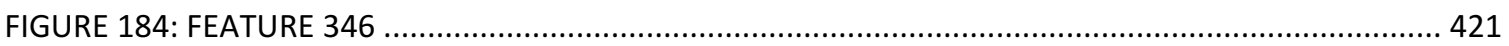

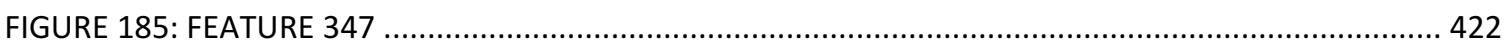

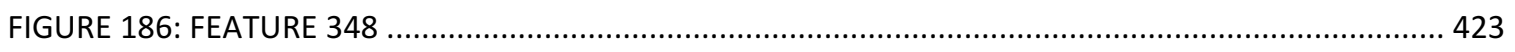

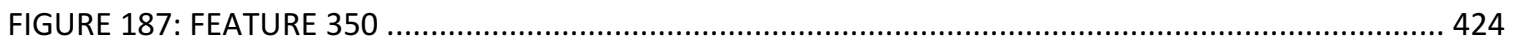




\section{List of Tables}

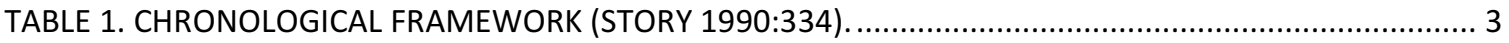

TABLE 2. ARCHITECTURAL SEQUENCE PROPOSED BY WILMSEN (1961)................................................. 14

TABLE 3. LOCATIONS OF PREVIOUSLY EXCAVATED STRUCTURES FROM THE GEORGE C. DAVIS SITE

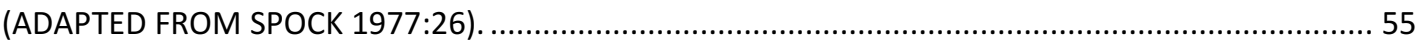

TABLE 4. STRUCTURES CLASSIFIED AS DOMICILES BY SPOCK (ADAPTED FROM SPOCK 1977:30)............... 59

TABLE 5. GEORGE C. DAVIS STRUCTURES CLASSIFIED AS SPECIAL PURPOSE STRUCTURES (ADAPTED FROM SPOCK 1977:30).

TABLE 6. POSSIBLE NON-MOUND STRUCTURES IDENTIFIED IN THE 2008 THC MAGNETOMETER SURVEY IN

THE VILLAGE AREA ADJACENT TO MOUND A (OSBURN ET AL. 2008).

TABLE 7. SUMMARY OF THE STRUCTURES IDENTIFIED IN THE GEORGE C. DAVIS MAGNETOMETER DATA.72

TABLE 8. STRUCTURES WITH PATTERNS SUGGESTING FOUR INTERIOR POSTS AND A CENTRAL HEARTH. . 75

TABLE 9. APPROXIMATE DIMENSIONS AND AREA OF THE PATTERNS OF RETURNS IDENTIFIED AS INTERIOR SUPPORT POSTS AND CENTRAL HEARTHS.

TABLE 10. REMAINING CIRCULAR STRUCTURES IN THE GEORGE C. DAVIS SITE MAGNETOMETER DATA... 81

TABLE 11. SUB-SQUARE TO RECTANGULAR STRUCTURES.

85

TABLE 12. LIST OF SUB-FEATURES ASSOCIATED WITH FEATURE 237........ 89

TABLE 13. RADIOCARBON DATES FROM PREVIOUSLY EXCAVATED STRUCTURES AT THE GEORGE C. DAVIS SITE (PERTTULA 1997; STORY 1997).

TABLE 14. 2003 DATING RESULTS FROM THE GEORGE C. DAVIS SITE.................................................. 106

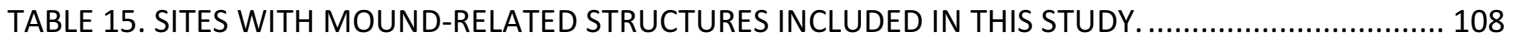

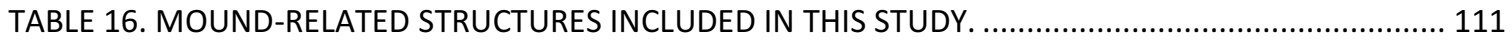

TABLE 17. MOUND-RELATED STRUCTURES FROM THE GEORGE C. DAVIS SITE..................................... 115

TABLE 18. WALL POST HOLE DATA FOR THE MOUND-RELATED STRUCTURES FROM THE GEORGE C. DAVIS SITE. 116

TABLE 19. RATIOS OF AVERAGE DISTANCE BETWEEN WALL POST HOLES AND AVERAGE DISTANCE TO STRUCTURE CENTERS FOR THE PREVIOUSLY EXCAVATED MOUND-RELATED STRUCTURES FROM THE GEORGE C. DAVIS SITE. 118

TABLE 20. MOUND-RELATED STRUCTURES INCLUDED IN THIS STUDY FROM THE HATCHEL SITE.............. 126

TABLE 21. DIAMETER AND DEPTH OF WALL POST HOLES FROM HATCHEL MOUND STRUCTURES........... 127

TABLE 22. HATCHEL MOUND STRUCTURE MEASUREMENTS BETWEEN WALL POST HOLES AND FROM WALL TO CENTER

TABLE 23. TYPES OF ENTRANCES RELATED TO THE HATCHEL MOUND STRUCTURES................................ 129

TABLE 24: POST HOLE MEASUREMENTS FOR HATCHEL EXTENDED ENTRANCES ...................................... 130

TABLE 25. RADIOCARBON DATES FROM THE HATCHEL MOUND (PERTTULA 1997). ................................. 132

TABLE 26. HARROUN MOUND C STRUCTURAL DETAILS (JELKS AND TUNNELL 1959)................................. 134

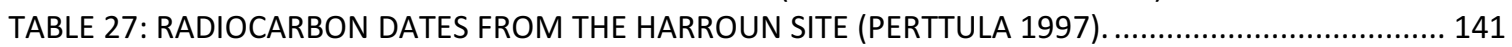

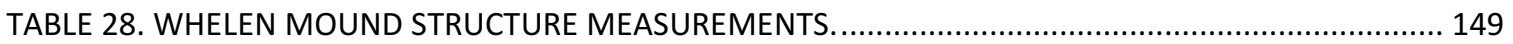

TABLE 29. EAST TEXAS CADDO SITES WITH NON-MOUND-RELATED STRUCTURES INCLUDED IN THIS STUDY..

TABLE 30. NON-MOUND-RELATED STRUCTURES INCLUDED IN THIS STUDY (EXCLUDING THE GEORGE C. DAVIS SITE STRUCTURES IDENTIFIED BY MAGNETOMETER SURVEY, SEE BELOW). ........................ 172

TABLE 31. POSSIBLE NON-MOUND STRUCTURES IDENTIFIED IN THE 2003 MAGNETOMETER DATA FROM THE GEORGE C. DAVIS SITE.

TABLE 32. POSSIBLE NON-MOUND STRUCTURES IDENTIFIED IN MAGNETOMETER DATA IN THE VILLAGE AREA ADJACENT TO MOUND A (OSBURN ET AL. 2008). 
TABLE 33. EXCAVATED NON-MOUND STRUCTURES FROM THE GEORGE C. DAVIS SITE (ADAPTED FROM

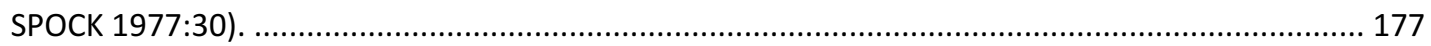

TABLE 34: WALL POST HOLE DATA FOR THE NON-MOUND STRUCTURES FROM THE GEORGE C. DAVIS SITE.

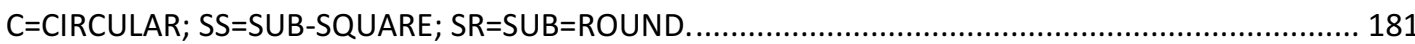

TABLE 35. WALL POST HOLE SPACING FOR THE NON-MOUND STRUCTURES FROM THE GEORGE C. DAVIS SITE.

TABLE 36. SUMMARY OF OAK HILL VILLAGE (41RK214) NON-MOUND STRUCTURES (ROGERS AND PERTTULA 2004). 190

TABLE 37. RECTANGULAR STRUCTURES FROM THE OAK HILL VILLAGE SITE (ADAPTED FROM ROGERS AND PERTTULA [2004:59, 75 AND TABLES 4 AND 14])

TABLE 38. THE FOUR OAK HILL VILLAGE SITE GRANARIES (ADAPTED FROM ROGERS AND PERTTULA [2004:75 AND TABLE 17]).

TABLE 39. SUMMARY OF THE 31 REMAINING OAK HILL VILLAGE CIRCULAR STRUCTURES WITHOUT EXTENDED ENTRANCES (ADAPTED FROM ROGERS AND PERTTULA 2004:75).

TABLE 40. POST HOLE DATA FROM PERIMETER POSTS OF THE MUSGANO STRUCTURE. ADAPTED FROM CLARK AND IVEY (1974).

TABLE 41: SPOONBILL SITE (41WD109) FEATURES. LOCATION IS RELATIVE TO THE CENTER OF THE SPOONBILL STRUCTURE AND DEPTH IS BELOW THE SCRAPED SURFACE. DATA AND INTERPRETATIONS ARE SUMMARIZED FROM BRUSETH AND PERTTULA (1981:44-46). ................ 213

TABLE 42. RADIOCARBON DATES FROM ROITSCH STRUCTURE 3 (PERTTULA 1997)..............................223

TABLE 43. SUMMARY WALL POST HOLE DATA FOR THE DESHAZO STRUCTURES 231

TABLE 44. DISTANCE BETWEEN EXTERIOR POST HOLES AND DISTANCES FROM WALL POST HOLES TO STRUCTURE CENTER AT DESHAZO.

TABLE 45. EAR SPOOL STRUCTURE 4 INTERIOR SUPPORT POSTS (PERTTULA AND SHERMAN 2009)....... 256

TABLE 46. STRUCTURES IDENTIFIED IN THE MAGNETOMETER DATA FROM THE HILL FARM SITE

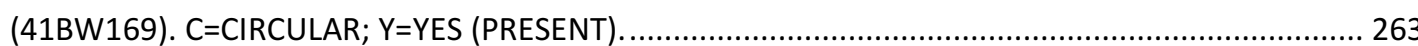

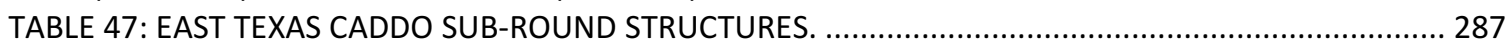

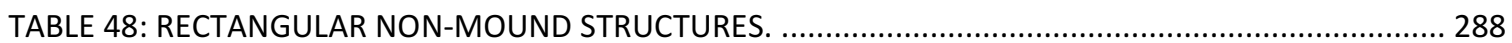

TABLE 49. NON-MOUND STRUCTURES WITH EXTENDED ENTRANCES AND ENTRANCE DETAILS.............298

TABLE 50. MOUND STRUCTURES WITH EXTENDED ENTRANCES AND ENTRANCE DETAILS..................... 299

TABLE 51. FREQUENCY OF MEAN DISTANCE BETWEEN WALL POSTS BY STRUCTURE SHAPE FOR NONMOUND STRUCTURES.

TABLE 52. RATIO OF THE MEAN DISTANCE BETWEEN WALL POST HOLES AND FROM THE WALL POST HOLES TO THE STRUCTURE CENTER FOR NON-MOUND STRUCTURES.

TABLE 53. RATIO OF THE MEAN DISTANCE BETWEEN WALL POST HOLES AND FROM THE WALL POST HOLES TO THE STRUCTURE CENTER FOR MOUND-RELATED STRUCTURES. C=CIRCULAR; SS=SUBSQUARE; SR=SUB-ROUND; R=RECTANGULAR.

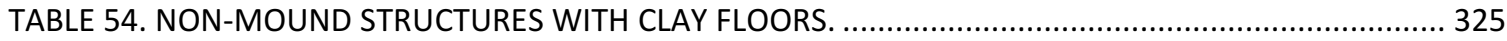

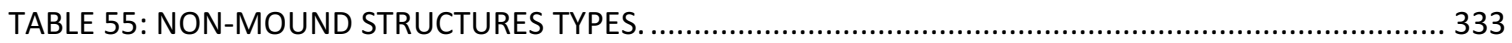

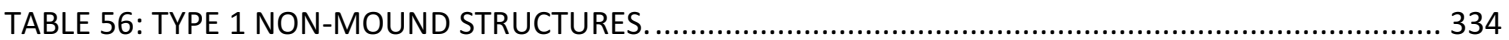

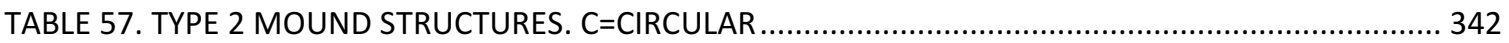

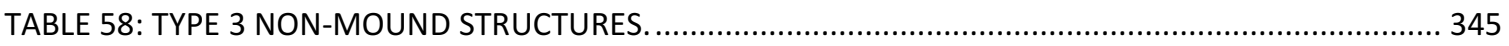

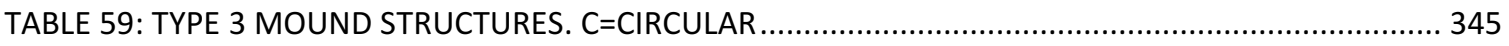

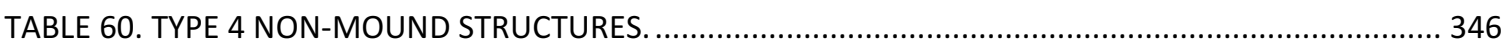

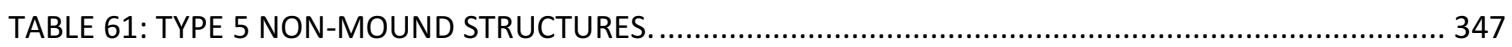

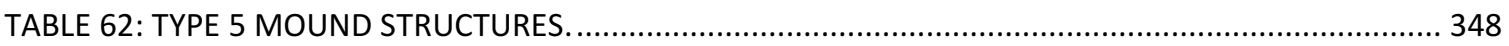

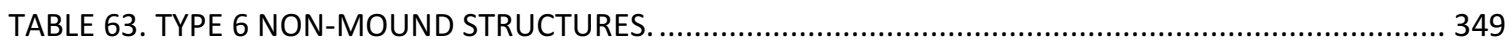

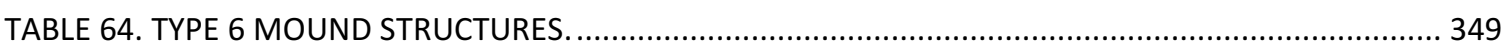




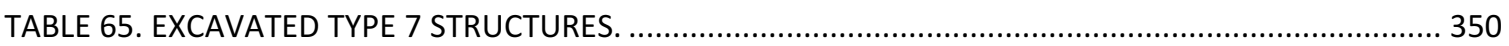

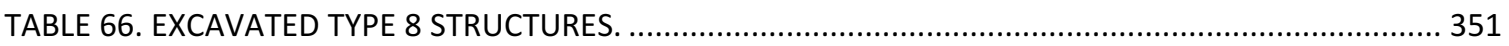

TABLE 67: SPECIAL PURPOSE STRUCTURES NOT BUILT ON MOUNDS. ................................................... 355

TABLE 68. GEORGE C. DAVIS SITE (41CE19) MAGNETOMETER FEATURES INCLUDED IN THIS DISSERTATION.

368 


\section{CHAPTER 1}

\section{INTRODUCTION}

\section{INTRODUCTION}

The cultural and archaeological tradition commonly recognized as Caddo or southern Caddoan-language speakers developed around A.D. 800-900 in northeast Texas, southeast Oklahoma, southwest Arkansas, and northwest Louisiana. This suite of developments included the appearance of hierarchically ranked sedentary societies, evidence for extensive interregional trade, the construction of well-planned centers marked by monumental architecture, and the appearance of elaborate mortuary rituals and ceremonial practices associated with complex symbolism (Perttula and Bruseth 1998; Perttula 1996, 1998; Story 1981, 1990). These developments are "characterized by dispersed but sedentary settlements, a horticultural to agricultural economy, and a complex socio-political structure (what Sabo [1995] calls a theocracy) denoted principally by a heterarchical network of mound centers and the differential treatment of the dead by rank, most notably in burial mound shaft tombs accompanied by elaborate grave goods" (Perttula 1996:297).

The Caddo archaeological area (Figure 1) was home to culturally diverse groups with some shared traditions and practices (Schambach 1982:7; Story 1990). While the "Caddo" reference implies a sense of cultural unity, shared traditions, or shared identities, there is considerable evidence of variability among the groups generally subsumed under this moniker. This variability is evident first from pre-Columbian archaeological contexts as well as from the early periods of sustained interaction with Europeans beginning in the late $17^{\text {th }}$ century A.D. Despite this variability, however, there is clear evidence for shared 
traditions and practices throughout the area. Traditions and practices associated with both prehistoric and historic Caddo architecture are the subject of this dissertation.

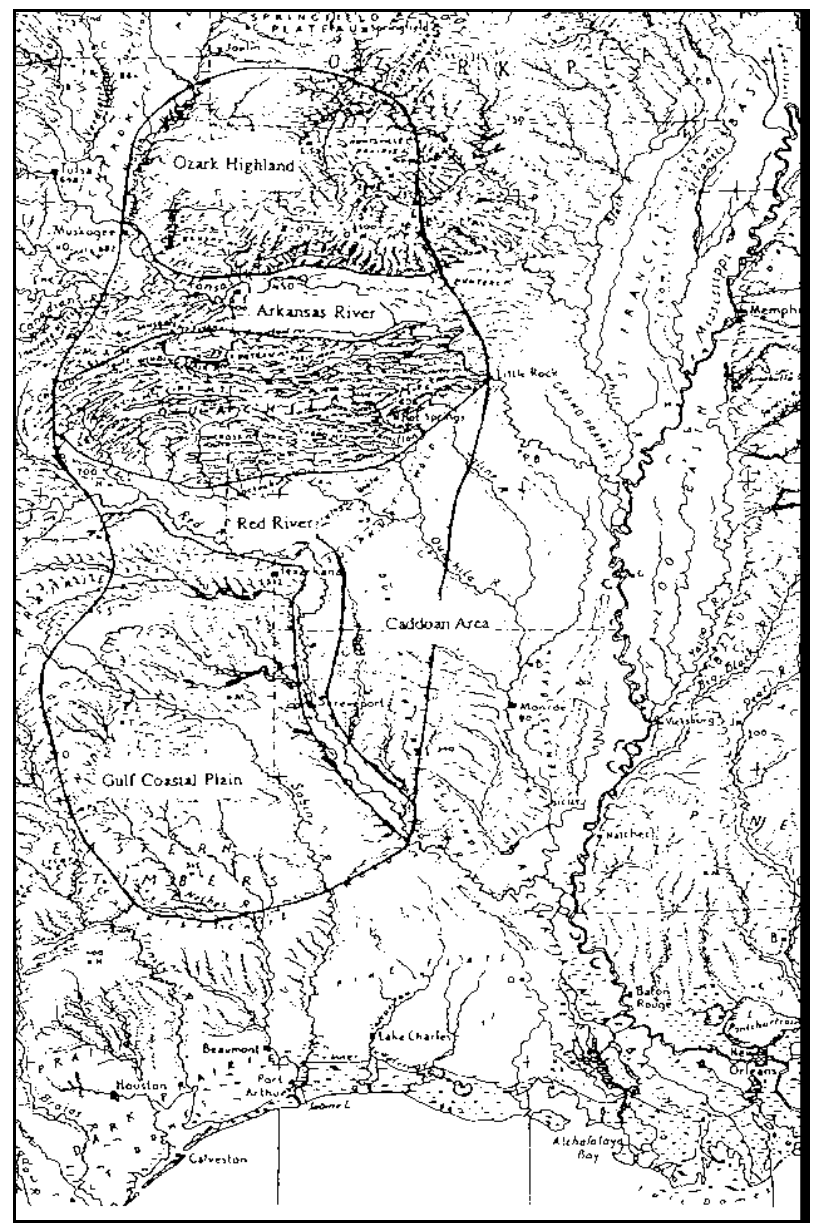

Figure 1. Approximate extent of the Caddoan archaeological area (Perttula and Bruseth 1998:1 and Figure 1-1). Reproduced courtesy of the Texas Archaeological Research Laboratory (TARL).

For the late pre-Columbian to early Historic periods this study employs the chronology proposed by Story (1990:334). Table 1 provides the general chronological framework. The periods beginning around A.D. 800 and continuing into the time of European exploration and expansion are associated with the development and 
fluorescence of archaeological and cultural traditions recognized as distinctive to the Caddo peoples (Perttula 1997; Schambach 1982; Story 1990). These traditions appear to have emerged from local Woodland period traditions and practices (Perttula and Bruseth 1998; Schambach 1982a, 1982b; Story 1990; Thurmond 1990) with "definite Southern Caddoan complexes...over virtually all of the Caddoan Area by A.D. 1000" (Story 1990:323).

Table 1. Chronological framework (Story 1990:334).

\begin{tabular}{|l|l|}
\hline \multicolumn{2}{|l|}{ Caddo Chronological Framework } \\
\hline Formative & A.D. $800-1000$ \\
\hline Early & A.D. $1000-1200$ \\
\hline Middle & A.D. $1200-1400$ \\
\hline Late & A.D. $1400-1680$ \\
\hline Historic & A.D. $1680-1860$ \\
\hline
\end{tabular}

The Caddo tradition is marked by the development of a hierarchically ranked social structure that included positions of ascribed and achieved status such as political and religious leaders, aids, counselors, priests, warriors, and commoners (Sabo 1998; Smith 1995; Wyckoff and Baugh 1980). Differential treatment of the dead is indicated by elite burials in mounds and cemeteries. Such burials were occasionally accompanied by grave goods made of exotic materials such as marine shell and copper acquired through long-distance exchange, indicating expansive trade networks (Brown 1983; Perttula 1997; Story 1990).

Although diverse in nature, certain trends and patterns began to emerge throughout the area around A.D. 800 and these continued to be developed, maintained, altered, and negotiated well into historic times. Caddo groups lived in dispersed but 
sedentary settlements that tended to be situated along the major rivers and minor streams and tributaries. These settlements ranged from isolated farmsteads and small hamlets to villages and large community centers.

Dee Ann Story (1990:334-341) has discussed four primary types of archaeological sites that characterize the post-A.D. 800-900 settlement pattern of the Southern Caddo groups. One class of sites includes limited use areas which are "special purpose camps and other areas where more ephemeral activities are carried out" (Story 1990:334). Burial loci comprise another type of site that includes burial mounds as well as family and community cemeteries. The last two site types in Story's classification, the types of sites from which most of the data used in this study come, are habitation loci, "marked by refuse, thinly distributed sheet trash as well as concentrated midden deposits, and cultural features" (Story 1990:334), as well as community/ceremonial centers. In her discussion of this final site category, Story (1990:340) states:

In contrast to the rather limited occurrence of burial mounds, mounds associated with structures - capping a structure and/or providing a platform for a structure are fairly common, though not truly numerous. They appear to denote former community centers and as such to have been an integral element in most prehistoric Caddoan settlement systems.

Throughout the early years of archaeological research in the Caddo area, emphasis was primarily given to the excavation of mounds and burials. Given this history, "the most fundamental building blocks of the Caddoan settlement system - the household and community - are poorly understood" (Story 1990:336). Despite this, with continued excavations since the 1930s, there is an abundance of data available for studies of architecture and architectural space from sites throughout the Caddo area. Story 
(1990:342) notes, "the community centers, especially, the structures they contain, are highly significant, rich in variety, and probably diverse in function".

This dissertation focuses on the nature of architecture and architectural space in the Caddo area of eastern Texas, in the southwestern portion of the Caddoan archaeological area. The study area is within the West Gulf Coastal Plain (Fenneman 1938:100-120; Story 1990) and is partly situated in the biogeographical area referred to as the Trans-Mississippi South (Schambach 1982a:7-10; 1998:xi-xii). The study area is environmentally diverse and spans a variety of biotic zones including the Post Oak Savanna, the Blackland Prairie, and the Pineywoods (Gould 1962; Story 1990). The major drainages of this environmentally diverse region are the Red, Cypress, Sabine, Sulphur, Neches, and Trinity rivers.

Caddo architecture, the primary subject of this dissertation, includes structures that range in shape from round or ovoid to rectangular or square. Evidence for these wooden pole grass and cane-covered structures includes post holes or post molds, wall trenches, wattle-impressed daub fragments, hearths, pits, the occasional prepared floor, and the occasional well-preserved burned superstructure of a building that includes structural elements such as charred timbers. The early European accounts and the Caddo archaeological record indicates that there was a wide range in size, shape, form, and use of architectural space in the Caddo area. Buildings have a variety of structural attributes, including partitions and extended entranceways, and may be found isolated or associated with plazas or earthen mounds. From these and other attributes, there remain several architectural elements that provide valuable insight into the nature of Caddo architecture and architectural space. Attributes such as structure size, shape, associated features, post placement, size and depth, orientation, and the spatial and temporal relationships 
between, as well as the geographic distribution of, different structures provide important elements for study.

This dissertation is a detailed examination of the architectural diversity found throughout the Caddo area of eastern Texas. The sites included in this study range from large multi-mound centers that have seen large-scale and long-term research, such as the George C. Davis site (41CE19), to the smaller hamlets and farmsteads that are as Story (Story 1990:336) puts it, "the most fundamental building blocks of the Caddoan settlement system". This study includes 265 structures from 31 sites throughout a small part of the broader Caddoan archaeological area, the Pineywoods, Post Oak Savanna and Blackland Prairie of eastern Texas.

The detailed portions of this study include data solely from structures identified on the basis of post hole patterns that are complete enough to provide suggestions of structure shape and size. These criteria preclude the inclusion of structures from sites where there are clear patterns of artifacts or features that suggest the presence of structures but lack identifiable post hole patterns. Structure areas from sites such as Hudnall-Pirtle (41RK4) (Bruseth 1991; Bruseth and Perttula 2006), Jamestown Mounds (41SM54), B. G. Price (41WD7), J. O. McCreight (41WD9), Colony Church (41RA31), Camp Joy Mound (41UR144), Tyson (41SY92) (Middlebrook 1993), Tallow Grove (41NA231), Beech Ridge (41NA242), and Naconiche Creek (41NA236) (Perttula 2008), and several others, fall into this later category.

As mentioned, 265 structures are included in this study of Caddo sites from eastern Texas. While this represents a large sample of the known Caddo structures from Texas, the list is not exhaustive. These structures include previously excavated structures and those that have been identified through geophysical methods. The majority of the 265 
structures are circular with simple entrances, although sub-square, rectangular, and subround structures are represented throughout the area. These structures range from small circular features (covering an area less than $2 \mathrm{~m}^{2}$ ) that likely represent the footprints of granaries or storage platforms (Rogers and Perttula 2004; Perttula 2005) to large structures covering over $200 \mathrm{~m}^{2}$ that are associated with earthen mounds.

\section{LAYOUT OF THE DISSERTATION}

With Chapter 1 as a general introduction to the research and the study area, Chapter 2 discusses some of the previous research on architecture in the Caddo area. Building upon the foundation provided in Chapters 1 and 2, Chapter 3 is a detailed look at accounts from primarily seventeenth and eighteenth century Spanish and French missionaries and explorers as well as nineteenth century images and accounts from the Caddo area.

While the early European accounts clearly touch on the architectural diversity in the Caddo area, the variations in the architectural traditions are most evident in the archaeological record. These traditions include a wide range of variability in structure size, shape, form, construction techniques, context, and use. In order to examine Caddo architecture as evidenced in the archaeological record, Chapters 4-6 examine excavated structures from the study area. Chapter 4 provides a detailed discussion of the architectural features from the George C. Davis site (41CE19) and offers an examination of archaeogeophysical data from recent research at this major mound site. The specific details on the data from this recent work at the site is presented in Appendix A. Chapter 5 presents details on excavated Caddo structures associated with earthen mounds from eastern Texas. Chapter 6 details excavated structures from eastern Texas that are not 
associated with earthen mounds. Chapter 7 provides a comparison of mound and nonmound architecture. Chapter 8 , the concluding chapter, provides a discussion of the nature of Caddo architecture from eastern Texas. 


\section{CHAPTER 2}

\section{CADDO ARCHITECTURE}

\section{INTRODUCTION}

The production of architecture "is the deliberate creation of space made tangible, visible, and sensible" (Tilley 1994:17). Architectural space, like the broader notion of community, is dynamic and socially constituted; thus, it is dependent upon human agency, practice, and tradition. Such acts as the creation, use, and abandonment/destruction of architectural space are dependent upon human agency, practice, and tradition. Therefore, architecture reflects aspects of the broader cultural realm in which it was created (Yaeger and Canuto 2000; Lewis et al. 1998; Story 1998; Sabo 1998; Tilley 1994; Wesson 1997). In this sense, architectural space can be understood as the material expression or physical manifestation of social, political, and ideological concepts.

The cultural landscape or built environment is inscribed with affirmations of identity, ideology, and tradition, and, through its historicity it provides a context for cultural practice (Alt 2001; Bourdieu 1977; Sullivan and Rodning 2001). Along with this contextual structure, the cultural landscape of a particular people is indicative of the creation and perpetuation of a shared history and creates a sense of the continuity or change of traditions. Ephemeral or esoteric concepts related to ideology, identity, and community are made physical or tangible by the construction, destruction, control, and manipulation of both the cultural landscape and architectural space. Additionally, cultural distinctions or categories centered on such things as status, access, kinship, or group 
membership can be revealed in the detailed study of the cultural landscape and architectural spaces.

The Caddo archaeological record is rich with data pertaining to architecture. These architectural data occur from the earliest to latest Caddo occupation periods throughout the region. These data suggest a range in size, shape, form, and use of various structures. Structures range from round or ovoid to rectangular. Additionally, there is strong evidence for a differentiation between "specialized" and "non-specialized" architectural space (Rogers 1982; Sabo 1998; Story 1990). The distinction between such spaces is based not only on structure location within a specific site or community but on structural form. "Specialized structures," for instance, are often identified on Caddo sites by a number of characteristics, including those structures found in association with mounds and those showing apparent signs of "deliberate destruction, capping with earth, and, often subsequent rebuilding on the resultant earthen platform" (Rogers 1982:105; Story 1990:340-341). Additionally, they may exhibit extended entranceways, are associated with special artifacts or features, and are, in some instances, buildings with unusual architectural details, such as their atypical large size, partitions, etc. (Rogers 1982:105; Story 1990:341-342).

While a comprehensive examination of architectural practices from throughout the Caddoan archaeological area has not been completed to date, there are previous studies that have examined architectural practices, variations, architectural change, and specific structural elements from the various parts of the region. This chapter provides a discussion of previous studies focusing on architecture in the Caddoan archaeological area in general and in the East Texas study area specifically. 


\section{Previous Architectural Studies in the CAdDoAn Area}

In addition to the excavations of burial mounds, M. R. Harrington's (1920) work included excavations of several structures from sites between the Red and Ouachita rivers in Southwest Arkansas. These structures include some in mounds and some built at ground level and covered by a small earthen mound upon or after abandonment. Harrington (1920) noted a variability in size and shape with structures ranging in diameter from approximately $4.8 \mathrm{~m}$ to $10 \mathrm{~m}$ and in shape from round or ovoid to square or rectangular. Harrington identified entranceways at five of the structures he excavated and noted that there was variability in the presence or absence of a fire hearth, central or otherwise, within the different structures. Finally, Harrington noted that many of the structures exhibited evidence of burning and subsequent covering or capping with approximately $0.3 \mathrm{~m}$ to $1.5 \mathrm{~m}$ of sand or clay, creating an earthen mound over the burned structure.

Based on Caddo ethnohistoric materials available at the time, Harrington (1920) discussed three primary types of Caddo buildings. The first primary type of building was the grass-lodge of the Caddo (Figure 2), a "dome-shaped edifice of poles covered with thatch, apparently identical with the "grass house" built by the Wichita" (Harrington 1920:247). These structures have "grass thatch extending entirely to the ground" (Harrington 1920:250). A second structure type discussed by Harrington (1920:252-253) was the walled house (Figure 3), "which must have had a wall of upright poles, five or six feet high, with canes interwoven to serve as lath, and then plastered with mud, probably mixed with Spanish moss, as were the houses of the Natchez, the whole surmounted by the domed roof of thatch." The final structure type discussed by Harrington (1920) was the earth-lodge. Harrington (1920) argued that the burned 
structures covered by the low earthen mounds, such as the one he investigated at the Washington group, represented earth lodges similar to those built by the Pawnee. Harrington (1920:256-258) suggested that these structures were "erected by first constructing a frame, probably in the form of a low dome, of very stout posts, upon which were placed smaller ones at right angles. These in turn were covered with brush and cane, and then finally with sedge or 'sage' grass, when the structure was ready for its heavy coating of earth."

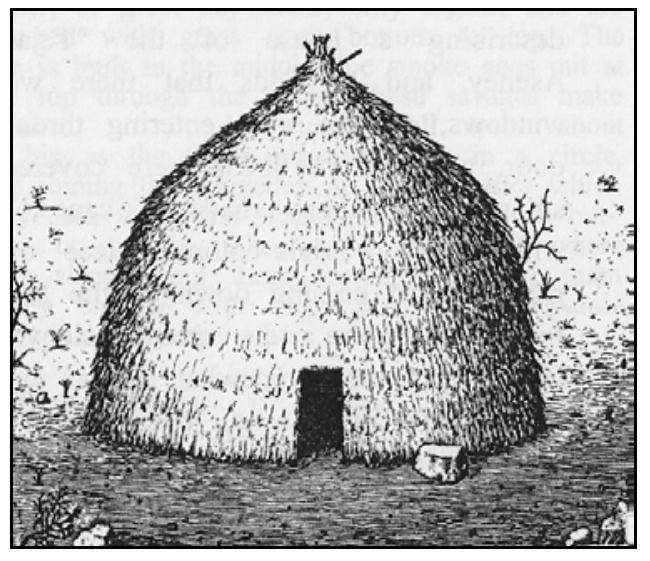

Figure 2. Grass covered building from Harrington (1920:250 and Figure 40). 


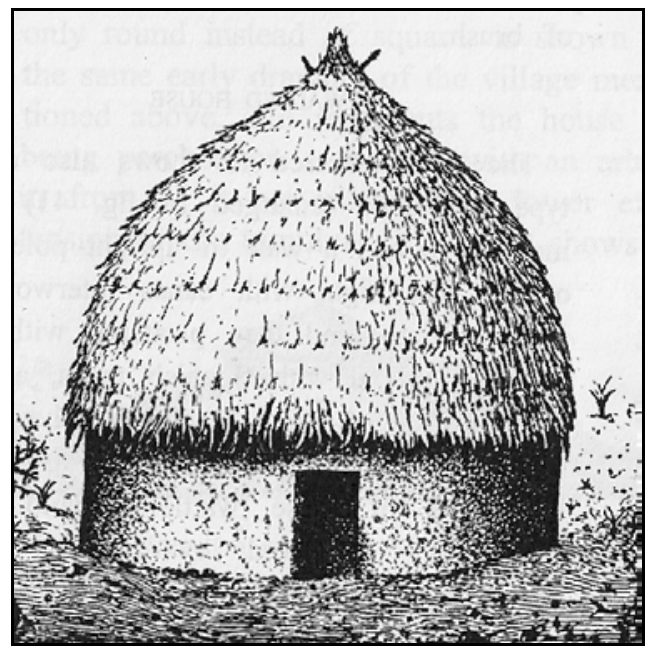

Figure 3: Walled building from Harrington (1920:250, Figure 41).

Clarence Webb's $(1940,1942)$ analysis of the structures from the Belcher site in Caddo Parish, Louisiana, provided a detailed look at architecture from a specific site in the Red River basin. Webb's excavations identified eight separate structures in the Belcher mound. Webb briefly reviewed the architectural characteristics of the earth lodges of the Pawnee and other Plains Caddoan groups, the "fire temple" of the Natchez and Taensas, and the large council houses of the Cherokees and Creeks. Webb (1940) provided details of the Belcher structures: four of the structures were superimposed one over the other and separated by approximately $0.6 \mathrm{~m}$ of sand with the fifth structure built on the ground surface adjoining Mound B (Webb 1940:54).

Webb's (1940) analysis of house types and their associated artifacts and features led him to six conclusions. First, the prevailing structure forms among the Southern Caddo groups were "grass lodges and lodges with wattle and daub walls and grass thatched roofs" (Webb 1940:73). Second, characteristics of the Belcher structures indicated the practices of building different types of structures and the burning of structures at the end of their use. Third, later Caddo groups built circular structures using 
wattle and daub walls and split cane and grass roofing. Forth, the rectangular structures at the Belcher site were built by an earlier group of Caddos that produced pottery with "simpler incised straight lines," and built structures using a wall-trench technique similar to that used in Middle Mississippian construction (Webb 1940:73). Fifth, there was no evidence of earth lodges used by Southern Caddo groups. Finally, the practice of digging deep pits and burials through the floors of structures while the structures were in use is not evident (Webb 1940).

Building upon Webb's analysis of the Belcher site structures, Edwin Wilmsen (1961) provided a brief analysis of structure data and suggested a developmental sequence for Caddo architectural forms. This analysis was based largely on a comparison of structure shapes from the George C. Davis, Belcher Mound, and Spiro sites, as well as external comparisons with structures from Tchefuncte, Adena, and Huasteca sites. Basing his study on construction details, Wilmsen (1961) arrived at a structural sequence tracing architectural form from the Early Caddo period (his Gibson Phase 1 and 2) through the early colonial period (Table 2).

Table 2. Architectural sequence proposed by Wilmsen (1961).

\begin{tabular}{|l|l|l|l|l|l|}
\hline $\begin{array}{l}\text { Chronological } \\
\text { Affiliation }\end{array}$ & $\begin{array}{l}\text { Structure } \\
\text { Shape }\end{array}$ & $\begin{array}{l}\text { Structure } \\
\text { Size }\end{array}$ & Post Detail & Centerpost & Entrance \\
\hline $\begin{array}{l}\text { Through Gibson } \\
\text { Phase 1 }\end{array}$ & circular & large & $\begin{array}{l}\text { uniformally small } \\
\text { and vertically set }\end{array}$ & Sometimes & Non-extended \\
\hline Gibson Phase 2 & $\begin{array}{l}\text { rounded } \\
\text { rectangular }\end{array}$ & large & $\begin{array}{l}\text { usually small } \\
\text { vertically set }\end{array}$ & Usually & Extended \\
\hline Fulton Aspect & circular & small & $\begin{array}{l}\text { uniformally small } \\
\text { vertically set }\end{array}$ & Yes & Extended \\
\hline Colonial Period & circular & large & $\begin{array}{l}\text { uniformally large } \\
\text { vertically set }\end{array}$ & $\begin{array}{l}\text { Yes } \\
\text { (early), non- } \\
\text { extended (later) }\end{array}$ \\
\hline
\end{tabular}


Another detailed study of Caddo architecture was Carolyn Spock's (1977) Master's thesis. Spock's study was an analysis of the architectural remains from the George C. Davis site in Cherokee County, Texas. Spock examined the 52 excavated structures from the site and provided a classification scheme that divided the structures into two broad classes, domiciles and special function. Based partly on form and partly on location, there has long been an analytical differentiation between what are often termed "specialized" and "non-specialized" architectural spaces (Rogers 1982; Lisk 1984:74-75; Sabo 1998; Story 1990). This concept of specialized and non-specialized structures has long been used throughout the Caddoan archaeological area.

Spock's (1977) most numerous class of structures, the domiciles, included those structures not associated with mounds and those generally lacking "specialized" structural attributes such as partitions and extended entrances. Spock's more elaborate classification concerned the special function structures. The specialized class of structures included those structures directly associated with mounds (although this is not the only classificatory requirement). It also included structures that were exceptionally large or small in size, unusually shaped, or characterized by unusual or distinctive interior features (Spock 1977:169). The special function structures were further subdivided into four subclasses (Spock 1977:169):

- $\quad$ based on size (unusually small structures, less than $2 \mathrm{~m}$ in diamter)

- mound association (on mound platforms or pre-mound structures)

- non-mound structures with distinctive architectural form and/or associated features

Another detailed site-specific analysis of Caddo architecture is Carolyn Good's (1982) examination of the structures from the Deshazo site (41NA27) in Nacogdoches 
County, Texas. Using a variety of evidence including structure size, location, form, associated artifacts and features, ethnohistoric accounts, and modern examples of the durability of wood used for fence posts, Good (1992:98) was able to arrive at a series of conclusions about the architectural character of the structures at this Historic Caddo Allen phase hamlet. Good's (1982:67-69) study addressed the probable duration of structures, between 10-15 years, which provided an estimate for the duration of occupation at the site of 30-80 years, based on structure overlapping. Through the analysis of the structure and burial data, Good (1982:93-95) provided a demographic analysis to estimate that the population of Deshazo ranged from 11 to 55 individuals depending upon the combinations of possibly contemporaneous structures. Good (1982:98) concluded that in terms of spatial arrangement, the site consisted of an open plaza with structures at both the north and south ends of the habitation area and a related cemetery across the creek to the south.

For the northern portion of the Caddoan area, Daniel Rogers (1982a, 1982b) provided a regional study in his examination of specialized structures from the Arkansas River Basin and Ozark Uplift. Rogers (1982a:49) defined specialized structures as "any of the variety of structures that provided a physical context for the integration of social organization beyond that of the household unit." This class of structures includes mortuaries, meeting halls, temples, elite residences, or other public buildings (Rogers 1982a:105, 1982b:89). Archaeologically, Rogers defined specialized structures as those directly associated with earthen mounds, those that appeared larger than typical structures, those "that are markedly different from contemporaneous domestic dwellings" (Rogers 1982b:49), and those associated with atypical artifact assemblages or features (Rogers 1982a:105). 
Focusing his study on the variability of structures geographically, functionally, and temporally, Rogers (1982a:105, 1982b:51) examined a corpus of structures beginning with those dating from the Fourche Maline phase (A.D. 1-800) and continuing through the Harlan phase (A.D. 850-1250), Spiro phase (A.D. 1250-1450), and the Fort Coffee phase (A.D. 1450-1650). Through the analysis of 45 specialized structures from 18 sites Rogers made several conclusions relating to the changing use of specialized structures. First, the evidence suggested that the practice of covering structural remains with earthen mounds was established as early as the Fourche Maline phase, although the evidence for specialized structures during this period $(\mathrm{n}=2)$ was scant (Rogers 1982a, 1982b). Like the architectural data from the Fourche Maline phase, the late Fort Coffee Phase had only two (or possibly three) structures tentatively designated as specialized in function. These structures differed from those of the other phases in that they were round and lacked interior supports. The lack of supporting contextual data concerning this rare structural form limited the interpretations that could be made concerning specialized buildings from this phase (Rogers 1982b).

Most of the data Rogers (1982b) considered was from Harlan and Spiro phase occupations. During the Harlan phase, specialized structures $(n=29)$ were mostly square with four interior posts. They had extended wall-trench entranceways, and were relatively large. In addition to these structural features, Harlan phase specialized structures were generally burned or dismantled with the remains being covered by a small earthen mound (Rogers 1982a:87).

Rogers (1982b) noted that a significant shift occurred during the Spiro phase, in that specialized structures were generally smaller than in the preceding Harlan phase and were mostly rectangular with two center posts, a pattern of construction similar to 
'ordinary' structures (Rogers 1982a:107). Also in the Spiro phase, "the practice of constructing single episode mounds over building remains disappears and special buildings are found associated with platform mounds or platform-burial mound combinations" (Rogers 1982b:87).

Rogers (1982b) interpreted these changes as relating to possible changes in residence rules or changes in the functions of specialized structures. As for the smaller size, the reduction in the number of specialized structure, and the possibility of functional change, he suggested that such shifts may be, "considered as one correlate of the centralization of authority and the further segregation of the elite" (Rogers 1982b:90). Rogers (1982:108) concluded his consideration of specialized structures by arguing that during the Harlan phase, specialized structures "were probably used as combined elite residences, temples, and mortuaries" while in the Spiro phase this class of buildings "served as mortuaries on platform and burial mounds; however, other possible functions are not known."

In addition to these studies, there have been studies of particular architectural elements of Caddo structures. These include an analysis of the frequency and location of interior hearths (Middlebrook and Middlebrook 1996) and entrance types (Kay and Sabo 2006; Perttula 2009), studies that include identifying different kinds of structure types (Perttula and Rogers 2007; Walker 2009), and a recent study on burning of structures from southwest Arkansas (Trubitt 2010).

Kay and Sabo (2006) completed a study of the structures with extended entrances from the Arkansas River Valley and western Ozark highlands. In this area, these structures are often rectangular. Structures with extended entrances are often considered specialized structures and are not as common as those with non-extended entrances. The 
extended entrance would set the structures apart from the rest of the buildings on a site or in the area and would seemingly provide limited access to the structure's interior. Kay and Sabo (2006:44) found that the Harlan-style charnel houses in this region had extended "entryways oriented generally to the southwest, thus aligned with the winter solstice sunset," and the direction of death. Kay and Sabo (2006:44) further suggested that these specialized structures are "an intelligible or coherent measure of widely shared death:winter symbolism and mortuary ritual."

In a response to Kay and Sabo's study, Perttula (2009) examined 79 extended entranceway structures from 39 sites distributed throughout the Caddo area. Perttula (2009:36) found that there was a range of orientation of entrances, with more north or south-oriented buildings occurring in the central Caddo area; buildings oriented to the sunrise occurred in the northern, southern, and central Caddo areas; more of the southern Caddo area entrances were oriented toward the sunset, and "winter-oriented special purpose structures are most common in the northern and central areas, with summeroriented special purpose structures more important in the southern Caddo area." Perttula (2009:39) found that death symbolism was not the primary determinant in building orientation throughout all parts of the Caddo area and that there was a clear practice of orienting buildings based on "site-specific decisions on the place of specialized buildings within living communities of Caddo peoples, which were built by a series of matrilineal households to face the social community, the village, the plaza, and other important ritual places in the Caddo constructed landscape writ large."

A recent study from Trubitt (2010) examined variations in Caddo architecture from southwest Arkansas. Specifically, Trubitt (2010:233) focused on sites dating from the twelfth to the seventeenth centuries A.D. and looked at "structure shape, on burning 
at termination, and on covering with soil". Trubitt (2010:242) noted that circular structures are the Caddo architectural norm in southwest Arkansas and "there is no clear temporal shift from straight sided to circular structures (or vice versa), and mound structures of both shapes have been interpreted as "special purpose, public, or ritual buildings.”

Trubitt (2010:242) has suggested that there may be a significant difference between covering a structure with clean fill versus midden soil and that "burying burning structures did not always mean creating mounds." She also noted that "perhaps covering with a layer of clean earth is what distinguished the mound and off-mound locations, suggesting that burning structures in certain places was marked by ritual" (Trubitt 2010:243). In discussing the different shapes and treatment of structures, circular vs. rectangular, burned, or not burned, Trubitt (2010:243) suggested that "the variation indicates more complexity than circular $=$ domestic versus rectangular $=$ public/ritual, burned $=$ special purpose, or burned $=$ mound construction..

In addition to these broader regional studies, there are several site-specific studies of Caddo architecture from throughout the Caddo area, some of which are discussed in more detail in later chapters of this dissertation. For example, for the Oak Hill Village site (41RK214), Perttula and Rogers (2007:76) grouped the many structures there into at least four different categories: large rectangular structures, circular structures, circular structures with extended entrances, and small structures ( $<3 \mathrm{~m}$ in diameter).

Walker (2009) addressed the use of archaeogeophysics as primary archaeological data and provides an excellent discussion of the structures recorded from the magnetometer surveys at the George C. Davis (41CE19) and Hill Farm (41BW169) sites. Walker classified the architectural features from the George C. Davis magnetometer data 
into three types of structures-“Button Houses" (Type 1), circular (Type 2), and subround (Type 3) - and hearths. At the Hill Farm site, Walker (2009) placed the structures into two architectural forms, circular structures with extended entrances and those without.

At the fourteenth to early fifteenth century Standridge site in the Ouachita Mountains in southwestern Arkansas, Early (1988) excavated five structures (including both rectangular and circular buildings) associated with the Standridge mound. The latest of these were a series of rectangular buildings, while the earliest structures included both circular and rectangular structures built on the pre-mound surface. Early (1988:163) concluded that the pre-mound circular structure was likely a domicile, while the rectangular structure (Feature 18) was likely a special purpose building. This rectangular building was covered by a low mound and subsequent rectangular buildings, with the earlier circular structure being covered by the mound in later construction episodes (Early 1988:163). Early (1988:162) suggested that the changes in building styles at Standridge related to "changes in function of the total site." Early (1988:163) noted that "in its initial Caddoan occupation the site served dual purposes as both a residence and a location for small scale ritual. From this beginning it evolved into a location used exclusively for special purpose activities, but on a seemingly small scale.”

At the Winding Stair site in the Ouachita Mountains, Early (2000:128) excavated the remains of a specialized structure dating to the $15^{\text {th }}$ century A.D. that may have served as an elite residence or "may have served as a setting for community rituals, especially those concerned with aspects of the food gathering and growing cycles." This structure was similar to the specialized structures from the Standridge mound (Early 1988). Early (2000:130) also discussed other specialized buildings from the Arkansas 
Valley, the Little Missouri River valley, the Ouachita River drainage basin, and the Ouachita Mountains, and noted that 'these 'special' buildings were focal points of dispersed Caddo communities. They conform to a widely shared and strikingly uniform set of ideas about shape and design in the built environment of socioreligious centers, and they were treated with a seemingly similar set of ritual practices when they were taken out of use." Early (2000:130) further noted that "rather than marking a cultural boundary between the Arkansas River valley and the southern Caddo area, they indicate that there was a shared set of fundamental values and practices between these two regions that support the notion of a common cultural heritage."

Through these studies, it is clear that there are shared architectural practices in the Caddo area and that these shared traditions "can only strengthen the idea that peoples living in the north, central, and southern parts of the Caddo archaeological area from as early as ca. A.D. 900 were Caddo peoples with the same cultural heritage" (Perttula 2009:39). As these studies have also shown, Caddo structures vary in size, shape, form, apparent use, and overall treatment, both temporally and geographically. Structures range from round or ovoid to square or rectangular and have different types of entrances. They have a variety of associated features and were built in varying types of locations for varying purposes.

\section{SUMMARY}

This dissertation builds upon these previous architecture studies and provides an examination of the structuring of architectural space by Caddo groups living in eastern Texas. This research is based on documentary, archaeological, and geophysical data, and will address the varying forms of structured space (i.e. how that space is organized, used, 
maintained, and negotiated). Through a detailed examination of these complementary datasets, this research examines the nature of the Caddo built environment, how Caddo cultural space was created, maintained, and altered, and how this relates to the broader Caddo society.

In this dissertation, I will provide descriptions and comparisons of Caddo architecture from eastern Texas sites and consider the nature of the various forms of Caddo architectural spaces in eastern Texas (i.e., buildings associated with earthen mounds, those with restricted access and ritual spaces, those accessible to the general public, and other types of buildings). This research will attempt to identify structure forms or types in the Caddo area of eastern Texas and discuss the differences between structures with specialized and non-specialized spaces. Through a detailed examination of diverse but complementary datasets, this research will explore the nature of Caddo architectural space by addressing three interrelated themes:

- Cultural significance of architectural space to the Caddo

- Physical form of structures and construction attributes

- Variation and change 


\section{CHAPTER 3}

\section{HISTORIC ACCOUNTS OF CADDO ARCHITECTURE}

\section{INTRODUCTION}

The Caddo area provides an excellent opportunity for research that utilizes both archaeological and ethnohistoric material. As Story (1990:346) has argued, we have the opportunity in the case of the Caddo to relate specific historical groups and their activities with the rich archaeological record of their pre-Columbian predecessors. This is due to the abundant and diverse archaeological record and, as Story (1990:346) notes, "because the Late prehistoric groups were relatively sedentary, were not severely displaced by intrusive Native Americans...prior to the early nineteenth century, and were visited fairly often by Europeans and Euramericans." Without integrating these diverse historical and archaeological datasets, "archaeologists can be guilty of overlooking valuable clues and the key actors of the past - the people who left the remains they study" (Story 1990:323). With the increased use and relative success of geophysical prospection in locating buried Caddo structures and other features, the potential for such research is enhanced (Perttula et al. 2008).

Studies of sixteenth, seventeenth, and eighteenth century European accounts and the nineteenth century images from the Caddo area have guided our perceptions concerning buildings and settlements of early colonial and late pre-Columbian Caddo groups. They have also informed us about the nature of Caddoan leadership, social organization, settlement, trade and interaction, ceremonialism, and architecture (e.g., Baugh 1998; Bolton 1908, 1987; Griffith 1954; Perttula 1997; Perttula et al. 2008; Sabo 1998; Schultz 2004; Smith 1995; Swanton 1942; Wyckoff and Baugh 1980). Still, with a 
focus on architecture there remains a wealth of information to be gleaned from the archival and ethnographic material. As archaeologists, anthropologists, historians, and archivists continue to refine and broaden the issues and questions that can be fruitfully addressed by the archaeological and ethnohistoric record, this material continues to provide new insight into the cultural practices of Caddo peoples.

This chapter provides a detailed examination of the archival material relating to architecture and the use of structured space by Caddo groups, and builds upon previous studies that have utilized such material (Baugh 1998; Bolton 1908, 1987; Griffith 1954; Perttula 1997; Perttula et al. 2008; Sabo 1998; Schultz 2004; Swanton 1942; Wyckoff and Baugh 1980). Accordingly, this study relies primarily upon accounts from Father Anastasius Douay (1687), Henrí Joutel (1687), Fray Francisco Casañas de Jesús María (1690-1691), Henrí de Tonti (1690), Massanet (1690), Hidalgo (1710 and 1716), and Fray Isidro Felis de Espinosa (1715-1717).

\section{STRUCTURED SPACES}

"The architectural heritage of the Hasinai provides one of the most important bridges through which the generations from the ancestors to the present offer a sketch of a people in balance and peace" (Newkumet and Meredith 1988:40). The architectural heritage of the Hasinai and other Caddo groups is comprised of several types of built or otherwise defined spaces that can be identified in the archaeological, ethnohistoric, and historic archival materials. Some of these types of spaces have a continued use and significance in modern times while others exist only in the archaeological and archival record, their purpose and significance left to memory, tradition, inference, and interpretation. Newkumet and Meredith (1988:35) note two types of spaces used today 
that have their roots in the past, "the only vestiges of the earlier style of living are the dance ground and the cah-cah-say'-day-ah, or arbor." While dance grounds and arbors may be more difficult than houses to define archaeologically, arbors have been identified in the study area from archaeological investigations, and dance grounds are suggested in the European accounts.

Arbors may be included among other daily, family, or communal use spaces such as houses, storage bins and platforms, garden plots, and trash areas. While some of these spaces comprise the bulk of those seen archaeologically, other, more restricted spaces,

such as those reserved for particular individuals or for specific uses by specific individuals, as well as religious, mythical, ceremonial, and symbolic spaces were certainly recorded and identified by Europeans. Undoubtedly, there were additional structures or spaces that are not identifiable archaeologically, have escaped recognition or recording by Europeans, or are otherwise missing from our interpretations of Caddo cultural space. Architectural spaces discussed in this chapter are divided into three broad headings: daily use, communal, and family spaces (including houses, arbors, granaries, etc); spaces reserved for particular activities and/or people (i.e., assembly houses and the reserved seats for the xinesi); and religious, ceremonial, and symbolic structures/spaces (i.e., the temple, the houses of the coninisi, etc).

\section{DAILY USE, COMMUNAL, AND FAMILY SPACES}

This category of structures is probably the most visible archaeologically in Caddo sites and includes those spaces that were most likely accessible to the broadest range of people in the community or family as a whole. This category includes those spaces that were most likely the least restricted and conversely used or accessed on a regular or daily 
basis. Houses, arbors and storage areas (including bins and platforms) are some of the spaces that fall into this category.

\section{Houses}

Caddo houses are often described as being round, wooden pole thatch structures. Newkumet and Meredith (1988:35) note that, "in the twentieth century, vernacular forms of architecture, of white weatherboard construction, have replaced the traditional Hasinai housing styles that were once so familiar in the southwest." The traditional styles of houses are clearly illustrated in Soule's 1868-1872 photographs (Figures 4 and 5) of a Caddo farmstead in the Binger area of western Oklahoma. The photos provide clear examples of the layout of a late nineteenth century Caddo farmstead as well as the form of several structures, including houses, storage buildings, arbors, and a collapsed building in the background.

As is apparent in the Soule photo and in the archaeological record of their ancestors, Caddo peoples constructed and used a variety of architectural forms. The open aired structure in the forefront of Figure 4 is similar to the one described in the early historic accounts of Caddo buildings. Upon arriving outside of a Cadodaquis (Kadohadacho) village along the Red River in 1687, Joutel and the French were greeted by the chief and several individuals who proceeded to carry the French party into the village upon their backs and shoulders. Following a ceremony in which a village elder washed their faces, the French were given a sign by the chief "to sit down on a kind of platform that was raised about four feet off the ground and made with wood and cane" (Foster 1998:244). The structure described by Joutel closely fits the one captured almost 200 years later by Soule's camera. 


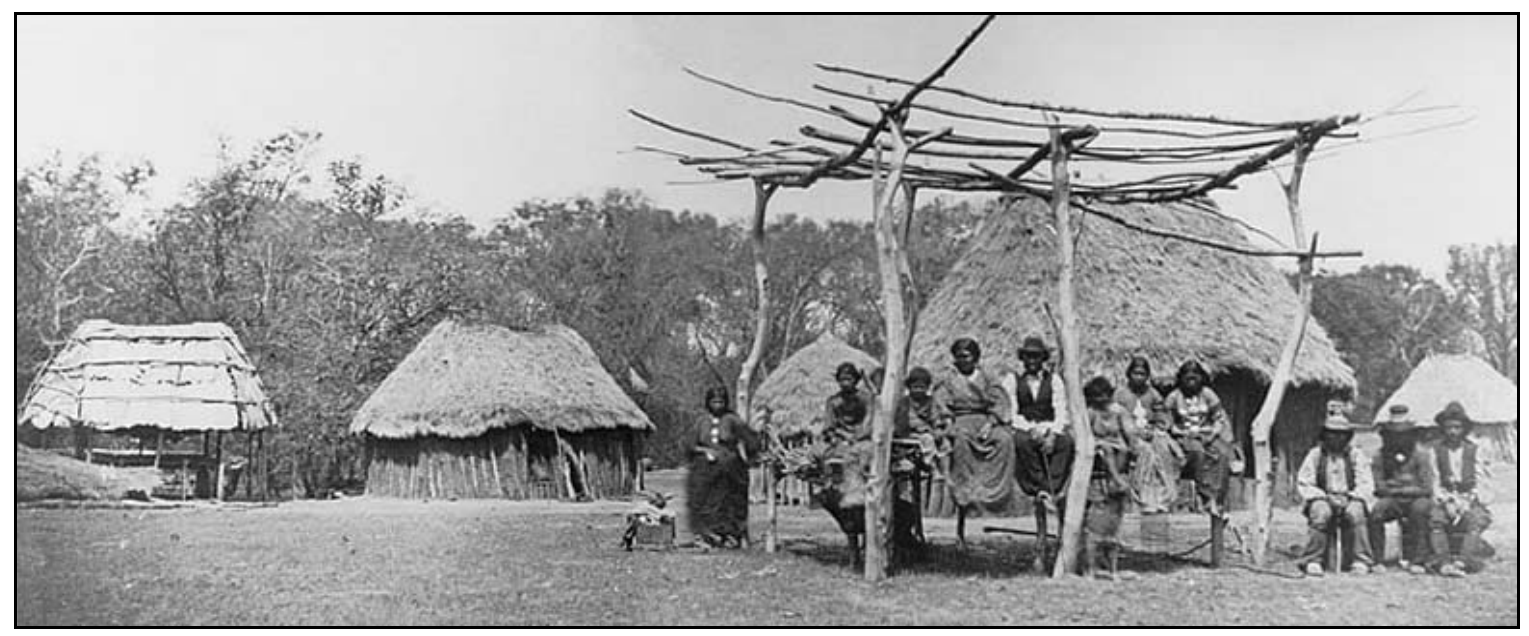

Figure 4. Portion of the Soule photograph entitled "Chief Long Hat's Camp."

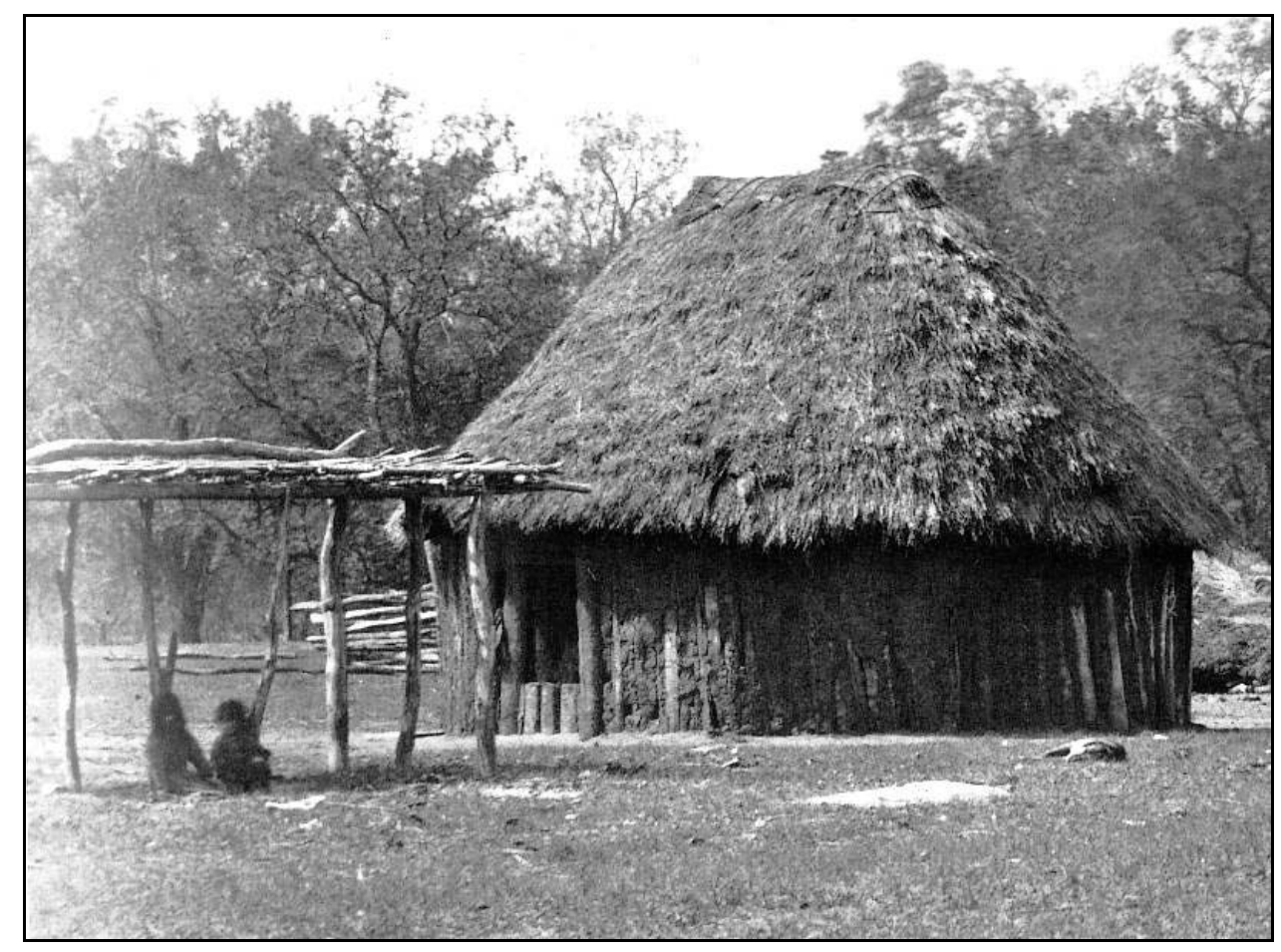

Figure 5. House and arbor from Soule photograph entitled "Chief Long Hat's Camp."

Newkumet and Meredith (1988:37) note that "the arbor is a popular structure still constructed near homes." Lasting about two years, modern arbors are usually made of 
willow, which provides for a lightweight but sturdy structure with all four sides open to the air. They have square or rectangular roofs supported by poles made of peeled oak with the pitch of the roof extending away from the central ridge of the structure (Newkumet and Meredith 1998:36).

The first part of the nineteenth century was a time of great upheaval and change for Caddo peoples but they were able to maintain and continue much of their traditional cultural practices (Carter 1995; Smith 1995:103-104). During this period AngloAmericans flooded into Texas along with native groups that were immigrating from the east. Despite these dramatic shifts, Caddo traditions continued. For instance, as Smith (1995:104) notes, in addition to speaking French and Spanish, the Caddoan language was still spoken, men wore their hair in a traditional manner, and "the tribes continued to live in their trademark grass houses."

William Parker noted that "the Caddo, Hainai, Anadarko, Waco, and Tawakoni live in houses built of a framework of poles, in a conical shape, thatched with long prairie grass, with low doors; the fires built in the center of the lodge; the lodge, circular, about twenty-five feet in diameter and twenty high" (Swanton 1942:152). While Parker may have observed traditional Caddo houses still in use in the 1850s and clearly such structures were photographed by Soule, James Mooney (1896:1094, quoted in Swanton 1942:153) in the 1890s stated that "they formerly lived in conical grass houses like the Wichita, but are now in log houses and generally wear citizen' dress excepting in the dance."

One surviving document from the seventeenth century that has captivated the imagination of archaeologists, historians, and others interested in Caddo native history and has been at the forefront of interpretations of settlement, site layout, and architecture, 
is the map of a Caddo settlement along the Red River from the 1691-1692 expedition led by Domingo Terán de los Rios (Figure 6). Frank Schambach (1982a:7) and others have noted that the nineteenth century farmstead depicted in Soule's photographs "matches those in the Terán map in most details, down to and including the beehive-shaped storage platforms" and arbors.

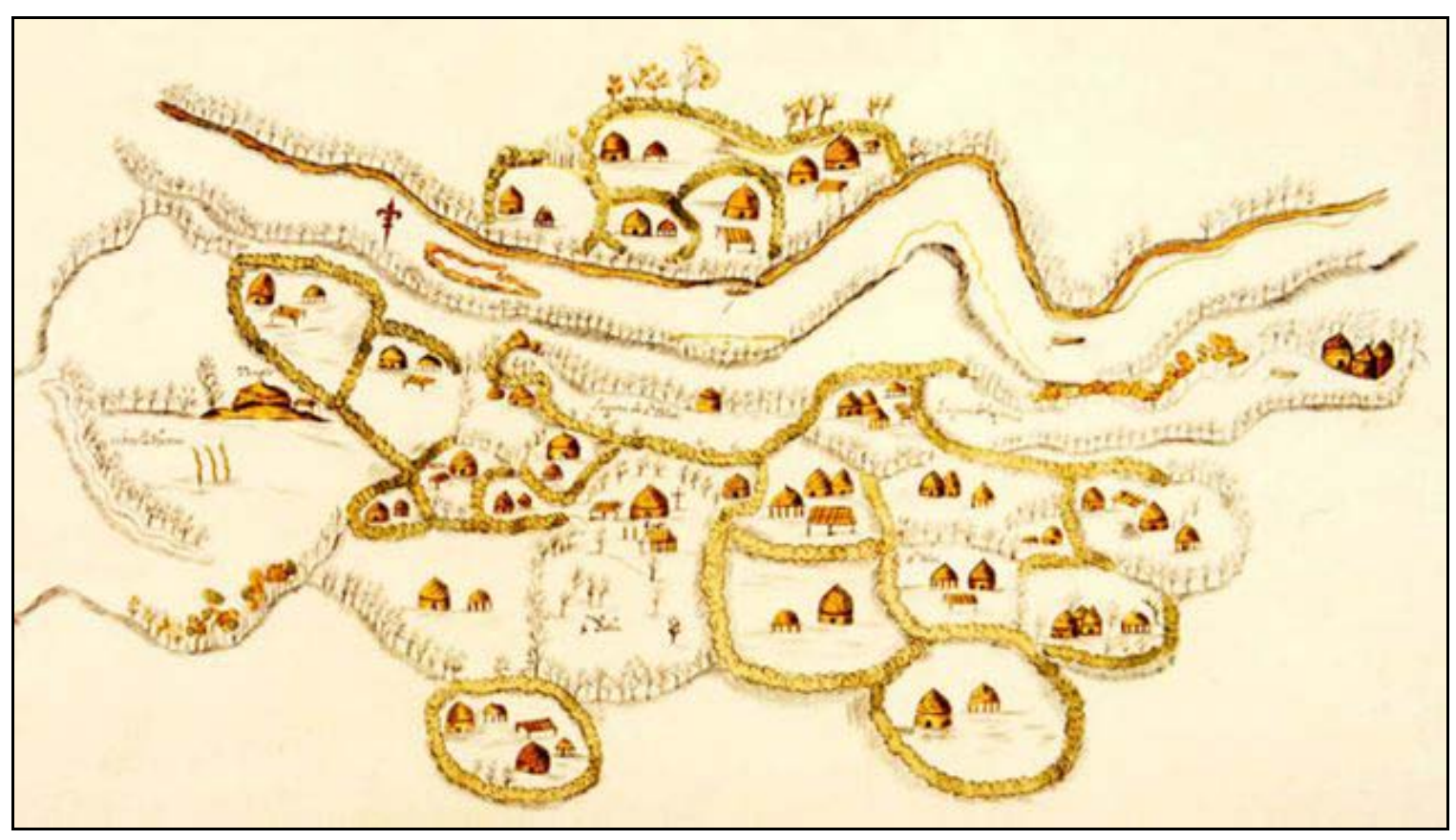

Figure 6. Map from the 1691-1692 expedition led by Domingo Terán de los Rios.

The Terán map is largely believed to be the earliest depiction of a dispersed Caddo community. The map depicts 25 clusters of buildings, 23 of which probably represent individual farmsteads or hamlets (Schambach 1993; Schambach et al. 1983; Wedel 1978). At the western edge of the map is a compound with a building atop a platform mound and an arbor near its base (Figure 7). At a distance estimated to be approximately $2.5 \mathrm{~km}$ east of this mound (Schambach 1993; Wedel 1978), and near the center of the settlement, is the compound labeled 'Caddi' (Figure 8). This compound is 
the largest clearing within the settlement and is the only one lacking a storage bin (Schambach 1993; Wedel 1978). Strikingly similar to those in Soule's photographs from approximately 180 years later, the compounds depicted in the Terán map clearly illustrate the round thatch-covered structures as well as the open sided shelters and storage platforms shown in Soule's photographs. The Terán map has also aided in interpreting archaeo-geophysical data from Caddo sites in the area of the Red River. At the Hill Farm site (41BW169), Perttula et al. (2008) have identified one of the compounds in the Terán map in recently collected magnetometer data (see Chapter 6 and Walker 2009).

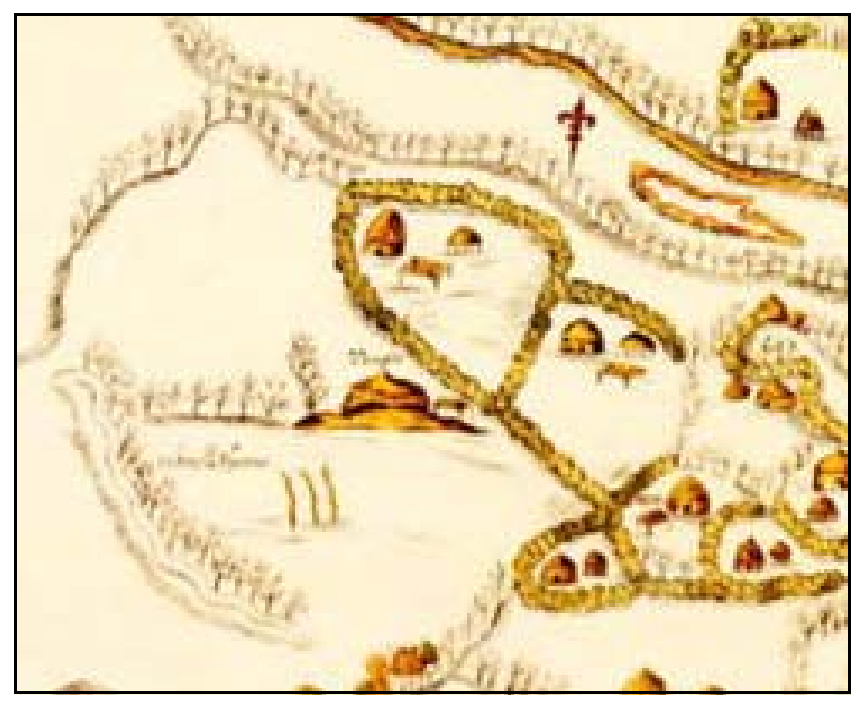

Figure 7. The temple or templo in the Terán Map. 


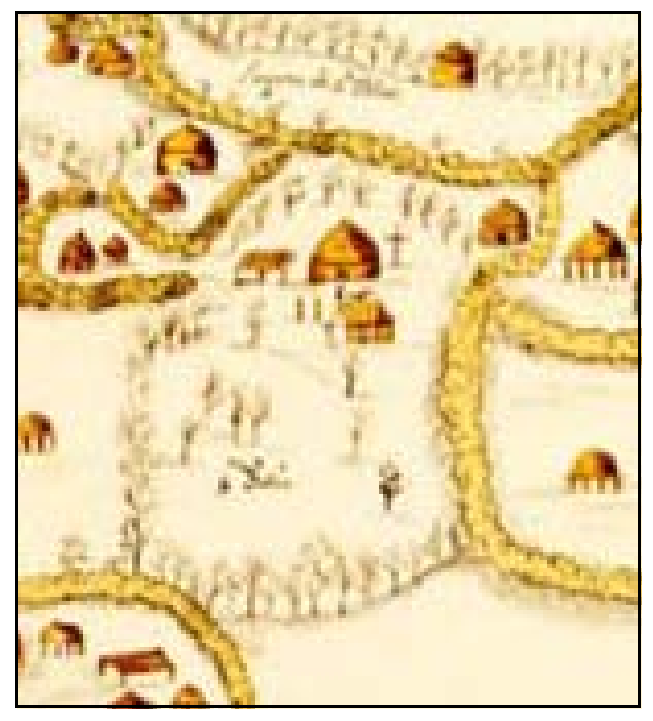

Figure 8. The Caddi's compound in the Terán Map.

Late seventeenth and early eighteenth century accounts, such as those from Henri Joutel's journal from 1684-1687, further enhance our understanding of these images while also illustrating the diversity in architectural practices documented in the Soule photographs and in the Terán map. In his description of a recently deceased Cenis (or Hasinai) chief's hut in which lived the Provençal that had deserted La Salle during his previous journey to East Texas (Foster 1998:206), Joutel (Foster 1998:208) notes:

There are normally eight or ten families in these huts, which are very large; some are 60 feet in diameter. The huts are made in a different method from those we had seen earlier. These are round, in the shape of beehives, or rather like large haystacks, being composed of the same except they are higher. They are covered with grass from the ground to the top. They make a fire in the center, the smoke going out through the top through the grass. 
Joutel (Foster 1998:208) continues by providing a description of the interior of the chief"s house, "once we were in the hut, which was one of the largest in the area, we were shown a place to put our packs and to sleep. These huts were much more comfortable than those we had seen before. The Indians raise their beds three feet high. They fashion them neatly with long reeds, making each bed separate with matting that forms a cradle."

A May or June 1686 account by Anastasius Douay provides similar information. Douay was among 10 Frenchmen that accompanied La Salle in his first expedition to the Hasinai. Douay describes the houses of the Cenis or Hasinai as being "fine, forty or fifty feet high, of the shape of bee-hives. Trees are planted in the ground and united above by the branches, which are covered with grass. The beds are ranged around the cabin, three or four feet from the ground; the fire is in the middle, each cabin holding two families" (Cox 1904:232; see also Swanton 1942:39, 148).

Fray Damián Massanet's 1690 account of a Nabedache chief's house matches closely the description provided by Joutel. Swanton (1942:149) suggests Massanet's description is of the same chief's house Joutel described in 1687, albeit with some differences in detail. Massanet's account states:

The house is built of stakes thatched over with grass, it is about twenty varas [ca. 55.6 feet] high, is round, and has no windows, daylight entering through the door only; this door is like a room-door such as we have here. In the middle of the house is the fire, which is never extinguished by day or by night, and over the door on the inner side there is a little mound of pebbles very prettily arranged. Ranged around one half of the house, inside, are ten beds, which consist of a rug made of reeds, laid on four forked sticks. Over the rug they spread buffalo skins, on which they sleep. At the head and foot of the bed is attached another carpet forming a sort of arch, which, lined with a very brilliantly colored piece of reed matting, makes what bears some resemblance to a very pretty alcove. In the other half of the house where there are no beds, there are some shelves about two varas [5.56 feet] high, and on them are ranged large round baskets made of reeds (in which they keep their corn, nuts, acorns, beans, etc), a row of very large earthen 
pots like out earthen jars, these pots being used only to make the atole when there is a large crowd on the occasion of some ceremony, and six wooden mortars for pounding the corn in rainy weather, (for, when it is fair, they pound it in the courtyard). [Massanet cited in Swanton 1942:149; see also Bolton 1916:377-378, 1987:70]

Foster (1998:237n) adds that Massanet also provided a description of a food storage area inside the house stating that "over the door on the inside there was a structure of rafters, very prettily arranged to hold jars or sacks of food items."

Joutel's 1687 account of the house of a Nasoni chief along the Red River is similar to the one he provides for the Cenis. In describing the Nasoni structure, however, he offers a more detailed description of the interior:

These Indians' huts are made like those of the Cenis except they are not as high. There is a large platform above the door that is made with pieces of wood placed standing up with other pieces across, and canes are arranged and pressed close together upon which they place their ears of corn. There is another platform opposite upon which they place their barrels or casks (which are made with canes and bark) in which they put their shelled corn, beans, nuts, acorns, and other things. Under this they put their pottery. Each family has their own personal barrels; and they have their beds to the right and the left in the manner that I described earlier. These Indians also have another large platform in front of their huts that is elevated about 10 or 12 feet upon which they place their ears of corn to dry after gathering them. This they are careful to sweep every day. [Foster 1998:237]

The accounts from others who visited Caddo groups in eastern Texas match closely the more detailed descriptions given above (e.g., Forrestal 1931; Padilla 1919; Swanton 1942:148-154). These accounts serve not only to confirm the observations of chroniclers such as Joutel, Massanet, and others, but also provide further details about structures, including furnishings, variety in structure size, food storage areas, and houses of other groups. Hidalgo (Hatcher 1927:56), for instance, stated that "their houses are 
made of grass, some of them quite large and tall. Others are medium sized and others still smaller like half an orange. In each of these many families live. They keep their corn in lofts and garrets and in big reed baskets." Hidalgo (Hatcher 1927:56) also noted that "the Indians have the doors of all their houses toward the east," which, he continued, "I heard them tell the soldiers...they did this because it never blows from that side, [but] I do not understand the mystery."

From his 1767 journey through East Texas, the Marqués de Rubí describes the interior of a Tejas (Cenis) house as being "divided inside with partitions made of woven reeds, which they also use to make the bedrooms, furnished with beds that are elevated, decent, and comfortable" (Jackson and Foster 1995). Casañas, in discussing daily activities such as dining, stated that "they eat while seated on benches of wood, all one piece and not very high from the ground" (Hatcher 1927:212). Casañas also provided a description of specialized furnishings found in the houses of the caddices and other nobles. He noted that "there is a certain bench which nobody is allowed to approach except the gran xinesi himself when on a visit. In all these houses there is also a high bed like an alcove where the xinesi may sleep and rest" (Hatcher 1927:217). These and other reserved spaces will be discussed in more detail below.

Espinosa provided further details of the interior of structures among the Hasinai:

in their houses they have large baskets make of heavy reeds into which they put their shelled corns and beans. In order that the weevil may not get in they cover the grain with a thick layer of ashes and then cover the baskets to keep out the rats. These Indians are so provident they make a string of the best ears of grain, leaving the shucks on, and put it up on a forked stick at a point in the house where the smoke will reach it (Hatcher 1927:156-57). 
Finally, Casañas offered descriptions of houses from provinces to the north of the Hasinai, in Caddo communities along the Red River. In his reference to the houses of the Cadaudachos, the Nasitox, and others, Casañas (Hatcher 1927) noted that they "are located closer together and are well arranged and plastered." This practice among Red River Caddo groups was also seen in 1689 by Henrí de Tonti (Cox 1904), who noted that their houses are made of straw and covered with plaster. Swanton (1942:153) briefly touched on this in his discussion of architecture depicted in the Terán map, concluding that "most of the houses seem to be grass houses of the conventional type or granaries, but a few, particularly one on a mound which is presumably a temple, have what look like wattle walls."

Perhaps some of the most intriguing accounts relating to Caddoan architecture concern the construction of architectural space. Espinosa offered a detailed description of the processes involved in constructing a new structure from the planning stages through completion. In this account, Espinosa's (Hatcher 1927:154-155) description of the structure itself is fairly consistent with descriptions given elsewhere:

Their houses are built of wood with very long, flexible laths. Their manner of building them is as follows. Whenever the owners of a house decide to build one, they advise the captains whom, in their language, they call caddi. The latter set the day and order the overseers whom they call tammas to go around to all the houses and give notice in order that all may aid in the building. These two messengers mount their horses - of which the Texas Indians have a great number since the first entry of the Spaniards. They carry in their hands a number of little sticks so that he who receives it may take care to cut and clean a lath and bring it and put it in the hole designated from it. Another member of the household is placed in charge of a sufficient number of men to continue the work of lacing the laths together. These thongs, made of the bark of a tree, are so strong that they can not be broken between the hands however thin they may be. To the Indian women, one or two from each house, is given the duty of bringing a load of grass. This grass is coarser than the largest wheat and is used to cover the whole roof. These arrangements being made, the tammas go and sleep at the place the building is to be done. When day breaks, they call the people designated together. 
At dawn, the captains arrive and take their places without putting their hands to the work other than to oversee it. At sunrise, upon the first call of the messenger, each comes running with his lath on his shoulder and puts it in the hole which he has previously dug. The laths are placed in a circle and in the middle they put a very tall pole with knots on it for climbing. Two Indians are placed on top on a cross made of two pieces of wood. Each throws out a noose and seizes a lath by the top. Working in unison they continue to tie them until they have formed a figure like a half orange.

They then cover the laths with heavy timers, all working at the same time and with such dexterity that, each working upward upon his own lath, they do not take more than an hour to finish it from bottom to top. Others came in to relieve them and cover the house with grass to a thickness of three hand breadths. They work from the bottom exactly opposite to the way the Spaniards thatch their houses. They work so dexterously that a little after midday they are finishing the hut, forming of carefully tied grass, the figure which their imagination suggests to them. The building finished, they cut the middle post off at the bottom and the building is thus left standing. During all this time, the overseer walks around with his rods made of two or three fresh, flexible branches for the purpose of hurrying the people. Even though they bring the materials they have been instructed to provide, he goes out to meet the man or woman who is late and who arrives after the work is begun. If the delinquent is a man, the overseer gives him four or five licks across the breast and, if it be a woman, he uncovers her shoulders and does the same thing. This is done without exception of persons, for even though it be his own wife or sister who is at fault, she receives her punishment. No one is offended at this but rather laughs at it. During all the time the people are working the householders are busy preparing food for everybody, having preciously provided quantities of deer meat and many pots of ground corn, which in this section of the Indies is called atole. Then they serve the food from the captains down to the smallest, in order, abundantly, and carefully, because they have earthen vessels, some large and some small, in which to serve the old and the young. This done, the crowd scatters and each goes to his own home much pleased. The difference they make in building these houses is they use more laths than usual for the captains and leading men. Consequently, their houses are very much larger. But no one, even though he be a leading captain, is excused from feeding all those who assemble. In fact, the feast is all the more abundant and more time is used in preparation so that everybody may be abundantly fed.

The significant role played by one figure not mentioned in the above quote, but mentioned elsewhere, is that of the priest or shaman. The priest or shaman was responsible for laying out the dimensions of each structure and for blessing the new 
house upon its completion (Griffith 1954:99; Sabo 1998:168). These actions suggest the sacredness and symbolic importance of house structures. As Sabo (1998:169) has argued, the shaman's role "indicates that the house was recognized as a (potentially) sacred place where qualities associated with the numinous realm could become manifested."

A similar, but less detailed account of construction techniques has been provided by Joutel (Foster 1998:208) who stated that "they cut full-length trees as thick around as a thigh and plant them in the ground upright in a circle, joining them at the top. Then they lath (lattent) the huts and thatch them from the ground to the top." The account of house construction from Casañas is even less detailed, its significance lying in what he chose to note. Casañas (Hatcher 1927:217) emphasized the communal nature of house construction, stating, "as regards other features of their government, these Indians help each other in such a manner that if one's house and all his possessions are burned up, they all gather together, build him a new house, and furnish him whatever he needs for his subsistence and comfort. All these things they do together." This communal activity is further emphasized during descriptions of the planting season, when "they come together and plant whatever each one has to plant, according to the size of the family - beginning first at the home of the gran xinesi. There they plant only a small spot in front of the house in order that he may have something green to enjoy" (Hatcher 1927:217). Following the planting of the plot for the xinesi, the group continued to the plots of the caddices, the other officials, and the viejos, and "in this way they continue working from the highest to the humblest" (Hatcher 1927:217).

As these accounts describe, all members of the dispersed community were called together to take active roles in the building of houses, thus signifying and reinforcing a notion of community through the creation of architectural space. Sabo (1998) has 
examined the symbolic elements inherent in the accounts of house construction. He has argued that the communal nature of house construction emphasizes the notion that houses, and likewise households, were not viewed as independent entities, but were seen as integral components of the broader community and "stood as visible symbols of the interconnectedness of families and households comprising villages and communities" (Sabo 1998:168). In addition, he argues for the possibility that the grass figure crowning the completed house could be a clan symbol, "providing an additional representation of larger social fields within which the house and its occupants were identified" (Sabo 1998:168).

\section{SPACES RESERVED FOR SPECIFIC ACTIVITIES AND/OR PEOPLE}

Several chroniclers noted the presence of assemblies and council meetings among the Caddo groups they encountered. As Casañas noted, "if the Caddi wants to do anything, he calls the old men together, listens to each of their views, and then decides to do what he thinks best, explaining his views to some of the old men and urging agreement" (Hatcher 1927:218). In these closed council meetings there was a clear deference given to age in speaking, sitting, "and in all other courtesies that Christians are accustomed to observe" (Hatcher 1927:218).

Massanet's 1690 account states:

Soon I noticed, outside the yard, opposite the door of the governor's house, another long building, in which no inmates could be seen. I asked who dwelt therein or what purpose it served, and was told that the captains were lodged in that house when the governor called them to a meeting. On the other side I saw yet another and smaller vacant house, and upon my inquiring about this one they answered that in the smaller house the pages of the captains were lodged, for theirs is a law providing that each captain shall bring his page when the governor 
assembles the captains, and they observe this custom. As soon as they arrive, they are lodged in that house, and for each one is laid a large, brightly colored reed mat, on which they sleep, with a bolster made of painted reeds at the head; and when they return home, each one carries with him his mat and pillow. While they attend the meeting the governor provides them with food, until he sends them home (Swanton 1942:149).

Three years before Massanet entered the Hasinai village, Joutel recorded the presence and use of assembly houses. From March 31, 1687, Joutel (Foster 1998:207) commented that "after we had smoked they led us to the chief's hut from which we proceeded quickly to where they were all in a large hut that was about a quarter of a league from there. Here they conducted their festivities and made their preparations for war. Upon our arrival, we found mats spread on the ground on which they made a sign for us to sit, and the elders also sat down themselves around us." In this meeting, a large meal was shared, tobacco was smoked, and the officials discussed their plans to go to war with the Canohatinno (Joutel 1998:207).

The following day, the French were again escorted to the assembly house where the elders were gathered. Finding the Hasinai officials seated upon reed mats, the day began with discussion and a smoke, followed by a meal and trade. The day was spent in assembly with the French securing provisions and a horse. Joutel learned from the Provençal that "the Indians had not entered their huts at all since they had built the assembly hut and that the women took care of bringing them food and the young people served them" (Foster 1998:209). Following up on this, Joutel (Foster 1998:213) noted that "these men had a large assembly hut where they prepared for war with feasts and rejoicing, and they did not return to their customary huts at all."

The Hasinai with whom Joutel met, likely the canahas and elders, were officials from throughout the dispersed Hasinai community. As indicated above, these officials 
"live temporarily in a special house (elongated rather than circular?) when called to the Caddi's compound" (Wyckoff and Baugh 1980:243), with assemblies being held in a separate structure.

Casañas and others described various spaces that were reserved for use by specific individuals and for specific purposes. Elevated seats called tapestles were reserved for the gran xinesi and the caddices. When seated upon these seats, the officials placed their feet on a high bench, thus being fully elevated. Proclamations were made from this elevated postion and, as Casañas stated, "whatever this official says or does is carefully heeded, just as the Catholics obey the Holy Gospels. If he issues a command it is more strictly obeyed by these Indians than the Ten Commandments are observed by the Christians. Therefore, the leaders do not take their seats on this elevation except for a special ceremony" (Hatcher 1927:213).

Interestingly, elevated seats were also used during the First Fruits ceremony. Joutel and Espinosa provided complementary accounts of this ceremony. Joutel stated that "as the corn was beginning to ripen, I watched a ceremony being conducted by one of the elders who had come to the hut. After the arrival, the women went to gather a great many ears of corn. They prepared it by parching and put it in a small basket which they carried on a ceremonial stool which is used only for that purpose and upon which no one sits. One day I wanted to sit on it and the good old woman told me that I must get up or I would die" (Joutel 1998:240).

\section{RELigious, CEREMONIAL, AND SYMBOLIC STRUCTURES/SPACES}

The seventeenth and eighteenth century accounts of the Caddo by French and Spanish chroniclers can be used to identify trends and/or patterns in the organization and 
use of space and offer rich details pertaining to those spaces within buildings and types of buildings themselves that are often described as "specialized" or special purpose in character (Rogers 1982a, 1982b; Story 1990). These religious or symbolic spaces were apparently prominent features in Caddo society. This section examines specific architectural and structural spaces that fall into a religious or symbolic category and what roles such spaces may have played.

Casañas provided a glimpse at otherworldly associations through the description of the supernatural or mythical foundation for a generalized architectural form. He noted that "another gross superstition they have, in which all of them believe implicitly, is that the old men made Heaven and that a woman, who sprang from an acorn, first gave them its outlines; and that it was done by placing timbers in the form of a circle and that Heaven was formed this way" (Hatcher 1927:296).

This belief in the otherworldly equivalent to earthly structures was reiterated in Casañas' discussions of death: "when a person dies, his soul - of which they are not ignorant and which in their idiom they call Cayo - goes to another house where a man guards all who are there until all are gathered together... when all the souls are gathered together they will enter another world to live anew" (Hatcher 1927:294). Death was accompanied by elaborate ceremonies including the shooting of arrows into the sky "to inform the master of the said house - who receives everybody" (Hatcher 1927:294). The shooting of arrows was accompanied by statements such as: "Here he comes! Make him work until we are all united" (Hatcher 1927:294).

One suggestion from Casañas for where the Caddo dead were buried was in reference to the death of a leading official, in that "the Indians go to the place of interment which is always near the house" (Hatcher 1927:297). During the ceremonies 
for the burial of these officials, the deceased was told "that everybody loves him dearly; that everybody is weeping for him; that he must go in peace; that he must work in that other house with the others who have gone before, until those who have begun to work shall have assembled; that he must take up his hatchet and all the rest of the things that are wrapped with him" (Hatcher 1927:298).

Casañas (Hatcher 1927:296) also noted that:

If someone dies or a house burns up they say that death is angry. Therefore, they make an offering of something by hanging it on a pole in front of the house.

When a house burns, they also say that the ground on which they lived, or the hill near the house, has been angered and burned the house; so they do not rebuild the home there but in another spot.

Following the death of a Xinesi all nine Hasinai tribes performed the requisite ceremonies including "placing the world in front of this door. This is done by setting up a very high pole with a large globe of grass on top. They indicate the moons by putting up some large sticks in the shape of the moon. Before these they dance ten days and nights and then they each go home" (Hatcher 1927:298).

Spaces used by religious and ritual practitioners are fundamental to the relationship and interaction between those of this world and the supernatural. Daniel Rogers (1982b:105) has argued that the "concept of cultural space relates to a variety of contexts, not the least of which is the interplay between the world of humans and the realm of the supernatural. In this context cultural space is physically represented by the buildings, grounds, and other enclosures that religious practitioners use." One example of architecture used by a religious practitioner is the temple of the xinesi or fire temple. This temple was the most sacrosanct of spaces, within which the xinesi maintained the sacred 
and perpetual fire and transcended the gap between this world and the otherworld (Sabo 1998).

Casañas provided a detailed discussion of the practices of the xinesi and some of the religious beliefs of the Hasinai. From his descriptions, the idea of shared traditions becomes apparent, in that "all the tribes of the region have the same errors, superstitions, and ceremonies" (Hatcher 1927:290). At the core of these traditions were the beliefs associated with the two children, the caninisí, who had died in a fire (Hatcher 1927:293) and hence "live" near the house of the xinesi and are "from the other side of heaven" (Hatcher 1927:290). The caninisi act as intermediaries between the xinesi and Ayo-aymay, the "great captain" or supreme being. Through the caninisi, the xinesi offered prophecies and, made pleas to Ayo-ay-may on behalf of the Hasinai.

His communications with the caninisi began with the calling of all the groups to the temple where he "gives orders to all the caddices and the old men to come into the house where he keeps the two children. This house is very much larger than the one where he lives" (Hatcher 1927:290). Inside this house is the sacred fire, which is kept burning all day and night. The accouterments associated with his communication with the caninisi included incense, two small reed boxes (representing the children), offerings brought by the officials (some placed directly into the boxes), a rattle, and a mortar (Hatcher 1927:291). Following the ceremony, and after the officials had left, the xinesi “comes out and goes home, about a hundred paces away" (Hatcher 1927:292).

Espinosa provided further details regarding the temple of the xinesi and the related structures of the caninisí. The caninisi (cononicis in Espinosa), as described by Espinosa "are two boys or small children whom their great captain sent from the cachao ayo, or the sky, for the purpose of discussing their problems with them" (Hatcher 
1927:160). The houses of the caninisi were two smaller structures and were located "about a gunshot distant" (Hatcher 1927:160) from the fire temple. The children were said to have lived in the houses until a little more than two years prior to Espinosa's visit. "He understood through an interpreter that the caninisi were there until the Hasinai's enemies the Yojaunes (a Tonkawa band) had burned the houses. That was when the children were seen rising skyward with the smoke, and they never came down again" (Carter 1995:120-121).

Espinosa's account differed from that of Casañas in that the caninisi lived in two separate "small houses about a gunshot distant" from the temple (Hatcher 1927:160-61) rather than in the temple itself as suggested in Casañas. This separation, if an accurate depiction by Espinosa, apparently provided for additional sacred and symbolic architectural spaces associated with these supernatural figures.

Espinosa's (Hatcher 1927:160) account offered a detailed description of the temple, or "house of the great captain":

They have especial superstitions in connection with fire and they worship it. There is a house set apart for this purpose where there is always a fire. They have appointed an old man whose duty it is to keep it up always. He is their chenesi or chief priest. They say that if it goes out everybody will die. This house which was rebuilt in December, 1716, is half way between the Naichas and the Ainas and is common to both people. They say it is the house of the great captain. It is large, round, and thatched, and has within it an altar made of reed mats. On the bed are three finer mats, two of them very small. To one side of the door, upon benches are other reed mats folded into a roll. In the front of the bed is a little square wooden bench, of one piece, with four feet, and slightly raised from the ground. Upon this bench there is usually tobacco and a pipe with feathers and earthenware vessels which are evidently incense burners in which they burn fat and tobacco. Their fire or bonfire is always made of four very large, heavy logs which point toward the four principal directions. The wood is brought in small and kept in a pile outside. Here the old men gather for their consultations and war dances and when they need rain for their crops. Ordinarily their prayers are vain and mere fables. The ashes from their fire continue to accumulate outside and when 
they bring any bones of the enemy whom they have killed, they bury them in these ashes. Near this house there are two other small houses about a gunshot distant. They call them the houses of the two cononicis.

The importance of the temple as a sacred place was further emphasized by Espinosa when he described the role of the temple as similar to that of the parish house or cathedral and referred to it as the "house of the great captain," the house of Ayo-Ay-May. Further emphasizing the significance of this space was the role it played in housing the sacred fire from which all home fires were lit. The function played by the fire temple in providing the fire for each house further illustrates the notion of community as embodied in the cultural landscape and sacred space (Sabo 1998).

Returning to ideological and ceremonial practices, "in the last decade of the twentieth century those dances [the Turkey Dance, the War Dance, and the Drum Dance or Victory Dance], like the Caddos who perform them, descend from those watched by Joutel during the days of victory celebration in the seventeenth century" (Carter 1995:49). Dancing and singing are fundamental Caddo traditions. Dances and songs such as the cah-kit-em'-bin, the drum dance, which provides the origin story of the Hasinai, or the nuh'-ka-oa-shun, the turkey dance, which relates "the stream of events that define the history of the Hasinai people" (Newkumet and Meredith 1988:3, 102), are integral components of Caddo culture. Newkumet and Meredith (1988:3-4) state that "at the heart of Hasinai existence are the cultural traditions that carry the people through space and time. In the movement of dance and the language of song, the reality of existence is projected into the future." While most traditional architectural forms are no longer in use by the Hasinai (see Newkumet and Meredith 1988:36-37), the dance ground, ko-na-cha$k a-w a-a h$-so, remains "the central focus of Hasinai culture and learning, as they have 
been for centuries." These fundamental components of Caddo culture have their roots in the past, and there are suggestions and examples of the use of such spaces in the historic and ethnohistoric record.

As for today:

The Whitebead Dance Ground is a level plaza in northern Caddo county. Around the central plaza are the wooded camp sites used by the Hasinai throughout the period of the dance cycle. The most frequently used dance ground is on tribal land immediately east of the Caddo Tribal Offices near Binger. It is a plaza surrounded by arbors, public buildings, and small family cabins. Both dance grounds are level areas that have been constructed along hill sides. An unusual dance space has been enclosed as a part of the Caddo office building. It has an earthen floor, but is roofed over and has masonry walls surrounding it (Newkumet and Meredith 1988:36).

Nineteenth and twentieth century accounts and photographs document the use and importance of dance grounds for the Caddo (e.g., Parsons 1941). Ethnohistoric accounts of festivals and ceremonies from Joutel, Casañas, Espinosa, and Morfi provide evidence for dance grounds and ritual structures among Caddo groups from centuries before. While a detailed examination of the use of space for each of the ceremonies of today and from the seventeenth, eighteenth, and nineteenth centuries is certainly warranted, it is beyond the scope of this work.

What is of significance to this study is that there is a clear indication of ritually reserved spaces such as dance grounds in the early historical accounts. At least one example indicates an open enclosure used during the September Festival. For instance, as part of the Festival, when the Pleiades were above the temple, the chief priest and a companion sat within a circle made of green reeds surrounding a large fire. Espinosa (Hatcher 1927:171-174) described the ceremony in detail, stating: 
From midnight on one of the Indians is stationed as a watchman or sentinel. He watches to see when the Pleiades are perpendicular - from the house. They call these stars las senates, i.e., "the women," because the devil has made them believe that these stars are people. He then informs the chief conjurer who goes in company with another conjurer to a circle made of green canes stuck in the ground where there is a big bonfire which three or four novices feed continually. The two men seated on an elevation serve as masters of ceremony. The Indians are formed, to their left, as follows, the old women in the first row, or file, behind them the married women and the young girls, and at the end the younger girls. The little girls are in front of this file. To the right there is an arbor with a bonfire under it. Three old men, dressed in the best they have, consisting of curious buffalo robes, go to this fire, each following in the footsteps of the one in front, while the women and children in the ranks begin singing. After a considerable pause, the old men again approach the circle dancing as they come...they then take hollow logs, covered on top with green branches, but the ends of them, and select eight strong Indian women, who, seated at intervals with sticks in each hand, use each the hollow log as a drum, to the accompaniment of the calabash which the old men play, and the songs of the men and women singers to the number of more than twenty. This music is for the dance in which they all engage, old women and girls, old men and boys, and little children. They dance in a circle, the men facing the women, keep time, moving only their feet.

Espinosa's account provided details concerning the use of open enclosures (the reed circle), the presence and use of arbors, and the details of the dance, held within a prepared dance ground area (Carter 1995:118-119).

Casañas described a ceremony lasting seven or eight days during which a large pole was erected in front of dancers. A fire was kept burning in front of the pole, and from the pole was hung "a portion of everything they are offering to God" (Hatcher 1927:214). In addition to this description, he provided the positions of individuals during these ceremonies, stating "nearby is a person who looks like a demon." He continued by writing that "every time a dance begins, a man steps forward as a preacher does and tells the people what they are to ask God for in the next dance," and finally, "on the last day of 
such a meeting the caddi comes forward and encourages the men" (Hatcher 1927:214). At these ceremonies, Casañas remarked that "we can garner in a great harvest [of souls/converts] because many tribes are gathered together in these meetings" (Hatcher 1927:214-215).

Casañas also provided an account of ceremonies honoring the caddices and the xinesi, "in celebration of the victories their ancestors have had" (Hatcher 1927:301). Several of the tribes gathered at these ceremonies, which lasted for three days and nights, and at which there was:

dancing, eating, and fun; all those who have come feast but the Xinesi. He goes without eating from three days and without sleeping for three nights. They do not let him sleep or eat. He does not even drink or rest, but he is continually stirring about from place to place as if making the sound of dancing. At these meetings and feasts certain superstitions are usually noted. The crowd that gather is very large for men, women, and children come to the feast because they are given plenty to eat (Hatcher 1927:301-302).

Casañas concluded this description by noting the preference of the caddi or xinesi to have someone "at their side whose importance they recognize, so that all the other Indians may see and know the estimation in which they, themselves, are held...to be at the side of the caddi would give him to understand that the minister is less than he and that the minister owes obedience to him" (Hatcher 1927:302).

\section{SUMMARY}

The ethnohistoric and archival records concerning the Caddo peoples that lived in the Caddo area are invaluable for examining architecture and the use of space during the early years of Caddo and European contact and interaction. These sources provide 
information on domestic, sacred, and otherworldly spaces as well as provide insights into the cultural significance of such spaces. Our understanding of Caddo cultural practice will continue to be enhanced as we further investigate the concepts and agency behind the creation, manipulation, use, and destruction of such spaces. When combined with the rich archaeological record from the Caddo area, these sources can aid in approaching an understanding of the role that architecture and architectural practice played in the broader Caddo society. The following chapters provide details on both mound and non-mound Caddo structures from throughout the study area. 


\section{CHAPTER 4}

\section{ARCHITECTURE FROM THE GEORGE C. DAVIS SITE}

\section{INTRODUCTION}

The George C. Davis site (41CE19) in Cherokee County, Texas (Figure 9), is one of the most well known Caddo sites in eastern Texas. The Davis site consists of a large village and three earthen mounds (A-C), with Mounds A and C likely built in the Formative Caddo period, between ca. A.D. 850-1000, and Mound B built around A.D. 1200 (Perttula 1997; Story 1997, 1998, 2000). The site appears to have been occupied from the ninth century into the early $14^{\text {th }}$ century A.D. (Story 1997, 1998, 2000).

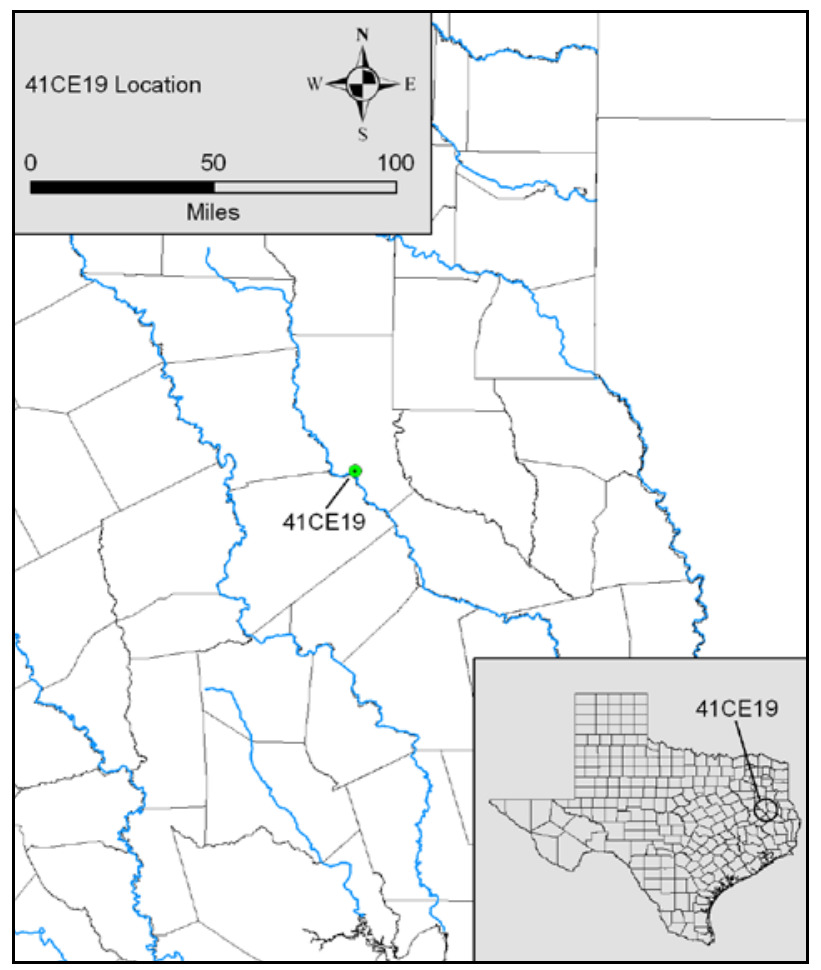

Figure 9. Location of the George C. Davis site. 
The Davis site was recorded in 1919 by J. E. Pearce of the University of Texas (UT), with funding from the Smithsonian Institution's Bureau of American Ethnology. E. B. Sayles conducted an uncontrolled surface collection at the site in 1933. The first extensive professional excavations at the site were conducted from 1939-1941 by a Works Progress Administration (WPA) crew directed by H. Perry Newell. The WPA excavations focused on Mound A and an adjacent area to the southeast. Subsequent excavations directed by Dee Ann Story in 1968, 1970, 1977, and 1978 focused on Mounds B and C, village areas, and the borrow pit. The 1978 Texas A\&M University excavations (Creel 1979), and those conducted by Prewitt and Associates, Inc. in 1980 (Fields and Thurmond 1980), investigated portions of the site to the north of Weeping Mary Road. Figure 10 provides a map of the site showing the previous excavations.

The Davis site has yielded more architectural data on structures from a single Caddo site than any other Caddo site in eastern Texas; over 50 structures have been at least partially excavated to date. The structures at the site include those associated with two of the three earthen mounds (Mounds A and B), the village structures, and the Mound C pre-mound burial pit feature. These previously excavated structures vary in size and shape from rectangular or square to small circular structures (such as Feature 7 with an interior area of $1.8 \mathrm{~m}^{2}$ ) to a large circular structure (Feature 111) associated with Mound B, and having an interior area of $254.5 \mathrm{~m}^{2}$. The smaller structures (such as Features 7, 50, and 52) may represent the post hole outlines of granaries or storage platforms as seen at other sites such as the Oak Hill Village (Perttula and Rogers 2007; Rogers and Perttula 2004) and Hatchel (Perttula 2005). Prior to recent work begun in earnest in 2003, the majority of structures identified at Davis were from the Mound A 
area excavations by the WPA with additional structures identified in subsequent excavations by Dee Ann Story and others.

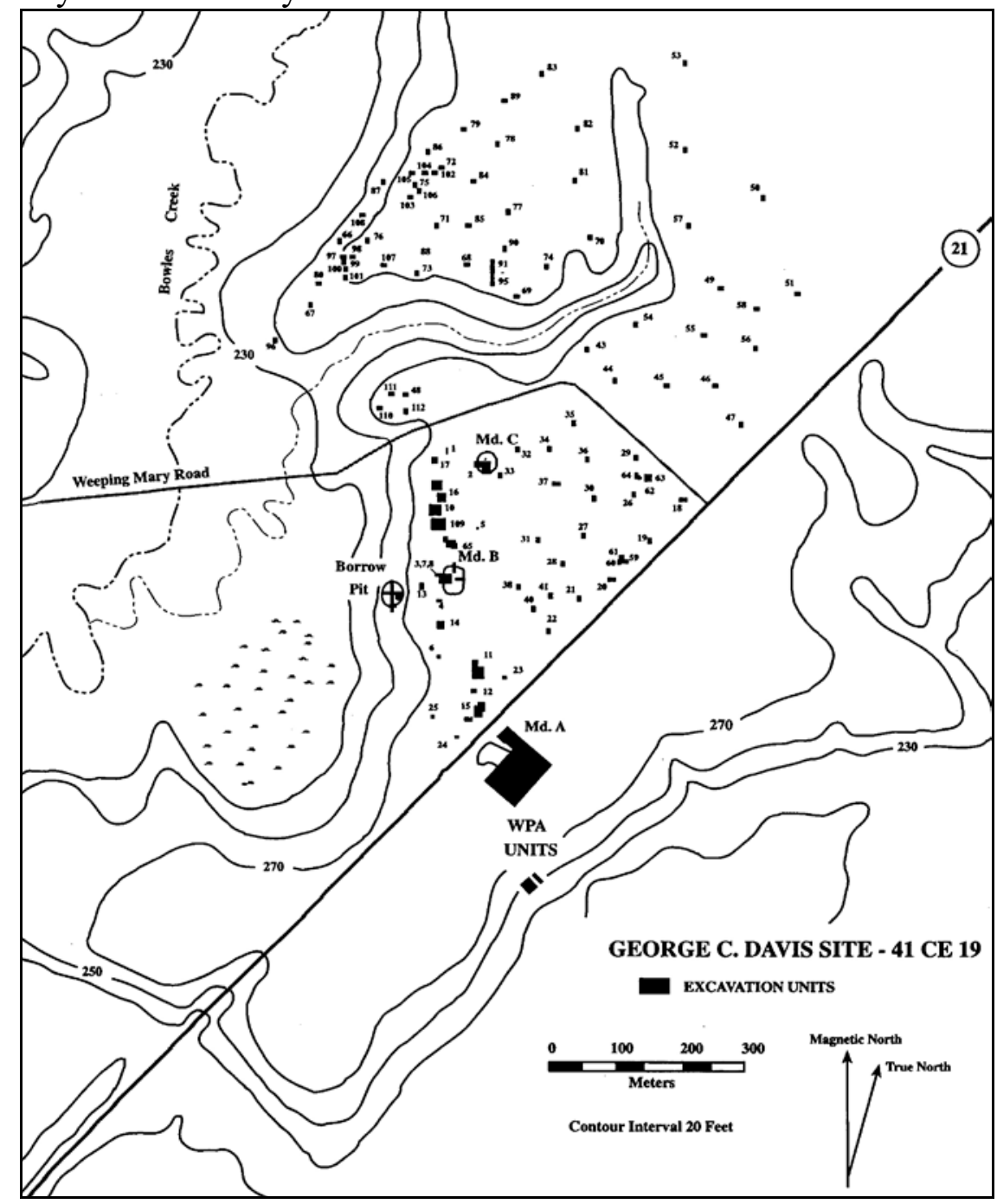

Figure 10. Map of previous excavations at the George C. Davis site (Story 1997). Reproduced courtesy of the Texas Archeological Society.

As reported elsewhere by Creel et al. (2005), Schultz et al. (2004), and Osburn et al. (2008), the primarily geophysical work conducted at the site since 2002 has substantially increased the catalog of known structures from the site. Between October 2002 and July 2003, a series of surveys were conducted at George C. Davis by UT- 
Austin and the Texas Archeological Research Laboratory (TARL) using primarily a cesium sensor magnetometer (Creel et al. 2005). The Texas Historical Commission (THC) conducted additional geophysical surveys in 2008 on the adjoining Indian Mound Nursery property (Osburn et al. 2008). These data provide information on such things as structure size, shape, and location, but lack the chronological information necessary to delineate the age of individual structures or determine which structures predated which. Nevertheless, this glimpse at structure form, intrasite distribution, and spatial patterning provides a wealth of information on intrasite spatial organization of structures and related features.

This chapter first provides a discussion of the previously excavated structures from the Davis site. This is followed by a discussion on the structures identified through magnetometer surveys at the site by archaeologists from UT-Austin, TARL, and the THC. Finally, the chapter includes a discussion of the results of the 2003 excavations at the site that were guided in large part by the findings from the magnetometer data.

\section{Previously ExCAVATEd Structures from The George C. DAVIS Site}

Prior to 2003, 52 structures had been at least partially excavated at the site. Fortythree of these were investigated as part of the WPA work in the Mound A area and nine were identified from work elsewhere at the site. Varying in size, shape, and presumed function, these structures include those associated with two of the three earthen mounds as well as those located within the "village area" (Table 3). The detailed study of the structures and associated features investigated prior to 1977 is the subject of Carolyn Spock's master's thesis (1977). Spock (1977:28) sums up the architectural forms present at the George C. Davis site by stating there is "much variability in the location, size, and 
shape of structures, in the arrangement of outer wall posts and interior posts, the form of hearths, and the kinds of pits present. To the architectural variation is to be added differences in the treatment of structures: some, for example, were deliberately destroyed."

Table 3. Locations of previously excavated structures from the George C. Davis site (adapted from Spock 1977:26).

\begin{tabular}{|c|c|c|c|}
\hline Location & Feature & Location & Feature \\
\hline \multirow{2}{*}{ under Mound B } & 111 & \multirow[t]{25}{*}{ Adjacent to Mound A } & 9 \\
\hline & 112 & & 10 \\
\hline ca. $5 \mathrm{~m}$ west of Mound B & 120 & & 11 \\
\hline \multirow[t]{7}{*}{ Under Mound A } & 31 & & 12 \\
\hline & 37 & & 13 \\
\hline & 38 & & 14 \\
\hline & 42 & & 15 \\
\hline & 43 & & 16 \\
\hline & 44 & & 17 \\
\hline & 45 & & 18 \\
\hline \multirow[t]{4}{*}{ On Mound A platforms } & 34 & & 19 \\
\hline & 36 & & 29 \\
\hline & 39 & & 30 \\
\hline & 40 & & 32 \\
\hline \multirow[t]{12}{*}{ Village area } & 2 & & 33 \\
\hline & 3 & & 35 \\
\hline & 4 & & 41 \\
\hline & 6 & & 46 \\
\hline & 7 & & 47 \\
\hline & 8 & & 48 \\
\hline & 54 & & 49 \\
\hline & 146 & & 50 \\
\hline & 160 & & 51 \\
\hline & 185 & & 52 \\
\hline & & & 53 \\
\hline & & & 55 \\
\hline
\end{tabular}


Spock's thesis includes an examination of 50 of the previously excavated structures from the site (those excavated prior to 1977; two additional structures, features 160 and 185, were excavated after Spock's study). Spock (1977:165-179) classifies the Davis structures into two broad categories: domiciles and special function structures. In her analysis, Spock (1977:166) classifies those structures not directly associated with mounds and those generally lacking "specialized" features or structural attributes such as partitions and extended entrances as domiciles. Spock's (1977:169) other architectural category, special function structures, includes those structures directly associated with mounds, structures that are exceptionally large or small in size, those with unusual shapes, and/or those characterized by unusual or distinctive interior features. Spock (1977:189) concludes her study by stating:

The pattern which can be seen at Davis shows a distribution - across the site and through time - of domiciles, small storage and/or special function structures (probably representing granaries or temporary housing for pages or dancers), larger community/special function structures (providing the meeting halls, religious centers, specialized dwellings, etc), and outside activity areas (for cooking, preparing hides or pottery, for drying food, etc). Some subsurface storage was suggested through the presence of pits.

Spock's analysis places 30 structures in the domicile category. Story (1998:40, fn. 7) notes that the two structures excavated after 1977 fit into Spock's domicile category. Table 4 is adapted from Spock (1977) and provides a summary of the 32 previously excavated structures categorized as domiciles.

As classified by Spock, the structures classified as domiciles are round $(\mathrm{n}=25)$, sub-round $(\mathrm{n}=3)$, or irregularly round $(\mathrm{n}=2)$, with diameters ranging from $5.7 \mathrm{~m}$ (Feature 17) to $13.2 \mathrm{~m}$ (Feature 49). Interior area for these structures ranges from $19.6 \mathrm{~m}^{2}$ (Feature 
120) to $136.8 \mathrm{~m}^{2}$ (Feature 49), with a mean area of $68.21 \mathrm{~m}^{2}$. Spock's domiciles are distributed throughout the site, with 17 structures located north of Mound A, five others to the east and one to the west of Mound A, one west of Mound B, and two are between Mounds A and B (Spock 1977:167). Center posts were identified in 10 of these structures but hearths were found in only two. At least one of the center posts was associated with a central hearth.

Some of these structures were only partially exposed with between six to 65 exterior wall post holes. The exterior post holes range from $9 \mathrm{~cm}$ to $51 \mathrm{~cm}$ in diameter and from $6 \mathrm{~cm}$ to $73 \mathrm{~cm}$ deep. The mean diameter of the exterior posts for the 32 domiciles ranges from $14 \mathrm{~cm}$ (Feature 8) to $26 \mathrm{~cm}$ (Feature 51). Interior posts posed a problem in Spock's analysis given the intense rebuilding in parts of the site (Figure 11) (Spock 1977). Spock was unable to definitely assign interior posts to 14 structures (these are marked as "?" on tables 4 and 5), although she was able to confidently assign 112 interior posts to 12 structures.

According to Spock's analysis, $20^{1}$ structures are classified as "special function structures" (Spock 1977:169). These structures (Table 5) are those "whose placement and architectural design make them unusual," they "are often exceptionally large or quite small structures, are of unusual shape or have distinctive interior features" (Spock 1977:169), and all but seven are directly associated with the mounds at the site. Spock (1977:169) divides the special function structures into four subclasses: based on size (interior area less than $\left.3 \mathrm{~m}^{2}\right)(\mathrm{n}=3)$; those built on mound platforms $(\mathrm{n}=4)$; pre-mound structures $(\mathrm{n}=9)$; and non-mound structures with distinctive architectural forms and/or associated features $(n=4)$.

\footnotetext{
${ }^{1}$ Spock includes 21 structures in her special function class. One of these, Feature 134, is the Mound C premound burial pit and is not included here.
} 


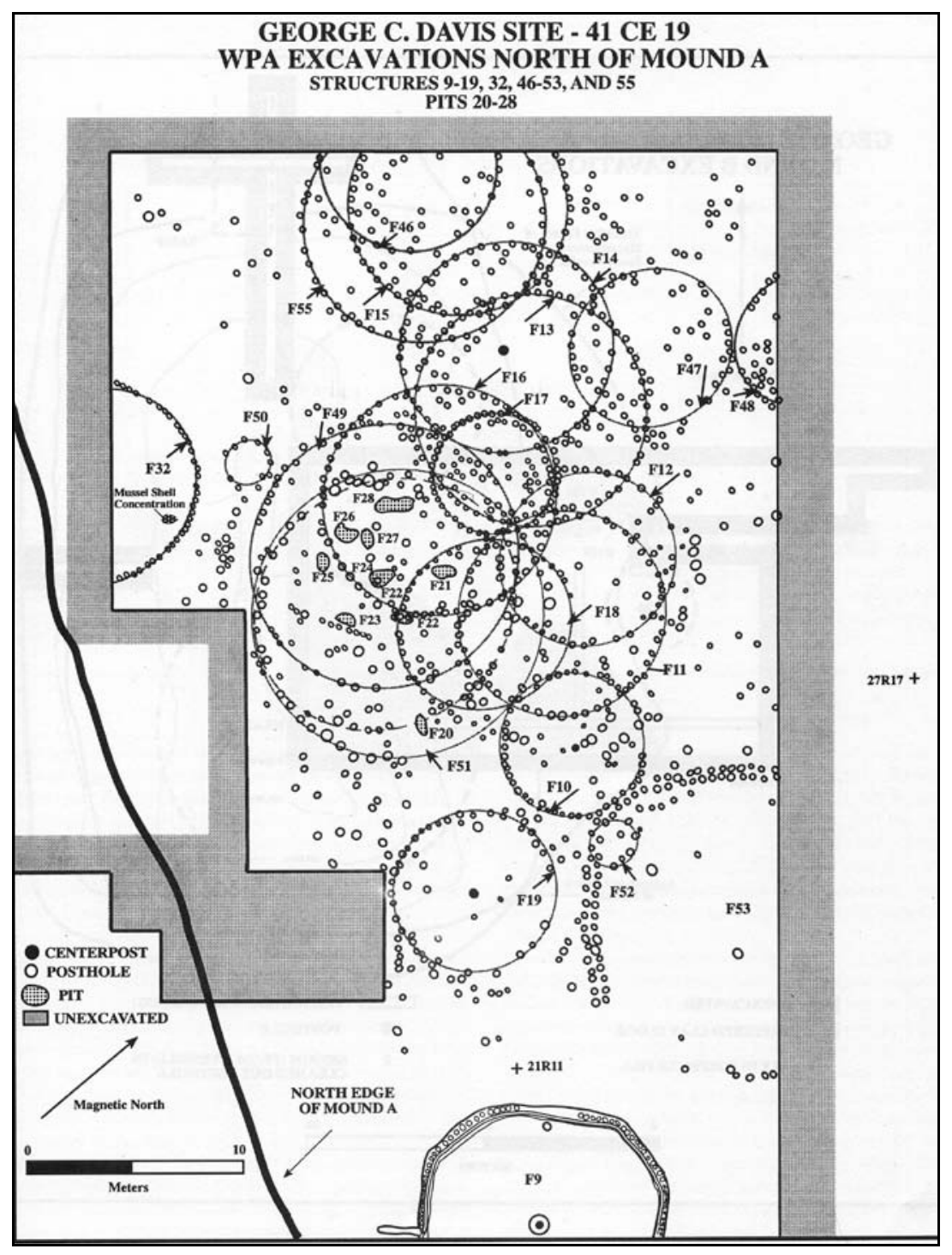

Figure 11. Area of overlapping structures adjacent to Mound A (Story 1998:29, Figure 214). Reproduced courtesy of TARL. 
Table 4. Structures classified as domiciles by Spock (adapted from Spock 1977:30).

\begin{tabular}{|c|c|c|c|c|c|c|c|c|c|c|c|c|c|c|c|c|c|c|c|c|c|c|c|}
\hline \multirow[b]{3}{*}{ 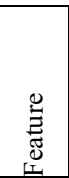 } & \multirow[b]{3}{*}{ 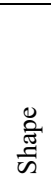 } & \multirow[b]{3}{*}{ 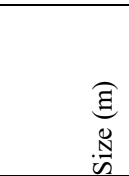 } & \multirow[b]{3}{*}{ 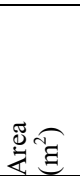 } & \multicolumn{7}{|c|}{ Exterior Posts } & \multicolumn{7}{|c|}{ Interior Posts } & \multicolumn{3}{|c|}{ Center Post } & \multicolumn{3}{|c|}{ Hearth } \\
\hline & & & & \multirow[b]{2}{*}{ 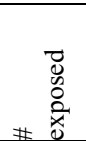 } & \multicolumn{3}{|c|}{ Diameter } & \multicolumn{3}{|c|}{ Depth } & \multirow[b]{2}{*}{ 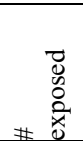 } & \multicolumn{3}{|c|}{ Diameter } & \multicolumn{3}{|c|}{ Depth } & \multirow[b]{2}{*}{ 泀 } & \multirow[b]{2}{*}{$\begin{array}{l}\overline{\tilde{0}} \\
\text { صू. }\end{array}$} & \multirow[b]{2}{*}{ 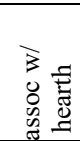 } & \multirow[b]{2}{*}{$\stackrel{\tilde{N}}{\tilde{n}}$} & \multirow[b]{2}{*}{ 言 } & \multirow[b]{2}{*}{ 怘 } \\
\hline & & & & & $\stackrel{x}{\stackrel{x}{\Sigma}}$ & $\stackrel{\Xi}{\Sigma}$ & 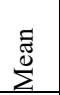 & 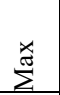 & $\stackrel{\Xi}{\Sigma}$ & 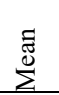 & & $\sum_{\Sigma}^{\star x}$ & $\Xi$ & $\sum_{\tilde{E}}^{\tilde{E}}$ & $\sum_{\Sigma}^{x}$ & $\Xi$ & 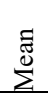 & & & & & & \\
\hline 2 & $\mathrm{c}$ & 9.2 & 66.5 & 13 & 21 & 12 & 16 & 34 & 9 & 20 & 1 & & & 31 & & & 31 & & & & & & \\
\hline 3 & $\mathrm{sr}$ & 8.2 & 52.8 & 35 & 21 & 12 & 17 & 27 & 6 & 15 & 22 & 21 & 6 & 17 & 21 & 3 & 10 & 21 & 21 & & & & \\
\hline 4 & ss & $10.7 \times 11.8$ & 99.4 & 57 & 31 & 12 & 18 & 37 & 6 & 15 & 8 & 34 & 14 & 20 & 31 & 9 & 18 & 18 & 12 & & & & \\
\hline 8 & $\mathrm{c}$ & 6.5 & 33.2 & 32 & 21 & 12 & 14 & 46 & 9 & 25 & 5 & & & 21 & & & 12 & & & & & & \\
\hline 10 & $\mathrm{c}$ & 6.5 & 33.2 & 50 & 34 & 11 & 15 & 43 & 9 & 26 & $?$ & & & & & & & 18 & 27 & & & & \\
\hline 11 & $\mathrm{c}$ & 9.5 & 70.9 & 54 & 24 & 12 & 16 & 70 & 9 & 25 & $?$ & & & & & & & & & & & & \\
\hline 12 & $\mathrm{c}$ & 8 & 50.3 & 39 & 27 & 12 & 17 & 46 & 15 & 27 & $?$ & & & & & & & & & & & & \\
\hline 13 & $\mathrm{c}$ & 10.7 & 89.9 & 63 & 24 & 14 & 18 & 49 & 6 & 30 & $?$ & & & & & & & & & & & & \\
\hline 14 & $\mathrm{c}$ & 9.7 & 73.9 & 44 & 27 & 12 & 17 & 61 & 15 & 37 & $?$ & & & & & & & 27 & 18 & & & & \\
\hline 15 & $\mathrm{c}$ & 9.9 & 77 & 38 & 24 & 15 & 19 & 55 & 21 & 39 & $?$ & & & & & & & & & & & & \\
\hline 16 & $\mathrm{c}$ & 10.5 & 86.6 & 57 & 34 & 12 & 20 & 70 & 18 & 33 & $?$ & & & & & & & & & & & & \\
\hline 17 & $\mathrm{c}$ & 5.7 & 25.5 & 61 & 21 & 12 & 17 & 37 & 6 & 22 & $?$ & & & & & & & & & & & & \\
\hline 18 & $\mathrm{c}$ & 8.4 & 55.4 & 37 & 31 & 12 & 16 & 64 & 12 & 27 & $?$ & & & & & & & & & & & & \\
\hline 19 & $\mathrm{c}$ & 7.2 & 40.7 & 32 & 27 & 15 & 19 & 55 & 12 & 30 & 14 & 24 & 15 & 17 & 37 & 8 & 26 & 21 & 46 & & & & \\
\hline 29 & $\mathrm{sr}$ & 8.8 & 60.8 & 35 & 21 & 12 & 18 & 82 & 15 & 53 & 11 & 24 & 12 & 18 & 73 & 24 & 39 & & & & & & \\
\hline 30 & $\mathrm{c}$ & 6.1 & 29.2 & 65 & 18 & 12 & 14 & 70 & 9 & 36 & & & & & & & & 20 & 32 & $\mathrm{x}$ & 48 & 20 & \\
\hline 32 & $\mathrm{c}$ & 9.2 & 66.5 & 34 & 18 & 12 & 15 & 27 & 12 & 20 & & & & & & & & & & & & & \\
\hline 33 & $\mathrm{c}$ & 10.7 & 89.9 & 39 & 31 & 12 & 22 & 92 & 37 & 69 & 8 & 34 & 12 & 20 & 73 & 31 & 50 & 18 & 134 & & 168 & 11 & \\
\hline 41 & $\mathrm{c}$ & 8.8 & 60.8 & 46 & 27 & 15 & 20 & 73 & 43 & 63 & 1 & & & 21 & & & 21 & 34 & 55 & & & & \\
\hline 46 & $\mathrm{c}$ & 8.9 & 62.2 & 15 & 21 & 9 & 18 & 37 & 12 & 26 & $?$ & & & & & & & & & & & & \\
\hline 47 & $\mathrm{c}$ & 7.2 & 40.7 & 26 & 21 & 12 & 16 & 49 & 12 & 48 & $?$ & & & & & & & & & & & & \\
\hline 48 & $\mathrm{c}$ & 7.2 & 40.7 & 12 & 27 & 15 & 20 & 37 & 18 & 28 & 15 & 31 & 15 & 20 & 31 & 6 & 16 & & & & & & \\
\hline 49 & $\mathrm{c}$ & 13.2 & 137 & 58 & 40 & 15 & 20 & 70 & 15 & 37 & $?$ & & & & & & & & & & & & \\
\hline 51 & $\mathrm{c}$ & 13 & 133 & 49 & 46 & 12 & 26 & 85 & 15 & 47 & $?$ & & & & & & & & & & & & \\
\hline 54 & ss & $9 \times 9.5$ & 67.2 & 46 & 23 & 9 & 17 & 40 & 6 & 17 & 21 & 20 & 11 & 16 & 38 & 3 & 16 & 18 & 12 & & & & \\
\hline 55 & $\mathrm{c}$ & 11.1 & 96.8 & 34 & 27 & 14 & 18 & 46 & 6 & 28 & $?$ & & & & & & & & & & & & \\
\hline 120 & $\mathrm{c}$ & 5 & 19.6 & 6 & & 16 & 17 & 62 & 10 & 38 & & & & & & & & & & & & & \\
\hline 139 & $\mathrm{sr}$ & $9.6 \times 9.9$ & 74.7 & 40 & & & & 81 & 40 & 56 & 1 & & & 16 & & & 27 & & & & & & \\
\hline 146 & $\mathrm{c}$ & 10.8 & 91.6 & 64 & 55 & 10 & 20 & 59 & 26 & 39 & 5 & $35 \times 45$ & 10 & 33 & & 28 & 50 & 20 & 20 & & & & \\
\hline 160 & $\mathrm{c}$ & 12.4 & 121 & 50 & & & & 69 & 22 & 44 & & & & & & & & & & & & & \\
\hline 185 & Ss & 12 & 113 & & & & & & & & & & & & & & & & & & & & \\
\hline
\end{tabular}


Table 5. George C. Davis structures classified as special purpose structures (adapted from Spock 1977:30).

\begin{tabular}{|c|c|c|c|c|c|c|c|c|c|c|c|c|c|c|c|c|c|c|c|c|c|c|c|c|c|c|c|}
\hline \multirow[b]{3}{*}{ 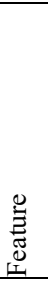 } & \multirow[b]{3}{*}{ 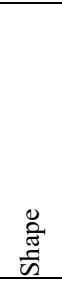 } & \multirow[b]{3}{*}{ 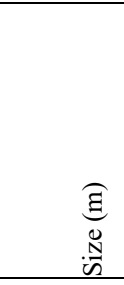 } & \multirow[b]{3}{*}{ 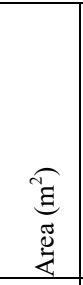 } & \multirow[b]{3}{*}{ 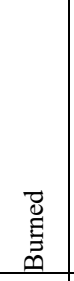 } & \multirow{3}{*}{ 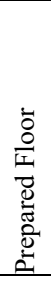 } & \multicolumn{7}{|c|}{ Exterior Posts } & \multicolumn{7}{|c|}{ Interior Posts } & \multicolumn{3}{|c|}{ Center Post } & \multicolumn{3}{|c|}{ Hearth } & \multicolumn{2}{|c|}{$\begin{array}{c}\text { Post } \\
\text { trenches }\end{array}$} \\
\hline & & & & & & \multirow[b]{2}{*}{$\begin{array}{l}\overrightarrow{0} \\
0 \\
0 \\
0 \\
0 \\
0 \\
\#\end{array}$} & \multicolumn{3}{|c|}{ Diameter } & \multicolumn{3}{|c|}{ Depth } & & \multicolumn{3}{|c|}{ Diameter } & \multicolumn{3}{|c|}{ Depth } & \multirow[b]{2}{*}{ 志 } & \multirow[b]{2}{*}{ 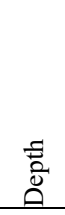 } & \multirow{2}{*}{ 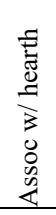 } & \multirow[b]{2}{*}{ 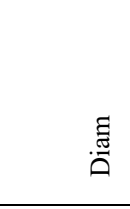 } & \multirow[b]{2}{*}{ 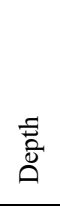 } & \multirow{2}{*}{$\begin{array}{l}\vec{\Xi} \\
. \Xi \\
\text { 至 } \\
\text { U. }\end{array}$} & & \\
\hline & & & & & & & $\stackrel{x}{x}^{x}$ & $\stackrel{\Xi}{\Sigma}$ & $\sum_{\Sigma}^{\Xi}$ & 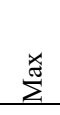 & 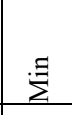 & $\sum_{\Sigma}^{\bar{E}}$ & 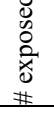 & $\stackrel{\star}{\Sigma}$ & $\stackrel{\Xi}{\Sigma}$ & $\stackrel{\mathrm{E}}{\Sigma}^{ \pm}$ & $\stackrel{\star x}{\Sigma}$ & $\stackrel{\Xi}{\Sigma}$ & $\sum_{\Sigma}^{\mathbb{E}}$ & & & & & & & 㤩 & 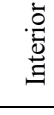 \\
\hline 6 & ss & $9.7 \times 10.3$ & 97 & & & 62 & 20 & 11 & 15 & 24 & 13 & 22 & 5 & 31 & 15 & 21 & 46 & 21 & 29 & 37 & 12 & & & & & & \\
\hline 7 & $\mathrm{c}$ & 1.5 & 1.8 & & & 7 & 16 & 13 & 15 & 16 & 10 & 13 & 1 & & & & & & & & & & & & & & \\
\hline 9 & ss & $9.9 \times 9.9$ & 93 & $\mathrm{x}$ & $\mathrm{x}$ & 148 & 18 & 6 & 15 & 107 & 61 & 98 & $?$ & 21 & 12 & 18 & 73 & 24 & 38 & 31 & 58 & $\mathrm{x}$ & 91 & 10 & $\mathrm{x}$ & $\mathrm{x}$ & \\
\hline 31 & $\mathrm{c}$ & 14.9 & 174 & & & 78 & 31 & 18 & 25 & 101 & 37 & 77 & 30 & 27 & 9 & 18 & 43 & 15 & 28 & 24 & 27 & $\mathrm{x}$ & $122 \times 107$ & 10 & $\mathrm{x}$ & & \\
\hline 34 & ss & $7.9 \times 7.9$ & 58.1 & & & 42 & 23 & 9 & 11 & 78 & 9 & 60 & & & & & & & & 24 & 84 & $\mathrm{x}$ & $244 \times 296$ & 3 & & & \\
\hline 35 & $\mathrm{~m}$ & $6.9 \times 9.3$ & 51.5 & $\mathrm{x}$ & $\mathrm{x}$ & 193 & 18 & 6 & 10 & 98 & 18 & 59 & 5 & 31 & 12 & 18 & 76 & 21 & 50 & & & & 82 & 9 & & $\mathrm{x}$ & $?$ \\
\hline & Mai & line, main & rench $p$ & sst hole & & 94 & 18 & 6 & 11 & 98 & 27 & 66 & & & & & & & & & & & & & & & \\
\hline & Outs & de of main & ine in tr & ench & & 8 & 12 & 6 & 8 & 70 & 55 & 65 & & & & & & & & & & & & & & & \\
\hline & Beh & d primary & ine opp & site en & & 20 & 12 & 6 & 8 & 61 & 46 & 54 & & & & & & & & & & & & & & & \\
\hline & Foul & short outer & renches & & & 23 & 12 & 6 & 10 & 73 & 52 & 66 & & & & & & & & & & & & & & & \\
\hline & In tr & nches arou & d entry & & & 48 & 18 & 6 & 11 & 70 & 18 & 45 & & & & & & & & & & & & & & & \\
\hline 36 & ss & 7.2 & 41.2 & & & 41 & 24 & 11 & 16 & 88 & 27 & 61 & & & & & & & & 21 & 72 & $\mathrm{x}$ & 183 & 9 & & & \\
\hline 37 & o & $7.4 \times 10.3$ & 61.5 & & & 89 & 18 & 12 & 14 & 79 & 6 & 55 & 17 & 24 & 12 & 15 & 61 & 24 & 46 & 21 & 59 & $\mathrm{x}$ & 79 & 14 & & & \\
\hline 38 & ro & $6.4 \times 7.2$ & 36.3 & & & 67 & 18 & 9 & 12 & 92 & 3 & 50 & 13 & 18 & 12 & 14 & 61 & 24 & 52 & 21 & 59 & $\mathrm{x}$ & 79 & 14 & & & \\
\hline 39 & ss & $8.7 \times 8.7$ & 66.3 & & & 48 & 21 & 15 & 17 & 82 & 38 & 71 & 2 & 15 & 12 & 14 & 67 & 52 & 59 & 17 & 53 & $\mathrm{x}$ & 113 & 7 & $\mathrm{x}$ & & \\
\hline 40 & ss & $7 \times 7$ & 44.1 & & & 41 & 26 & 11 & 16 & 73 & 34 & 58 & & & & & & & & 21 & 79 & $\mathrm{x}$ & 79 & 9 & $\mathrm{x}$ & & \\
\hline 42 & $\mathrm{c}$ & 11.8 & 109 & & & 51 & 24 & 12 & 17 & 82 & 40 & 67 & 45 & 27 & 9 & 19 & 82 & 15 & 43 & & & & & & & & \\
\hline 43 & $\mathrm{c}$ & $7.2 \times 7.8$ & 44.2 & & $\mathrm{x}$ & 71 & 21 & 9 & 13 & 85 & 24 & 59 & 25 & 31 & 9 & 16 & 131 & 9 & 35 & 15 & 73 & $\mathrm{x}$ & 95 & 9 & & $\mathrm{x}$ & \\
\hline & Tren & h post hol & & & & 26 & 21 & 9 & 13 & 85 & 31 & 56 & & & & & & & & & & & & & & & \\
\hline & Non & trench post & noles & & & 45 & 21 & 9 & 13 & 82 & 24 & 61 & & & & & & & & & & & & & & & \\
\hline 44 & $\mathrm{c}$ & $8.9 \times 9.3$ & 64.3 & & & 84 & 18 & 9 & 14 & 95 & 49 & 75 & 20 & 21 & 9 & 12 & 52 & 21 & 31 & 23 & 73 & $\mathrm{x}$ & 61 & 6 & & $\mathrm{x}$ & $\mathrm{x}$ \\
\hline & Tren & h post hol & & & & 7 & 18 & 9 & 12 & 79 & 61 & 73 & 14 & 9 & 9 & 9 & 31 & 27 & 29 & & & & & & & & \\
\hline & Non & trench post & holes & & & 77 & 18 & 9 & 14 & 95 & 49 & 75 & 6 & 21 & 15 & 19 & 52 & 21 & 34 & & & & & & & & \\
\hline
\end{tabular}




\begin{tabular}{|c|c|c|c|c|c|c|c|c|c|c|c|c|c|c|c|c|c|c|c|c|c|c|c|c|c|c|c|}
\hline \multirow{2}{*}{ 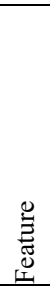 } & \multirow{2}{*}{ 悹 } & \multirow{2}{*}{ 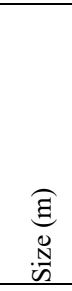 } & \multirow{2}{*}{$\underset{\Im}{\overparen{\Xi}}$} & \multirow{2}{*}{ 总 } & \multirow{2}{*}{ 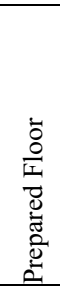 } & \multicolumn{7}{|c|}{ Exterior Posts } & \multicolumn{7}{|c|}{ Interior Posts } & \multicolumn{3}{|c|}{ Center Post } & \multicolumn{3}{|c|}{ Hearth } & \multicolumn{2}{|c|}{$\begin{array}{c}\text { Post } \\
\text { trenches }\end{array}$} \\
\hline & & & & & & $\begin{array}{l}\vec{D} \\
0 \\
0 \\
0 \\
0 \\
0 \\
0 \\
\#\end{array}$ & \multicolumn{3}{|c|}{ Diameter } & \multicolumn{3}{|c|}{ Depth } & \multicolumn{4}{|c|}{ Diameter } & \multicolumn{3}{|c|}{ Depth } & ڤี. & 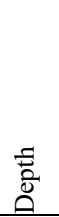 & 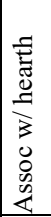 & \multicolumn{2}{|r|}{ 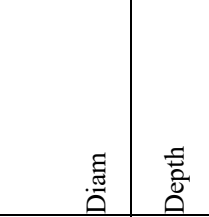 } & 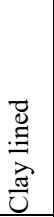 & $\stackrel{\mathscr{g}}{\stackrel{\Xi}{\Xi}}$ & 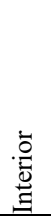 \\
\hline \multirow[t]{5}{*}{45} & $\mathrm{c}$ & 13.9 & 152 & & & 100 & 24 & 6 & 15 & 134 & 12 & 78 & 66 & 24 & 4 & 16 & 95 & 9 & 33 & 46 & 61 & $\mathrm{x}$ & 107 & 20 & & $\mathrm{x}$ & \\
\hline & \multirow{2}{*}{\multicolumn{5}{|c|}{$\begin{array}{l}\text { Main outline, trench post holes } \\
\text { Supplemental trench post } \\
\text { holes }\end{array}$}} & 64 & 24 & 9 & 16 & 134 & 82 & 105 & & & & & & & & & & & & & & & \\
\hline & & & & & & 8 & 24 & 12 & 15 & 64 & 24 & 46 & & & & & & & & & & & & & & & \\
\hline & \multicolumn{5}{|c|}{ Main outline, non-trench } & 28 & 21 & 6 & 11 & 49 & 12 & 24 & & & & & & & & & & & & & & & \\
\hline & \multicolumn{5}{|c|}{ Extra wall post holes } & 71 & 20 & 9 & 16 & 64 & 37 & 52 & 8 & 27 & 15 & 19 & 52 & 24 & 42 & & & & & & & & \\
\hline 50 & $\mathrm{c}$ & 1.9 & 2.8 & & & 10 & 18 & 12 & 15 & 40 & 12 & 20 & $?$ & & & & & & & & & & & & & & \\
\hline 52 & $\mathrm{c}$ & 1.9 & 2.8 & & & 10 & 21 & 15 & 18 & 52 & 24 & 34 & $?$ & & & & & & & & & & & & & & \\
\hline \multirow[t]{2}{*}{111} & $\mathrm{c}$ & 18 & 255 & $\mathrm{x}$ & $\mathrm{x}$ & 52 & $24 \times 34$ & 3 & 11 & 123 & 16 & 69 & 5 & 19 & 10 & 14 & 60 & 36 & 44 & & & & 118 & 6 & $\mathrm{x}$ & & \\
\hline & Maj & r post $\mathrm{l}$ & & & & 28 & $24 \times 34$ & 7 & 15 & 123 & 26 & 93 & & & & & & & & & & & & & & & \\
\hline 112 & $\mathrm{c}$ & 11 & 95 & & & 12 & & 17 & 25 & 79 & 27 & 64 & 1 & & & 22 & & & 27 & & & & & & & & \\
\hline 125 & c & 7.4 & 43 & & & 88 & 20 & 8 & 12 & 60 & 26 & 43 & 5 & 70 & 20 & 47 & 83 & 70 & 65 & & & & $106 \times 110$ & 45 & $\mathrm{x}$ & & \\
\hline
\end{tabular}


The 20 structures Spock classifies as special function structures are round $(n=10)$, sub-round $(n=3)$, oval $(n=1)$, rounded oval $(n=1)$, sub-square $(n=1)$, square with diagonal corners $(n=2)$, square with rounded corners $(n=2)$, and the feature referred to as the maze, Feature 35 (Figure 12). This structure is generally circular with protrusions on the east and west side of the structure.

The round (circular) structures range in size from $1.5 \mathrm{~m}$ to $18 \mathrm{~m}$ in diameter with a mean diameter of $8.73 \mathrm{~m}$. These structures have interior areas ranging from $1.8 \mathrm{~m}^{2}$ to $255 \mathrm{~m}^{2}$ with a mean interior area of $85.45 \mathrm{~m}^{2}$. Table 5 provides the measurements and structure data for the remainder of the special function structures from the George C. Davis site.

Only three of the previously excavated special function structures at the George C. Davis site appeared to be burned and only four had prepared floors. Thirteen of the specialized structures are associated with mounds: four on Mound A platforms, seven under Mound A, and two under Mound B.

Construction techniques vary for the specialized structures and include single set posts as well as post trenches. At least one and possibly two of these structures have interior post trenches, four have exterior post trenches, and one has both interior and outline trenches. Center posts were identified in 12 of these structures and hearths were found in 14. At least 11 of the center posts were associated with central hearths. 


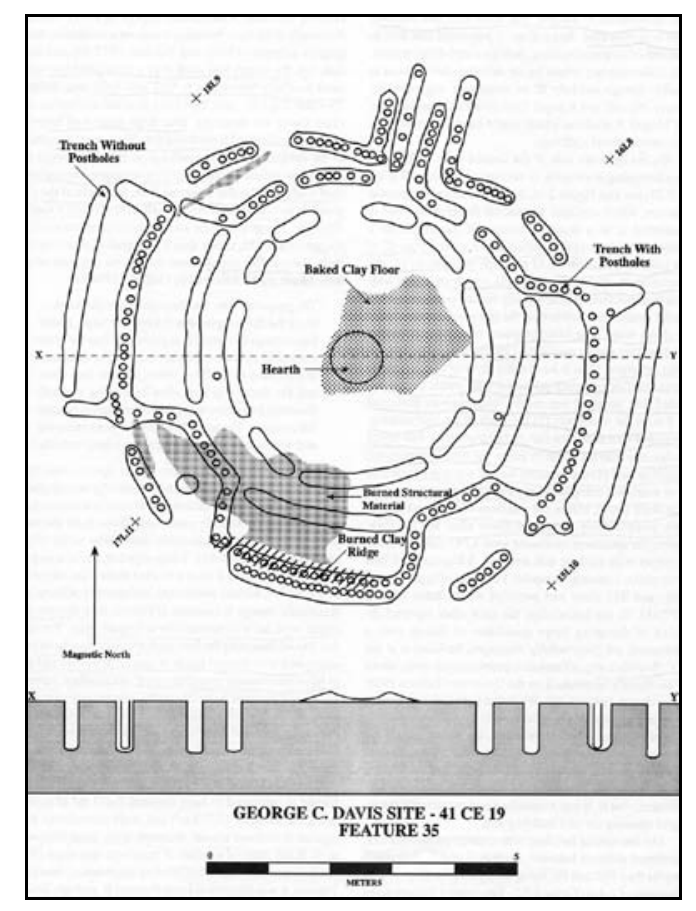

Figure 12. Plan of Feature 35, "the maze" (Story 1998:35, Figure 2-20). Reproduced courtesy of TARL.

Some of these structures were only partially exposed, the exposed portions having from seven (Feature 7) to 193 (Feature 35) exterior post holes. The exterior posts range from $3 \mathrm{~cm}$ to $34 \mathrm{~cm}$ in diameter and from $3 \mathrm{~cm}$ to $134 \mathrm{~cm}$ deep. The mean diameter of the exterior posts from each of the 20 specialized structures ranges from 6 to $25 \mathrm{~cm}$ and the mean depth ranges from 13 to $105 \mathrm{~cm}$. As with the domiciles, interior posts posed a problem in identification and assignment to individual structures given the intense rebuilding in parts of the site (Spock 1977). Spock was able to confidently assign 268 interior posts to 17 structures (see Table 4). The interior posts range from $4 \mathrm{~cm}$ to $70 \mathrm{~cm}$ in diameter and from $9 \mathrm{~cm}$ to $131 \mathrm{~cm}$ deep. The mean diameter of the interior posts from each of the 20 specialized structures ranges from 9 to $47 \mathrm{~cm}$ and the mean depth of these ranges from 27 to $65 \mathrm{~cm}$. Center posts range in diameter from 15 to $46 \mathrm{~cm}$ and in depth from 12 to $84 \mathrm{~cm}$. The 14 hearths range from $61 \mathrm{~cm}$ to $183 \mathrm{~cm}$ in diameter, with the 
largest hearths measuring $244 \times 296 \mathrm{~cm}$ (Feature 34). Hearth depths range from 3 to 45 $\mathrm{cm}$. Six of the hearths were clay-lined.

Two (Features 9 and 35), and possibly three (Feature 6), of the specialized structures have extended entrances (Spock 1977:40). The extended entrances for Features 9 and 35 measure approximately $2 \mathrm{~m}$ and $1.5 \mathrm{~m}$ long, respectively. The Feature 9 (Figure 13) entrance was "outlined by two trenches 0.6 to $0.7 \mathrm{~m}$ apart. One measured $1.75 \mathrm{~m}$ long, the other $1.9 \mathrm{~m}$ long; trench depths were ca. $0.3 \mathrm{~m}$," and the entrance was "paved with a layer of grayish-white, hard packed clay which measured $2.14 \mathrm{~m}$ long, 0.46 to 0.61 $\mathrm{m}$ wide and was raised $0.31 \mathrm{~m}$ above the structure's rim. A second layer, $9 \mathrm{~cm}$ thick, and consisting of compact reddish clay, overlay most of the grayish-white clay" (Spock 1977:44-47). Feature 9 was built in a $0.37 \mathrm{~m}$ deep pit and the floor was a $2-3 \mathrm{~cm}$ thick prepared clay lining that "extended across the structure and lipped up to the post trench," and extended into and lined the central hearth (Spock 1977: 44-47). All of the Feature 9 exterior wall posts were set in a 0.2 to $0.3 \mathrm{~m}$ wide and $1.12 \mathrm{~m}$ deep post trench. Feature 9 is not the only structure built in a pit or depression, as "features 37 and 38 were built in a depression below the terrace surface," under the southeastern portion of Mound A (Spock 1977:64-67).

Feature 35 also had a prepared floor, an extended entrance, and post trenches. The Feature 35 floor was described as "an area of burned clay approximately $1.5 \mathrm{~m}$ northsouth by $2.9 \mathrm{~m}$ east-west, part of it forming a clay ridge about $2.7 \mathrm{~m}$ long and 10 to $20 \mathrm{~cm}$ wide" on the southern edge of Feature 35 (Spock 1977:80). The north-facing entrance was constructed of parallel post trenches about $0.35 \mathrm{~m}$ apart and extending about $1.5 \mathrm{~m}$ (Spock 1977:81). 


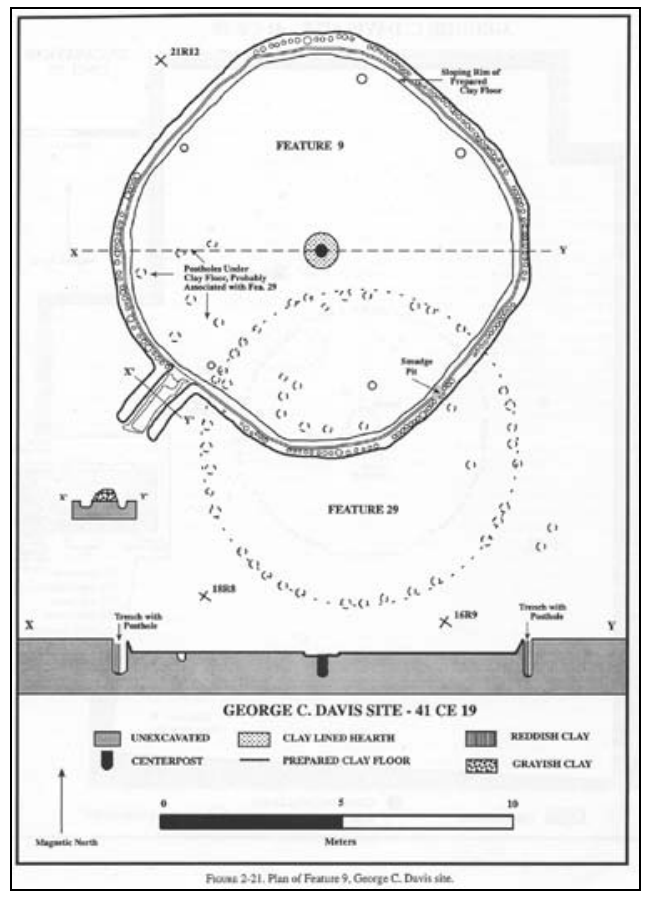

Figure 13. Example of George C. Davis structure with extended entrance (Feature 9) (Story 1998:37, Figure 2-21). Reproduced courtesy of TARL.

While Features 9 and 35 are the only two special purpose structures with definite extended entrances, at least three others, Features 43-45, have post trenches (Table 5), and at least two additional features (43 and 111) have prepared floors. In addition, at least one structure (Feature 45) (Figure 14) has a partition or exterior wall along the exterior of the structure that likely functioned as a controlled entryway (Spock 1977:100).

There is clearly a great deal of variation in the previously excavated domestic and specialized structures at the George C. Davis site. Some of this architectural diversity can also be observed in the magnetometer data. The remainder of this chapter discusses the magnetometer survey results from the site as well as the 2003 excavations that were guided by that research. 


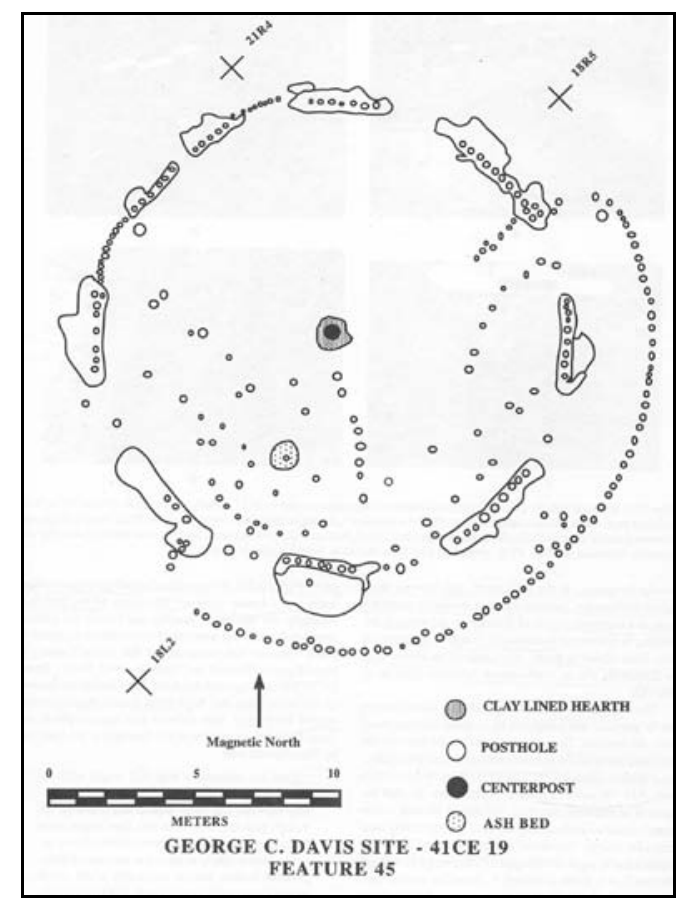

Figure 14. Feature 45, a structure with an exterior partition (Story 1998:33, Figure 2-18).

\section{MAGNeTOMETER SURVEY METHOdS ${ }^{2}$}

Although ground-penetrating radar (GPR) and conductivity have both been used at the George C. Davis site, the majority of the data, and indeed the most impressive results, were obtained through magnetometry. This research was based largely on the summer 2001 GPR survey by The University of Texas at El Paso and the subsequent summer 2002 magnetometer survey of $2,700 \mathrm{~m}^{2}$ by the Texas Historical Commission (THC) (Bruseth and Pierson 2004; Creel et al. 2005). By the end of the summer 2003 season, a total of $173,702 \mathrm{~m}^{2}$ (17.37 hectares) had been surveyed (Figure 15) (Creel et al. 2005; Schultz et al. 2004). Following that widespread survey, the THC returned to the site in 2008 to explore part of the site at the Indian Mound Nursery, which was owned by

\footnotetext{
2 Portions of this section come from Creel et al. 2005.
} 
the Texas Forest Service; the property now belongs to the THC. The THC conducted a magnetometer survey of a $100 \times 100 \mathrm{~m}$ grid on that part of the site (Osburn et al. 2008). The 2008 THC survey resulted in the recording of at least 10 additional Caddo structures (Table 6), and at least six partial arcs that may represent additional structures. The following discussion provides the details of the UT-TARL magnetometer surveys at the site.

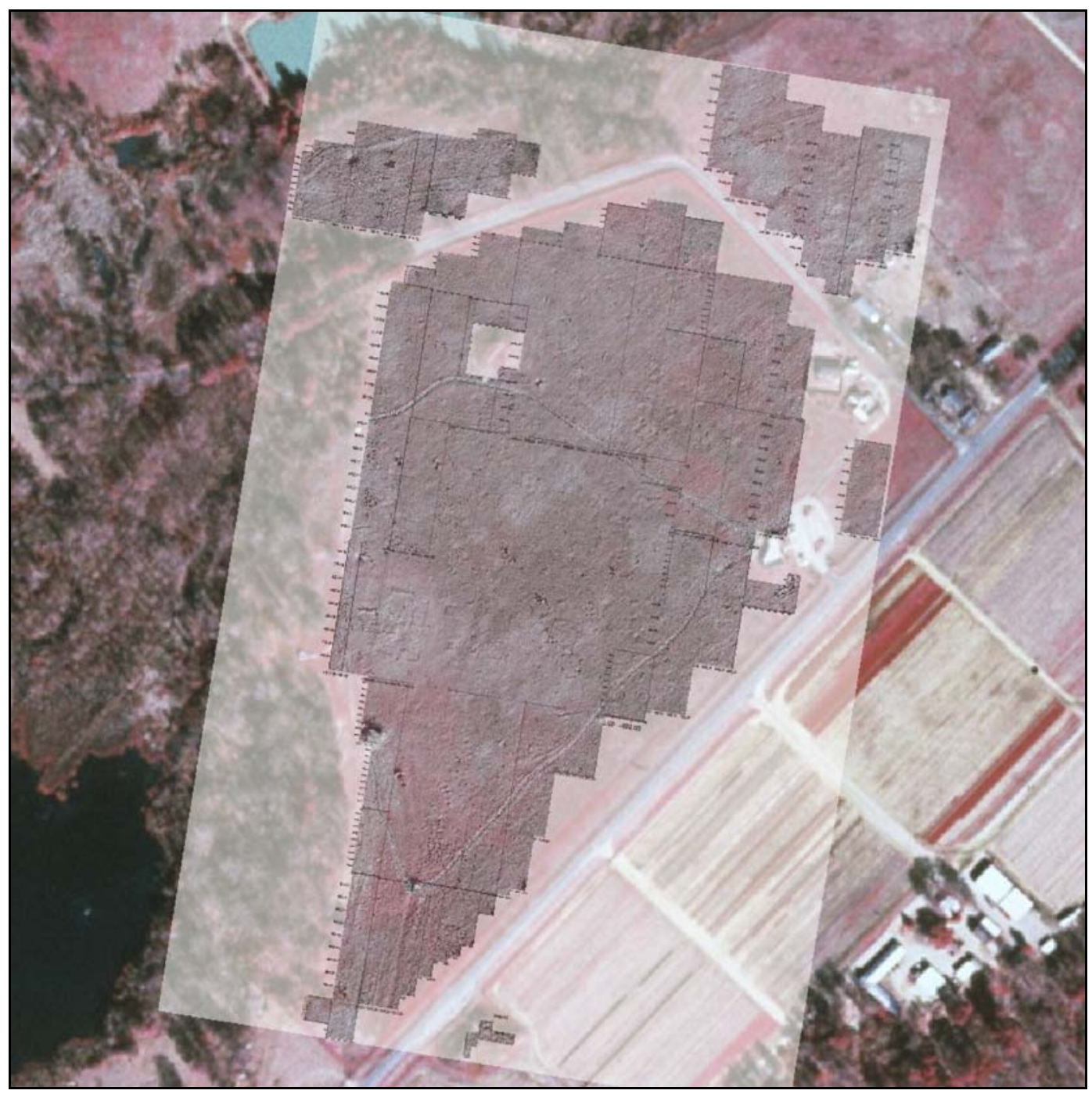

Figure 15. Overlay of the George C. Davis site magnetometer survey area on the aerial photograph of the site area. 
Table 6. Possible non-mound structures identified in the 2008 THC magnetometer survey in the Village area adjacent to Mound A (Osburn et al. 2008).

\begin{tabular}{|l|l|l|l|l|}
\hline Structure & \multicolumn{1}{|c|}{ Size $(\mathbf{m})$} & Area $\left.\mathbf{( m}^{\mathbf{2}}\right)$ & Shape (Osburn et al.) & \multicolumn{1}{c|}{ Shape (this study) } \\
\hline 1 & 8.7 & 59.42 & Round & Circular \\
\hline 2 & $20.2 \times 20.5$ & 414.10 & Round-flattened sides & $\begin{array}{l}\text { Sub-square with rounded to diagonal } \\
\text { corners }\end{array}$ \\
\hline 3 & $18 \times 17.5$ & 315.00 & Round-oval & Circular \\
\hline 4 & 16.4 & 211.13 & Round & Circular \\
\hline 5 & $16.8 \times 17.5$ & 294.00 & Round-oval & Circular \\
\hline 6 & 16.5 & 213.72 & Round & Circular \\
\hline 7 & $17.0 \times 17.3$ & 294.10 & Round-flattened sides & Circular \\
\hline 8 & 16.3 & 208.57 & Round & Circular \\
\hline 9 & 18 & 254.34 & Round & Circular \\
\hline 10 & 15.9 & 198.46 & Round & Circular \\
\hline
\end{tabular}

The UT-TARL data were collected using a dual-sensor Geometrics G858 portable cesium sensor magnetometer pulled along on a non-magnetic cart. Data collection speeds using the cart averaged 1.5 ha/day but collected as much as 2.5 ha in a single day. In order to record and later correct for the diurnal variations of the Earth's magnetic field, a stationary G-856 proton magnetometer was used to collect data at 10 second intervals. The collection grid was tied to the existing site grid using the permanent grid markers north of Mound B and north of Weeping Mary Road. Whenever possible, data were collected in $30 \times 100 \mathrm{~m}$ collection blocks using reference stakes set out using either a total data station (TDS) or a transit. The collection blocks were oriented north-south with $1 \mathrm{~m}$ interval grid lines and the data were collected in a zig-zag pattern with marks spaced at $10 \mathrm{~m}$ intervals. Data were collected at 0.1 second intervals with two sensors spaced 50 $\mathrm{cm}$ apart, $25 \mathrm{~cm}$ on either side of the grid line. Following this general collection strategy, approximately 2.2 million magnetometer readings were collected (Creel et al. 2005; Walker 2009).

MagMap2000 was used for downloading the data, correcting collection errors, such as missed marks, and for applying the base station correction. The data were 
despiked in order to remove zero readings and unusually high or unusually low readings. Following despiking, the data were imported into ArcGIS and gridded using a Kriging algorithm. Generally, grids were produced using a linear model and a fixed radius of $1 \mathrm{~m}$, with a few exceptions using a fixed radius of $1.5 \mathrm{~m}$. The sensor readings assigned during Kriging were then classified from low to high. This classification generally consisted of 12-15 classes. Each class was color coded to allow for easy interpretation of the divergence of mapped anomalies from the mean magnetometer reading (Creel et al. 2005). Each collection area was zero-based to a standard reading to facilitate smoothly lacing the grids together into one map (for further details regarding data processing see Creel et al. [2005]). Throughout this dissertation, the magnetometer results are displayed using a stretched gray-scale color ramp. Unless otherwise noted, stronger magnetic values are lighter in color. Most images were produced using ArcGIS.

The interpretation of the magnetometer data has been conservative as well as a collaborative effort among the researchers involved in the project (Creel et al. 2005, 2008; Walker 2009). When a magnetic pattern is identified that appears to correspond to either a complete or a partially recognized structure, that pattern is recorded as a feature and assigned a number. If potential features are identified within or otherwise associated with that feature, those patterns are assigned sub-feature numbers. Feature numbers have been assigned only to those anomalies most confidently recognizable as archaeological features (Creel et al. 2005). I will focus primarily on clearly defined architectural features. There are several anomalies that may represent archaeological features (Creel et al. 2005; Creel et al. 2008; Walker 2009) that will not be discussed in detail in this dissertation. It is also quite likely that additional features exist in the dataset that have not yet been identified. For a more detailed discussion of the magnetometer work itself at the George C. Davis site, as well as a use of these data to explore spatial patterning at the 
site, mound construction, and other topics, the reader is referred to Creel et al. (2005), Creel et al. (2008), and Walker (2009).

In 2003, excavations at the George C. Davis site were conducted in conjunction with, and were guided by, the results of the magnetometer survey. The excavations were designed to address two specific goals. One general objective was to provide the material record necessary for assessing and refining interpretations of the magnetometer data, specifically data from certain geophysical structural anomalies. The second goal of the 2003 excavations was to target specific architectural features with small excavation units. The primary purpose of this approach was to retrieve dateable materials from specific features while minimizing direct impacts to other features. With these objectives in mind, specific features were targeted that were interpreted as representing a specific architectural form or type (see below).

The primary reference points for all excavations were the permanent grid markers north of Mound B. Using these reference points, grid coordinates were acquired from the magnetometer data for each of the features slated to be investigated in 2003. Excavation units were placed using these grid coordinates and set using a TDS. Standard archaeological recording procedures employed previously at the George C. Davis site (e.g., Story 1981, 1997) were followed during the course of the investigations. Excavated plow zone deposits from the one large unit excavated in 2003 (Unit 113) were dry screened through 1/4-inch wire mesh with all artifacts bagged and recorded. Excavated feature fill was bagged and saved for flotation. Special samples, including radiocarbon samples, Oxidizable Carbon Ratio (OCR) soil samples, or flotation samples were assigned lot numbers and recorded on a master lot list. 


\section{RESULTS OF THE UT-TARL MAGNETOMETER SURVEY}

Architectural features are the most abundant and potentially diverse feature class in the George C. Davis magnetometer data (Creel et al. 2005, 2008; Walker 2009). The magnetometer work conducted at the site since 2003 has substantially increased the database of known structures from the site (Creel et al. 2005, 2008; Schultz et al. 2004; Walker 2009). The majority of structures identified in the magnetometer data are roughly circular $(n=60)$, represented primarily by the structure perimeter, and range in size from approximately $3 \mathrm{~m}$ to over $20 \mathrm{~m}$ in diameter.

Interestingly, several of the circular structures identified in the George C. Davis dataset are fairly large, with at least 17 having a diameter of $15 \mathrm{~m}$ or more. The large size of some of the structures identified in the magnetometer data bring to mind structures from sites such as Werner in Northwest Louisiana where an earthen mound was built

over a $28 \mathrm{~m}$ diameter structure (Webb 1983). Table 7 provides summary data for those structures identified in the magnetometer data that are included in this study.

The variation seen in the previously excavated structures from the site is also evident in the magnetometer data. Among the architectural features there are different shapes of structures and various types of associated interior and/or architectural features and treatments. Images (Figures 133-187) and summary tables of each structure are presented in Appendix A. A map of the site showing the distribution of all the magnetometer features discussed in this dissertation is also included in Appendix A (Figure 132). 
Table 7. Summary of the structures identified in the George C. Davis magnetometer data.

\begin{tabular}{|c|c|c|c|c|c|c|c|}
\hline Feature & $\begin{array}{l}\text { Dimensions/ } \\
\text { Diameter (m) }\end{array}$ & $\begin{array}{l}\text { Area } \\
\left(\mathbf{m}^{2}\right)\end{array}$ & Type & Feature & $\begin{array}{l}\text { Dimensions/ } \\
\text { Diameter (m) }\end{array}$ & $\begin{array}{l}\text { Area } \\
\left(\mathrm{m}^{2}\right)\end{array}$ & Type \\
\hline 179 & 20.3 & 323.65 & circular & 280 & 11.1 & 96.77 & circular \\
\hline 220 & 5.6 & 24.63 & circular & 281 & $6.8 \times 6.8$ & 46.24 & sub-square \\
\hline 237 & 10.6 & 88.25 & circular & 284 & 16.1 & 203.58 & circular \\
\hline 238 & 21 & 346.36 & circular & 285 & 11.69 & 107.33 & circular \\
\hline 239 & 17.5 & 240.53 & circular & 290 & 7.3 & 41.85 & circular \\
\hline 241 & 13.5 & 143.14 & circular & 291 & 6.7 & 35.26 & circular \\
\hline 242 & 13 & 132.73 & circular & 292 & 7.2 & 40.72 & circular \\
\hline 243 & 13.6 & 145.27 & circular & 301 & 3.45 & 9.35 & circular \\
\hline 244 & 12.3 & 118.82 & circular & 302 & 3.15 & 7.79 & circular \\
\hline 245 & 11.5 & 103.87 & circular & 305 & 18.25 & 261.59 & circular \\
\hline 246 & 10 & 78.54 & circular & 306 & 7.9 & 49.02 & circular \\
\hline 247 & 15.4 & 186.27 & circular & 307 & 7.6 & 45.36 & circular \\
\hline 250 & 8 & 50.24 & sub-squre & 308 & 6.9 & 37.39 & circular \\
\hline 251 & 7 & 38.47 & sub-square & 310 & 6.17 & 29.9 & circular \\
\hline 252 & 11.7 & 107.51 & sub-square & 312 & 11.5 & 103.87 & circular \\
\hline 253 & 14.9 & 174.37 & sub-square & 313 & 13.8 & 149.57 & circular \\
\hline 254 & $10.7 \times 10.7$ & 114.49 & sub-square & 314 & 5.6 & 24.63 & circular \\
\hline 255 & 18.4 & 265.9 & circular & 315 & 8.3 & 54.11 & circular \\
\hline 256 & 16.1 & 203.58 & circular & 318 & 10.9 & 93.31 & circular \\
\hline 257 & 16.7 & 219.04 & circular & 320 & 7.1 & 39.59 & circular \\
\hline 258 & 17.7 & 246.06 & circular & 321 & 5.9 & 27.34 & circular \\
\hline 259 & 20.1 & 317.31 & circular & 322 & 5.8 & 26.42 & circular \\
\hline 260 & $5 \times 6$ & 30 & sub-square & 327 & 6.75 & 35.78 & circular \\
\hline 263 & 6.6 & 34.21 & Circular & 328 & 6.4 & 32.17 & circular \\
\hline 264 & 15 & 176.71 & Circular & 334 & 6.7 & 35.26 & circular \\
\hline 265 & 16.2 & 206.12 & Circular & 335 & 9.5 & 70.88 & circular \\
\hline 266 & 9.5 & 70.88 & Circular & 338 & 10.4 & 84.95 & circular \\
\hline 267 & 16.2 & 206.12 & Circular & 339 & 12.5 & 122.72 & circular \\
\hline 269 & 18.1 & 257.3 & Circular & 340 & 15.5 & 188.69 & circular \\
\hline 274 & 13 & 132.73 & circular & 343 & 4.7 & 17.35 & circular \\
\hline 275 & 4.6 & 16.62 & Circular & 346 & 10 & 78.54 & circular \\
\hline 276 & 8.7 & 59.45 & Circular & 347 & $4.6 \times 4.8$ & 22.08 & sub-square \\
\hline 277 & 13.2 & 136.85 & Circular & 348 & 9 & 63.62 & circular \\
\hline 278 & 10.3 & 83.32 & Circular & 350 & 6 & 28.27 & circular \\
\hline
\end{tabular}

\section{Circular Structures}

The majority of structures $(\mathrm{n}=60)$ identified in the magnetometer data are circular (Figure 16). These structures consist of generally circular patterns of high positive 72 
magnetic returns corresponding to the structure perimeter with some examples having identifiable magnetic signatures of possible interior features such as posts, pits, or hearth remnants. The circular structures range from $3.15 \mathrm{~m}$ to $21 \mathrm{~m}$ in diameter with a mean diameter of $11.08 \mathrm{~m}$. The estimated area of the circular structures ranges from $7.79 \mathrm{~m}^{2}$ to $346.36 \mathrm{~m}^{2}$ with a mean area of $113.45 \mathrm{~m}^{2}$. Based on their association with high magnetic returns either around the structure perimeter or within the structure itself, at least 21 of the circular structures may have been burned, or at least partially burned (Figures 17). There are additional circular anomalies with diameters exceeding $21 \mathrm{~m}$, some as large as about $54 \mathrm{~m}$, that may represent an open enclosure of some sort rather than a roofed structure (Creel et al. 2008; Walker 2009). This is a possibility that warrants further investigations as such features might represent open-aired structures, may demarcate ritual spaces such as dance grounds, or may be something similar to "Woodhenge" from the Cahokia site in Illinois

There are at least nine circular structures that stand out as having multiple clearly identifiable interior features (Features 237, 241, 242, 244-247, 335, and 336, see Table 8). These structures offer additional architectural detail in that they are generally represented by the circular structure outline, four large patterns of magnetic returns within the interior, and a pattern of generally high magnetic returns in the center of the structure itself. These structures correspond to Walker's (2009) Type 1 structures. Three of these structures, Features 237, 241 and 242, were partially excavated as part of the 2003 season (see below). Figure 18 provides images of these features as identified in the magnetometer data (larger images for each feature are provided in Appendix A). 


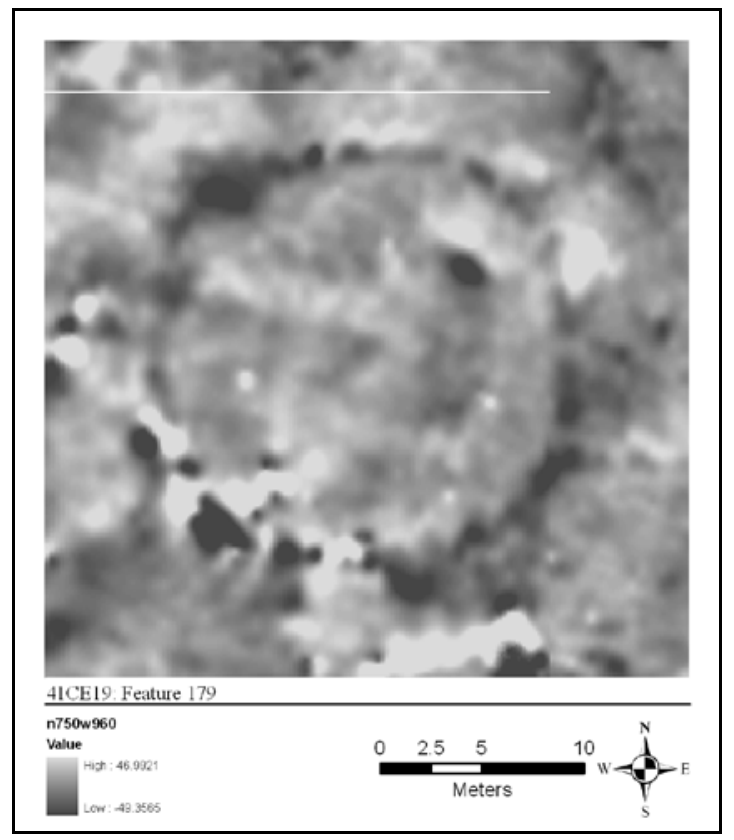

Figure 16: Example of circular structure from the George C. Davis site magnetometer data (Feature 179).

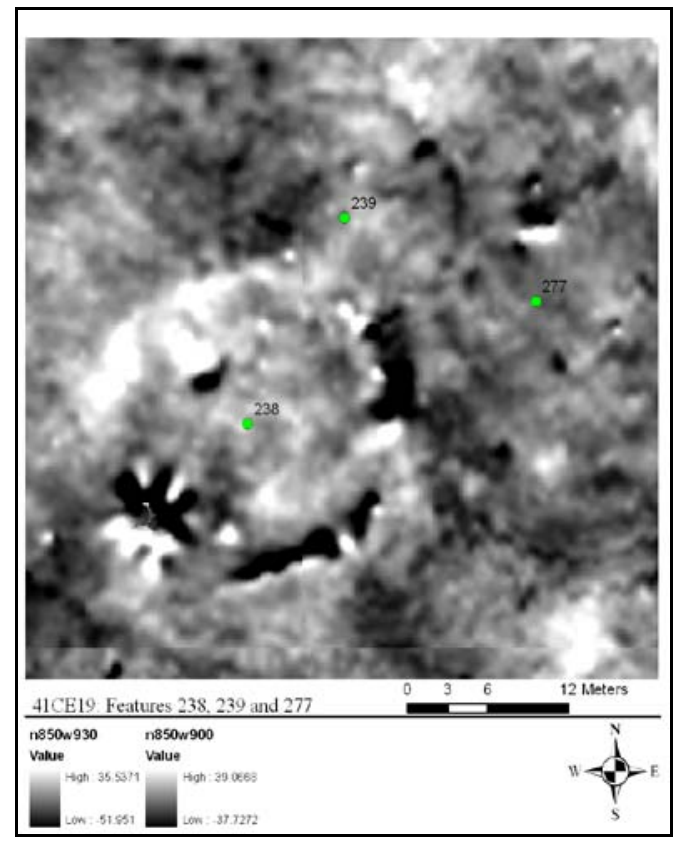

Figure 17. Example of a probable burned circular structure from the George C. Davis site magnetometer data (Feature 238). 
Features 246 and 338 have faint outlines but have interior features that suggest they also fit this structure pattern. Feature 247, the largest of these structures, is faint but also appears to fit this pattern. In addition, some of the interior features of structures 243 , $244,246,247,335$, and 338 are faint, but the pattern of returns suggests they belong in this category of structures. These structures are similar in form to Features 31, 42, and 125 from the George C. Davis site (Figure 19 and 20) (Spock 1977). However, the large interior features found in structures 31 and 42 (Figure 20) were interpreted as large interior pits, rather than post holes (Spock 1977; Story 1998).

Table 8. Structures with patterns suggesting four interior posts and a central hearth.

\begin{tabular}{|r|r|r|l|}
\hline & & \multicolumn{1}{|l|}{$\begin{array}{l}\text { Area } \\
\left(\mathbf{m}^{2} \mathbf{)}\right.\end{array}$} & Comments \\
\hline 237 & Dimensions/Diameter $\mathbf{( m )}$ & 88.25 & Partially excavated \\
\hline 241 & 10.60 & 143.14 & Partially excavated \\
\hline 242 & 13.00 & 132.73 & Partially excavated \\
\hline 243 & 13.6 & 145.27 & Circular; faint interior features \\
\hline 244 & 12.30 & 118.82 & Circular \\
\hline 245 & 11.50 & 103.87 & Circular \\
\hline 246 & 10.00 & 78.54 & Circular \\
\hline 247 & 15.40 & 186.27 & Circular \\
\hline 335 & 9.5 & 70.88 & Probably burned \\
\hline 338 & 10.40 & 84.95 & Probably burned \\
\hline
\end{tabular}



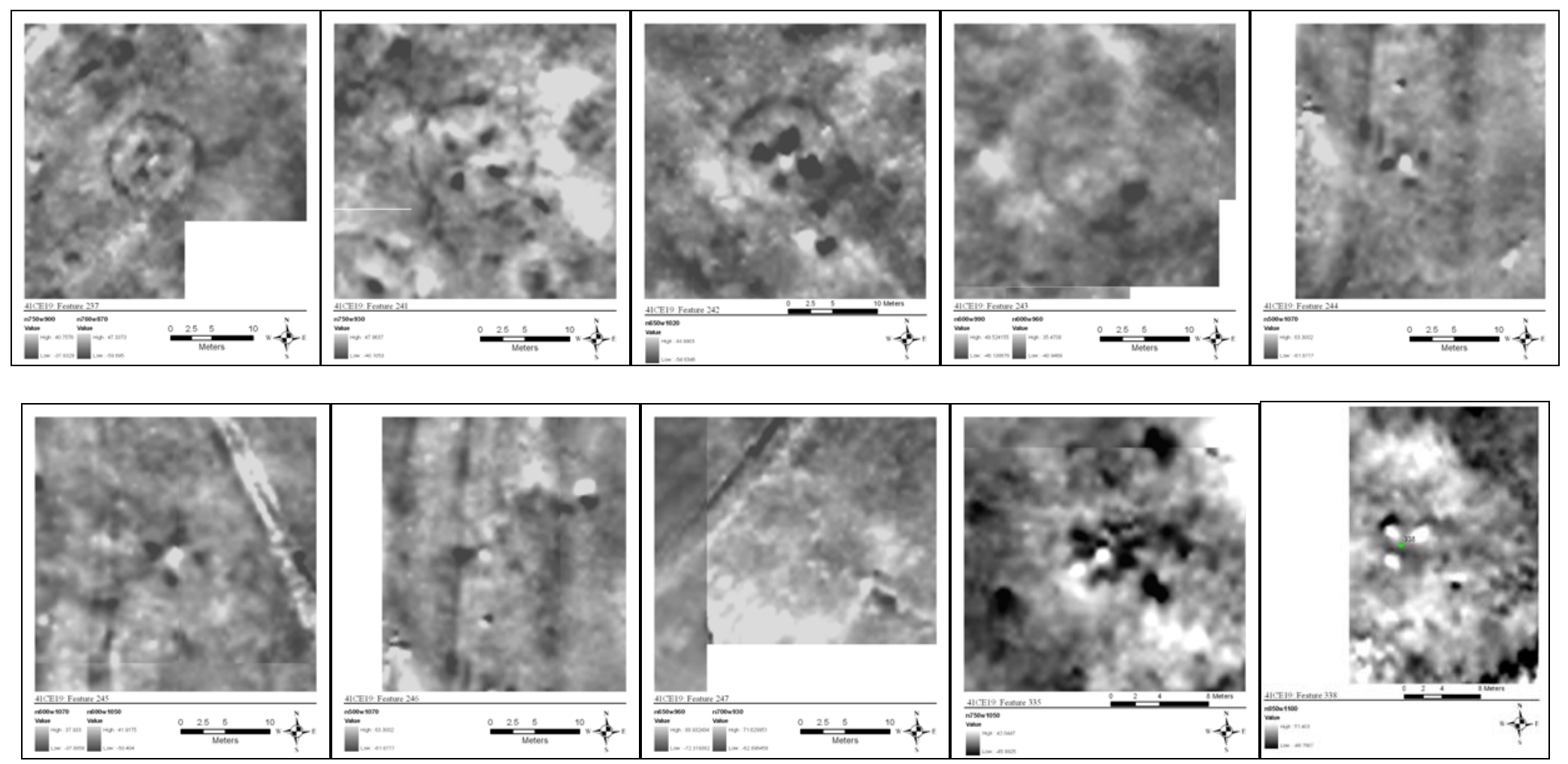

Figure 18. Features 237, 241, 242-247, 335, and 338. 


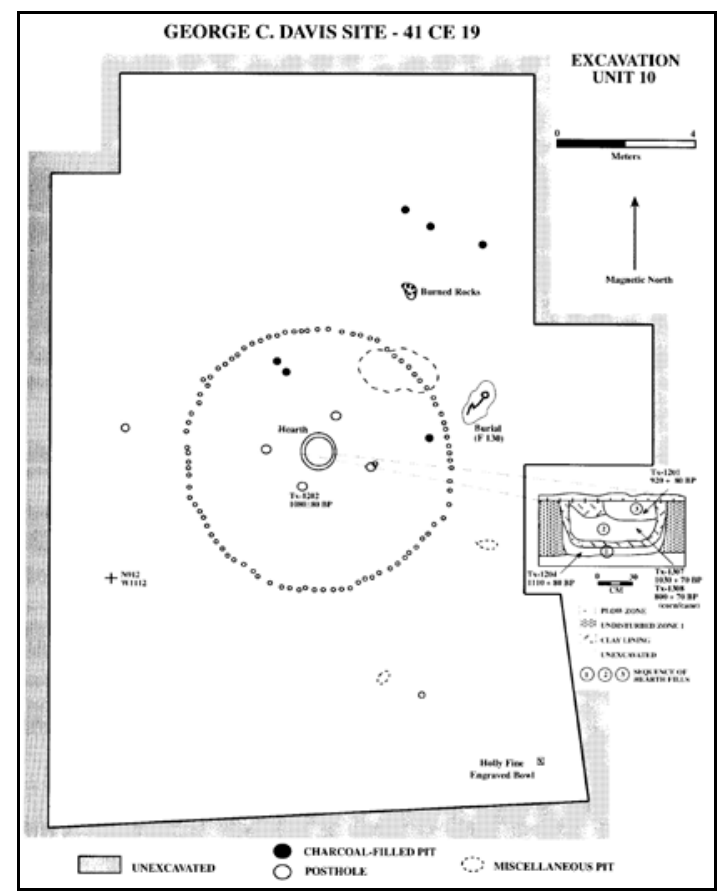

Figure 19. Feature 125 (Story 1998:38, Figure 2-22). Reproduced courtesy of TARL.

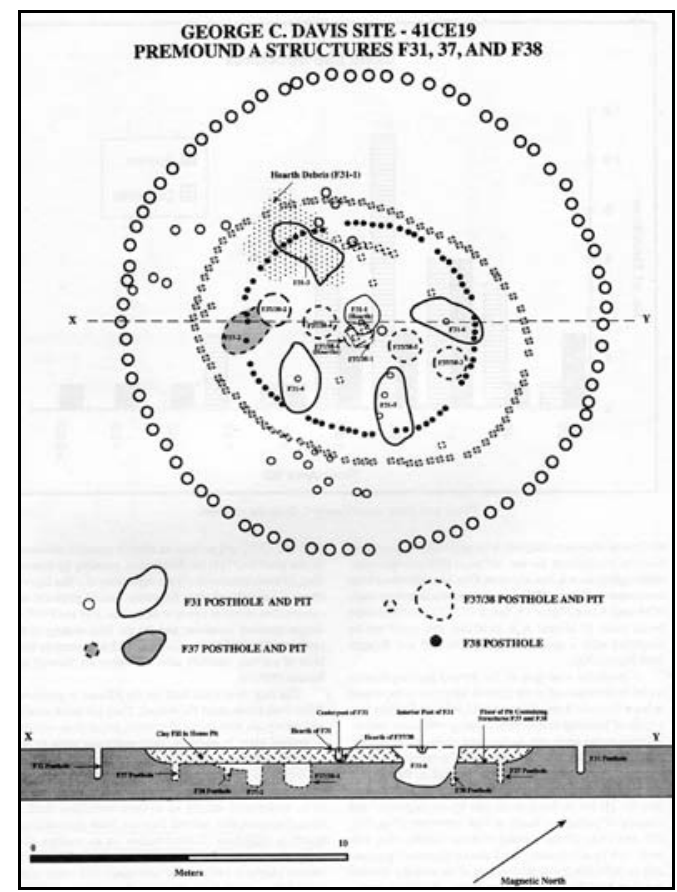

Figure 20. Features 31, 37, and 38 (Story 1998:32, Figure 2-17). Reproduced courtesy of TARL. 
The mean diameter of these structures is $11.98 \mathrm{~m}$ with a range from $9.5 \mathrm{~m}$ to 15.4 $\mathrm{m}$ (Table 8). These structures have interior areas ranging from approximately $70.88 \mathrm{~m}^{2}$ (Feature 335 ) to $186.27 \mathrm{~m}^{2}$ (Feature 247), with a mean interior area of $115.28 \mathrm{~m}^{2}$.

The surface area for the magnetic returns interpreted as interior support posts has been estimated from the approximate area of the measurable patterns of returns corresponding to these features. Surface area is used here given the variability in feature shape. As noted in Walker (2009), however, measurements from geophysical features should be considered as approximations given that they represent measurements of the magnetic signature of the features and not the actual features themselves. As Table 9 illustrates, the approximate area for the patterns interpreted as interior posts ranges from $0.95 \mathrm{~m}^{2}$ to $3.83 \mathrm{~m}^{2}$. These features have a mean area of $1.82 \mathrm{~m}^{2}$. Although there is considerable range in their size, it must be emphasized that these figures are approximations of the patterns of magnetic returns, not necessarily the size of the post hole or postmold itself. As an example, the returns identified as Feature 241.1 (the northwest post in Feature 241) measure approximately $1.9 \mathrm{~m} \mathrm{x} 1 \mathrm{~m}$. This feature was excavated as part of the 2003 fieldwork and upon excavation, was determined to be approximately $70 \mathrm{~cm}$ wide in profile, $30 \mathrm{~cm}$ smaller than the patterns in the magnetometer data. Additionally, as suggested elsewhere (Perttula and Sherman 2009; Schambach et al. 2003), the placement of fairly large posts may have required a sloping and elongated post hole to allow for the post to be slid into place.

The patterns interpreted as hearths associated with these structures have surface areas ranging from $0.94 \mathrm{~m}^{2}$ to $2.62 \mathrm{~m}^{2}$, with a mean surface area of $1.81 \mathrm{~m}^{2}$. All of the hearths that are visible are represented by patterns of high magnetic returns, given that these features have been thermally altered. 
Table 9. Approximate dimensions and area of the patterns of returns identified as interior support posts and central hearths.

\begin{tabular}{|c|c|c|c|c|c|c|c|c|c|c|c|c|c|c|c|c|c|}
\hline \multirow[b]{2}{*}{ 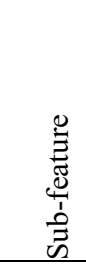 } & \multirow[b]{2}{*}{$\begin{array}{l}\vec{w} \\
0 \\
0\end{array}$} & \multicolumn{2}{|c|}{$\begin{array}{c}\text { Interior Support } \\
\text { Post }\end{array}$} & \multicolumn{2}{|c|}{ Central Hearth } & \multirow[b]{2}{*}{ 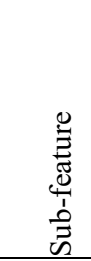 } & \multirow[b]{2}{*}{$\begin{array}{l}\vec{w} \\
0 \\
0\end{array}$} & \multicolumn{2}{|c|}{$\begin{array}{c}\text { Interior Support } \\
\text { Post }\end{array}$} & \multicolumn{2}{|c|}{ Central Hearth } & \multirow[b]{2}{*}{ 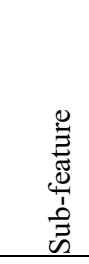 } & \multirow[b]{2}{*}{$\begin{array}{l}\overrightarrow{0} \\
0 \\
2\end{array}$} & \multicolumn{2}{|c|}{$\begin{array}{c}\text { Interior Support } \\
\text { Post }\end{array}$} & \multicolumn{2}{|c|}{$\begin{array}{l}\text { Central } \\
\text { Hearth }\end{array}$} \\
\hline & & 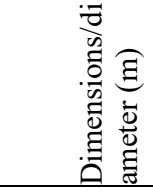 & 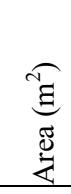 & 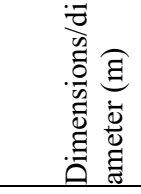 & 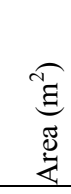 & & & 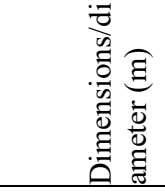 & 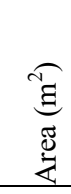 & 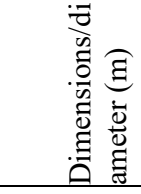 & 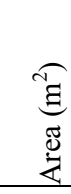 & & & 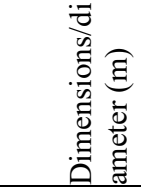 & 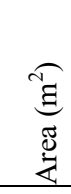 & 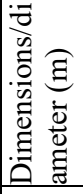 & 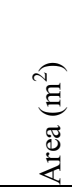 \\
\hline 237.1 & nw & $1.4 \times 1$ & 1.23 & & & 243.1 & nw & $1.1 \times 1$ & 1 & & & 247.1 & nw & $2.2 \times 1.4$ & 3.17 & & \\
\hline 237.5 & sw & $1.2 \times 0.8$ & 1.02 & & & 243.2 & ne & $1.88 \times 1$ & 1.8 & & & 247.2 & ne & $2.8 \times 1.7$ & 4.6 & & \\
\hline 237.2 & ne & $1.45 \times 1.1$ & 1.38 & & & 243.3 & sw & $2.4 \times 1.3$ & 2.77 & & & 247.3 & se & $2.1 \times 1.8$ & 3.17 & & \\
\hline 237.3 & se & $1.1 \times 0.6$ & 0.6 & & & Mean & & & 1.85 & & & 247.4 & sw & $1.9 \times 2$ & 3.13 & & \\
\hline 237.4 & & & & $1.45 \times 0.7$ & 0.94 & 244.2 & ne & $1.65 \times 1.16$ & 1.4 & & & Mean & & & 3.52 & & \\
\hline Mean & & & 1.06 & & & 244.3 & nw & 1 & 0.7 & & & 335.2 & & $1.45 \times 1.1$ & 0.86 & & \\
\hline 241.3 & sw & $1.8 \times 1.25$ & 2.32 & & & 244.4 & $\mathrm{~s}$ & $1.52 \times 0.8$ & 1.01 & & & 335.3 & & $1.45 \times 1.1$ & 1.08 & & \\
\hline 241.4 & se & $2 \times 1$ & 1.95 & & & 244.1 & & & & 1.66 & 2.25 & 335.4 & & $1.45 \times 0.7$ & 0.92 & & \\
\hline 241.5 & nw & $1.3 \times 1$ & 1.14 & & & Mean & & & 1.04 & & & 335.1 & & & & 1.24 & 1.21 \\
\hline 241.1 & ne & $1.3 \times 1.1$ & 1.32 & & & 245.5 & $\mathrm{n}$ & $1.9 \times 1.3$ & 2.11 & & & Mean & & & 0.95 & & \\
\hline 241.2 & & & & $2.2 \times 1$ & 2.27 & 245.4 & $\mathrm{e}$ & $1.7 \times 1.25$ & 1.57 & & & 336.1 & & & 1.1 & & \\
\hline Mean & & & 1.68 & & & 245.3 & $\mathrm{~s}$ & $1.4 \times 1.2$ & 1.65 & & & 336.2 & & & 2.08 & & \\
\hline 242.3 & $\mathrm{~W}$ & $3 \times 2.5$ & 3.7 & & & 245.2 & $\mathrm{w}$ & $1.8 \times 1.14$ & 1.78 & & & 336.3 & & & 1.55 & & \\
\hline 242.2 & $\mathrm{n}$ & $3 \times 2.35$ & 5.15 & & & 245.1 & & & & $1.88 \times 1.6$ & 2.61 & Mean & & & 1.58 & & \\
\hline 242.4 & $\mathrm{e}$ & 1.4 & 5.11 & & & Mean & & & 1.78 & & & 338.1 & nw & $1.6 \times 0.9$ & 1.1 & & \\
\hline 242.5 & $\mathrm{~s}$ & $2.35 \times 1.7$ & 1.38 & & & 246.4 & $\mathrm{~W}$ & $2.3 \times 1.5$ & 3.1 & & & 338.2 & ne & $1.8 \times 1.2$ & 2.08 & & \\
\hline 242.1 & & & & 1.5 & 1.86 & 246.3 & $\mathrm{e}$ & $1.8 \times 0.8$ & 1.55 & & & 338.3 & sw & $1.5 \times 1.1$ & 1.55 & & \\
\hline Mean & & & 3.83 & & & 246.2 & $\mathrm{n}$ & $1.8 \times 1.3$ & 1.99 & & & Mean & & & 1.58 & & \\
\hline & & & & & & 246.1 & & & & & 1.47 & & & & & & \\
\hline & & & & & & Mean & & & 2.21 & & & & & & & & \\
\hline
\end{tabular}


The remaining 51 circular structures include those with possible identifiable interior features and those without any visible interior features (Table 10). The diameters of these structures range from $3.15 \mathrm{~m}$ to $21 \mathrm{~m}$ with a mean diameter of $11.02 \mathrm{~m}$. They have areas ranging from $7.79 \mathrm{~m}^{2}$ to $346.36 \mathrm{~m}^{2}$ and a mean area of $114.89 \mathrm{~m}^{2}$. It is quite possible that the smaller structures (Features 301 and 302, with respective diameters of $3.15 \mathrm{~m}$ and $3.45 \mathrm{~m}$ ) represent granaries or storage platforms (Figure 21) (Rogers and Perttula 2004; Perttula 2005; Perttula and Rogers 2007; Spock 1977).

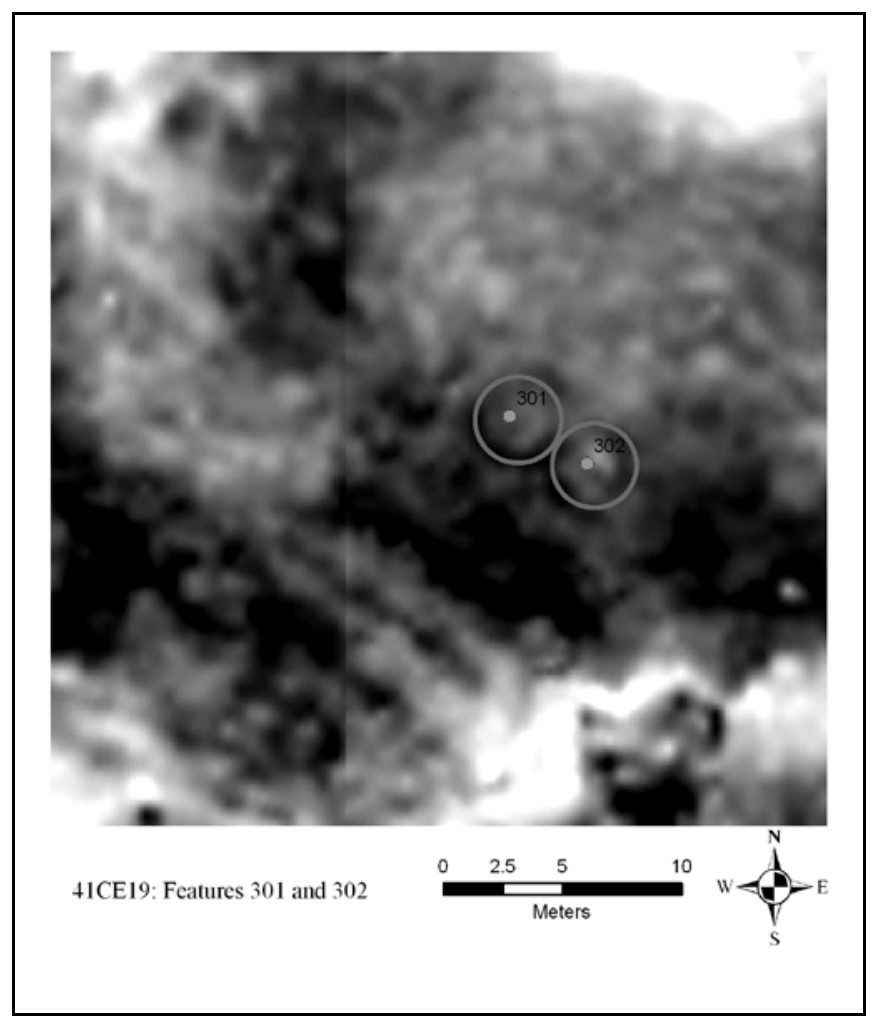

Figure 21. Small circular structures from the George C. Davis site magnetometer data, possible granaries or storage platforms.

At least 32 circular structures have returns suggestive of what may be interior features such as pits, posts, or hearths. These possible features vary from fairly clearly definable large interior posts ( $\mathrm{n}=8$ structures) and hearths ( $\mathrm{n}=15$ structures) (Figure 22), 
to more ephemeral patterns that suggest the presence of hearths or other burned features, pits and posts. At least two circular structures (Feature 314 and 350) appear to have extended entrances (Figure 23). The patterns of magnetic returns interpreted as possible entrances measure $1.2 \mathrm{~m}$ wide $\times 1.7-3.5 \mathrm{~m}$ long and $1.5 \mathrm{~m}$ wide $\times 2.2 \mathrm{~m}$ long, and face to the southwest and southeast, respectively.

Table 10. Remaining circular structures in the George C. Davis site magnetometer data.

\begin{tabular}{|c|c|c|c|c|c|c|c|}
\hline Feat & $\begin{array}{l}\text { Dimensions/ } \\
\text { Diameter (m) }\end{array}$ & Area $\left(\mathrm{m}^{2}\right)$ & Type & Feat & $\begin{array}{l}\text { Dimensions/ } \\
\text { Diameter (m) }\end{array}$ & $\begin{array}{l}\text { Area } \\
\left(\mathbf{m}^{2}\right)\end{array}$ & Type \\
\hline 179 & 20.30 & 323.65 & circular & 291 & 6.70 & 35.26 & circular \\
\hline 220 & 5.60 & 24.63 & circular & 292 & 7.20 & 40.72 & circular \\
\hline 238 & 21.00 & 346.36 & circular & 301 & 3.45 & 9.35 & circular \\
\hline 239 & 17.50 & 240.53 & circular & 302 & 3.15 & 7.79 & circular \\
\hline 243 & 13.60 & 145.27 & circular & 305 & 18.25 & 261.59 & circular \\
\hline 255 & 18.40 & 265.90 & circular & 306 & 7.90 & 49.02 & circular \\
\hline 256 & 16.10 & 203.58 & circular & 307 & 7.60 & 45.36 & circular \\
\hline 257 & 16.70 & 219.04 & circular & 308 & 6.90 & 37.39 & circular \\
\hline 258 & 17.70 & 246.06 & circular & 310 & 6.17 & 29.90 & circular \\
\hline 259 & 20.10 & 317.31 & circular & 312 & 11.50 & 103.87 & circular \\
\hline 263 & 6.60 & 34.21 & circular & 313 & 13.80 & 149.57 & circular \\
\hline 264 & 15.00 & 176.71 & circular & 314 & 5.60 & 24.63 & circular \\
\hline 265 & 16.20 & 206.12 & circular & 315 & 8.30 & 54.11 & circular \\
\hline 266 & 9.50 & 70.88 & circular & 318 & 10.90 & 93.31 & circular \\
\hline 267 & 16.20 & 206.12 & circular & 320 & 7.10 & 39.59 & circular \\
\hline 269 & 18.10 & 257.30 & circular & 321 & 5.90 & 27.34 & circular \\
\hline 274 & 13.00 & 132.73 & sub round & 322 & 5.80 & 26.42 & circular \\
\hline 275 & 4.60 & 16.62 & circular & 327 & 6.75 & 35.78 & circular \\
\hline 276 & 8.70 & 59.45 & circular & 328 & 6.40 & 32.17 & circular \\
\hline 277 & 13.20 & 136.85 & circular & 334 & 6.70 & 35.26 & circular \\
\hline 278 & 10.30 & 83.32 & circular & 339 & 12.50 & 122.72 & circular \\
\hline 280 & 11.10 & 96.77 & circular & 340 & 15.50 & 188.69 & circular \\
\hline 284 & 16.10 & 203.58 & circular & 343 & 4.70 & 17.35 & circular \\
\hline 285 & 11.69 & 107.33 & circular & 346 & 10.00 & 78.54 & circular \\
\hline \multirow[t]{2}{*}{290} & 7.30 & 41.85 & circular & 348 & 9.00 & 63.62 & circular \\
\hline & & & & 350 & 6.00 & 28.27 & circular \\
\hline
\end{tabular}




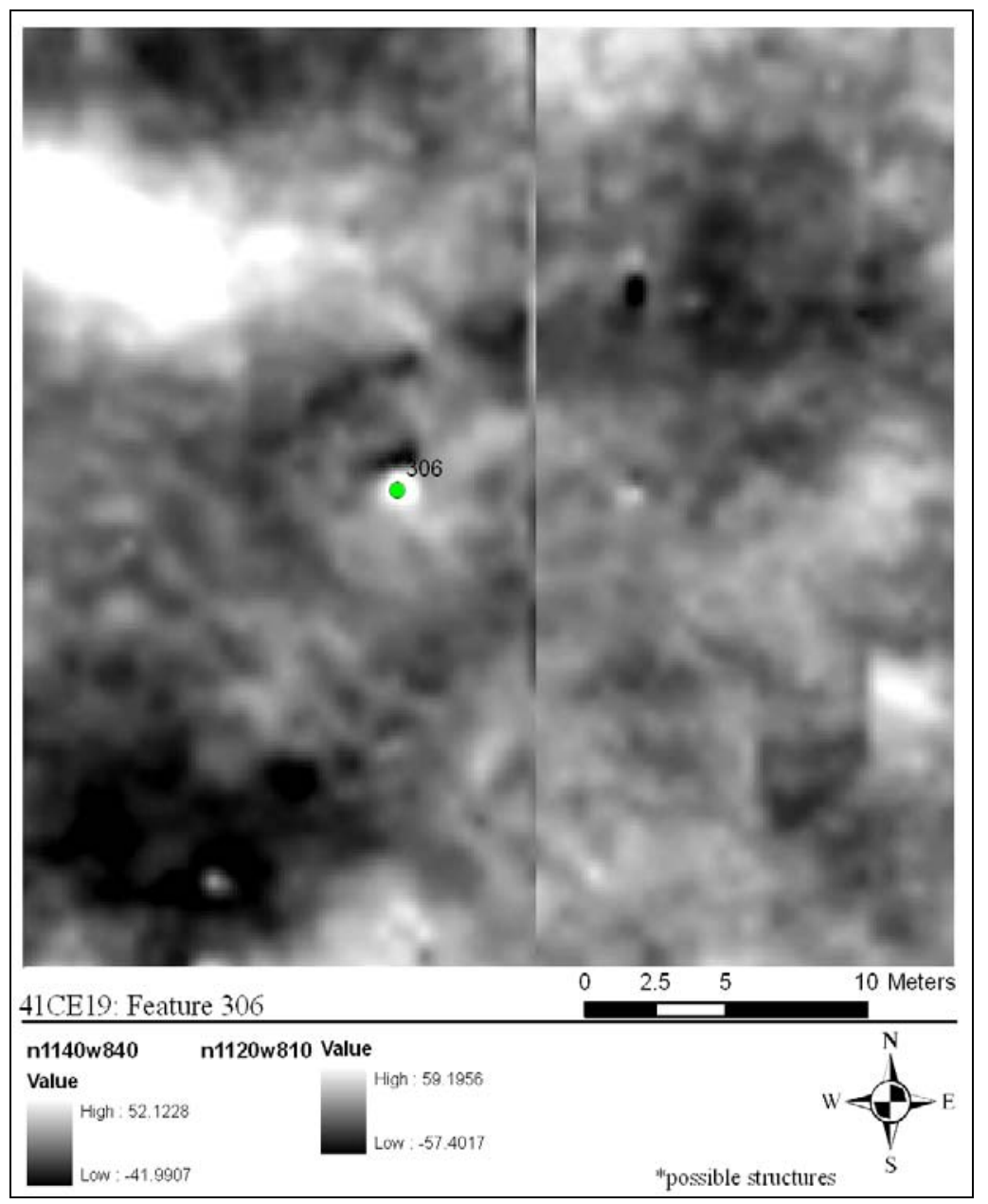

Figure 22: Example of circular structure with probable central hearth. 


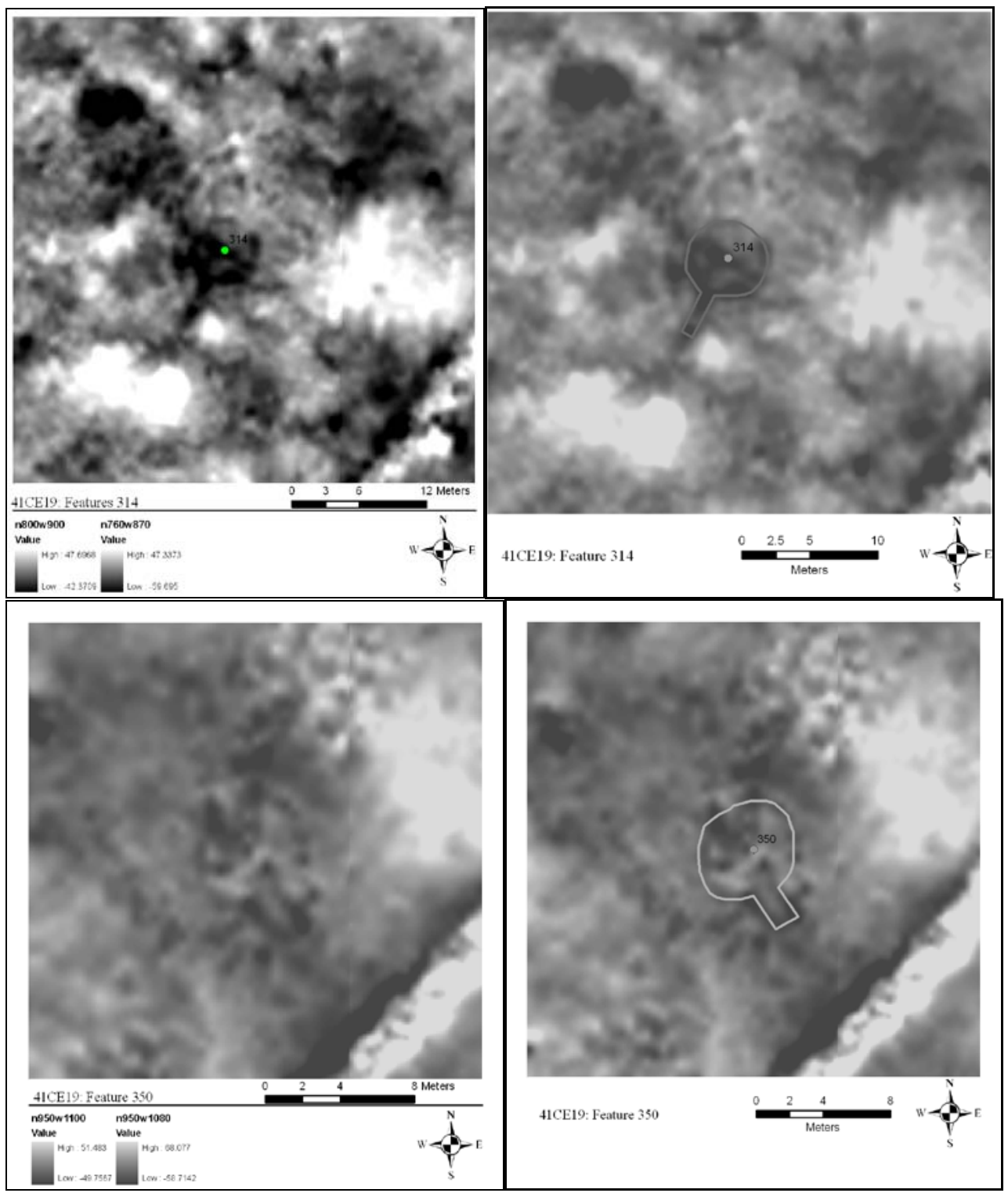

Figure 23. Circular structures with possible extended entrances from the George C. Davis site magnetometer data.

\section{Sub-Square Structures}

There are at least three and possibly eight or more patterns of magnetic returns that have been interpreted as representing sub-square to rectangular structures (Features $250,251,252,253,254,260,281$, and 347$)$. The patterns of returns for these possible 
structures range in size from $4.6 \mathrm{~m} \times 4.8 \mathrm{~m}$ to $11.7 \mathrm{~m} \times 11.7 \mathrm{~m}$. The areas of these structures range from $22.08 \mathrm{~m}^{2}$ to $174.37 \mathrm{~m}^{2}$, with a mean area of $72.92 \mathrm{~m}^{2}$. Figure 24 provides two clear examples of sub-square structures, Features 252 and 281, measuring $11.7 \mathrm{~m} \times 11.7 \mathrm{~m}$ and $6.8 \mathrm{~m} \times 6.8 \mathrm{~m}$ in size respectively. At least one sub-square structure appears to have been burned (Feature 260). Table 11 provides the dimensions of the subsquare structures.
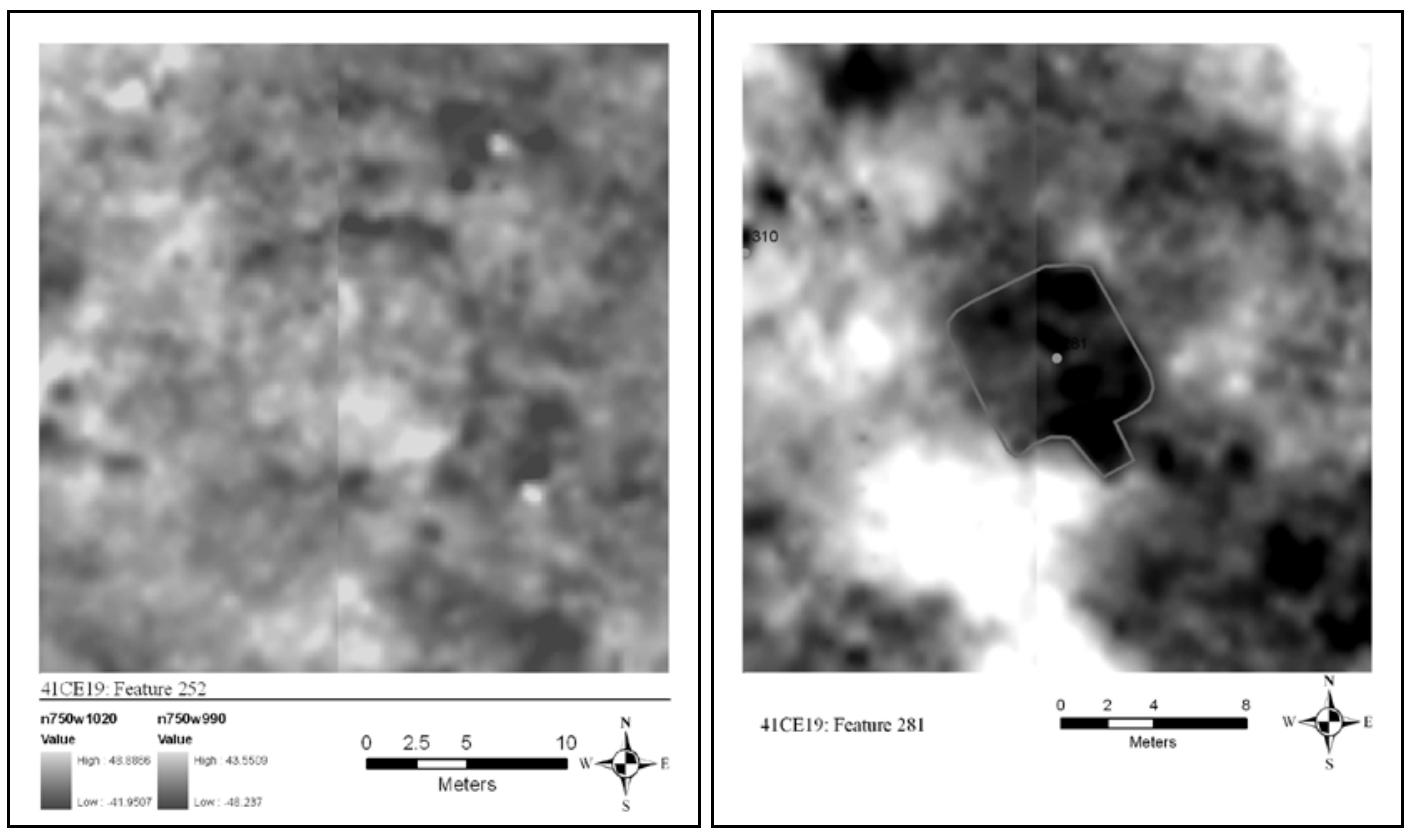

Figure 24. Examples of sub-square structures, Features 252 and 281.

In at least one and possibly two instances (see Feature 281 in Figure 24), there are patterns that suggest sub-square structures with extended entrances. The possible entrance for Feature 281 measures approximately $2 \mathrm{~m}$ long x $1.8 \mathrm{~m}$ wide. The possible south-facing entrance for Feature 347 is $1.8 \mathrm{~m} \times 1.8 \mathrm{~m}$, while the longer patterns of returns oriented to the west measure $4 \mathrm{~m}$ long $\times 2 \mathrm{~m}$. 
Table 11. Sub-square to rectangular structures.

\begin{tabular}{|r|r|r|l|}
\hline Feat & $\begin{array}{l}\text { Dimensions/ } \\
\text { Diameter } \mathbf{( m )}\end{array}$ & $\begin{array}{l}\text { Area } \\
\left(\mathbf{m}^{\mathbf{2}} \mathbf{)}\right.\end{array}$ & Notes \\
\hline 250 & 8 & 50.24 & \\
\hline 251 & 7 & 38.47 & \\
\hline 252 & $11.7 \times 11.7$ & 136.89 & \\
\hline 254 & $10.7 \times 10.7$ & 114.49 & \\
\hline 260 & $5 \times 6$ & 30 & \\
\hline 281 & $6.8 \times 6.8$ & 46.24 & S/SE facing extended entrance \\
\hline 347 & $4.6 \times 4.8$ & 22.08 & W or S facing extended entrance (possibly) \\
\hline
\end{tabular}

\section{EXCAVATIONS RESULTS 3}

One component of the remote sensing research at the George C. Davis site was ground-truthing select features identified in the magnetometer data. The structures to be examined during the 2003 excavations were those with four large interior posts and a central hearth. Portions of Features 237, 241, and 242, each with this structure form, were the targets of the 2003 excavations. Figure 25 provides a view of the magnetometer data with the targeted features identified and Figure 26 provides images of these structures as represented in the magnetometer data.

An excavation block (Unit 113) was initially placed over a pattern of magnetic returns interpreted as a circular structure with a central hearth and four large interior posts (Feature 237) (Figure 27). In addition, smaller units were opened over specific patterns of magnetic anomalies interpreted as architectural features associated with the three other structures. With the exceptions of the Unit 113 excavation block placed over Feature 237, excavation unit size was kept to a minimum in order to maximize potential data recovery while minimizing overall disturbances. Hearths from four structures and at least one interior post from three structures were located following these methods. In addition, the block excavation of Feature 237 led to the identification and partial excavation of the

\footnotetext{
${ }^{3}$ Portions of this section come from the author's contributing sections of the draft Texas Antiquities permit report (Wilson and Schultz, n.d.).
} 
exterior wall of the structure. Due to time constraints, only two of the interior post holes were excavated and, while archaeomagnetic samples were collected from four hearths, only one hearth was bisected and profiled.

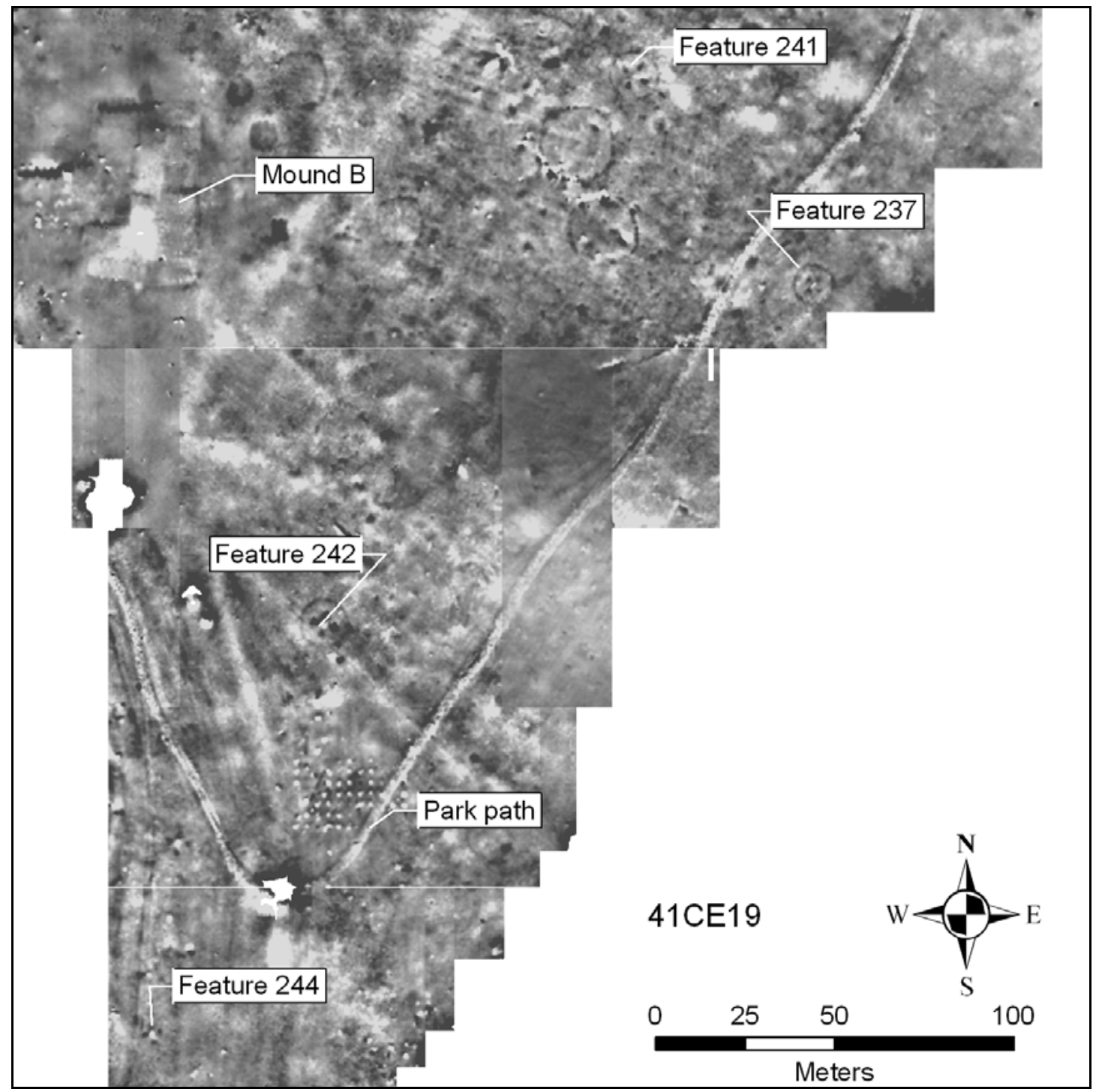

Figure 25. Shaded relief map of magnetometer data with targeted features. 

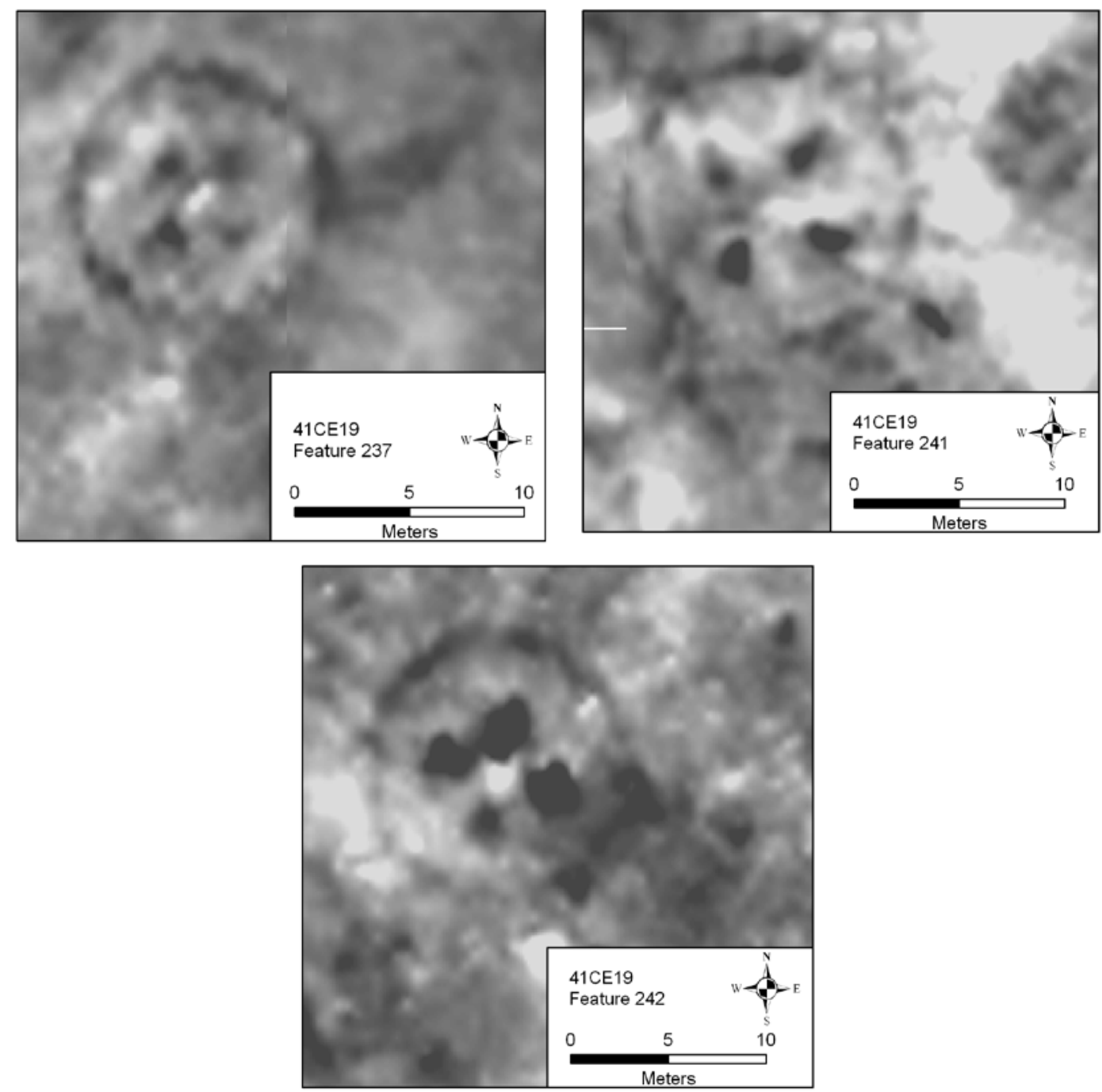

Figure 26. Features 237, 241, and 242. Structures partially excavated in 2003.

\section{Feature 237 - Unit 113}

Feature 237 was recorded from the magnetometer data as a circular structure measuring $10.6 \mathrm{~m}$ in diameter with four large interior posts and a central hearth (see Figure 26). Unit 113 was opened over a portion of Feature 237 and covered approximately one-third of the structure (Figure 27). Unit 113 extended from the 
approximate center of the feature to just beyond the exterior ring of posts and measured approximately $7.7 \mathrm{~m} \times 5.5 \mathrm{~m}$ in size, covering approximately $42.17 \mathrm{~m}^{2}$, as calculated using ArcGIS based on the TDS points along the sides of the unit.

The bulk of the plow zone was removed using a front-end loader with the remainder shovel skimmed to expose the red clay subsoil throughout the unit at approximately $35 \mathrm{~cm}$ below surface ( $\mathrm{cm} \mathrm{bs).} \mathrm{Features} 237.4$ and 237.6, the hearth and outer ring of posts respectively, were the most readily identifiable features. Features 237.1-237.3, the interior posts, proved more difficult to identify with little or no discernable color change on the surface. These features were located using a systematic pattern of soil probes placed using the grid coordinates for the posts from the magnetometer data. Figure 28 provides a plan view of Unit 113 and Table 12 provides a list of sub-features associated with Feature 237 and identified in Unit 113. Only one interior post, Feature 237.1, was actually excavated in the work in this unit.

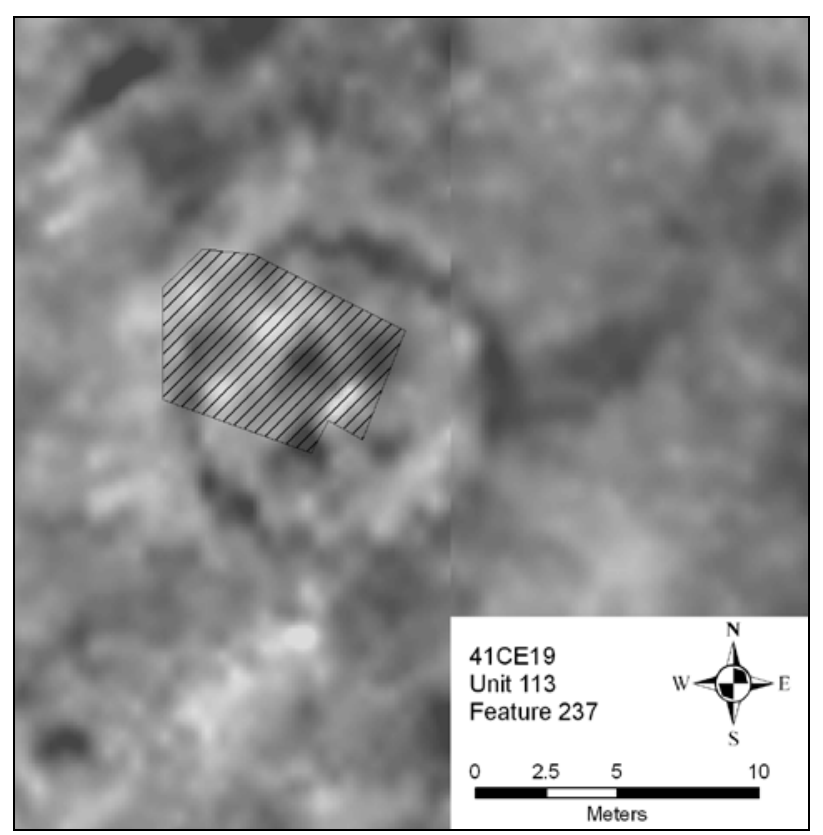

Figure 27. Unit 113 and Feature 237. 
Table 12. List of sub-features associated with Feature 237.

\begin{tabular}{|r|l|}
\hline Feature & Description \\
\hline 237 & Circular structure, center at N768, W873, diameter 10.6 m \\
\hline 237.1 & Interior support post \\
\hline 237.2 & Interior support post \\
\hline 237.3 & Interior support post \\
\hline 237.4 & Central hearth \\
\hline 237.5 & Pit located at perimeter of Feature 237 \\
\hline 237.6 & Yellow stain at northwest edge of Feature 237 (post trench) \\
\hline
\end{tabular}

Feature 237.1 was $1.07 \mathrm{~m}$ in diameter. The post feature was bisected, with the western half removed and all fill saved for flotation. The post hole extended to approximately $75 \mathrm{~cm}$ bs (ca. $39 \mathrm{~cm}$ below the scraped surface of the unit). Figure 29 provides a view of Feature 237.1. The profile (Figure 30) included three layers. Both the upper and middle layers were a dark reddish-brown (5YR3/4) sandy loam mottled with black (10YR2/1) charred material. The distinction between the two layers was in the increase in mottling in the middle layer. The lower layer included reddish-brown (5YR4/4) sandy loam with little to no charred material. The surrounding matrix consisted of a dark red (10R3/6) sandy clay. Charcoal and OCR samples were collected from the feature and the remainder of the feature fill was saved for flotation, which yielded very little material (see Perttula n.d.). 


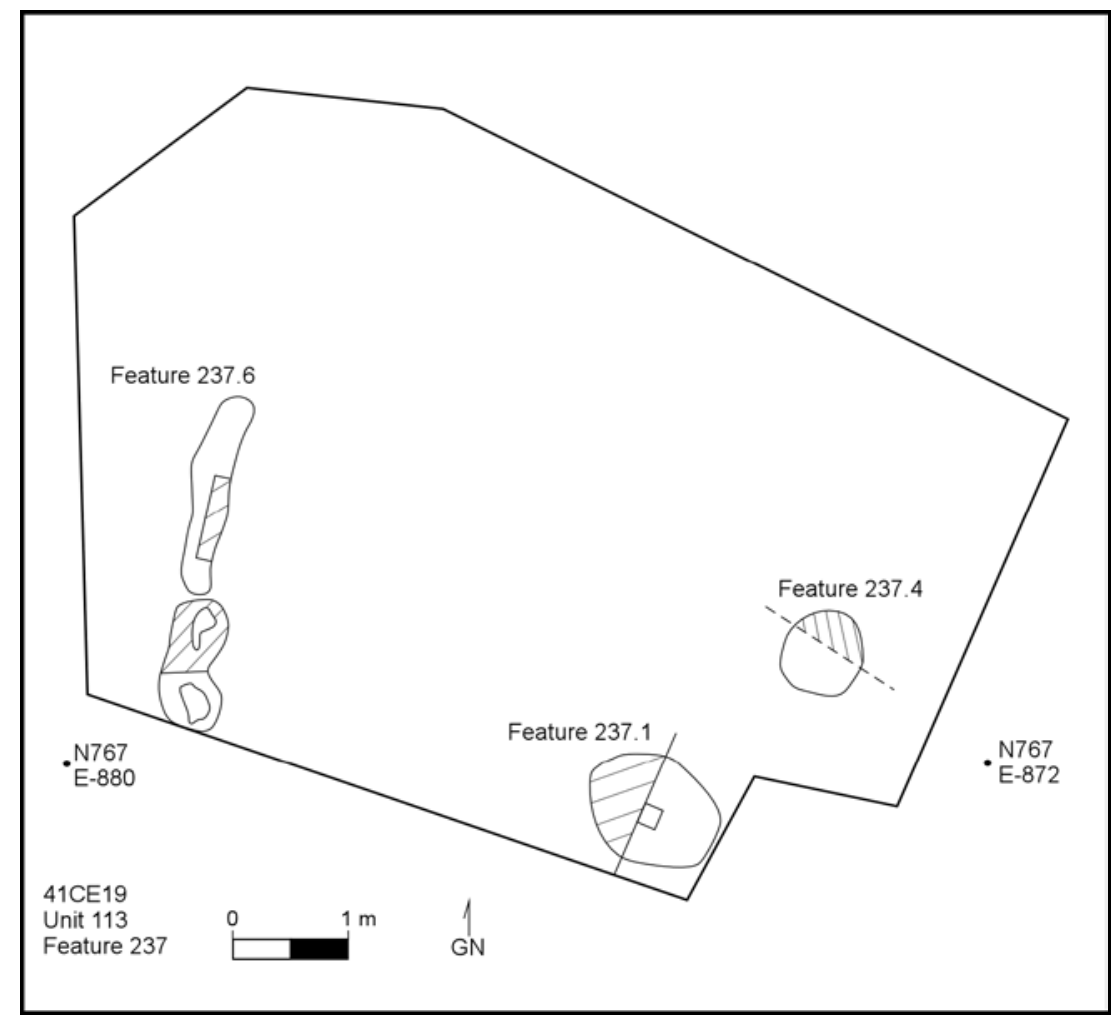

Figure 28. Plan view of Unit 113 and Features 237.1, 237.4, and 237.6.

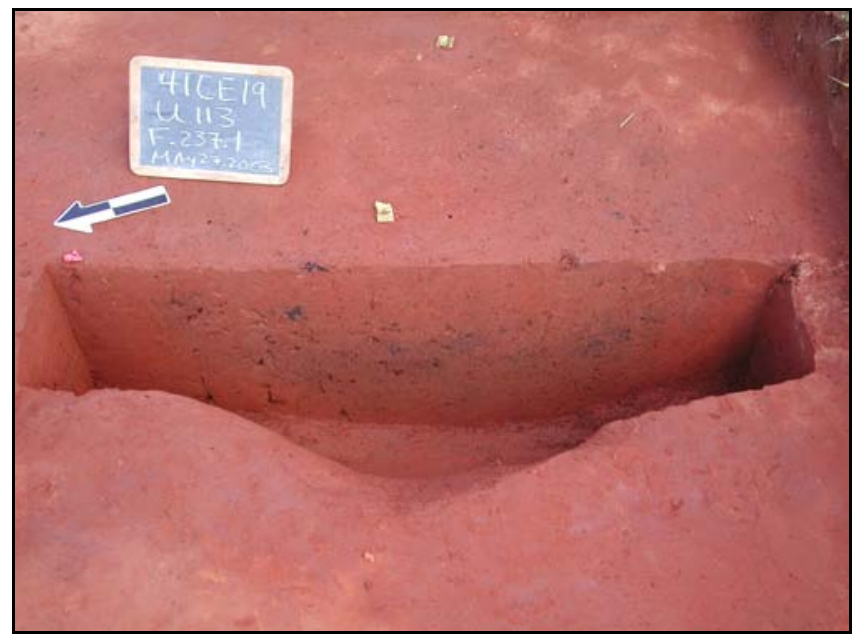

Figure 29. Plan and profile view of Feature 237.1. 


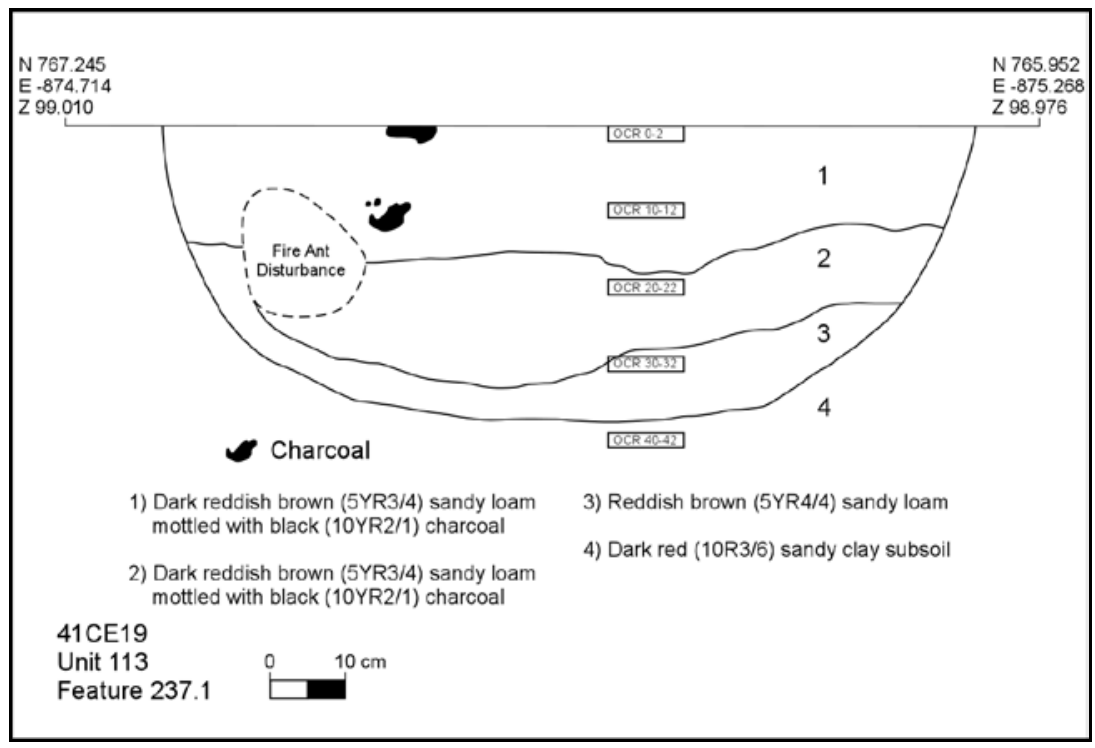

Figure 30. Profile of Feature 237.1.

The hearth (Feature 237.4) was initially identified as a large dark stain (Figure 31) at the plow zone/subsoil interface. The feature represents the bottom remnant of a hardbaked, heavily-fired clay hearth. The hearth had a diameter of ca. 70-75 cm. Samples for archaeomagnetic dating were collected from the edges of the feature. The northern half of the hearth was removed (Figure 32) and all fill was saved for flotation. The fill directly below the hearth was red with gray clay mottling. A single sample of charred material was collected for AMS dating from below the hearth. Previously excavated hearths from the Davis site have diameters ranging from 48 to $183 \mathrm{~cm}$ and depths from 3 to $45 \mathrm{~cm}$ bs (Newell and Krieger 1949; Spock 1977). 


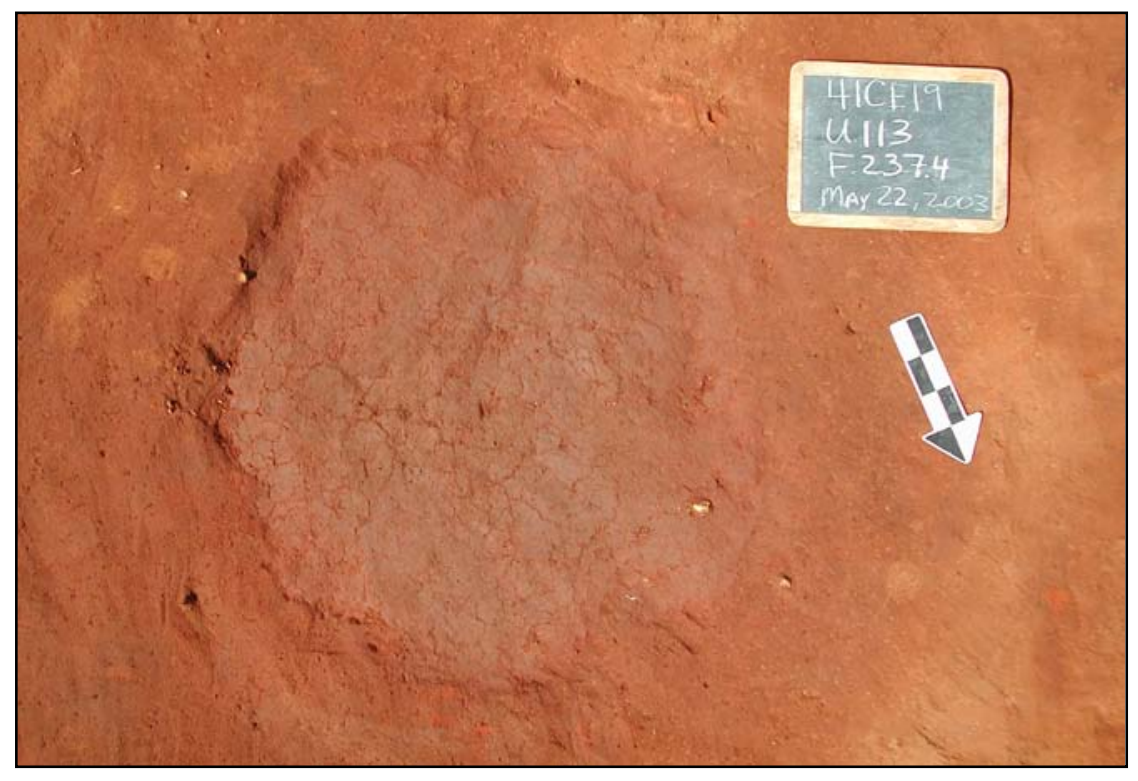

Figure 31. View of Feature 237.4.

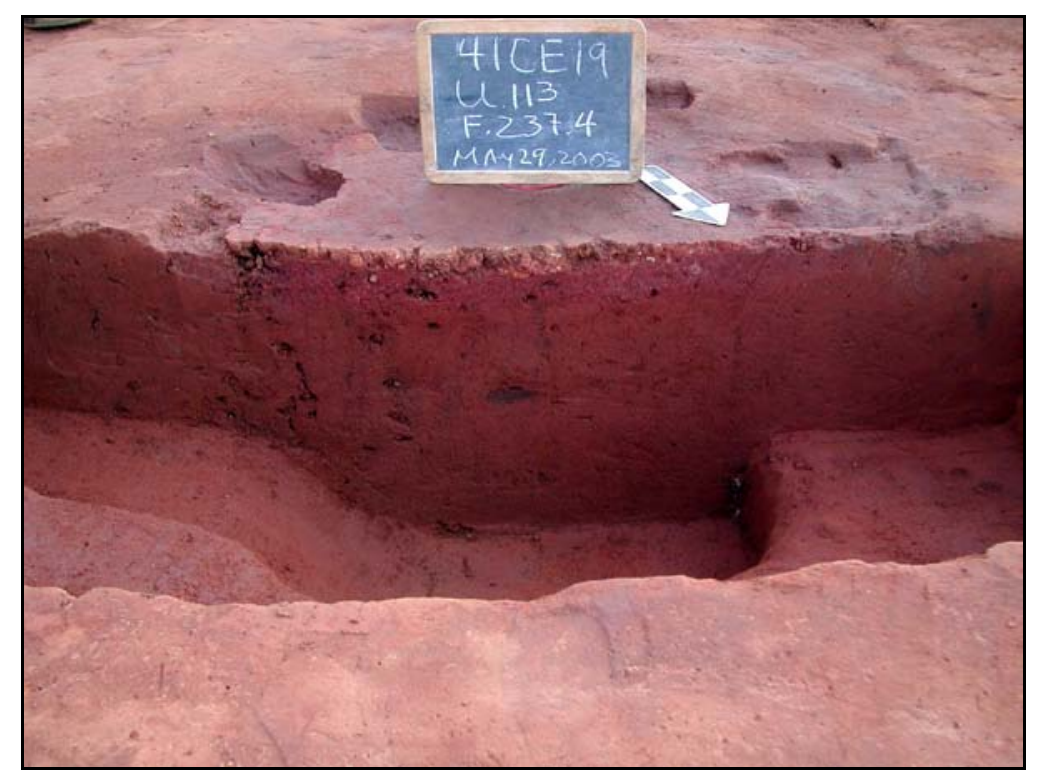

Figure 32. Feature 237.4.

The outer ring of the structure (Feature 237.6) was observed as a mottled yellow clay line thought to be a wall trench. It was difficult to delineate the exact boundaries of the possible post trench given the subtle and diffuse edges of the feature. As individual 
posts could not be identified, the feature was bisected lengthwise, removing the eastern half. The excavated portion of the post trench is approximately $75 \mathrm{~cm}$ long. As with Feature 237.1, once the feature was bisected the subtle variation in soil color was more evident. Following a heavy rain, two individual post holes became apparent. Unfortunately, Feature 237.6 was bisected directly on top of these post holes. Each post hole was assigned a separate sub-feature number: Features 237.7, and 237.8. Figure 33 provides a profile of Features 237.7, and 237.8. Feature 237.6 excavations were extended to include a $40 \times 40 \mathrm{~cm}$ area excavated along the eastern edge of the trench. This provided a profile view of the post trench (Figure 34).

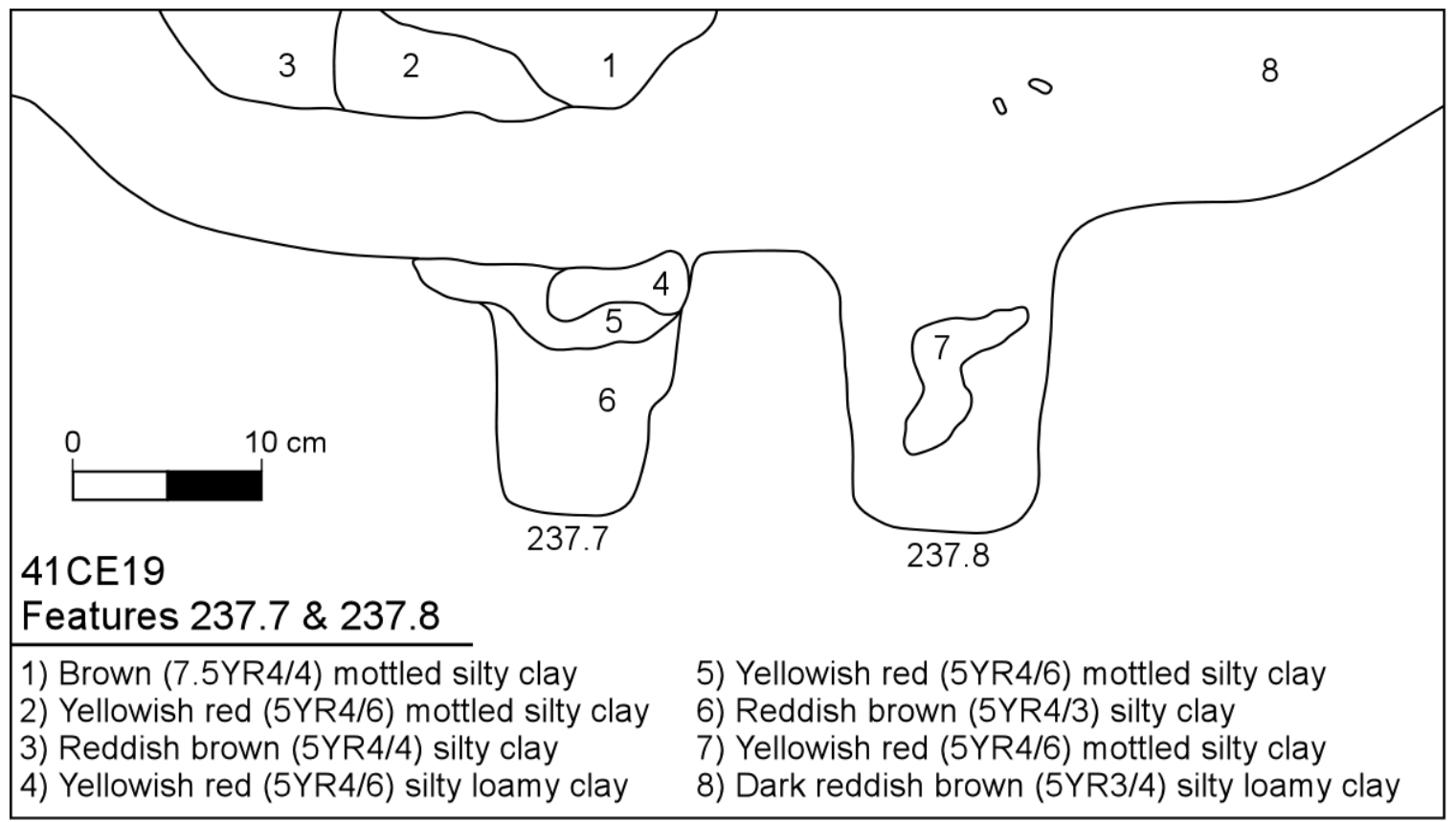

Figure 33. Profile of Features 237.6, 237.7 and 237.8.

This feature is a wall trench filled with brown (7.5YR4/4) mottled clay, charcoal, and reddish-brown (5YR4/3) soil. Post holes appear to have been dug into the bottom of the trench. The brown clay may represent fill packed around the posts at the time of 
construction and the reddish-brown fill may be remnants of the rotted post material or perhaps a chock set in place to hold the posts upright during their placement in the post trench.

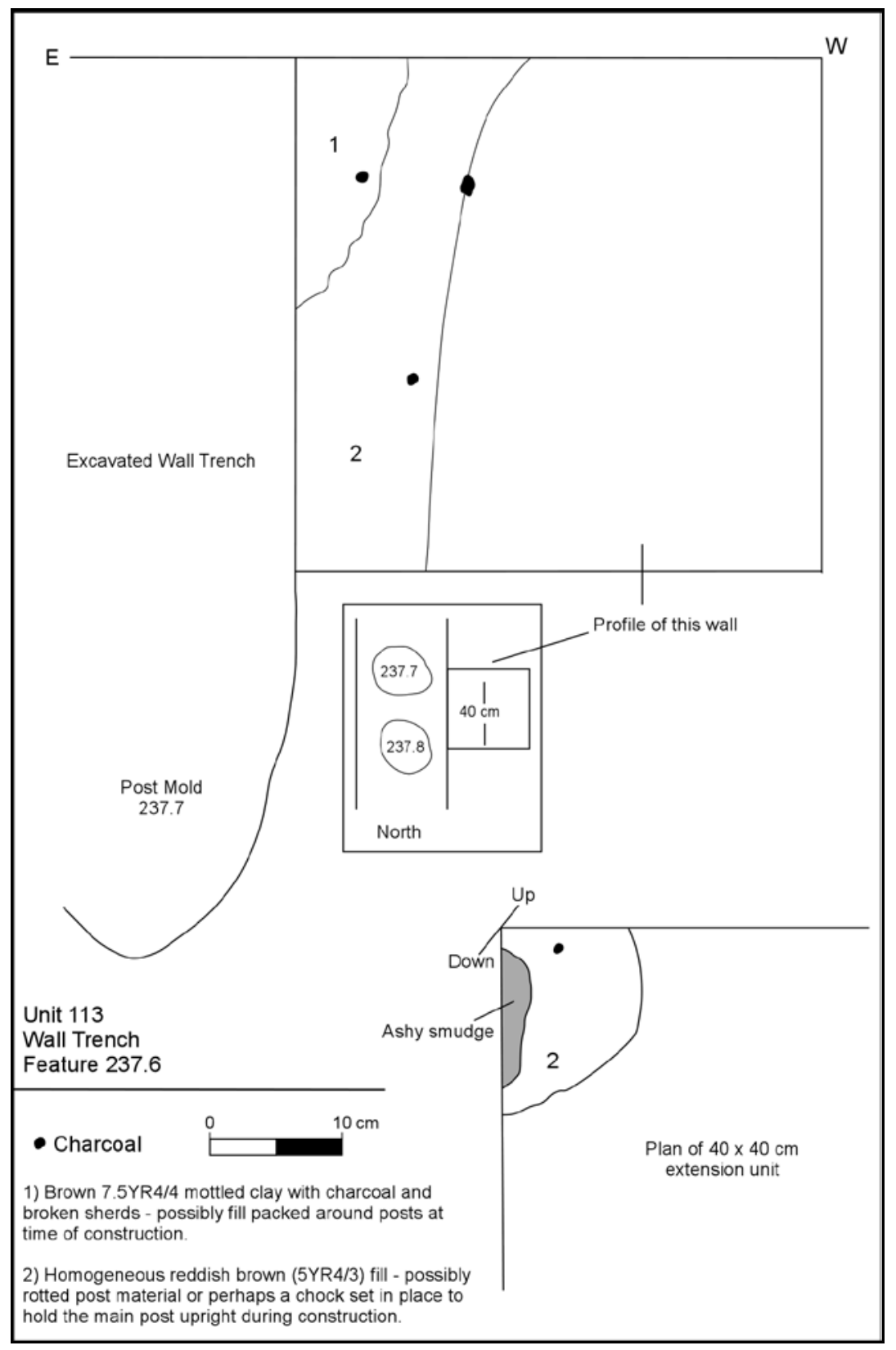

Figure 34. Profile and plan of Feature 237.6. 
Wall-trench architecture is not unheard of at the George C. Davis site. Five previously excavated structures from the site (Features 9, 31, 35, 43, 44, and 45) have post trenches: four with exterior post trenches and one with both exterior and interior trenches (Feature 44). The Feature 237 post trench is similar in character to those described for previously excavated structures at the George C. Davis site. In describing the exterior post trench associated with Feature 9, for example, Spock (1977:47-48) notes:

there was much difficulty in identifying the posts set into the trench. Where a dark disturbed soil filled the trench, the posts were faintly visible; where red clay was used as trench fill, the posts were more apparent. Nonetheless, it was observed that the posts were for the most part set on the trench bottom, a few extending slightly below this. When seen in profile, the post stains faded out toward the surface, blending into the upper part of the trench fill.

\section{Feature 242 - Unit 116}

The excavations in Feature 242 were conducted using small units placed over specific architectural features. Feature 242 was identified in the magnetometer data as a $13 \mathrm{~m}$ diameter circular structure with four interior posts and a central hearth. Two units, both originally assigned unit number 116, were opened over the features. A 1 x $1 \mathrm{~m}$ unit (Unit 116) was opened over the southeastern portion of the central hearth, Feature 242.2, and a $1 \times 2 \mathrm{~m}$ unit (Unit 116B) was opened over the southeastern interior post, Feature 242.1 (Figure 35). 


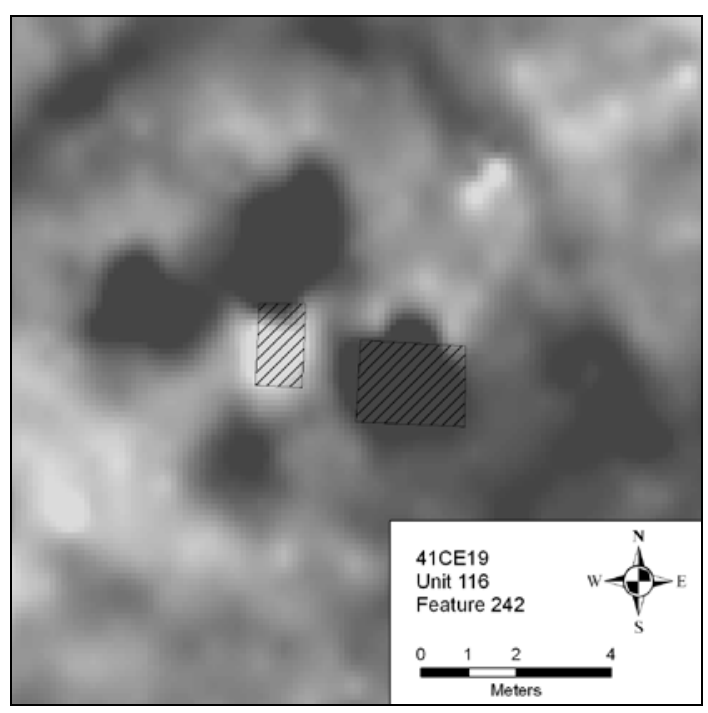

Figure 35. Unit 116 in Feature 242.

Due to time constraints, the decision was made to focus only on the collection of samples for potential dating from Feature 242.2 (the central hearth). Given this, Feature 242.1 (an interior support post) was not completely excavated, although a small sample of charred material was collected from the feature and submitted for AMS dating.

The southeastern edge of the hearth was identified directly below the plow zone (approximately $30 \mathrm{~cm} \mathrm{bs)} \mathrm{in} \mathrm{the} \mathrm{northwest} \mathrm{corner} \mathrm{of} \mathrm{Unit} \mathrm{116.} \mathrm{The} \mathrm{unit} \mathrm{was} \mathrm{expanded} 1$ $\mathrm{m}$ to the north in order to expose more of the hearth. Once Feature 242.2 was delineated (Figure 36), the remnants of a second larger hearth (Feature 242.3) were defined and this hearth appeared to extend below Feature 242.2. Archaeomagnetic samples were collected from Features 242.2 (inner hearth) and 242.3 (outer hearth). Work ceased after the archaeomagnetic samples were collected. All fill between the two hearths and the disturbed remnants of the hearths were collected as separate lots for later processing. 


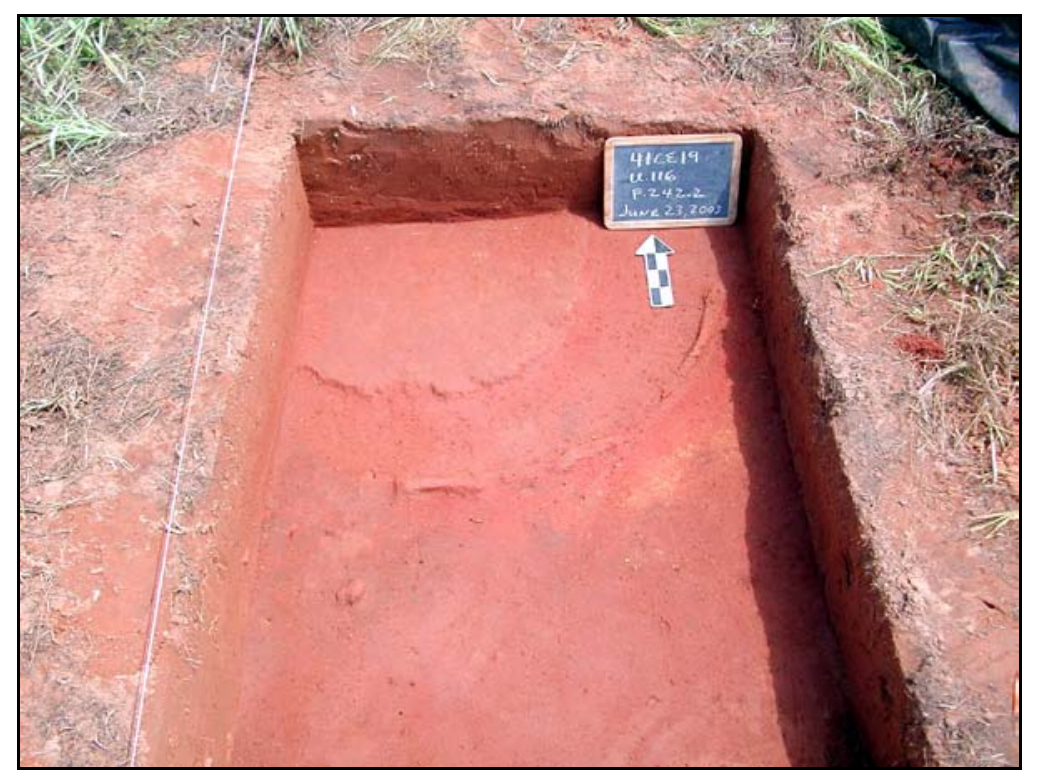

Figure 36. Features 242.2 (inner hearth) and 242.3 (outer hearth).

\section{Feature 241 - Unit 117}

Like Units 116 and 116B, Units 117 and 117B were relatively small units, targeted at specific architectural features within Feature 241. Feature 241 (Figure 37) was identified in the magnetometer data as a circular structure measuring $13.5 \mathrm{~m}$ in diameter with four large interior posts and a central hearth. A $0.50 \times 0.50 \mathrm{~m}$ unit (Unit 117) was placed over the central hearth (Feature 241.2), and a 1 x $1 \mathrm{~m}$ unit (Unit 117B) was situated over the northwest interior post (Feature 241.1).

The remnants of the hearth, Feature 241.2, were located directly below the plow zone at approximately $25 \mathrm{~cm}$ bs. The unit was expanded to approximately $0.80 \times 1.3 \mathrm{~m}$ in size to expose more of this central hearth. Feature 241.2 (Figure 38) appeared to be more disturbed than the hearths of Features 237 and 242. Samples of charred material were collected for radiocarbon dating as were samples for archaeomagnetic dating. All excavated or newly disturbed sediment portions of the hearth were collected for flotation. 


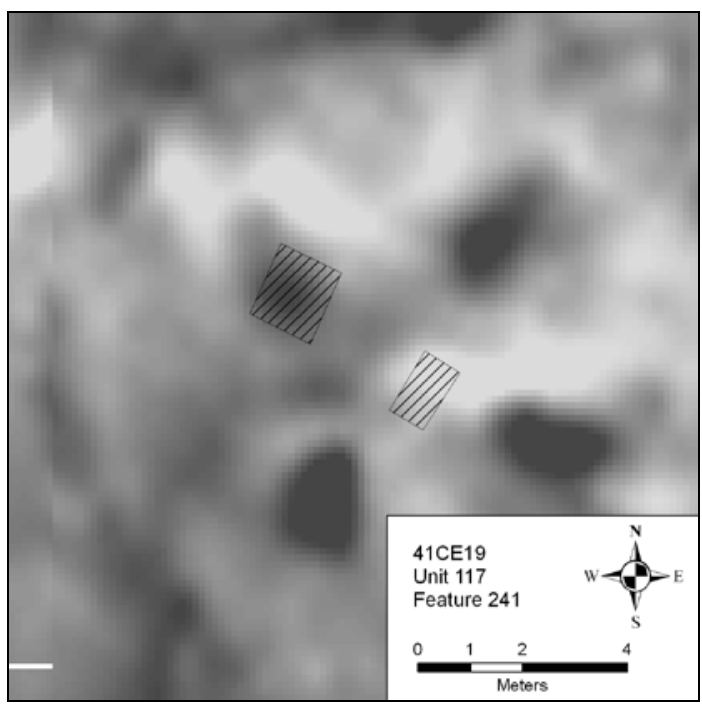

Figure 37. Unit 117 and Unit 117B.

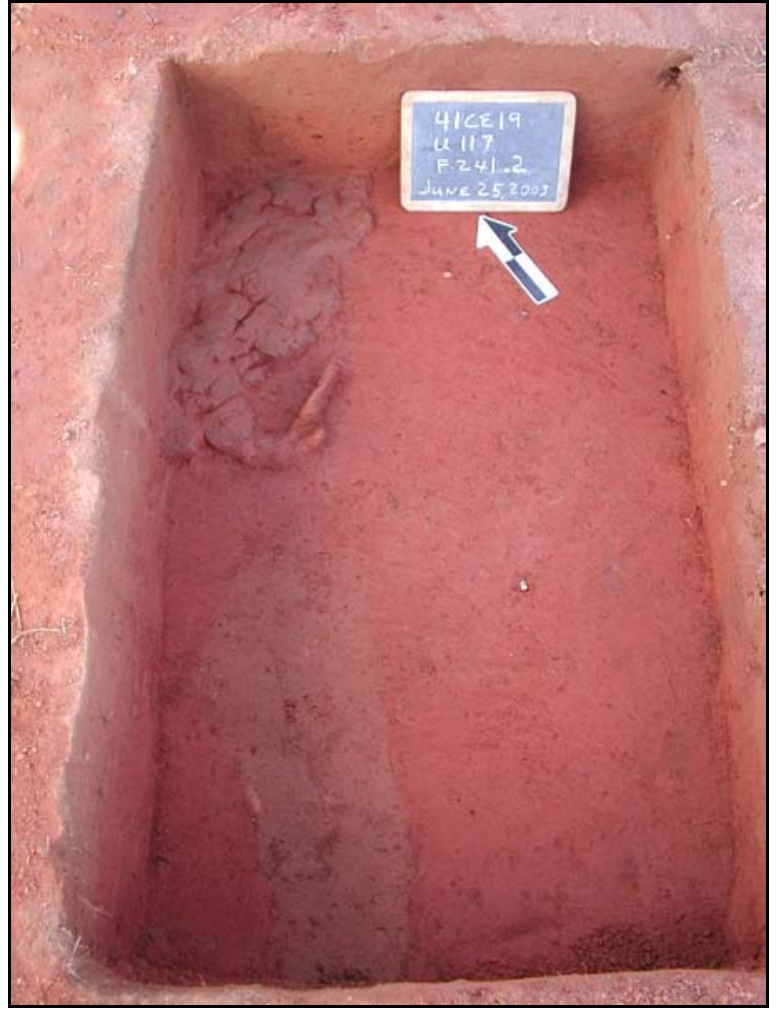

Figure 38. Features 241.2 (the hearth is in the northwest corner). 
The interior post, Feature 241.1, was first recognized as a light colored and yellow gravelly area directly below the plowzone at approximately $25 \mathrm{~cm}$ bs. Unit $117 \mathrm{~B}$ was expanded to approximately $1.3 \mathrm{~m}$ x $1.5 \mathrm{~m}$ in size once the feature was located. Feature 241.1 was difficult to see in plan view and was delineated largely on the basis of soil texture. The eastern half of the feature was removed and all fill was saved for flotation. As with Features 237.1 and 237.6-8, Feature 241.1 was clearly visible in profile (Figures 39 and 40). Feature 241.1 was approximately $65 \mathrm{~cm}$ in diameter and extended to a depth of approximately $104 \mathrm{~cm}$ bs (ca. $74 \mathrm{~cm}$ below the surface of the unit). This post hole was significantly deeper than Feature 237.1, the interior support post excavated in Unit 113, which appeared to extend to a depth of only $75 \mathrm{~cm} \mathrm{bs}$. Based on this difference and considering the diameter of the post and the subtle color differences between feature fill and the surrounding soil at the George C. Davis site, it is likely that Feature 237.1 actually extends below the depth of the feature recognized during the excavations.

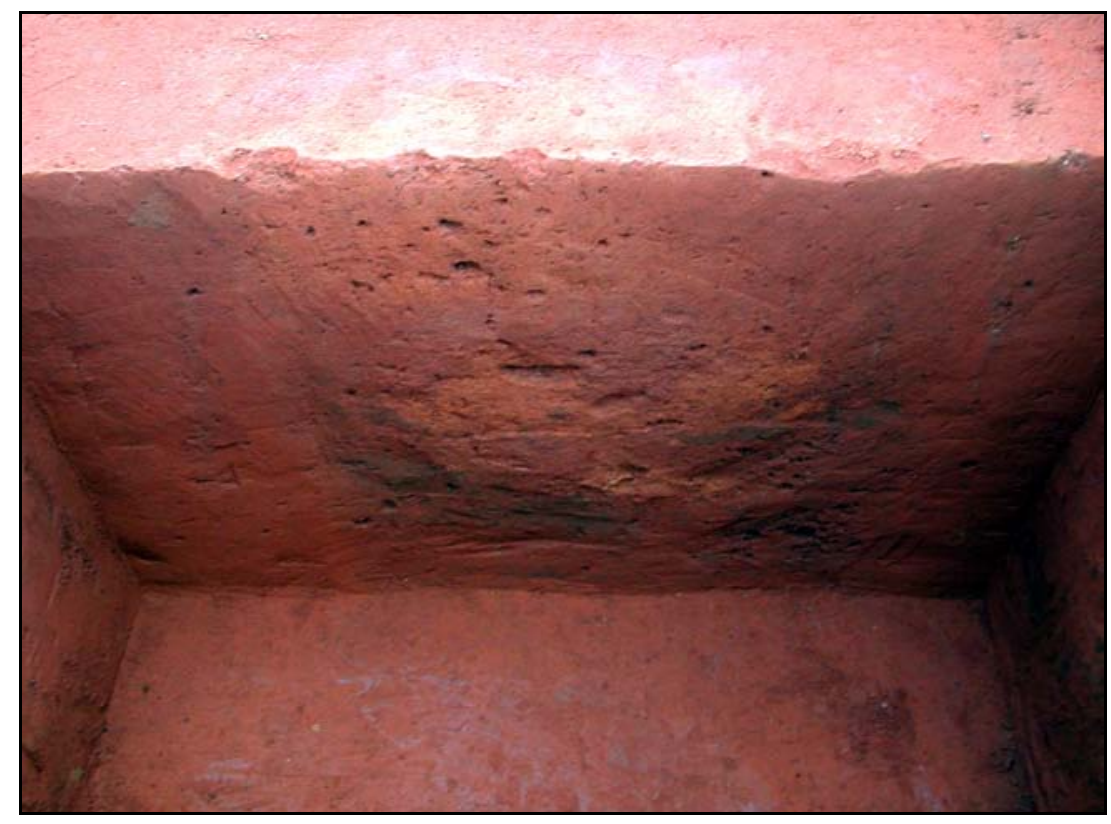

Figure 39. View of Feature 241.1. 


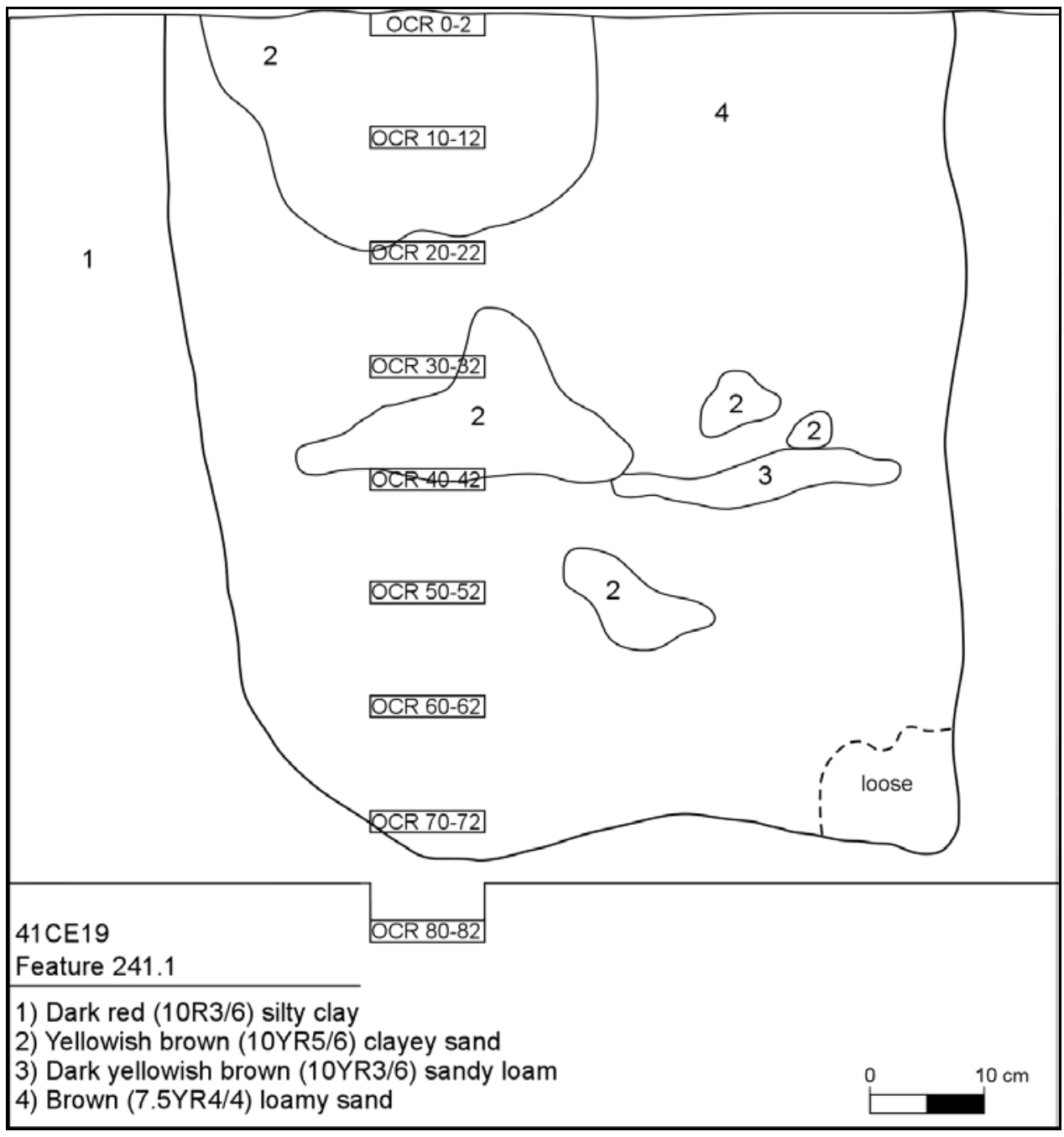

Figure 40. Profile of Feature 241.1.

At least eight previously excavated structures at the Davis site have interior posts that extend deeper than $70 \mathrm{~cm}$ bs and at least 24 structures had exterior posts extending to depths of $70 \mathrm{~cm}$ or greater (Spock 1977). This being said, shallow interior posts have been found at the site as well, with several structures having interior posts no deeper than $35 \mathrm{~cm} \mathrm{bs}$, and some that were quite shallower. This difference may be indicative of different uses for the various interior posts, including: support posts for different forms of structures, whether flexed pole or rigid pole structures, or supports for beds, screens, 
racks, or other interior furnishings or features that may not require as substantially set a post. Likewise, the difference in exterior post size, depth, and spacing likely indicates different architectural forms of the various circular buildings.

\section{Summary of 2003 Excavations}

Three Caddo structures were at least partially investigated during the 2003 fieldwork at the George C. Davis site. With the exception of one large block (Unit 113), these excavations targeted specific features identified in the site's magnetometer data. Using small excavation units that targeted specific features, the hearth and interior posts of these structures were located, profiled, and contents sampled. As indicated by Perttula's (n.d.) analysis of the artifacts recovered from Feature 237, as well as the location, form, and associated features of each structure, Features 237, 241, and 242 fit Spock's (1977) broad classification of domestic structures. In his analysis of the small amount of artifacts recovered in 2003, Perttula (n.d.) notes that the small collection "comprises primarily domestic debris from an Early Caddo (pre-A.D. 1300) occupation (cf. Story 2000).”

There is considerable variety in building forms and associated features at the George C. Davis site (Newell and Krieger 1949; Spock 1977; Story 1998). Through the addition of manual excavations, the 2003 field work provides a more refined understanding of the anomalies identified in the George C. Davis magnetometer dataset. These results provide a better understanding of the correlation between the architectural features identified in the magnetometer data and the rich archaeological record from the site. 


\section{DATES FROM GEORGE C. DAVIS STRUCTURES}

Prior to the 2003 season, the George C. Davis site had 130 radiocarbon dates that were primarily from the 1968-1970 mound and village excavations by Dee Ann Story (Perttula 1997; Story 1997, 1998). Table 13 provides the dates from previously excavated structures (Perttula 1997; Story 1997). With support from the Smithsonian Institution's National Museum of Natural History, the 2003 excavations of three Caddo structures at the George C. Davis site yielded five radiocarbon dates from charred material submitted to Beta Analytic, Inc. (Table 14). While the dates generally fall within the temporal range of previous dates from the site, some of the samples of carbonized materials submitted in 2003 were not from ideal contexts. In addition to these dates, archaeomagnetic samples were collected in 2003 from the excavated hearths and were processed at the paleomagnetism laboratory at UT-Austin. The archaeomagnetic samples resulted in dates well outside the possible range for the George C. Davis site (Creel, personal communication, Gose, personal communication). As a result, no reliable dates were obtained from this method.

Two radiocarbon samples were recovered from Feature 237, one from the central hearth, Feature 237.4, and one from a post hole for an interior support post (Feature 237.1). Sample Beta-181492 (UT sample/lot number CE19-5378-22) from Feature 237.1 yielded a measured radiocarbon age of $680 \pm 40$ B.P., a conventional radiocarbon age of $670 \pm 40$ B.P., and a 2 sigma calibrated age range of AD 1275 to 1395 (B.P. 675-555). Sample Beta-181493 (UT sample/lot number CE19-5378-28) was collected from directly below the hearth (Feature 237.4). This sample has a measured radiocarbon age of $950 \pm$ 40 B.P., a conventional radiocarbon age of $940 \pm 40$ B.P., and a 2 sigma calibrated age range of A.D. 1010 to 1195 (B.P. 940 to 755$)$. 
In addition to the Feature 237 samples, two samples were recovered from Feature 242 (Feature 242.2, the central hearth, and Feature 242.1, an interior post hole). Sample Beta-181495 (UT sample/lot number CE19-5380-4) has a measured radiocarbon age of $860 \pm 40$ B.P., a conventional radiocarbon age of $860 \pm 40$ B.P., and a 2 sigma calibrated age range of A.D. 1040-1260 (910 to 690 B.P.). Sample Beta-181496 (UT sample/lot number CE19-5380-32) has a measured radiocarbon age of $1630 \pm 40$ B.P., a conventional radiocarbon age of $1600 \pm 40$ B.P., and a 2 sigma calibrated age range of AD 390 to 550 (BP 1560 to 1400). This later sample was collected from the upper portion of the post hole, near where it was first identified.

One radiocarbon sample was collected from the hearth of Feature 241 (Feature 241.2). The small sample of charred material yielded a measured radiocarbon age of 1180 $\pm 50 \mathrm{BP}$, a conventional radiocarbon age of $1170 \pm 50 \mathrm{BP}$, and a 2 sigma calibrated age range of $\mathrm{AD} 720$ to 745 (BP 1230 to 1205) and AD 760 to 990 (BP 1190 to 960). This sample was collected from the burned clay of the hearth at the level at which the feature was first identified.

Table 13. Radiocarbon dates from previously excavated structures at the George C. Davis site (Perttula 1997; Story 1997).

\begin{tabular}{|c|c|c|c|c|c|c|}
\hline Area & Feature & Specific Provenience & Assay No. & Raw Age (BP) & Corrected Age & $\begin{array}{c}\text { Calibrated } 1 \text { sigma } \\
\text { age range }(\mathrm{AD})\end{array}$ \\
\hline \multirow{5}{*}{$\begin{array}{l}\rightleftarrows \\
\stackrel{\Xi}{\Sigma}\end{array}$} & \multirow[t]{5}{*}{31} & Pit in Floor & C-153 & $1553 \pm 175$ & $1794 \pm 180$ & $\begin{array}{l}52-434 \\
25-44\end{array}$ \\
\hline & & Feature 31 pit & M-1168 & $655 \pm 75$ & $896 \pm 85$ & $\begin{array}{l}1151-1219 \\
1044-1105 \\
1112-1147 \\
\end{array}$ \\
\hline & & Same pit as C- 153 & Tx-105 & $1120 \pm 90$ & $1361 \pm 99$ & $598-787$ \\
\hline & & Sec. 13 & Tx-1395 & $830 \pm 80$ & $806 \pm 90$ & $\begin{array}{l}1159-1295 \\
1063-1076 \\
\end{array}$ \\
\hline & & Unspecified Post holes & Tx-1399 & $1130 \pm 60$ & $1106 \pm 72$ & $882-1015$ \\
\hline
\end{tabular}




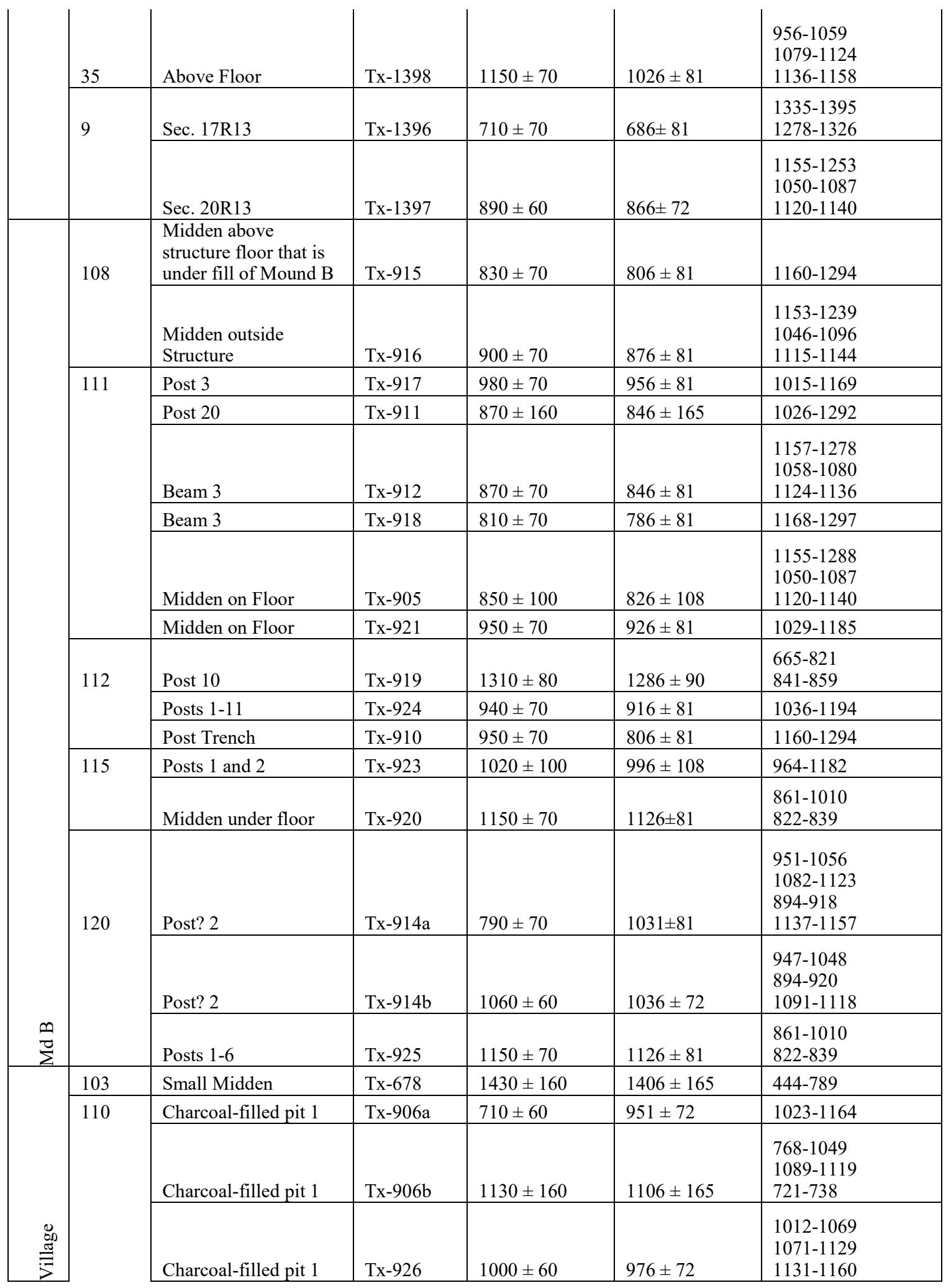




\begin{tabular}{|c|c|c|c|c|c|}
\hline & Charcoal-filled pit 2 & $\mathrm{Tx}-907$ & $960 \pm 70$ & $936 \pm 81$ & $1024-1180$ \\
\hline & $\begin{array}{l}\text { Charcoal-filled pits } 7 \text {, } \\
17\end{array}$ & Tx-908 & $1230 \pm 100$ & $1206 \pm 108$ & $\begin{array}{l}757-897 \\
910-959 \\
712-745 \\
\end{array}$ \\
\hline & Charcoal-filled pit 7 & Tx-909 & $1170 \pm 120$ & $1146 \pm 127$ & $772-1017$ \\
\hline \multirow[t]{5}{*}{125} & Hearth 1 & Tx-1204 & $1110 \pm 80$ & $1086 \pm 90$ & $861-1035$ \\
\hline & Hearth 2 & Tx-1307 & $1030 \pm 70$ & $1006 \pm 81$ & $\begin{array}{l}976-1067 \\
1073-1128 \\
1132-1160 \\
\end{array}$ \\
\hline & Hearth 2 & Tx-1308 & $800 \pm 70$ & $1041 \pm 81$ & $\begin{array}{l}892-1047 \\
1096-1116 \\
\end{array}$ \\
\hline & Hearth 3 & Tx-1201 & $920 \pm 80$ & $896 \pm 90$ & $\begin{array}{l}1151-1219 \\
1043-1107 \\
1111-1148 \\
\end{array}$ \\
\hline & Post hole 82 & Tx-1202 & $1080 \pm 80$ & $1056 \pm 90$ & $\begin{array}{l}884-1048 \\
1093-1117 \\
\end{array}$ \\
\hline \multirow[t]{2}{*}{126} & Charcoal-filled pit 13 & $\mathrm{Tx}-1214$ & $790 \pm 80$ & $766 \pm 90$ & $\begin{array}{l}1168-1307 \\
1362-1377 \\
\end{array}$ \\
\hline & Charcoal-filled pit 8 & Tx-1215 & $850 \pm 90$ & $826 \pm 99$ & $\begin{array}{l}1157-1287 \\
1055-1083 \\
\end{array}$ \\
\hline \multirow[t]{2}{*}{137} & Charcoal-filled pit $16 \mathrm{~b}$ & Tx-1208 & $1070 \pm 70$ & $1046 \pm 81$ & $\begin{array}{l}890-1046 \\
1098-1115 \\
\end{array}$ \\
\hline & Charcoal-filled pit 15 & Tx-1209 & $860 \pm 80$ & $836 \pm 90$ & $\begin{array}{l}1157-1283 \\
1057-1081 \\
\end{array}$ \\
\hline \multirow[t]{3}{*}{139} & Tree mold & Tx-1212 & $1160 \pm 90$ & $1136 \pm 99$ & $673-1048$ \\
\hline & Charcoal-filled pit 21 & $\mathrm{Tx}-1211$ & $860 \pm 80$ & $836 \pm 90$ & $1057-1081$ \\
\hline & Post hole 83 & Tx-1213 & $950 \pm 80$ & $926 \pm 90$ & $1028-1195$ \\
\hline \multirow[t]{4}{*}{146} & Charcoal-filled pit 69 & $\mathrm{Tx}-1221$ & $1000 \pm 80$ & $976 \pm 90$ & $993-1169$ \\
\hline & Charcoal-filled pit 71 & Tx-1222 & $1100 \pm 80$ & $1076 \pm 90$ & $\begin{array}{l}865-1043 \\
827-833 \\
\end{array}$ \\
\hline & Post hole 164 & $\mathrm{Tx}-1223$ & $1290 \pm 80$ & $1266 \pm 90$ & $\begin{array}{l}678-827 \\
833-865 \\
\end{array}$ \\
\hline & Charcoal-filled pit 62 & Tx-1224 & $980 \pm 70$ & $956 \pm 81$ & $1015-1169$ \\
\hline 160 & Charcoal-filled pit 54 & Tx-1210 & $890 \pm 80$ & $866 \pm 90$ & $\begin{array}{l}1154-1257 \\
1048-1092 \\
1117-1143 \\
\end{array}$ \\
\hline \multirow[t]{2}{*}{165} & Charcoal-filled pit 1 & Tx-1216 & $780 \pm 70$ & $756 \pm 81$ & $\begin{array}{l}1192-1307 \\
1361-1378 \\
\end{array}$ \\
\hline & Post hole 63 & $\mathrm{Tx}-1217$ & $1020 \pm 70$ & $996 \pm 81$ & $\begin{array}{l}986-1069 \\
1071-1129 \\
1131-1160\end{array}$ \\
\hline
\end{tabular}


Table 14. 2003 dating results from the George C. Davis site.

\begin{tabular}{|c|c|c|c|c|c|c|}
\hline Feat & Sample & $\begin{array}{l}\text { Specific Area } \\
\text { of Sample and } \\
\text { sample material }\end{array}$ & $\begin{array}{l}\text { Measured } \\
\text { Radiocarbon } \\
\text { Age } \\
\end{array}$ & $\begin{array}{l}13 \mathrm{C} / 12 \mathrm{C} \\
\text { Ratio }\end{array}$ & $\begin{array}{l}\text { Conventional } \\
\text { Radiocarbon } \\
\text { Age } \\
\end{array}$ & 2 Sigma Calibration \\
\hline 237.1 & $\begin{array}{l}\text { CE19- } \\
5378-22\end{array}$ & $\begin{array}{l}\text { Interior post, } \\
\text { charred } \\
\text { material }\end{array}$ & $680+/-40 \mathrm{BP}$ & $-25.4 \mathrm{o} / \mathrm{oo}$ & $670+/-40 \mathrm{BP}$ & $\begin{array}{l}\text { Cal AD } 1275 \text { to } 1395 \\
\text { (Cal BP } 675 \text { to 555) }\end{array}$ \\
\hline 237.4 & $\begin{array}{l}\text { CE19- } \\
5378-28\end{array}$ & $\begin{array}{l}\text { Central hearth, } \\
\text { charred } \\
\text { material } \\
\end{array}$ & $950+/-40 \mathrm{BP}$ & $-25.9 \mathrm{o} / \mathrm{oo}$ & $940+/-40 \mathrm{BP}$ & $\begin{array}{l}\text { Cal AD } 1010 \text { to } 1195 \\
\text { (Cal BP } 940 \text { to } 755)\end{array}$ \\
\hline 242.1 & $\begin{array}{l}\text { CE19- } \\
5379-1\end{array}$ & $\begin{array}{l}\text { Post, charred } \\
\text { material }\end{array}$ & $1180+/-50 \mathrm{BP}$ & $-25.9 \mathrm{o} / \mathrm{oo}$ & $1170+/-50 \mathrm{BP}$ & $\begin{array}{l}\text { Cal AD } 720 \text { to } 745 \\
\text { (Cal BP } 1230 \text { to } 1205) \\
\& \text { Cal AD } 760 \text { to } 990 \\
\text { (Cal BP } 1190 \text { to } 960) \\
\end{array}$ \\
\hline 241.2 & \begin{tabular}{|l} 
CE19- \\
$5380-4$
\end{tabular} & $\begin{array}{l}\text { Hearth, charred } \\
\text { material }\end{array}$ & $860+/-40 \mathrm{BP}$ & $-25.3 \mathrm{o} / \mathrm{oo}$ & $860+/-40 \mathrm{BP}$ & $\begin{array}{l}\text { Cal AD } 1040 \text { to } 1260 \\
\text { (Cal BP } 910 \text { to } 690 \text { ) }\end{array}$ \\
\hline 241.1 & $\begin{array}{l}\text { CE19- } \\
5380-32\end{array}$ & $\begin{array}{l}\text { Post, charred } \\
\text { material }\end{array}$ & $1630+/-40 \mathrm{BP}$ & $-26.70 / 00$ & $1600+/-40 \mathrm{BP}$ & $\begin{array}{l}\text { Cal AD } 390 \text { to } 550 \\
\text { (Cal BP } 1560 \text { to } 1400)\end{array}$ \\
\hline
\end{tabular}

\section{SUMMARY AND CONCLUSIONS}

To date, as many as 133 features have been identified as Caddo structures at the George C. Dais site. Fifty-six of these structures (42\%) have been at least partially excavated. The George C. Davis structures provide data on a range of structure forms, from sub-square to rectangular to the more commonly seen circular Caddo structures. The approximate area of these buildings ranges from $1.80 \mathrm{~m}^{2}$ to $346 \mathrm{~m}^{2}$. Presumed functions include domiciles and probable granaries or storage platforms as well as special purpose structures that were constructed on or under mounds and were likely associated with the civic and/or ceremonial leaders and ritual/communal activities that took place at the site.

In addition to details on single structures, the data obtained from excavations and geophysical surveys provide information on the spatial patterning of structures at the site. For example, these data show evidence of intensive rebuilding of structures in several areas and include several examples of superimposed structures, a practice which is clear 
in previous excavations at the site, particularly in the Mound A area, as well as in the magnetometer data. In addition, Walker (2009) has argued that the spatial patterning of anomalies in the magnetometer data suggests that there are multiple plazas and community areas at the site.

From archaeological and geophysical data on individual structures to data on the spatial patterning of these structures (Walker 2009), the George C. Davis site offers a sampling of the architectural diversity seen throughout one part of the Caddo area. The George C. Davis site offers specific architectural data on more structures from a single site than any other site in the region. That being said, however, the architectural patterns seen in the structures at the George C. Davis site are just a small sampling of the character of the Caddo architectural tradition. The next chapter will examine architecture from Caddo mound sites throughout eastern Texas, followed by Chapter 6, which discusses Caddo architecture from non-mound sites. 


\section{CHAPTER 5}

\section{STRUCTURES ASSOCIATED WITH CADDO MOUNDS}

\section{INTRODUCTION}

This chapter discusses the architecture of the 50 known structures associated with earthen mounds from 13 East Texas Caddo sites (Figure 41 and Table 15). These structures have sufficient enough architectural data to allow for their detailed analysis and comparison with other Caddo sites in the region.

Table 15. Sites with mound-related structures included in this study.

\begin{tabular}{|l|l|c|}
\hline Site & Site & Number of recorded mound-related structures in this study \\
\hline Hatchel & $41 \mathrm{BW} 3$ & 13 \\
\hline George C Davis & $41 \mathrm{CE} 19$ & 16 \\
\hline Sanders & $41 \mathrm{LR} 2$ & 2 \\
\hline Whelan & $41 \mathrm{MR} 2$ & 4 \\
\hline Oak Hill Village & $41 \mathrm{RK} 214$ & 3 \\
\hline Holdeman & $41 \mathrm{RR} 11$ & 1 \\
\hline Fasken & $41 \mathrm{RR} 14$ & 1 \\
\hline Roitsch & $41 \mathrm{RR} 16$ & 1 \\
\hline Redwine & $41 \mathrm{SM} 193$ & 1 \\
\hline Bryan Hardy & $41 \mathrm{SM} 55$ & 1 \\
\hline Keith & $41 \mathrm{TT} 11$ & 1 \\
\hline Harroun & $41 \mathrm{UR} 10$ & 4 \\
\hline Dalton & $41 \mathrm{UR} 11$ & 2 \\
\hline
\end{tabular}

Several mound associated structures identified in the study have been omitted from this analysis for various reasons. In most instances, too little of the structure pattern was recorded to allow for detailed analysis. In other cases, features or artifacts related to 
structures such as a packed floor level, a hearth and center post, burned daub, etc. were recorded, but no structure post pattern was recorded.

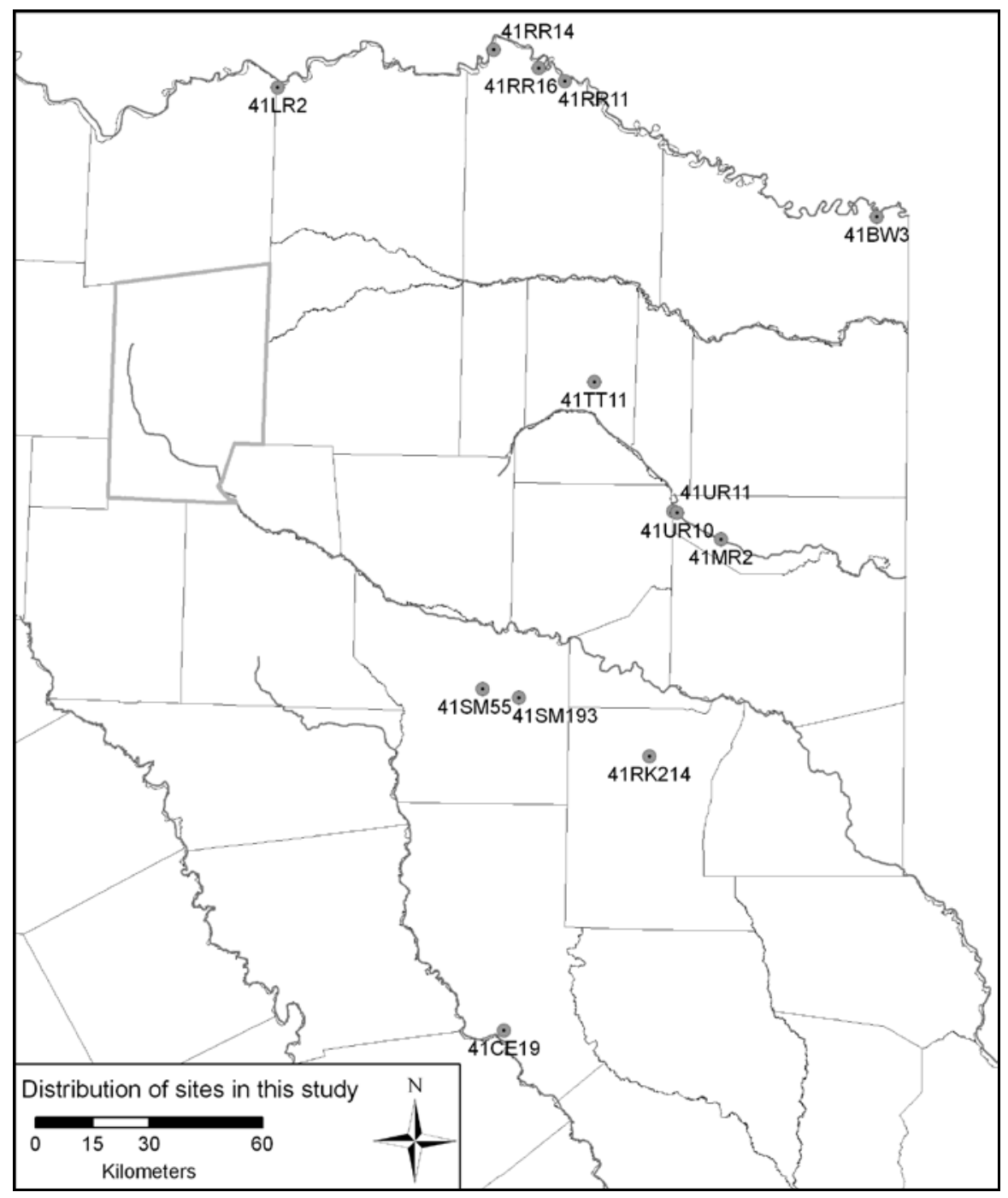

Figure 41. Distribution of mound sites included in this study. 


\section{Caddo Area Mounds}

Mounds in the Caddo area typically fall into one of three classes, burial mound, platform mound, or structural mound (sometimes referred to as sub-structural) (Brown et al. 1978; Story 1990; Vogel 2005). Burial mounds are mounds that contain one or more interments of high ranking individuals and sometimes cover and/or contain large shaft tombs. Burial mounds are found throughout the Red, Sulphur, Cypress, Sabine, and Neches drainage basins (Story 1990). Platform mounds are generally square or rectangular with one or more flat-topped stages that were used as platforms for important public buildings (Vogel 2005). Sub-structural mounds are low mounds that typically cover one or more structures, but were not used as platform mounds (Brown et al. 1978).

Schambach (1996:40) has suggested that post-A.D. 1250-1300 Caddo ceremonialism is one in which there was a shift from "individual-oriented ceremonialism to public building-oriented ceremonialism," by which he meant that important buildings were interred in the major mounds rather than important people. Whereas structural mounds in the Arkansas Basin have been viewed as capping the remains of charnel houses (i.e., the Harlan-style charnel house, see Bell 1972; Brown et al. 1978; Kay and Sabo 2006; Vogel 2005), the structural mounds in the East Texas study area likely capped specialized structures where social, political, or religious leaders "could perform sacred rites, where ritual paraphernalia could be kept, and around which members of the society could periodically congregate to reaffirm what was important and right" (Story 1990:341). Perttula (2005:39) has noted that the Late Caddo mound building practices in the Pineywoods of East Texas generally consisted of sub-structural mounds, which are those that "cap a burned circular structure that was constructed on the ground surface or in a small, shallow pit." Perttula (2005:39) further noted that there are no known platform or burial mounds in the area that date from the Late Caddo period. 


\section{MOUND-RELATED STRUCTURES}

Caddo architecture is typically described as consisting of round beehive-shaped structures; however, there is considerable variation in the shape of Caddo structures throughout the Caddoan archaeological area as a whole, and within the sample of structures examined in this dissertation. Mound related structures include circular, subround (including oval structures), rectangular, and sub-square structures, many with rounded or diagonal corners, and with considerable architectural variation within these groups.

Of the 50 mound-related structures in East Texas, 38 are circular, three are subround (mainly oval or rounded oval), five are rectangular, and four are square or subsquare with rounded or diagonal corners. Table 16 provides a list of the mound-related structures included in this study and their shape and size.

Limited post hole data are available from several of the structures. In ideal cases, site files, reports, and articles provide at least minimum, maximum and average post hole diameter and depth. In most cases, however, only minimum and maximum or average post hole diameter and depth are given. Post spacing and wall to center measurements were not often provided in reports and site files. In cases where such data were not available, plan maps were used to measure the distances.

Table 16. Mound-related structures included in this study.

\begin{tabular}{|l|l|l|l|l|l|}
\hline Site & Structure & Shape & Size $(\mathrm{m})$ & $\begin{array}{l}\text { Area } \\
\left(\mathrm{m}^{2}\right)\end{array}$ & Notes \\
\hline & 31 & circular & 14.90 & 174.40 & \\
\cline { 2 - 6 } & & $\begin{array}{l}\text { sub-square with } \\
\text { rounded/diagonal } \\
\text { corners }\end{array}$ & $7.9 \times 7.9$ & 58.10 & \\
\hline
\end{tabular}




\begin{tabular}{|c|c|c|c|c|c|}
\hline & 36 & $\begin{array}{l}\text { sub-square with } \\
\text { rounded/diagonal } \\
\text { corners }\end{array}$ & 7.20 & 41.20 & \\
\hline & 37 & sub-round & $7.4 \times 10.3$ & 61.50 & \\
\hline & 38 & sub-round & $6.4 \times 7.2$ & 36.30 & \\
\hline & 39 & $\begin{array}{l}\text { sub-square with } \\
\text { rounded/diagonal } \\
\text { corners }\end{array}$ & $8.7 \times 8.7$ & 66.30 & \\
\hline & 40 & $\begin{array}{l}\text { sub-square with } \\
\text { rounded/diagonal } \\
\text { corners }\end{array}$ & $7 \times 7$ & 44.10 & \\
\hline & 42 & circular & 11.80 & 109.40 & \\
\hline & 43 & circular & $7.2 \times 7.8$ & 44.20 & \\
\hline & 44 & sub-round & $8.9 \times 9.3$ & 64.30 & \\
\hline & 45 & circular & 13.90 & 151.70 & \\
\hline & $45 \mathrm{a}$ & circular & 4.65 & 16.98 & \\
\hline & 111 & circular & 18.00 & 254.50 & \\
\hline & 112 & circular & 11.00 & 95.00 & \\
\hline & 321 & circular & 5.9 & 27.34 & \\
\hline & 322 & circular & 5.8 & 26.42 & \\
\hline & 1 & rectangular & $\begin{array}{l}3.05 \mathrm{x} \\
3.66 \\
\end{array}$ & 11.16 & \\
\hline Sanders & 2 & rectangular & $\begin{array}{l}3.05 \times \\
2.59\end{array}$ & 7.82 & \\
\hline & A & circular & 5.18 & 21.07 & \\
\hline & B & circular & 5.79 & 26.33 & \\
\hline & $\mathrm{C}$ & circular & 5.90 & 27.34 & \\
\hline Whelan & $\mathrm{D}$ & circular & 6.30 & 31.17 & \\
\hline & 4 & circular & 7.50 & 44.18 & \\
\hline & 24 & circular & 7.70 & 46.57 & \\
\hline Oak Hill Village & 25 & circular & 7.80 & 47.78 & \\
\hline Holdeman & 1 & rectangular & $\begin{array}{l}3.05 \mathrm{x} \\
6.10 \\
\end{array}$ & 18.61 & \\
\hline Fasken & 1 & sub-round & $3.5 \mathrm{x} ?$ & & $\begin{array}{l}\text { at least } 3.5 \mathrm{~m} \text { along the east } \\
\text { wall }\end{array}$ \\
\hline & 1 & circular & 9.14 & 65.67 & \\
\hline & 5 & circular & 3.66 & 10.51 & \\
\hline & 7 & circular & 9.14 & 65.61 & \\
\hline & 12 & circular & 8.87 & 61.79 & $9.14 \times 7.62 \mathrm{~m}$ in field notes \\
\hline & 13 & circular & 9.06 & 64.47 & $9.20 \times 8.93 \mathrm{~m}$ in field notes \\
\hline & 14 & circular & 8.84 & 61.36 & \\
\hline & 15 & circular & 9.75 & 74.72 & \\
\hline & 16 & circular & 7.32 & 42.03 & \\
\hline & 17 & circular & 6.40 & 32.18 & \\
\hline Hatchel & 18 & circular & 8.60 & 58.03 & \\
\hline
\end{tabular}




\begin{tabular}{|l|l|l|l|l|l|} 
& 22 outer & circular & 10.22 & 82.03 & $10.64 \times 9.81 \mathrm{~m}$ in field notes \\
\cline { 2 - 7 } & 22 inner & circular & 8.53 & 57.15 & \\
\cline { 2 - 7 } & 25 & circular & 14.98 & 176.24 & \\
\hline Roitsch & 2 & rectangular & $4.75 \times 9$ & 42.75 & \\
\hline Redwine & 1 & circular & 5.50 & 23.74 & \\
\hline \multirow{3}{*}{$\begin{array}{l}\text { Bryan Hardy } \\
\text { Keith }\end{array}$} & 1 & circular & 5.48 & 23.59 & \\
\cline { 2 - 7 } & 1 & circular & 9.10 & 65.04 & \\
& 1 & circular & 5.48 & 23.59 & \\
\cline { 2 - 7 } & 2 & circular & 4.26 & 14.25 & \\
\cline { 2 - 7 } & 3 & circular & 5.18 & 21.07 & \\
\cline { 2 - 7 } & 4 & circular & 6.04 & 28.65 & \\
\hline \multirow{5}{*}{ Dalton } & $\mathrm{A}$ & circular & 4.60 & 16.62 & \\
\cline { 2 - 7 } & $\mathrm{B}$ & circular & 5.50 & 23.76 & \\
\hline
\end{tabular}

\section{George C. Davis (41CE19)}

The majority of mound-related structures within the study area are from the George C. Davis $(n=16)$ and the Hatchel $(n=13)$ sites. None of the other sites have more than four mound-related structures (see Table 16).

The 16 structures from the George C. Davis site range in shape from circular to subround (oval) to subsquare with rounded or diagonal corners. Chapter 4 provides a discussion of the more than 50 mound and non-mound related George C. Davis structures as categorized by Spock (1977) as either specialized structures or domiciles. The following discussion includes only the 16 structures associated with Mounds A or B from the George C. Davis site.

The mound-related structures from the George C. Davis site represent a diverse array of architectural patterns and practices of use of space. In addition to a range in structure size and shape, Spock (1977:159) notes that "some floor areas appear to have been purposefully cleaned; others are quite littered with artifacts, and a few have prepared clay surfaces. The post hole outlines of some structure are separated from those of other buildings, while some structures are found amid a confusing array of post holes 
representing multiple re-use of an area. There are structures distant from mounds, near mounds, under mounds, and on mound platforms."

Nine of the mound-related structures from the George C. Davis site are circular, three are subround (oval), and the remaining four are sub-square with rounded or diagonal corners. The Davis mound structures have areas ranging from $16.98 \mathrm{~m}^{2}$ to 254.5 $\mathrm{m}^{2}$, with a mean area of $79.48 \mathrm{~m}^{2}$. With the exception of Structures 111 and 112, both associated with Mound B, all of these features are associated with Mound A (Table 17). The seven circular structures tend to be larger, with areas ranging from $16.98 \mathrm{~m}^{2}$ to 254.5 $\mathrm{m}^{2}$, with a mean area of $120.88 \mathrm{~m}^{2}$. The smallest of these, Feature $45 \mathrm{a}$, with an area of $16.98 \mathrm{~m}^{2}$, was not discussed as a separate structure by Spock (1977) or Newell and Krieger (2000) and may actually be an internal feature within Feature 45. Story (1990:341) noted the presence of this structure and stated that "inside of F-45 was a miniature structure that appears to be a model of the building within that building." If that is the case, then Feature 45a could be an example of a model of the temple that was described as being in the caddi's residence in European accounts. While Feature 45 has not been identified as being a caddi's residence, its association with Mound A suggests a special purpose for this building, possibly as a residence for an elite individual or as a location for rituals.

Alternatively, Feature 45a may be a storage area or granary related to other contemporary structures. Similar features have been documented elsewhere at the George C. Davis site and at sites such as Oak Hill Village (Rogers and Perttula 2004). If Feature $45 \mathrm{a}$ is removed from the consideration of structure size, then the circular structure areas associated with mounds range from $44.2 \mathrm{~m}^{2}$ to $254.5 \mathrm{~m}^{2}$, with a mean area of $138.2 \mathrm{~m}^{2}$. The three sub-round (oval) structures have areas ranging from $36.3 \mathrm{~m}^{2}$ to $64.3 \mathrm{~m}^{2}$, with a mean area of $54.03 \mathrm{~m}^{2}$. The sub-square structures with rounded or diagonal corners are 
similar in size to the sub-round structure group, with areas ranging from $41.2 \mathrm{~m}^{2}$ to 66.3 $\mathrm{m}^{2}$, with a mean area of $52.43 \mathrm{~m}^{2}$.

Table 17. Mound-related structures from the George C. Davis site.

\begin{tabular}{|c|c|c|c|c|}
\hline Location & Feature & Shape & Size $(\mathrm{m})$ & Area $\left(\mathrm{m}^{2}\right)$ \\
\hline \multirow[t]{2}{*}{ under Mound B } & 111 & circular & 18.00 & 254.50 \\
\hline & 112 & circular & 11.00 & 95.00 \\
\hline \multirow[t]{8}{*}{ Under Mound A } & 31 & circular & 14.90 & 174.40 \\
\hline & 37 & oval - sub-round & $7.4 \times 10.3$ & 61.50 \\
\hline & 38 & oval - sub-round & $6.4 \times 7.2$ & 36.30 \\
\hline & 42 & circular & 11.80 & 109.40 \\
\hline & 43 & circular & $7.2 \times 7.8$ & 44.20 \\
\hline & 44 & oval - sub-round & $8.9 \times 9.3$ & 64.30 \\
\hline & 45 & circular & 13.90 & 151.70 \\
\hline & $45 \mathrm{a}$ & circular & 4.65 & 16.98 \\
\hline \multirow{6}{*}{$\begin{array}{l}\text { On Mound A } \\
\text { platforms }\end{array}$} & 34 & sub-square with rounded/diagonal corners & $7.9 \times 7.9$ & 58.10 \\
\hline & 36 & sub-square with rounded/diagonal corners & 7.20 & 41.20 \\
\hline & 39 & sub-square with rounded/diagonal corners & $8.7 \times 8.7$ & 66.30 \\
\hline & 40 & sub-square with rounded/diagonal corners & $7 \times 7$ & 44.10 \\
\hline & 321 & circular & 5.9 & 27.34 \\
\hline & 322 & circular & 5.8 & 26.42 \\
\hline
\end{tabular}

The wall post holes for the 16 mound related structures from the George C. Davis site have mean diameters ranging from $0.11 \mathrm{~m}$ to $0.25 \mathrm{~m}(\bar{x}=0.16 \mathrm{~m}, \mathrm{~s}=0.0448)$. Mean depths for the wall posts range from $0.5 \mathrm{~m}$ to $0.78 \mathrm{~m}(\bar{x}=0.65 \mathrm{~m}, \mathrm{~s}=0.0876)$ (Table 18). Three of these structures (Features 43, 44, and 45) have wall trenches as well as non-wall trench post holes, with one (Feature 111) having what Story (1997) and Spock (1977) refer to as major and minor post holes, making a distinction between the 28 posts "probably set in sloping individual trenches dug perpendicular to the wall" and the 24 posts that were "closely set in a shallow, trough-like depression and located 5 to $20 \mathrm{~cm}$ outside of and parallel to the major wall posts" (Spock 1977:106-109). 
Table 18. Wall post hole data for the mound-related structures from the George C. Davis site.

\begin{tabular}{|l|l|l|l|l|l|l|l|}
\hline \multicolumn{2}{|l|}{} & \multicolumn{3}{l|}{ Diameter $(\mathbf{m})$} & \multicolumn{3}{l|}{ Depth (m) } \\
\hline & $\begin{array}{l}\text { No. exposed } \\
\text { or visible }\end{array}$ & Max & Min & Mean & Max & Min & Mean \\
\hline 31 & 78 & 0.31 & 0.18 & 0.25 & 1.01 & 0.37 & 0.77 \\
\hline 34 & 42 & 0.23 & 0.09 & 0.11 & 0.78 & 0.09 & 0.60 \\
\hline 36 & 41 & 0.24 & 0.11 & 0.16 & 0.88 & 0.27 & 0.61 \\
\hline 37 & 89 & 0.18 & 0.12 & 0.14 & 0.79 & 0.06 & 0.55 \\
\hline 38 & 67 & 0.18 & 0.09 & 0.12 & 0.92 & 0.03 & 0.50 \\
\hline 39 & 48 & 0.21 & 0.15 & 0.17 & 0.82 & 0.38 & 0.71 \\
\hline 40 & 41 & 0.26 & 0.11 & 0.16 & 0.73 & 0.34 & 0.58 \\
\hline 42 & 51 & 0.24 & 0.12 & 0.17 & 0.82 & 0.40 & 0.67 \\
\hline 43 & 71 & 0.21 & 0.09 & 0.13 & 0.85 & 0.24 & 0.59 \\
\hline 43 trench post holes & 26 & 0.21 & 0.09 & 0.13 & 0.85 & 0.31 & 0.56 \\
\hline 43 non-trench post holes & 45 & 0.21 & 0.09 & 0.13 & 0.82 & 0.24 & 0.61 \\
\hline 44 & 84 & 0.18 & 0.09 & 0.14 & 0.95 & 0.49 & 0.75 \\
\hline 44 trench post holes & 7 & 0.18 & 0.09 & 0.12 & 0.79 & 0.61 & 0.73 \\
\hline 44 non-trench post holes & 77 & 0.18 & 0.09 & 0.14 & 0.95 & 0.49 & 0.75 \\
\hline 45 & 100 & 0.24 & 0.06 & 0.15 & 1.34 & 0.12 & 0.78 \\
\hline 45 wall, trench post holes & 64 & 0.24 & 0.09 & 0.16 & 1.34 & 0.82 & 1.05 \\
\hline 45 supplemental trench post holes & 8 & 0.24 & 0.12 & 0.15 & 0.64 & 0.24 & 0.46 \\
\hline 45 wall, non-trench post holes & 28 & 0.21 & 0.06 & 0.11 & 0.49 & 0.12 & 0.24 \\
\hline 45 exterior partition post holes & 71 & 0.20 & 0.09 & 0.16 & 0.64 & 0.37 & 0.52 \\
\hline 45 a & 18 & 0.18 & 0.08 & 0.12 & x & x & x \\
\hline 111 & 52 & 0.29 & 0.03 & 0.11 & 1.23 & 0.16 & 0.69 \\
\hline 111 major post holes & 28 & 0.29 & 0.07 & 0.15 & 1.23 & 0.26 & 0.93 \\
\hline 111 minor post holes & 24 & 0.10 & 0.03 & 0.06 & 0.78 & 0.16 & 0.40 \\
\hline 112 & 12 & 0.30 & 0.17 & 0.25 & 0.79 & 0.27 & 0.64 \\
\hline 321 & no measurement & & & & & \\
\hline 322 & no measurement & & & & & \\
\hline
\end{tabular}

The wall trench post holes tend to be between $0.12 \mathrm{~m}$ to $0.16 \mathrm{~m}$ in diameter while the non-wall trench post holes have a wider range of $0.06 \mathrm{~m}$ to $0.25 \mathrm{~m}$. The means for these two groups of post holes are practically the same, with the wall trench post holes having a mean diameter of $0.14 \mathrm{~m}$ and the non-trench post holes having a mean diameter of $0.15 \mathrm{~m}$. This similarity in post hole size holds true for post hole depth as well where the mean post hole depth for the wall trench post holes ranges from $0.59 \mathrm{~m}$ to $0.78 \mathrm{~m}(\bar{x}=$ 
$0.71 \mathrm{~m}, \mathrm{~s}=0.1021)$ and the mean post hole depth for the non-wall trench post holes ranges from $0.50 \mathrm{~m}$ to $0.77 \mathrm{~m}(\bar{x}=0.63 \mathrm{~m}, \mathrm{~s}=0.0805)$. The mean depths do not, however, capture the variation in post hole depth for these sixteen structures because by comparing only the minimum and maximum depths for each structure there is a range from extremely shallow post holes $(0.03 \mathrm{~m}$ or $0.06 \mathrm{~m})$ to fairly deep post holes $(1.23 \mathrm{~m}$ and $1.34 \mathrm{~m})$.

All but two of these 16 structures would fall into the category of small "pole" buildings, having post hole diameters averaging less than $0.20 \mathrm{~m}$, as opposed to large "post" buildings, those with post hole diameters averaging more than $0.20 \mathrm{~m}$ (Lacquement 2007:55). Features 31 and 112 each have mean post hole diameters of 0.25 m. Feature 31, with 78 exposed wall post holes, has a post hole diameter range of 0.18 to $0.21 \mathrm{~m}$, while Feature 112, with only 12 wall post holes exposed, has a post hole diameter range of $0.17 \mathrm{~m}$ to $0.30 \mathrm{~m}$.

The largest structure excavated at the site has the smallest average post hole diameter. Fifty-two wall posts were exposed for Feature 111, including 28 major and 24 minor post holes. The diameter for the Feature 111 post holes ranges from 0.03 to $0.29 \mathrm{~m}$ with a mean diameter of $0.11 \mathrm{~m}$. Only one other structure, Feature 34, has as small a mean diameter post hole size.

Average wall post hole spacing for 13 structures ranges from $0.32 \mathrm{~m}$ to $0.67 \mathrm{~m}(\bar{x}$ $=0.50 \mathrm{~m}, \mathrm{~s}=0.1293)$. The average distances from the wall post holes to the center of the structure for the 13 structures range from $2.28 \mathrm{~m}$ to $9.19 \mathrm{~m}(\bar{x}=5.00 \mathrm{~m}, \mathrm{~s}=1.9136)$. There is a wide range in ratios of average distance between wall post holes and average distance to structure centers (Table 19). The ratio of those measurements ranges from 1:4.85 to $1: 18.15$, with the smallest ratio characterizing Feature $45 \mathrm{a}$, which may not actually represent a separate structure. With the exception of Feature $45 \mathrm{a}$, the ratio for the 
circular and sub-round structures ranges from $1: 10.38$ to $1: 18.15$, while the ratio for the sub-square structures is much smaller, ranging from 1:6.31 to 1:7.62. When the mean post hole spacing from these two groups is compared, the circular and sub-round structures have spacing ranging from 0.32 to $0.67(\bar{x}=0.47 \mathrm{~m}, \mathrm{~s}=0.1396)$ while the subsquare structures have a spacing ranging from $0.55 \mathrm{~m}$ to $0.61 \mathrm{~m}(\bar{x}=0.59 \mathrm{~m}, \mathrm{~s}=0.0252)$.

Table 19. Ratios of average distance between wall post holes and average distance to structure centers for the previously excavated mound-related structures from the George C. Davis site.

\begin{tabular}{|l|c|c|c|c|}
\hline Site & Structure & Shape & Area & Ratio \\
\hline George C. Davis & 31 & circular & 174.4 & $1: 12.47$ \\
\hline George C. Davis & 34 & sub-square & 58.1 & $1: 7.36$ \\
\hline George C. Davis & 36 & sub-round & 41.2 & $1: 6.76$ \\
\hline George C. Davis & 37 & sub-round & 61.5 & $1: 14.22$ \\
\hline George C. Davis & 38 & sub-round & 36.3 & $1: 10.71$ \\
\hline George C. Davis & 39 & sub-square & 66.3 & $1: 7.62$ \\
\hline George C. Davis & 40 & sub-square & 44.1 & $1: 6.31$ \\
\hline George C. Davis & 42 & circular & 109.4 & $1: 10.38$ \\
\hline George C. Davis & 43 & sub-round & 44.2 & $1: 13.43$ \\
\hline George C. Davis & 44 & circular & 65 & $1: 11.5$ \\
\hline George C. Davis & 45 & circular & 151.7 & $1: 18.15$ \\
\hline George C. Davis & 111 & circular & 254.5 & $1: 14.59$ \\
\hline George C. Davis & $45 \mathrm{a}$ & circular & 16.98 & $1: 4.85$ \\
\hline
\end{tabular}

Comparing the circular to the sub-round and sub-square structures yields the following measurements for average post hole spacing: circular (including Feature 45a), $0.35 \mathrm{~m}$ to $0.67 \mathrm{~m}(\bar{x}=0.53 \mathrm{~m}, \mathrm{~s}=0.1237)$; sub-round, $0.32 \mathrm{~m}$ to $0.34 \mathrm{~m}(\bar{x}=0.33 \mathrm{~m}, \mathrm{~s}=$ $0.0110)$; and sub-square, $0.55 \mathrm{~m}$ to $0.61 \mathrm{~m}(\bar{x}=0.59 \mathrm{~m}, \mathrm{~s}=0.0252)$. Average distance from wall post holes to the structure center ranges from $2.28 \mathrm{~m}$ to $9.19 \mathrm{~m}(\bar{x}=6.12 \mathrm{~m}, \mathrm{~s}=$ 2.4014) for the circular structures (including Feature $45 \mathrm{a}), 3.45 \mathrm{~m}$ to $4.55 \mathrm{~m}(\bar{x}=3.97 \mathrm{~m}$, $\mathrm{s}=0.5524)$ for the sub-round structures, and $3.72 \mathrm{~m}$ to $4.65 \mathrm{~m}(\bar{x}=4.11 \mathrm{~m}, \mathrm{~s}=0.4650)$ for the sub-square structures. 
Eleven of the mound-related structures from Davis have center post holes, all of which were directly related to central hearths. All of the center posts were located under central hearths, and tended to extend up to the lower part of the hearth remnant. The central post holes have diameters ranging from $0.15 \mathrm{~m}$ to $0.46 \mathrm{~m}(\bar{x}=0.23 \mathrm{~m}, \mathrm{~s}=0.0842)$ and depths ranging from $0.27 \mathrm{~m}$ to $0.84 \mathrm{~m}(\bar{x}=0.61 \mathrm{~m}, \mathrm{~s}=0.1794)$.

Feature 42 is the only Davis mound structure definitely lacking evidence for a central hearth. Feature 112 was not sufficiently excavated to determine if a hearth was associated with the structure. The twelve (possibly 13, see Feature 321 discussion below) recorded hearths from the Davis mound structures are generally circular in shape with at least two being somewhat irregularly shaped. The hearths range in size from about $61 \mathrm{~cm}$ in diameter to $1.83 \mathrm{~m}$ in diameter, with one of the irregular-shaped hearths being the largest, measuring $2.44 \mathrm{~m} \times 2.96 \mathrm{~m}$. Eleven of the 12 hearths that were excavated had depths ranging from $3 \mathrm{~cm}$ to $20 \mathrm{~cm}(\bar{x}=10 \mathrm{~cm}, \mathrm{~s}=4.73)$. Five of the excavated hearths were clay-lined. One of these features was described as an ash bed rather than a hearth (Spock 1977). This feature is associated with Structure 45a. Like the other central hearths, the Feature $45 \mathrm{a}$ ash bed covered a possible center post.

Only one of the George C. Davis mound structures, Structure 111-the largest excavated structure at the site, and the largest previously excavated structure in this study—appears to have been burned (Spock 1977; Story 1997). Spock (1977:109-110) stated that "the prepared clay floor had been baked, and charred beams were found in the depression just outside the major post outline. In addition, several sherds from a Holly Fine Engraved bottle found in the trough on the west side of F111 were well-oxidized from burning. Other sherds from the same bottle, found in an interior post hole, F111-2, had not been affected by fire.” Spock (1977:110) concluded by noting that Structure 111 appears to have been at least partially dismantled prior to burning. 
In addition to being the only excavated burned mound structure at the site and one of only two mound-related structures from George C. Davis with a prepared clay floor, Structure 111 had other interesting features. As discussed above, the excavated portion of Structure 111 had an outer wall that included 28 major post holes, with diameters ranging from $7 \mathrm{~cm}$ to $22 \mathrm{~cm}$ and an average depth of $89 \mathrm{~cm}$, and a second exterior outline of 24 minor post holes, separated from the major post holes by about $10-20 \mathrm{~cm}$. The minor post holes had an average diameter of $6 \mathrm{~cm}$ and average depth of $40 \mathrm{~cm}$ (Spock 1977; Story 1997:72-73). Story (1997:72) noted that the major post holes that were sectioned were set "in individual, downward sloping trenches dug perpendicular to the wall. Probably all of the major wall posts were similarly set, perhaps to facilitate erection of what must have been rather long poles." In Chapter 4, this practice was also suggested for the placement of some of the large interior post holes recorded in the magnetometer data from the George C. Davis site. As for the purpose of the outer ring of minor post holes, Story (1997:72) suggested that "since they contained smaller poles it seems probable that they relate to the wall construction and not to the roof."

Two of the George C. Davis mound structures were recorded as a result of the extensive magnetometer survey of the site. Structures 321 and 322 (Figure 42) were both recorded on Mound A. Both features are interpreted as circular structures with diameters of approximately $5.9 \mathrm{~m}$ (Feature 321) and $5.8 \mathrm{~m}$ (Feature 322), having interior areas of approximately $27.34 \mathrm{~m}^{2}$ and $26.42 \mathrm{~m}^{2}$ respectively. Feature 321 has a possible central hearth based on the area of highly magnetic returns in the approximate center of the structure, indicating a thermally altered feature. It is possible that a third circular structure is represented in the Mound A magnetometer data, with its center located approximately $10 \mathrm{~m}$ to the west of Feature 322. 

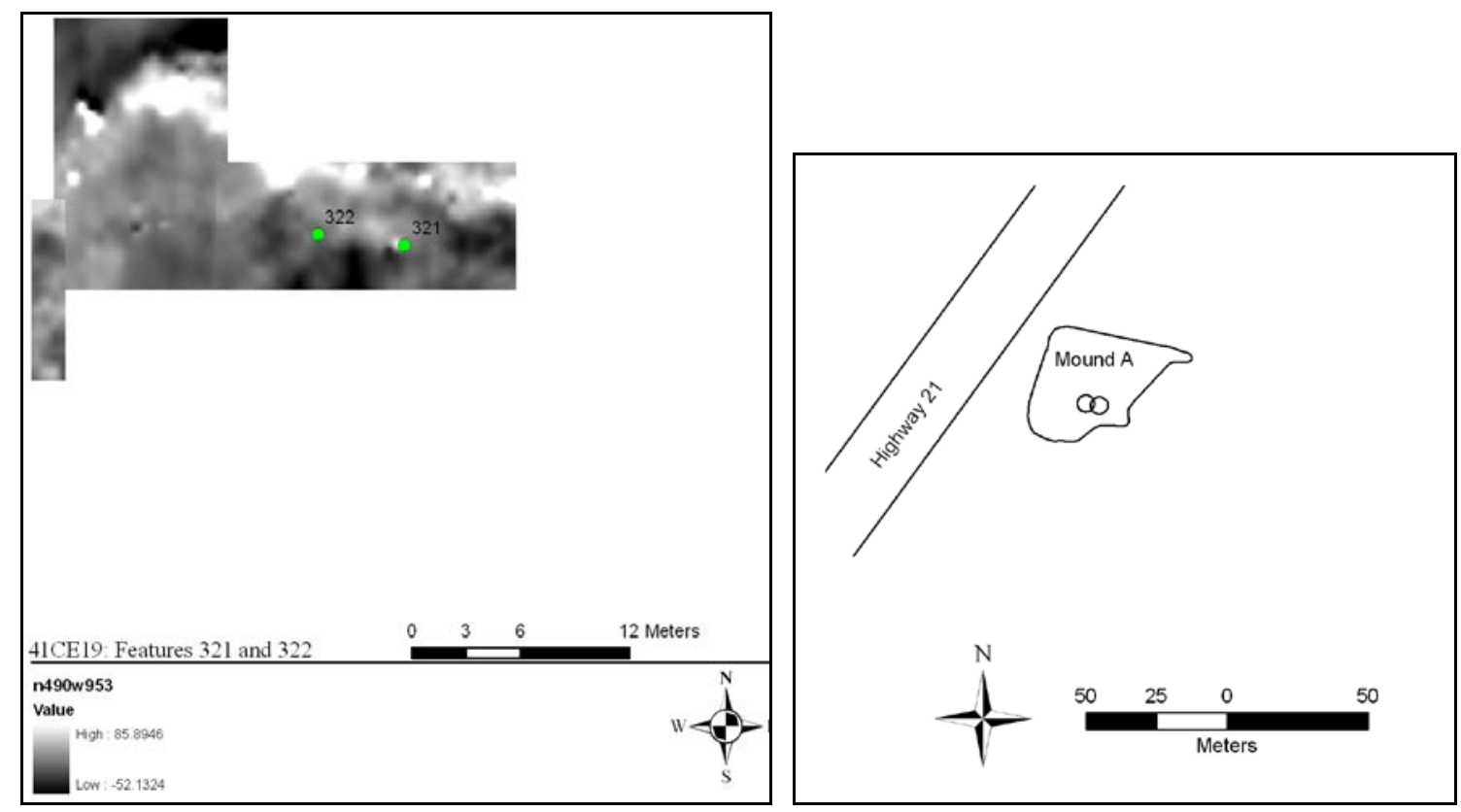

Figure 42. Structures 321 and 322 from the George C. Davis site.

All of the mound-related structures from the George C. Davis site are considered special function structures. They are recognized as special function structures mainly on the basis of their close spatial association with mounds, but also because of unique associated features, large size, or unique architectural attributes (see Chapter 4, and Spock 1977).

The spatial alignment of structures is one of the intriguing practices associated with mound structure construction, use, destruction, and reuse. Structures 34, 36, 39, and 40 are all located on Mound A platforms at George C. Davis. Although Krieger described theses features as having been constructed on a single platform, what Krieger referred to as the primary mound platform (Newell and Krieger 1949, 2000:66-70), Spock (1977:75) noted that "field profiles indicate that at least two, and possibly four, levels existed." Although Spock stated that the floor levels were not distinct, she noted that based on the positioning and fill of the hearth and post holes of Feature 34, "it is apparent that Feature 
34 is later in time that Feature 36." Interestingly, in her discussion of Feature 34, Spock (1977:76) commented that "one of the more unusual details concerning this structure is the presence of a center posthole cutting through the fill of the hearth, the only known occurrence of this sequence at the site. This would seem to indicate that the hearth was in use before the centerpost was set". This practice of post hole setting is similar to that found in the Titus phase (ca. AD 1430-1680) mound at the Pilgrim's Pride site (41CP304), where a marker post was erected through the mound and through the central hearth of the structure capped by the mound (Perttula 2005).

The green clay altar (Feature 56) was also found on this mound platform and "appears to have the same orientation - essentially east-west - as Features 34/36" (Spock 1977:76). Features 39 and 40 were located at slightly higher levels than Features 34 and 36, and Spock (1977:85) suspected that they may be later; Feature 40 may be the later of the two given the placement and fill of the hearth.

The pre-Mound A Features 31, 37, and 38 are examples of directly superimposed structures from the site. Feature 37, built in a slight depression on the pre-Mound A terrace surface, encircled Feature 38 (Newell and Krieger 1949, 2000; Spock 1977:64). Spock (1977:66) notes that Feature 38 was the later of the two, "having four wall postholes which cut across the long oval pit" associated with Feature 37 (Features 37-2). In discussing the abandonment of these structures, Spock (1977:66) indicated that they were "perhaps deliberately dismantled (no evidence of burning) the interior were cleaned and filled with $0.55 \mathrm{~m}$ of grayish clay mottled with yellow and green." Feature 31 was built on this fill, "raised slightly above the terrace surface by the clay filling of Features 37 and 38" and was centered directly over Features 37 and 38 (Spock 1977:63).

Other superimposed pre-Mound A structures include Feature 43, which overlies the earlier Feature 44. Although not perfectly aligned, the central hearths of these 
structures are offset by only about $2.5 \mathrm{~m}$. Features 45 and 45 a may be a special case of directly superimposed structures, in that a smaller structure was built within a larger building. Spock (1977:100-101) did not explore the possibility that Feature 45a was a separate structure from Feature 45, but referred to it as an enclosure encircling Feature 45-2, the ash bed. Spock (1977) did note that there did not appear to be any signs of in situ burning in Feature 45-2. If the possibility of Feature 45a being a Caddo constructed model of the Temple is a likely scenario, then the Feature 45 ash bed and the post hole below it may be associated with this feature and may represent their larger-scale counterparts

\section{Hatchel (41BW3)}

Thirteen of the mound-related structures on Caddo sites in East Texas are from the Hatchel site (41BW3) in Bowie County, Texas. In addition to the extensive associated village deposits (Perttula 2005), the large platform mound at the Hatchel site was found to have structures on seven of the 11 mound stages, including the pre-mound surface (the mound floors were designated floors A-K, with A representing the latest addition and $\mathrm{K}$ representing the pre-mound surface) (Jackson 2004). The extensive mound excavations, under the direction of William Beatty, Jr. for the UT-WPA, revealed at least 16 circular Caddo structures (Creel 1996) as well as several concentrations of post holes that did not conform to any discernable pattern. Some ambiguous or irregular structure forms were assigned by the WPA, with over 20 possible Caddo structures and associated outbuildings (arbors, drying racks, granaries, etc) represented throughout the mound (Jackson 2004).

A single large (15 m diameter) circular structure (Feature 25) was located on the pre-mound surface (Figure 43). The outline of this structure consisted of 81 post holes 
with an interior partition made up of an arc of 26 posts. The Feature 25 post holes ranged in diameter from approximately $15 \mathrm{~cm}$ to $46 \mathrm{~cm}$ with depths from about $33 \mathrm{~cm}$ to $82 \mathrm{~cm}$ (TARL n.d.: 398). Perttula (2005:183) has suggested that this pre-mound structure may date to Middle Caddo times based on the association of a Crockett Curvilinear Incised vessel with the structure floor.

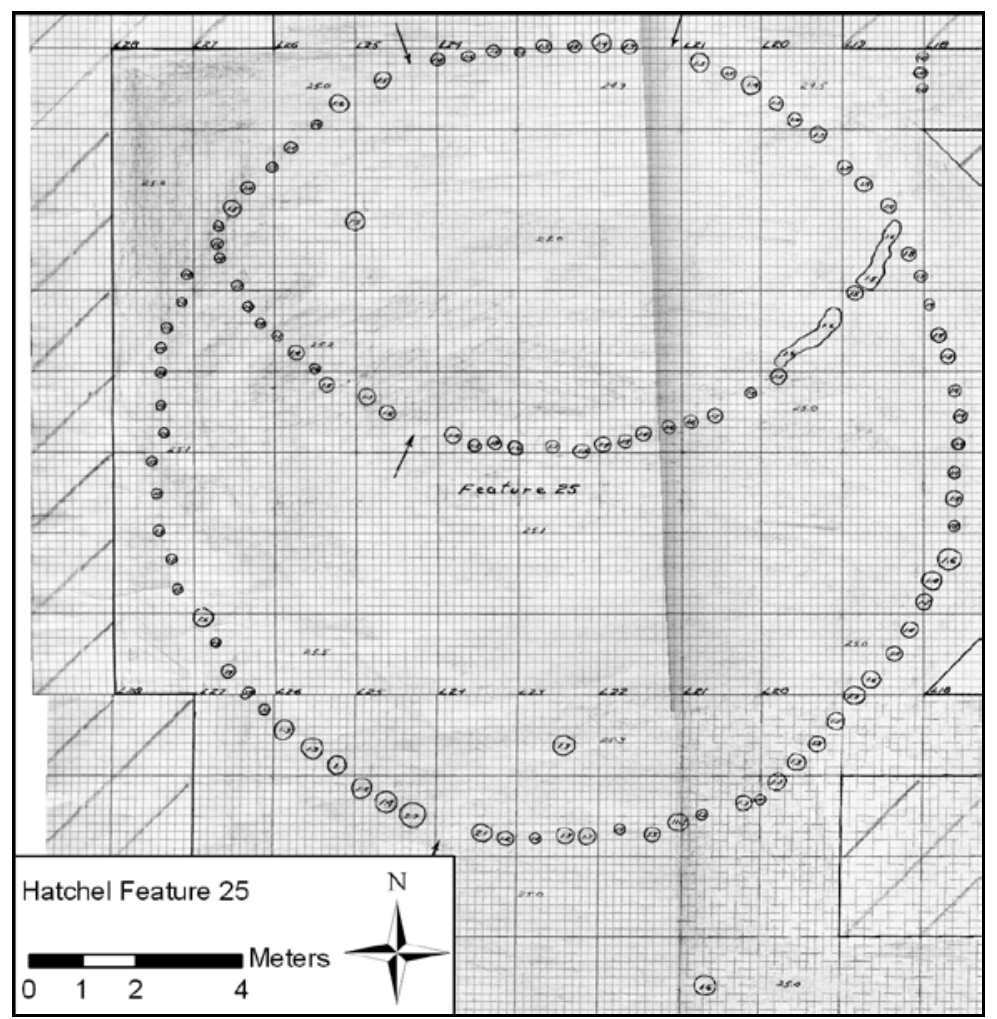

Figure 43. Feature 25 from the Hatchel site. Reproduced courtesy of TARL.

The subsequent structures found throughout the mound have diameters ranging from $3.66 \mathrm{~m}$ (Feature 5) to over $10 \mathrm{~m}$, with an average diameter of 9-10 m (Jackson 2004:60). Several of the mound structures had interior hearths, storage or refuse pits, and extended entranceways pointing to the south, southwest, or southeast (in the general direction of the village areas). In addition, some structures (Features 4 and 16) had 
interior partitions, while Feature 7 had an arc of posts forming an exterior wall or partition along the front of the structure, similar to Feature 45 from the George C. Davis site (Newell and Krieger 1949:47-49; Spock 1977; Story 1998). Several of the mound structures were burned. Vertical alignment of structures was clear throughout the mound with, for example, the hearths of Features 4 and 7 almost directly aligned and Feature 18 (which was built atop a small rise in the center of mound Floor $\mathrm{H}$ ) situated almost in direct alignment below Feature 22 from Mound Floor G (TARL n.d.:335).

Of the 20 or more possible structures associated with the Hatchel Mound, 13 have been included in this study (Table 20). The remaining structures were too incomplete, had ambiguous forms, or the areas of post hole concentrations were too dense to identify definite post hole patterns of individual structures. For example, as Beatty (TARL n.d. F2:141) noted in his description of Feature 3, a group of 82 post holes on mound Floor A, given the large number of postholes and the overall irregular shape, "any pattern desired might be formed." This was true in several instances.

The mound-related structures from the Hatchel site are all circular and have floor areas ranging from 10.51 to $176.24 \mathrm{~m}^{2}\left(\bar{x}=65.52 \mathrm{~m}^{2}, \mathrm{~s}=38.15\right)$. The two largest structures in the sample, Features 25 and 19/20, are $14.98 \mathrm{~m}$ and $12 \mathrm{~m}$ in diameter, with areas of $176.24 \mathrm{~m}^{2}$ and $113.10 \mathrm{~m}^{2}$, respectively. Feature 25 is the pre-mound structure and Feature 19/20 (originally assigned two feature numbers by the excavators, but determined to likely be one structure with double walls) was located on Mound floor H.

The average diameter of the exterior post holes of the 13 Hatchel mound structures, those posts forming the structure wall, ranges from $12 \mathrm{~cm}$ to $30 \mathrm{~cm}(\overline{\mathrm{x}}=18$ $\mathrm{cm}, \mathrm{s}=4.15)$. Structure 25, the largest of the Hatchel mound structures, has the largest diameter wall posts as well. If Feature 25 is omitted, mean wall post diameter is $0.18 \mathrm{~m}$ $(\bar{x}=0.18 \mathrm{~m}, \mathrm{~s} 0.0201)$. The 13 Hatchel mound structures would fit into the category of 
small "pole" buildings, as opposed to large "post" buildings, those with post hole diameters averaging more than $20 \mathrm{~cm}$ (Lacquement 2007:55).

Table 20. Mound-related structures included in this study from the Hatchel site.

\begin{tabular}{|c|c|c|c|c|c|c|}
\hline Site & Structure & $\begin{array}{l}\text { Mound } \\
\text { Floor }\end{array}$ & Shape & $\begin{array}{l}\text { Size } \\
\text { (m) }\end{array}$ & $\begin{array}{l}\text { Area } \\
(\mathrm{m} 2)\end{array}$ & Notes \\
\hline Hatchel & 1 & A & circular & 9.14 & 65.67 & \\
\hline Hatchel & 5 & $\mathrm{~B}$ & circular & 3.66 & 10.51 & \\
\hline Hatchel & 7 & $\mathrm{C}$ & circular & 9.14 & 65.61 & \\
\hline Hatchel & 12 & $\mathrm{D}$ & circular & 8.87 & 61.79 & ca. 8.87 (9.14 x 7.62 in field notes $)$ \\
\hline Hatchel & 13 & $\mathrm{E}$ & circular & 9.06 & 64.47 & ca 9.06 (9.20 x 8.93 in field notes $)$ \\
\hline Hatchel & 14 & $\mathrm{E}$ & circular & 8.84 & 61.36 & \\
\hline Hatchel & 15 & $\bar{F}$ & circular & 9.75 & 74.72 & \\
\hline Hatchel & 16 & $\mathrm{H}$ & circular & 7.32 & 42.03 & \\
\hline Hatchel & 17 & $\mathrm{H}$ & circular & 6.40 & 32.18 & \\
\hline Hatchel & 18 & $\mathrm{H}$ & circular & 8.60 & 58.03 & \\
\hline Hatchel & 22 outer & G & circular & 10.22 & 82.03 & ca. 10.22 (10.64 x 9.81 in field notes $)$ \\
\hline Hatchel & 22 inner & G & circular & 8.53 & 57.15 & \\
\hline Hatchel & 25 & K & circular & 14.98 & 176.24 & \\
\hline
\end{tabular}

Mean wall post hole depth follows a similar pattern with Feature 25 having the deepest posts. The average post hole depth for all 13 structures ranges from $0.15 \mathrm{~m}$ to $0.46 \mathrm{~m}(\bar{x}=0.23 \mathrm{~m}, \mathrm{~s}=0.0783)$. Removing Feature 25 from the sample results in a range of $0.15 \mathrm{~m}$ to $0.27 \mathrm{~m}(\bar{x}=0.21 \mathrm{~m}, \mathrm{~s}=0.0385)$, a smaller average depth and standard deviation (Table 21).

Mean spacing between wall post holes (measured from center to center) ranges from $0.41-0.86 \mathrm{~m}(\bar{x}=0.55 \mathrm{~m}, \mathrm{~s}=0.1088)$. The average spacing from the wall posts to the center of the structures ranges from $1.76 \mathrm{~m}$ to $7.52 \mathrm{~m}(\bar{x}=4.14 \mathrm{~m}, \mathrm{~s}=1.38)$. Clearly there is a fairly wide range in both wall post spacing and distance from structure wall to center. The relationship between these two measurements ranges from 1:6.0 to 1:13.7, 
with an average ratio of 1:8.48. Again, the outlier is Feature 25. Table 22 provides the measurements for between the wall post holes, the distance from the wall to the center, and the relationship between the two.

Table 21. Diameter and depth of wall post holes from Hatchel mound structures.

\begin{tabular}{|c|c|c|c|c|c|c|c|}
\hline \multirow[b]{2}{*}{ 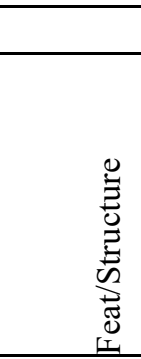 } & \multirow[b]{2}{*}{ 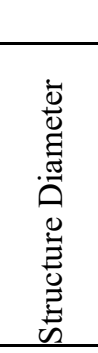 } & \multicolumn{3}{|c|}{ Diameter (m) } & \multicolumn{3}{|c|}{ Depth (m) } \\
\hline & & $\sum_{\Sigma}^{\star 凶}$ & $\stackrel{\Xi}{\Sigma}$ & $\sum_{\mathbb{E}}^{\tilde{E}}$ & 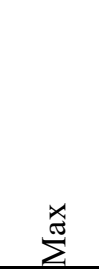 & $\stackrel{\Xi}{\Sigma}$ & 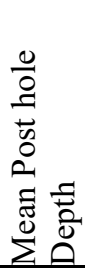 \\
\hline 1 & 9.14 & $\mathrm{n} / \mathrm{a}$ & $\mathrm{n} / \mathrm{a}$ & 0.15 & $\mathrm{n} / \mathrm{a}$ & $\mathrm{n} / \mathrm{a}$ & 0.18 \\
\hline 5 & 3.66 & $\mathrm{n} / \mathrm{a}$ & $\mathrm{n} / \mathrm{a}$ & 0.18 & $\mathrm{n} / \mathrm{a}$ & $\mathrm{n} / \mathrm{a}$ & 0.18 \\
\hline 7 & 9.14 & $\mathrm{n} / \mathrm{a}$ & $\mathrm{n} / \mathrm{a}$ & 0.12 & 0.61 & 0.06 & 0.22 \\
\hline 12 & 8.87 & $\mathrm{n} / \mathrm{a}$ & $\mathrm{n} / \mathrm{a}$ & 0.18 & $\mathrm{n} / \mathrm{a}$ & $\mathrm{n} / \mathrm{a}$ & 0.15 \\
\hline 13 & 9.06 & $\mathrm{n} / \mathrm{a}$ & $\mathrm{n} / \mathrm{a}$ & 0.15 & $\mathrm{n} / \mathrm{a}$ & $\mathrm{n} / \mathrm{a}$ & 0.21 \\
\hline 14 & 8.84 & $\mathrm{n} / \mathrm{a}$ & $\mathrm{n} / \mathrm{a}$ & 0.15 & $\mathrm{n} / \mathrm{a}$ & $\mathrm{n} / \mathrm{a}$ & 0.21 \\
\hline 15 & 9.75 & $\mathrm{n} / \mathrm{a}$ & $\mathrm{n} / \mathrm{a}$ & 0.18 & $\mathrm{n} / \mathrm{a}$ & $\mathrm{n} / \mathrm{a}$ & 0.24 \\
\hline 16 & 7.32 & $\mathrm{n} / \mathrm{a}$ & $\mathrm{n} / \mathrm{a}$ & 0.18 & $\mathrm{n} / \mathrm{a}$ & $\mathrm{n} / \mathrm{a}$ & 0.18 \\
\hline 17 & 6.40 & $\mathrm{n} / \mathrm{a}$ & $\mathrm{n} / \mathrm{a}$ & 0.18 & 0.30 & $\mathrm{n} / \mathrm{a}$ & 0.18 \\
\hline 18 & 8.60 & 0.52 & 0.09 & 0.18 & 0.58 & 0.09 & 0.24 \\
\hline 22 outer & 10.22 & $\mathrm{n} / \mathrm{a}$ & $\mathrm{n} / \mathrm{a}$ & 0.18 & 60.00 & $\mathrm{n} / \mathrm{a}$ & 0.27 \\
\hline 22 inner & 8.53 & $\mathrm{n} / \mathrm{a}$ & $\mathrm{n} / \mathrm{a}$ & 0.18 & 60.00 & $\mathrm{n} / \mathrm{a}$ & 0.27 \\
\hline 25 & 14.98 & 0.46 & 0.15 & 0.30 & 0.82 & 0.33 & 0.46 \\
\hline
\end{tabular}

Table 22. Hatchel mound structure measurements between wall post holes and from wall to center.

\begin{tabular}{|l|l|c|}
\hline & \multicolumn{2}{|c|}{ Exterior Posts } \\
\hline & Between Wall Posts (m) & Wall to center post hole (m) \\
\hline
\end{tabular}




\begin{tabular}{|c|c|c|c|c|c|c|c|c|c|c|c|}
\hline 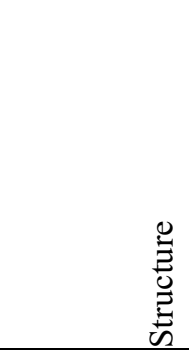 & 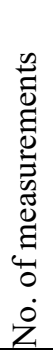 & $\stackrel{\Xi}{\Sigma}$ & $\sum^{\frac{x}{\pi}}$ & $\stackrel{\mathbb{E}}{\Sigma}^{\mathbb{E}}$ & $\begin{array}{l}\overrightarrow{0} \\
\text { 岕 }\end{array}$ & 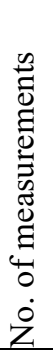 & $\stackrel{\Xi}{\Sigma}$ & 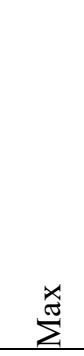 & 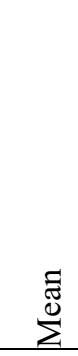 & 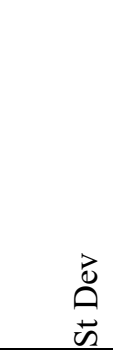 & $\begin{array}{l}\text { Ratio - } \\
\text { Average } \\
\text { Distance } \\
\text { between } \\
\text { exterior Post } \\
\text { holes and } \\
\text { average } \\
\text { distance to } \\
\text { center }\end{array}$ \\
\hline 1 & \multicolumn{5}{|c|}{ no measurement } & 17 & 2.33 & 2.64 & 2.43 & 0.0669 & \\
\hline 5 & 12 & 0.50 & 1.29 & 0.86 & 0.2602 & 11 & 1.59 & 1.90 & 1.76 & 0.0998 & $1: 2.05$ \\
\hline 7 & 22 & 0.21 & 0.99 & 0.61 & 0.2400 & 31 & 3.25 & 4.53 & 4.00 & 0.3283 & $1: 6.56$ \\
\hline 12 & 9 & 0.38 & 0.85 & 0.55 & 0.1750 & 14 & 4.56 & 4.98 & 4.76 & 0.1172 & $1: 8.65$ \\
\hline 13 & 19 & 0.19 & 0.61 & 0.41 & 0.1140 & 25 & 4.10 & 4.50 & 4.29 & 0.1284 & $1: 10.46$ \\
\hline 14 & 12 & 0.47 & 0.68 & 0.58 & 0.0636 & 14 & 3.85 & 4.08 & 3.98 & 0.0658 & $1: 6.86$ \\
\hline 15 & 46 & 0.27 & 0.78 & 0.48 & 0.1309 & 43 & 4.10 & 5.03 & 4.65 & 0.2492 & $1: 9.69$ \\
\hline 16 & 43 & 0.31 & 1.16 & 0.50 & 0.1635 & 42 & 3.57 & 3.94 & 3.74 & 0.0763 & $1: 7.48$ \\
\hline 17 & 18 & 0.22 & 0.69 & 0.51 & 0.1215 & 20 & 2.95 & 3.14 & 3.07 & 0.0550 & $1: 6.02$ \\
\hline 18 & 37 & 0.33 & 0.70 & 0.47 & 0.0904 & 43 & 3.98 & 4.97 & 4.32 & 0.2690 & 1:9.19 \\
\hline 22outer & 42 & 0.21 & 0.94 & 0.54 & 0.1545 & 47 & 4.56 & 5.32 & 5.03 & 0.1496 & 1:9.31 \\
\hline 22inner & 33 & 0.32 & 1.10 & 0.59 & 0.1902 & 36 & 4.01 & 4.47 & 4.22 & 0.1023 & $1: 7.15$ \\
\hline 25 & 77 & 0.30 & 0.98 & 0.55 & 0.1088 & 81 & 7.24 & 7.78 & 7.52 & 0.1281 & $1: 13.67$ \\
\hline 25 partition & 23 & 0.29 & 0.78 & 0.48 & 0.1319 & & & neasur & ment & & \\
\hline
\end{tabular}

Six of the Hatchel mound structures have extended entrances (Table 23). In addition, at least two (or three if Feature 22 actually represents two sequent structures) have possible non-extended entrances that were identified by Beatty. No recognizable entrances were identified for the remaining structures. All of the entrances face south $(n=5)$, southwest $(n=1)$, or southeast $(n=2)$. Two gaps in the Feature 25 wall that could represent non-extended entrances face to the north. In addition, there is one possible extended entrance on Feature 14 that faces to the east. However, the post hole pattern for this possible entrance may actually be related to additional structures, arbors, ramadas, etc. With the exception of the two possible north-facing entrances related to Feature 25, nine of the entrances face generally southward, toward the Hatchel village area (Perttula 2005, 2009). Finally, the Feature 25 interior partition has a gap in the post holes that likely represents a passageway through the wall. 
Table 23. Types of entrances related to the Hatchel mound structures.

\begin{tabular}{|c|c|c|c|c|}
\hline Structure & Type & $\begin{array}{l}\text { Approximate } \\
\text { Length (m) }\end{array}$ & $\begin{array}{l}\text { Approximate } \\
\text { Width (m) }\end{array}$ & Entrance Facing \\
\hline 1 & $\begin{array}{l}\text { non- } \\
\text { extended }\end{array}$ & $\mathrm{n} / \mathrm{a}$ & $\mathrm{n} / \mathrm{a}$ & $\mathrm{n} / \mathrm{a}$ \\
\hline 5 & extended & 1.03 & 1.15 & southwest \\
\hline 7 & extended & 1.85 & 1.30 & southeast \\
\hline 12 & $\begin{array}{l}\text { non- } \\
\text { extended }\end{array}$ & $\mathrm{n} / \mathrm{a}$ & $\mathrm{n} / \mathrm{a}$ & $\mathrm{n} / \mathrm{a}$ \\
\hline 13 & $\begin{array}{l}\text { non- } \\
\text { extended }\end{array}$ & $\mathrm{n} / \mathrm{a}$ & $\mathrm{n} / \mathrm{a}$ & $\mathrm{n} / \mathrm{a}$ \\
\hline 14 & extended & 2.07 & 1.90 & $\begin{array}{l}\text { south (one possible east entrance, but } \\
\text { unlikely) }\end{array}$ \\
\hline 15 & extended & 1.65 & 1.11 & south \\
\hline 16 & extended & 2.61 & 1.06 & southeast \\
\hline 17 & $\begin{array}{l}\text { non- } \\
\text { extended }\end{array}$ & $\mathrm{n} / \mathrm{a}$ & $\mathrm{n} / \mathrm{a}$ & $\mathrm{n} / \mathrm{a}$ \\
\hline 18 & extended & 1.95 & 1.10 & south \\
\hline 22outer & $\begin{array}{l}\text { non- } \\
\text { extended }\end{array}$ & $\mathrm{n} / \mathrm{a}$ & 3.00 & south \\
\hline 22inner & $\begin{array}{l}\text { non- } \\
\text { extended }\end{array}$ & $\mathrm{n} / \mathrm{a}$ & $\mathrm{n} / \mathrm{a}$ & south \\
\hline 25 & $\begin{array}{l}\text { non- } \\
\text { extended }\end{array}$ & $\mathrm{n} / \mathrm{a}$ & 1.34 & south \\
\hline 25 & $\begin{array}{l}\text { non- } \\
\text { extended }\end{array}$ & $\mathrm{n} / \mathrm{a}$ & 1.12 & north \\
\hline 25 & & $\mathrm{n} / \mathrm{a}$ & 1.36 & north \\
\hline 25 Partition & $\begin{array}{l}\text { non- } \\
\text { extended }\end{array}$ & $\mathrm{n} / \mathrm{a}$ & 1.31 & south or north \\
\hline
\end{tabular}

The extended entrances range in length from approximately 1.03-2.61 m with an average length of $1.86 \mathrm{~m}$. The approximate widths range from 1.06-3 $\mathrm{m}$, with an average width of $1.43 \mathrm{~m}$. Average post hole diameters ranges from $0.12 \mathrm{~m}$ to $0.18 \mathrm{~m}$ with a mean diameter of $0.15 \mathrm{~m}$. The entrance posts tended to be relatively shallow with average depths ranging from $0.12 \mathrm{~m}$ to $0.18 \mathrm{~m}$, and with a mean average depth of $0.16 \mathrm{~m}$. Finally, the average distance between entrance post holes ranges from $0.17 \mathrm{~m}$ to $0.56 \mathrm{~m}$ with a mean spacing of 0.36 . Table 24 provides the various post hole measurements recorded for the Hatchel extended entrances. 
Based on the feature forms and Beatty's descriptions of the various Hatchel structures, at least four of the structures (Features 1, 5, 7, and 13) showed signs of being burned. At least one clearly was not burned (Feature 13), and it was unclear as to whether or not the remaining eight were burned.

Table 24: Post hole measurements for Hatchel extended entrances.

\begin{tabular}{|c|c|c|c|c|c|c|c|c|c|c|}
\hline \multirow[b]{2}{*}{ 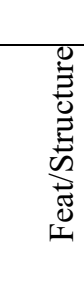 } & \multirow[b]{2}{*}{ 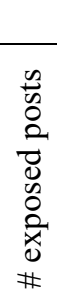 } & \multicolumn{5}{|c|}{ Diameter } & \multicolumn{3}{|c|}{ Depth } & \multirow[b]{2}{*}{ n } \\
\hline & & 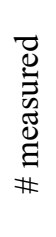 & 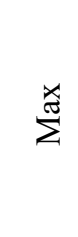 & 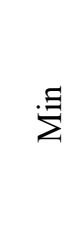 & 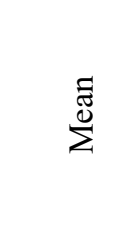 & $\infty$ & 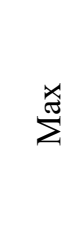 & $\dot{\Sigma}$ & $\sum_{\bar{\Sigma}}^{\bar{\Xi}}$ & \\
\hline 5 & 5 & 5 & 0.18 & 0.14 & 0.17 & 0.0152 & $\mathrm{x}$ & 0.15 & & \\
\hline 7 & 7 & 5 & & & 0.12 & & & & 0.18 & \\
\hline 14 & 7 & 4 & 0.18 & 0.13 & 0.16 & 0.0238 & 0.15 & 0.06 & 0.12 & 0.0424 \\
\hline 15 & 18 & 18 & 0.18 & 0.11 & 0.14 & 0.0178 & 0.30 & 0.09 & 0.18 & 0.0537 \\
\hline 16 & 15 & & & & 0.18 & & & & 0.18 & \\
\hline 18 & 21 & 21 & 0.18 & 0.12 & 0.15 & 0.0160 & 0.21 & 0.12 & 0.17 & 0.0332 \\
\hline Min & & & & & 0.12 & & & & 0.12 & \\
\hline Max & & & & & 0.18 & & & & 0.18 & \\
\hline Mean & & & & & 0.15 & & & & 0.166 & \\
\hline $\mathrm{s}$ & & & & & 0.0216 & & & & 0.0261 & \\
\hline
\end{tabular}

Only one of the structures (Feature 14) had a possible prepared floor. Feature 14 is described in UT-WPA notes as being located on a red clay deposit that may have been placed to form the structure floor. The various mound stages were clearly prepared prior to the buildings being constructed, but no clearly definable prepared floor was otherwise recorded for structures on these mound platforms.

Interior features for the Hatchel mound structures include interior post holes, hearths, storage pits, and ash deposits without any indications of burning. All of the Hatchel structures have interior post holes. Although some of these post holes may 
belong to structures that were not recorded, many of them were probably related to interior features such as benches, beds, screens, or platforms. Some were likely interior support posts, although none of the Hatchel mound structures clearly have the four large interior support posts like those found at the George C. Davis site, Earspool (see below), and others in East Texas.

Central posts were recorded in at least three and possibly four of the structures (Features 13, 15, and 18, with one possibly in Feature 7). The center posts range in diameter from $15 \mathrm{~cm}$ to $35 \mathrm{~cm}$, with depths ranging from $15 \mathrm{~cm}$ to $70 \mathrm{~cm}$. The possible center post of Feature 7 was the only one associated with a central hearth.

Interior hearths were recorded in seven of the Hatchel mound structures, with five of those being centrally located. None of the hearths were clearly clay-lined. The hearth remnants were generally irregular in shape and varied in size from $0.46 \times 0.61 \mathrm{~m}$ in Feature 15 to $2.0 \times 1.3 \mathrm{~m}$ associated with Feature 1. Depths were available for five of the hearths and these ranged from $0.21 \mathrm{~m}$ to $0.76 \mathrm{~m}$. The contents of the Hatchel mound structure hearths included ashes, charcoal, and burned clay, with the Feature 22 hearth recorded as also containing 10 ceramic sherds, two mussel shells, and three animal bones.

The Hatchel site appears to have been occupied from as early as ca. A.D. 1000 to the late eighteenth century (Creel 1996; Perttula 2005). There are four radiocarbon dates from the Hatchel Mound (Perttula 1997), with additional dates from the Village deposits (Perttula 2005). As shown in Table 25, two of the dates from the mound are from separate mound floors $(\mathrm{K}$ and $\mathrm{H})$, with the other two coming from Features 18 and 4 (Perttula 1997). Recent work in the village areas of the site (Perttula 2005) has resulted in five additional radiocarbon dates and 10 Oxidizable Carbon Ratio (OCR) dates. Perttula (2005:184) notes that these dates: 
indicate that the Hatchel site was first settled before A.D. 1300. This is contemporaneous with the Middle Caddoan period Haley phase [A.D. 1200-1400] and lends credence to the suggestion first made by Krieger (1946) that the initial mound construction in the primary platform mound took place before the Late Caddo Texarkana phase. Other dated samples argue for the continuous Caddo settlement of the Hatchel village from at least the thirteenth century to the mid- or late seventeenth century, the same time as the construction and use of most of the platform mound, according to Creel (1996).

Table 25. Radiocarbon dates from the Hatchel Mound (Perttula 1997).

\begin{tabular}{|c|c|c|c|c|c|}
\hline Provenience & Assay No & Raw Age (BP) & $\begin{array}{c}\text { Corrected Age } \\
\text { (BP) }\end{array}$ & $\begin{array}{c}\text { Calibrated } 1 \text { sigma } \\
\text { age range }(\mathrm{AD})\end{array}$ & $\begin{array}{l}\text { Relative area under } \\
\text { probability distribution }\end{array}$ \\
\hline Floor K & Tx-1903 & $1250 \pm 70$ & $1250 \pm 81$ & 695-869 & 1.00 \\
\hline Floor $\mathrm{H}$ & Tx-1904 & $810 \pm 40$ & $810 \pm 57$ & 1193-1282 & 1.00 \\
\hline $\begin{array}{l}\text { Feature 18, } \\
\text { Floor } \mathrm{H}\end{array}$ & Tx-1905 & $1000 \pm 40$ & $1000 \pm 57$ & $\begin{array}{l}988-1055 \\
1083-1122 \\
138-1157\end{array}$ & $\begin{array}{l}0.59 \\
0.28 \\
0.13\end{array}$ \\
\hline $\begin{array}{l}\text { Feature 4, } \\
\text { Floor B }\end{array}$ & Tx-1906 & $660 \pm 40$ & $660 \pm 57$ & $\begin{array}{l}1342-1392 \\
1291-1319\end{array}$ & $\begin{array}{l}0.64 \\
0.36\end{array}$ \\
\hline
\end{tabular}

\section{Harroun (41UR10)}

Four burned structures were recorded in three of the four earthen mounds at the Harroun site in Upshur County. The four Late Caddo (Titus phase) circular Harroun structures range from $4.26 \mathrm{~m}$ to $6.04 \mathrm{~m}$ in diameter (Jelks and Tunnell 1959), with areas ranging from $14.25 \mathrm{~m}^{2}$ to $28.65 \mathrm{~m}^{2}$. Structures 1 and 2 were found in Mound C, a low oval-shaped earthen mound, Structure 3 was recorded in Mound B, and Structure 4 was in Mound D (Figure 44).

Structure 1 was built on the original floodplain surface and measured $5.48 \mathrm{~m}$ in diameter $\left(\right.$ area $\left.=23.59 \mathrm{~m}^{2}\right)$. Structure 2 measured $4.26 \mathrm{~m}$ in diameter and was centered over House 1, separated from it by a 0.3-0.9 m thick deposit of clean sand (Table 26) (Jelks and Tunnell 1959). Figure 45 provides a plan map of Structures 1 and 2. Structure 1 had an exterior wall defined by at least 29 post holes, although according to Jelks and 
Tunnell (1959), disturbances on the south and west sides of the structure probably destroyed at least five additional post holes. The 29 post holes were spaced from $0.21 \mathrm{~m}$ to $0.62 \mathrm{~m}$ apart $(\bar{x}=0.48 \mathrm{~m}, \mathrm{~s}=0.0959)$. The distances from the wall post holes to the center range from $2.65 \mathrm{~m}$ to $2.91 \mathrm{~m}(\mathrm{n}=28, \bar{x}=2.78 \mathrm{~m}, \mathrm{~s}=0.0782)$. The ratio of average distance between wall post holes and average distance to the center is 1:5.79. Wall post hole diameters range from $0.11 \mathrm{~m}$ to 0.23 , with a mean of approximately $0.16 \mathrm{~m}$. Post hole depths ranged from $0.40 \mathrm{~m}$ to $0.61 \mathrm{~m}$ below the floor level (Jelks and Tunnell 1959).

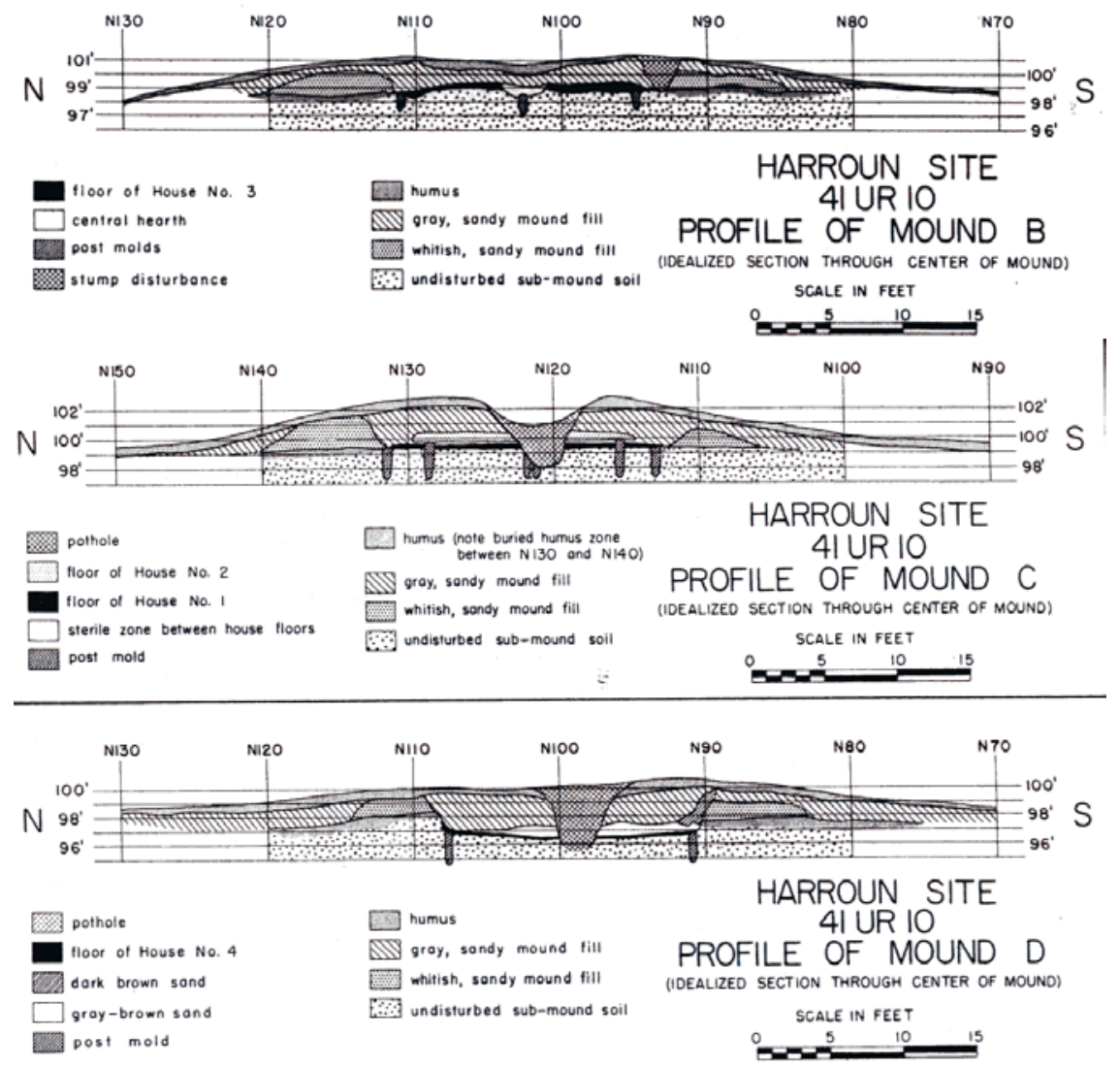

Figure 44. Harroun Mounds B, C and D Profiles (Jelks and Tunnell 1959: Figures 3 and 7). Reproduced courtesy of The University of Texas Department of Anthropology. 
Table 26. Harroun Mound C structural details (Jelks and Tunnell 1959).

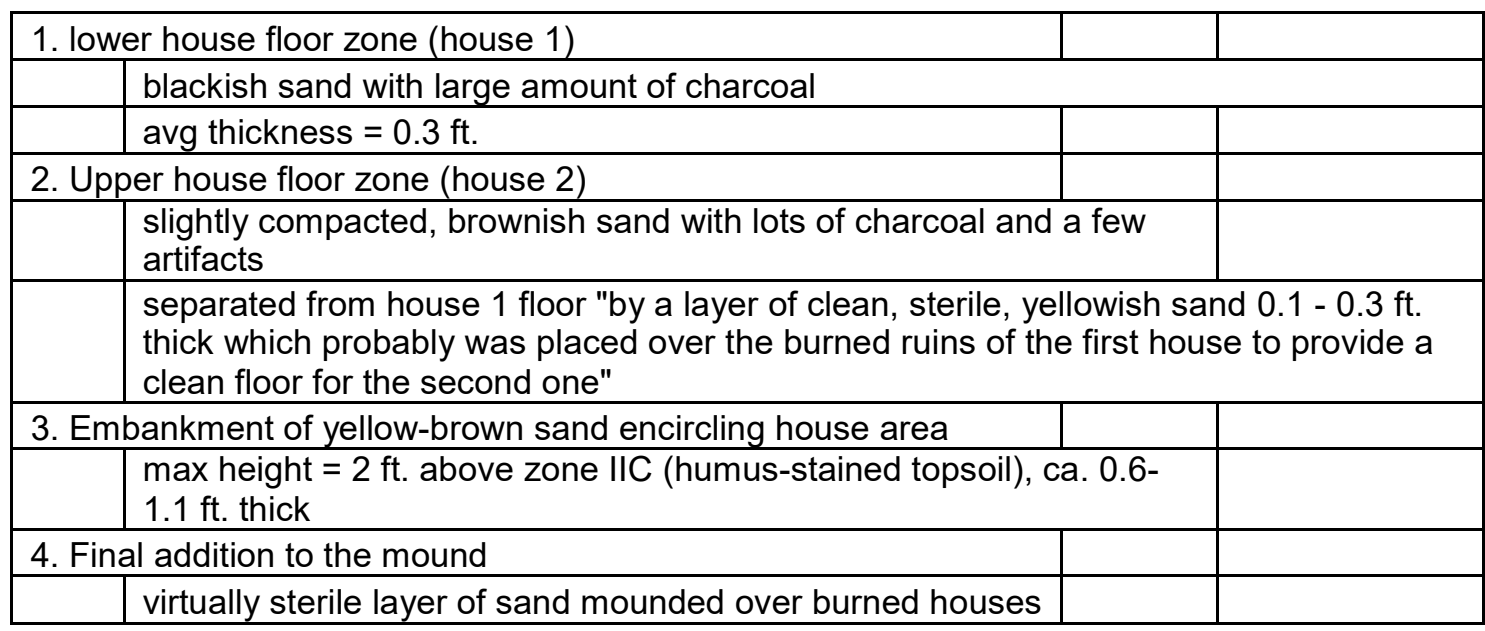

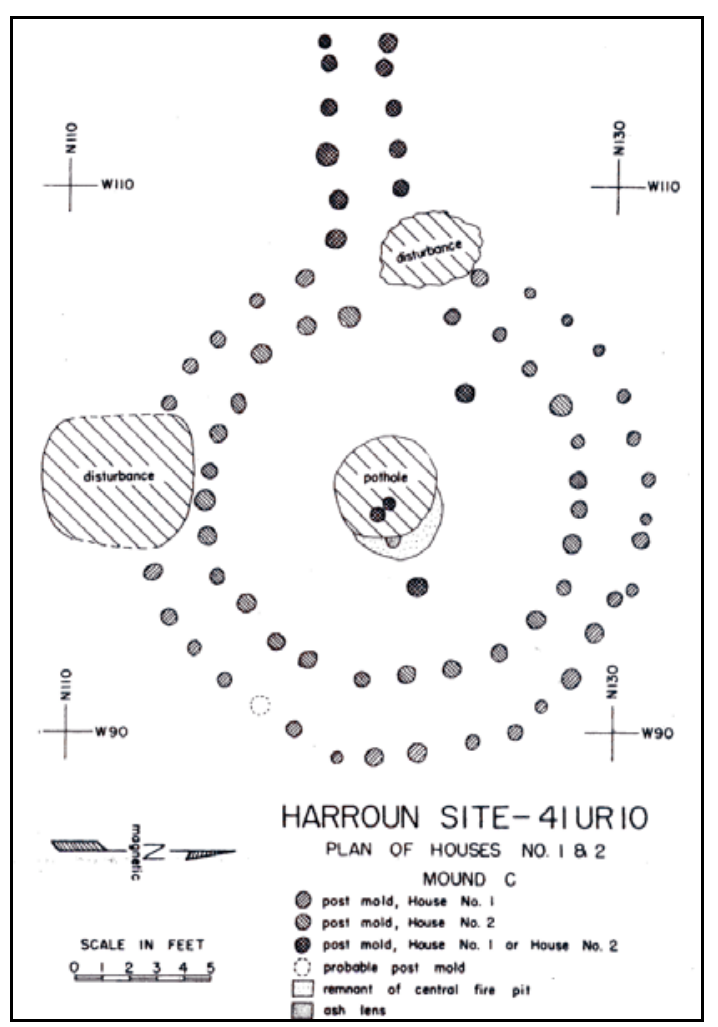

Figure 45. Harroun Structures 1 and 2 (Jelks and Tunnell 1959:29: Figure 8). Reproduced courtesy of TARL. 
An extended entrance was located on the west side of House 1 and it was represented by two parallel rows of post holes and "an elongated area of organically stained soils" (Jelks and Tunnell 1959:28-30). The extended entrance faced west and measured $2.4 \mathrm{~m} \times 0.8 \mathrm{~m}$. The entrance consisted of 11 post holes with diameters ranging from 0.14 to $0.26 \mathrm{~m}$, with a mean diameter of $0.19 \mathrm{~m}$. Other associated features included a non-clay-lined central hearth measuring approximately $0.91 \mathrm{~m}$ in diameter (the hearth was heavily disturbed by a pothole), a center post below the hearth with a diameter of approximately $0.17 \mathrm{~m}$ that extended approximately $0.31 \mathrm{~m}$ below the Structure 1 floor, two interior post holes, and a $9 \mathrm{~cm}$ thick midden accumulation (Jelks and Tunnell 1959; Thurmond 1990).

Structure 2 is the smallest of the recorded Harroun mound structures, measuring $4.26 \mathrm{~m}$ in diameter with an area of $14.25 \mathrm{~m}^{2}$ (Jelks and Tunnell 1959:30-31). Structure 2 was centered over Structure 1 and separated from it by 0.3-0.9 m of clean sand (Jelks and Tunnell 1959:30-31). Like Structure 1, Structure 2 probably had a central hearth covering a single post hole and probably had its entrance facing to the west. The center posts of Structures 1 and 2 were slightly offset (Jelks and Tunnel 1959:30-31) and the Structure 2 center post was smaller than the Structure 1 post, measuring $0.13 \mathrm{~m}$ in diameter. Jelks and Tunnell (1959:30-31) noted that "House 2 must have had its entranceway on the west side because the organically stained outline showed clearly in the mound fill well above the House 2 floor level. Possibly both houses had their entranceways in this same area." The plan map indicates that the extended entrance could be associated with either Structures 1 or 2, or both. Like Structure 1, Structure 2 was burned.

The post holes for Structure 2 have diameters ranging from $0.14 \mathrm{~m}$ to $0.26 \mathrm{~m}$, slightly larger than the Structure 1 post holes, with depths ranging from $0.49 \mathrm{~m}$ to $0.61 \mathrm{~m}$ below the Structure 2 floor zone. The mean diameter of the Structure 2 post holes was 
approximately $0.19 \mathrm{~m}$. Structure 2 wall post hole spacing ranges from $0.32 \mathrm{~m}$ to $0.64 \mathrm{~m}$ $(\bar{x}=0.48 \mathrm{~m}, \mathrm{~s}=0.0834)$. The distances from the wall post holes to the center of the structure range from $1.91 \mathrm{~m}$ to $2.25 \mathrm{~m}(\mathrm{n}=26, \bar{x}=2.08 \mathrm{~m}, \mathrm{~s}=0.0938)$. The ratio of average distance between wall post holes and average distance to the center is 1:4.33.

Both Structures 1 and 2 had clearly been burned and Jelks and Tunnell recovered charcoal and burned daub. In addition, both Houses 1 and 2 had a $0.75 \mathrm{~m}$ high sand embankment against the outer wall. Jelks and Tunnell (1959:27) described the embankment by noting: "apparently this embankment was built while one of the houses was still standing since its inner edge is almost vertical in places as though it had been banked against the outside wall of the house."

Mound B covered a single circular structure (Structure 3) built on the floodplain surface (Figure 46). Structure 3 measures $5.18 \mathrm{~m}$ in diameter, with an area of $21.07 \mathrm{~m}^{2}$. Fifty-nine post holes were assigned to Structure 3, 23 of which belonged to the structure wall. The mean wall post hole diameter was $0.15 \mathrm{~m}$. The wall post holes were spaced from 0.32 to $0.75 \mathrm{~m}$ apart $(\mathrm{n}=16, \bar{x}=0.52 \mathrm{~m}, \mathrm{~s}=0.1445)$. The distances from the wall post holes to the center range from $2.23 \mathrm{~m}$ to $2.67 \mathrm{~m}(\mathrm{n}=22, \bar{x}=2.44 \mathrm{~m}, \mathrm{~s}=0.1421)$. The ratio of average distance between wall post holes and average distance to the center is 1:4.69, similar to the ratio for Structure 2. Diameters for all 59 post holes range from $0.8 \mathrm{~m}$ to $0.40 \mathrm{~m}$, with the depths ranging from $0.09 \mathrm{~m}$ to $0.76 \mathrm{~m}$ (Jelks and Tunnell 1959:20), with the deepest probably being the large interior support posts. 


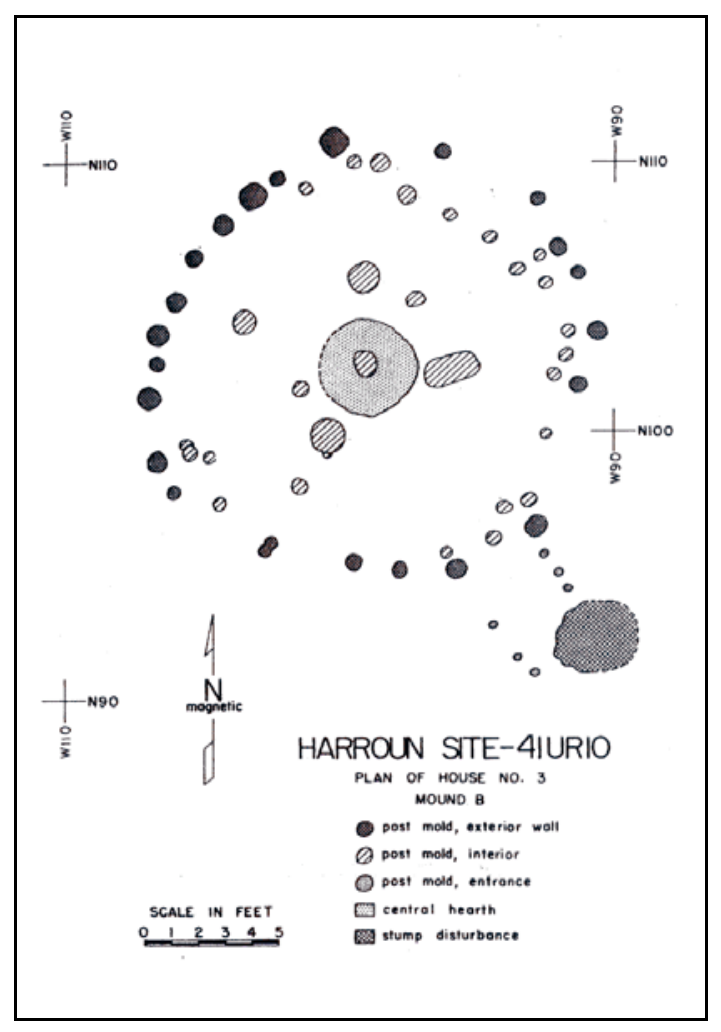

Figure 46. Harroun Structure 3 (Jelks and Tunnell 1959:Figure 3). Reproduced courtesy of TARL.

Structure 3 had a southeast facing extended entranceway measuring $1.5 \times 0.9 \mathrm{~m}$ in length and width. The entrance consisted of two parallel lines with three post holes each, although, due to disturbance, it is unlikely that all the entrance post holes were identified (Jelks and Tunnell 1959:20). The entrance post holes range in size from $0.08 \mathrm{~m}$ to 0.10 m. Like the other Harroun structures, House 3 had a central hearth covering a single post hole. The non-clay-lined central hearth was the largest recorded from the Harroun mound structures, measuring $1.22 \mathrm{~m}$ in diameter. The hearth was $0.30 \mathrm{~m}$ deep and covered a 0.30 $\mathrm{m}$ diameter center post.

Structure 3 had several interior post holes, including a cluster recorded in front of the entrance and a cluster found along the northeast wall, that likely represented interior 
features such as benches, racks, storage platforms, beds, or screens (Jelks and Tunnell 1959:20). Along with the 30 irregularly spaced interior posts, four large interior posts were identified that "probably held the bases of relatively heavy roof supports" (Jelks and Tunnell 1959:20). The four large interior posts ranged in size from approximately $22 \mathrm{~cm}$ to about $30 \times 61 \mathrm{~cm}$. The distances from the center of the four large support posts to the center of the structure ranged from $0.91 \mathrm{~m}$ to $1.44 \mathrm{~m}(\bar{x}=1.08 \mathrm{~m}, \mathrm{~s}=0.2461)$, similar in distance to comparable structures from the George C. Davis and Earspool sites.

A $30 \mathrm{~cm}$ deep midden accumulation was identified on the floor of the structure and, like Houses 1 and 2, a $75 \mathrm{~cm}$ high sand embankment was found against the outside wall of the structure. The structure was burned and covered by the mound. Jelks and Tunnell (1959:22) summarized the character of Structure 3:

House no. 3, a circular wattle-and-daub structure with a southeastern facing entranceway, was built on the surface of the Cypress Creek floodplain. There were probably four interior roof support posts, 2 or more interior platforms for sleeping or storage, and a centrally located, prepared hearth with a clay base. Possibly, a low embankment of sand was thrown against the wall around the exterior of the house.

Structure 4 was located under Mound D and measured $6.04 \mathrm{~m}$ in diameter with an area of $28.65 \mathrm{~m}^{2}$, making it the largest of the Harroun mound structures (Figure 47). The wall of Structure 4 included at least 27 post holes, with a few more probably located in the unexcavated portions of the structure outline. The wall post holes have diameters ranging from $0.09 \mathrm{~m}$ to $0.18 \mathrm{~m}$, with a mean of approximately $0.13 \mathrm{~m}$. No depth data was available for the Structure 4 post holes. The wall post holes were spaced from $0.24 \mathrm{~m}$ to $0.85 \mathrm{~m}$ apart $(\mathrm{n}=23, \bar{x}=0.57 \mathrm{~m}, \mathrm{~s}=0.1365)$. The distances from the wall post holes to the center ranged from $2.64 \mathrm{~m}$ to $2.92 \mathrm{~m}(\mathrm{n}=26, \bar{x}=2.80 \mathrm{~m}, \mathrm{~s}=0.0676)$. The ratio of 
average distance between wall post holes and average distance to the center was 1:4.91, slightly smaller than the next largest structure at the Harroun site, Structure 1.

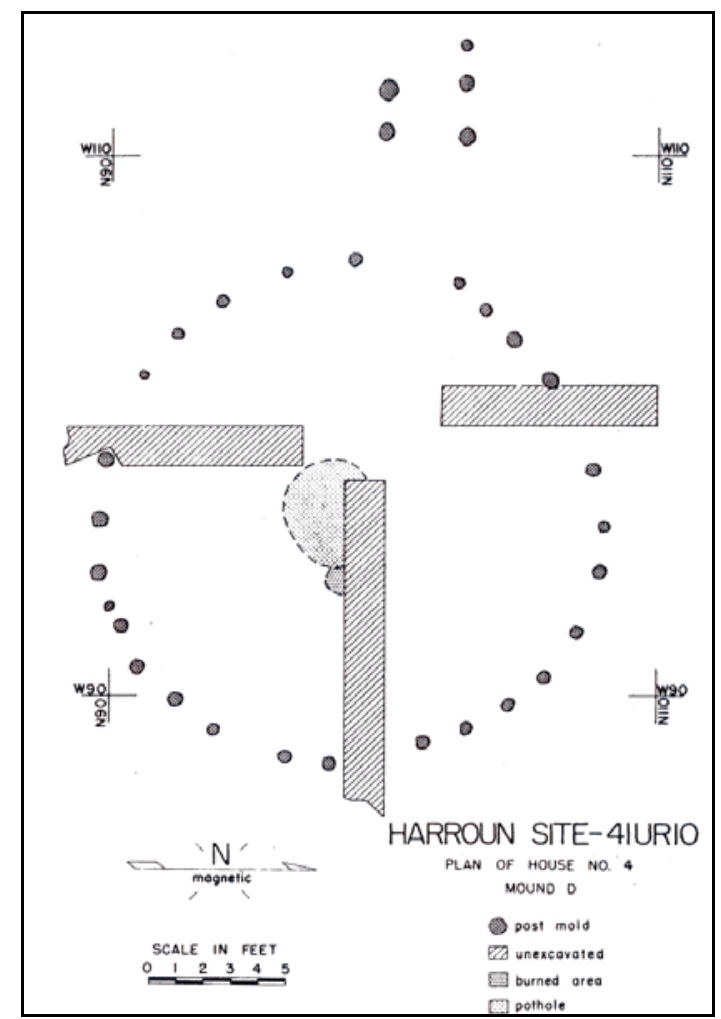

Figure 47. Harroun Structure 4 (Jelks and Tunnell 1959:36:Figure 10). Reproduced courtesy of TARL.

Interestingly, Structure 4 was built within a $0.45 \mathrm{~m}$ deep pit dug into the original floodplain surface (Jelks and Tunnell 1959:34). Structure 4's west facing extended entrance measured $2.4 \times 0.91 \mathrm{~m}$ in length and width (Jelks and Tunnell 1959:34), and was defined by two parallel lines consisting of a total of five posts. The entrance "sloped downward from the surface of the floodplain into the house pit" (Jelks and Tunnell 1959:34). The structure had a central hearth with a post hole below and a 5-6 cm deep midden accumulation on the floor. The hearth measured approximately $1.06 \mathrm{~m}$ in diameter. 
Like the other Harroun mound structures, Structure 4 had a sand embankment built against its wall. The Structure 4 berm was smaller than the ones associated with the other structures and measured $45 \mathrm{~cm}$ high and 1.22 to $1.83 \mathrm{~m}$ in width (Jelks and Tunnell 1959:34). The floor of the structure was composed of a $6 \mathrm{~cm}$ think layer of hard-packed sandy clay, and "just above the house floor was a 1' [30 cm] thick layer of dark graybrown sand containing several charred poles and a large amount of charcoal, ash, and burned clay daub. Above that was the sandy fill making up the bulk of the mound" (Jelks and Tunnell 1959:34).

Jelks and Tunnell (1959:30) noted that "the sparse occurrence of artifacts and other cultural refuse suggests that neither House no. 1 nor House no. 2 was an ordinary domicile. It appears likely, rather, that both were ceremonial structures of some sort. This hypothesis is supported by the fact that the houses were considered important enough to be afforded burial beneath a mound, probably after having been ceremonially cremated" (Jelks and Tunnell 1959:30). They summarized the Mound C structures by stating that:

A circular house (House No. 1) was built on the south bank of the Harroun site lake, was occupied for an unknown period of time, then was burned - perhaps intentionally. After a thin layer of sand had been strewn over the burned ruins, a second, smaller house (House 2) was erected on the remains of the earlier house. House No. 2 was likewise destroyed by fire, after which the remains of both houses were buried under a mound of sand (Jelks and Tunnell 1959:31).

As noted above, the Harroun structures date to the Late Caddo Titus phase (ca. A.D. 1430-1680) (Jelks and Tunnell 1959; Perttula 2009; Thurmond 1990). At least five radiocarbon dates are available from the Harroun site (Perttula 1997). One of the dates is from Mound B, two are from Mound C, and two are from structures in Mound D (Table 27). 
Table 27: Radiocarbon dates from the Harroun site (Perttula 1997).

\begin{tabular}{|c|c|c|c|c|c|}
\hline Provenience & Assay No. & Raw Age (BP) & $\begin{array}{l}\text { Corrected Age } \\
\text { (B.P.) }\end{array}$ & $\begin{array}{l}\text { Calibrated } 1 \text { sigma } \\
\text { age range }(\mathrm{AD})\end{array}$ & $\begin{array}{l}\text { Relative area under } \\
\text { probability distribution }\end{array}$ \\
\hline $\begin{array}{l}\text { Structure under } \\
\text { Mound D }\end{array}$ & Tx-84 & $490 \pm 100$ & $490 \pm 108$ & $\begin{array}{l}1386-1515 \\
1311-1352 \\
1593-1620 \\
\end{array}$ & $\begin{array}{l}0.72 \\
0.17 \\
0.10\end{array}$ \\
\hline $\begin{array}{l}\text { Beam above } \\
\text { House } 4 \text { floor, } \\
\text { Mound D }\end{array}$ & Tx-241 & $345 \pm 75$ & $345 \pm 85$ & $1479-1641$ & 1.00 \\
\hline Mound B & Tx-238 & $265 \pm 65$ & $265 \pm 76$ & $\begin{array}{l}1511-1599 \\
1616-1680 \\
1756-1804 \\
\end{array}$ & $\begin{array}{l}0.39 \\
0.34 \\
0.20 \\
\end{array}$ \\
\hline Mound C & Tx-239 & $330 \pm 110$ & $330 \pm 117$ & 1444-1668 & 0.98 \\
\hline Mound C & Tx-240 & $555 \pm 70$ & $555 \pm 81$ & $\begin{array}{l}1382-1437 \\
1308-1357\end{array}$ & $\begin{array}{l}0.56 \\
0.44\end{array}$ \\
\hline
\end{tabular}

\section{Dalton (41UR11)}

The Late Caddo Charles Dalton site (41UR11) consists of a single low, roughly circular, mound covering an area of approximately $250 \mathrm{~m}^{2}$. Excavations in 1958, under the direction of E. Mott Davis and William A. Davis, focused on the mound and the immediately adjacent area. Excavations of approximately $60 \%$ of the mound found that the $16.8 \mathrm{~m}$ diameter, $0.8 \mathrm{~m}$ high, mound capped two burned overlapping circular structures (Structures A and B) (Figure 48) (Davis and Gipson 1960). The remainder of the mound was not excavated due to the presence of a large tree. 


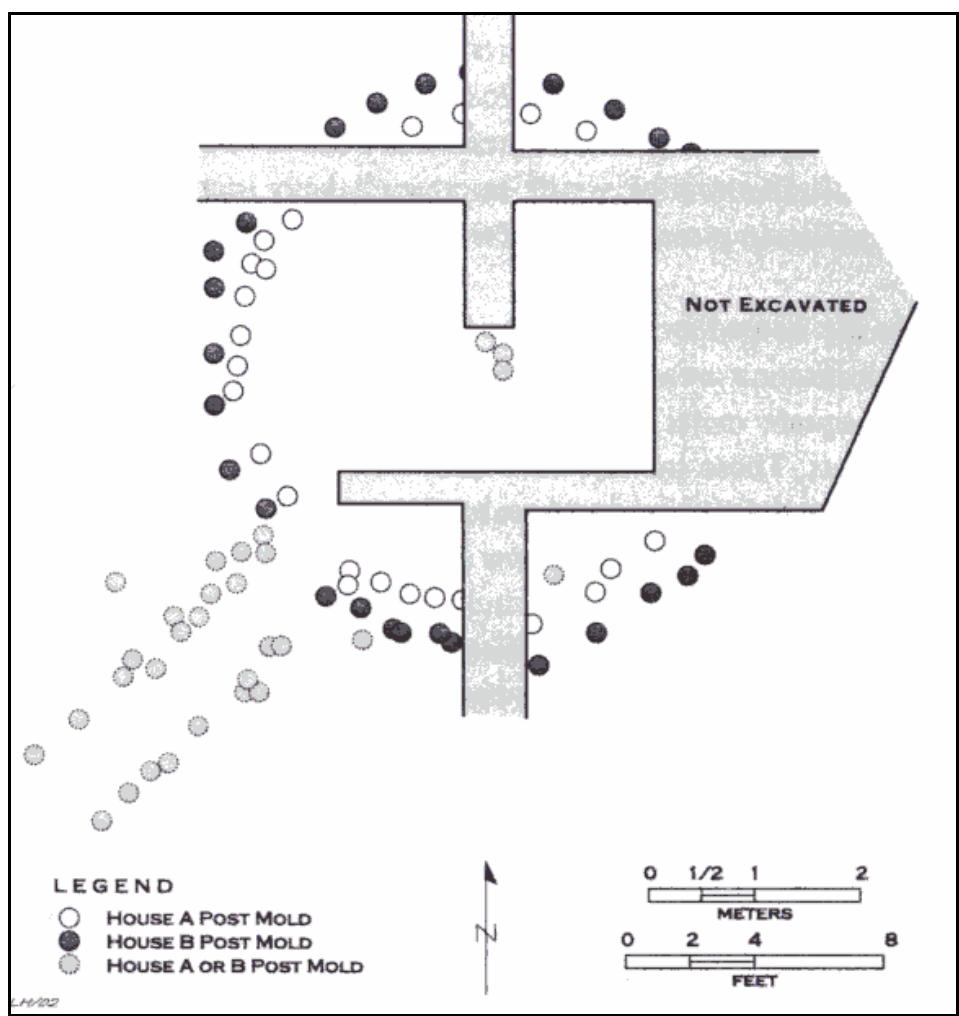

Figure 48. Dalton Structures A and B. Reproduced courtesy of TARL.

The earlier of the two structures, Structure A, measured $4.6 \mathrm{~m}$ in diameter, with an area of $16.62 \mathrm{~m}^{2}$, while the larger Structure B measured $5.50 \mathrm{~m}$ in diameter, with an area of $23.76 \mathrm{~m}^{2}$ (Davis and Gipson 1960). Nineteen wall posts were assigned to Structure A and 22 were assigned to Structure B. Again, several post holes were likely not recorded due to the incomplete excavation of the mound (see Figure 48). The wall post holes have diameters ranging from approximately $0.17 \mathrm{~m}$ to $0.21 \mathrm{~m}$, with a mean of approximately $0.19 \mathrm{~m}$. Structure A wall post holes were spaced from $0.23 \mathrm{~m}$ to $0.68 \mathrm{~m}$ apart $(\mathrm{n}=13, \bar{x}=0.40 \mathrm{~m}, \mathrm{~s}=0.1432)$ and the Structure B post holes were spaced $0.32 \mathrm{~m}$ to $0.67 \mathrm{~m}$ apart $(\mathrm{n}=14, \bar{x}=0.51 \mathrm{~m}, \mathrm{~s}=0.1112)$. The distances from the wall post holes to the center for Structure A ranged from $2.25 \mathrm{~m}$ to $2.56 \mathrm{~m}(\mathrm{n}=19, \bar{x}=2.43 \mathrm{~m}, \mathrm{~s}=0.0991)$. For Structure B, the range was from $2.54 \mathrm{~m}$ to $2.85 \mathrm{~m}(\mathrm{n}=19, \bar{x}=2.71 \mathrm{~m}, \mathrm{~s}=0.0911)$. 
The ratio of average distance between wall post holes and average distance to the center for Structure A was 1:6.08 and for Structure B the ratio was 1:5.31.

No evidence for central hearths was found in either structure, although Davis and Gibson (1960:12) noted that if the structures had central hearths, evidence for them may have been destroyed by later burning of the structures. Both structures did have center posts (Davis and Gipson 1960:12). Three center post holes were recorded and Davis and Gibson (1960:14) commented that they did not "consider it possible to correlate [a] specific center post hole with particular structures." That being said, however, their discussion of the center posts noted that the northernmost post hole was the deepest and may be related to the older of the two structures, Structure A, but that "if one uses the center posts molds as pivot points for a compass, the middle mold best matches the House A post mold ring and the southern mold best matches the House B ring" (Davis and Gibson 1960:14). Another possibility is that at least two of the post holes may relate to a single structure (either A or B) and may indicate repair and replacement of the center post. The diameters of the center post holes measured $0.62 \mathrm{~m}$ at their opening, $0.21 \mathrm{~m}$ and $0.24 \mathrm{~m}$ at their bases.

Structure A had a prepared red clay floor measuring 0.03-0.09 m thick and $6.10 \mathrm{~m}$ in diameter. In addition, Structure A had a southwest-facing extended entrance (measuring $3.7 \times 0.9 \mathrm{~m}$ ) and was built within a $5.5 \mathrm{~m}$ diameter, $0.09-0.12 \mathrm{~m}$ deep pit surrounded by a low earthen embankment (Davis and Gipson 1960). The red clay floor of the larger Structure B was built directly over the ashy zone of Structure A, leading Davis and Gipson (1960:18) to suggest that this "may indicate that the time between the destruction of House A and the construction of House B was relatively short, or it may simply signify that the area was cleared off before work began on House B.” They continued by noting that the later is probably the case and that any debris associated with 
Structure A appeared to have been cleared away prior to construction of Structure B (Davis and Gibson 1960:18).

Structure B was built within the same prepared pit and also had an earthen embankment around the wall (Davis and Gipson 1960). Structure B had a southwestfacing extended entrance (measuring $1.7 \times 0.9 \mathrm{~m}$ ) that overlapped the Structure A entrance. Like Structure A, Structure B had a prepared clay floor, a feature not all that common in the study area. Structure B was burned and subsequently covered by sand, creating the mound. In describing the zone of the mound representing the destruction of Structure B, Davis and Gipson (1960:18) described it as looking like "a surface on which charred sticks and poles were scattered. The situation is about what one would expect from the incomplete combustion of a pole and brush structure."

A corrected radiocarbon date of AD 1470 was obtained from House B (calibrated one sigma age range of $\mathrm{AD} 1316-1626)$, dating the structure to the Titus phase (Davis and Gipson 1960; Perttula 1997, 2009). The ceramics from the mound were noted as being essentially the same as the assemblage from the Harroun and Whelan sites, "in which characteristic Titus focus [phase] types (Ripley and Taylor Engraved, Maydelle Incised, Bullard Brushed) are accompanied by a significant number of Pease BrushedIncised sherds" (Davis and Gipson 1960:65).

Davis and Gipson (1960:21) interpreted the Dalton structures as being ceremonial rather than simple domiciles. There was no concentration of occupational debris associated with the structures and they further noted:

there is archeological and ethnohistoric evidence for the ceremonial construction and burning of houses by the Caddo, extending from Haley focus times to the late 17th century. The occasion for this practice was not always the same: at the Belcher site, in the Haley and Belcher foci, the structures were destroyed as part of the obsequies for important personages, whereas among the historic Hasinai the 
practice is reported as being part of the ceremonial preparations for the setting out of a war party. (Davis and Gipson 1960:21).

As discussed by Davis and Gibson (1960), the architecture from the Dalton site was similar to that from both the Harroun site, discussed above, and the Whelan site (41MR2), which consisted of four earthen mounds and a fairly extensive village area.

\section{Whelan (41MR2)}

The Whelan Site (41MR2) is a Late Caddo Whelan phase (ca. A.D. 1350-A.D. 1450) mound site that was excavated in 1958. It had four small and roughly circular mounds designated mounds A ( $20 \times 1.5 \mathrm{~m}$ in diameter and height), B ( $15 \times 0.8 \mathrm{~m}), \mathrm{C}$ (17 x $1 \mathrm{~m})$ (not investigated), and D (20 x $1.5 \mathrm{~m})$ (not investigated) (Figure 49). Excavations of Mound B identified a single hearth $(0.76 \mathrm{~m}$ diameter $)$ surrounded by a $2.7 \mathrm{~m}$ diameter carbon-stained area $0.38 \mathrm{~m}$ below the surface of the mound (Davis 1958). Excluding this feature, the mound fill was relatively free of occupation debris. Structure outlines were found in Mound A and in the occupation area southeast of Mound A (Davis 1958).

Partial outlines of at least three and possibly four superimposed circular structures were identified by E. Mott Davis in Mound A (Davis 1958:26). The structures were recorded as Houses A-D in Davis (1958) and Structures A-C in Lisk (1984); Davis' House C was omitted by Lisk (1984:58) because of its poor definition. Rather than being built on deliberate mound capping zones, subsequent structures appeared to be built upon the accumulation of occupational debris (Davis 1958; Thurmond 1990:168). 


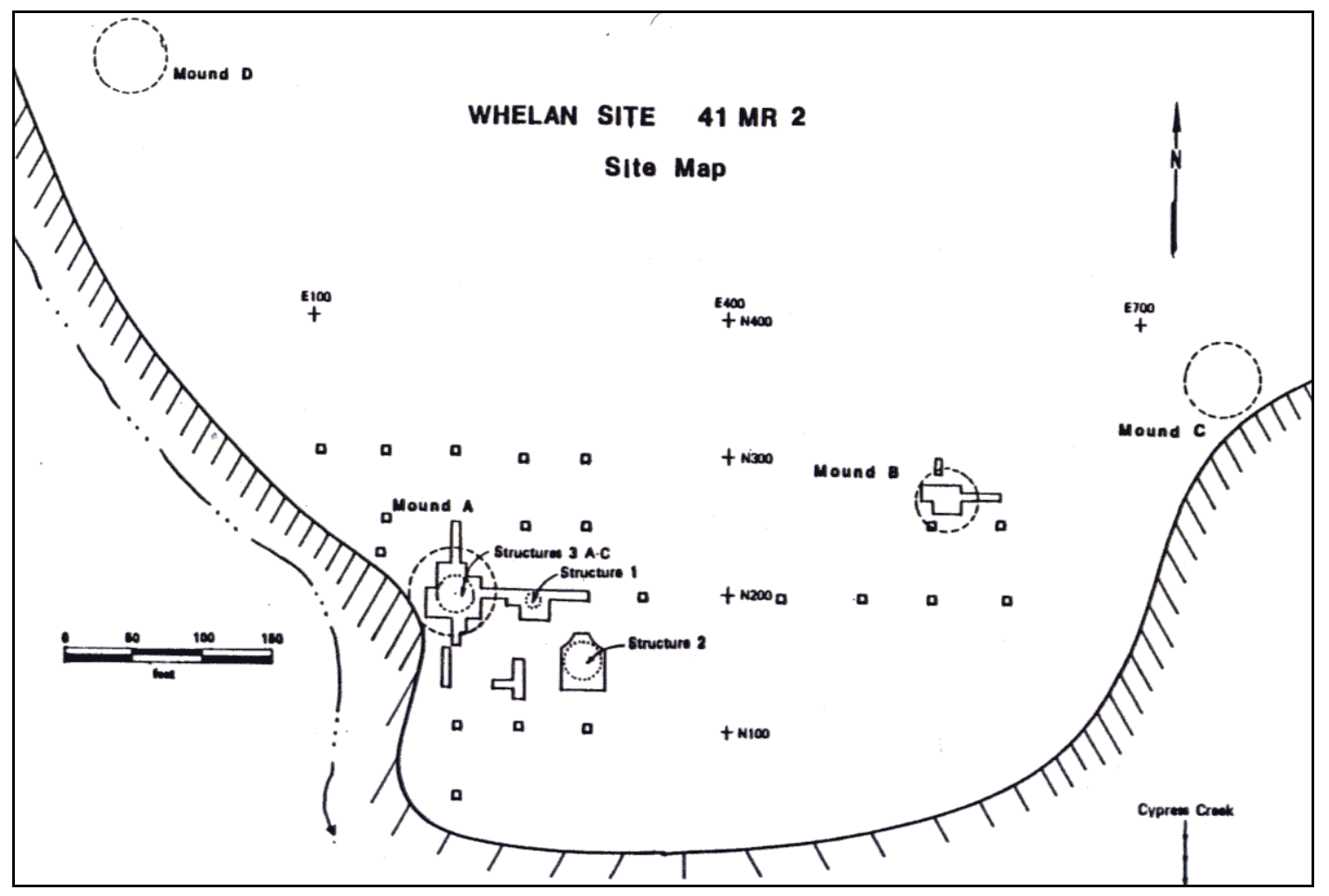

Figure 49. Whelan Site (Lisk 1984)

Davis' House C was defined on the basis of post holes possibly associated with House D. Lisk (1984:61) provided a brief discussion of the identification of Davis' House $\mathrm{C}$ and: "in one quadrant two posthole arcs were detected at the same elevation, while in another they were clearly visible at two different elevations. There was one instance of a posthole intersecting another. The second set of postholes had a greater average spacing interval of 0.48 to 0.6 meters; the diameter spanned by these postholes was $5.9 \mathrm{~m}$." No differences in fill were noted and no separate features were identified and associated with House C. Alternative explanations offered by Davis for House C included the possibility of a double row of post holes associated with a single structure, or evidence of repair (Lisk 1984:61). Davis (1958:32) suggested that perhaps: 
Houses $\mathrm{C}$ and $\mathrm{D}$ represent in actuality only one house with two concentric rings of post molds. In such a case the instances of one post mold intruding into another, cited earlier as evidence for two separate, sequent structures, might represent repair work on one structure which, as indicated by the accumulation of ashes and dirt on the floor, was used for a long time.

Lisk's (1984:61) House C corresponds to Davis' House D. In this study I am following Davis' designation of Houses A, B, C, and D for the Whelan site structures. Given evidence for structure repair from other Caddo sites, such as Oak Hill Village and Deshazo, it is quite likely that, as suggested by Davis above, Davis' House C represents repair work to a single and earlier structure. In the examples of structures from Oak Hill Village and Deshazo, structures repaired or built from the materials used in previous structures had smaller diameters than the earlier structures (Good 1982; Rogers and Perttula 2004). Based on that, House C may actually represent a rebuilt House D.

Davis' House D was the earliest Mound A structure and was built on the original floodplain floor. The structure measured approximately $6.3 \mathrm{~m}$ in diameter. Post hole diameters averaged approximately $0.17 \mathrm{~m}$ with average depths of approximately $0.85 \mathrm{~m}$ (Davis 1958). Post hole spacing ranged from $0.36 \mathrm{~m}$ to $0.47 \mathrm{~m}$ with a mean wall post hole spacing of $0.41 \mathrm{~m}$. The mean distance from the wall post holes to the approximate center of the structure was $3.25 \mathrm{~m}$. The ratio of the average distance between wall post holes and the average distance to the center was 1:7.93.

House C measured approximately $5.9 \mathrm{~m}$ in diameter. Post hole diameter averaged approximately $0.53 \mathrm{~m}$ with depths averaging about $0.15 \mathrm{~m}$. Post hole spacing ranged from $0.40 \mathrm{~m}$ to $0.53 \mathrm{~m}$ apart, with a mean wall post hole spacing of $0.48 \mathrm{~m}$. The mean distance from the wall post holes to the approximate center of the structure was $2.97 \mathrm{~m}$. The ratio of the average distance between wall post holes and the average distance to the center was 1:6.19. 
Houses B and A had diameters of approximately $5.7 \mathrm{~m}$ and $5.1 \mathrm{~m}$ respectively. Both of these structures had central post holes overlain by hearths ranging in size from $0.09 \mathrm{~m}$ to $0.15 \mathrm{~m}$. Additionally, these structures shared a number of post holes that "have discrete upper and lower fills" (Lisk 1984:62). Davis (1958:27-28) notes that given heavy disturbance most of the House A and B post holes were destroyed, therefore the structure patterns were incomplete. The outline of House B consisted of post holes ranging in spacing from 0.42 to $0.54 \mathrm{~m}$ apart and extending to a depth of $0.84 \mathrm{~m}$.

The final structure built on Mound A (House A) had perimeter post holes extending to a depth of $0.42 \mathrm{~m}$. Davis (1958:28) noted differences in post depth between the House A and B perimeter posts: "the latter depth is to be expected in Caddoan houses, especially where the posts were bent inward and their tips tied together as the presence of centerposts indicates. It is possible that the relatively shallow depth of the House A postholes indicates that the structure was differently constructed, but we have no way of telling." In addition to possibly representing a different building type (i.e., Davis' interpretation due to the shallowness of the post holes), House A was the only building with signs of burning (Lisk 1984:62). Finally, the destruction of this structure was "accompanied by some burning and was followed by the placement of a relatively sterile earth cap to form the final, rounded surface of the mound" (Thurmond 1990:168).

Davis (1958:33) mentioned "a peculiar soil feature associated with some of the post molds of House A":

the soil discoloration associated with a few of these molds extended radially outward (i.e. away from the center of the structure) from the mold proper for a distance of a little over 1.5 feet [0.46 m], almost as if the posts had been placed at the inner end of a radial slot. The 'slots' were not sharply defined in every case. We were unable to determine why they were there. It is hoped that other excavations may turn up a similar phenomenon under circumstances more susceptible of interpretation (Davis 1958:33). 
This may be an example of having the post hole extended outward or sloping to allow for inserting the post, perhaps similar to the post holes of Feature 111 at the George C. Davis site mentioned above. This may also be a possible explanation for the extended magnetic returns related to the large interior support posts in the magnetometer data from the George C. Davis site.

Whelan mound Houses A, B, C, and D range in diameter from $5.18 \mathrm{~m}$ to $6.30 \mathrm{~m}$ with areas ranging from $21.07 \mathrm{~m}^{2}$ to $31.17 \mathrm{~m}^{2}$. Mean spacing between wall post holes ranges from $0.39 \mathrm{~m}$ (House $\mathrm{B}$ ) to $0.48 \mathrm{~m}$ (House $\mathrm{C})(\bar{x}=0.42 \mathrm{~m}, \mathrm{~s}=0.0395)$. The average spacing from the wall posts to the center of the structure ranges from $2.64 \mathrm{~m}$ to $3.25 \mathrm{~m}(\bar{x}=2.91 \mathrm{~m}, \mathrm{~s}=0.2639)$ (Table 28).

Table 28. Whelen mound structure measurements.

\begin{tabular}{|l|r|c|r|r|r|}
\hline House & $\begin{array}{c}\text { Size } \\
(\mathrm{m})\end{array}$ & $\begin{array}{c}\text { Area } \\
\left(\mathrm{m}^{2}\right)\end{array}$ & $\begin{array}{c}\text { Mean spacing } \\
\text { between wall } \\
\text { post holes }\end{array}$ & $\begin{array}{c}\text { Mean spacing from wall } \\
\text { post holes to center }\end{array}$ & $\begin{array}{c}\text { Ratio of average distance } \\
\text { between wall post holes and } \\
\text { average distance to the center }\end{array}$ \\
\hline A & 5.18 & 21.07 & 0.41 & 2.64 & $1: 6.44$ \\
\hline B & 5.79 & 26.33 & 0.39 & 2.78 & $1: 7.13$ \\
\hline C & 5.9 & 27.34 & 0.48 & 2.97 & $1: 6.19$ \\
\hline D & 6.30 & 31.17 & 0.41 & 3.25 & $1: 7.93$ \\
\hline
\end{tabular}

House $\mathrm{A}$ is the only structure that appears to have been burned. The Mound A structures had wall post holes ranging in depth from $0.84 \mathrm{~m}$ for Houses D and B to the much shallower House A postholes with depths averaging $0.42 \mathrm{~m}$. As discussed above, Davis (1958) suggests that the shallowness of the House A post holes may represent a different construction technique or style of building. Unfortunately, post hole diameters are not provided. 
Mound A also had a series of at least three superimposed center post holes and central hearths (Davis 1958:30). Davis assigned hearths and central posts to Houses D, B and A. The superimposed hearths and post holes were recorded by Davis (1958) as Fireplaces and Post Molds 1-4. Fireplace and Post Mold 1 were assigned to House D as a central hearth covering a center post. The hearth had a depth of approximately $0.09 \mathrm{~m}$ while the center post extended to a depth of $0.79 \mathrm{~m}$ (Davis 1958). Davis (1958) assigned Fireplace and Post Mold 2 to House B and Fireplace and Post Mold 3 to House A. The ash-filled central hearth of House B had a depth of approximately $0.15 \mathrm{~m}$ and the post hole extended to $0.76 \mathrm{~m}$ deep. The House A central hearth was filled with ashes and extended to a depth of approximately $0.09 \mathrm{~m}$. The House A center post extended to a depth of $0.82 \mathrm{~m}$.

In discussing assigning the hearths and center posts to Houses A, B, and D, Davis noted that Structure C lacked those features. Davis (1958:32) suggested that Houses C and D may represent a single structure with two concentric rings of post molds.

Given the incomplete perimeters, no entrance was found for either Houses A or B. The cap on Mound A measured about 0.91 m. In summing up Mound A, Davis (1958:33) stated:

Our minimal history of the mound is, then, as follows: a house (House D and possibly House $\mathrm{C}$ as part of it) was built at ground level and used for a long enough time for about a foot $[30 \mathrm{~cm}]$ of ashes and dirt to accumulate on the floor. Then a new house, House B, was built at the higher level. Finally House A was built, and its destruction was accompanied by some burning. Eventually the cap of the mound, Zone III, was adder over the remains of House A. 


\section{Redwine (41SM193) and Bryan Hardy (41SM55)}

Both the Redwine (41SM193) and Bryan Hardy (41SM55) sites were first excavated in the 1950s and 1960s by Sam Whiteside (Walters and Haskins 1998, 2000). These two Middle Caddo sites are located within the Harris Creek drainage in the Sabine River basin and each contains small mounds covering a single circular Caddo structure (Walters and Haskins 1998, 2000).

Excavations at the Redwine site uncovered four Caddo burials and a house mound as well as two non-mound related structures (Walters and Haskins 1998:1). Later excavations at the site recovered almost 6000 artifacts and identified several features including post holes, a hearth, and two pits (Walters and Haskins 1998:4). The site is described by Walters and Haskins (1998:35) as having "habitation areas, work areas, and ceremonial areas. The types of artifacts and features at Redwine suggest that the site was occupied on a year-round basis for at least 20 years, and the spatial pattern of artifacts and midden deposits are consistent with a community having 4-6 houses in a semi-circle around a vacant plaza area."

The Redwine mound measured approximately $0.73 \mathrm{~m}$ high by $7.3 \mathrm{~m}$ in diameter and was constructed with sandy loam in a single episode "over charcoal-stained soil associated with the construction, use, and destruction of a circular structure" (Walters and Haskins 1998:23). The burned circular structure (Figure 50) was defined by a partial outline of 23 wall posts and measured approximately $5.5 \mathrm{~m}$ in diameter, with an area of $23.74 \mathrm{~m}^{2}$. The structure pattern was incomplete with a gap in the southern and western portions due to the structure and mound only being partially excavated. 


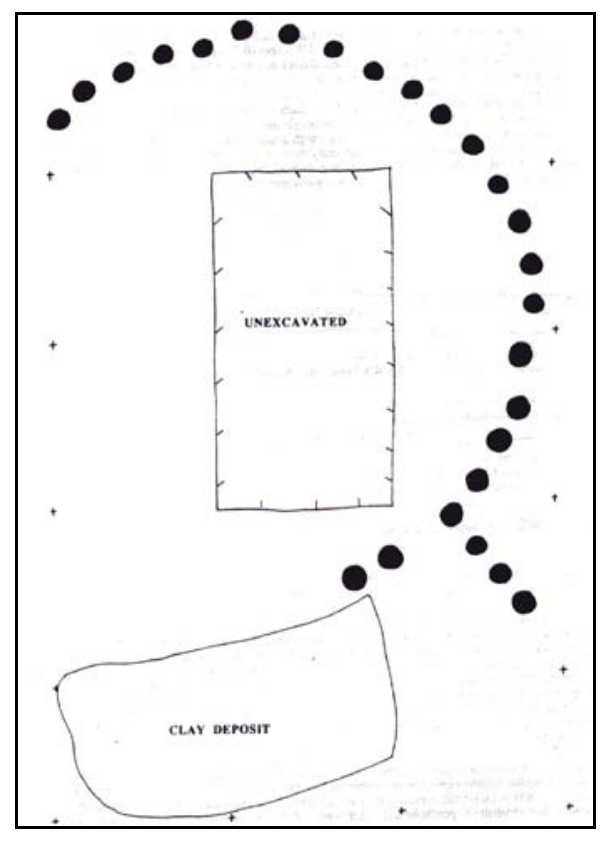

Figure 50. Plan of structure under the Redwine Site Mound (Walters and Haskins 1998:24 and Figure 9). Reproduced courtesy of the Friends of Northeast Texas Archaeology.

The wall post holes had diameters ranging from approximately $0.18 \mathrm{~m}$ to $0.25 \mathrm{~m}$ ( $\mathrm{n}=23, \bar{x}=0.23 \mathrm{~m}, \mathrm{~s}=0.0204)$. The wall post holes were spaced from approximately 0.38 to $0.53 \mathrm{~m}$ apart $(\mathrm{n}=21, \bar{x}=0.43 \mathrm{~m}, \mathrm{~s}=0.0423)$. The distances from the wall post holes to the center of the structure range from $2.67 \mathrm{~m}$ to $2.84 \mathrm{~m}(\mathrm{n}=21, \bar{x}=2.75 \mathrm{~m}, \mathrm{~s}=$ 0.0432). The ratio of average distance between wall post holes and average distance to the center is 1:6.40. Three posts defined part of an extended entrance that faced the main part of the site, to the south-southeast. The extended entrance, while incomplete, measured at least $1.20 \mathrm{~m}$ in length and had an approximate width of $0.75 \mathrm{~m}$. The distance between the entrance posts was similar to that for the rest of the structure, ranging from approximately $0.36 \mathrm{~m}$ to $0.41 \mathrm{~m}$, with a mean of $0.38 \mathrm{~m}$. The diameters of the three entrance post holes were approximately $0.23 \mathrm{~m}, 0.23 \mathrm{~m}$, and $0.26 \mathrm{~m}$. 
Since a large area $\left(4.6 \mathrm{~m}^{2}\right)$ of the structure interior was not excavated, no interior features were found (Walter and Haskins 1998:23). Situated immediately outside the structure to the west of the entrance was an "enigmatic deposit of clay covering about 50 square feet $\left[4.6 \mathrm{~m}^{2}\right.$ ]" (Walter and Haskins 1998:23). Walters and Haskins (1998:25) note that while no data were available on the nature of the clay deposit, "its placement clearly suggests its function was related to the use of the special building subsequently covered by the earthen mound." Perhaps the clay deposit was part of an earthen berm around the structure.

A single radiocarbon date was obtained from the Redwine site. Charred nutshells from the hearth yielded a calibrated age range of AD 1302-1434 (calibrated at $2 \sigma$ ) (Walters and Haskins 1998:35).

Like the Redwine site, the Middle Caddo Bryan Hardy site had a low earthen mound built over a burned circular structure (Structure 1) with an extended entrance. The Bryan Hardy structure, however, had clear evidence for a low earthen berm around a portion of its exterior (Figure 51). The Bryan Hardy mound was a low, dome-shaped mound measuring approximately $15 \mathrm{~m}$ in diameter with a maximum height of about $1 \mathrm{~m}$ (Walters and Haskins 2000). Whiteside excavated a portion of Structure 1, where he "exposed the house outline, excavated 6-8 posts, and used a soil probe on the remainder to determine their depths" (Walters and Haskins 2000:4). Whiteside's excavations uncovered seven interior features including a central hearth and six interior post holes. He specifically noted the scarcity of artifacts found in the structure other than those associated with the entrance (Walters and Haskins 2000:4). 


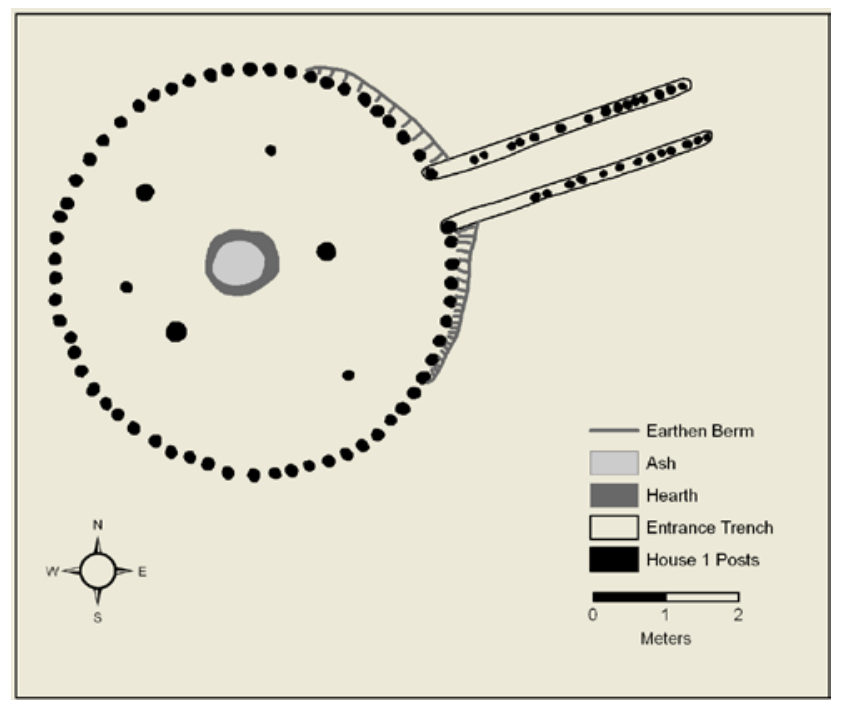

Figure 51. Plan map of the House 1 from the Bryan Hardy site (adapted from Walters and Haskins 2000:5 and Figure 3).

Bryan Hardy Structure 1 measures approximately $5.48 \mathrm{~m}$ in diameter, with an approximate area of $23.59 \mathrm{~m}^{2}$. The outline of Structure 1 included 61 post holes with diameters ranging from approximately $0.14 \mathrm{~m}$ to $0.21 \mathrm{~m}(\mathrm{n}=61, \bar{x}=0.17 \mathrm{~m}, \mathrm{~s}=0.0141)$. Two of the wall post holes (measuring approximately 0.17 and $0.21 \mathrm{~m}$ in diameter) were located within the trenches used for the extended entrance (see Figure 51). If these two were removed from the wall post hole measurements, the range would remain the same, as would the mean $(\mathrm{n}=59,0.14 \mathrm{~m} \text { to } 0.21 \mathrm{~m}, \bar{x}=0.17 \mathrm{~m}, \mathrm{~s}=0.0134)^{4}$. The wall post holes had an average depth of 0.76 m (Walters and Haskins 2000:4). An earthen berm was found around a portion of House 1, primarily around and on both sides of the area of the extended entrance where it met the house wall perimeter (see Figure 51).

Structure 1 had an approximately $1.02 \mathrm{~m}$ diameter central hearth containing ash deposits, as well as a compacted floor, possibly indicating a prepared floor, although

\footnotetext{
${ }^{4}$ Walters and Haskins (2000) note that posthole size ranges from $0.22 \mathrm{~m}$ to $0.30 \mathrm{~m}$. The discrepancy in the measurements included here likely come from my measuring the postholes plotted on a copy of the plan map that was georeferenced using ArcGIS.
} 
Walters and Haskins (2000) indicate that compaction was noted in other areas of the site as well, and six interior posts measuring approximately $0.13 \mathrm{~m}$ to $0.28 \mathrm{~m}(\mathrm{n}=6, \bar{x}=0.20$ $\mathrm{m}, \mathrm{s}=0.0655)$. While all six of the interior posts may represent either interior supports for the structure or supports for internal racks, beds, etc, the three largest post holes $(0.24$ $\mathrm{m}, 0.26 \mathrm{~m}$, and $0.28 \mathrm{~m}$ in diameter are the most likely structural supports, based on their placement and size.

Structure 1 also had a northeast-facing extended entrance measuring ca. $0.75 \mathrm{~m}$ wide by $3.7 \mathrm{~m}$ long. The extended entrance consisted of two parallel wall trenches with 30 relatively tightly spaced posts (diameters ranging from $5-13 \mathrm{~cm}$ ) placed in individual holes, which were then packed with clay (Walters and Haskins 2000:4). Based on measurements taken from the plan map, the entrance posts were spaced approximately 0.12 to $1.26 \mathrm{~m}$ apart $(\mathrm{n}=28, \bar{x}=0.27 \mathrm{~m}, \mathrm{~s}=0.2268)$, although the largest gaps may be due to disturbance or may be gaps where post holes were no longer visible. If the large gap is removed from the calculations, then the range in spacing was from $0.12 \mathrm{~m}$ to 0.63 $\mathrm{m}(\mathrm{n}=27, \bar{x}=0.23 \mathrm{~m}, \mathrm{~s}=0.1182)$. The entrance post holes were considerably smaller than the rest of the post holes related to the structure, with a range from 0.08 to $0.21 \mathrm{~m}$ (n $=31, \bar{x}=0.12 \mathrm{~m}, \mathrm{~s}=0.0235)^{5}$. The largest two post holes $(0.17 \mathrm{~m}$ and $0.21 \mathrm{~m})$ were the two located at the wall of the structure (see Figure 51). Removing those two measurements - since they were part of the structure wall - leaves a much smaller range of entrance post size, 0.08 to $0.14(\mathrm{n}=29, \bar{x}=0.11 \mathrm{~m}, \mathrm{~s}=0.0127)$, similar to that presented in Walters and Haskins (2000). Although there is a much tighter range and considerably smaller standard deviation, the entrance post hole mean remains almost the same. In addition to having much smaller posts, the extended entrance posts appear to

\footnotetext{
${ }^{5}$ Again, there is a discrepancy between the measurements presented in Walters and Haskins (2000), a range of $0.05 \mathrm{~m}$ to $0.13 \mathrm{~m}$, and the measurements taken from the plan map. It is quite possible that the posthole size depicted on the plan map is inaccurate.
} 
have been placed in groups much like some of the wall posts seen at the George C. Davis site.

Charred posts from Structure 1 at the Bryan Hardy site yielded a age range of cal AD 1345-1391 (calibrated at $1 \sigma$ ) and cal AD 1297-1317 (calibrated at $1 \sigma$ ) (Walters and Haskins 2000:4; Perttula 1998:Table 1). Walters and Haskins (2000:4) noted that "there is a $67 \%$ chance that the calibrated age of the Bryan Hardy charred post falls between AD 1297-1391."

The presence of a similar unexcavated mound at the Tom Moore site (41PN149) suggested to Walters and Haskins (2000:25) that "although there are temporal and spatial differences between these sites, they share common ceramic assemblages" and "the pottery at each of the sites is consistent with Middle Caddoan period wares documented elsewhere in the middle reaches of the Sabine River basin at that time." It is quite possible that the $8 \mathrm{~m}$ diameter by $1 \mathrm{~m}$ high mound at Tom Moore site covers a burned circular structure similar to those found at the Bryan Hardy and Redwine sites. The Redwine and Bryan Hardy sites are:

similar to several other Middle Caddoan sites in the general area in that they are located on landforms that had no history of previous occupations, they are considerable distances from available water, apparently are occupied year-round for short periods of time (20+ years), and have a single earthen mound covering a burned house. Whether this was the typical settlement pattern in the Middle Caddoan period is unknown, as is their association with other homesteads or larger centers (Walters and Haskins 2000:24).

\section{Sanders (41LR2)}

At the Sanders site (41LR2), 1931 excavations by Jackson (2000) identified rectangular structures associated with two earthen mounds. The Middle Caddo structures are considerably different from any of the other structures included in this study, with the 
possible exception of the circular non-mound structures from the Spider Knoll site (discussed in Chapter 6, see Fields et al. 1994). Each structure had at least one open side, with the Mound 1 structure (Structure 1) open on both the north and south sides. The Mound 1 structure measured approximately $3.05 \mathrm{~m}$ x $3.66 \mathrm{~m}$ and had no post holes on the north or south side. The post holes on the eastern side were large and deep with those on the west described as small and shallow (Jackson 2000). Jackson (2000) referred to this structure as a lodge or lean-to. Limited information was available on the post holes from the Sanders structures. Based on the plans maps, the wall posts of Structure 1 appear to have been spaced approximately $0.7 \mathrm{~m}$ to $1.22 \mathrm{~m}$ apart $(\mathrm{n}=7, \bar{x}=0.90 \mathrm{~m}, \mathrm{~s}=0.2065)$.

The Mound 2 structure (Structure 2) was located $0.9 \mathrm{~m}$ below the mound surface, just north of the center of the mound, and measured approximately $3.05 \mathrm{~m} \times 2.59 \mathrm{~m}$. Structure 2 had a similar open form, lacking post holes on the west end, which Jackson described by stating "the entire west end was open" (Jackson 2000:36). Three additional structures were identified at $0.61 \mathrm{~m}, 1.6 \mathrm{~m}$, and $3.04 \mathrm{~m}$ below the surface of the north end of Mound 2, but were not excavated (Jackson 2000:36-37). Jackson noted that the presence of these multiple structures at various depths indicated at least four distinct occupation levels and he continued by noting that "potsherds from the various levels do not differ materially except that the percentage of sherds bearing designs decreases towards the lower levels" (Jackson 2000:36-37).

Rather than being either domiciles of important personages or other types of ceremonial structures, the Sanders structures recorded by Jackson may be similar to arbors or ramadas recorded at other Caddo sites. Another possibility is that these structures may represent open-aired structures to be used as summer houses. A third possibility is that these structures represent enclosed rectangular buildings, but that other 
wall post holes were not recorded by Jackson. As represented by Jackson, the Sanders structures are unique as mound structures within the study area.

\section{Holdeman (41RR11)}

The Dan Holdeman site (41RR11) in Red River County was a multi-mound site with a related village area and several burials/cemeteries. The site included components from Formative Caddo through Late Caddo (McCurtain phase) (Perino 1995). The Sanders phase (ca. A.D. 1000-1300) mound investigated by Perino in 1983 measured approximately $12.2 \mathrm{~m}$ in diameter and $0.52 \mathrm{~m}$ in height (Perino 1995). Perino (1995) mentioned multiple Caddo structures, including at least two associated with five of the storage pits east of the mound, and at least three associated with the mound; however, the 1995 report only offered details on one mound-related structure.

Perino (1995:7) mentioned that there were three structures associated with the mound, but "the earliest two houses were marked by incomplete post mold patterns". While the sketch of the mound excavations showed several post holes, only details on the latest structure were provided (referred to here as Structure 1). Structure 1 (Figure 52) was rectangular and measured approximately $3.05 \mathrm{~m}$ wide by $6.10 \mathrm{~m}$ long, with an area of approximately $18.61 \mathrm{~m}^{2}$. The structure possibly had diagonal or rounded corners. Structure 1 also had a long southwest facing extended entrance measuring $3.05 \mathrm{~m}$ long by $0.69 \mathrm{~m}$ wide. The extended entrance was marked by narrow wall trenches (Perino 1995:7-10) that were approximately 0.19 to $0.24 \mathrm{~m}$ wide. The northern entrance trench had at least 10 post holes while only five were recorded in the southern trench, probably a result of the entire trench not being recorded. The gap between wall post holes at the entrance was approximately $0.81 \mathrm{~m}$. Entrance post holes were spaced from approximately $0.13 \mathrm{~m}$ to $0.68 \mathrm{~m}$ apart $(\mathrm{n}=14, \bar{x}=0.25 \mathrm{~m}, \mathrm{~s}=0.1703)$. 


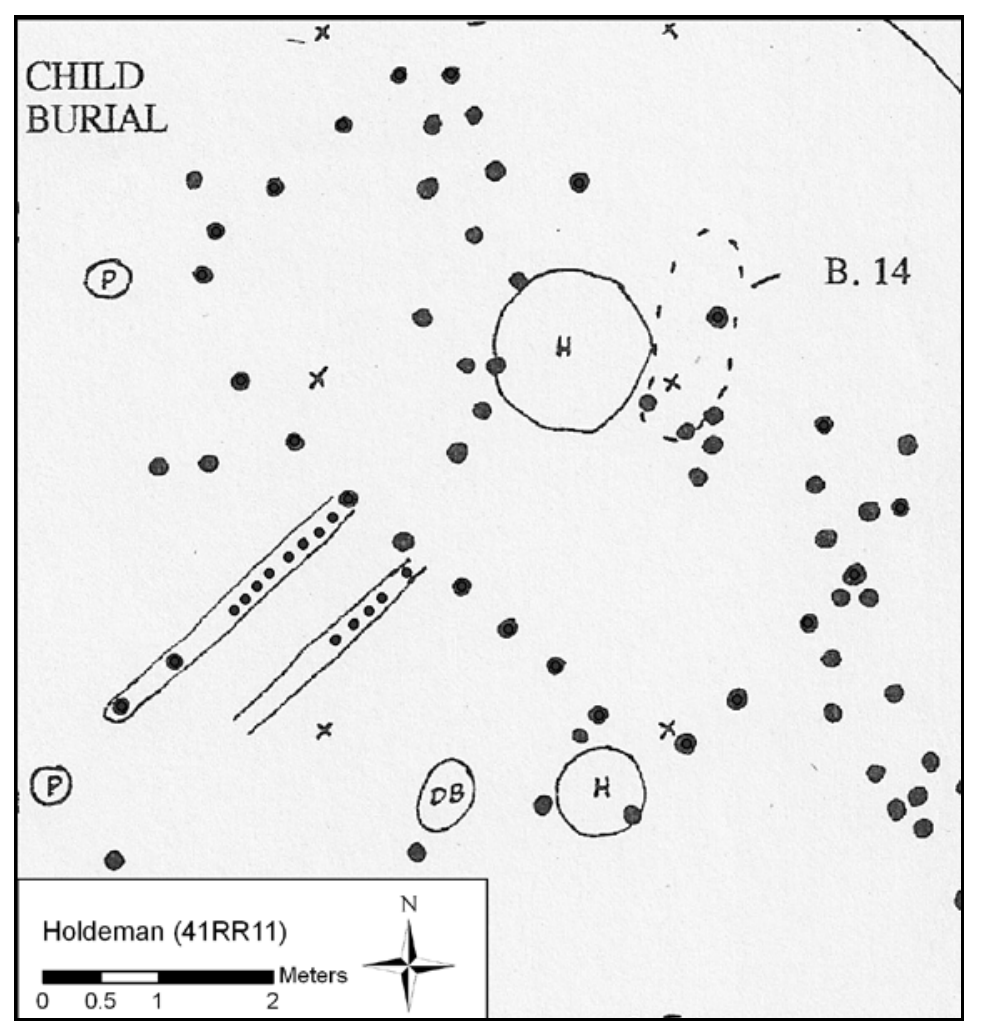

Figure 52. Plan map of the Holdeman mound structure (adapted from Perino 1995). Reproduced courtesy of the Friends of Northeast Texas Archaeology.

While post hole diameter and depth was not provided for this structure by Perino (1995), measurements taken from the plan map, while approximate, clearly indicate that the posts used for the entrance were generally smaller than those used for the rest of the structure. Wall post hole diameter ranged from approximately $0.12 \mathrm{~m}$ to $0.18 \mathrm{~m}$, with a mean diameter of approximately $0.15 \mathrm{~m}$. The largest entrance posts were those at the outer end of the entrance, furthest away from the structure. Based on the plan map (see Figure 52), these post holes had diameters of approximately $12-14 \mathrm{~cm}$.

A hearth was located inside the structure, directly across from the entrance, near one of the walls (see Figure 52). The hearth measured approximately $1.40 \mathrm{~m}$ in diameter. 
The hearth had post trenches on either side of it, possibly representing a cooking platform (Perino 1995:7-10).

Several other features were found beneath the mound, including two hearths, two dog burials, two smudge pits, and the McCurtain phase (Perttula 1995) grave of a child (Perino 1995:10). Perino (1995) does not discuss whether these features were directly associated with Structure 1, other than to note that the smudge pits were located $0.60 \mathrm{~m}$ beyond and outside the entrance. Perino (1995:7) suggested that Structure 1 "was placed in the mound at the original ground level, or conversely it was constructed at the original ground level with soil berms placed around it." If the latter is the case, then this would be the only East Texas Caddo case of a rectangular structure associated with an earthen berm.

In his analysis of the chronological placement of the mortuary remains, Perttula (1995:68) noted that Perino's interpretations of the burials at the site being primarily of Sanders phase age "cause him to overlook the real possibility that the mound north of the spring branch was a place of burial after the Sanders phase, as well as deny the possibility that many of the pit and house features under the mound actually originated from, and cut through, the mound surface, and thus do not solely represent house and mortuary use prior to their being capped with an earth mound." Perttula (1995:73) concluded that "there was a substantial Early McCurtain phase (ca. AD 1300-1500) use of the Holdeman site - both for habitation use and burial interment - while Perino proposed a much more extensive Sanders phase settlement at Holdeman and only minimal Late Caddoan occupation."

Limited data were available on post hole size and depth and there were several post holes probably related to Structure 1 that were interior supports and furnishings. In looking at post hole spacing, I relied on measurements taken from the plan map from 
Perino's (1995) report. The structure outline consisted of at least 22 post holes, with others probably destroyed by disturbance or they were not detected during the excavations. Wall post hole spacing ranged from $0.39 \mathrm{~m}$ to $0.97 \mathrm{~m}(\mathrm{n}=18, \bar{x}=0.66 \mathrm{~m}, \mathrm{~s}$ $=0.1756)$. There were a few fairly large gaps between wall post holes that were not measured for the post spacing presented here. The reason for that omission is that they were considerably larger gaps than the rest of the post hole spacings and may be the result of post holes having been destroyed or otherwise not visible or recorded. That being said, however, the large gaps on the northeastern wall are somewhat regular and may actually represent the use of widely spaced posts in the construction of Structure 1. If the larger gaps (measuring $1.31 \mathrm{~m}, 1.46 \mathrm{~m}$, and $1.68 \mathrm{~m}$ ) are included, then the range of post spacing is from $0.39 \mathrm{~m}$ to $1.68 \mathrm{~m}(\mathrm{n}=21, \bar{x}=0.78 \mathrm{~m}, \mathrm{~s}=0.3405)$.

\section{Roitsch (41RR16)}

At least one mound structure has been recorded at the Roitsch site (41RR16, also known as the Sam Kaufman site), also located in Red River County, that had enough of a post hole pattern to be included in this study (Skinner et al. 1969:19). Structure 2 was located in the East Mound and likely dated to around the end of the Sanders phase to the early McCurtain phase (Bruseth 1998; Perttula et al. 2001). Evidence for additional mound-related structures was recorded by S. Alan Skinner in the West Mound and included signs of superimposed burned structures (Perttula et al. 2001; Skinner et al. 1969).

The approximately $1 \mathrm{~m}$ high East Mound was constructed between A.D. 12751383 (Perttula et al. 2001) and covered the remains of a burned rectangular structure that appears to have had diagonal/rounded corners. Structure 2 measured $4.75 \mathrm{~m} \mathrm{x} 9 \mathrm{~m}$, with an area of approximately $42.75 \mathrm{~m}^{2}$ (Figure 53). This structure was situated near the center 
of the east mound and was overlain by mound fill. The northern and eastern edges of Structure 2 were defined by 17 post holes. Structure 2 had a prepared clay floor. In addition, the structure had a $0.55 \mathrm{~m}$ diameter hearth, probably centrally located, although the structure may have actually extended further to the west. The western extent of the structure outline was based on the apparent extent of the prepared clay floor.

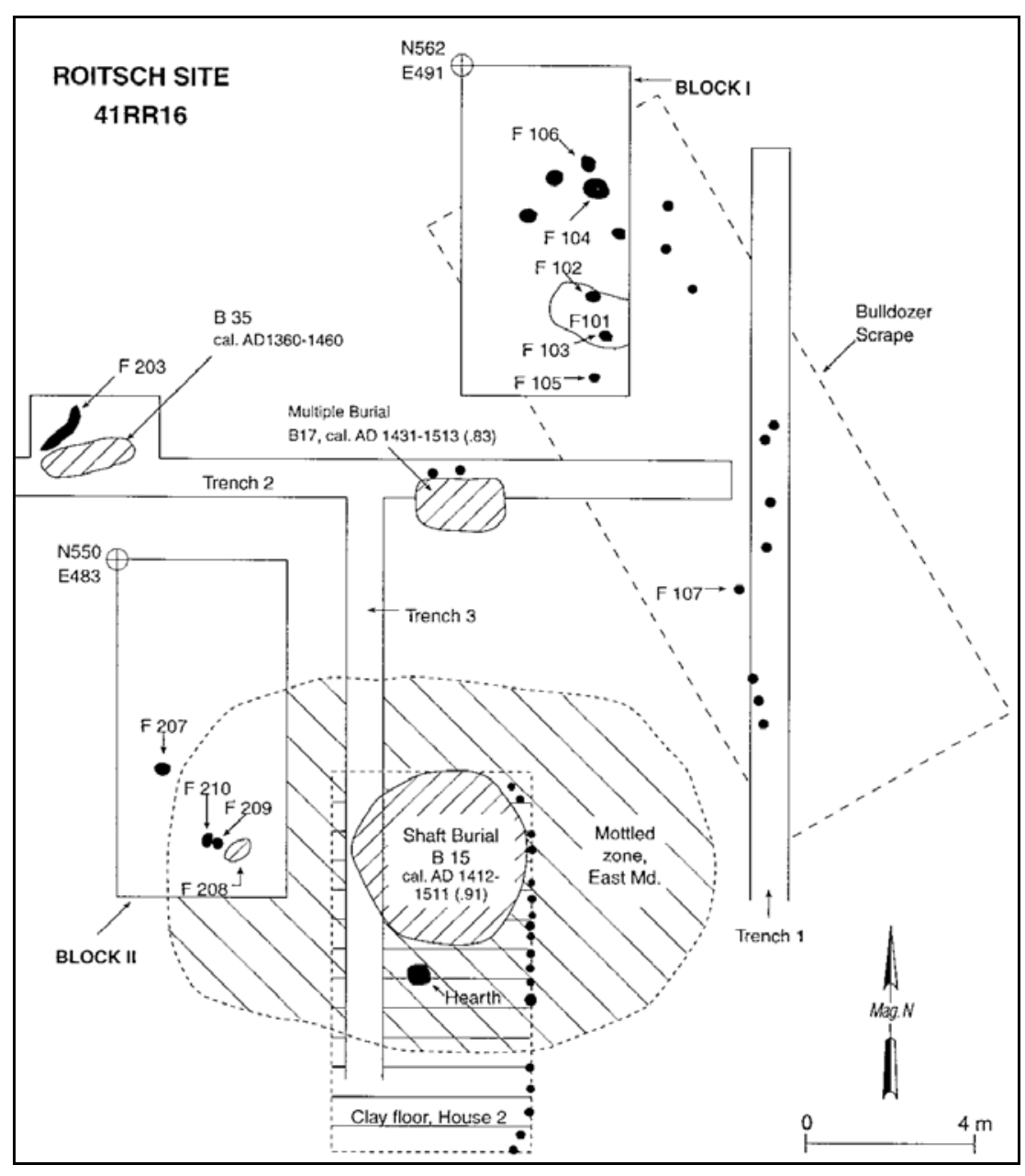

Figure 53. Structure from the East Mound at the Roitsch site (Perttula et al. 2001:171, Figure 3). Reproduced courtesy of the Texas Archeological Society. 
No entrance for Structure 2 was identified, although based on the other rectangular structures in the study area, the structure probably would have had an extended entrance. The floor level was defined by the red clay floor covered by a $0.1-0.3$ $\mathrm{m}$ thick layer of tan sand. The northern portion of Structure 2 was disturbed by a later shaft burial that went through the floor of the structure (Perttula et al. 2001; Skinner et al. 1969:19). The shaft burial included 11 individuals, including a principal older male and female and nine other individuals (Perttula et al. 2001; Skinner et al. 1969:19). The shaft burial was dated to cal A.D. 1412-1511 (Perttula et al. 2001).

Additional mound burials were recorded by later excavations at the site during the 1991-1992 Texas Archeological Society field school (Perttula et al. 2001). Burial 36 was a child burial that was recorded at the western side of the East Mound. The burial pit "was dug from the surface under the mound, probably from the McCurtain phase house floor covered by the East Mound" (Perttula et al. 2001:175). The practice of placing a child burial under a house floor is a fairly common practice in the Caddo area (Good 1982; Kelley 1997; Parsons n.d.).

Based on the plan map (Perttula et al. 2001), wall post hole diameter for Structure 2 ranged from approximately $0.15 \mathrm{~m}$ to $0.30 \mathrm{~m}(\mathrm{n}=18, \bar{x}=0.21 \mathrm{~m}, \mathrm{~s}=0.0321)$. The wall post holes were spaced approximately 0.25 to $1.64 \mathrm{~m}$ apart $(\mathrm{n}=15, \bar{x}=0.48 \mathrm{~m}, \mathrm{~s}=$ 0.3337). The distances from the wall post holes to the presumed central hearth ranged from $2.67 \mathrm{~m}$ to $5.04 \mathrm{~m}(\mathrm{n}=18, \bar{x}=3.63 \mathrm{~m}, \mathrm{~s}=0.8265)$. The ratio of average distance between wall post holes and average distance to the center was 1:7.56.

\section{Fasken (41RR14)}

The Formative to Middle Caddo Fasken Mounds (41RR14) site includes three earthen mounds, Mounds A-C, with Mound A (measuring $90 \mathrm{~m}$ x $55 \mathrm{~m}$ x $4.3 \mathrm{~m}$ ) being 
one of the largest mounds in the western part of the Caddo area (Perttula et al. 2001). The site was investigated as part of the 1991 and 1992 Texas Archeological Society Field School.

Several post holes from structures were identified at the site, with at least 11 found beneath the red clay cap of Mound C (Perttula et al. 2001). These post holes corresponded to the partial outline of a rectangular structure (Structure 1) measuring at least $3.5 \mathrm{~m}$ along its east wall (Figure 54) (Perttula et al. 2001). Perttula et al. (2001) noted that a line of eight post holes corresponded to the southern portion of the east wall, with three additional post holes that corresponded to the eastern part of the south wall. The 11 post holes had an average diameter of $15 \mathrm{~cm}$ and a maximum depth of $48 \mathrm{~cm}$. Based on measurements taken from the plan map (Perttula et al. 2001:Figure 45), the wall post holes were spaced approximately 0.33 to $0.41 \mathrm{~m}$ apart $(\mathrm{n}=8, \bar{x}=0.38 \mathrm{~m}, \mathrm{~s}=$ 0.0307). Several other post holes were identified in the mound but did not correspond to identifiable structure patterns and were not necessarily associated with Structure 1.

Structure 1 was dated to the Middle Caddo period based on two radiocarbon dates from levels in Mound C associated with house floors (Perttula et al. 2001:232). The calibrated 1 sigma dates range from A.D. 1157-1242 (0.74 probability) and A.D. 10431188 (1.00 probability) (Perttula 1997; Perttula et al. 2001: 232). A possible wall trench was identified in Mound B, associated with a prepared clay floor, and was interpreted as likely representing part of an entranceway, although a definable post hole pattern was not observed (Perttula et al. 2001:228-229). Perttula et al. (2001:232-233) suggested that Mound C likely had multiple, non-residential structures associated with it, with the last one capped by a final red clay cap. 


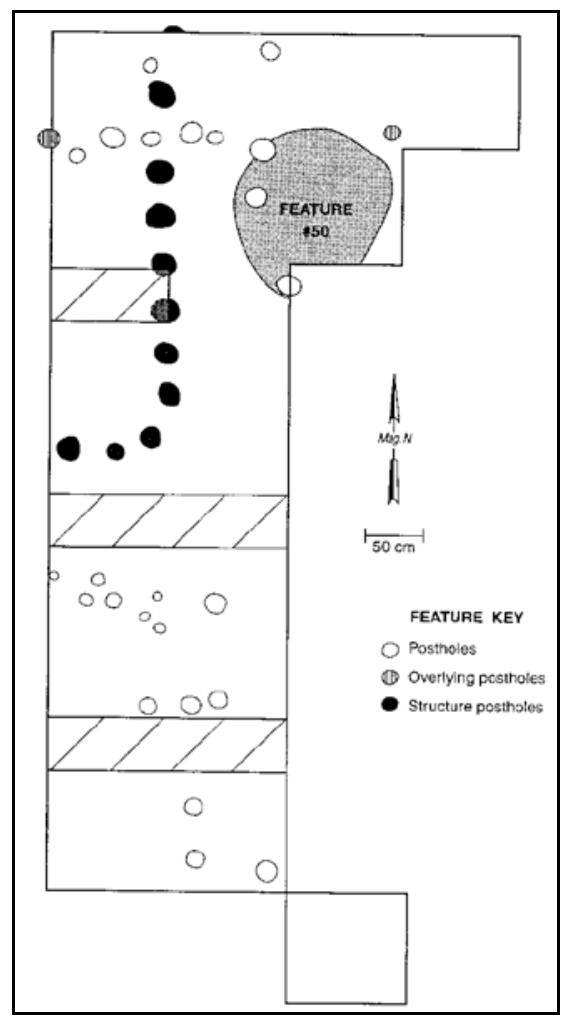

Figure 54. Structure from the Fasken mound (Perttula et al. 2001: 228, Figure 45). Reproduced courtesy of the Texas Archeological Society.

\section{Keith (41TT11)}

The Keith Site (41TT11) covers an area of $75,000+\mathrm{m}^{2}$ and includes a small cemetery, an occupation area, a probable borrow pit, a midden area, and an Early to Middle Caddo earthen mound (Goldschmidt 1935b; Thurmond 1990:78, 183-185). In 1934, at the time of clearing and excavations by a UT crew under the direction of W. R. Goldschmidt, the mound measured 73 (n-s) x 49 (e-w) x 4.6 m (height). According to Goldschmidt (1935:98), the top of the mound may have been a flat rectangular area at one time. Several mound stages were evident and Thurmond (1990:184) noted that four 
major construction episodes were identified with evidence of "significant time lapses" between construction events.

Given the nature of the mound, it has been suggested that there were probably structures on the original pre-mound surface and then on each of the mound platforms (Thurmond 1990:184). This would have created four sequent structures within the mound, and the possibility of a fifth atop the final mound platform (although no evidence for this was found) (Thurmond 1990:184). Despite the likelihood of multiple sequent structure, features and material remains associated with only two structures were identified, one on the third mound platform and the other on the pre-mound surface. In addition, an area of post holes, pits, ash, and charcoal off the mound was interpreted as an outdoor activity area (Goldschmidt 1935; Thurmond 1990:184).

Thurmond (1990) noted that the mound and sub-mound material culture remains corresponded to an Early Caddo occupation with additional Early Caddo debris recovered from the nearby terrace. Late Caddo debris was found on the terrace and within the vicinity and on the surface of the mound, along with several Titus phase burials (Perttula et al. 2010). One radiocarbon date from material apparently produced "prior to the construction of the second mound platform" provided a calibrated one-sigma date range of A.D. 1340-1480 (Thurmond 1990:184).

Limited information was recorded for Structure 1. Atop the center of the third mound platform, excavators identified a heavy concentration of charcoal and wattleimpressed daub (Goldschmidt 1935a, 1935b; Thurmond 1990:184). Despite this concentration of material, no post holes were identified. Thurmond (1990) noted that this was the remains of a burned structure destroyed immediately prior to the addition of the final mound platform and that the location of the concentration of material suggested that the structure was located at the center of the third platform. 


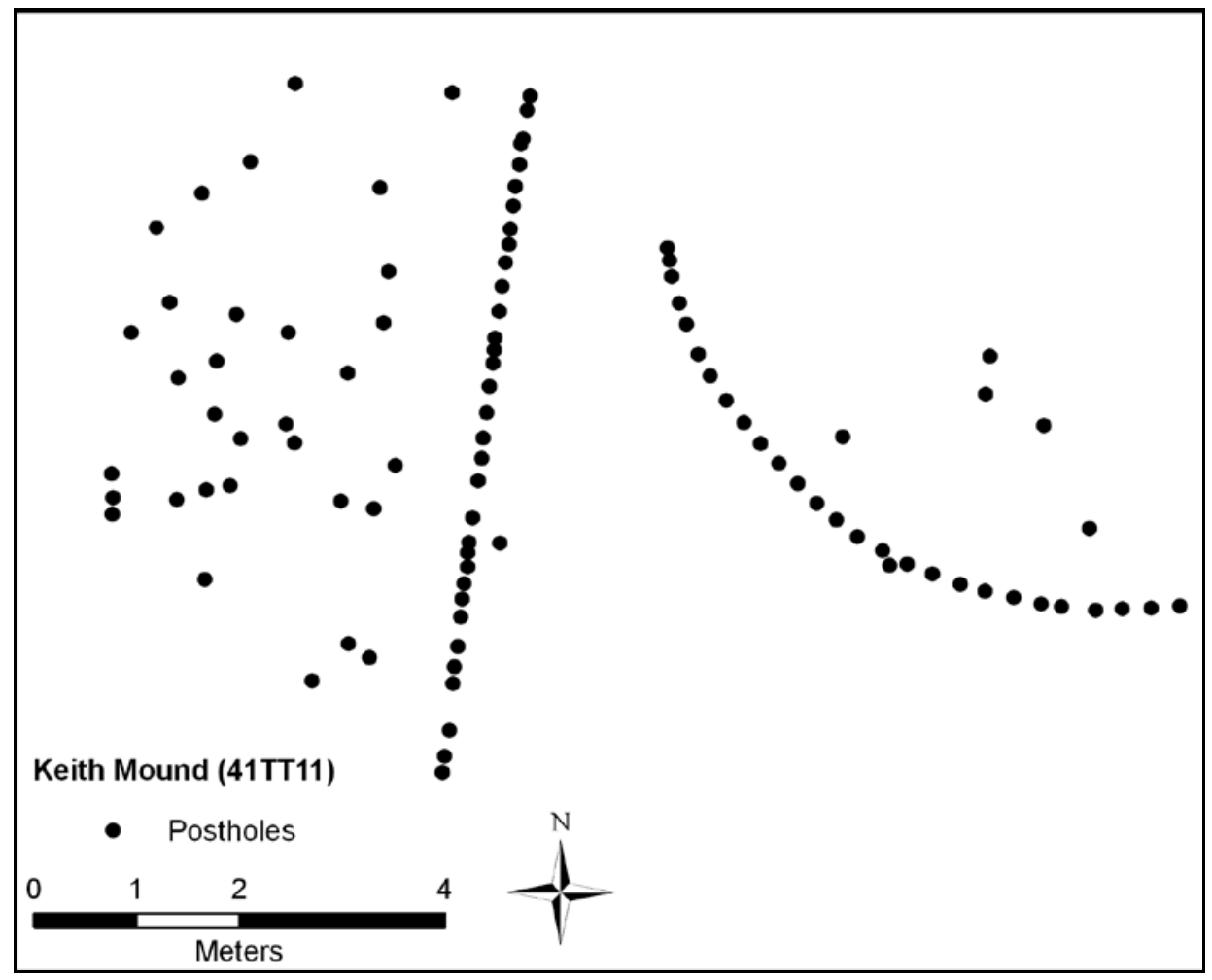

Figure 55. Structure 2 from the Keith mound.

The remains of Structure 2 (originally Feature 1) and its associated features were more substantial (Figure 55). The southern portion of Structure 2 was identified on the pre-mound surface (Goldschmidt 1935:99-100; Thurmond 1990). A total of 191 post holes were identified in this mound level and corresponded to a large semi-circle, straight lines, and scattered post holes not corresponding to a clear pattern (Goldschmidt 1935:99100). The semi-circle indicated a circular structure with a diameter of approximately 9.1 $\mathrm{m}$ and an area of $65.04 \mathrm{~m}^{2}$. The exposed portion of the pattern consisted of at least 24 post holes ranging from approximately $0.04 \mathrm{~m}$ to $0.27 \mathrm{~m}$ in diameter with a mean diameter of about $0.15 \mathrm{~cm}$ (Goldschmidt 1935:100). The wall post holes were spaced approximately 0.12 to $0.34 \mathrm{~m}$ apart $(\mathrm{n}=25, \bar{x}=0.26 \mathrm{~m}, \mathrm{~s}=0.0480)$. Within the perimeter 
of the structure were two midden deposits (ca. 2 x $4 \mathrm{~m}$ ) and several isolated post holes. No entranceway or central hearth were found, although less than half of the structure was exposed.

Approximately $3.6 \mathrm{~m}$ to the east and $1.82 \mathrm{~m}$ to the west of the structure were north-south running lines of post holes (Goldschmidt 1935:99-100). Within these walls, running along the interior of the east wall, was a partially exposed $1.5 \mathrm{~m} \mathrm{x} 4 \mathrm{~m}$ midden deposit. In addition to this, a $3 \mathrm{~m}$ diameter area of post holes, pits, ash, and charcoal was located directly beyond the western wall (Thurmond 1990). Goldschmidt (1935:100) noted that "the straight lines represent portions of a rectangular enclosure can only be surmised, but it is fairly certain from historical accounts that this interpretation is correct."

\section{Oak Hill Village (41RK214)}

At least 43 structures of varying size and shape were uncovered at the Oak Hill Village site as well as a central plaza area and a small earthen mound (Perttula and Rogers 2007; Rogers and Perttula 2004). Three circular structures (Structures 4, 24, and 25 ) were at least partially covered by the small mound at the northern end of the site. The mound was constructed during the middle-era village, dating from approximately the middle to late thirteenth to the middle fourteenth century (A.D. 1250-1350) (Perttula and Rogers 2007; Rogers and Perttula 2004:346). Of the three structures, only Structure 4 was almost entirely covered by the mound, with Structures 24 and 25 only partially, and possibly incidentally, covered with mound construction fill. Whether these structures were directly covered after abandonment, as with the Redwine and Bryan Hardy mound structures and others discussed in this chapter, is not clear. What is evident, as discussed by Perttula and Rogers (2007:86) is that "the combination of mound, plaza, and 
encircling circular residential structures, indicates the mature development of the Oak Hill Village during the middle-era." In addition, Perttula and Rogers (2007) noted "the obvious concentration of structures near the earthen mound, and the rebuilding of many structures here, seems analogous to the 'inner precincts' defined by Story (1998:26) for the Early to Middle Caddo period George C. Davis village and mound center."

Structures 4, 24 and 25 had diameters of $7.5 \mathrm{~m}, 7.8 \mathrm{~m}$, and $7.7 \mathrm{~m}$, respectively. The mean wall post hole spacing for these structures ranged from $0.516 \mathrm{~m}$ for Structure 25 to 0.539 for Structure 24 and $0.542 \mathrm{~m}$ for Structure 4 . A center post was found only in Structure 25, although the other two structures were not excavated fully enough to reveal a possible center post. No obvious entrances were identified for these structures (Rogers and Perttula 2004; Perttula and Rogers 2007).

\section{SUMMARY}

This chapter has discussed the architectural character of 48 previously excavated mound structures and another two possible structures on Mound A recorded in the magnetometer survey at the George C. Davis site. The following chapter provides a discussion of the non-mound structures included in this study.

Architectural data on these 50 structures come from 13 sites located throughout eastern Texas. These sites include major multi-mound centers such as the George C. Davis site, Harroun, and Whelan, as well as smaller sites with a single sub-structural mound such as Bryan Hardy and Redwine. In addition, these sites and structures span the range of Caddo history from Formative Caddo through Middle Caddo times, and then into the Late Caddo period (including structures built during the McCurtain, Whelan, and Titus phases). These 50 structures likely represent special purpose structures, including those for which access was restricted to only the political or religious elite. 


\section{CHAPTER 6}

\section{NON-MOUND CADDO ARCHITECTURE IN EASTERN TEXAS}

\section{INTRODUCTION}

In addition to the 50 mound-related structures discussed in Chapter 5, this study includes 128 previously excavated non-mound structures as well as 87 structures recorded through magnetometer surveys. These 215 structures are from 24 sites throughout eastern Texas (Table 29 and Figure 56). These structures provide sufficient architectural data to allow for detailed analysis and comparison that is the objective of this study.

Table 29. East Texas Caddo sites with non-mound-related structures included in this study.

\begin{tabular}{|l|l|c|}
\hline Site & Site Trinomial & Number of recorded non-mound structures in this study* \\
\hline A.C. Saunders & 41 AN19 & 1 \\
\hline Lang Pasture & 41 AN38 & 2 \\
\hline Hill Farm & 41 BW169 & 3 \\
\hline Hatchel & 41 BW3 & 113 \\
\hline George C. Davis & 41 CE19 & 1 \\
\hline Harold Williams & 41 CP10 & 2 \\
\hline Pilgrims Pride & 41 CP304 & 2 \\
\hline Spider Knoll & $41 \mathrm{DT} 11$ & 1 \\
\hline New Hope & 41 FK107 & 5 \\
\hline Hurricane Hill & 41 HP106 & 2 \\
\hline Whelan & 41 MR2 & 1 \\
\hline Foggy Fork & 41 NA235 & 9 \\
\hline Deshazo & 41 NA27 & 1 \\
\hline Henry M & 41 NA60 & 1 \\
\hline Musgano & 41 RK19 & 40 \\
\hline Oak Hill Village & 41 RK214 & 2 \\
\hline Roitsch & 41 RR16 & 1 \\
\hline Blount & 41 SA123 & 3 \\
\hline Walter Bell & 41 SB50 & 2 \\
\hline Bryan Hardy & 41 SM55 & 4 \\
\hline Earspool & 41 TT653 & 2 \\
\hline
\end{tabular}




\begin{tabular}{|l|l|l|} 
Rookery Ridge & 41UR133 & 2 \\
\hline Spoonbill & 41WD109 & 1 \\
\hline Hines & 41WD87 & 3 \\
\hline
\end{tabular}

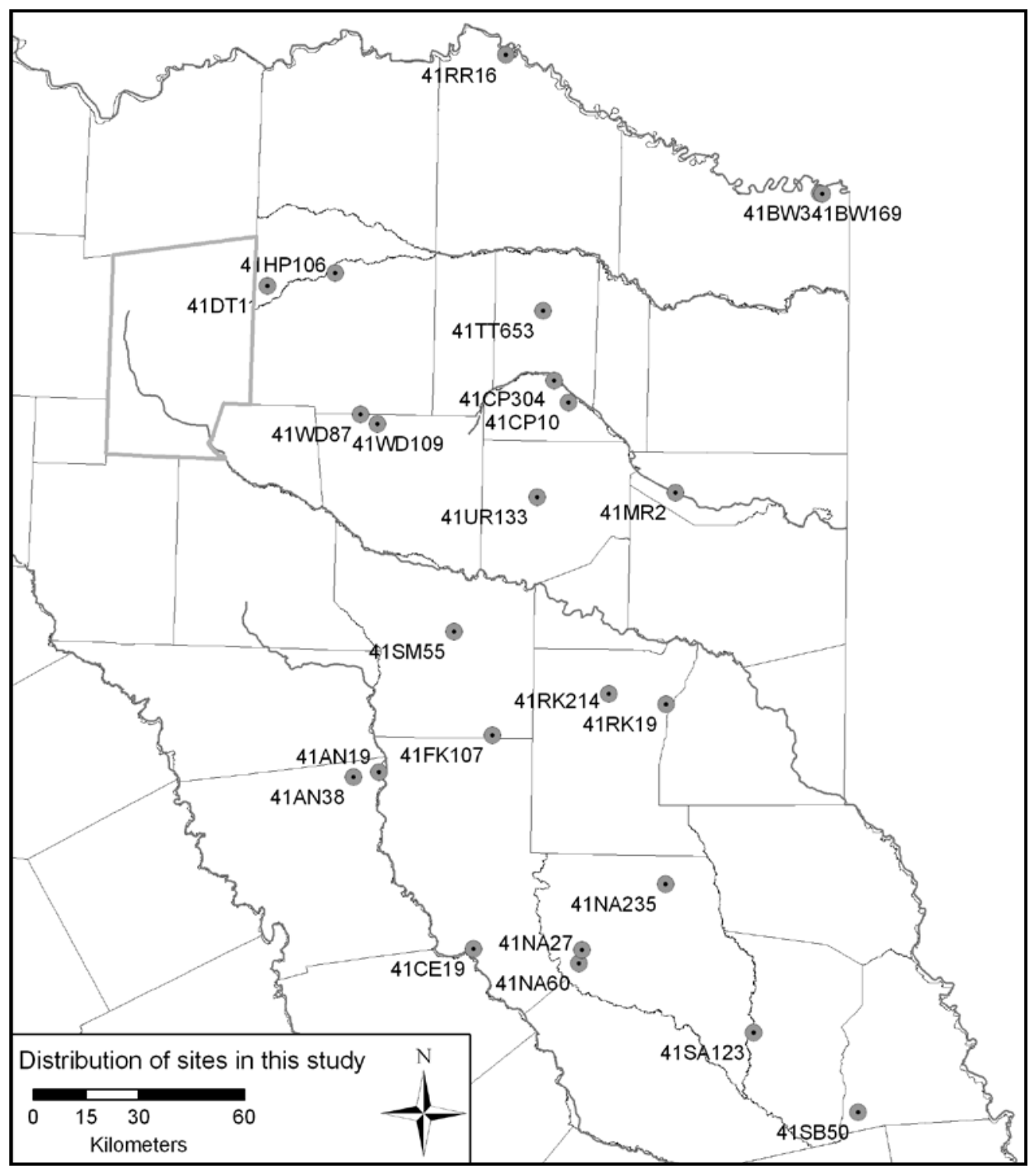

Figure 56: Distribution of sites with non-mound structures included in this study.

There are several other non-mound structures or structure areas recorded throughout the study area, but I have had to omit them from consideration for some of the 171 
same reasons discussed in Chapter 5. Namely, in most instances too little of the structure pattern was recorded to allow for detailed analysis of post hole attributes, structure size, etc. Structure areas indicated by a packed floor area, burned daub, a circular pattern of burned earth, or structure patterns that are too incomplete have also been omitted.

\section{NON-MOUND-RELATED STRUCTURES}

Of the 215 non-mound structures in eastern Texas (excluding Feature 35, the "maze", from the George C. Davis site), 185 are circular, four are sub-round, 10 are rectangular, 15 are sub-square, most with rounded or diagonal corners. Eighty-seven of these structures were recorded through magnetometer surveys at the George C. Davis and Hill Farm sites (see Chapter 4; Creel et al. 2005; Osburn et al. 2008; Schultz et al. 2004; Walker 2009). Tables 30 through 32 provide structure shape and size by site.

Table 30. Non-mound-related structures included in this study (excluding the George C.

Davis site structures identified by magnetometer survey, see below).

\begin{tabular}{|c|c|c|c|c|}
\hline Site & Structure & Shape & $\begin{array}{c}\text { Dimensions/ } \\
\text { Diameter (m) }\end{array}$ & $\operatorname{Area}\left(\mathrm{m}^{2}\right)$ \\
\hline A.C. Saunders & 3 & circular & $14 \times 13.2$ & 149.50 \\
\hline \multirow{2}{*}{ Lang Pasture } & 1 & circular & 6.80 & 36.32 \\
\hline & 2 & circular & 9.00 & 63.59 \\
\hline \multirow{11}{*}{ Hill Farm } & 1 & circular & 11.5 & 103.82 \\
\hline & 2 & circular & 15 & 176.63 \\
\hline & 3 & circular & 7 & 38.47 \\
\hline & 4 & circular & $14.5-17.5$ & $165.05-240.41$ \\
\hline & 5 & circular & 12 & 113.04 \\
\hline & 6 & circular & 10 & 78.5 \\
\hline & 7 & circular & 8 & 50.24 \\
\hline & 8 & circular & 10 & 78.5 \\
\hline & 9 & circular & 10 & 78.5 \\
\hline & 11 & circular & 10 & 78.5 \\
\hline & 13 & circular & 8 & 50.24 \\
\hline \multirow{2}{*}{ Hatchel } & 1 & circular & 7.14 & 40.02 \\
\hline & $1 \mathrm{a}$ & circular & 9.50 & 70.85 \\
\hline
\end{tabular}




\begin{tabular}{|c|c|c|c|c|}
\hline & 2 & circular & 3.05 & 7.35 \\
\hline \multirow{39}{*}{ George C. Davis } & 2 & circular & 9.2 & 66.5 \\
\hline & 3 & sub-round & 8.2 & 52.8 \\
\hline & 4 & sub-square with rounded/diagonal corners & $10.7 \times 11.8$ & 126.3 \\
\hline & 6 & sub-square with rounded/diagonal corners & $9.7 \times 10.3$ & 99.9 \\
\hline & 7 & circular & 1.5 & 1.8 \\
\hline & 8 & circular & 6.5 & 33.2 \\
\hline & 9 & sub-square with rounded/diagonal corners & $9.9 \times 9.9$ & 98.0 \\
\hline & 10 & circular & 6.5 & 33.2 \\
\hline & 11 & circular & 9.5 & 70.9 \\
\hline & 12 & circular & 8.0 & 50.3 \\
\hline & 13 & circular & 10.7 & 89.9 \\
\hline & 14 & circular & 9.7 & 73.9 \\
\hline & 15 & circular & 9.9 & 77.0 \\
\hline & 16 & circular & 10.5 & 86.6 \\
\hline & 17 & circular & 5.7 & 25.5 \\
\hline & 18 & circular & 8.4 & 55.4 \\
\hline & 19 & circular & 7.2 & 40.7 \\
\hline & 29 & sub-round & 8.8 & 60.8 \\
\hline & 30 & circular & 6.1 & 29.2 \\
\hline & 32 & circular & 9.2 & 66.5 \\
\hline & 33 & circular & 10.7 & 89.9 \\
\hline & 35 & maze & $6.9 \times 9.3$ & 51.5 \\
\hline & 41 & circular & 8.8 & 60.8 \\
\hline & 46 & circular & 8.9 & 62.2 \\
\hline & 47 & circular & 7.2 & 40.7 \\
\hline & 48 & circular & 7.2 & 40.7 \\
\hline & 49 & circular & 13.2 & 136.8 \\
\hline & 50 & circular & 1.9 & 2.8 \\
\hline & 51 & circular & 13.0 & 132.7 \\
\hline & 52 & circular & 1.9 & 2.8 \\
\hline & 53 & sub-square with rounded/diagonal corners & 14.0 & 153.9 \\
\hline & 54 & sub-square with rounded/diagonal corners & $9.0 \times 9.5$ & 85.5 \\
\hline & 55 & circular & 11.1 & 96.8 \\
\hline & 120 & circular & 5.0 & 19.6 \\
\hline & 125 & circular & 7.4 & 43.0 \\
\hline & 139 & sub-round & $9.6 \times 9.9$ & 95.0 \\
\hline & 146 & circular & 10.8 & 91.6 \\
\hline & 160 & circular & 12.4 & 120.8 \\
\hline & 185 & sub-square with rounded/diagonal corners & 12.0 & 113.0 \\
\hline Harold Williams & 7 & circular & $6.7 \times 5$ & 26.96 \\
\hline \multirow{2}{*}{ Pilgrims Pride } & 1 & circular & 7.00 & 38.48 \\
\hline & 2 & circular & $8.5-9$ & 60.10 \\
\hline \multirow{2}{*}{ Spider Knoll } & 1 & circular & 8.00 & 50.24 \\
\hline & 2 & circular & 10.00 & 78.50 \\
\hline
\end{tabular}




\begin{tabular}{|c|c|c|c|c|}
\hline New Hope & 1 & circular & 8.80 & 60.79 \\
\hline \multirow{5}{*}{ Hurricane Hill } & $\mathrm{A}$ & circular & $6 \times 7.5$ & 35.87 \\
\hline & $\mathrm{B}$ & circular & $7.1 \times 7.6$ & 41.41 \\
\hline & $\mathrm{C}$ & circular & 6.00 & 28.26 \\
\hline & $\mathrm{D}$ & rectangular & $\mathrm{n} / \mathrm{a}$ & $\mathrm{n} / \mathrm{a}$ \\
\hline & $\mathrm{E}$ & rectangular & $\mathrm{n} / \mathrm{a}$ & $\mathrm{n} / \mathrm{a}$ \\
\hline \multirow{2}{*}{ Whelan } & 1 & circular & 3.00 & 7.16 \\
\hline & 2 & circular & 7.80 & 49.39 \\
\hline Foggy Fork & 1 & circular & 8.00 & 50.24 \\
\hline \multirow{9}{*}{ Deshazo } & 1 & circular & 12.20 & 116.90 \\
\hline & 2 & circular & 9.40 & 69.40 \\
\hline & 3 & circular & 9.80 & 75.43 \\
\hline & 4 & circular & 9.60 & 72.38 \\
\hline & 5 & circular & 9.60 & 72.38 \\
\hline & 6 & circular & 11.90 & 111.22 \\
\hline & 7 & circular & 9.00 & 63.62 \\
\hline & 8 & circular & 9.20 & 66.48 \\
\hline & 9 & circular & 9 & 63.59 \\
\hline Henry M & 1 & circular & 8.80 & 60.82 \\
\hline Musgano & 1 & circular & 6.00 & 28.27 \\
\hline \multirow{25}{*}{ Oak Hill Village } & 1 & circular & 8 & 50.27 \\
\hline & 2 & circular & 6.5 & 33.18 \\
\hline & 3 & circular & 5.9 & 27.34 \\
\hline & 5 & circular & 6.5 & 33.18 \\
\hline & 6 & circular & 5.25 & 21.65 \\
\hline & 7 & circular & 8.1 & 51.53 \\
\hline & 8 & circular & 6.4 & 32.17 \\
\hline & 9 & circular & 9 & 63.62 \\
\hline & 10 & circular & 6 & 28.27 \\
\hline & 11 & circular & 3 & 7.07 \\
\hline & 12 & circular & 8.8 & 60.82 \\
\hline & 13 & circular & 8.5 & 56.75 \\
\hline & 14 & circular & 7.5 & 44.18 \\
\hline & 15 & circular & 2.4 & 4.52 \\
\hline & 16 & circular & 2.6 & 5.31 \\
\hline & 17 & circular & 6.5 & 33.18 \\
\hline & 18 & circular & 8.7 & 59.45 \\
\hline & 19 & circular & 6 & 28.27 \\
\hline & 20 & circular & 6.5 & 33.18 \\
\hline & 21 & circular & 6.8 & 36.32 \\
\hline & 22 & circular & 3 & 7.07 \\
\hline & 23 & circular & 2.5 & 4.91 \\
\hline & 26 & circular & 7.1 & 39.59 \\
\hline & 27 & circular & 1.6 & 2.01 \\
\hline & 28 & circular & 9.45 & 70.14 \\
\hline
\end{tabular}




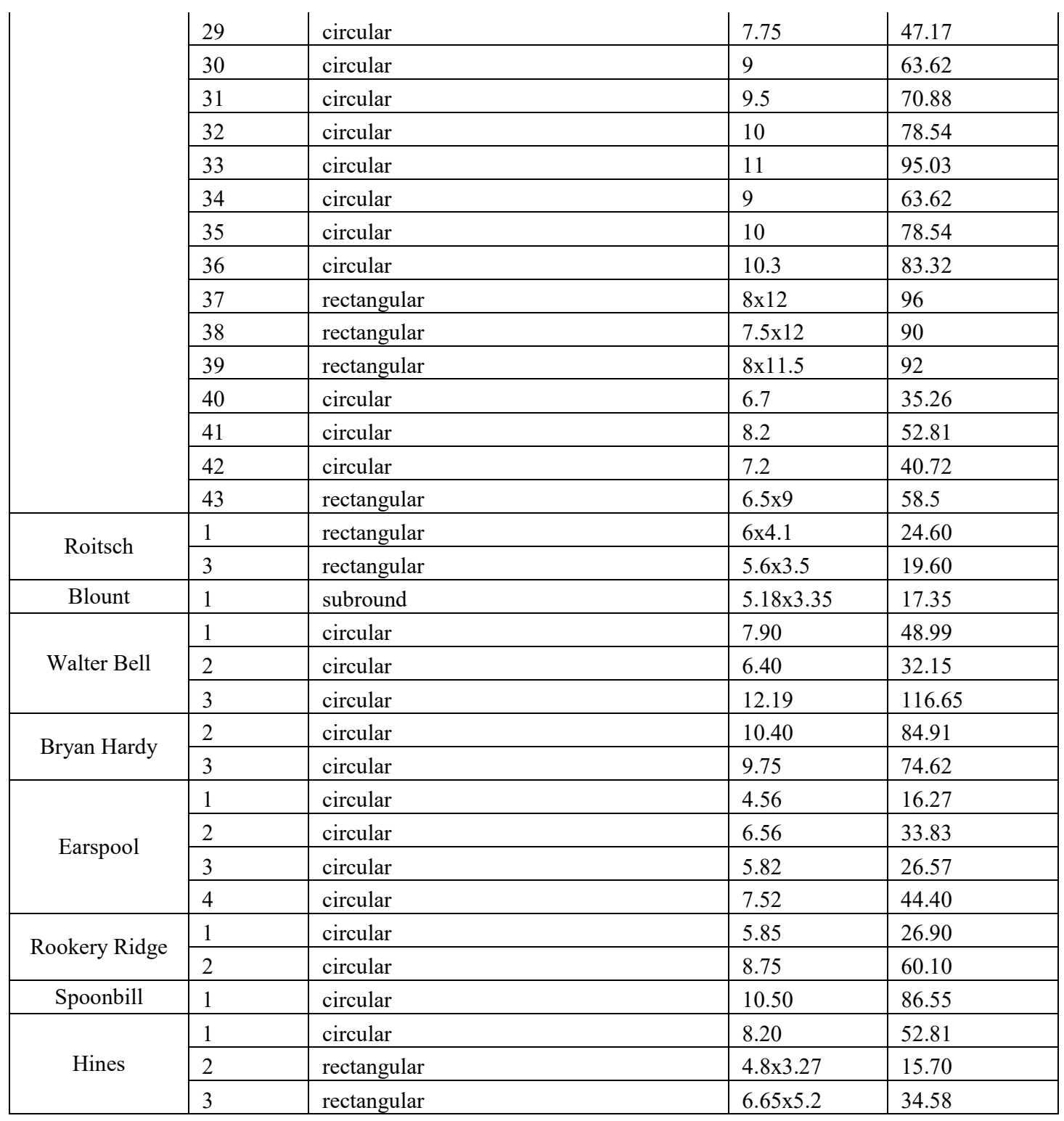

Table 31. Possible non-mound structures identified in the 2003 magnetometer data from the George C. Davis site.

\begin{tabular}{|c|c|c|c|c|c|c|c|}
\hline Feature & $\begin{array}{l}\text { Dimensions/ } \\
\text { Diameter (m) }\end{array}$ & $\begin{array}{l}\text { Area } \\
\left(\mathbf{m}^{2}\right)\end{array}$ & Type & Feature & $\begin{array}{l}\text { Dimensions/ } \\
\text { Diameter (m) }\end{array}$ & $\begin{array}{l}\text { Area } \\
\left(\mathbf{m}^{2}\right)\end{array}$ & Type \\
\hline 179 & 20.3 & 323.65 & circular & 280 & 11.1 & 96.77 & circular \\
\hline
\end{tabular}




\begin{tabular}{|l|l|l|l|}
\hline 220 & 5.6 & 24.63 & circular \\
\hline 237 & 10.6 & 88.25 & circular \\
\hline 238 & 21 & 346.36 & circular \\
\hline 239 & 17.5 & 240.53 & circular \\
\hline 241 & 13.5 & 143.14 & circular \\
\hline 242 & 13 & 132.73 & circular \\
\hline 243 & 13.6 & 145.27 & circular \\
\hline 244 & 12.3 & 118.82 & circular \\
\hline 245 & 11.5 & 103.87 & circular \\
\hline 246 & 10 & 78.54 & circular \\
\hline 247 & 15.4 & 186.27 & circular \\
\hline 250 & 8 & 50.24 & sub-square \\
\hline 251 & 7 & 38.47 & sub-square \\
\hline 252 & 11.7 & 107.51 & sub-square \\
\hline 253 & 14.9 & 174.37 & sub-square \\
\hline 254 & $10.7 \times 10.7$ & 114.49 & sub-square \\
\hline 255 & 18.4 & 265.9 & circular \\
\hline 256 & 16.1 & 203.58 & circular \\
\hline 257 & 16.7 & 219.04 & circular \\
\hline 258 & 17.7 & 246.06 & circular \\
\hline 259 & 20.1 & 317.31 & circular \\
\hline 260 & $5 \times 6$ & 30 & sub-square \\
\hline 263 & 6.6 & 34.21 & Circular \\
\hline 264 & 15 & 176.71 & Circular \\
\hline 265 & 16.2 & 206.12 & Circular \\
\hline 266 & 9.5 & 70.88 & Circular \\
\hline 267 & 16.2 & 206.12 & Circular \\
\hline 269 & 18.1 & 257.3 & Circular \\
\hline 274 & 13 & 132.73 & circular \\
\hline 275 & 4.6 & 16.62 & Circular \\
\hline 276 & 8.7 & 59.45 & Circular \\
\hline 277 & 13.2 & 136.85 & Circular \\
\hline 278 & 10.3 & & \\
\hline & & Circular \\
\hline
\end{tabular}

\begin{tabular}{|c|c|c|c|}
\hline 281 & $6.8 \times 6.8$ & 46.24 & sub-square \\
\hline 284 & 16.1 & 203.58 & circular \\
\hline 285 & 11.69 & 107.33 & circular \\
\hline 290 & 7.3 & 41.85 & circular \\
\hline 291 & 6.7 & 35.26 & circular \\
\hline 292 & 7.2 & 40.72 & circular \\
\hline 301 & 3.45 & 9.35 & circular \\
\hline 302 & 3.15 & 7.79 & circular \\
\hline 305 & 18.25 & 261.59 & circular \\
\hline 306 & 7.9 & 49.02 & circular \\
\hline 307 & 7.6 & 45.36 & circular \\
\hline 308 & 6.9 & 37.39 & circular \\
\hline 310 & 6.17 & 29.9 & circular \\
\hline 312 & 11.5 & 103.87 & circular \\
\hline 313 & 13.8 & 149.57 & circular \\
\hline 314 & 5.6 & 24.63 & circular \\
\hline 315 & 8.3 & 54.11 & circular \\
\hline 318 & 10.9 & 93.31 & circular \\
\hline 320 & 7.1 & 39.59 & circular \\
\hline 327 & 6.75 & 35.78 & circular \\
\hline 328 & 6.4 & 32.17 & circular \\
\hline 334 & 6.7 & 35.26 & circular \\
\hline 335 & 9.5 & 70.88 & circular \\
\hline 338 & 10.4 & 84.95 & circular \\
\hline 339 & 12.5 & 122.72 & circular \\
\hline 340 & 15.5 & 188.69 & circular \\
\hline 343 & 4.7 & 17.35 & circular \\
\hline 346 & 10 & 78.54 & circular \\
\hline 347 & $4.6 \times 4.8$ & 22.08 & sub-square \\
\hline 348 & 9 & 63.62 & circular \\
\hline 350 & 6 & 28.27 & circular \\
\hline & & & \\
\hline
\end{tabular}

Table 32. Possible non-mound structures identified in magnetometer data in the Village area adjacent to Mound A (Osburn et al. 2008).

\begin{tabular}{|l|l|l|l|l|}
\hline Structure & Size (m) & Area $\left.\mathbf{( m}^{\mathbf{2}}\right)$ & $\begin{array}{c}\text { Shape (Osburn et al. } \\
\mathbf{2 0 0 8})\end{array}$ & Shape (this dissertation) \\
\hline 1 & 8.7 & 59.42 & Round & Circular \\
\hline
\end{tabular}




\begin{tabular}{|l|l|l|l|l|}
\hline 2 & $20.2 \times 20.5$ & 414.10 & Round-flattened sides & $\begin{array}{l}\text { Sub-square with rounded/diagonal } \\
\text { corners }\end{array}$ \\
\hline 3 & $18 \times 17.5$ & 315.00 & Round-oval & Circular \\
\hline 4 & 16.4 & 211.13 & Round & Circular \\
\hline 5 & $16.8 \times 17.5$ & 294.00 & Round-oval & Circular \\
\hline 6 & 16.5 & 213.72 & Round & Circular \\
\hline 7 & $17.0 \times 17.3$ & 294.10 & Round-flattened sides & Circular \\
\hline 8 & 16.3 & 208.57 & Round & Circular \\
\hline 9 & 18 & 254.34 & Round & Circular \\
\hline 10 & 15.9 & 198.46 & Round & Circular \\
\hline
\end{tabular}

\section{George C. Davis (41CE19)}

Two sites contribute the largest sample of non-mound Caddo architecture in East Texas, George C. Davis and Oak Hill Village. Thirty-nine of the 52 previously excavated structures from the George C. Davis site are not located on, in, or under one of the three earthen mounds at the site. The other structures are directly associated with either Mound A or Mound B (see Chapter 5). In addition to the previously excavated structures, at least 75 and as many as many as 105 potential non-mound structures have been identified by large-scale magnetometer surveys (Tables 31 and 32, see also Chapter 4; Creel et al. 2005; Osburn et al. 2008; Schultz et al. 2004; Walker 2009), with at least two possible structures identified on Mound A. Since the structures identified in the magnetometer survey have been discussed in detail in Chapter 4, and the moundassociated structures from the site have been considered in Chapter 5, in this chapter I will primarily address the excavated non-mound structures (Table 33).

Table 33. Excavated non-mound structures from the George C. Davis site (adapted from Spock 1977:30).

\begin{tabular}{|c|l|l|l|l|}
\hline \multicolumn{1}{|c|}{ Location } & Feature & \multicolumn{1}{c|}{ Shape } & $\begin{array}{c}\text { Dimensions/ } \\
\text { Diameter }(\mathbf{m})\end{array}$ & $\begin{array}{c}\text { Area } \\
\left(\mathbf{m}^{2}\right)\end{array}$ \\
\hline Adjacent to Mound A & 9 & Sub-square with rounded/diagonal corners & $9.9 \times 9.9$ & 98.0 \\
\hline & 10 & Circular & 6.5 & 33.2 \\
\hline & 11 & Circular & 9.5 & 70.9 \\
\hline
\end{tabular}




\begin{tabular}{|c|c|c|c|c|}
\hline & 12 & Circular & 8.0 & 50.3 \\
\hline & 13 & Circular & 10.7 & 89.9 \\
\hline & 14 & Circular & 9.7 & 73.9 \\
\hline & 15 & Circular & 9.9 & 77.0 \\
\hline & 16 & Circular & 10.5 & 86.6 \\
\hline & 17 & Circular & 5.7 & 25.5 \\
\hline & 18 & Circular & 8.4 & 55.4 \\
\hline & 19 & Circular & 7.2 & 40.7 \\
\hline & 29 & Sub-round & 8.8 & 60.8 \\
\hline & 30 & Circular & 6.1 & 29.2 \\
\hline & 32 & Circular & 9.2 & 66.5 \\
\hline & 33 & Circular & 10.7 & 89.9 \\
\hline & 35 & maze & $6.9 \times 9.3$ & 51.5 \\
\hline & 41 & Circular & 8.8 & 60.8 \\
\hline & 46 & Circular & 8.9 & 62.2 \\
\hline & 47 & Circular & 7.2 & 40.7 \\
\hline & 48 & Circular & 7.2 & 40.7 \\
\hline & 49 & Circular & 13.2 & 136.8 \\
\hline & 50 & Circular & 1.9 & 2.8 \\
\hline & 51 & Circular & 13.0 & 132.7 \\
\hline & 52 & Circular & 1.9 & 2.8 \\
\hline & 53 & Sub-square with rounded/diagonal corners & 14.0 & 153.9 \\
\hline & 55 & Circular & 11.1 & 96.8 \\
\hline \multirow[t]{8}{*}{ Village area around Mound A } & 2 & Circular & 9.2 & 66.5 \\
\hline & 3 & Sub-round & 8.2 & 52.8 \\
\hline & 4 & Sub-square with rounded/diagonal corners & $10.7 \times 11.8$ & 126.3 \\
\hline & 6 & Sub-square with rounded/diagonal corners & $9.7 \times 10.3$ & 99.9 \\
\hline & 7 & Circular & 1.5 & 1.8 \\
\hline & 8 & Circular & 6.5 & 33.2 \\
\hline & 54 & Sub-square with rounded/diagonal corners & $9.0 \times 9.5$ & 85.5 \\
\hline & 146 & Circular & 10.8 & 91.6 \\
\hline \multirow[t]{2}{*}{ Between Mounds A and B } & 139 & Sub-round & $9.6 \times 9.9$ & 95.0 \\
\hline & 160 & Circular & 12.4 & 120.8 \\
\hline ca. $5 \mathrm{~m}$ west of Mound B & 120 & Circular & 5.0 & 19.6 \\
\hline Between Mounds B and C & 125 & Circular & 7.4 & 43.0 \\
\hline North of Weeping Mary Road & 185 & Sub-square with rounded/diagonal corners & 12.0 & 113.0 \\
\hline
\end{tabular}

As noted in Chapters 4 and 5, structures from the George C. Davis site represent a diverse array of architectural patterns and use of space. There are 39 previously excavated structures from the George C. Davis site, including the Feature 35 maze. These structures range in shape from circular $(n=29)$ to sub-round $(n=3)$ to sub-square with 
rounded or diagonal corners $(n=6)$, as well as the unique and peculiar "maze" (Feature $35)$.

With the exception of Feature 35, the remaining 38 non-mound structures have areas ranging from $1.8 \mathrm{~m}^{2}$ to $153.9 \mathrm{~m}^{2}$ with a mean area of $69.13 \mathrm{~m}^{2}(\mathrm{~s}=38.5188)$. As noted in Table 34, these structures are located throughout the site. The sub-square structures with rounded or diagonal corners tend to be larger than the other structure categories, with areas ranging from approximately $85.5 \mathrm{~m}^{2}$ to $153.9 \mathrm{~m}^{2}(\bar{x}=112.77, \mathrm{~s}=$ 24.504). The circular structures have diameters ranging from $1.5 \mathrm{~m}$ to $13.2 \mathrm{~m}(\bar{x}=8.21, \mathrm{~s}$ $=3.0647)$ and areas ranging from $1.8 \mathrm{~m}^{2}$ to $136.8 \mathrm{~m}^{2}\left(\bar{x}=60.06 \mathrm{~m}^{2}, \mathrm{~s}=36.3905\right.$. Similar to smaller structures from other sites, the smallest of these - Features 7, 50, and 52, with diameters of only $1.5 \mathrm{~m}, 1.9 \mathrm{~m}$, and $1.9 \mathrm{~m}$ respectively (areas of $1.8 \mathrm{~m}^{2}, 2.8 \mathrm{~m}^{2}$, and 2.8 $\mathrm{m}^{2}$ ) - are likely non-residential structures such as granaries (Rogers and Perttula 2004; Perttula 2005; Spock 1977). If these smaller structures are removed from structure size consideration, then the circular structures range in size from $5 \mathrm{~m}$ to $13.2 \mathrm{~m}(\bar{x}=8.95, \mathrm{~s}=$ 2.2266) with areas ranging from $19.6 \mathrm{~m}^{2}$ to $136.8 \mathrm{~m}^{2}(\bar{x}=66.71, \mathrm{~s}=32.2359)$. The subround structures are the smallest in size, with areas ranging from approximately $52.8 \mathrm{~m}^{2}$ to $95 \mathrm{~m}^{2}\left(\bar{x}=69.53 \mathrm{~m}^{2}, \mathrm{~s}=22.4146\right)$.

Lacquement (2007:55) has suggested that applying the division between small pole buildings and large post buildings, a distinction used in structural engineering, archaeologically "enables one to distinguish between houses based on post size instead of or in combination with insertion method." Twenty-nine of the structures may be considered small "pole" buildings (Lacquement 2007:55), with wall post hole diameters averaging less than $20 \mathrm{~cm}$. The remaining nine may fit in the category of large "post" buildings; that is, those with post hole diameters averaging $20 \mathrm{~cm}$ or more (Lacquement 2007:55). 
Mean post hole diameters among all the structures range from $12 \mathrm{~cm}$ to $34.5 \mathrm{~cm}$ $(\bar{x}=18.22, \mathrm{~s}=4.047)$. The minimum post hole size is $6 \mathrm{~cm}$ with the maximum being 55 $\mathrm{cm}$. All but one of the sub-square structures are small pole buildings (Lacquement 2007) with average wall post hole size ranging from 15 to $20 \mathrm{~cm}(\bar{x}=17.57, \mathrm{~s}=1.988)$. Two of the three sub-round structures are small pole buildings with wall post hole diameters ranging from $17 \mathrm{~cm}$ to $34.5 \mathrm{~cm}(\bar{x}=23.17, \mathrm{~s}=9.8277)$, while the circular structures have mean wall post hole diameters ranging from $12 \mathrm{~cm}$ to $28 \mathrm{~cm}(\bar{x}=17.86, \mathrm{~s}=3.4093)$. Twenty-one of the 29 circular structures have wall post hole diameters averaging less than $20 \mathrm{~cm}$. Table 34 provides a summary of post hole sizes from the George C. Davis non-mound structures.

With the exception of Feature 35, only one non-mound structure has wall post trenches (Feature 9). Structure 9 is a sub-square small pole structure with post hole diameters ranging from $6 \mathrm{~cm}$ (the smallest diameter post hole from the non-mound structures) to $18 \mathrm{~cm}$, with a mean post hole diameter of $15 \mathrm{~cm}$. The other sub-square structures have single set posts with average post hole diameters ranging from $15 \mathrm{~cm}$ to $20 \mathrm{~cm}(\bar{x}=18 \mathrm{~m}, \mathrm{~s}=1.7888)$. While the variation in post hole diameter between the single set post sub-square structures and Feature 9 is minimal, variation in post hole depth is considerable. Feature 9 has wall post hole depths ranging from $61 \mathrm{~cm}$ to $107 \mathrm{~cm}$, with a mean depth of $98 \mathrm{~cm}$, while the remaining sub-square structures have post hole depths ranging from $6 \mathrm{~cm}$ to $44 \mathrm{~cm}$, with average post hole depths ranging from $15 \mathrm{~cm}$ to $30 \mathrm{~cm}(\bar{x}=23.67 \mathrm{~cm}, \mathrm{~s}=6.6232)$. The use of wall trenches as well as the significant difference in post hole depth suggests that Feature 9 represents a different architectural style than the other sub-square structures from the George C. Davis site and is perhaps a special purpose structure (Spock 1977). 
Table 34: Wall post hole data for the Non-mound structures from the George C. Davis site. $c=$ circular; $s s=$ sub-square; $s r=s u b=$ round.

\begin{tabular}{|c|c|c|c|c|c|c|c|c|c|}
\hline \multirow[b]{2}{*}{ Feature } & \multirow[b]{2}{*}{ Shape } & \multirow[b]{2}{*}{ Area (m2) } & \multirow{2}{*}{$\begin{array}{c}\text { No. of } \\
\text { exposed } \\
\text { or visible } \\
\text { post holes }\end{array}$} & \multicolumn{3}{|c|}{ Diameter $(\mathrm{cm})$} & \multicolumn{3}{|c|}{ Depth $(\mathrm{cm})$} \\
\hline & & & & Max. & Min. & Mean & Max. & Min. & Mean \\
\hline 2 & $\mathrm{c}$ & 66.50 & 13 & 0.21 & 0.12 & 0.16 & 0.34 & 0.09 & 0.20 \\
\hline 3 & $\mathrm{sr}$ & 52.80 & 35 & 0.21 & 0.12 & 0.17 & 0.27 & 0.06 & 0.15 \\
\hline 4 & ss & 126.26 & 57 & 0.31 & 0.12 & 0.18 & 0.37 & 0.06 & 0.15 \\
\hline 6 & ss & 99.91 & 62 & 0.20 & 0.11 & 0.15 & 0.24 & 0.13 & 0.22 \\
\hline 7 & $\mathrm{c}$ & 1.80 & 7 & 0.16 & 0.13 & 0.15 & 0.16 & 0.10 & 0.13 \\
\hline 8 & $\mathrm{c}$ & 33.20 & 32 & 0.21 & 0.12 & 0.14 & 0.46 & 0.09 & 0.25 \\
\hline 9 & Ss & 98.01 & 148 & 0.18 & 0.06 & 0.15 & 1.07 & 0.61 & 0.98 \\
\hline 10 & $\mathrm{c}$ & 33.20 & 50 & 0.34 & 0.11 & 0.15 & 0.43 & 0.09 & 0.26 \\
\hline 11 & $\mathrm{c}$ & 70.90 & 54 & 0.24 & 0.12 & 0.16 & 0.70 & 0.09 & 0.25 \\
\hline 12 & $\mathrm{c}$ & 50.30 & 39 & 0.27 & 0.12 & 0.17 & 0.46 & 0.15 & 0.27 \\
\hline 13 & $\mathrm{c}$ & 89.90 & 63 & 0.24 & 0.14 & 0.18 & 0.49 & 0.06 & 0.30 \\
\hline 14 & $\mathrm{c}$ & 73.90 & 44 & 0.27 & 0.12 & 0.17 & 0.61 & 0.15 & 0.37 \\
\hline 15 & $\mathrm{c}$ & 77.00 & 38 & 0.24 & 0.15 & 0.19 & 0.55 & 0.21 & 0.39 \\
\hline 16 & $\mathrm{c}$ & 86.60 & 57 & 0.34 & 0.12 & 0.20 & 0.70 & 0.18 & 0.33 \\
\hline 17 & $\mathrm{c}$ & 25.50 & 61 & 0.21 & 0.12 & 0.17 & 0.37 & 0.06 & 0.22 \\
\hline 18 & $\mathrm{c}$ & 55.40 & 37 & 0.31 & 0.12 & 0.16 & 0.64 & 0.12 & 0.27 \\
\hline 19 & $\mathrm{c}$ & 40.70 & 32 & 0.27 & 0.15 & 0.19 & 0.55 & 0.12 & 0.30 \\
\hline 29 & $\mathrm{sr}$ & 60.80 & 35 & 0.21 & 0.12 & 0.18 & 0.82 & 0.15 & 0.53 \\
\hline 30 & $\mathrm{c}$ & 29.20 & 65 & 0.18 & 0.12 & 0.14 & 0.70 & 0.09 & 0.36 \\
\hline 32 & $\mathrm{c}$ & 66.50 & 34 & 0.18 & 0.12 & 0.15 & 0.27 & 0.12 & 0.20 \\
\hline 33 & $\mathrm{c}$ & 89.90 & 39 & 0.31 & 0.12 & 0.22 & 0.92 & 0.37 & 0.69 \\
\hline 41 & $\mathrm{c}$ & 60.80 & 46 & 0.27 & 0.15 & 0.20 & 0.73 & 0.43 & 0.63 \\
\hline 46 & $\mathrm{c}$ & 62.20 & 15 & 0.21 & 0.09 & 0.18 & 0.37 & 0.12 & 0.26 \\
\hline 47 & $\mathrm{c}$ & 40.70 & 26 & 0.21 & 0.12 & 0.16 & 0.49 & 0.12 & 0.48 \\
\hline 48 & $\mathrm{c}$ & 40.70 & 12 & 0.27 & 0.15 & 0.20 & 0.37 & 0.18 & 0.28 \\
\hline 49 & $\mathrm{c}$ & 136.80 & 58 & 0.40 & 0.15 & 0.20 & 0.70 & 0.15 & 0.37 \\
\hline 50 & $\mathrm{c}$ & 2.80 & 10 & 0.18 & 0.12 & 0.15 & 0.40 & 0.12 & 0.20 \\
\hline 51 & $\mathrm{c}$ & 132.70 & 49 & 0.46 & 0.12 & 0.26 & 0.85 & 0.15 & 0.47 \\
\hline 52 & $\mathrm{c}$ & 2.80 & 10 & 0.21 & 0.15 & 0.18 & 0.52 & 0.24 & 0.34 \\
\hline 53 inner & Ss & 153.86 & 34 & 0.34 & 0.15 & 0.20 & 0.40 & 0.12 & 0.29 \\
\hline 53 outer & Ss & 153.86 & 36 & 0.24 & 0.15 & 0.19 & 0.43 & 0.21 & 0.30 \\
\hline 54 & Ss & 85.50 & 46 & 0.23 & 0.09 & 0.17 & 0.40 & 0.06 & 0.17 \\
\hline 55 & $\mathrm{c}$ & 96.80 & 34 & 0.27 & 0.14 & 0.18 & 0.46 & 0.06 & 0.28 \\
\hline 120 & $\mathrm{c}$ & 19.60 & 6 & 0.18 & 0.16 & 0.17 & 0.62 & 0.10 & 0.38 \\
\hline 125 & $\mathrm{c}$ & 43.00 & 88 & 0.20 & 0.08 & 0.12 & 0.60 & 0.26 & 0.43 \\
\hline 139 & $\mathrm{sr}$ & 95.04 & 40 & 0.47 & 0.23 & 0.35 & 0.81 & 0.40 & 0.56 \\
\hline 146 & $\mathrm{c}$ & 91.60 & 64 & 0.55 & 0.10 & 0.20 & 0.59 & 0.26 & 0.39 \\
\hline 160 & $\mathrm{c}$ & 120.80 & 50 & 0.44 & 0.20 & 0.28 & 0.69 & 0.22 & 0.44 \\
\hline 185 & SS & 113.04 & 11 & 0.21 & 0.16 & 0.19 & 0.44 & 0.10 & 0.29 \\
\hline
\end{tabular}


Mean wall post hole depth for the 37 single set post structures ranges from $13 \mathrm{~cm}$ to $69 \mathrm{~cm}(\bar{x}=32.63 \mathrm{~m}, \mathrm{~s}=13.1116)$. The mean depths do not, however, capture the entire variation in post hole depth for these structures. In comparing the minimum and maximum depths for each structure, there is a range from $6 \mathrm{~cm}$ to $92 \mathrm{~cm}$. The maximum post hole depth ranges from 16 to $92 \mathrm{~cm}(\bar{x}=52.42 \mathrm{~cm}, \mathrm{~s}=18.19)$ while the minimum post hole depth ranges from 6 to $43(\bar{x}=15.24 \mathrm{~m}, \mathrm{~s}=9.2428)$

The wall post hole spacing from all 38 structures ranges from $9 \mathrm{~cm}$ to $1.77 \mathrm{~m}$ with mean wall post hole spacing for the 38 non-mound structures, with the inner and outer walls of Feature 53 treated separately, ranging from $17 \mathrm{~cm}$ (Feature 9) to $89 \mathrm{~cm}$ (Feature 33) $(\bar{x}=54 \mathrm{~cm}, \mathrm{~s}=15.09)$. The distance from the wall post holes to the approximate center of the structures ranges from $73 \mathrm{~cm}$ to $9.11 \mathrm{~m}$. The mean distances from the wall post holes to the center ranges from $79 \mathrm{~cm}$ (Feature 7) to $8.12 \mathrm{~m}$ (Feature 53 outer wall) $(\bar{x}=4.63 \mathrm{~m}, \mathrm{~s}=1.7326)$.

There is a wide range in ratios of average distance between wall post holes and average distance to the structure centers. The ratio of those measurements ranges from 1:1.1 (Feature 7) to 1:33.1 (Feature 9), with the smallest being Feature 7, a possible granary. With the three possible granaries, Features 7, 50 and 52 excluded, the ratio ranges from 1:6.3 (Features 33 and 139) to 1:33.1 (Feature 9). As discussed previously, Feature 9 is the only non-mound structure from the George C. Davis site (with the exception of Feature 35) that was constructed using post trenches. If Feature 9 and the possible granaries are excluded, the range in ratios is much smaller, although still fairly large, ranging from 1:6.3 to 1:15.6 (Feature 53 outer wall). The exceedingly large ratio for Feature 9, 1:33.1, lends further support to the suggestion that the structure represents a different architectural style. The ratio for the circular structures ranges from 1:1.1 to 
1:13.9, or $1: 6.3$ to 13.9 without Features 7,50 and 52. The range for the sub-round structures is much smaller, ranging from $1: 6.3$ to $1: 7.3$. The ratio for the sub-square structures ranges from 1:9.0 to 33.1, or from 1:9.0 to 1:15.6 with Feature 9 excluded.

When the mean post hole spacing from these three groups is compared, the circular structures have spacing ranging from 0.28 to $0.89 \mathrm{~m}(\mathrm{n}=29, \bar{x}=0.53 \mathrm{~m}, \mathrm{~s}=$ 0.1481); the sub-round post hole spacing ranges from 0.56 to $0.81 \mathrm{~m}(\mathrm{n}=3, \bar{x}=0.69 \mathrm{~m}, \mathrm{~s}$ $=0.1250)$; and the sub-square structures have a spacing ranging from $0.17 \mathrm{~m}$ to $0.66 \mathrm{~m}(\mathrm{n}$ $=7, \bar{x}=0.50 \mathrm{~m}, \mathrm{~s}=0.1554)$. Average distance from wall post holes to the center ranges from $0.79 \mathrm{~m}$ to $6.99 \mathrm{~m}(\mathrm{n}=24, \bar{x}=6.12 \mathrm{~m}, \mathrm{~s}=2.4014)$ for the circular structures including Features 7, 50 and 52, and from $2.83 \mathrm{~m}$ to $6.99 \mathrm{~m}(\mathrm{n}=21, \bar{x}=4.68 \mathrm{~m}, \mathrm{~s}=$ 1.2284) without the three possible granaries. The measurements range from $4.09 \mathrm{~m}$ to $5.13 \mathrm{~m}(\mathrm{n}=3, \bar{x}=4.54 \mathrm{~m}, \mathrm{~s}=0.5339)$ for the sub-round structures and $4.86 \mathrm{~m}$ to $8.12 \mathrm{~m}$ $(\mathrm{n}=6, \bar{x}=6.30 \mathrm{~m}, \mathrm{~s}=0.1 .30)$ for the sub-square structures. Table 35 provides the wall post hole spacing measurements for the non-mound George C. Davis structures. 
Table 35. Wall post hole spacing for the Non-mound structures from the George C. Davis site.

\begin{tabular}{|c|c|c|c|c|c|c|c|c|c|c|c|c|c|}
\hline \multirow{2}{*}{ 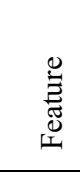 } & \multirow{2}{*}{ 胥 } & \multirow[b]{2}{*}{$\begin{array}{l}\text { Area } \\
\left(\mathrm{m}^{2}\right)\end{array}$} & \multirow{2}{*}{ 兽 } & \multicolumn{4}{|c|}{ Wall Post hole Spacing $(\mathrm{cm})$} & \multirow{2}{*}{ 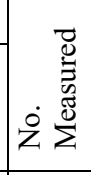 } & \multicolumn{5}{|c|}{ Wall to center $(\mathrm{m})$} \\
\hline & & & & Max & Min & Mean & St Dev & & Max & Min & Mean & St Dev & Ratio* \\
\hline 2 & $\mathrm{c}$ & 66.50 & 10 & 1.77 & 0.45 & 0.76 & 0.5093 & $\mathrm{n}$ & $\mathrm{n}$ & $\mathrm{n}$ & $\mathrm{n}$ & $\mathrm{n}$ & \\
\hline 3 & $\mathrm{sr}$ & 52.80 & 27 & 0.72 & 0.35 & 0.56 & 0.0951 & 34 & 4.39 & 3.79 & 4.09 & 0.1542 & $1: 7.3$ \\
\hline 4 & Ss & 126.26 & 46 & 0.79 & 0.28 & 0.56 & 0.1249 & 58 & 6.57 & 5.16 & 5.89 & 0.3778 & $1: 10.5$ \\
\hline 6 & Ss & 99.91 & 58 & 1.48 & 0.23 & 0.57 & 0.3722 & 62 & 6.29 & 4.91 & 5.61 & 0.4327 & $1: 9.8$ \\
\hline 7 & $\mathrm{c}$ & 1.80 & 7 & 0.80 & 0.53 & 0.69 & 0.0889 & 7 & 0.83 & 0.73 & 0.79 & 0.0419 & $1: 1.1$ \\
\hline 8 & $\mathrm{c}$ & 33.20 & 20 & 0.78 & 0.17 & 0.41 & 0.1819 & 32 & 3.37 & 3.04 & 3.26 & 0.0826 & $1: 7.9$ \\
\hline 9 & Ss & 98.01 & 134 & 0.30 & 0.09 & 0.17 & 0.0425 & 147 & 6.09 & 5.19 & 5.63 & 0.2039 & $1: 33.1$ \\
\hline 10 & $\mathrm{c}$ & 33.20 & 42 & 0.77 & 0.25 & 0.42 & 0.1041 & 45 & 3.61 & 2.95 & 3.29 & 0.1749 & $1: 7.8$ \\
\hline 11 & $\mathrm{c}$ & 70.90 & 57 & 0.26 & 0.91 & 0.52 & 0.1585 & 57 & 4.95 & 4.40 & 4.69 & 0.1309 & $1: 9$ \\
\hline 12 & $\mathrm{c}$ & 50.30 & 24 & 0.66 & 0.31 & 0.47 & 0.0794 & 37 & 4.24 & 3.89 & 4.02 & 0.0667 & $1: 8.5$ \\
\hline 13 & $\mathrm{c}$ & 89.90 & 47 & 0.70 & 0.37 & 0.52 & 0.0868 & 57 & 5.55 & 5.31 & 5.41 & 0.0578 & $1: 10.4$ \\
\hline 14 & $\mathrm{c}$ & 73.90 & 33 & 0.75 & 0.25 & 0.58 & 0.1205 & 42 & 5.09 & 4.71 & 4.87 & 0.0926 & $1: 8.4$ \\
\hline 15 & $\mathrm{c}$ & 77.00 & 30 & 0.70 & 0.36 & 0.55 & 0.0794 & 34 & 5.11 & 4.86 & 4.97 & 0.0671 & $1: 9$ \\
\hline 16 & $\mathrm{c}$ & 86.60 & 49 & 0.23 & 0.85 & 0.55 & 0.1474 & 53 & 5.55 & 5.14 & 5.28 & 0.0839 & $1: 9.6$ \\
\hline 17 & $\mathrm{c}$ & 25.50 & 58 & 0.52 & 0.17 & 0.28 & 0.0702 & 60 & 2.92 & 2.72 & 2.83 & 0.0439 & $1: 10.1$ \\
\hline 18 & $\mathrm{c}$ & 55.40 & 19 & 0.65 & 0.30 & 0.45 & 0.0926 & 31 & 4.25 & 3.66 & 3.96 & 0.1466 & $1: 8.8$ \\
\hline 19 & $\mathrm{c}$ & 40.70 & 21 & 0.22 & 0.72 & 0.48 & 0.1345 & 30 & 3.90 & 3.43 & 3.69 & 0.1094 & $1: 7.7$ \\
\hline 29 & $\mathrm{sr}$ & 60.80 & 31 & 1.38 & 0.31 & 0.69 & 0.3254 & 35 & 4.51 & 4.29 & 4.40 & 0.0644 & $1: 6.4$ \\
\hline 30 & $\mathrm{c}$ & 29.20 & 65 & 0.73 & 0.16 & 0.28 & 0.1152 & 65 & 3.23 & 2.70 & 2.96 & 0.1547 & $1: 10.6$ \\
\hline 32 & $\mathrm{c}$ & 66.50 & 33 & 0.64 & 0.25 & 0.37 & 0.0989 & $\mathrm{n}$ & $\mathrm{n}$ & $\mathrm{n}$ & $\mathrm{n}$ & $\mathrm{n}$ & $\mathrm{N}$ \\
\hline 33 & $\mathrm{c}$ & 89.90 & 34 & 1.10 & 0.50 & 0.89 & 0.1524 & 37 & 6.10 & 5.02 & 5.59 & 0.3654 & $1: 6.3$ \\
\hline 41 & $\mathrm{c}$ & 60.80 & 39 & 0.85 & 0.35 & 0.57 & 0.1088 & 47 & 4.68 & 4.40 & 4.52 & 0.0677 & $1: 7.9$ \\
\hline 46 & $\mathrm{c}$ & 62.20 & 8 & 0.84 & 0.58 & 0.71 & 0.1003 & $\mathrm{n}$ & $\mathrm{n}$ & $\mathrm{n}$ & $\mathrm{n}$ & $\mathrm{n}$ & $\mathrm{N}$ \\
\hline 47 & $\mathrm{c}$ & 40.70 & 13 & 0.66 & 0.34 & 0.49 & 0.0806 & 23 & 3.84 & 3.47 & 3.63 & 0.0944 & $1: 7.4$ \\
\hline 48 & $\mathrm{c}$ & 40.70 & 7 & 0.55 & 0.33 & 0.42 & 0.0922 & $\mathrm{n}$ & $\mathrm{n}$ & $\mathrm{n}$ & $\mathrm{n}$ & $\mathrm{n}$ & $\mathrm{N}$ \\
\hline 49 & $\mathrm{c}$ & 136.80 & 27 & 0.95 & 0.29 & 0.54 & 0.1742 & 39 & 6.32 & 5.87 & 6.13 & 0.1286 & $1: 11.4$ \\
\hline 50 & $\mathrm{c}$ & 2.80 & 9 & 0.91 & 0.47 & 0.62 & 0.1380 & 10 & 1.30 & 1.00 & 1.12 & 0.0940 & 1:1.8 \\
\hline 51 & $\mathrm{c}$ & 132.70 & 39 & 0.94 & 0.30 & 0.69 & 0.1617 & 48 & 6.90 & 6.44 & 6.65 & 0.1005 & $1: 9.6$ \\
\hline 52 & $\mathrm{c}$ & 2.80 & 8 & 0.82 & 0.54 & 0.67 & 0.1172 & 9 & 1.10 & 0.96 & 1.04 & 0.0485 & 1:1.6 \\
\hline $53 \mathrm{i}$ & Ss & 153.86 & 33 & 0.85 & 0.40 & 0.51 & 0.1062 & 33 & 8.77 & 6.22 & 7.71 & 0.9009 & $1: 15.1$ \\
\hline 530 & Ss & 153.86 & 32 & 0.71 & 0.31 & 0.52 & 0.1032 & 34 & 9.11 & 6.77 & 8.12 & 0.8415 & $1: 15.6$ \\
\hline 54 & ss & 85.50 & 35 & 0.78 & 0.27 & 0.54 & 0.1221 & 46 & 5.20 & 4.45 & 4.86 & 0.2117 & $1: 9$ \\
\hline 55 & $\mathrm{c}$ & 96.80 & 24 & 0.30 & 0.96 & 0.69 & 0.1541 & 29 & 5.83 & 5.30 & 5.53 & 0.1392 & $1: 9$ \\
\hline 120 & $\mathrm{c}$ & 19.60 & 5 & 0.57 & 0.39 & 0.45 & 0.0749 & $\mathrm{n}$ & $\mathrm{n}$ & $\mathrm{n}$ & $\mathrm{n}$ & $\mathrm{n}$ & $\mathrm{N}$ \\
\hline 125 & $\mathrm{c}$ & 43.00 & 87 & 0.49 & 0.16 & 0.28 & 0.0643 & 87 & 4.09 & 3.79 & 3.91 & 0.0679 & $1: 13.9$ \\
\hline 139 & $\mathrm{sr}$ & 95.04 & 36 & 1.04 & 0.68 & 0.81 & 0.1047 & 38 & 5.51 & 4.75 & 5.13 & 0.1835 & $1: 6.3$ \\
\hline 146 & $\mathrm{c}$ & 91.60 & 53 & 0.88 & 0.36 & 0.65 & 0.0998 & 63 & 7.32 & 6.74 & 6.99 & 0.1296 & $1: 10.8$ \\
\hline 160 & $\mathrm{c}$ & 120.80 & 40 & 0.63 & 0.27 & 0.47 & 0.0844 & 48 & 6.38 & 6.06 & 6.20 & 0.0672 & $1: 13.2$ \\
\hline 185 & Ss & 113.04 & 11 & 0.98 & 0.40 & 0.66 & .2013 & $\mathrm{n}$ & $\mathrm{n}$ & $\mathrm{n}$ & $\mathrm{n}$ & $\mathrm{n}$ & $\mathrm{N}$ \\
\hline
\end{tabular}


Twelve of the non-mound structures from George C. Davis have center post holes, with only three being directly related to central hearths. The central post holes have diameters ranging from $18 \mathrm{~cm}$ to $37 \mathrm{~cm}(\bar{x}=23.58 \mathrm{~cm}, \mathrm{~s}=6.8684)$ and depths ranging from $12 \mathrm{~cm}$ to $134 \mathrm{~cm}$ from the Feature 33 hearth $(\bar{x}=34.25 \mathrm{~cm}, \mathrm{~s}=34.5888)$. The depths for the center posts excluding the exceedingly deep Feature 33 hearth range from $12 \mathrm{~cm}$ to $58 \mathrm{~cm}(\bar{x}=28.45 \mathrm{~cm}, \mathrm{~s}=17.1719)$. Central hearths were recorded in only four of the non-mound structures from the George C. Davis site. These hearths, associated with Features 9, 30, 33, and 125, range in size from $48 \mathrm{~cm}$ to $1.68 \mathrm{~m}(\bar{x}=103.75 \mathrm{~cm}, \mathrm{~s}=$ 49.7217), with depths ranging from $10 \mathrm{~cm}$ to $45 \mathrm{~cm}(\bar{x}=21.5 \mathrm{~cm}, \mathrm{~s}=16.2993)$. Two of the four hearths were clay-lined. It is possible that the lack of hearths or center posts for most of the non-mound structures may be attributed to the high concentration of rebuilding in certain areas of the site and possibly disturbance from subsequent building episodes (Spock 1977), or even to modern disturbance such as plowing of the site's archaeological deposits.

Only two of the non-mound structures, Features 9 and 35, appear to have been burned (Spock 1977). In addition, only Features 9 and 35 had prepared floors and had extended entrances. The Feature 9 floor consisted of a 2-3 cm thick clay lining that completely covered the structure floor (Spock 1977). The burning of Feature 9 is supported by the fact that the clay floor "was hard, cracked, and buckled from firing and the underlying soil was affected to a depth of $10 \mathrm{~cm}$. Charred posts were found in the house fill, most aligned either parallel or perpendicular to the encircling post trench. Within the post trench, the top 2 to $5 \mathrm{~cm}$ of several posts were charred" (Spock 1977:4447).

Feature 9 had a southwest-facing extended entrance consisting of two parallel trenches 0.6-0.7 $\mathrm{m}$ apart and extending 1.7-1.9 $\mathrm{m}$ away from the structure walls (Spock 
1977). The entrance "was paved with a layer of grayish-white, hard packed clay which measured $2.14 \mathrm{~m}$ long, $0.46 \mathrm{~m}$ to $0.61 \mathrm{~m}$ wide and was raised $0.31 \mathrm{~m}$ above the structure's rim. A second layer, $9 \mathrm{~cm}$ thick, and consisting of compact reddish clay, overlay most of the grayish-white clay" (Spock 1977:47). Finally, Feature 9 was built in a $0.37 \mathrm{~m}$ deep pit. This is the only excavated semi-subterranean non-mound structure from the George C. Davis site.

At least 74 non mound structures have been identified in magnetometer surveys of the George C. Davis site (Creel et al. 2005; Osburn et al. 2008). Most of these structures are circular, but there are a few sub-square structures. These structures have areas ranging from $7.79 \mathrm{~m}^{2}$ to $414.1 \mathrm{~m}^{2}(\bar{x}=131.23 \mathrm{~cm}, \mathrm{~s}=98.5701)$. Many of these features have central hearths and some clearly have interior support posts. In addition, some appear to have been burned (see Chapter 4 for a detailed discussion of these features).

While all of the mound-related structures from the George C. Davis site have been classified as special purpose structures (see Spock 1977, and Chapter 4), it is clear that at least some of the non-mound structures likely fit into that category as well. Spock (1977:169) included seven non-mound structures in the category of specialized structures. I have included Features 6, 7, 9, 35, 50, 52, 53 and 125 in the specialized architectural category. Features 7, 50, and 52 have been previously discussed as likely being specialized structures (granaries) given their small size, but not ceremonial structures or ones associated with an elite figure. Spock (1977:170) noted that "a general lack of subsurface storage pits would indicate that use of above-ground granaries at the Davis site is likely."

Spock (1977) included Features 6 and 125 as special function structures given their architectural attributes or apparent use as specialized buildings. Feature 6 is a subsquare structure with walls aligned to the cardinal directions. In addition, this structure is 
similar in form to Features 34, 39, and 40, which were located on Mound A platforms (Spock 1977). Feature 125, located between Mounds B and C, was included due to the apparent reuse and renewal of its central hearth. The hearth was clay-lined and had been refurbished at least three times. Spock (1977:178) commented that "the hearth with its obvious renewal was not matched by that of any other structure at the site - on, under, or near the mounds. The radiocarbon dating of the three different levels of the hearth (woody charcoal dates on Hearth 1, A.D. 780-960, on Hearth 2, A.D. 870-1030, and on Hearth 3, A.D. 950-1130) supports the fact that it was renewed on several occasions during the life of the building." In addition, the structure had four large interior support posts similar in form to the circular four support post structures discussed in Chapter 4, and similar to Features 31 and 42.

\section{Oak Hill Village (41RK214)}

While the George C. Davis site provides a large number of non-mound structures with a considerable amount of variety in architectural form and use, the Oak Hill Village site provides architectural data from a primarily Middle Caddo community with mainly circular structures situated around a central plaza. The Oak Hill Village site (41RK214) is perhaps one of the more significant East Texas Caddo sites excavated within the past decade, particularly in terms of information obtained on community layout, development, and use of architectural space (Rogers and Perttula 2004; Perttula and Rogers 2007). At least 43 structures of varying size and shape were recorded at the site as well as a central plaza area and a small earthen mound (Perttula and Rogers 2007; Rogers and Perttula 2004). Table 36 provides summary data for these structures. While there were a few isolated structures at the site, most were situated in spatially distinct clusters, some of which were "composed of many dwellings that represented successive building episodes" 
(Rogers and Perttula 2004:49). In fact, there were "as many as five episodes of house building" at the site (Rogers and Perttula 2004:49).

The 43 structures at the site were grouped into eight Structure Groups (A-H) (Figure 57) with several examples of rebuilding throughout. Rogers and Perttula (2004:49) explained that "the use of the term structure group in these cases is an arbitrary means of facilitating their description and analysis." The rebuilding and extensive reuse of the various structure groups resulted in several examples of overlapping post hole patterns. In discussing the practice of rebuilding, Rogers and Perttula (2004:49) noted that "newer dwelling was placed adjacent to the first and closely paralleled it in the number, spacing, and size of the wall posts used, suggesting the reuse of existing materials". Supporting the idea of reuse of existing materials, the second structure was usually smaller. 


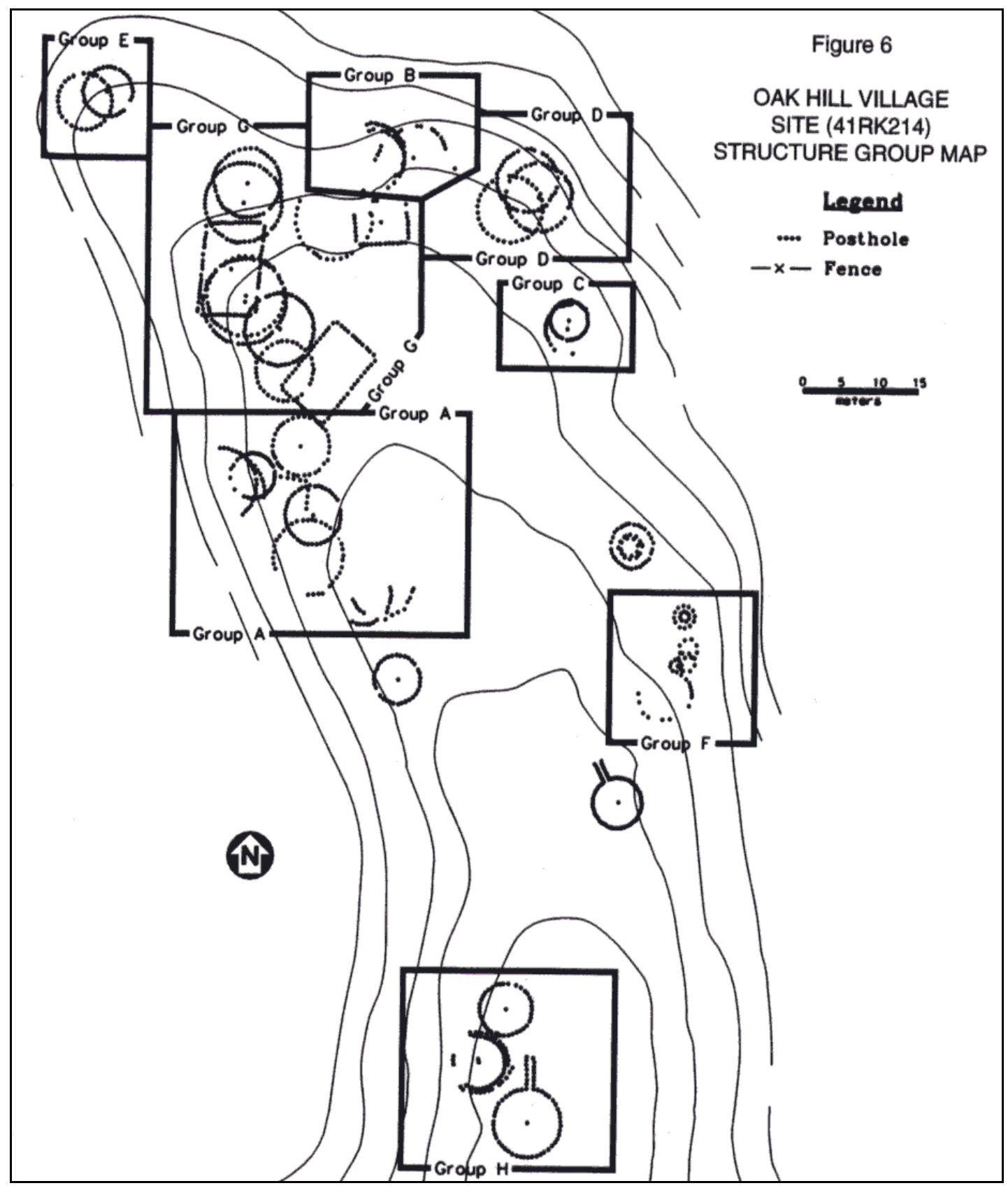

Figure 57. Plan of the Oak Hill Village site (Rogers and Perttula 2004:Figure 6). 
Table 36. Summary of Oak Hill Village (41RK214) non-mound structures (Rogers and Perttula 2004).

\begin{tabular}{|c|c|c|c|c|c|c|c|c|c|c|c|c|c|c|c|c|c|c|c|c|c|}
\hline \multirow[b]{3}{*}{ 荵 } & \multirow[b]{3}{*}{ 胥 } & \multirow[b]{3}{*}{ 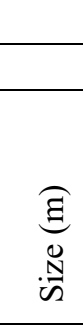 } & \multirow[b]{3}{*}{ 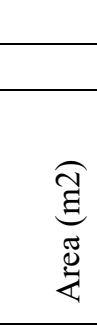 } & \multicolumn{18}{|c|}{ Exterior Posts } \\
\hline & & & & & \multicolumn{4}{|c|}{ Diameter $(\mathrm{cm})$} & \multicolumn{4}{|c|}{ Depth (m) } & \multicolumn{4}{|c|}{ Between wall posts $(\mathrm{cm})$} & \multicolumn{5}{|c|}{ Wall to center post hole (m) } \\
\hline & & & & 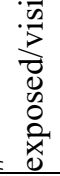 & 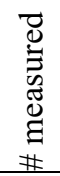 & $\stackrel{\gtrless}{\check{\Xi}}$ & 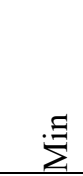 & $\sum_{\Sigma}^{\mathbb{E}}$ & 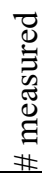 & 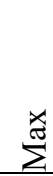 & $\dot{\Sigma}$ & $\stackrel{\tilde{\Xi}}{\stackrel{\Xi}{\Sigma}}$ & $\stackrel{\Xi}{\Sigma}$ & $\stackrel{\check{\Xi}}{\Sigma}$ & $\sum_{\Sigma}^{\mathbb{E}}$ & $\begin{array}{l}\overrightarrow{\tilde{D}} \\
\stackrel{\Delta}{\tilde{n}}\end{array}$ & $\stackrel{\Xi}{\Sigma}$ & $\stackrel{\star 凶}{\Sigma}$ & $\sum_{\Sigma}^{\mathbb{\Xi}}$ & $\stackrel{\overrightarrow{\tilde{U}}}{\stackrel{\vec{n}}{\Delta}}$ & Ratio* \\
\hline 1 & $\mathrm{c}$ & 8.00 & 50.27 & 33 & 31 & 0.21 & 0.12 & & & & & & 0.54 & 0.98 & 0.70 & 0.0825 & 3.71 & 3.98 & 3.86 & 0.70 & $1: 5.4$ \\
\hline 2 & $\mathrm{c}$ & 6.50 & 33.18 & 71 & & 0.47 & 0.10 & & & & & & 0.10 & 0.25 & & & & & & & $1: 11.57$ \\
\hline 3 & $\mathrm{c}$ & 5.90 & 27.34 & 36 & 30 & 0.41 & 0.10 & & & & & & 0.30 & 0.62 & 0.41 & 0.0770 & 2.76 & 3.10 & 2.94 & 0.109 & $1: 7.1$ \\
\hline 5 & $\mathrm{c}$ & 6.50 & 33.18 & 35 & & 0.27 & 0.11 & & & & & & 0.44 & 0.61 & & & & & & & \\
\hline 6 & $\mathrm{c}$ & 5.25 & 21.65 & 39 & 34 & & & & & & & & 0.21 & 0.66 & 0.41 & 0.0744 & 2.39 & 2.69 & 2.52 & 0.06 & $1: 6.1$ \\
\hline 7 & $\mathrm{c}$ & 8.10 & 51.53 & 39 & 31 & 0.29 & 0.14 & 0.19 & & & & & 0.19 & 0.68 & 0.57 & 0.1000 & 3.71 & 4.14 & 4.00 & 3.70 & $1: 7$ \\
\hline 8 & $\mathrm{c}$ & 6.40 & 32.17 & 24 & 24 & & & & & & & & 0.25 & 0.60 & 0.38 & 0.1006 & 2.83 & 3.60 & 3.08 & 0.21 & $1: 8.1$ \\
\hline 9 & $\mathrm{c}$ & 9.00 & 63.62 & 48 & 48 & 0.35 & 0.10 & 0.21 & & & & & 0.41 & 0.71 & 0.52 & 0.0651 & 4.41 & 4.81 & 4.65 & 0.79 & $1: 8.9$ \\
\hline 10 & $\mathrm{c}$ & 6.00 & 28.27 & 31 & & 0.25 & 0.15 & & & & & & 0.38 & 0.77 & & & & & & & \\
\hline 11 & $\mathrm{c}$ & 3.00 & 7.07 & 12 & 8 & & & & & & & & 0.40 & 0.69 & 0.53 & 0.0900 & na & $\mathrm{Na}$ & na & na & na \\
\hline 12 & $\mathrm{c}$ & 8.80 & 60.82 & 39 & 39 & 0.26 & 0.11 & 0.17 & & & & & 0.29 & 0.89 & 0.63 & 0.1500 & 4.07 & 4.50 & 4.34 & 0.08 & $1: 6.9$ \\
\hline 13 & $\mathrm{c}$ & 8.50 & 56.75 & 32 & 32 & 0.24 & 0.15 & & & & & & 0.67 & 0.92 & 0.79 & 0.0500 & 4.14 & 4.43 & 4.26 & 0.07 & $1: 5.4$ \\
\hline 14 & $\mathrm{c}$ & 7.50 & 44.18 & 42 & 41 & 0.22 & 0.10 & & & & & & 0.44 & 0.71 & 0.55 & 0.0533 & 3.72 & 3.93 & 3.81 & 0.056 & $1: 6.9$ \\
\hline 15 & $\mathrm{c}$ & 2.40 & 4.52 & 8 & 8 & & & & & & & & 0.90 & 1.02 & 0.95 & 0.0400 & na & $\mathrm{Na}$ & na & na & na \\
\hline 16 & $\mathrm{c}$ & 2.60 & 5.31 & 8 & 8 & & & & & & & & 0.85 & 1.02 & 0.94 & 0.0500 & na & $\mathrm{Na}$ & na & na & na \\
\hline 17 & $\mathrm{c}$ & 6.50 & 33.18 & 33 & 29 & & & & & & & & 0.48 & 0.68 & 0.58 & 0.0500 & 3.05 & 3.35 & 3.22 & 3.05 & $1: 5.5$ \\
\hline 18 & $\mathrm{c}$ & 8.70 & 59.45 & 47 & 46 & & & & & & & & 0.43 & 0.77 & 0.59 & 0.0700 & 4.34 & 4.54 & 4.40 & 0.05 & $1: 7.5$ \\
\hline 19 & $\mathrm{c}$ & 6.00 & 28.27 & & 28 & & & & & & & & 0.39 & 0.61 & 0.49 & 0.0500 & 3.27 & 3.78 & 3.40 & 0.09 & $1: 6.9$ \\
\hline 20 & $\mathrm{c}$ & 6.50 & 33.18 & & 21 & & & & & & & & 0.42 & 0.84 & 0.61 & 0.1100 & 3.44 & 4.58 & 4.02 & 0.15 & $1: 6.6$ \\
\hline 21 & $\mathrm{c}$ & 6.80 & 36.32 & 39 & 39 & & & & & & & & 0.22 & 0.72 & 0.53 & 0.1100 & 3.34 & 3.55 & 3.42 & 0.05 & $1: 6$ \\
\hline 22 & $\mathrm{c}$ & 3.00 & 7.07 & 12 & & 0.25 & 0.15 & & & & & & 0.75 & 1.10 & & & & & & & \\
\hline
\end{tabular}




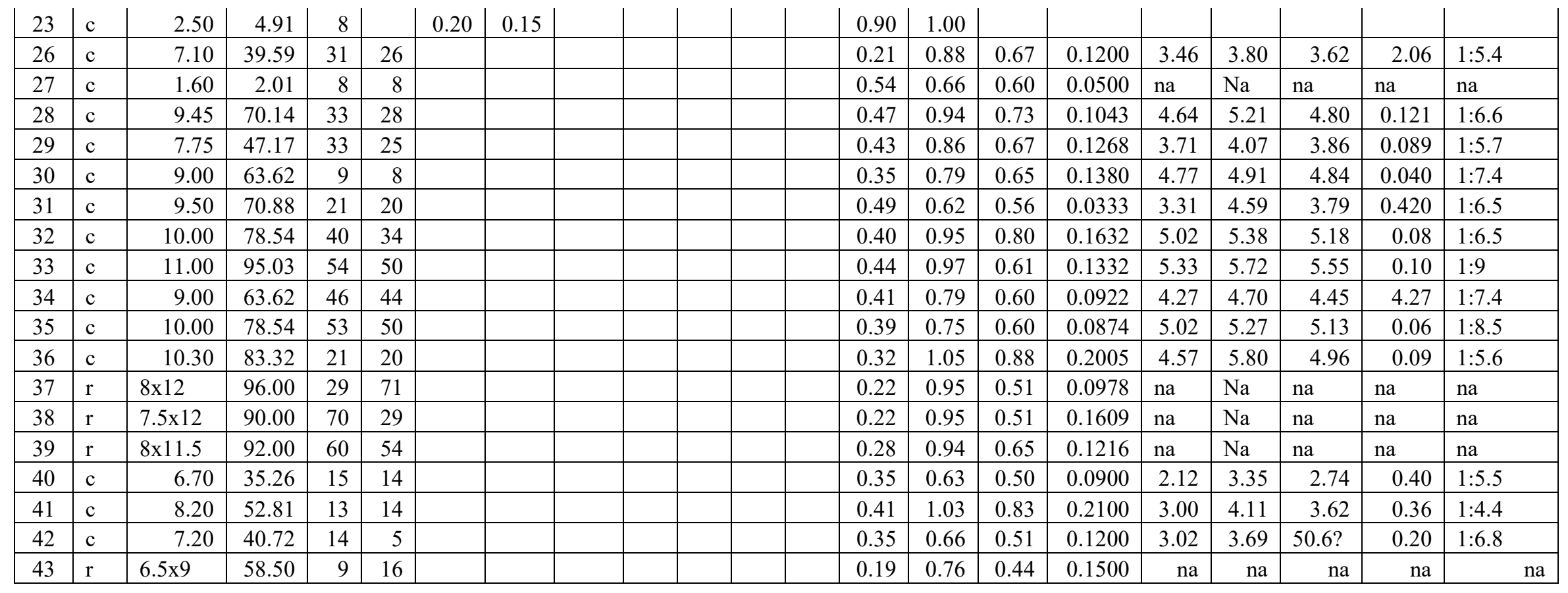

*Average Distance b/w Exterior Post holes and Average Distance to Center; $\mathrm{c}=$ circular; $\mathrm{r}=$ rectangular 
The oldest structures at the site, dating to between cal AD 1155-1285, were the four rectangular structures (Structures 37, 38, 39, and 43) (Table 37). Structure 37 measured about $8 \times 12 \mathrm{~m}$, but with only the south half of the structure identified. Structure 38 measured $12 \times 7.5 \mathrm{~m}$, was oriented north-south, and had evidence of repair. Measuring 11.5 x $8 \mathrm{~m}$, Structure 39 also showed evidence of repair. In terms of repair for both Structures 38 and 39, "some wall posts appear to have been replaced" (Rogers and Perttula 2004:78). Finally, Structure 43 measured approximately 6.5 x $9 \mathrm{~m}$ and was defined by portions of the northern and eastern walls (Rogers and Perttula 2004).

Table 37. Rectangular structures from the Oak Hill Village Site (adapted from Rogers and Perttula [2004:59, 75 and Tables 4 and 14])

\begin{tabular}{|c|c|c|c|c|}
\hline Structure & 37 & 38 & 39 & 43 \\
\hline Estimated Size (m) & $8 \times 12$ & $7.5 \times 12$ & $8 \times 11.5$ & $6.5 \times 9$ \\
\hline Shape & Rect. & Rect. & Rect. & Rect. \\
\hline Approximate interior area $\left(\mathrm{m}^{2}\right)$ & 96 & 90 & 92 & 58.5 \\
\hline No. of wall post holes identified & 29 & 70 & 60 & 9 \\
\hline No. of wall post holes measured & & 29 & 54 & \\
\hline \multicolumn{5}{|l|}{ Wall post hole spacing $(\mathrm{cm})$} \\
\hline \begin{tabular}{l|l} 
& Minimum \\
\end{tabular} & 22 & 22 & 28 & 19 \\
\hline Maximum & 95 & 95 & 94 & 76 \\
\hline Mean & 51 & 51 & 65 & 44 \\
\hline \begin{tabular}{l|l} 
& Std Dev \\
\end{tabular} & 9.78 & 16.09 & 12.16 & 15 \\
\hline Structure Group & $\mathrm{G}$ & $\mathrm{G}$ & $\mathrm{G}$ & A \\
\hline
\end{tabular}

Interior compartments, as represented by several interior post holes, may have been associated with structures 38 and 39, although in both instances these associations are not definite (Rogers and Perttula 2004:78). Features 261, 101 and 235, a hearth and two small pits, respectively, may be associated with Structure 39, although like the interior compartments, this is not clear. A radiocarbon date from the hearth (Feature 261) indicates that the hearth may date later than Structure 39 (Rogers and Perttula 2004:78). 
Two radiocarbon dates were obtained from wood charcoal from two Structure 39 post holes. The sample from post hole 1 yielded a date range of cal A.D. 1151-1222 $(\mathrm{p}=0.56)$ (calibrated at $1 \sigma)$ (Rogers and Perttula 2004). The post hole 3 sample yielded a cal A.D. 1207-1285 $(\mathrm{p}=0.94)$ (calibrated at $1 \sigma)$ age range (Rogers and Perttula 2004:78). These radiocarbon dates "are among the oldest dates derived from posthole charcoal at the site" (Rogers and Perttula 2004:78). The construction of the rectangular structures was placed at between cal AD 1155-1285, predating the creation and use of the plaza and the other structures at the site. At Oak Hill Village, "this form of building was probably abandoned around AD 1250 in favor of circular houses" (Rogers and Perttula 2004:346).

The 39 circular structures from the Oak Hill Village site range in size from $1.6 \mathrm{~m}$ to $11 \mathrm{~m}$ in diameter. The smaller of these, at least four and possibly six structures (Cruse and Perttula 1996:23), have been interpreted as representing granaries (Rogers and Perttula 2004:72). Cruse and Perttula (1996:23) included Structures 22 and 23 as possible granaries based on their diameter, $3 \mathrm{~m}$ and $2.5 \mathrm{~m}$ respectively; however, these have been reinterpreted by Rogers and Perttula (2004:87) as being architectural components, specifically, interior compartments associated with Structure 10. The remaining four small structures (Structures 11, 15, 16, and 27) interpreted as granaries (Figure 58) measure $3 \mathrm{~m}$ or less in diameter (Table 38). 


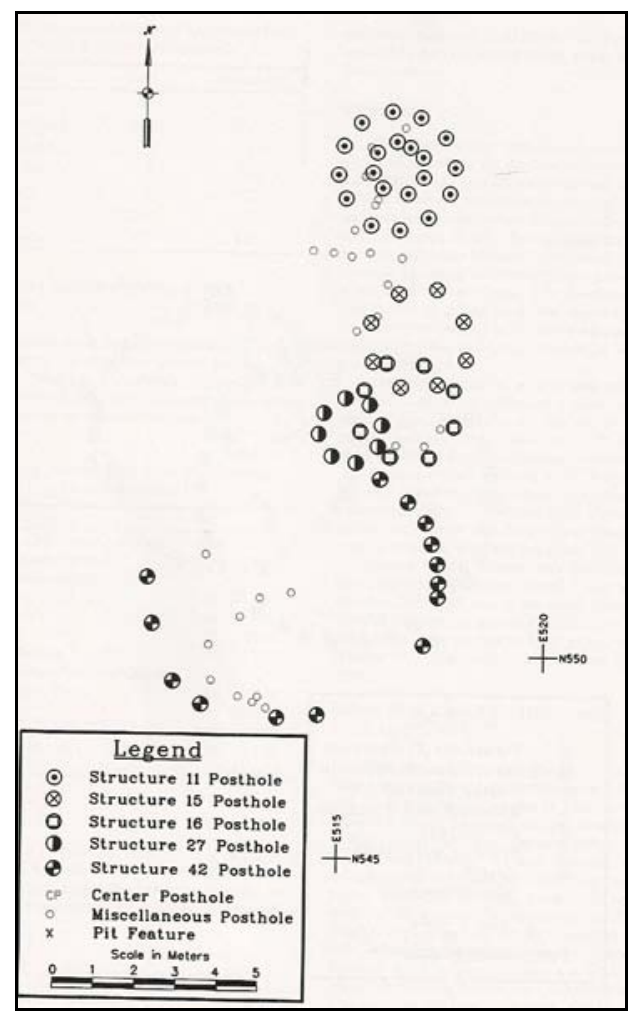

Figure 58. Possible granaries from the Oak Hill Village site. (Rogers and Perttula 2004:Figure 16)

Table 38. The four Oak Hill Village site granaries (adapted from Rogers and Perttula [2004:75 and Table 17]).

\begin{tabular}{|c|c|c|c|c|}
\hline Structure & 11 & 15 & 16 & 27 \\
\hline Estimated diameter $(\mathrm{m})$ & 3 & 2.4 & 2.6 & 1.6 \\
\hline Area $\left(\mathrm{m}^{2}\right)$ & 7.07 & 4.52 & 5.31 & 2.01 \\
\hline Shape & circular & circular & circular & circular \\
\hline No. of wall post holes identified & 12 & 8 & 8 & 8 \\
\hline No. of wall post holes measured & 8 & 8 & 8 & 8 \\
\hline \multicolumn{5}{|l|}{ Wall post hole spacing $(\mathrm{cm})$} \\
\hline \begin{tabular}{l|l} 
& Minimum \\
\end{tabular} & 0.4 & 0.9 & 0.85 & 0.54 \\
\hline Maximum & 0.69 & 1.02 & 1.02 & 0.66 \\
\hline Mean & 0.53 & 0.95 & 0.94 & 0.6 \\
\hline $\begin{array}{l}\text { Std Dev } \\
\text { Structure Group }\end{array}$ & $\begin{array}{l}0.09 \\
\mathrm{~F}\end{array}$ & $\begin{array}{l}0.04 \\
\mathrm{~F}\end{array}$ & $\begin{array}{l}0.05 \\
\mathrm{~F}\end{array}$ & $\begin{array}{l}0.05 \\
\mathrm{~F}\end{array}$ \\
\hline
\end{tabular}


The remaining circular structures include 31 with non-extended entrances, and two with extended entrances. The 31 circular structures without extended entrances range in size from $5.25 \mathrm{~m}$ to $11 \mathrm{~m}(\bar{x}=7.87 \mathrm{~m}, \mathrm{~s}=1.47)$ in diameter with areas ranging from $21.65 \mathrm{~m}^{2}$ to $95.03 \mathrm{~m}^{2}(\bar{x}=50.27, \mathrm{~s}=18.67)$ (Table 39$)$. The two structures with extended entrances, Structures 2 and 18 (Figure 59), measure $6.5 \mathrm{~m}$ and $8.7 \mathrm{~m}$ in diameter, respectively, with areas of $33.18 \mathrm{~m}^{2}$ and $59.45 \mathrm{~m}^{2}$. Structure 18 had 47 wall post holes and a center post. The entrance was north-facing, and consisted of at least 15 individually set posts that extended approximately $4 \mathrm{~m}$ from the structure walls, with a width of approximately $1 \mathrm{~m}$. The entrance post holes "were spaced at similar distances as the wall post holes, varying from 38 to 85 cm" (Rogers and Perttula 2004:81). Rogers and Perttula (2004:81) noted that Structure 18 "surely must have served a very specialized function," as indicated not only by its unique architecture, but also "evidenced by its elevated position on the landscape." Rogers and Perttula (2007:86) suggested that Structure 18 dates to the Late Village era (A.D. 1350-1450). 
Table 39. Summary of the 31 remaining Oak Hill Village circular structures without extended entrances (adapted from Rogers and Perttula 2004:75).

\begin{tabular}{|c|c|c|c|c|c|c|c|c|c|c|c|c|c|c|c|c|c|}
\hline \multirow[b]{2}{*}{ 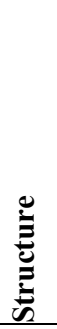 } & \multirow[b]{2}{*}{ 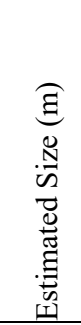 } & \multirow[b]{2}{*}{ 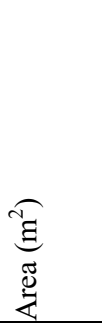 } & \multirow{2}{*}{ 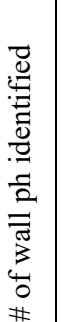 } & \multirow{2}{*}{ 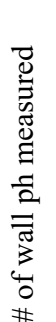 } & \multicolumn{4}{|c|}{$\begin{array}{l}\text { Wall post hole } \\
\text { spacing }(\mathrm{cm})\end{array}$} & \multicolumn{5}{|c|}{ Wall to center post hole (m) } & \multicolumn{4}{|c|}{ Post hole diameter } \\
\hline & & & & & 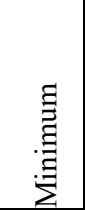 & 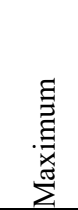 & $\sum_{\Sigma}^{\mathbb{E}}$ & $\begin{array}{l}\vec{D} \\
\stackrel{\vec{D}}{i n} \\
\stackrel{\vec{D}}{i}\end{array}$ & 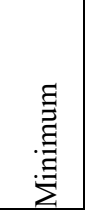 & $\begin{array}{l}\text { 声 } \\
\text { 离 } \\
\text { 岕 }\end{array}$ & $\sum_{\Sigma}^{\bar{E}}$ & $\begin{array}{l}\overrightarrow{0} \\
\stackrel{\overrightarrow{0}}{\vec{n}} \\
\text { in }\end{array}$ & $\stackrel{\circ}{\overparen{E}}$ & $\begin{array}{l}\text { 苇 } \\
\text { 慁 }\end{array}$ & 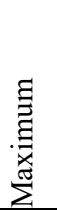 & $\sum_{\Sigma}^{\text {ॠू }}$ & 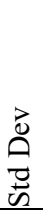 \\
\hline 1 & 8 & 50.27 & 33 & 31 & 54 & 98 & 70 & 8.25 & 3.71 & 3.98 & 3.86 & 0.7 & $1: 5.4$ & 12 & 21 & & \\
\hline 3 & 5.9 & 27.34 & 36 & 30 & 30 & 62 & 40.53 & 7.7 & 2.76 & 3.1 & 2.94 & 0.109 & $1: 7.1$ & 10 & 41 & & \\
\hline 4 & 7.5 & 44.18 & 15 & 15 & 33 & 74 & 54.2 & 12.29 & 4.29 & 5.21 & 4.71 & 0.3 & $1: 8.7$ & & & & \\
\hline 5 & 6.5 & 33.18 & 35 & & 44 & 61 & & & & & & & & 11 & 27 & & \\
\hline 6 & 5.25 & 21.65 & 39 & 34 & 21 & 66 & 41 & 7.44 & 2.39 & 2.69 & 2.52 & 0.06 & $1: 6.1$ & & & & \\
\hline 7 & 8.1 & 51.53 & 39 & 31 & 19 & 68 & 57 & 10 & 3.71 & 4.14 & 4 & 3.7 & $1: 7$ & 14 & 29 & 19 & 4 \\
\hline 8 & 6.4 & 32.17 & 24 & 24 & 25 & 60 & 38.17 & 10.06 & 2.83 & 3.6 & 3.08 & 0.21 & $1: 8.1$ & & & & \\
\hline 9 & 9 & 63.62 & 48 & 48 & 41 & 71 & 52 & 6.51 & 4.41 & 4.81 & 4.65 & 0.79 & $1: 8.9$ & 10 & 35 & 21 & 6 \\
\hline 10 & 6 & 28.27 & 31 & & 38 & 77 & & & & & & & & 15 & 25 & & \\
\hline 12 & 8.8 & 60.82 & 39 & 39 & 29 & 89 & 63 & 15 & 4.07 & 4.5 & 4.34 & 0.08 & $1: 6.9$ & 11 & 26 & 17 & 4 \\
\hline 13 & 8.5 & 56.75 & 32 & 32 & 67 & 92 & 79 & 5 & 4.14 & 4.43 & 4.26 & 0.07 & $1: 5.4$ & 15 & 24 & & \\
\hline 14 & 7.5 & 44.18 & 42 & 41 & 44 & 71 & 54.95 & 5.33 & 3.72 & 3.93 & 3.81 & 0.056 & $1: 6.9$ & 10 & 22 & & \\
\hline 17 & 6.5 & 33.18 & 33 & 29 & 48 & 68 & 58 & 5 & 3.05 & 3.35 & 3.22 & 3.05 & $1: 5.5$ & & & & \\
\hline 19 & 6 & 28.27 & & 28 & 39 & 61 & 49 & 5 & 3.27 & 3.78 & 3.4 & 0.09 & $1: 6.9$ & & & & \\
\hline 20 & 6.5 & 33.18 & & 21 & 42 & 84 & 61 & 11 & 3.44 & 4.58 & 4.02 & 0.15 & $1: 6.6$ & & & & \\
\hline 21 & 6.8 & 36.32 & 39 & 39 & 22 & 72 & 53 & 11 & 3.34 & 3.55 & 3.42 & 0.052 & $1: 6$ & & & & \\
\hline 24 & 7.7 & 46.57 & 19 & 17 & 32 & 80 & 51.57 & 11.9 & 2.87 & 3.84 & 3.27 & 0.32 & $1: 6.3$ & & & & \\
\hline 25 & 7.8 & 47.78 & & 16 & 35 & 65 & 53.87 & 8.13 & 3.8 & 4.02 & 3.9 & 0.5 & $1: 7.2$ & & & & \\
\hline 26 & 7.1 & 39.59 & 31 & 26 & 21 & 88 & 67 & 12 & 3.46 & 3.8 & 3.62 & 2.06 & $1: 5.4$ & & & & \\
\hline 28 & 9.45 & 70.14 & 33 & 28 & 47 & 94 & 73.1 & 10.43 & 4.64 & 5.21 & 4.8 & 0.121 & 1:6.6 & & & & \\
\hline 29 & 7.75 & 47.17 & 33 & 25 & 43 & 86 & 67.08 & 12.68 & 3.71 & 4.07 & 3.86 & 0.089 & $1: 5.7$ & & & & \\
\hline 30 & 9 & 63.62 & 9 & 8 & 35 & 79 & 64.63 & 13.8 & 4.77 & 4.91 & 4.84 & 0.04 & $1: 7.4$ & & & & \\
\hline 31 & 9.5 & 70.88 & 21 & 20 & 49 & 62 & 56.15 & 3.33 & 3.31 & 4.59 & 3.79 & 0.42 & $1: 6.5$ & & & & \\
\hline 32 & 10 & 78.54 & 40 & 34 & 40 & 95 & 80 & 16.32 & 5.02 & 5.38 & 5.18 & 0.08 & $1: 6.5$ & & & & \\
\hline 33 & 11 & 95.03 & 54 & 50 & 44 & 97 & 61 & 13.32 & 5.33 & 5.72 & 5.55 & 0.095 & $1: 9$ & & & & \\
\hline 34 & 9 & 63.62 & 46 & 44 & 41 & 79 & 60 & 9.22 & 4.27 & 4.7 & 4.45 & 4.27 & $1: 7.4$ & & & & \\
\hline 35 & 10 & 78.54 & 53 & 50 & 39 & 75 & 60 & 8.74 & 5.02 & 5.27 & 5.13 & 0.064 & $1: 8.5$ & & & & \\
\hline 36 & 10.3 & 83.32 & 21 & 20 & 32 & 105 & 88 & 20.05 & 4.57 & 5.8 & 4.96 & 0.09 & $1: 5.6$ & & & & \\
\hline 40 & 6.7 & 35.26 & 15 & 14 & 35 & 63 & 50 & 9 & 2.12 & 3.35 & 2.74 & 0.4 & $1: 5.5$ & & & & \\
\hline 41 & 8.2 & 52.81 & 13 & 14 & 41 & 103 & 83 & 21 & 3 & 4.11 & 3.62 & 0.36 & $1: 4.4$ & & & & \\
\hline 42 & 7.2 & 40.72 & 14 & 5 & 0.35 & 0.66 & 0.51 & 0.12 & 3.02 & 3.69 & $50.6 ?$ & 0.2 & $1: 6.8$ & & & & \\
\hline
\end{tabular}



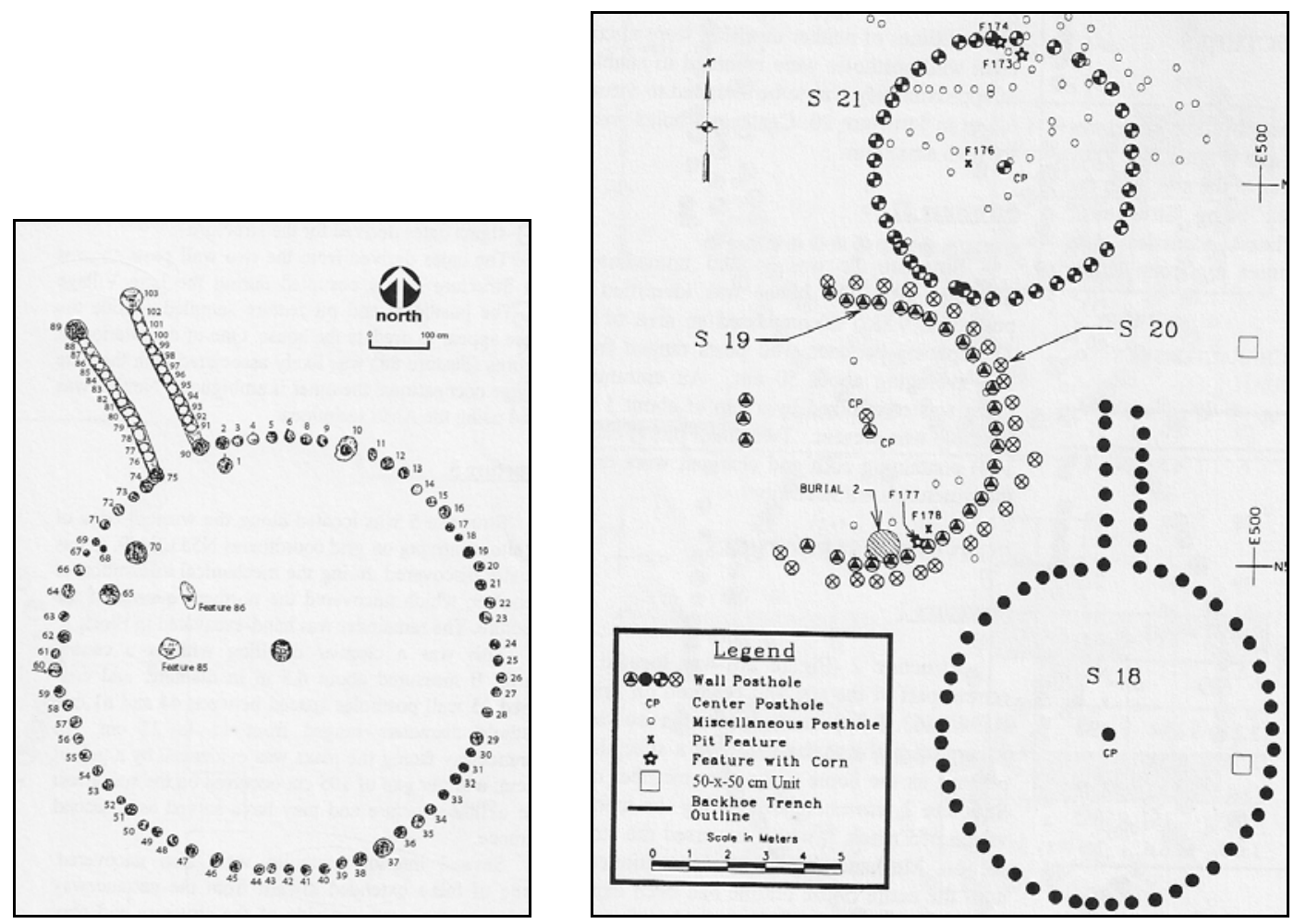

Figure 59. Structures 2 (left) and 18 from the Oak Hill Village site (adapted from Rogers and Perttula 2004:Figures 19 and 20).

Structure 2 was located in the south central part of the site and "appears to have been isolated from other structures, and may have served a specialized function, perhaps as the home of an elite member of the village" (Rogers and Perttula 2004:81). Structure 2 had 71 wall post holes spaced approximately 0.10 to $0.25 \mathrm{~cm}$ apart (Rogers and Perttula 2004:81). The wall post holes had diameters ranging from approximately $0.10 \mathrm{~m}$ to 0.47 $\mathrm{m}$. The ratio of average distance between wall post holes and average distance to the center is $1: 11.57$, considerably greater than any other Oak Hill Village structure (Rogers and Perttula 2004:81), and greater than any other in this study with the exception of the A. C. Saunders structure and Features 9, 53, 125, and 160 from the George C. Davis site. 
Given the larger ratio, Rogers and Perttula (2004:81) suggested that "it may have been laid out differently or independently of all others." The Structure 2 extended entrance faced northwest, toward the plaza, and consisted of two roughly parallel shallow trenches with closely spaced upright posts (Rogers and Perttula 2004:81). The entrance trenches extended approximately $2.15 \mathrm{~m}$ and $2.9 \mathrm{~m}$ away from the structure with a total of 27 post holes, 14 in the shorter trench and 13 in the longer. Structure 2 is the only structure at the Oak Hill Village site with post trenches, further suggesting that the structure was built for a specialized purpose (Rogers and Perttula 2004; Perttula and Rogers 2007). Structure 2 dates to the Middle Village era (A.D. 1250-1350) (Rogers and Perttula 2004:86).

Most of the Oak Hill Village structure had center posts and central hearths (Rogers and Perttula 2004). Rogers and Perttula (2004:111) provided a general discussion of these associated features, noting that "the average diameter of recorded center posts at the site was approximately $35 \mathrm{~cm}$, while some, such as those from Structures 1 and 7 were $50 \mathrm{~cm}$ in diameter." In addition, several small and large pits were recorded at the site. Many of these were located in the structure areas but were not directly noted as being associated with specific structures. Some, such as Features 85, 86, 163, and 164, were associated with Structures 2 or 10, those individual structures not located in the main domestic structure areas.

While many of the structures had interior posts, the form of Structure 5 is similar to structures at the George C. Davis site, the Earspool site, and others in eastern Texas. Structure 5 has at least four interior support posts arranged in a squarish pattern around a center post. According to Rogers and Perttula (2004:84), Structure 5 dates to the Middle Village era (A.D. 1250-1350) (Rogers and Perttula 2004:346) and was probably built around A.D. 1230-1272. 
Most of the Oak Hill Village structures date to the Middle Village era. Rogers and Perttula (2004:86) suggest that structures in Structure Groups A, B, C, D, and G were constructed during this time as well as the plaza and the small earthen mound. Rogers and Perttula (2004:86) further suggest that other structures in Structure Groups D, E, G, and $\mathrm{H}$ were constructed and used during the Late Village era.

\section{Pilgrims Pride (41CP304)}

The 1999 excavations at the Pilgrim's Pride site (41CP304) recorded over 400 cultural features "including several midden areas and structure areas, and the definition of a Late Caddo Titus phase residential area that covered about 6 acres (170 m north-south $\mathrm{x}$ 140 m east-west)" (Perttula 2005:65). The site was divided into nine different areas, including midden and structure areas and a Titus phase mound and cemetery. Post hole patterns related to at least three or more circular structures were recorded at the Pilgrim's

Pride site, with several other structure areas noted as well. Structure 1 was recorded in Area I of the site and Structure 2 was recorded in Area VIII (Figures 60 and 61) (Perttula 2005). At least one structure, as well as possible outbuildings, was recorded in Area II, although I have excluded it from the detailed part of this study because of the incomplete structure pattern. 


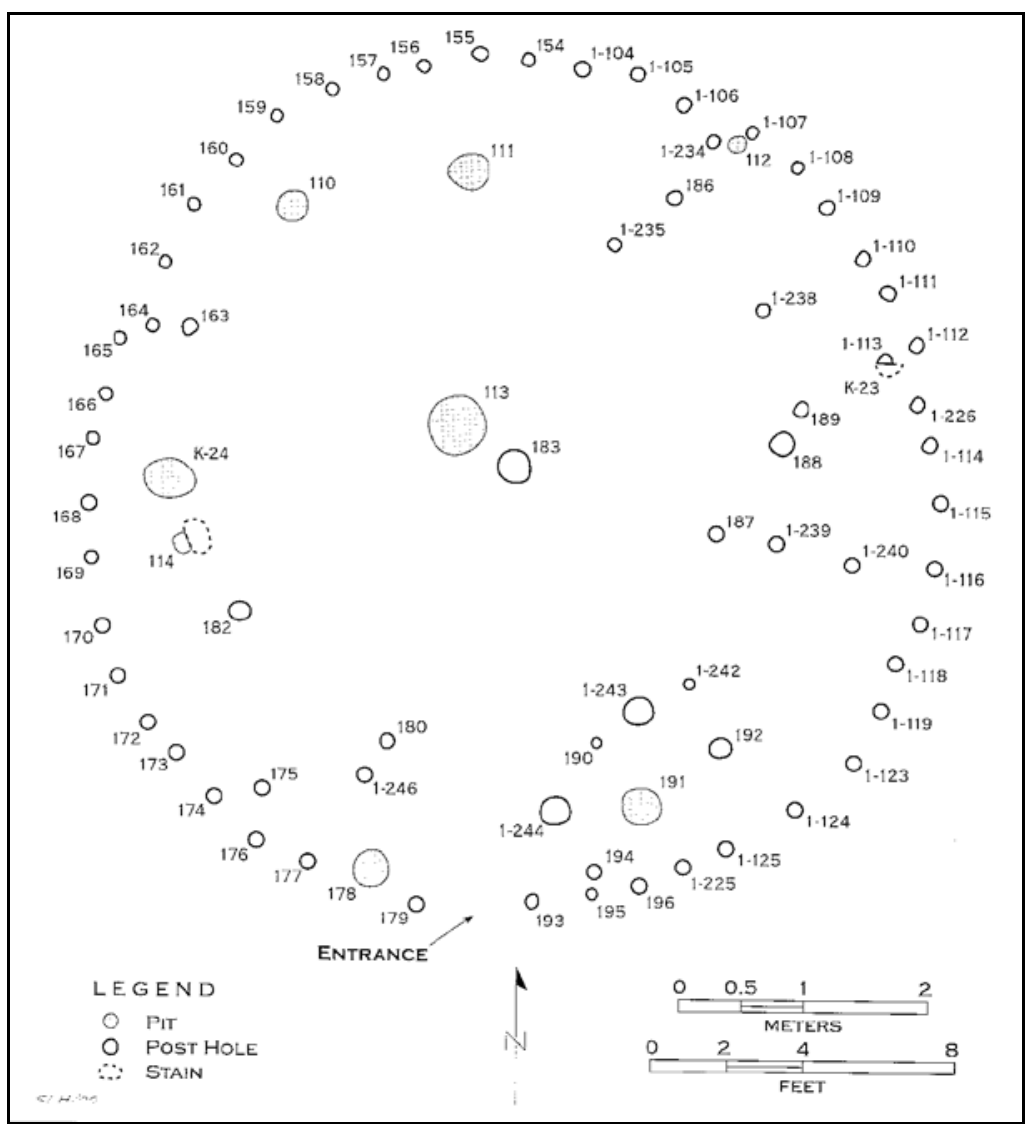

Figure 60. Structure 1 from the Pilgrim's Pride site (Perttula 2005:70, Figure 4-13).

Structure 1 measured about $7 \mathrm{~m}$ in diameter with an area of approximately 38.48 $\mathrm{m}^{2}$. The features associated with Structure 1 included several interior and exterior post holes, a central hearth and support post, and at least six smudge pits (Perttula 2005). The outline of the structure included 45 regularly spaced post holes with diameters measuring about $0.15 \mathrm{~m}$ (Perttula 2005). The wall post holes had diameters ranging from approximately $0.12 \mathrm{~m}$ to $0.19 \mathrm{~m}(\mathrm{n}=41, \bar{x}=15.7 \mathrm{~cm}, \mathrm{~s}=0.0155)$. Post hole depths were recoded as the depth below the scraped surface and ranged from approximately $0.08 \mathrm{~m}$ to $0.25 \mathrm{~m}(\mathrm{n}=41, \bar{x}=0.16 \mathrm{~cm}, \mathrm{~s}=0.0412)$. The wall post holes were spaced from approximately 0.33 to $0.71 \mathrm{~m}$ apart $(\mathrm{n}=42, \bar{x}=0.46 \mathrm{~m}, \mathrm{~s}=0.0812)$. The distances from 
the wall post holes to the center post ranged from $3.21 \mathrm{~m}$ to $3.66 \mathrm{~m}(\mathrm{n}=45, \bar{x}=3.42 \mathrm{~m}, \mathrm{~s}$ $=0.1261)$. The ratio of average distance between wall post holes and average distance to the center was 1:7.4. A possible entrance was represented by an approximately $0.94 \mathrm{~m}$ gap in the south wall or Structure 1 (Perttula 2005).

The interior smudge pits were pits with dark carbon-rich fill that extended to depths of less than $0.15 \mathrm{~m}$ below the scraped surface (Perttula 2005). No central hearth was recorded for Structure 1, although a central support post was recorded. Perttula (2005) noted that the structure most likely had a shallow central hearth which would have been located in the modern plow zone above the central support post. The central support post measured approximately $21 \mathrm{~cm}$ in diameter with a depth of $24.5 \mathrm{~cm}$ below the scraped surface.

Midden areas were located to the south and northwest of the structure. A burial pit was located immediately to the south of Structure 1. Several pits and post holes to the northwest of Structure 1, some corresponding to roughly rectangular patterns, may represent the locations of exterior structures such as ramadas, arbors, granaries, etc., possibly associated with the structure (Perttula 2005).

Outdoor activity areas were recorded in Area VIII as was the incomplete pattern of a single circular Titus phase structure (Structure 2). The structure measured approximately $8.5-9 \mathrm{~m}$ in diameter and had a possible south-facing extended entry (Perttula 2005). The features associated with Structure 2 included 17 post holes, a central support post, and five smudge pits (Perttula 2005). The possible entrance was defined by four post holes. The Structure 2 post holes measured about $20 \mathrm{~cm}$ in diameter and were larger than the Structure 1 post holes (about $15 \mathrm{~cm}$ in diameter). Given the greater post hole size, Perttula (2005:75) speculated that "a larger and taller building may have stood 
in Area VIII." The five smudge pits were recorded inside the probable structure outline, as was a center post (Perttula 2005). Unfortunately, the Structure 2 post hole pattern is fairly incomplete, a condition attributed to poor preservation as well as the probability of other shallower post holes that may not have been recorded or observed during the monitoring in Area VIII (Perttula 2005). The postholes that were recorded as part of Structure 2 have diameters ranging from approximately $0.12 \mathrm{~m}$ to $0.26 \mathrm{~m}(\mathrm{n}=12, \bar{x}=$ $0.20 \mathrm{~m}$ ) and depths ranging from 0.04 to $0.28 \mathrm{~m}$ below the scraped surface $(\mathrm{n}=12, \bar{x}=$ $0.17 \mathrm{~cm})$.

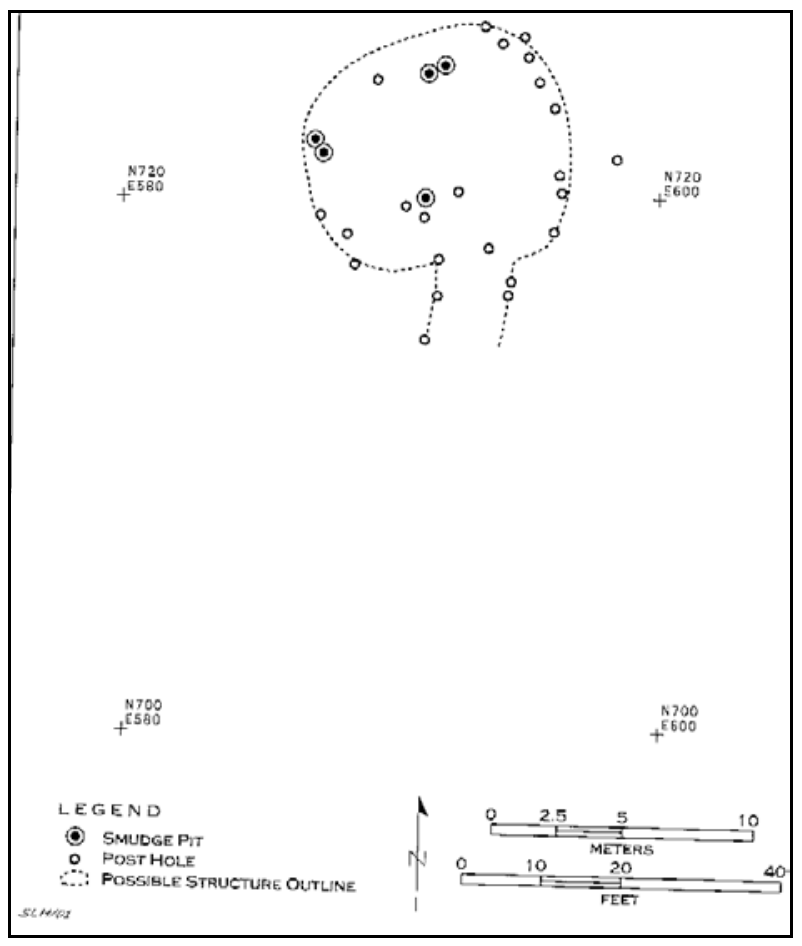

Figure 61. Structure 2 from the Pilgrim's Pride site (Perttula 2005:80, Figure 4-25).

Perttula (2005:80-81) notes that none of the structures at the Pilgrim's Pride site appear to have been burned, and given the low density of artifacts in the post holes 202 
associated with the Titus phase structures in the residential areas, the structure areas appear not to have been used heavily before the houses were built. Perttula (2005:80) also suggested that the paucity of materials in the post holes and the limited amount of trash or midden accumulation in the immediate vicinity of the structures was indicative of the fact that the structures were likely only used for a few years.

\section{Bryan Hardy (41SM55)}

In addition to the mound structure from Bryan Hardy discussed in Chapter 5, two overlapping circular structures (Houses 2 and 3) were found at the site. These two structures were located about $45 \mathrm{~m}$ to the north of the House mound (Walters and Haskins 2000). Unfortunately, limited information is available on the details of these two structures. Houses 2 and 3 (Figure 62) measured $10.4 \mathrm{~m}$ and $9.75 \mathrm{~m}$ in diameter with areas of $84.91 \mathrm{~m}^{2}$ and $74.62 \mathrm{~m}^{2}$ respectively. The House 2 outline consisted of 42 exterior posts spaced about $0.90 \mathrm{~m}$ apart (Walters and Haskins 2000). A non-extended entrance was possibly represented by a $0.9 \mathrm{~m}$ gap on the east side of the wall outline (Walters and Haskins 2000:6). No signs of burning were found. The only features identified in the limited excavations of the structures interior were a central hearth underlain by a post hole extending to a depth of $0.81 \mathrm{~m}$ (Walters and Haskins 2000:6-7).

A poorly preserved burial (Burial 1) was found on the northeast side of House 2. The burial was extended and supine with the head to the southeast and the "burial pit extended into the house between two posts" (Walters and Haskins 2000:7). Burial 1 was thought to be an infant due to "the small size of the offerings, and [the burial's] placement partially inside the house" (Walters and Haskins 2000:7). 


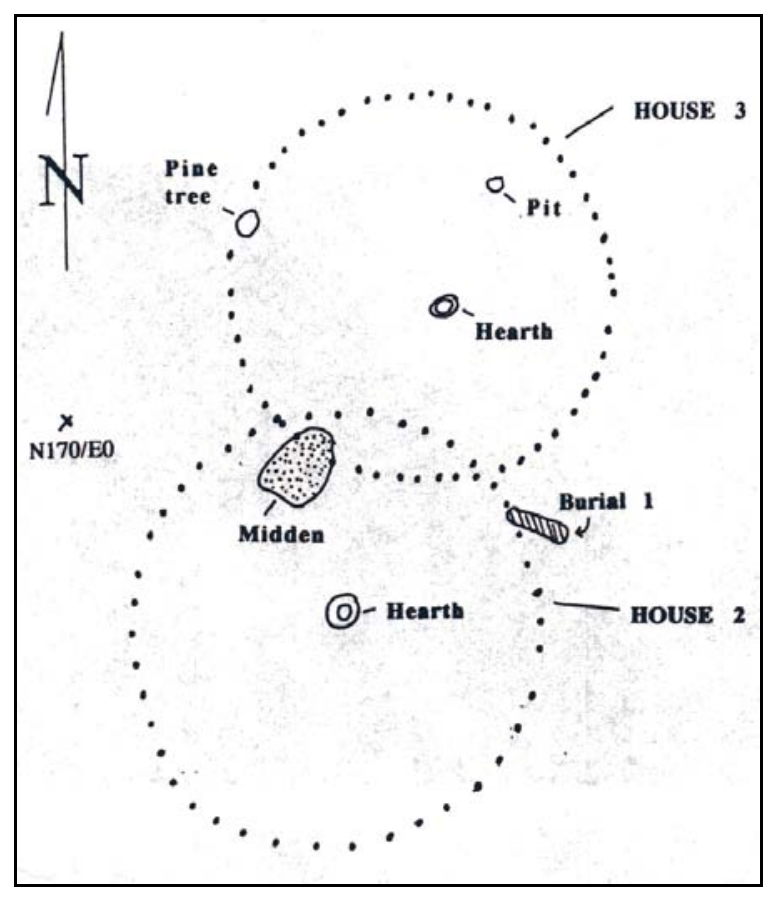

Figure 62. Plan map of Structures $2 \& 3$ from the Bryan Hardy site (Walters and Haskins 2000:7 and Figure 5). Reproduced courtesy of the Friends of Northeast Texas Archaeology.

Bryan Hardy Houses 2 and 3 overlapped, and Structure 3 possibly predated Structure 2 "given one instance of a House 2 post intersecting a House 3 post" (Walters and Haskins 2000:6). The $9.73 \mathrm{~m}$ diameter House 3 outline consisted of 50 posts spaced about $0.6 \mathrm{~m}$ apart. There was a central hearth with a diameter of $0.60 \mathrm{~m}$ that extended to a depth of $0.30 \mathrm{~m}$. There was no mention of a central post under the hearth. A $0.60 \mathrm{~m}$ diameter and $0.30 \mathrm{~m}$ deep pit feature was found in the northeast portion of the structure (see Figure 62). As for an entrance, "there may have been 2 entrances to House 3, one consisting of a $0.9 \mathrm{~m}$ gap in the east wall, and another in the southwest corner" (Walters and Haskins 2000:6). The possible entrance in the southwest corner had a "very dark, heavy midden deposit" (Walters and Haskins 2000:6). 
Charred posts from the entrance yielded date ranges (at 1 sigma) of cal A.D. 1345-1391 and cal A.D. 1297-1317 (Walters and Haskins 2000:4; Perttula 1998:Table 1). Walters and Haskins (2000:4) noted that "there is a $67 \%$ chance that the calibrated age of the Bryan Hardy charred post falls between AD 1297-1391."

\section{Musgano (41RK19)}

The Musgano Site (41RK19) covers approximately five acres and is situated on an upland landform between Martin Creek and Dry Creek (Clark and Ivey 1974:14-41; Perttula 2004:25), two tributaries to the Sabine River. Several features were identified at the site including post holes, pits, two burned areas, midden areas, and a single $6 \mathrm{~m}$ diameter circular Middle Caddo structure with an approximate area of $28.27 \mathrm{~m}^{2}$ (Figure $63)$.

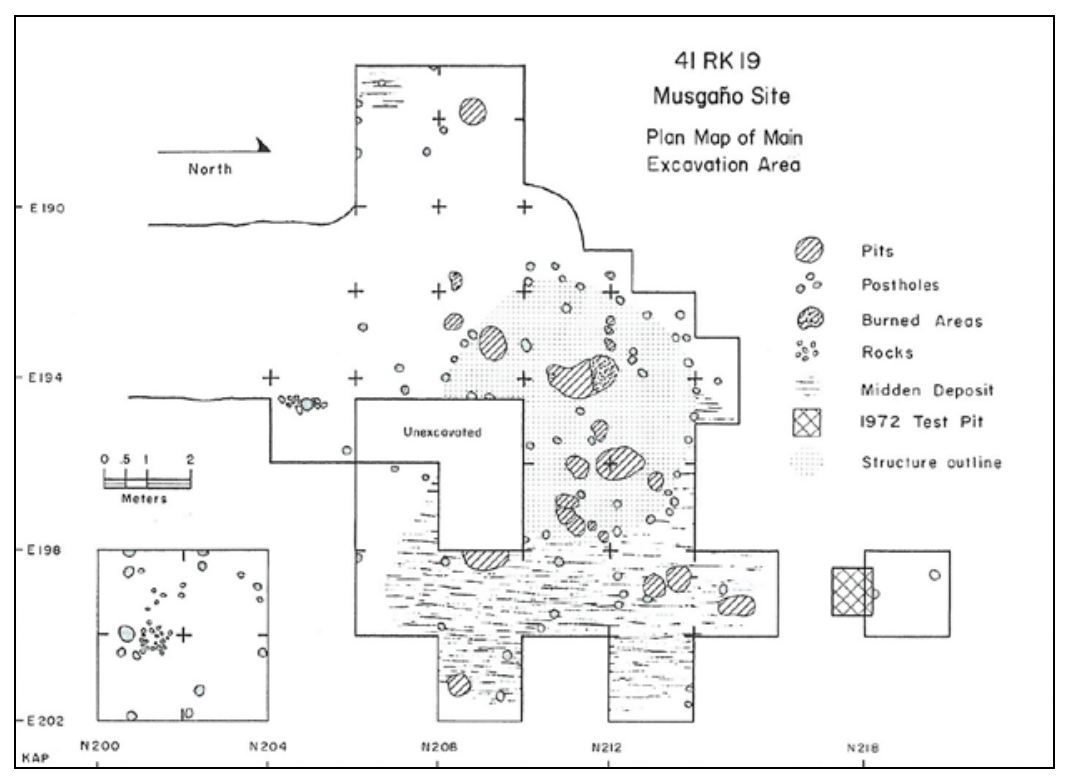

Figure 63. The Musgano site features and structure Reproduced courtesy of TARL. 
Ninety post holes (at least 19 of which defined the outline of the structure) and 21 pits (14 trash and storage pits from within the structure outline) were found at Musgano (Clark and Ivey 1974). The post holes had round bottoms and generally measured about $0.20 \mathrm{~m}$ in diameter (Clark and Ivey 1974). Thirteen additional post holes were found in the interior of the structure although Clark and Ivey (1974) could not confidently state that they were directly associated or contemporaneous with the structure. If they were, they likely represented interior supports and/or possible interior furnishings, stands, etc. Several pits were located within the structure and may be associated with the use of the building. There was no evidence that the structure had a prepared floor. A burned area associated with a large pit was located near the center of the structure, probably representing a $0.40 \mathrm{~m}$ in diameter and $0.13 \mathrm{~m}$ deep central hearth that contained charcoal, bone, shell, nuts, and one flake (Clark and Ivey 1974).

Table 40 provides the post hole data for those posts assigned to the perimeter wall of the Musgano structure by Clark and Ivey (1974). There is a discrepancy between their post hole data table and the number of post holes indicated in the text and plan map as being associated with the structure outline. The text and plan map indicate 19 post holes, while their post hole data table notes 21 post holes associated with the structure pattern. The post holes associated with the exterior wall have diameters ranging from $0.13 \mathrm{~m}$ to $0.37 \mathrm{~m}(\mathrm{n}=21, \bar{x}=0.18 \mathrm{~m}, \mathrm{~s}=0.0497)$ and depths ranging from $0.05 \mathrm{~m}$ to $0.28 \mathrm{~m}(\mathrm{n}=$ $21, \bar{x}=0.17 \mathrm{~m}, \mathrm{~s}=0.0781)$. The wall post holes were spaced approximately 0.30 to 0.65 $\mathrm{m}$ apart $(\mathrm{n}=8, \bar{x}=0.52 \mathrm{~m}, \mathrm{~s}=0.1223)$. The distances from the wall post holes to the center range from $2.81 \mathrm{~m}$ to $3.15 \mathrm{~m}(\mathrm{n}=19, \bar{x}=2.95 \mathrm{~m}, \mathrm{~s}=0.0968)$. The ratio of average distance between wall post holes and average distance to the center is 1:5.7. 
Table 40. Post hole data from perimeter posts of the Musgano structure. Adapted from Clark and Ivey (1974).

\begin{tabular}{|c|c|c|c|c|c|c|c|c|}
\hline 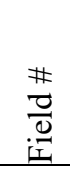 & 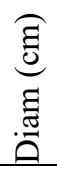 & 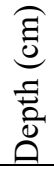 & 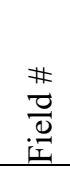 & 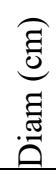 & 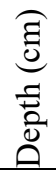 & $\begin{array}{l}\# \\
\frac{\overrightarrow{0}}{0} \\
.0 \\
\end{array}$ & 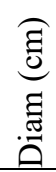 & 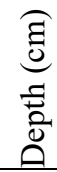 \\
\hline 68 & 21 & 22 & 113 & 14 & 8 & 151 & 20 & 28 \\
\hline 69 & 18 & 20 & 117 & 17 & 13 & 152 & 13 & 28 \\
\hline 74 & 37 & 24 & 138 & 17 & 10 & 169 & 19 & 22 \\
\hline 99 & 19 & 10 & 141 & 19 & 11 & 172 & 16 & 27 \\
\hline 110 & 17 & 5 & 142 & 17 & 16 & 173 & 14 & 27 \\
\hline 111 & 14 & 9 & 143 & 16 & 9 & 183 & 16 & 17 \\
\hline 112 & 13 & 7 & 150 & 16 & 23 & 186 & 19 & 11 \\
\hline
\end{tabular}

In addition to the possible interior features, several post holes, pits and two midden areas were located outside of the structure perimeter. The additional post holes (see Figure 63) may represent affiliated ramadas, granaries, or elevated storage facilities. A burned area representing a possible $0.45 \times 0.25 \mathrm{~m}$ deep hearth was identified outside of the structure to the southwest (Clark and Ivey 1974).

About $3 \mathrm{~m}$ east of the structure, excavators identified more than 10 post holes and five pits associated with a relatively large midden area with lithics, animal bones, and the highest concentration of sherds in the main excavation areas (Clark and Ivey 1974:26). Given the concentration of the midden area to the east of the structure, Clark and Ivey (1974:22-23) suggested the entrance was in this area. In addition, post hole patterns to the east of the structure suggest that the structure may have had an extended entranceway. This is based on the argument offered for an east-facing entrance and the pattern of post holes extending to the east away from the structure perimeter. In addition, Clark and Ivey (1974:24) thought that the concentration of exterior features may "represent a granary 
built on stilts possibly having a smoky fire under it to keep out vermin and prevent mildew."

\section{Hines (41WD87)}

Three overlapping structures, consisting of a total of 217 post holes, were recorded at the Early Caddo period Hines site (41WD87), located along Burke Creek in Wood County (Bruseth and Perttula 1981) (Figure 64). The three structures "consisted of a compacted mass of charcoal, clay daub with wattle impressions and numerous artifacts" (Bruseth and Perttula 1981:23). The burned layer of house debris was 10-20 cm below the midden layer and about $4 \mathrm{~m}$ in diameter (Bruseth and Perttula 1981:24).

Excavation trenches were originally focused on artifact clusters recognized in systematic surface collections at the Hines site and were then extended beyond the one defined midden area. Bruseth and Perttula (1981:22) noted that house patterns from the Deshazo site were found around a midden area and the expectations at Hines were that a similar association of midden and Caddo structures might be present there. Unlike Deshazo, however, the Hines structures were found below the midden deposit/artifact cluster and not around it (Bruseth and Perttula 1981:22).

Hines Structure 1 was a circular structure defined by an outline of 34 post holes. Structure 1 measured approximately $8.20 \mathrm{~m}$ in diameter, with an interior area of approximately $52.81 \mathrm{~m}^{2}$. Based on measurements taken from the plan map (Bruseth and Perttula 1981:25), the wall post holes of Structure 1 had diameters ranging from approximately $0.11 \mathrm{~m}$ to $0.29 \mathrm{~m}(\mathrm{n}=34, \bar{x}=0.17 \mathrm{~m}, \mathrm{~s}=0.0458)$. The wall post holes were spaced from approximately $0.5 \mathrm{~m}$ to $0.86 \mathrm{~m}$ apart $(\mathrm{n}=27, \bar{x}=0.62 \mathrm{~m}, \mathrm{~s}=0.0679)$. The distances from the wall post holes to the center post ranged from $3.71 \mathrm{~m}$ to $4.53 \mathrm{~m}$ (n 
$=30, \bar{x}=4.19 \mathrm{~m}, \mathrm{~s}=0.2604)$. The ratio of average distance between wall post holes and average distance to the center was 1:6.8.

In addition to the wall post holes, there were at least five interior post holes associated with Structure 1. At least one of these would have likely served as a central support post and had a diameter of approximately $0.26 \mathrm{~m}$ (Bruseth and Perttula 1981). Based on the spacing and size of the other interior posts, it is likely that they served as interior support posts. Two of the interior posts overlap, probably an indication of repair by replacement of the original post (Bruseth and Perttula 1981). The four interior posts had diameters ranging from $0.21 \mathrm{~m}$ to $0.29 \mathrm{~m}$. The mean diameter of the four interior posts was $0.26 \mathrm{~m}$, approximately $0.09 \mathrm{~m}$ larger than the mean diameter of the wall post holes, indicating the use of larger wooden posts for structure support.

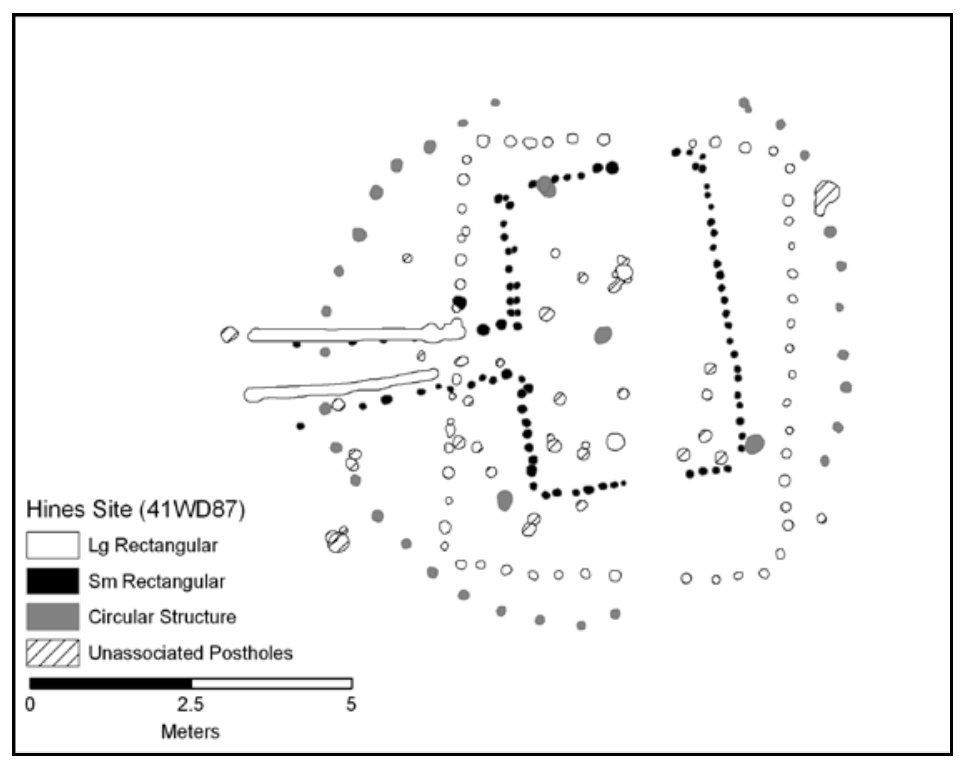

Figure 64. Hines (41WD87) structures. 
Two rectangular structures (Structures 2 and 3) overlapped and post-dated Structure 1. Structure 2, the smaller of the two rectangular structures, was defined by a wall outline of at least 61 post holes, with at least 16 additional post holes recorded for the west-facing extended entrance. In addition, at least seven post holes were recorded along the interior wall of the structure. The locations and the fact that these posts were set directly adjacent to the structure wall, as well as their size, suggested that they may be the product of repair or replacement of some of the wall posts or may represent posts used for interior furnishings (Bruseth and Perttula 1981).

Structure 2 measured approximately $4.80 \times 3.27 \mathrm{~m}$ with an interior area of approximately $15.70 \mathrm{~m}^{2}$. Based on measurements taken from the plan map, the wall post holes of Structure 2 had diameters ranging from $0.08 \mathrm{~m}$ to $0.20 \mathrm{~m}(\mathrm{n}=61, \bar{x}=0.12 \mathrm{~m}, \mathrm{~s}=$ $0.0209)$. The wall post holes were spaced $0.13 \mathrm{~m}$ to $0.48 \mathrm{~m}$ apart $(\mathrm{n}=57, \bar{x}=0.22 \mathrm{~m}, \mathrm{~s}=$ 0.0592). The distances between the recorded entrance posts ranged from $0.17 \mathrm{~m}$ to 0.54 $\mathrm{m}(\mathrm{n}=11, \bar{x}=0.28 \mathrm{~m}, \mathrm{~s}=0.1095)$. No interior support posts were recorded, although there were several unassociated post holes, some of which may have been associated with at least one of the three structures. The west-facing entrance measured approximately $3.50 \mathrm{~m}$ long and varied in width from approximately $1.26 \mathrm{~m}$ at the western end to approximately $0.70 \mathrm{~m}$ at the entrance to the structure.

The most recent structure was likely Structure 3, the large rectangular structure that measured approximately $6.65 \times 5.20 \mathrm{~m}$, with an area of approximately $34.58 \mathrm{~m}^{2}$ (Bruseth and Perttula 1981). The structure had at least 57 post holes. Based on measurements taken from the plan map, the wall post holes of Structure 3 had diameters ranging from $0.09 \mathrm{~m}$ to $0.18 \mathrm{~m}(\mathrm{n}=54, \bar{x}=0.14 \mathrm{~m}, \mathrm{~s}=0.0246)$. The wall post holes were spaced $0.22 \mathrm{~m}$ to $0.48 \mathrm{~m}$ apart $(\mathrm{n}=51, \bar{x}=0.38 \mathrm{~m}, \mathrm{~s}=0.0609)$. 
Two interior posts were recorded as being associated with Structure 3 (Bruseth and Perttula 1981). The size and spacing of the two interior posts suggested they were roof supports. The two interior support posts measured $0.25 \mathrm{~m}$ and $0.27 \mathrm{~m}$ in diameter and they were approximately $2.60 \mathrm{~m}$ apart. The northern support was spaced approximately $2.01 \mathrm{~m}$ from the northern wall, $4.66 \mathrm{~m}$ from the southern wall, $2.65 \mathrm{~m}$ from the eastern wall, and $2.54 \mathrm{~m}$ from the western wall. The southern support post was spaced approximately $4.63 \mathrm{~m}$ from the northern wall, $2.04 \mathrm{~m}$ from the southern wall, 2.66 $\mathrm{m}$ from the eastern wall, and $2.57 \mathrm{~m}$ from the western wall.

The Structure 3 entrance was approximately $3.27 \mathrm{~m}$ long and consisted of two roughly parallel trenches. The width of the entrance, based on measuring from the middle of one trench to the other varied from about $0.92 \mathrm{~m}$ at the western end of the trench to approximately $0.59 \mathrm{~m}$ at the structure entrance. No individual posts were recorded in the entrance trenches (Bruseth and Perttula 1981).

As noted, the large rectangular structure was determined to probably be the most recent structure at the Hines site. Bruseth and Perttula's (1981) construction sequence was based on the evidence that interior posts from the circular structure were cut by later posts of the rectangular structures. Based on the interior supports of the large rectangular house, as well as entrance location and evidence of burning of the larger structure, it appears as though the smaller structure was built second and the larger rectangular structure last. This is an interesting and potentially unique case in East Texas where a circular Caddo structure predated the construction of rectangular structures.

Bruseth and Perttula (1981:24) believed that the positioning of the structures suggested a sequential building episode: 
The slight shift of each successive structure is similar to the pattern observed at the Deshazo site in east central Texas, where house pattern shifts were thought to be due to house rebuilding and the lesser difficulties of digging holes for new posts. If we assume a maximum of 20 years occupation per house, then we can project a 60 year occupation length for the total house sequence (Bruseth and Perttula 1981:24).

In addition to three sequent structures, a $2 \mathrm{~m}$ diameter basin-shaped pit (first used for storage, and then as a receptacle for trash) estimated to be $30 \mathrm{~cm}$ deep was identified 2 m north of Hines Structure 1 (the circular structure) (Bruseth and Perttula 1981:24-26). The pit contained large sherds, lithics, and faunal remains (Bruseth and Perttula 1981:26). There are several instances known in earlier Caddo sites where structures occurred in proximity to a large outdoor storage pit (cf. Perttula 2008).

\section{Spoonbill (41WD109)}

The multiple component (Early, Middle, and Late Caddo) Spoonbill site (41WD109) is situated on a terrace about $2 \mathrm{~m}$ above the Caney Creek floodplain. Bruseth and Perttula (1981) estimated that about $25 \%$ of the site had been destroyed by construction prior to their work on the site as part of the Lake Fork Creek Reservoir project, with a large portion of the site having been previously removed for road fill. Several features (Table 41) were found at Spoonbill including human burials, hearths, pits, and several post holes, including at least 32 post holes that defined a circular house pattern (Bruseth and Perttula 1981). Radiocarbon dates suggest that the structure dates to the Middle Caddo period (Perttula 1997).

The Spoonbill structure is an approximately $10.5 \mathrm{~m}$ diameter circular structure with an outline defined by 32 perimeter post holes. Figure 65 provides a plan view of the 
structure $^{6}$. The full extent of the structure was not delineated, and no entrance was defined. Limited data were available regarding wall post hole diameters and depths. The wall post holes were spaced approximately 0.44 to $0.68 \mathrm{~m}$ apart $(\mathrm{n}=22, \bar{x}=0.59 \mathrm{~m}, \mathrm{~s}=$ 0.0595). The distances from the wall post holes to the center post ranged from $5.13 \mathrm{~m}$ to $5.38 \mathrm{~m}(\mathrm{n}=30, \bar{x}=5.26 \mathrm{~m}, \mathrm{~s}=0.0651)$. The ratio of average distance between wall post holes and average distance to the center was 1:8.9.

Table 41: Spoonbill site (41WD109) features. Location is relative to the center of the Spoonbill structure and depth is below the scraped surface. Data and interpretations are summarized from Bruseth and Perttula (1981:44-46).

\begin{tabular}{|c|c|c|c|c|c|c|}
\hline Feature & Type & Location & Shape & Size & Contents & Details \\
\hline 1 & hearth & $14.5 \mathrm{~m} \mathrm{SW}$ & $\begin{array}{l}\text { circular plan; } \\
\text { basin-shaped } \\
\text { profile }\end{array}$ & $\begin{array}{l}40 \mathrm{~cm} \text { diam; } 12 \\
\mathrm{~cm} \text { deep at center }\end{array}$ & $\begin{array}{l}\text { charcoal frag, sherds, } \\
\text { lithic debris, floral } \\
\text { remains }\end{array}$ & $\begin{array}{l}10-20 \mathrm{~cm} \text { scraped away; } \\
\text { oxidized 2-3 cm border of } \\
\text { red dirt }\end{array}$ \\
\hline 2 & hearth & $\begin{array}{l}\text { within } \\
\text { structure } \\
\text { perimeter, } \\
3.75 \mathrm{~m} \mathrm{NW}\end{array}$ & $\begin{array}{l}\text { circular plan; } \\
\text { cylindrical } \\
\text { profile, slightly } \\
\text { concave } \\
\text { bottom }\end{array}$ & $61.5 \mathrm{~cm}$ diameter & $\begin{array}{l}\text { sherds, carbonized } \\
\text { seed fragments (upper } \\
\text { \& middle part of the } \\
\text { hearth); carbonized } \\
\text { macrofloral remains } \\
\text { (lower part of the } \\
\text { hearth) }\end{array}$ & $\begin{array}{l}3 \mathrm{~cm} \text { yellowish red } \\
\text { oxidized border; layered } \\
\text { fill, upper- } 15 \mathrm{~cm} \text {, middle- } \\
21 \mathrm{~cm} \text {, bottom- } 7 \mathrm{~cm}\end{array}$ \\
\hline 3 & pit & $21 \mathrm{~m} \mathrm{SW}$ & $\begin{array}{l}\text { oval plan; } \\
\text { basin-shaped }\end{array}$ & $\begin{array}{l}90 \times 130 \mathrm{~cm} ; 25 \\
\mathrm{~cm} \text { max depth }\end{array}$ & $\begin{array}{l}\text { sherds, bone, } \\
\text { carbonized wood \& } \\
\text { seeds }\end{array}$ & \\
\hline 4 & pit & $\begin{array}{l}\text { just inside } \\
\text { structure }\end{array}$ & & $\begin{array}{l}10 \mathrm{~cm} \text { deep from } \\
\text { scraped surface }\end{array}$ & & $\begin{array}{l}15 \mathrm{~cm} \text { of midden scraped } \\
\text { from above feature; } 20 \mathrm{~cm} \\
\text { diameter x } 25 \mathrm{~cm} \text { deep } \\
\text { post hole dug into center of } \\
\text { pit fill, oxidized zone } \\
\text { suggests post burned in } \\
\text { place }\end{array}$ \\
\hline 5 & pit & $10 \mathrm{~m} \mathrm{~W}-\mathrm{SW}$ & $\begin{array}{l}\text { circular plan; } \\
\text { basin-shaped } \\
\text { profile }\end{array}$ & $\begin{array}{l}80 \mathrm{~cm} \text { diameter; } \\
15 \mathrm{~cm} \text { deep }\end{array}$ & $\begin{array}{l}\text { sherds, large burned } \\
\text { bones, compacted area } \\
\text { of carbonized nutshells }\end{array}$ & $\begin{array}{l}2 \text { overlapping circular } \\
\text { holes dug through pit fill- } \\
\text { listed here as Features } 5 \mathrm{a} \\
\text { and } 5 \mathrm{~b} ; 2-3 \mathrm{~cm} \text { thick dark } \\
\text { reddish-brown oxidation } \\
\text { zone in north half of pit, } 4 \\
-5 \mathrm{~cm} \text { from base }\end{array}$ \\
\hline $5 \mathrm{a}$ & & $\begin{array}{l}\text { dug through } \\
\text { feature } 5 \text { fill }\end{array}$ & circular & $18 \mathrm{~cm}$ diameter & $\begin{array}{l}\text { carbonized hickory } \\
\text { nutshells }\end{array}$ & predated $5 \mathrm{~b}$ \\
\hline
\end{tabular}

${ }^{6}$ There is a discrepancy between the plan map and the report text related to the directions of features from the structure. Based on the feature descriptions and the site map (Bruseth and Perttula 1981:41), it appears as if the north arrow on the structure plan map may be reversed. If not, then the feature description locations, relative to the structure, are incorrect. I have chosen to follow the descriptions from the text and have left the plan map as it was in Bruseth and Perttula (1981). 


\begin{tabular}{|c|c|c|c|c|c|c|}
\hline $5 b$ & & $\begin{array}{l}\text { dug through } \\
\text { feature } 5 \text { fill }\end{array}$ & & $22 \mathrm{~cm}$ diameter & & \\
\hline 6 & 2 pits & $9 \mathrm{~m} \mathrm{~W}-\mathrm{SW}$ & $\begin{array}{l}\text { N pit, } \\
\text { elliptical; S pit, } \\
\text { circular; both } \\
\text { basin-shaped }\end{array}$ & $\begin{array}{l}\mathrm{N} \text { pit, } 45 \text { × } 25 \mathrm{~cm} \text {; } \\
\mathrm{S} \text { pit, } 45 \mathrm{~cm} \\
\text { diameter; both } 10 \\
\mathrm{~cm} \text { deep or less }\end{array}$ & & $\begin{array}{l}2 \text { overlapping pits; } \\
\text { outlined by } 2-4 \mathrm{~cm} \text { thick } \\
\text { oxidized zone; probably } \\
\text { hearths }\end{array}$ \\
\hline 7 & pit & $\begin{array}{l}7.5 \mathrm{~m} \mathrm{~W}- \\
\text { SW }\end{array}$ & $\begin{array}{l}\text { circular plan } \\
\text { and cylindrical } \\
\text { profile }\end{array}$ & $\begin{array}{l}30 \mathrm{~cm} \text { diameter, } \\
18 \mathrm{~cm} \text { deep }\end{array}$ & charcoal fragments & \\
\hline 8 & pit & $8 \mathrm{~m} \mathrm{~W}-\mathrm{SW}$ & circular plan & $\begin{array}{l}20 \mathrm{~cm} \text { diameter, } 3 \\
\mathrm{~cm} \text { deep }\end{array}$ & $\begin{array}{l}\text { carbonized nutshell } \\
\text { and charcoal } \\
\text { fragments }\end{array}$ & \\
\hline 9 & pit & $\begin{array}{l}11.5 \mathrm{~m} \mathrm{~W}- \\
\mathrm{SW}\end{array}$ & $\begin{array}{l}\text { circular plan, } \\
\text { flat-bottomed } \\
\text { cylindrical } \\
\text { profile }\end{array}$ & $\begin{array}{l}12 \mathrm{~cm} \text { diameter, } \\
11.5 \mathrm{~cm} \text { deep }\end{array}$ & $\begin{array}{l}\text { carbonized nutshell } \\
\text { fragments }\end{array}$ & \\
\hline 10 & pit & $7 \mathrm{~m} \mathrm{~W}-\mathrm{NW}$ & $\begin{array}{l}\text { circular plan, } \\
\text { flat-bottomed } \\
\text { cylindrical } \\
\text { profile }\end{array}$ & $\begin{array}{l}5 \mathrm{~cm} \text { deep - most } \\
\text { of pit scraped } \\
\text { away }\end{array}$ & $\begin{array}{l}\text { charred corncobs, } \\
\text { fibrous charcoal }\end{array}$ & $\begin{array}{l}\text { at least } 6 \text { corncob } \\
\text { fragments aligned parallel }\end{array}$ \\
\hline 11 & pit & $16 \mathrm{~m} \mathrm{~N}$ & $\begin{array}{l}\text { circular plan, } \\
\text { basin-shaped } \\
\text { profile with a } \\
\text { deep conical } \\
\text { sub-pit }\end{array}$ & $\begin{array}{l}\text { main pit, } 150 \mathrm{~cm} \\
\text { diameter, } 30 \mathrm{~cm} \\
\text { deep; sub-pit, } 40 \\
\mathrm{~cm} \text { diameter top, } \\
20 \mathrm{~cm} \text { diameter } \\
\text { flat bottom, } 75 \mathrm{~cm} \\
\text { deep }\end{array}$ & $\begin{array}{l}\text { small sherd, bone, } \\
\text { mussel shell, charcoal, } \\
\text { flakes }\end{array}$ & $\begin{array}{l}\text { sub-pit in eastern part of } \\
\text { basin-shaped pit }\end{array}$ \\
\hline
\end{tabular}

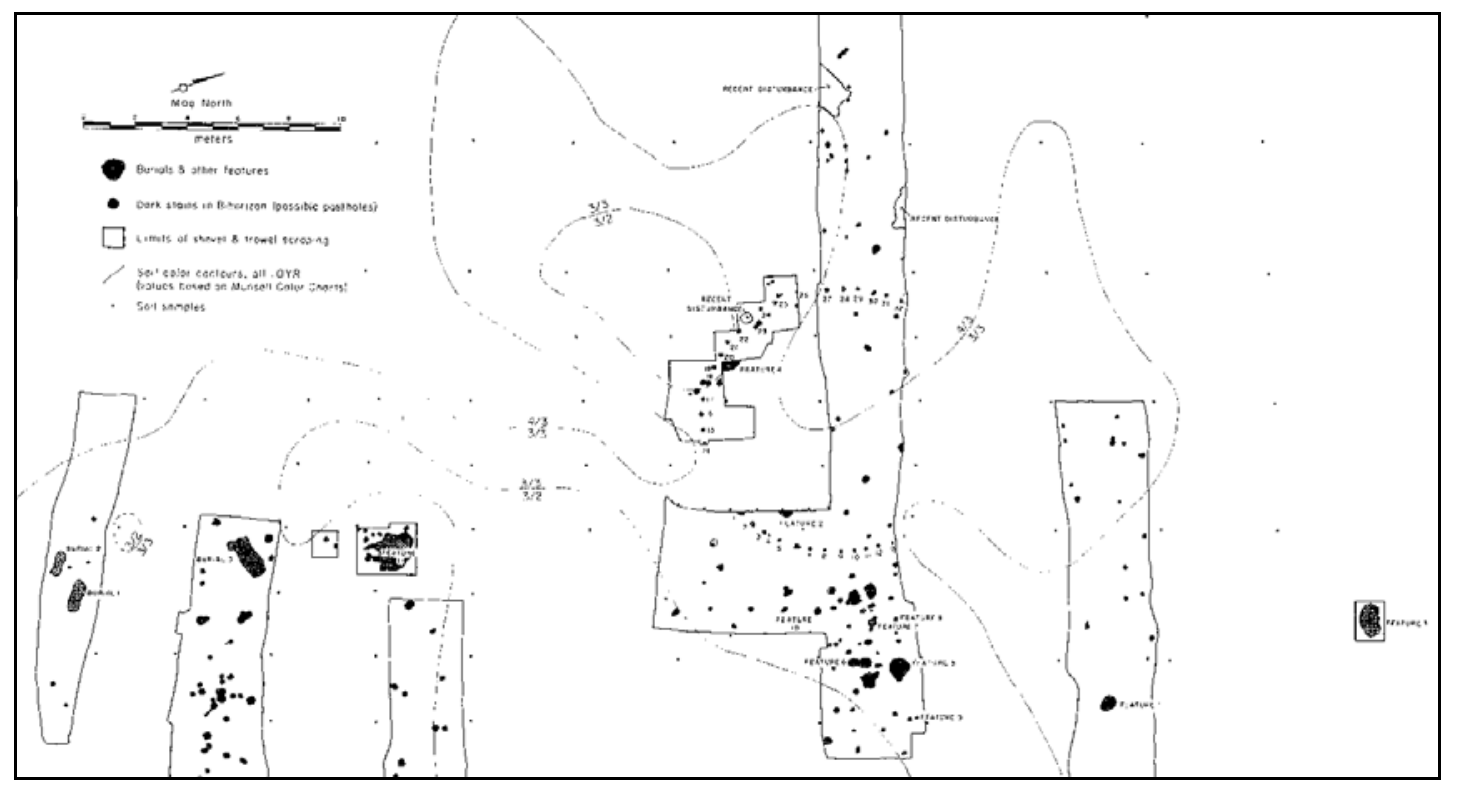

Figure 65. Caddo Structure from the Spoonbill site (Bruseth and Perttula 1981:Figure 339a). 
The three burials (of Middle Caddo and Late Caddo, Titus phase age) encountered in the work were located from about 22-29 $\mathrm{m}$ north-northwest of the center of the structure. The preservation of the burials was poor; however, based on the size of the burial pits, Burial 1 was likely a child and Burial 2 was probably an infant. No interpretation of Burial 3 was provided and it was poorly preserved.

\section{Whelan (41MR2)}

In addition to the structures recorded in Mound A at the Whelan site (see Chapter 5), two non-mound structures were recorded in the occupation area southeast of Mound A (Structures 1 and 2 in Davis 1958). Structure 1 had a diameter of $3 \mathrm{~m}$ and was located approximately $18 \mathrm{~m}$ east of Mound A. The structure outline consisted of 22 post holes spaced about $0.42 \mathrm{~m}$ apart (Lisk 1984:62). The post holes ranged in diameter from $0.14 \mathrm{~m}$ to $0.18 \mathrm{~m}$ with an average diameter of about $15 \mathrm{~cm}$ (Davis 1958:34). The wall post holes were spaced from $0.34 \mathrm{~m}$ to $0.49 \mathrm{~m}$ apart $(\mathrm{n}=22, \bar{x}=0.43 \mathrm{~m}, \mathrm{~s}=0.0434)$. The distances from the wall post holes to the approximate center ranged from $1.42 \mathrm{~m}$ to $1.58 \mathrm{~m}(\mathrm{n}=22$, $\bar{x}=1.48 \mathrm{~m}, \mathrm{~s}=0.0502)$. The ratio of average distance between wall post holes and average distance to the center was 1:3.4 (Davis 1958:34-35). Davis (1958:35) suggested that given the small size of Structure 1, and the fact that no interior features were recorded, Structure 1 was likely a storage platform or some other type of ancillary structure.

Structure 2 (Figure 66) was located approximately $30 \mathrm{~m}$ southeast of Mound A and measured $7.8 \mathrm{~m}$ in diameter. The post holes forming the outline of Structure 2 were spaced from approximately $0.27 \mathrm{~m}$ to $0.65 \mathrm{~m}$ apart $(\mathrm{n}=30, \bar{x}=0.49 \mathrm{~m}, \mathrm{~s}=0.1002)$. The distances from the wall post holes to the center post ranged from $3.54 \mathrm{~m}$ to $4.56 \mathrm{~m}(\mathrm{n}=$ 
$43, \bar{x}=4.12 \mathrm{~m}, \mathrm{~s}=0.3076)$. The ratio of average distance between wall post holes and average distance to the center was 1:8.4 (Davis 1958:34-35). At least nine additional post holes were identified scattered around the interior of the structure, most likely reflecting the locations of interior supports. Davis (1958) also stated that given the difficulty in identifying post holes in this area of the site, many probably went unrecorded. The Structure 2 post holes were not fully excavated, and therefore no depths are available.

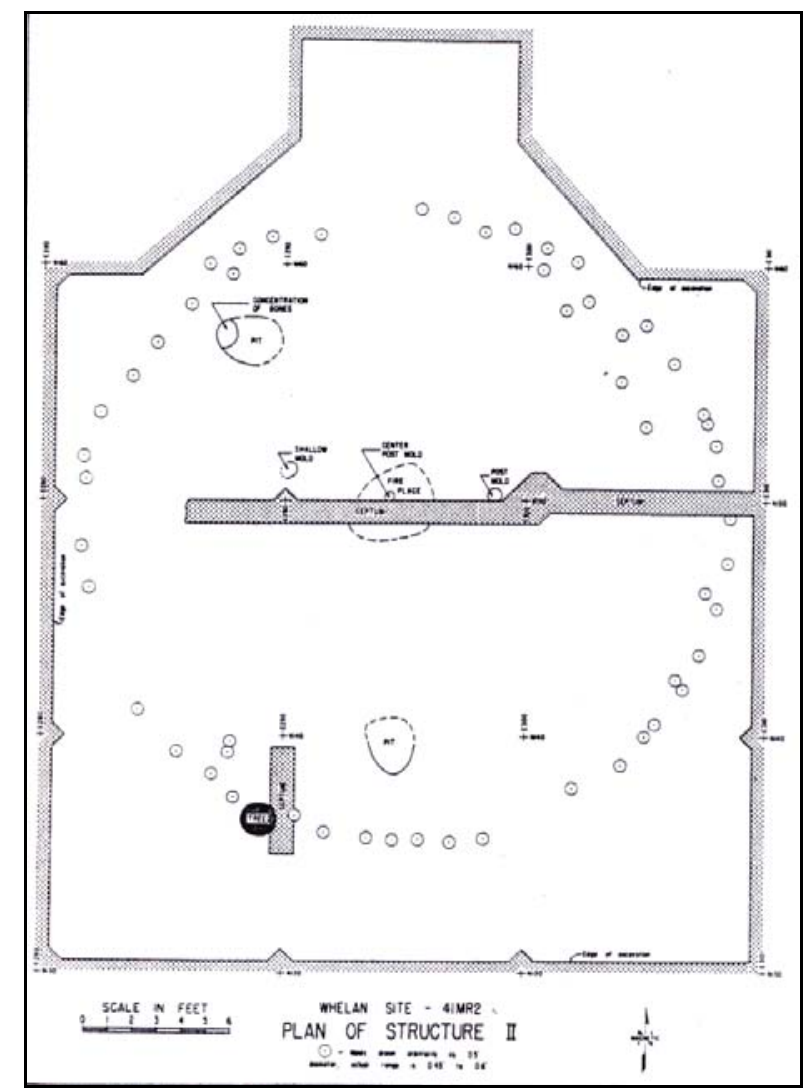

Figure 66. Whelan Structure 2 (Lisk 1984).

The interior of Structure 2 consisted of a $0.30 \mathrm{~m}$ deep dark brown midden accumulation interpreted by Davis (1958:36) as house fill. Below this fill excavators identified two pits interpreted by Davis as refuse pits and an unprepared central hearth, 
measuring about $1.38 \mathrm{~cm}$ in diameter, overlying a central post hole measuring about 15 $\mathrm{cm}$ in diameter (Davis 1958:38). Structure 2 was interpreted as a domicile by Davis (1958:36-38), based on the "refuse pits within the house and the abundance of cultural material in the fill." The midden accumulation in Structure 2 was interpreted to be the result of the use of the structure for waste disposal following its abandonment.

\section{Henry M. Site (41NA60)}

A single circular structure measuring approximately $8.8 \mathrm{~m}$ in diameter was recorded at the Henry M. site during 1985-1991 excavations. The structure dates to the Allen phase, probably to the early eighteenth century (Perttula et al. 2010). Several post holes and likely post hole stains were recorded and at least eight were assigned to the outer wall of the structure, along with 15 post hole-like stains that were not investigated during the archaeological work. The post holes associated with the structure ranged in size from about 15 to $20 \mathrm{~cm}$ in diameter (Perttula et al. 2010). Too few wall posts were recorded by cross-sectioning to arrive at an accurate assessment of wall post hole spacing. Based on the plan map (Perttula et al. 2010:Figure 4), the approximate distances from the wall postholes to the center post ranged from $4.21 \mathrm{~m}$ to $4.66 \mathrm{~m}(\mathrm{n}=9, \bar{x}=4.42$ $\mathrm{m}, \mathrm{s}=0.1499)$.

The structure had an initial central post within an irregularly shaped post hole measuring 50-60 $\mathrm{cm}$ in diameter (Perttula et al. 2010). The second central post hole, likely indicating rebuilding or repair, measured about $40 \mathrm{~cm}$ in diameter and "was filled with ash, midden sediments, a rock, a burned deer antler, and a large conch shell (Busycon sp.) scoop or cup" (Perttula et al. 2010:4). The central posts extended to a depth of at least $45 \mathrm{~cm}$. Three of the post holes were irregular in outline and may represent 
superimposed structures or may indicate repair. Additionally, Perttula et al. (2010:4 and Figures 4 and 7) noted the structure was at least partially rebuilt or repaired given several overlapping post hole features and two central posts.

A grouping of postholes immediately to the north of the structure may represent an arbor, ramada, or granary (Perttula et al. 2010). While a small gap in the partial arc of the structure may represent a west-facing entrance, Middlebrook and Perttula (2008) suggested, based on Good's (1982) analysis of the structures from the Deshazo site and the relation of platforms with historic Caddo structures, that the outdoor platform/granary/arbor may be located in front of the structure, thus possibly placing the entrance on the north side (see also Perttula et al. 2010:4). Middlebrook and Perttula (2008:20) concluded that "[G]iven that Caddo wood structures would probably only last at most 20 years before they begin to deteriorate (see Good 1982:69), available feature evidence suggests that the houses and midden deposit were created over a ca. 20-40 year period by one or two Caddo families."

\section{Blount (41SA123)}

At least one probable structure was identified among the many late prehistoric features at the Late Caddo period Blount site (41SA123). These features included several post holes, at least one hearth, a small pit, and an oval midden, measuring about $27.43 \mathrm{~m}$ long by $15.24 \mathrm{~m}$ wide with an average thickness of about 31-46 cm (Jelks 1965:101). The oval pit, which Jelks called a trash pit, had a diameter of about $0.46 \mathrm{~m}$ and extended to about $0.46 \mathrm{~m}$ deep. The pit was located about $1.22 \mathrm{~m}$ southeast of the structure and contained bone, sherds, charcoal, and "other debris" (Jelks 1965:102). This feature 
provides another example of a storage pit located near a Caddo structure that was later filled with trash.

Jelks described the midden as a "typical one for the region" (Jelks 1963, 1965:101), and it was situated in an area with several post holes. The partial outline of only one oval or sub-round structure was recorded that measured $5.18 \mathrm{~m}$ long by $3.35 \mathrm{~m}$ wide (Jelks 1963, 1965:101). A small hearth near the southern end of the structure and an interior support post were found within the structure perimeter and no entrance was recorded. Jelks $(1963,1965: 101)$ believed that the midden "evidently accumulated around a small cluster of buildings over a period of several decades - or possibly several centuries" and "probably a sequence of different buildings stood on the spot through time, new ones being built to replace those that burned or fell into disrepair." A single calibrated 1 sigma radiocarbon date of A.D. 1405-1510 $(\mathrm{p}=0.92)$ was obtained from the site.

\section{Harold Williams (41CP10)}

The Harold Williams site (41CP10) consists of three areas, A-C. Area A included three burials while Area B consisted of a midden area 75 × $60 \mathrm{~m}$ in size, a Titus phase cemetery with 25 individuals, and a single oval structure (Turner and Smith 2002). The Area $\mathrm{C}$ excavations identified lithics, ceramics, charcoal fragments and 39 pieces of daub, indicating a light occupation in this part of the site (Turner and Smith 2002). The midden in Area B contained "a dense concentration of daub, probably from a burned Caddoan house, along with ceramics, lithic debris, arrowpoints, animal bone, and charred plant remains" (Turner and Smith 2002:19). Multiple structures were likely present at the site through time and Turner and Smith (2002) noted that the large quantities of daub 
associated with the Middle Caddo component at the site illustrates that structures were likely present during that time. Additionally, the Middle Caddo infant interments and offerings were likely "within or immediately adjacent to a house, which is a Caddoan burial custom" (Turner and Smith 2002:65). This being said, however, only a single structure, likely built during the Titus phase, was recorded in Area B (Turner and Smith 2002; Woodall 1967).

The Titus phase structure, Feature 7, measured $6.7 \times 5.0 \mathrm{~m}$ and was associated with a concentration of daub (Figure 67) (Thurmond 1990; Turner and Smith 2002; Woodall 1967). The circular to oval structure included at least 17 or 18 recorded post holes with average diameters of $20 \mathrm{~cm}$ (Woodall 1967), and from the plan map, it appears as though at least 11 of these formed part of the circular structure outline. Woodall (1967:10) stated that "unfortunately, recent erosion has cut through this portion of the site, removing any additional evidence such as a house floor or hearth." Thurmond later noted that "Woodall makes no note of artifact association, so the chronological placement of the structure is also undeterminable" (Thurmond 1990:146). However, based on their reanalysis of the recovered artifacts, Turner and Smith (2002:65) have argued that "based on the artifacts from within and adjacent to the structure, the Feature 7 house probably was built and used by Titus phase peoples." 


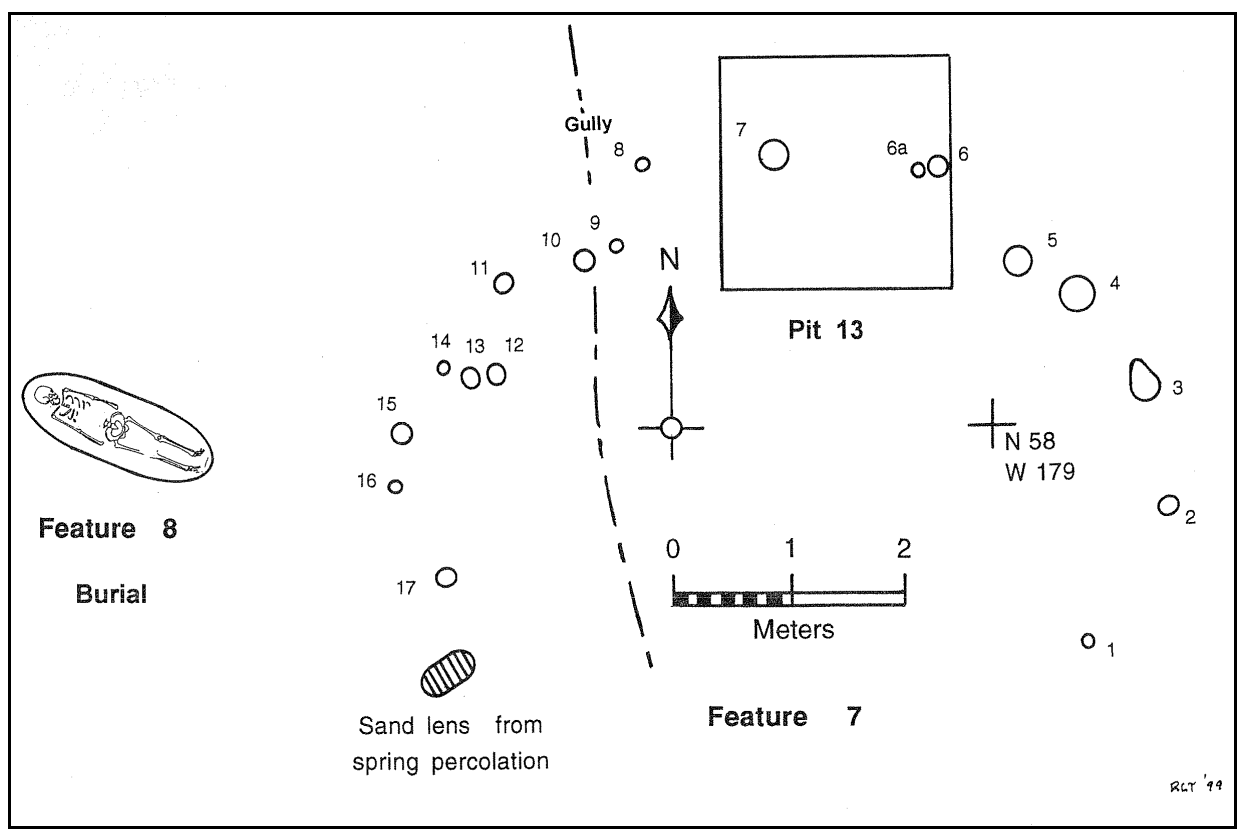

Figure 67. Feature 7 from the Harold Williams Site (41CP10) (Turner and Smith 2002:38 and Figure 24). Reproduced courtesy of the Texas Archeological Society.

\section{Roitsch (41RR16)}

Three rectangular structures were found at the Roitsch (Sam Kaufman) site (41RR16) during excavations by Skinner et al. (1969). Two of these structures (Structures 1 and 3) were located in the village area while Structure 2 was associated with the east mound and was discussed in Chapter 5.

Roitsch Structure 1 was outlined by 56 post holes and was situated not far to the north of the East mound. The structure measured $6 \times 4.1 \mathrm{~m}$ and was rectangular with rounded corners. The perimeter post holes had diameters ranging from $0.08 \mathrm{~m}$ to $0.15 \mathrm{~m}$. Based on the plan map, the post holes forming the outline of Structure 1 were spaced approximately $0.20 \mathrm{~m}$ to $0.57 \mathrm{~m}$ apart $(\mathrm{n}=53, \bar{x}=0.33 \mathrm{~m}, \mathrm{~s}=0.0752)$. No interior features or support posts were identified. No entrance was identified. Materials recovered 
from the fill above the floor level included long-stemmed Red River clay pipes and grogtempered Caddo pottery (Skinner et al. 1969:19).

Structure 3 was defined by a layer of burned wood, bark, charcoal, and daub identified to the east of House 2 in a backhoe trench (Skinner et al. 1969:21). The rectangular shape of the structure was defined by 18 perimeter posts. Based on one possible corner (the southwest corner), the structure may have had rounded or diagonal corners. A southwest-facing extended entrance was identified by two poorly preserved parallel rows of post holes. The entrance appears to have been at least $1.3 \mathrm{~m}$ long and $1.16 \mathrm{~m}$ wide at the furthest point from the structure. The Structure 3 post holes ranged from $0.07 \mathrm{~m}$ to $0.34 \mathrm{~m}$ deep. Interior post holes roughly the same size and depth as the perimeter posts may represent the remains of support posts while interior burned areas may be either hearths, burned posts (Skinner et al. 1969: 21), or the remnants of the burned superstructure. Burials 3, 4, and 5 are located directly to the southwest of Structure 3, all less than $5 \mathrm{~m}$ from the structure entrance (Skinner et al. 1969).

As noted in Chapter 5, the construction of the East Mound and the use of Structure 2 likely dated to between about A.D. 1275-1383 (Perttula et al. 2001), during the early part of the McCurtain phase. Structures 1 and 3 appear to date to an Early Caddo occupation of the site, beginning around A.D. 1000 to A.D. 1100 (Perttula et al. 2001). Radiocarbon dates from burned portions of the superstructure of Structure 3 are provided in Table 42 (Bruseth 1998; Perttula 1997; Skinner et al. 1969). 
Table 42. Radiocarbon dates from Roitsch Structure 3 (Perttula 1997).

\begin{tabular}{|l|l|l|l|l|l|}
\hline Provenience & $\begin{array}{c}\text { Assay } \\
\text { No. }\end{array}$ & $\begin{array}{c}\text { Raw Age } \\
\text { (BP) }\end{array}$ & $\begin{array}{c}\text { Corrected } \\
\text { Age (B.P.) }\end{array}$ & $\begin{array}{c}\text { Calibrated 1 sigma } \\
\text { age range (AD) }\end{array}$ & $\begin{array}{l}\text { Relative area under } \\
\text { probability } \\
\text { distribution }\end{array}$ \\
\hline & & & & $1154-1250$ & 0.61 \\
Structure 3 & Tx-882 & $870 \pm 70$ & $870 \pm 81$ & $\begin{array}{l}1048-1092 \\
1117-1142\end{array}$ & 0.25 \\
& & & & $982-1068$ & 0.14 \\
\hline & & & & $1072-1128$ & 0.53 \\
Structure 3 & Tx-883 & $1000 \pm 70$ & $1000 \pm 81$ & $1131-1160$ & 0.32 \\
\hline Structure 3 & Tx-884 & $910 \pm 70$ & $910 \pm 81$ & $1040-1200$ & 0.15 \\
\hline & & & & $1151-1216$ & 1.00 \\
& & & & $1044-1105$ & 0.40 \\
Structure 3 & Tx-885 & $900 \pm 70$ & $900 \pm 81$ & $1112-1147$ & 0.38 \\
\hline
\end{tabular}

\section{A. C. Saunders (41AN19)}

Originally recorded and excavated in 1931, with subsequent excavations in 1933 and 1935, the A. C. Saunders site (41AN19) is a Late Caddo, Frankston phase (ca. A.D. 1400-1650) site situated just west of the Neches River (Jackson 1936; Kleinschmidt 1982, 1984). The 1933 excavations were by E. B. Sayles, with the 1931 and 1935 excavations conducted under the direction of A. T. Jackson of UT-Austin. Kleinschmidt (1982) provided a full analysis of the excavations and the recovered material culture remains, which had never been fully studied.

The site is situated on an upland landform and consists of a single low artificial mound that was trenched by Jackson's excavations. This mound consisted of a nearly sterile $1.06 \mathrm{~m}$ thick layer of ash that was $45.7 \mathrm{~m}$ in diameter. In addition, a $15-79 \mathrm{~cm}$ deep, 15.2-18.3 m diameter, oval-shaped midden area was excavated by Jackson about 38 m south of the Ash Mound. A good deal of material culture remains were recovered from these excavations, including several sherds (7000+), lithics, bone, shell, etc. 
Several features were found below the midden, including a large circular structure (Feature 3) (Jackson 1936; Kleinschmidt 1982, 1984). The outline of this structure consisted of 98 (or 99 post holes in Jackson's records) relatively closely-spaced post holes that ranged from 32 to $71 \mathrm{~cm}$ in diameter (Figure 68). Feature 3 measured $14 \mathrm{~m}$ east-west by $13.2 \mathrm{~m}$ north-south, covering an area of $149.5 \mathrm{~m}^{2}$. A gap at the eastern side of the structure outline may have represented a non-extended entranceway. Jackson identified seven interior post holes; Kleinschmidt's (1982) examination of the Saunders data suggested that three of these post holes likely represented interior support posts located near the center of the structure. The available data from the other four post holes was not sufficient enough to convincingly argue for their association with this structure and they may have been associated with a separate occupational event (Kleinschmidt 1982).

Based on the plan map (Kleinschmidt 1982), the wall post holes were spaced 0.20 $\mathrm{m}$ to $0.62 \mathrm{~m}$ apart $(\mathrm{n}=85, \overline{\mathrm{x}}=0.39 \mathrm{~m}, \mathrm{~s}=0.0950)$. The distances from the wall post holes to the approximate center ranged from $6.22 \mathrm{~m}$ to $6.74 \mathrm{~m}(\mathrm{n}=90,=6.50 \mathrm{~m}, \mathrm{~s}=0.1161)$. The ratio of average distance between wall post holes and average distance to the center was $1: 16.5$. The center post had a diameter of approximately $0.33 \mathrm{~m}$. While no central hearth was recorded, one possible hearth (Feature 4) was recorded on the structure interior, two were recorded along the structure wall (Features 5 and 6), in a location that seems to suggests they were likely not in use while the structure was standing, and two were recorded in the immediate vicinity of the structure (Features 7 and 8), but outside the structure walls (Kleinschmidt 1982). Kleinschmidt's analysis of the Saunders archeological remains suggests that this structure was built during the sixteenth century (Kleinschmidt 1982; Perttula 2004a) 


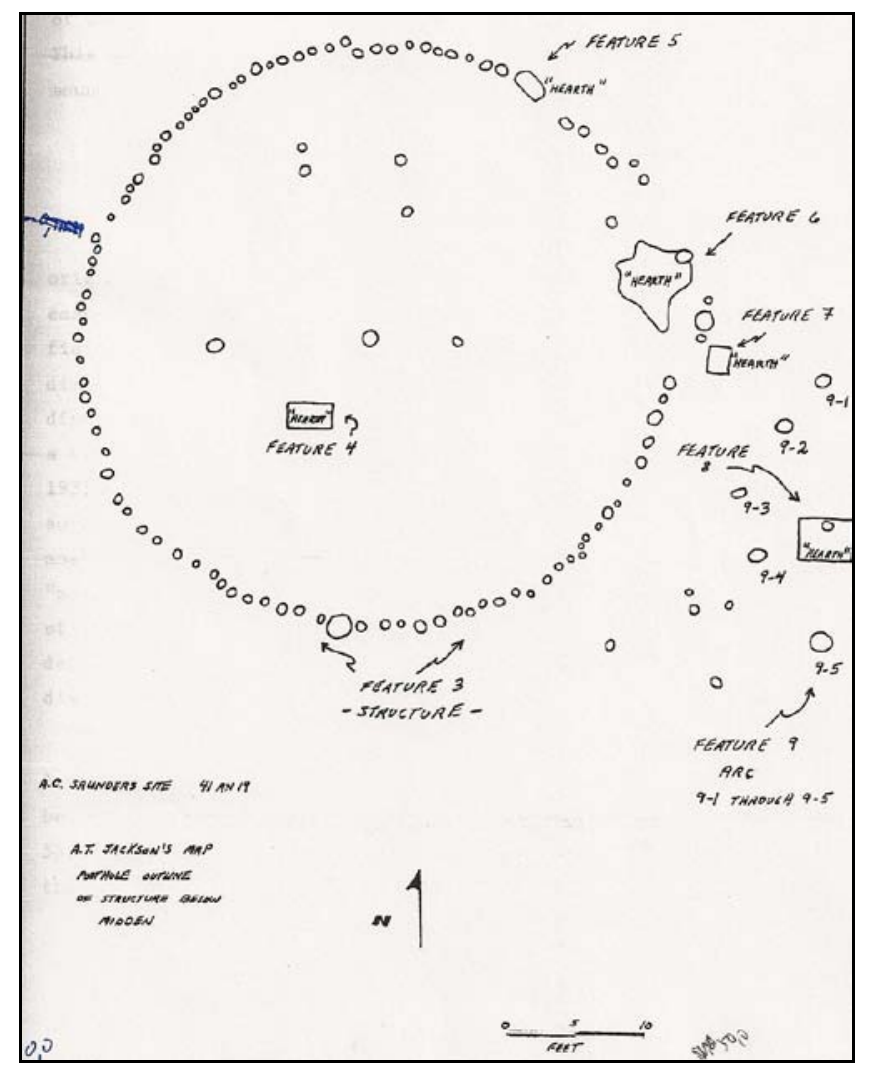

Figure 68. Feature 3 from the A. C. Saunders site (Kleinschmidt 1982).

\section{Spider Knoll (41DT11)}

The Early to Middle Caddo period Spider Knoll site (41DT11) consisted of three distinct activity areas, including an area primarily used for trash disposal (south edge of the site), an area used for outside activities (eastern half of the site), and the north portion of the site, used for outside activities and for the construction and use of possible residences or shelters (Fields et al. 1997). Several pits, post holes, hearths, and a spatially distinct midden were found at the site. 
The postholes likely corresponded to multiple arbors and drying racks as well as to at least two possible houses. Fields et al. (1997:59) noted that "the postholes do not form patterns that can be interpreted unquestionably as representing houses. Yet, many of the postholes can be grouped into arcs suggestive of structural walls. The two longest arcs, both encompassing semicircular arcs, account for 13 of these postholes, and it is hypothesized that these represent two houses." They further suggested that the possible structures may be open structures rather than traditional fully enclosed house (Fields et al, 1997:59).

Structure 1, the western structure, was a semi-circle consisting of six post holes with diameters ranging from 10 to $23 \mathrm{~cm}(\bar{x}=15.3, \sigma=4.2)$ (Fields et al. 1997:59). If the arc represented part of a circular structure, then the possible structure had a maximum diameter of about $8 \mathrm{~m}$ with post holes spaced from 2.1 to $3.9 \mathrm{~m}$ apart $(\bar{x}=2.8, \sigma=0.7)$ (Fields et al. 1997:59). A pit was located within the Structure 1 outline.

Structure 2, the eastern structure, had seven post holes with diameters ranging from 9 to $21 \mathrm{~cm}(\bar{x}=15.9, \sigma=3.5)$ (Fields et al. 1997:59). Based on the arc of post holes, this possible circular structure could have had a maximum diameter of about $10 \mathrm{~m}$, with post holes spaced from 2 to $3.7 \mathrm{~m}$ apart $(\bar{x}=2.7, \sigma=0.7$ ) (Fields et al. 1997:59).

A hearth and two pits were situated near the center of Structure 2, possibly representing a central hearth. Fields et al. (1997:59) noted that "the hearth central to the eastern arc may well be associated with this possible structure given the correspondence between the corrected radiocarbon assays from this hearth and one of the postholes in the arc $(1065 \pm 55$ and $1095 \pm 55$ B.P., respectively)." In addition to the central hearth and pits, a second hearth and small pit were situated along the structure's eastern side, a small pit was along the structure's northern edge, and an additional pit was located to the 
southwest of the structure. "The hearth along the eastern edge probably is not associated given its radiocarbon assay of $850 \pm 90$ B.P., and it may represent use of this area for outside activities associated with occupation of the western structure" (Fields et al. 1997:59).

The Spider Knoll structures may be similar to the structures found at the Sanders site (see Chapter 5), although those from the Sanders site were situated on a mound platform. Fields et al. (1997:61) summarized the possible Spider Knoll structures as follows:

The incomplete post hole patterns, small post hole size, and wide spacing between the post holes indicate that, if the arcs in the western subarea do represent structures, these were not the sorts of substantial, permanently occupied houses typically found at Caddoan residential sites. Rather, they may have been more akin to large arbors or sun/wind screens that were used seasonally.

\section{Deshazo (41NA27)}

The Deshazo site (41NA27) was divided by Story (1982:35) into seven areas of artifact concentrations during 1975 and 1976 excavations, A-G, with the bulk of cultural materials recovered from Areas A, C, and D. Archaeological features from this historic Caddo Allen phase hamlet (that probably dates from the late seventeenth century to the early eighteenth century) included nine circular Caddo structures. Eight structures, Structures 1-7 and 9, were identified in Area D and one (Structure 8) was found in Area A (Figure 69). The structures have been interpreted as domiciles, with the possible exception of Structure 8 given its location on the opposite side of the creek from the other eight structures, and on the same side of the tributary as the associated family cemetery (Good 1982:51). 


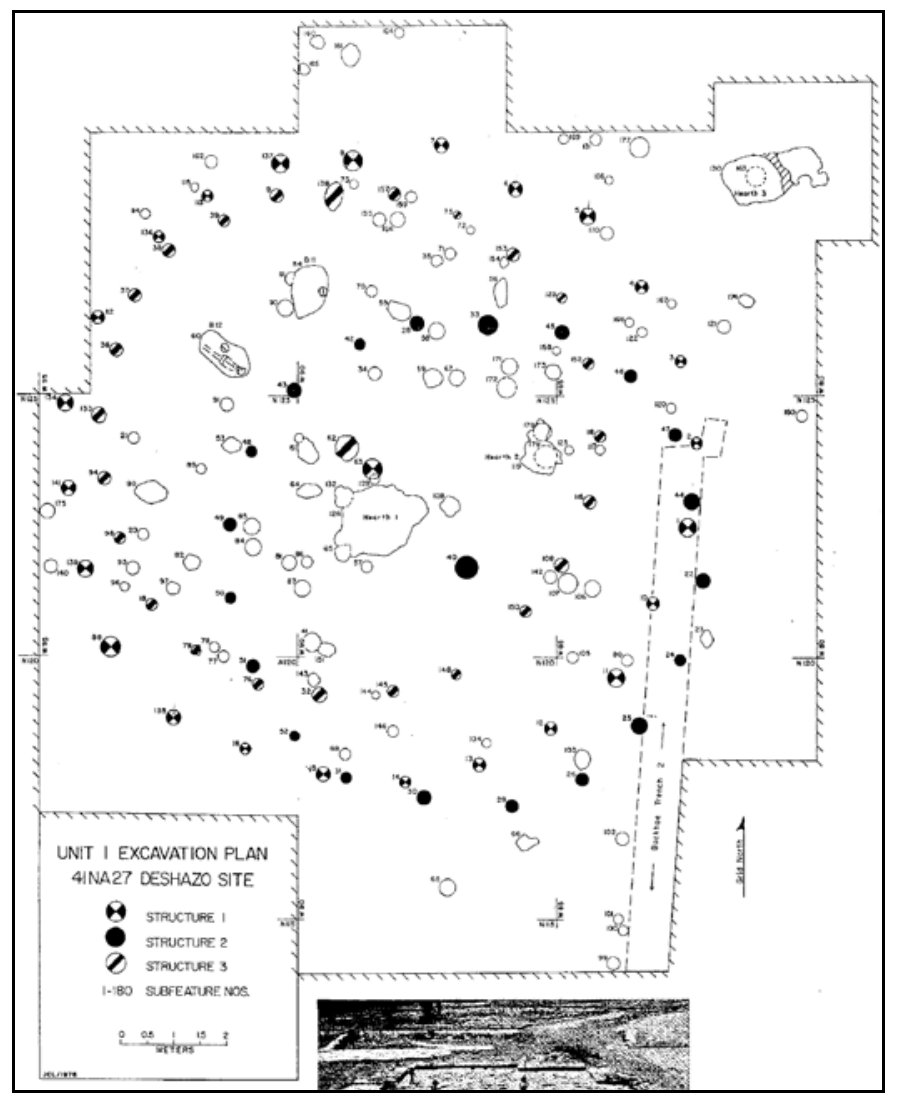

Figure 69. Structures 1-3 from the Deshazo site (Good 1982:54, Figure 17)

Each of the fully exposed structures had evidence of a center post, an exterior wall with between 20-24 posts, and a diameter ranging from 9.0-12.2 m. No prepared floors were found associated with any of the structures; in fact, excavations were unable to determine floor levels for individual structures due largely to past plowing and erosion at the site (Good 1982:53).

Structures 1, 2, and 3 were identified in excavation unit 1 in Area D along with two burials (Burials 11 and 12) and three hearths (Hearths 1, 2, and 3). All three structures were circular with diameters of $12.2 \mathrm{~m}$ (Structure 1), $9.4 \mathrm{~m}$ (Structure 2), and 
$9.8 \mathrm{~m}$ (Structure 3). Each structure had a center post and the post hole patterns of each closely overlapped the other structures.

Although the hearths were located within Structures 1, 2, and 3, Good (1982:7172) was unable to associate the hearths with individual houses. Despite this, Good (1982:73) suggested that Hearth 1 postdated the construction of Structure 1, although the relationship between Hearth 1 and the other two structures was not determined. Given its location, Hearth 2 was probably associated with either Structure 1 or Structure 2 and would have been located between the exterior wall and the center post (Good 1982:76). Finally, Hearth 3 was located outside of the exterior walls of the three structures. Hearth 3 had a post hole beneath it, however, although no associated structure was identified (Good 1982:76-78). In addition to the three hearths, Burials 11 and 12 probably "represent juvenile interments in shallow, basin-shaped graves associated with structures" (Good 1982:88). Like the other features from Unit 1, it was difficult to associate the burials with individual structures. Both burials 11 and 12 were found in shallow, oval, basin-shaped pits near the wall of Structure 3, presumably buried within or under the floor of the structure (Good 1982:90).

Three overlapping circular structures (Structures 4-6) were identified north of Structures 1-3 in Units 3 and 11. More than 113 features were identified in this area that corresponded to the three structures as well as additional outlying features interpreted as possible ramadas or storage platforms. Structures 4-6 measured $9.6 \mathrm{~m}, 9.6 \mathrm{~m}$, and $11.9 \mathrm{~m}$ in diameter, respectively. No prepared floors, hearths, or midden areas were found in association with these structures (Good 1982).

Structure 7 measured $9.0 \mathrm{~m}$ in diameter and was identified southeast of structures 1-3. This structure had several associated interior features, including an "arc of 
disturbances northwest of the center post lying about $1.5 \mathrm{~m}$ inside the arc of the exterior support posts, and the cluster of disturbances southwest of the center post close to the wall of the structure" (Good 1982:55). These interior features likely represent support posts or supports for interior shelves, racks or furnishings (Good 1982).

A single structure was identified on the same side of the creek as the Historic Caddo cemetery. Structure 8 consisted of an arc of five post holes (Good 1982:55). The structure was not further excavated due to disturbances prior to the 1976 excavations. Based on the arc of five post holes, Structure 8 had an estimated diameter of $9.2 \mathrm{~m}$.

Structure 9 consisted of 10 post holes forming an arc that represented approximately half of a circular structure. Structure 9 was approximately $9 \mathrm{~m}$ in diameter with an area of approximately $63.59 \mathrm{~m}^{2}$. No internal structural features were identified in the limited excavations that only exposed a portion of the outer wall and not the interior of the structure. Burial 13, "an apparent juvenile burial," was "located against the southeast wall of the structure" (Good 1982:55).

Summary post hole data for the wall post holes associated with each structure are provided in Table 43. Mean wall post hole diameters ranged from $0.23 \mathrm{~m}$ to $0.27 \mathrm{~m}$. Mean depth ranged from $0.22 \mathrm{~m}$ to $0.53 \mathrm{~m}$. The center post holes for the structures ranged in diameter from $0.29 \mathrm{~m}$ to $0.49 \mathrm{~m}$, with depths ranging from $0.18 \mathrm{~m}$ to $0.68 \mathrm{~m}$. Good (1982:63-64) provided measurements for distances between wall post holes and from the center posts to the wall (Table 44). The wall post holes for the nine structures had a mean spacing ranging from 1.197 to $1.71 \mathrm{~m}$, a much larger spacing than that seen with structures from other sites. The mean distances from the center to the wall posts for the nine Deshazo structures ranged from $4.6 \mathrm{~m}$ to $6.1 \mathrm{~m}$. While the mean spacing between posts at the Deshazo site was larger than that seen at other East Texas Caddo sites, the 
ratio of the average distances between exterior post holes and average distance to center post holes was actually smaller than that seen in most other structures in this study.

Table 43. Summary wall post hole data for the Deshazo structures.

\begin{tabular}{|c|c|c|c|c|c|c|c|c|c|c|c|}
\hline \multirow[b]{2}{*}{$\begin{array}{l}\stackrel{0}{\Xi} \\
\stackrel{己}{0} \\
\stackrel{\Xi}{\Xi}\end{array}$} & \multirow[b]{2}{*}{$\begin{array}{c}\text { Number of } \\
\text { wall post } \\
\text { holes }\end{array}$} & \multicolumn{4}{|c|}{ Diameter } & \multicolumn{4}{|c|}{ Depth } & \multicolumn{2}{|c|}{ Center Post } \\
\hline & & $\stackrel{\Xi}{\Sigma}$ & $\stackrel{\gtrless}{\stackrel{\varpi}{\Xi}}$ & $\stackrel{\Xi}{\Sigma}$ & 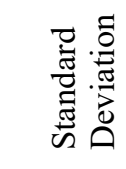 & $\stackrel{\Xi}{\Sigma}$ & 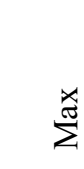 & $\stackrel{\Xi}{\Sigma}$ & 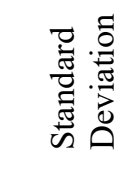 & $\begin{array}{l}\bar{\Xi} \\
\stackrel{\Xi}{\Xi} \\
\stackrel{\Xi}{0}\end{array}$ & 華苍 \\
\hline 1 & 24 & 0.19 & 0.41 & 0.30 & 0.0534 & 0.31 & 0.68 & 0.47 & 0.0758 & 0.40 & 0.46 \\
\hline 2 & 20 & 0.17 & 0.51 & 0.27 & 0.0812 & 0.22 & 0.70 & 0.53 & 0.1155 & 0.48 & 0.68 \\
\hline 3 & 25 & 0.11 & 0.52 & 0.27 & 0.0941 & 0.14 & 0.72 & 0.35 & 0.1270 & 0.49 & 0.18 \\
\hline 4 & 20 & 0.14 & 0.35 & 0.23 & 0.0501 & 0.11 & 0.36 & 0.22 & 0.0702 & 0.34 & 0.22 \\
\hline 5 & 20 & 0.21 & 0.33 & 0.25 & 0.0339 & 0.16 & 0.45 & 0.32 & 0.0826 & 0.42 & 0.20 \\
\hline 6 & 15 & 0.18 & 0.38 & 0.26 & 0.0470 & 0.12 & 1.33 & 0.33 & 0.3090 & 0.34 & 0.20 \\
\hline 7 & 18 & 0.15 & 0.33 & 0.23 & 0.0484 & 0.29 & 0.64 & 0.51 & 0.0946 & 0.29 & 0.57 \\
\hline 8 & 5 & $\mathrm{n} / \mathrm{a}$ & $\mathrm{n} / \mathrm{a}$ & $\mathrm{n} / \mathrm{a}$ & $\mathrm{n} / \mathrm{a}$ & $\mathrm{n} / \mathrm{a}$ & $\mathrm{n} / \mathrm{a}$ & $\mathrm{n} / \mathrm{a}$ & $\mathrm{n} / \mathrm{a}$ & $\mathrm{n} / \mathrm{a}$ & $\mathrm{n} / \mathrm{a}$ \\
\hline 9 & 10 & 0.14 & 0.40 & 0.25 & 0.0749 & 0.26 & 0.48 & 0.38 & 0.058 & $\mathrm{n} / \mathrm{a}$ & $\mathrm{n} / \mathrm{a}$ \\
\hline
\end{tabular}

Good (1982) explains the similarity between the ratios of these distances by arguing that in building the structures, the center was first established, followed by establishing the radius of the structure, using that measurement for the placement of all the wall post holes. Good (1982:64) suggests that "the distance between the exterior postholes was established at a little better than $1 / 3$ the radius, regardless of the length of the radius". Good (1982:64) does not point towards the use of a standard unit of measurement, but suggests that the process was repeated for each structure independently. Clearly, as Good (1982:64) argues, the Caddo builders recognized the "spacing and number of the exterior supports required for structural integrity in relation to the size of the structure. Having this understanding would allow shamans to designate precisely the number of support posts required for a particular structure" when they sent 
the tammas to order members of the community to prepare poles for the construction of building. This in turn suggests that "initial measurements were made and spacing determined well in advance of actual construction" (Good 1982:65).

Table 44. Distance between exterior post holes and distances from wall post holes to structure center at Deshazo.

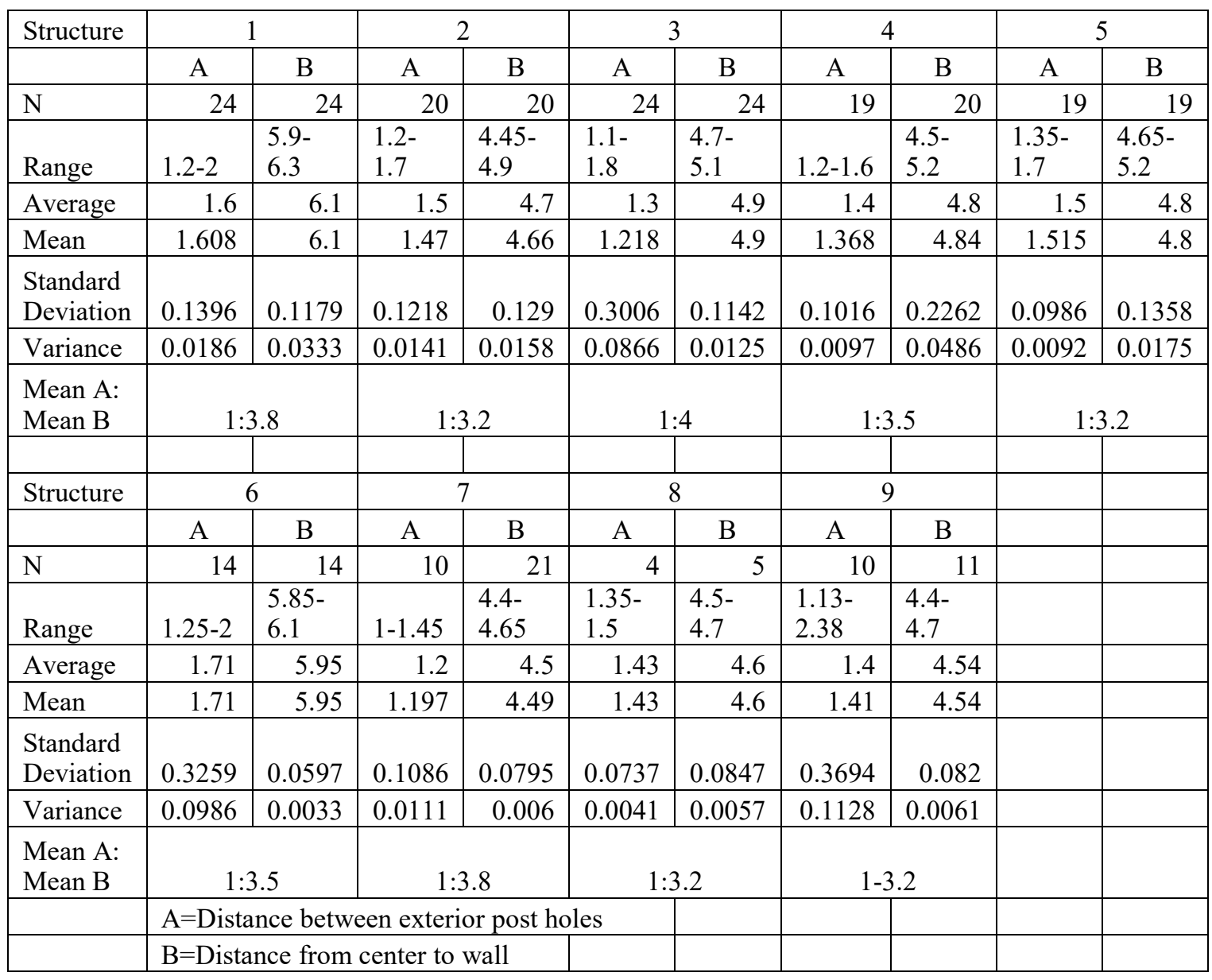

At Deshazo, it is clear that structures were rebuilt using the same location in many instances. The sequence of structures in each unit was contemporaneous and structure replacement "was determined by the rate of deterioration of the structure materials" 
(Good 1982:69) rather than increases in population. Based on records from the Texas Forest Service, the support timbers for the Deshazo structures would have remained sound for at least 10 years and possibly up to 30 years, with an average lifespan of around 20 years (Good 1982:69).

\section{New Hope (41FK107)}

A single structure and evidence for associated activity areas were recorded at the New Hope site (41FK107) in Franklin County (Figure 70), in the Big Cypress Creek basin. Although only nine post holes were recorded, Nelson and Perttula (2006) suggested that the circular structure measured approximately $8.8 \mathrm{~m}$ in diameter. The nine wall post holes had an average diameter of $0.19 \mathrm{~m}$ and average depth of $0.35 \mathrm{~m}$ bs. Based on the plan map (Nelson and Perttula 2006:30), the wall post holes were spaced at least $0.92 \mathrm{~m}$ to $1.76 \mathrm{~m}$ apart $(\mathrm{n}=6, \bar{x}=1.27 \mathrm{~m}, \mathrm{~s}=0.3359)$. The distances from the wall post holes to the center of the structure ranged from $4.18 \mathrm{~m}$ to $4.40 \mathrm{~m}(\mathrm{n}=9, \bar{x}=4.30 \mathrm{~m}, \mathrm{~s}=$ 0.0731). The ratio of average distance between wall post holes and average distance to the center was 1:3.3. The New Hope site structure also had a central hearth. The basinshaped hearth had straight sides and a flat base and extended to $0.20-0.43 \mathrm{~m}$ bs (Nelson and Perttula 2006:28).

Radiocarbon dates were obtained from charred hickory nutshells (Carya sp.) from the hearth fill (Nelson and Perttula 2006). These produced a 2 sigma date of cal. AD 1280-1420 (Nelson and Perttula 2006:30). Based on the radiocarbon date from the hearth as well as the predominantly Middle Caddo ceramic assemblage recovered at the site (Nelson and Perttula 2006:31-33), Nelson and Perttula (2006) concluded that the 
principal component of the New Hope site would have been during the Middle Caddo period.

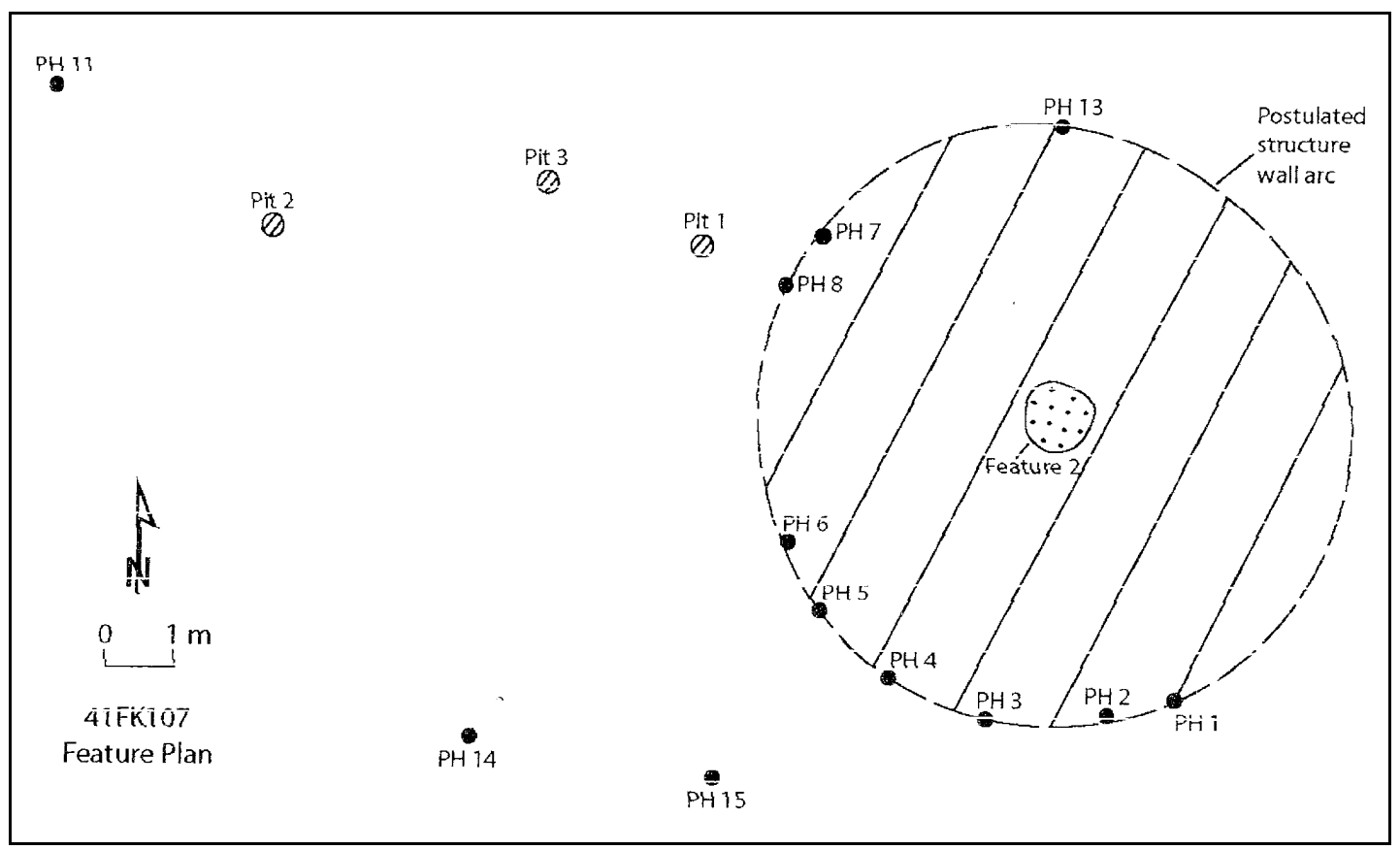

Figure 70. New Hope site (41FK107) (Nelson and Perttula 2006:30). Reproduced courtesy of the Friends of Northeast Texas Archaeology.

\section{Walter Bell 41SB50}

At least two and likely three circular structures were excavated at the Walter Bell site (41SB50) prior to the construction of Lake Sam Rayburn on the Angelina River. Figure 71 provides a view of the excavated areas of the site. These $15^{\text {th }}$ century (ca. postA.D. 1450) late Angelina phase structures (Jelks 1965) were separated by an open area with little habitation debris (Perttula 2008) and were $7.9 \mathrm{~m}$ (Structure 1), $6.4 \mathrm{~m}$ (Structure 2) and possibly $12.2 \mathrm{~m}$ (Structure 3) in diameter. 
Structures 1 and 2 were each represented by a ring of post holes indicating that they were built of individually set vertical posts (Jelks 1965). Structure 3 was identified as an arc of posts within the Structure 2 outline and was interpreted by Jelks (1965) as a separate structure. Both Structures 1 and 2 were interpreted as having been of wattle-anddaub construction based on the recovery of wattle-impressed daub fragments (Jelks 1965).

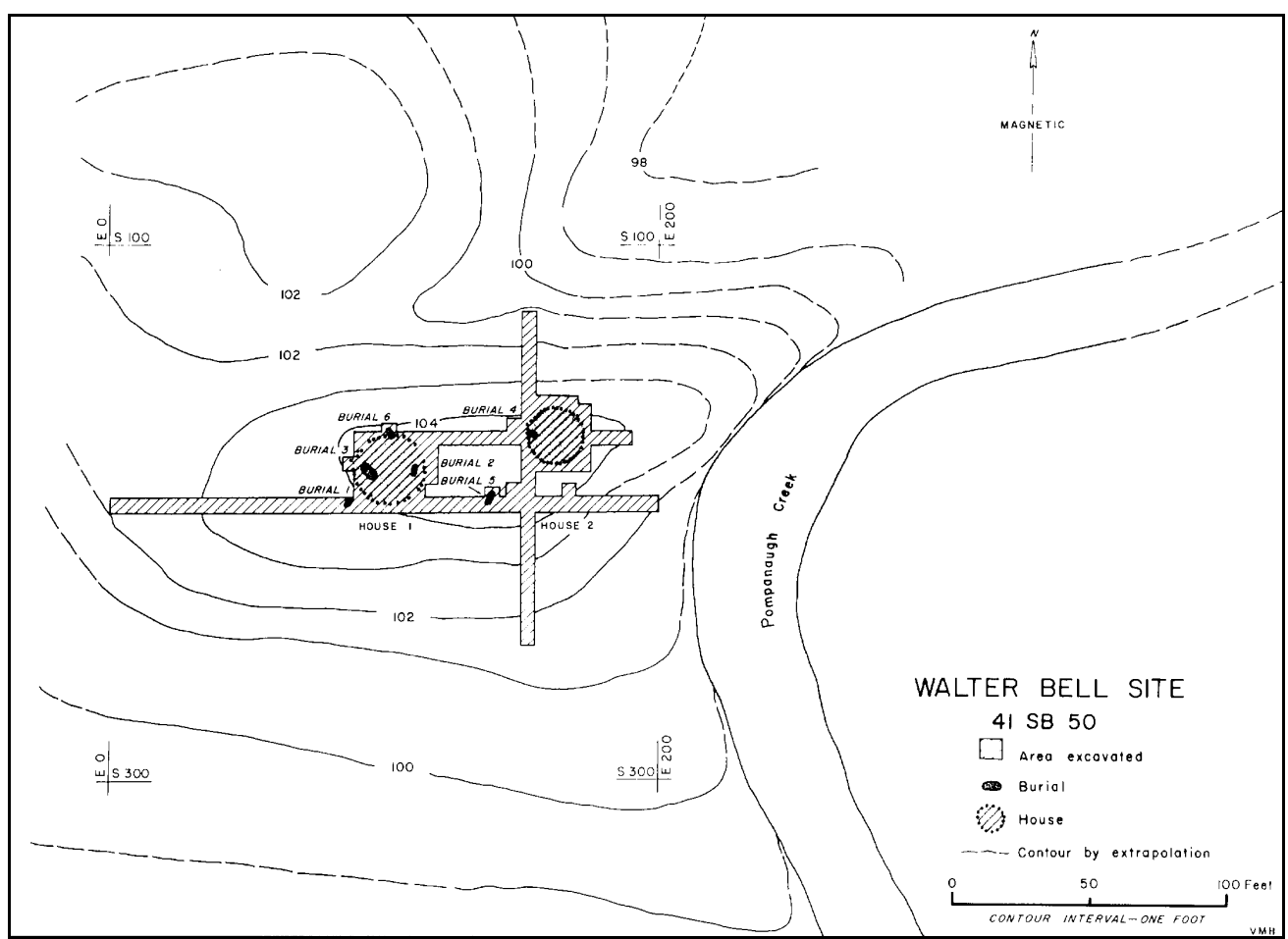

Figure 71. Site map of the Walter Bell Site (Jelks 1965:312 and Figure 20).

The Structure 1 posts were set 0.54 to $0.94 \mathrm{~m}$ apart and had diameters ranging from 0.09 to $0.15 \mathrm{~m}$. Jelks (1965:56) noted that a gap on the west side may have been indicative of a non-extended entrance that was $2.1 \mathrm{~m}$ wide, although it may be a gap in identified post holes, given that two other gaps were also present on the southeast and 
northwest sides that measured 1.46 and $1.2 \mathrm{~m}$ wide, respectively. For Jelks (1965:56), it was difficult to discern the exact number of posts that made up the perimeter of the structure, but it probably had between 30 and 40 posts. Seven post holes were identified on the structure interior, but no hearth was found. The floor of the structure was likely in the midden level immediately above where the structure was first identified, "probably not far from the modern surface of the ground" (Jelks 1965:56). This explains the shallowness of the perimeter poles since none were deeper than $0.15 \mathrm{~m}$ below the dark midden zone (Zone 2) that extended to about 0.15-0.30 m bs (Jelks 1965).

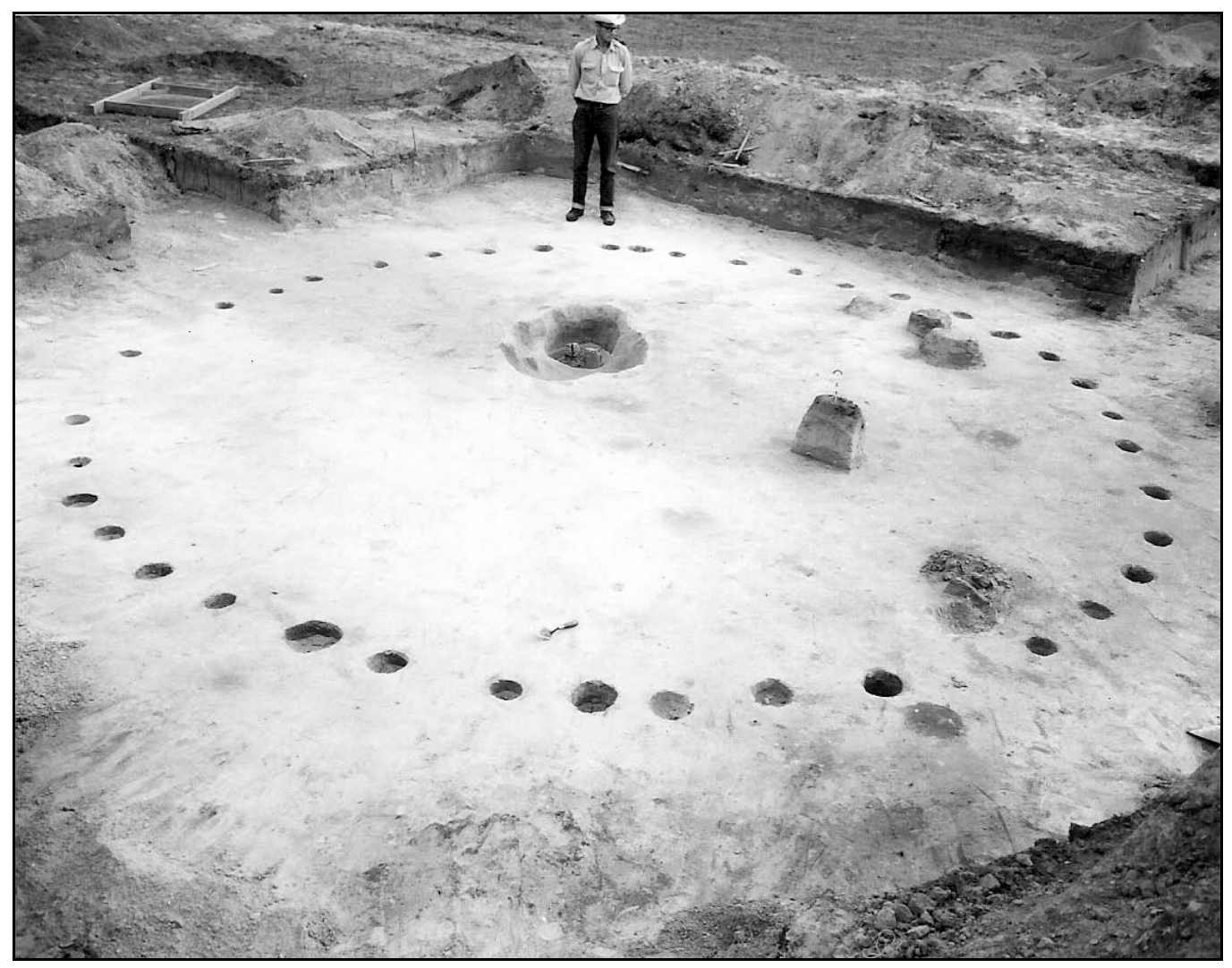

Figure 72. Structure 2 at the Walter Bell Site (Jelks 1965:314 and Figure 22). 
Structure 2 (Figure 72) was situated about $18.2 \mathrm{~m}$ to the east-northeast of Structure 1 and was represented by 39 perimeter post holes measuring about 0.12 to 0.21 $\mathrm{m}$ in diameter and extending to an average depth of about $0.46 \mathrm{~m}$ bs (Jelks 1965:58). No definite entrance was identified and the posts tended to be spaced from 0.30 to $0.61 \mathrm{~m}$ apart with the exception of three large gaps, one on the northeast side and two adjacent gaps on the northwest side, measuring about $1.5 \mathrm{~m}, 1.68 \mathrm{~m}$ and $1.68 \mathrm{~m}$ wide respectively (Jelks 1965:58). No prepared floor was found, but "the floor of House 2 was probably at or above the modern surface of the ground as no hard-packed zone or other definite indication of a floor was found. Perhaps the original floor was disrupted by the plow" (Jelks 1965:58). The structure had at least two large interior posts, each measuring about $0.31 \mathrm{~m}$ in diameter, one of which was a center post. An arc of six post holes (Structure 3) cut across the southwest portion of Structure 2. "The molds were comparable in size, depth and spacing to those of Houses 1 and 2, therefore they probably represent a third house" (Jelks 1965:60). Based on the arc, Structure 3 probably measured $12.2 \mathrm{~m}$ or more in diameter.

The semi-flexed burial of a middle-aged male, Burial 4, was located on the east side of Structure 2, "at a spot where the wall of House 3 passed over one end of the grave" (Jelks 1965:59, 64-65). It was not possible to ascertain "whether the burial was earlier or later than the house or if the association between the two was accidental or intentional" (Jelks 1965:59).

\section{Rookery Ridge (41UR133)}

Two Late Caddo Titus phase circular structures were found at the Rookery Ridge site (41UR133), along with several other features, including four burials and two midden 
areas. The site appears to have been a single Late Caddo occupation likely dating to the end of the Whelan phase and the beginning years of the Titus phase (Parsons, personal communication 2009). Radiocarbon dates suggest the site was occupied around A.D. 1400-1450 (Parsons, personal communication 2009).

Structure 1 (Figure 73) was recorded in Block B and measured $5.85 \mathrm{~m}$ in diameter with an interior area of approximately $26.9 \mathrm{~m}^{2}$ (Parsons, personal communication 2009). The structure was defined by a central hearth underlain by a central post hole and a circle of 42 wall post molds. Parsons (personal communication 2009) specifically notes that the stains were post molds rather than post holes.

The central hearth was roughly circular-shaped, with a basin-shaped base, and measured approximately $1 \mathrm{~m}$ in diameter and extended to a depth of approximately $18 \mathrm{~cm}$ below the scraped surface. A central post had been removed to allow for the excavation of the hearth, a common practice in Caddo construction that is documented in the early European accounts (see Chapter 3). The center post had a diameter of approximately 30 $\mathrm{cm}$ near the surface, larger than the Structure 1 wall posts, tapering to a diameter of about $20 \mathrm{~cm}$ at its base (Parsons, personal communication 2009). The post extended to a depth of approximately $60 \mathrm{~cm}$ bs.

The wall post molds had diameters ranging from 0.13 to $0.20 \mathrm{~m}(\bar{x}=0.35 \mathrm{~m})$ and depths ranging from approximately $0.61-0.82 \mathrm{~cm}$ bs, with a mean depth of approximately $0.75 \mathrm{~cm}$ bs and a median depth of approximately $73 \mathrm{~cm}$ bs (Parsons, personal communication 2009). The wall post molds were spaced from approximately 0.35 to 0.42 $\mathrm{m}$ apart $(\bar{x}=0.402)$. Based on the plan map, the distances from the wall post molds to the center post ranged from $2.69 \mathrm{~m}$ to $3 \mathrm{~m}(\mathrm{n}=41, \bar{x}=2.89 \mathrm{~m}, \mathrm{~s}=0.0867)$. The ratio of average distance between wall post molds and average distance to the center was 1:7.2. 
The entrance of the structure consisted of two roughly parallel trenches extending about 4 $\mathrm{m}$ to the north-northeast (see Figure 73). The trenches had widths varying from approximately 0.25 to $0.35 \mathrm{~m}$ and the centers of the trenches were spaced from $0.75 \mathrm{~m}$ to $1 \mathrm{~m}$ apart, narrowing as it neared the structure wall, resulting in a $0.70 \mathrm{~m}$ entrance gap between the two wall posts on either side of the entrance (Parsons, personal communication 2009). The depth of the trenches increased as the entrance extended away from the structure. The depth of the trenches near the structure was approximately $57 \mathrm{~cm}$ bs, extending to $68 \mathrm{~cm}$ bs and finally $75 \mathrm{~cm}$ bs, approximating the depth of the wall posts (Parsons, personal communication 2009).

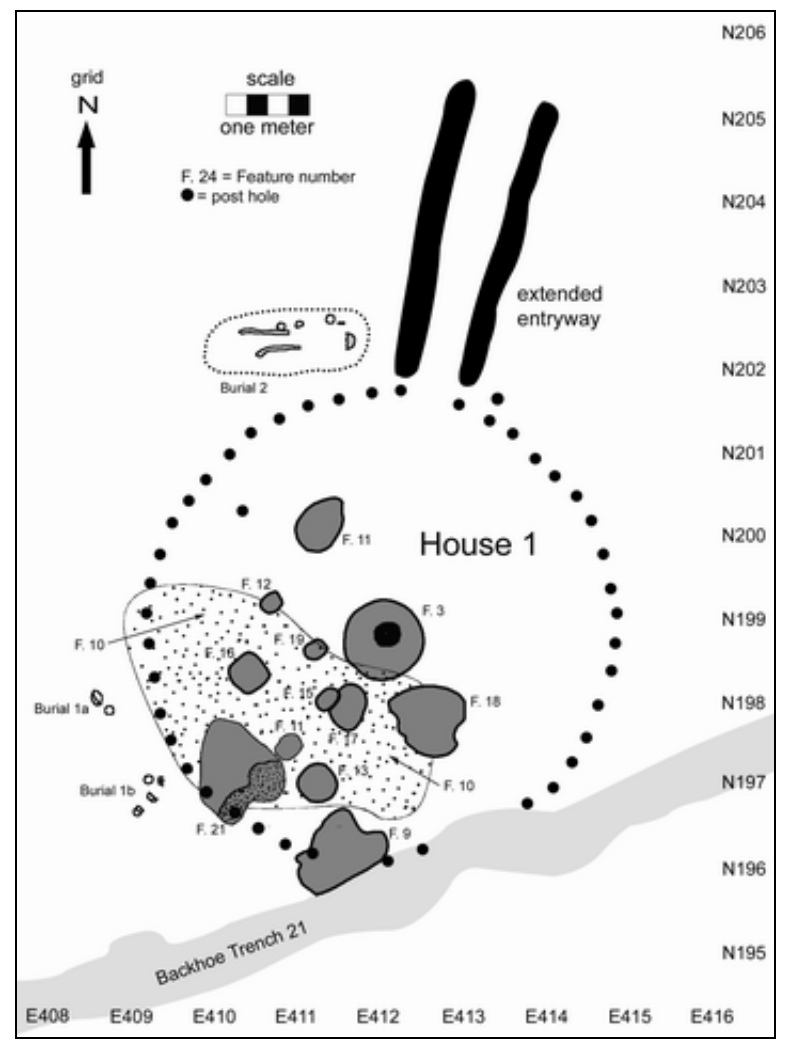

Figure 73. Rookery Ridge Structure 1 (Parsons, n.d.). 
Structure 1 appears to have had a 0.4-0.5 m high earthen berm around at least a portion of the structure (Parsons, personal communication 2009), similar to those found associated with mound structures at Bryan Hardy and Morse Mounds site (Middlebrook, personal communication 2009; Parsons, personal communication 2009; Walters and Haskins 2000). Although a berm is not shown in the plan map (see Figure 73), and was not clearly identified during the excavations, Parsons (personal communication 2009) argues that the placement of Burial 1a suggests that a berm was in place when the child was interred. If Structure 1 at Rookery Ridge was associated with an earthen mound, in addition to a berm, evidence of the mound has long since been plowed away or eroded (Parsons, personal communication 2009).

Structure 1 had several associated features, including multiple smudge pits, possible cooking pits, and other pits of undetermined use. There were at least three and possibly four smudge pits within the structure as well as three additional hearths (Parsons, personal communication 2009). Most of these features are located opposite the entrance, in the southern half of the structure (see Figure 73).

Parsons (personal communication 2009) suggests that the area between the central hearth and the entrance may have been kept cleared to allow for easy passage in this area and possibly to allow for ceremonies, meetings, etc., related to its possible specialized function. Interestingly, the structure was only partially burned as indicated by Feature 10, an area of burned structural members and charcoal covering an area of approximately 6.5 $\mathrm{m}^{2}$, and an area that corresponded with that portion of the structure with most of the smudge pits (with the exception of Feature 11) (Parsons, personal communication 2009). Perhaps the fire was accidental and not necessarily associated with the deliberate destruction of the building (Parsons, personal communication 2009). 
Two child burials (Burials 1a and 1b), estimated to have been about 18 to 24 months of age at death, were located immediately to the west of Structure 1, approximately 50-60 cm from the structure wall (Parsons 2002). Although the burial of infants and children under house floors is a fairly common practice in the Caddo area, Burials $1 \mathrm{a}$ and $1 \mathrm{~b}$ were located outside of the structure.

Rookery Ridge Structure 2 (Figure 74) was located approximately 21 m northwest of Structure 1 in another excavation block. Structure 2 measured $8.75 \mathrm{~m}$ in diameter, having an interior area of approximately $60.1 \mathrm{~m}^{2}$ (Parsons 1998). A gap in the post hole pattern along the northeast side of the structure that measured approximately $1 \mathrm{~m}$ was interpreted as a possible non-extended entrance (Parsons 1998). The wall outline consisted of thirty-seven post molds, with as many as possibly five additional post molds destroyed during excavations (Parsons, personal communication 2009).

The wall post molds had diameters ranging from 13 to $18 \mathrm{~cm}$, with depths ranging

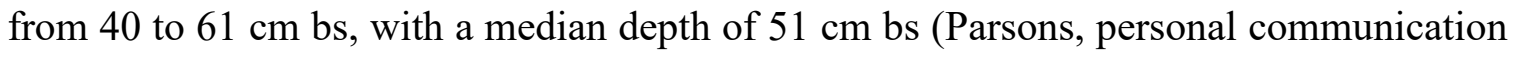
2009). Excluding the possible entrance, the wall post molds were spaced from approximately 44 to $75 \mathrm{~cm}$ apart $(\bar{x}=64.6 \mathrm{~cm})$ and were less regularly spaced than the Structure 1 wall posts (Parsons, personal communication 2009). Based on the plan map, the distances from the wall post molds to the center post ranged from $4.21 \mathrm{~m}$ to $4.47 \mathrm{~m}$ (n $=37, \bar{x}=4.31 \mathrm{~m}, \mathrm{~s}=0.0604)$. The ratio of average distance between wall post molds and average distance to the center (with the possible entrance gap included) was 1:6.7.

Structure 2 had a central hearth with a diameter of approximately $90 \mathrm{~cm}$. The hearth extended to a depth of about $13 \mathrm{~cm}$ below the scraped surface. Below the hearth was a $33 \mathrm{~cm}$ diameter central post hole that extended to a depth of approximately $70 \mathrm{~cm}$ bs (Parsons, personal communication 2009). In addition to the hearth and center post, an 
infant grave (with two miniature vessels) was found in a small oblong pit located approximately $3 \mathrm{~m}$ southwest of the hearth. Several small circular features were also recorded within the structure, including at least three possible smudge pits and eight other pits of undetermined function (Parsons, personal communication 2009). Some of the later may represent large pits or interior support posts.

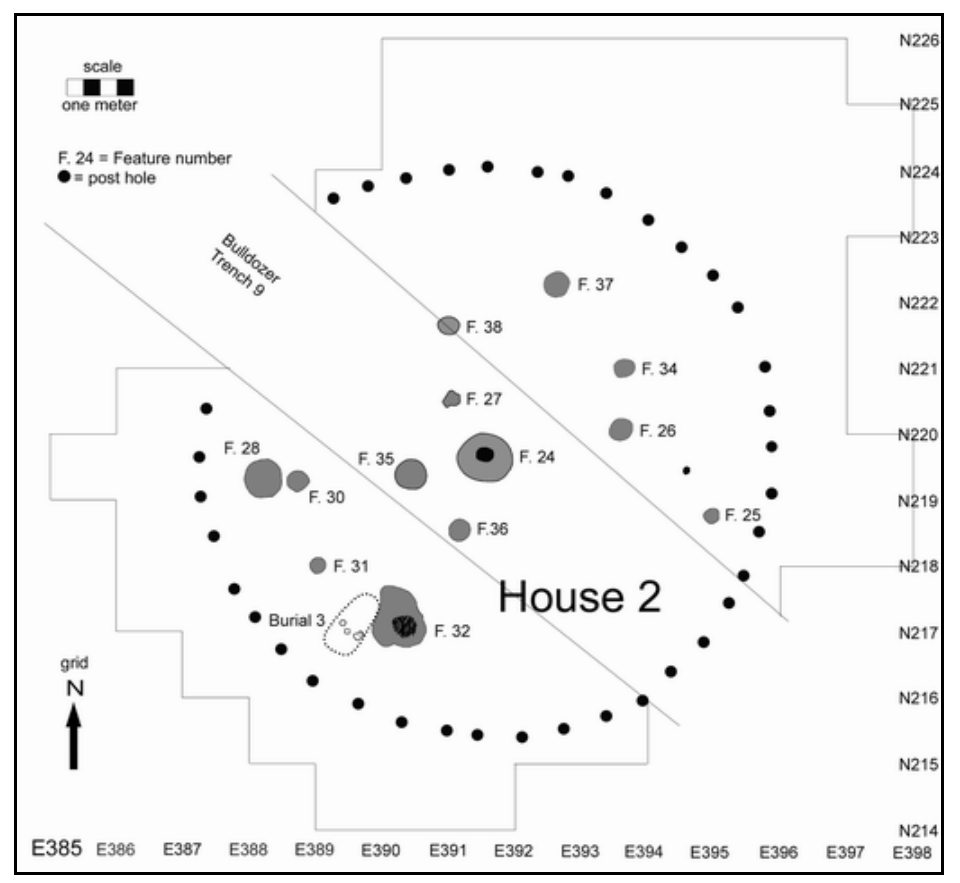

Figure 74. Rookery Ridge Structure 2 (Parsons n.d.).

In comparing the two structures, Structure 2 does not appear to have been constructed with nearly as much care as Structure 1. In support of this, Parsons (personal communication 2009) considered the difference in wall post size, spacing, and depth. These observations, according to Parsons (2009 personal communication) fit those recorded in Spanish accounts that indicate that "the houses of important men were "better made through having more rib-poles than others" (Bolton 1987:113). This argument 
lends further support to Parsons' suggestion that Structure 1 was a specialized structure while Structure 2 was perhaps a domicile for a non-elite member of the community.

\section{Lang Pasture Site (41AN38)}

Two structures and two possible ramadas or arbors were recorded at the Lang Pasture site. In all, 65 post holes, 21 pits, one outdoor hearth, a concentration of firecracked rock, and nine Caddo burials were recorded at the site (Perttula et al. 2009:5-3). The structures were both recorded as partial outlines of wall posts within the Texas Department of Transportation (TXDOT) right-of-way (ROW), with the remainder of each structure extending beyond the project area and onto private property (Perttula et al. 2009).

Structure 1 was a 14th to 15 th century A.D. circular Caddo house with several associated outdoor features (Perttula et al. 2009:5-3). Structure 1 was located about $5.5 \mathrm{~m}$ north of Structure 2 and was defined by a partial outline of 17 wall post holes, representing the eastern portion of the circular structure. Structure 1 had a diameter of approximately $6.8 \mathrm{~m}$, with an interior area of approximately $36.32 \mathrm{~m}^{2}$ (Perttula et al. 2009). The structure may have had interior support posts, as possibly represented by Features 67 and 73 (Perttula et al. 2009). If that is the case, and speculatively, perhaps this structure fits the form identified at the George C. Davis site and others as having four interior support posts and a central hearth (i.e., Walker's [2009] Type 1 structure).

The wall post holes had diameters ranging from approximately $0.14 \mathrm{~m}$ to $0.22 \mathrm{~m}$ $(\mathrm{n}=17, \overline{\mathrm{x}}=0.1847 \mathrm{~m}, \mathrm{~s}=0.0243)$. Post hole depths ranged from approximately $0.48 \mathrm{~m}$ to $0.71 \mathrm{~m}(\mathrm{n}=17, \overline{\mathrm{x}}=0.5729 \mathrm{~m}, \mathrm{~s}=0.0757)$ (Perttula et al. 2009), and "the posts themselves were probably about $10 \mathrm{~cm}$ in diameter." The wall post holes were spaced 
from approximately 0.34 to $0.68 \mathrm{~m}$ apart $(\mathrm{n}=9, \overline{\mathrm{x}}=0.4956 \mathrm{~m}, \mathrm{~s}=0.1158)$. Given disturbances from a fiber optic cable and phone line, spaces between only 10 of the 13 possible wall post holes were measured. Based on the estimated size of Structure 1, distances from the possible wall post holes to the approximate center of the structure were also measured. The distances ranged from $3.05 \mathrm{~m}$ to $3.45 \mathrm{~m}(\mathrm{n}=13, \overline{\mathrm{x}}=3.249 \mathrm{~m}, \mathrm{~s}$ $=0.1201)$. The ratio of average distance between wall post holes and average distance to the center was $1: 6.6$

Structure 2 was defined by 13 post holes. Of these, nine or 10 may represent wall posts. Structure 2 was estimated to be approximately $9 \mathrm{~m}$ in diameter, although only about $30 \%$ of this structure was uncovered (Perttula et al. 2009). The wall post holes had diameters ranging from approximately $0.12 \mathrm{~m}$ to $0.35 \mathrm{~m}(\mathrm{n}=13, \overline{\mathrm{x}}=0.2254 \mathrm{~m}, \mathrm{~s}=$ $0.0642)$, with post hole depths ranging from approximately $0.50 \mathrm{~m}$ to $0.90 \mathrm{~m}(\mathrm{n}=13, \overline{\mathrm{x}}=$ $0.6762 \mathrm{~m}, \mathrm{~s}=0.1436$ ) (Perttula et al. 2009). The larger post hole diameter and depth associated with Structure 2 fits with the size difference between the two structures, in that "Structure 2 is $32 \%$ larger in diameter than Structure 1, and presumably needed larger poles to form the taller peaked roof' (Perttula et al. 2009:5-15). Furthermore, the wide range in post hole size and depth, based on the coefficient of variation values (21.66 and 18.34, respectively), suggested that poles were chosen less selectively and that they pointed to "somewhat haphazard construction efforts" associated with Structure 2 when contrasted with Structure 1 (Perttula et al. 2009:5-15). The "deliberate selection of larger posts associated with Structure 2 and its surrounding outdoor activity areas raises the possibility that timbers available for construction at the time of the Structure 2 occupation were naturally larger, and that by the time of the Structure 1 occupation (which presumably came slightly later), the larger timber had been culled, at least to the extent 
where it affected timber selection choices in the construction of Structure 1 and its associated Structure 3.”

Given that the post hole pattern for Structure 2 is so incomplete, I have not measured the distances between wall posts or the distances from the wall to the center. Perttula et al. (2009:5-15), however, noted that "the Structure 2 posts were widely set, much more so than with the construction of Structure 1, except in two instances where postholes were very close to one another"; there were two instances of closely spaced posts that likely represented wall repair. The remaining wall posts all appear to have been spaced approximately 1.4 to $1.6 \mathrm{~m}$ apart. According to paleobotanical analysis, the Structure 2, wall posts included both pine and oak wood (Perttula et al. 2009).

Structure 3 was an area defined by 15 post holes and two pits (four of the posts extended through the large pit). This structure likely represented a rectangular outdoor activity area such as an arbor or ramada that measured approximately $2 \times 4 \mathrm{~m}$ (Perttula et al. 2009). The postholes associated with Structure 3 were generally smaller and set shallower than those associated with Structures 1 or 2 (Perttula et al. 2009). The Structure 3 post holes had diameters ranging from approximately $0.10 \mathrm{~m}$ to $0.23 \mathrm{~m}(\mathrm{n}=$ $15, \overline{\mathrm{x}}=0.176 \mathrm{~m}, \mathrm{~s}=0.0422$ ), with post hole depths ranging from approximately $0.39 \mathrm{~m}$ to $0.82 \mathrm{~m}(\mathrm{n}=15, \overline{\mathrm{x}}=0.55 \mathrm{~m}, \mathrm{~s}=0.1227)$ (Perttula et al. 2009). Perttula et al. (2009) noted that Features 78 and 89, both deeper set posts associated with Structure 3, may represent two of the corners. A second outdoor activity area was recorded just to the northeast of Structure 2 and included six pits or post holes and a cluster of fire-cracked rock.

Only one pit was uncovered in Structure 1, although given that less than half the structure was recorded, there were likely other pits and features within the structure. Two pits were recorded within Structure 2. The remaining 15 pits excavated at the site were 
located within the outdoor activity areas (Perttula et al. 2009). Pits included large storage pits, most ranging from $132 \times 70 \mathrm{~cm}$ to $118 \times 148 \mathrm{~cm}$ in length and width, with depths ranging from 38 to $94 \mathrm{~cm}$ bs (Perttula et al. 2009); small storage pits, with diameters less than $80 \mathrm{~cm}$ and depths as shallow as $30 \mathrm{~cm}$ bs; cooking pits; and four smudge pits. The largest pit, Feature 76, measured $360 \times 210 \mathrm{~cm}$ in length and width, with a depth of 135 $\mathrm{cm}$ bs. With an estimated volume of $7.18 \mathrm{~m}^{2}$, this pit could have held enough maize "to meet the dietary requirements of 8-9 families for a year, suggesting that it may have been a shared multi-household storage feature. This also suggests that the Lang Pasture site was occupied by multiple Caddo households" (Perttula et al. 2009). This large pit feature was also used for a child or juvenile burial after its use as a storage pit, with the burial pit being dug into the pit floor.

Other features from the Lang Pasture site include a midden deposit about $10 \mathrm{~m}$ from the excavated area and a family household cemetery with at least nine burials. Artifact distributions at the site, especially ceramic vessel sherds and pipe fragments, indicate that the outdoor activity areas played an important role in the daily lives of the Caddo inhabitants (Perttula et al. 2009). Most ceramic vessel sherds and pipe fragments were found discarded in the activity areas. The low densities of sherds within the structure walls suggests that they were swept to gather up broken vessels and vessel fragments that had been previously broken" (Perttula et al. 2009:5-61). The cleaning of the Structure 1 floor could also help explain why so few artifacts accumulated in the post hole fill (Perttula et al. 2009).

The Lang Pasture site dates to the late 14th to early 15th century A.D. (Perttula et al. 2009). Perttula et al. (2009:5-59) suggests that the features from the Lang Pasture site represent a household compound in which "individual structures were grouped together 
into a small compound arrayed around an open courtyard, with outdoor activity areas and ancillary facilities (i.e., ramadas, granaries, or other sorts of elevated platforms) and shared trash/midden disposal areas." Interestingly, Perttula et al. (2009:5-59) concludes that the high number of large storage pits at the site "suggests that above-ground granaries were not at use at the Lang Pasture site during the prehistoric Caddo occupation."

\section{Hatchel (41BW3)}

The Caddo structures identified in the 1938-1939 WPA village excavations at the Hatchel site were similar in size and shape to the mound structures. In all, more than 350 post holes, six to 10 pit features, several burials, and multiple structures were identified in the WPA Village Plot 1 and 2 areas (Perttula 2005:185-193). Perttula (2005) provides detailed descriptions of the village structures and identifies a previously unidentified circular structure that was overlapped by the smaller F-1 structure identified by the WPA (Perttula 2005:186 and Figure 9). The structures ranged from the small $3.05 \mathrm{~m} \mathrm{F-2,} \mathrm{a}$ possible granary, to the two structures identified as F-1 and the large $(11 \mathrm{~m})$ charcoalstained circular structure area just to the north of the WPA F-1 and F-2 (Perttula 2005:186 and Figure 8). Although the Caddo occupations at the Hatchel site appear to extend from as early as the thirteenth century A.D., the features discussed here from the village excavations are likely associated with the Late Caddo Texarkana phase occupation (ca. A.D. 1400-1600+) (Perttula 2005:183).

Based on recent work at the Hatchel site, Perttula (2005) identified at least five different village areas to the south, southeast, and east of the Hatchel platform mound. While no new structures have yet been recorded in these areas, it is likely that "these 
villages areas represent different individual compounds or sets of related compounds of Caddo families and/or extended families that contained grass-covered house structure, above-ground granaries, and outdoor ramadas or arbors" (Perttula 2005:3), much like those seen in the 1691 Terán map, and found elsewhere at the Hatchel site (Perttula 2008; Perttula et al. 2008).

Post hole patterns for at least three structures (F-1, F-1a, and F-2) were recorded in the Hatchel Village excavations of Village Plot 1. F-1 represented at least two overlapping circular structures, the first measuring approximately $9.5 \mathrm{~m}$ in diameter (F1a), with an area of approximately $70.85 \mathrm{~m}^{2}$, and the second measuring approximately $7.14 \mathrm{~m}$ in diameter (F-1) (recorded by the WPA as measuring approximately $7.3 \mathrm{~m}$ by 6.6 $\mathrm{m}$ ), with an area of approximately $40.02 \mathrm{~m}^{2}$. The smaller structure was recorded as F-1 by the WPA, who did not recognize the larger arc of post holes as a structure, with the larger structure (F-1a identified by Perttula [2005]). The exterior wall of neither structure was well defined (Perttula 2005). The smaller structure was represented by as many as 20 or 21 exterior wall post holes while the larger structure had 30 to 34 wall post holes. Several interior post holes were recorded, as were three larger support posts or possible pits (Perttula 2005). Unfortunately, however, it was not clear which interior features may have been associated with either structure (Perttula 2005). There was no clear entrance for either structure, although the WPA plan suggested the presence of a north-facing extended entrance for the smaller structure. As Perttula (2005:186) noted, however, "the post hole pattern of the entranceway in plan maps and photographs is not very compelling."

The larger structure likely predated the smaller structure and the "smaller version of F-1 probably represents a rebuilding of the larger structure in approximately the same 
place." (Perttula 2005:186) The larger structure did clearly predate Feature 2, "as the walls of the larger structure cut across the central part of this smaller structure" (Perttula 2005:186).

F-2 measured approximately $3.05 \mathrm{~m}$ in diameter and had as many as 20 wall post holes, although given the close spacing of many of the post holes, some may have represented rebuilding or repair (Perttula 2005). The Feature 2 wall post holes averaged approximately $15 \mathrm{~cm}$ in diameter with depths of about $48 \mathrm{~cm}$ bs (Perttula 2005:186). Whereas F-1 probably represented a domicile, given its small size and direct association with F-1, F-2 was likely a granary (Perttula 2005), similar to those recognized at the Oak Hill Village (Perttula and Rogers 2007; Rogers and Perttula 2004) and George C. Davis sites.

As discussed in Chapter 5, the Hatchel site was occupied from as early as ca. A.D. 1000 to as late as the mid-eighteenth century (Creel 1996; Perttula 2005). While there are no dates from the specific village structures discussed above, in addition to the four radiocarbon dates from the Hatchel Mound (Perttula 1997) discussed earlier, five radiocarbon dates and 30 OCR dates have been obtained from Village areas of the site (Perttula 1997, 2005). As noted by Perttula (2005:184-185), the dates from Area II of the village provide "solid evidence for the settlement of the Hatchel site before ca. A.D. 1300," while dates from Area III and Area V "provide absolute dates from later Texarkana phase occupations in those village areas, ranging between cal. A.D. 1500 and 1650 at 1 sigma and between cal. A.D. 1460 and 1660 at 2 sigma. The calibrated intercepts on these two samples range from A.D. 1530 to 1630." In addition, Perttula (2005:193) noted that "the Caddo pottery from Village Plots 1 and 2 only include sherds from Late Caddo, Texarkana phase [ca. A.D. 1400-1700] vessels.” 


\section{Earspool (41TT653)}

The Earspool Site (41TT653) is a Titus phase (ca. AD 1400-1650) farmstead situated along a narrow ridge overlooking two tributaries of East Piney Creek (Galan 1998:21; Perttula and Sherman 2009), a stream that drains north into the White Oak Creek basin. Areas of high artifact density, two burials, 10 pit features, four structures and their associated features, and outdoor/extramural activity areas were uncovered during the 1997-1998 excavations (Perttula and Sherman 2009).

The four circular structures identified at the Earspool site ranged in size from approximately $4.65 \mathrm{~m}$ to $7.52 \mathrm{~m}$ with interior floor areas of $16.27 \mathrm{~m}^{2}$ to $44.41 \mathrm{~m}^{2}$. Figure 75 provides plan maps of the four Earspool structures.

Structures 1 and 3 appear to have been the earliest of the four structures at the site, relating to the Component 1 occupation (Perttula and Sherman 2009). In addition, Structures 1 and 3 were both built within pits. The Structure 1 pit extended to approximately $40-45 \mathrm{~cm}$ bs while the Structure 3 pit extended to about $25-35 \mathrm{~cm}$ bs (Perttula and Sherman 2009). In addition to both being built within pits, Structures 1 and 3 each had prepared clay floors of reddish-brown clay (Perttula and Sherman 2009). The remnants of the Structure 1 floor measured $4.5 \mathrm{~m}$ in diameter, covering an area of ca. $14.84 \mathrm{~m}^{2}$. The clay floor extended to the wall posts, almost completely covering the structure floor. The Structure 1 clay floor varied in thickness from $2-10 \mathrm{~cm}$, with the thinner portions located near the central hearth and the thicker portions along the exterior wall. Following the use of the clay floor, a sandy loam floor, approximately $4 \mathrm{~cm}$ thick, was installed in Structure 1 (Perttula and Sherman 2009). 


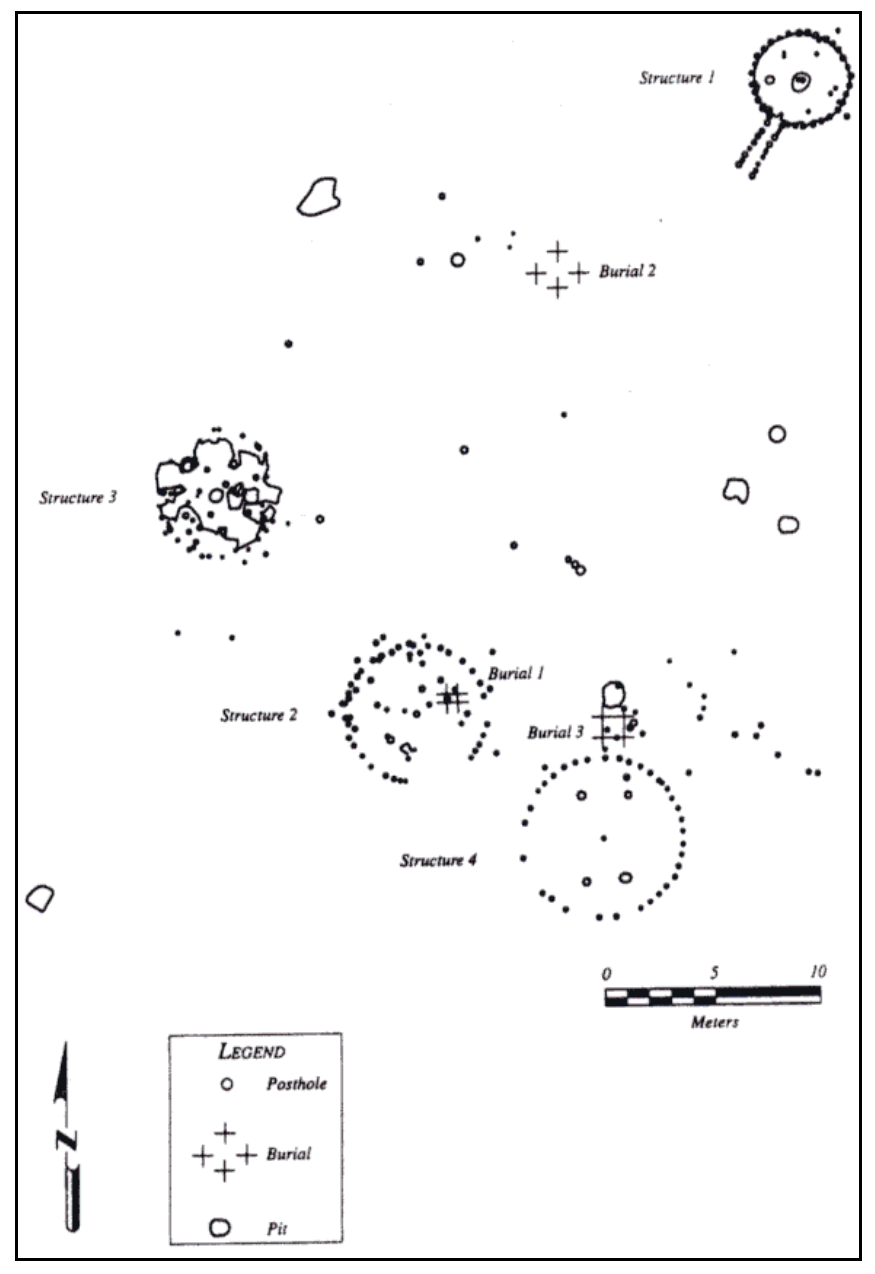

Figure 75. Plan of the structures from the Earspool site (from Galan 1998

The remains of the Structure 3 clay floor had a diameter of approximately $5 \mathrm{~m}$, covering an area of about $15.81 \mathrm{~m}^{2}$. The thickness varied from 1-4 cm, with the exception of the area at the center of the structure where the clay floor filled a basin-shaped pit, probably a hearth, and was about $13 \mathrm{~cm}$ thick (Perttula and Sherman 2009). Below the clay floor was an earlier intentionally installed surface, noted by Perttula and Sherman (2009) to be a $1-4 \mathrm{~cm}$ thick sandy loam floor. Like the Structure 1 clay floor, the Structure 3 floor extended to the structure wall, thus completely covering the structure 
floor. The basin-shaped pit/hearth filled in by the Structure 3 clay floor was likely associated with the original occupation of the structure. The roof support posts of both Structure 1 and Structure 3 were in place prior to the installation of the clay floors.

Structure 1 measured $4.56 \mathrm{~m}$ in diameter with an interior area of $16.27 \mathrm{~m}^{2}$. This circular structure had a prepared clay floor, a central post, a hearth, a single pit (located below the clay floor), an ash lens stain (also located below the clay floor), and a southwest-facing extended entrance (Perttula and Sherman 2009). The Structure 1 extended entrance was defined by 20 posts and was slightly sloped. The exterior wall consisted of 35 wall posts, with 21 being combination post hole/post molds. At least six interior posts were recorded that probably represented interior benches, with at least three additional interior posts that likely represented structure support posts (Perttula and Sherman 2009).

The Structure 1 hearth had a diameter of $85 \mathrm{~cm}$ and extended to a depth of $18 \mathrm{~cm}$. The clay floor of Structure 1 partially lined the central hearth, which was in place prior to the laying down of the clay floor (Perttula and Sherman 2009). The Structure 1 center post had a diameter of $25 \mathrm{~cm}$ and extended to a depth of $40 \mathrm{~cm}$ below the base of the central hearth (Perttula and Sherman 2009).

The wall post holes of Structure 1 had diameters ranging from approximately 10 $\mathrm{cm}$ to $45 \mathrm{~cm}(\mathrm{n}=28, \bar{x}=19.39 \mathrm{~cm}, \mathrm{~s}=7.0256)$. Post hole depths ranged from approximately $19 \mathrm{~cm}$ to $70 \mathrm{~cm}(\mathrm{n}=22, \bar{x}=44.95 \mathrm{~cm}, \mathrm{~s}=12.9816)$. The wall post holes were spaced from approximately 0.240 to $0.556 \mathrm{~m}$ apart $(\mathrm{n}=32, \bar{x}=0.437 \mathrm{~m}, \mathrm{~s}=0.060)$. The distances from the wall post holes to the central hearth ranged from $2.182 \mathrm{~m}$ to 2.461 $\mathrm{m}(\mathrm{n}=32, \bar{x}=2.276 \mathrm{~m}, \mathrm{~s}=0.071)$. The ratio of average distance between wall post holes and average distance to the center was 1:5.2 (Perttula and Sherman 2009). The Structure 
1 extended entrance post holes had diameter ranging from approximately $10 \mathrm{~cm}$ to 28.5 $\mathrm{cm}(\mathrm{n}=18, \bar{x}=18.64 \mathrm{~cm}, \mathrm{~s}=5.6797)$. The entrance post hole depths ranged from approximately $16 \mathrm{~cm}$ to $55 \mathrm{~cm}(\mathrm{n}=18, \bar{x}=26.56 \mathrm{~cm}, \mathrm{~s}=8.8731)$. Based on an analysis of the 21 post hole/post mold combinations associated with Structure 1, Perttula and Sherman (2009:136) found that "the holes excavated to seat posts were about twice the size of the posts themselves. If the size relationship is valid for the entire site, then the wood posts used for exterior walls can be expected to have ranged between 5 and $15 \mathrm{~cm}$ in diameter and averaged $8.5 \mathrm{~cm} . "$

Upon abandonment, Structure 1 was burned with the walls and roof of the structure collapsing within the structure pit, leaving behind burned structural material, including daub/burned clay. "[A]s Structure 1 was being burned, the daub/burned clay and other burning structure remains were intentionally smothered by a sandy deposit" (Perttula and Sherman 2009:101-105). The covering of Structure 1 would have created a small earthen mound, although, due to the methods used in exposing and excavating the structure, direct evidence of a mound was not recorded (Perttula and Sherman 2009). That being the case, however, Perttula and Sherman (2009) thought that the presence of a marker post placed through the burned remains and hearth of Structure 1 lended strong support to the argument for the presence of an earthen mound, as did recorded observations from archaeologists prior to excavations at the site. In addition, the presence of the marker post through the center of Structure 1 suggested that "the memory of the location of this structure was strong among the later residents of the Ear Spool site" (Perttula and Sherman 2009:141).

The marker post had a diameter of $17 \mathrm{~cm}$ and extended to a depth of $30 \mathrm{~cm}$. The Structure 1 marker post appears to have been excavated at an angle to aid in setting the 
post, possibly similar to the large interior support posts seen in some of the structures from the George C. Davis site (Perttula and Sherman 2009). Perttula and Sherman (2009:83-85) suggested that the marker post "was intended to mark the burned Component I structure and its central hearth for later residents of the Ear Spool site, and it was probably erected during Component II times." Three additional marker posts were recorded in other areas of the site, not directly marking a structure, and they appeared "to be sequential center posts (set or reset three times) for a courtyard or open area where outdoor work activities took place" (Perttula and Sherman 2009:85).

Structure 3 had a diameter of approximately $5.82 \mathrm{~m}$, with an interior area of about $26.57 \mathrm{~m}^{2}$. Several post holes were associated with Structure 3, with 17 making up the exterior wall and 33 recorded within the interior of the structure. In addition to post holes, Structure 3 had a sandy loam floor, a later prepared clay floor, a central hearth, and a smudge pit located directly to the east of the structure (Perttula and Sherman 2009). Structure $3 \mathrm{had}$ an original, pre-clay floor hearth, measuring 66 × $55 \mathrm{~cm}$ and with a basin extending approximately $13 \mathrm{~cm}$ deep, which was later filled with the clay floor (Perttula and Sherman 2009). The later hearth was placed on top of the clay floor and measured about $8 \mathrm{~cm}$ thick.

The wall post holes of Structure 3 had diameters ranging from approximately 11 $\mathrm{cm}$ to $23 \mathrm{~cm}(\mathrm{n}=14, \bar{x}=15.43 \mathrm{~cm}, \mathrm{~s}=3.3904)$. Post hole depths ranged from approximately $15 \mathrm{~cm}$ to $48 \mathrm{~cm}(\mathrm{n}=13, \bar{x}=27.54 \mathrm{~cm}, \mathrm{~s}=9.9215)$. The wall post holes were spaced from approximately 0.324 to $0.688 \mathrm{~m}$ apart $(\mathrm{n}=11, \bar{x}=0.6 \mathrm{~m}, \mathrm{~s}=0.111)$. The distances from the wall post holes to the central hearth ranged from $2.767 \mathrm{~m}$ to 3.031 $\mathrm{m}(\mathrm{n}=17, \bar{x}=2.909 \mathrm{~m}, \mathrm{~s}=0.072)$. The ratio of average distance between wall post holes and average distance to the center was 1:4.9 (Perttula and Sherman 2009). 
The later Component II structures at the site were larger than the earlier Component I structures (Perttula and Sherman 2009). Structure 2 measured approximately $6.56 \mathrm{~m}$, with an interior area of approximately $33.83 \mathrm{~m}^{2}$, while Structure 4 measured approximately $7.52 \mathrm{~m}$ in diameter with an interior area of approximately 44.40 $\mathrm{m}^{2}$ (Perttula and Sherman 2009). The Structure 2 exterior wall was defined by 36 post holes. Structure 2 had a center post and at least six additional interior support posts as well as 19 additional interior post holes likely representing interior partitions or supports for benches, racks, etc. (Perttula and Sherman 2009). The center post had a diameter of $27 \mathrm{~cm}$ and extended to a depth of approximately $11 \mathrm{~cm}$ below the hearth. Ten exterior post holes likely represented ancillary outdoor structures in activity areas. Perttula and Sherman (2009) suggested that the close proximity of many of the interior and exterior post holes to the structure wall was indicative of repair of the structure.

The wall post holes of Structure 2 had diameters ranging from approximately 12 $\mathrm{cm}$ to $26 \mathrm{~cm}(\mathrm{n}=32, \bar{x}=17.63 \mathrm{~cm}, \mathrm{~s}=3.1927)$. Post hole depths ranged from approximately $5 \mathrm{~cm}$ to $17 \mathrm{~cm}(\mathrm{n}=20, \bar{x}=10.75 \mathrm{~cm}, \mathrm{~s}=3.3067)$. The wall post holes were spaced from approximately 0.25 to $0.81 \mathrm{~m}$ apart $(\mathrm{n}=36, \bar{x}=0.52 \mathrm{~m}, \mathrm{~s}=0.169)$. The distances from the wall post holes to the central hearth ranged from $3.17 \mathrm{~m}$ to $3.35 \mathrm{~m}$ $(\mathrm{n}=36, \bar{x}=3.28 \mathrm{~m}, \mathrm{~s}=0.041)$. The ratio of average distance between wall post holes and average distance to the center was 1:6.4.

No central hearth was recorded for Structure 2, although a single smudge pit was recorded inside Structure 2, to the south of the center post. In addition, an infant burial was located about $1.5 \mathrm{~m}$ east of the center post under the structure floor. Perttula and Sherman (2009:125-127) noted that "the placement of the burials of children inside of residential structures is a well-documented prehistoric Caddo mortuary practice, and in 
the case of Burial 1 at Ear Spool, most likely was part of a deliberate action by the Caddo residents there to create a social memory within the community, and a way to anchor the residential features here to the evolving social landscape." Finally, Structure 2 was burned upon abandonment.

Structure 4 from Ear Spool had a well-defined structure perimeter consisting of 36 post holes that defined most of the outer wall (Perttula and Sherman 2009). Interior features associated with Structure 4 included a smudge pit near the northern structure wall, and five interior post holes, including a center post and four large interior support posts. The center post had a diameter of $17 \mathrm{~cm}$ and extended to a depth of $20 \mathrm{~cm}$ below the scraped excavation surface. The large interior support posts had diameters ranging from $31 \mathrm{~cm}$ to $46.5 \mathrm{~cm}$, and they extended to depths below the scraped excavation surface ranging from $9 \mathrm{~cm}$ to $12 \mathrm{~cm}$ (Table 45). Structure 4 had a possible non-extended entrance on the western side of the structure, indicated by larger gaps between wall posts. Exterior features in the vicinity of Structure 4 included five post holes, likely representing associated outdoor facilities, and the grave of a child or adolescent, Burial 3, located about $1.5 \mathrm{~m}$ north of the structure (Perttula and Sherman 2009).

Table 45. Ear Spool Structure 4 interior support posts (Perttula and Sherman 2009).

\begin{tabular}{|c|c|c|}
\hline & \multicolumn{2}{|c|}{ Structure 4 interior support post holes } \\
\hline Feature & Diameter $(\mathrm{cm})$ & Depth $(\mathrm{cm})$ \\
\hline 134 & 37 & 9 \\
\hline 135 & 31.5 & 12 \\
\hline 136 & 46.5 & 12 \\
\hline 137 & 31 & \\
\hline
\end{tabular}


The wall post holes of Structure 4 had diameters ranging from approximately 13 $\mathrm{cm}$ to $20 \mathrm{~cm}(\mathrm{n}=33, \bar{x}=15.62 \mathrm{~cm}, \mathrm{~s}=1.9487)$. Post hole depths were not available. The wall post holes were spaced from approximately 0.18 to $0.83 \mathrm{~m}$ apart ( $\mathrm{n}=26, \bar{x}=0.54 \mathrm{~m}$, $\mathrm{s}=0.112$ ). The distances from the wall post holes to the central hearth ranged from 3.69 $\mathrm{m}$ to $3.86 \mathrm{~m}(\mathrm{n}=26, \bar{x}=3.76 \mathrm{~m}, \mathrm{~s}=0.049)$. The ratio of average distance between wall post holes and average distance to the center was 1:6.9.

In summing up the architecture from the Ear Spool site, Perttula and Sherman (2009:149) were able to conclude that "based on the patterned post feature variation observed at the Ear Spool site, it is conceivable that two distinct and potentially sequent architectural traditions were present: one defined by small structures with widely spaced posts (Structures 1 and 3), and one defined by large structures with closely spaced posts." Structures 1 and 3 were the earliest structures at the site, both being occupied during Component I, with Structure 3 likely representing the earliest Titus phase structure (Perttula and Sherman 2009). Structures 2 and 4 are later Component II Titus phase structures. Variation in the patterns of post features at the Ear Spool site indicated "at least three, and possibly four, distinct occupational episodes within the two Titus phase components. If this is accurate, what is remarkable about the layout of the Ear Spool site is how little overprinting of archeological features and deposits occurred. This fact argues rather strongly for the existence of a level of long-term planning in site use and prior knowledge of feature and structure locations that transcended individual and sequent site occupations" (Perttula and Sherman 2009:151). 


\section{Hurricane Hill (41HP106)}

The Hurricane Hill Site on the South Sulphur river is divided into three areas, the North, South, and Southwest rises (Perttula 1999). Several midden areas, multiple burials, and over 225 features, including pits, hearths, and post holes, were excavated at the site. At least five structures were identified at Hurricane Hill, including three circular and two rectangular buildings. The three Middle Caddo (ca. A.D. 1250-1375) circular structures (A-C) were all recorded on the South Rise while the two Early Caddo (ca. A.D. 10001200) rectangular buildings (D and E) were recorded on the North Rise (Figures 76 and 77) (Perttula 1999, 2004).
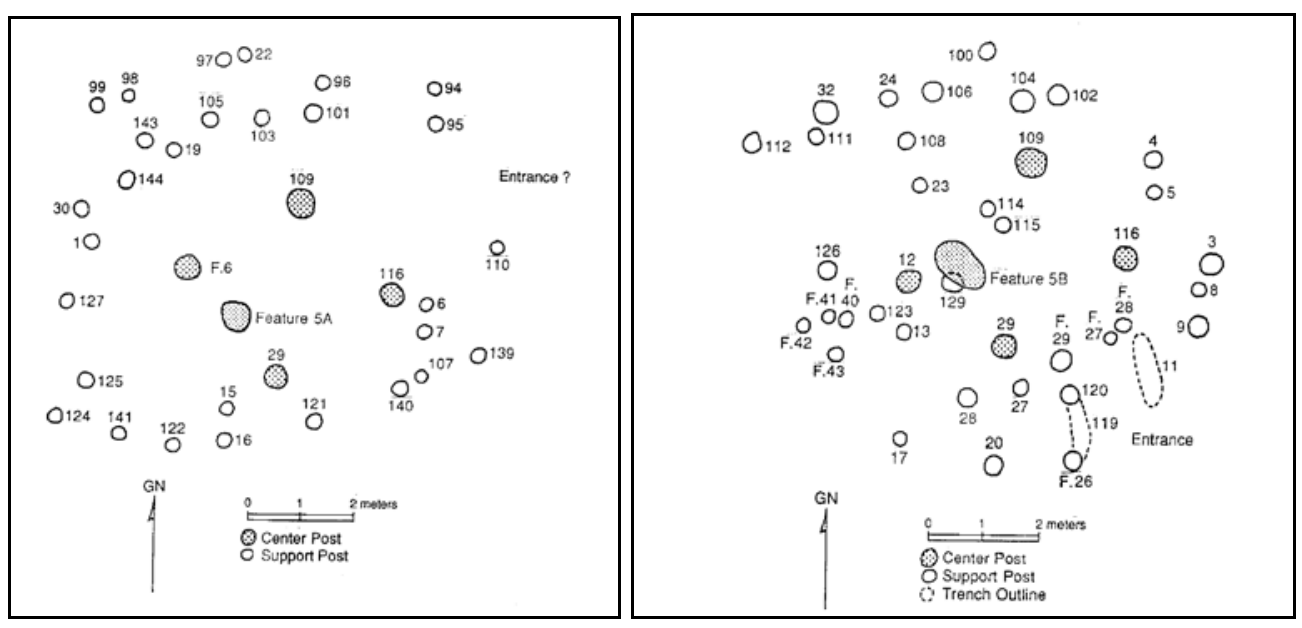

Figure 76. Structures A (left) and B (right) from the Hurricane Hill site (Perttula 1999, Figures 6-21 and 6-22). Reproduced courtesy of the Friends of Northeast Texas Archaeology.

Features recorded on the South Rise included 98 post holes or probable post holes, 23 pits, two partly overlapping hearths (central hearths of Structures A and B), and burials, including three human and one dog burial (Fields et al. 1997; Perttula 1999). In 
addition, there were three middens that were likely associated with superimposed Structures A and B, and one midden to the west of Structure C (Fields et al. 1997; Perttula 1999).

While complete wall patterns were not evident for the South Rise structures, enough of a pattern was evident for Perttula (1999) to define the later Structure A as measuring $6 \times 7.5 \mathrm{~m}$ with an east facing non-extended entrance and the earlier, and larger, Structure B as measuring $7.1 \times 7.6 \mathrm{~m}$ with a possible south-facing extended entrance. Perttula (1999:106) noted that "the entrance was marked by two parallel stains or trenches," and that "although the eastern trench lacks postholes, the fact that the western trench has postholes at either end strongly suggest that both trenches did have wooden posts in them to make a covered entranceway."

Large interior support posts were present in each structure and were arranged in a somewhat square pattern similar in form to the four support post structures found at the George C. Davis site and other East Texas Caddo sites (Creel et al. 2005; Fields et al. 1998; Perttula 1999; Perttula and Sherman 2009). In addition, the partially overlapping hearths suggested that the structures were used sequentially.

Structure $\mathrm{C}$ was recorded as a partly exposed $6 \mathrm{~m}$ diameter circular structure. Perttula (1999:110) thought that Structure C may represent an arbor or ramada rather than a domicile.

Excluding the interior support posts, the Structure A post holes had an average diameter of $24 \mathrm{~cm}$. The Structure B post holes had an average diameter of $27 \mathrm{~cm}$. The generally larger Structure A interior support posts ranged in size from $25 \mathrm{~cm}$ to $52.5 \mathrm{~cm}$, with an average diameter of $39.75 \mathrm{~cm}$. The Structure B interior support post holes ranged in size from $37.5 \mathrm{~cm}$ to $52.5 \mathrm{~cm}$, with an average diameter of $44.13 \mathrm{~cm}$. The Structure B 
center post (situated below Feature 5B, the Structure B hearth) had a diameter of $39 \mathrm{~cm}$ (Perttula 1999).

In addition to interior support posts, both Structures A and B had superimposed central hearths (Features 5A and 5B). The Structure A hearth (Feature 5A) was the later of the two hearths and extended from 16-28 cm bs (Perttula 1999). Feature 5B extended from 31-42 cm bs (Perttula 1999). An archaeomagnetic date of A.D. 1300 was obtained from the Structure A hearth basin walls (Perttula 1999).

There was also a $15 \mathrm{~cm}$ thick pit associated with the interior of Structure B (Feature 12) and two pits (Features 30 and 38) were associated with the interior of Structure A. Additional large pits were situated outside of the structures (Perttula 1999).

Two partly exposed rectangular structures (Structures D and E) were recorded on the North Rise. These appeared "to be of Early Caddoan affiliations, based on the archaeological content of the soil zones and midden deposits in proximity to the posthole patterns" (Perttula 1999:94). Structure D, the later of these two Early Caddo structures, was partly delineated by 15 outer wall post holes (Perttula 1999:96). The diameter of the wall postholes ranged from $0.16 \mathrm{~m}$ to $0.26 \mathrm{~m}(\mathrm{n}=15, \bar{x}=0.21 \mathrm{~m}, \mathrm{~s}=0.0324)$. The wall postholes had depths ranging from 0.31 to $0.65 \mathrm{~m}(\mathrm{n}=6, \bar{x}=0.47 \mathrm{~m}, \mathrm{~s}=0.1192)$. Structure D was interpreted as a rectangular structure oriented with magnetic north (Perttula 1999:96). The only non-post hole feature identified in the interior of the structure was a $16 \mathrm{~cm}$ deep basin-shaped rock hearth containing large amounts of firecracked rock (Perttula 1996:94-96). Rather than being primarily a cooking feature, Perttula (1999:94) suggested that the rock hearth "was probably used more as a source of radiating heat." 
Structure E was delineated by 10 post holes corresponding to nine wall post holes and one feature representing either a center post or a small pit (Perttula 1999:98). The exposed portions of the structure measured $5 \mathrm{~m}$ along one wall and slightly less along an intersecting wall. Based on the exposed wall segments, Perttula (1999:98) suggested that "the structure was aligned parallel to the crest of the North Rise." The diameter of the wall post holes ranged from $0.22 \mathrm{~m}$ to $0.25 \mathrm{~m}(\mathrm{n}=9, \bar{x}=0.23 \mathrm{~m}, \mathrm{~s}=0.0122)$. The wall post holes had depths ranging from 0.45 to $0.53 \mathrm{~m}(\mathrm{n}=4, \bar{x}=0.50 \mathrm{~m}, \mathrm{~s}=0.0340)$. The possible center post had a diameter of $0.36 \mathrm{~m}$ (Perttula 1999).

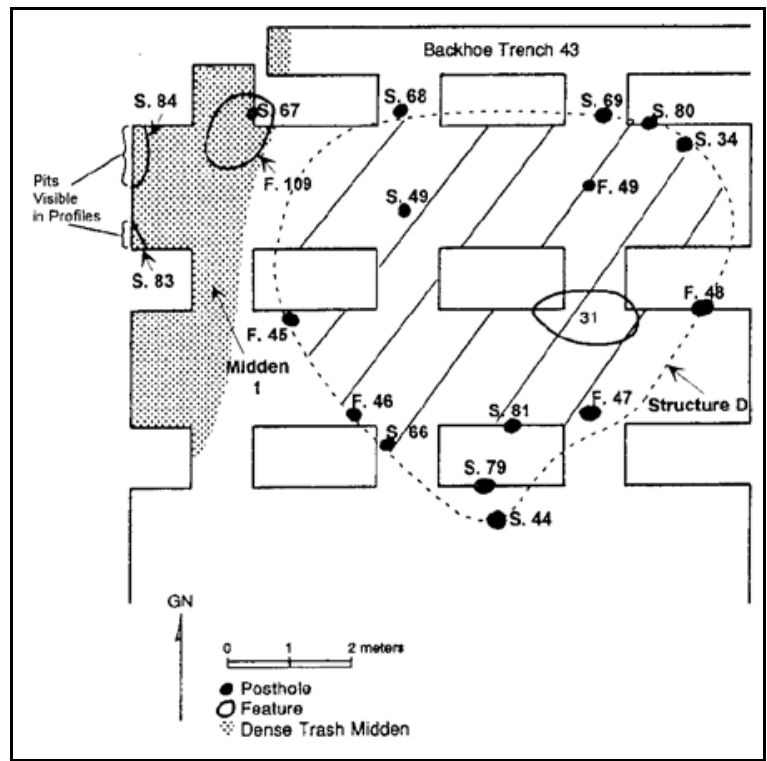

Figure 77. Hurricane Hill Structure D (Perttula 1999). Reproduced courtesy of the Friends of Northeast Texas Archaeology.

\section{Hill Farm (41BW169)}

The Hill Farm Site (41BW169) is a Late Caddo site occupied from approximately A.D. 1500 into the late seventeenth century (Perttula et al. 2008; Walker 2009). The site 
is considered part of the surrounding Hatchel site, which is a component of the larger Hatchel-Mitchell-Moores site complex occupied from approximately the $13^{\text {th }}$ century A.D. into the eighteenth century (Perttula 2005; Perttula et al. 2008; Walker 2009).

Archaeogeophysical investigations at the Hill Farm site revealed multiple Caddo structures and associated features as well as several relic meander scars of the nearby Red River, the later helping in planning field investigations as well as assisting with the interpretation of the site's place within the broader Hatchel village (Grealy and Conyers 2008; Perttula et al. 2008; Sundermeyer et al. 2008; Walker 2009). The multiple Caddo features were recorded as part of a magnetometer survey conducted southeast of the Hatchel Mound that included $2420 \times 20$ m survey blocks in two areas of the site, chosen based on shovel test data (Schultz and Walker 2006; Perttula et al. 2008; Walker 2009; Walker and Schultz 2008). For a more detailed discussion of the collection methods, data processing, and archaeogeophysical interpretations, the reader is referred to Perttula et al. (2008), Walker (2009), and Walker and Schultz (2008).

At least 10 and possibly 11 circular Caddo structures were identified in the magnetometer data from the Hill Farm site (Table 46) (Perttula et al. 2008; Schultz and Walker 2006; Walker 2009; Walker and Schultz 2008). As Walker (2009:135-154) discusses, while none of the Hill Farm structures have been ground truthed through excavations, associated shovel test data as well as the broader understanding of the nature of the archaeological remains from the Hatchel site lends support to the use of the Hill Farm dataset as primary archaeological data in assessing not only types of features and architectural styles associated with the site, but the broader organization of space and settlement dynamics at a sixteenth to seventeenth century A.D. Nasoni Caddo Village (see also Perttula et al. 2008). 
Table 46. Structures identified in the magnetometer data from the Hill Farm Site (41BW169). $c=$ circular; $y=y e s$ (present).

\begin{tabular}{|c|c|c|c|c|c|c|c|c|c|c|c|}
\hline \multirow[b]{3}{*}{ 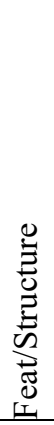 } & \multirow[b]{3}{*}{ 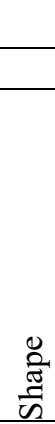 } & \multirow[b]{3}{*}{ 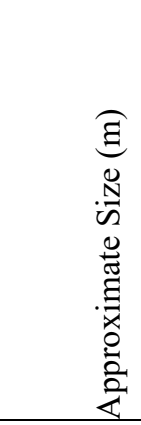 } & \multirow{3}{*}{ 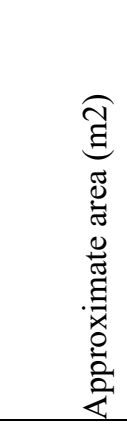 } & \multirow[b]{3}{*}{ అִ } & \multirow{2}{*}{\multicolumn{2}{|c|}{ Hearth }} & \multicolumn{4}{|c|}{ Entrance ( $\mathrm{e}=$ extended $)$} & \multirow[b]{3}{*}{ Notes } \\
\hline & & & & & & & \multirow[b]{2}{*}{ 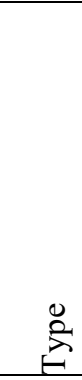 } & \multicolumn{2}{|c|}{ Size } & \multirow[b]{2}{*}{ 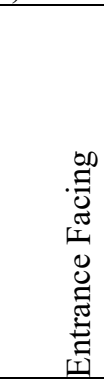 } & \\
\hline & & & & & 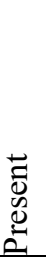 & 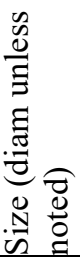 & & 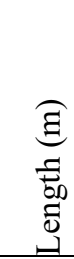 & 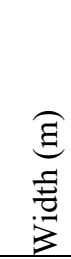 & & \\
\hline 1 & $\mathrm{c}$ & 11.50 & 103.82 & $\mathrm{y}$ & $\mathrm{y}$ & $\mathrm{n} / \mathrm{a}$ & $\mathrm{n} / \mathrm{a}$ & $\mathrm{n} / \mathrm{a}$ & $\mathrm{n} / \mathrm{a}$ & $\mathrm{n} / \mathrm{a}$ & \\
\hline 2 & $\mathrm{c}$ & 15.00 & 176.63 & & $\mathrm{y}$ & $\mathrm{n} / \mathrm{a}$ & $\mathrm{n} / \mathrm{a}$ & $\mathrm{n} / \mathrm{a}$ & $\mathrm{n} / \mathrm{a}$ & $\mathrm{n} / \mathrm{a}$ & \\
\hline 3 & $\mathrm{c}$ & 7.00 & 38.47 & & & $\mathrm{n} / \mathrm{a}$ & $\mathrm{n} / \mathrm{a}$ & $\mathrm{n} / \mathrm{a}$ & $\mathrm{n} / \mathrm{a}$ & $\mathrm{n} / \mathrm{a}$ & $\begin{array}{l}\text { feature is large di-pole; } \\
\text { burned structure or large } \\
\text { borrow pit }\end{array}$ \\
\hline 4 & $\mathrm{c}$ & $\begin{array}{l}14.5- \\
17.5 \\
\end{array}$ & $\begin{array}{l}165.05- \\
240.41\end{array}$ & & $\mathrm{y}$ & $\mathrm{n} / \mathrm{a}$ & $\mathrm{n} / \mathrm{a}$ & $\mathrm{n} / \mathrm{a}$ & $\mathrm{n} / \mathrm{a}$ & $\mathrm{n} / \mathrm{a}$ & \\
\hline 5 & $\mathrm{c}$ & 12.00 & 113.04 & & & $\mathrm{n} / \mathrm{a}$ & $\mathrm{e}$ & $\mathrm{n} / \mathrm{a}$ & $\mathrm{n} / \mathrm{a}$ & nw & $\begin{array}{l}\text { patterns of returns w/in } \\
\text { structure may be small } \\
\text { storage pits }\end{array}$ \\
\hline 6 & $\mathrm{c}$ & 10.00 & 78.50 & & $\mathrm{y}$ & $\mathrm{n} / \mathrm{a}$ & $\mathrm{n} / \mathrm{a}$ & $\mathrm{n} / \mathrm{a}$ & $\mathrm{n} / \mathrm{a}$ & $\mathrm{n} / \mathrm{a}$ & \\
\hline 7 & $\mathrm{c}$ & 8.00 & 50.24 & & $\mathrm{y}$ & $\mathrm{n} / \mathrm{a}$ & $\mathrm{n} / \mathrm{a}$ & $\mathrm{n} / \mathrm{a}$ & $\mathrm{n} / \mathrm{a}$ & $\mathrm{n} / \mathrm{a}$ & \\
\hline 8 & $\mathrm{c}$ & 10.00 & 78.50 & & $\mathrm{y}$ & $\mathrm{n} / \mathrm{a}$ & $\mathrm{n} / \mathrm{a}$ & $\mathrm{n} / \mathrm{a}$ & $\mathrm{n} / \mathrm{a}$ & $\mathrm{n} / \mathrm{a}$ & possible structure \\
\hline 9 & $\mathrm{c}$ & 10.00 & 78.50 & $\mathrm{y}$ & $\mathrm{y}$ & $\mathrm{n} / \mathrm{a}$ & e & $\mathrm{n} / \mathrm{a}$ & $\mathrm{n} / \mathrm{a}$ & se & $\begin{array}{l}\text { structure appears to have } \\
\text { been burned }\end{array}$ \\
\hline 11 & $\mathrm{c}$ & 10.00 & 78.50 & $\mathrm{y}$ & $\mathrm{y}$ & $\mathrm{n} / \mathrm{a}$ & $\mathrm{n} / \mathrm{a}$ & $\mathrm{n} / \mathrm{a}$ & $\mathrm{n} / \mathrm{a}$ & $\mathrm{n} / \mathrm{a}$ & $\begin{array}{l}\text { structure appears to have } \\
\text { been burned }\end{array}$ \\
\hline 13 & $\mathrm{c}$ & 8.00 & 50.24 & & & $\mathrm{n} / \mathrm{a}$ & $\mathrm{n} / \mathrm{a}$ & $\mathrm{n} / \mathrm{a}$ & $\mathrm{n} / \mathrm{a}$ & $\mathrm{n} / \mathrm{a}$ & possible structure \\
\hline
\end{tabular}

The Hill Farm structures have diameter ranging from $7 \mathrm{~m}$ to $17.5 \mathrm{~m}$, with a mean diameter of $10.82 \mathrm{~m}$. These structures likely represent residential or special purpose buildings, along with at least one possible granary (Feature 3) (Perttula et al. 2008; Schultz and Walker 2006; Walker 2009). The approximate interior area of the Hill Farm structures ranges from $38.47 \mathrm{~m}^{2}$ (Feature 3) to $240.41 \mathrm{~m}^{2}$ (Feature 4), with a mean area of $98.80 \mathrm{~m}^{2}$. All of the structures, with the exception of Feature 3, have possible interior 263 
features such as central hearths, with possible pits being identified in at least one other structure (Feature 5) (Walker 2009). At least three structures may have been burned and at least two have patterns of magnetic returns suggesting possible extended entrances, a structural feature that has been suggested to be associated with special purpose Caddo structures.

The Area A structures include Features 1-8 and 13, with Feature 3 being the most tentative of these. Figure 78 provides an image of the magnetometer results from Area A while Figure 79 provides an image showing the interpretation of the features. As discussed by Walker (2009), Feature 3 may either represent a burned Caddo structure or a possible borrow pit. Excluding Feature 3, then, the Area A structures range in size from 8 $\mathrm{m}$ to $17.5 \mathrm{~m}(\mathrm{n}=8, \bar{x}=11.5 \mathrm{~m}, \mathrm{~s}=3.3274)$, with areas ranging from $50.24 \mathrm{~m}^{2}$ to 240.41 $\mathrm{m}^{2}\left(\mathrm{n}=8, \bar{x}=111.42 \mathrm{~m}^{2}, \mathrm{~s}=66.1217\right)$. Based on the high magnetic returns associated with Feature 1, it is likely that it represents a burned structure (Walker 2009). The remaining Area A structures all have central hearths, with Feature 5 also having multiple interior anomalies that may represent small pits or large interior post holes (Walker 2009). Feature 5 also has a northwest-facing extended entrance, possibly oriented to face the Hatchel platform mound. 


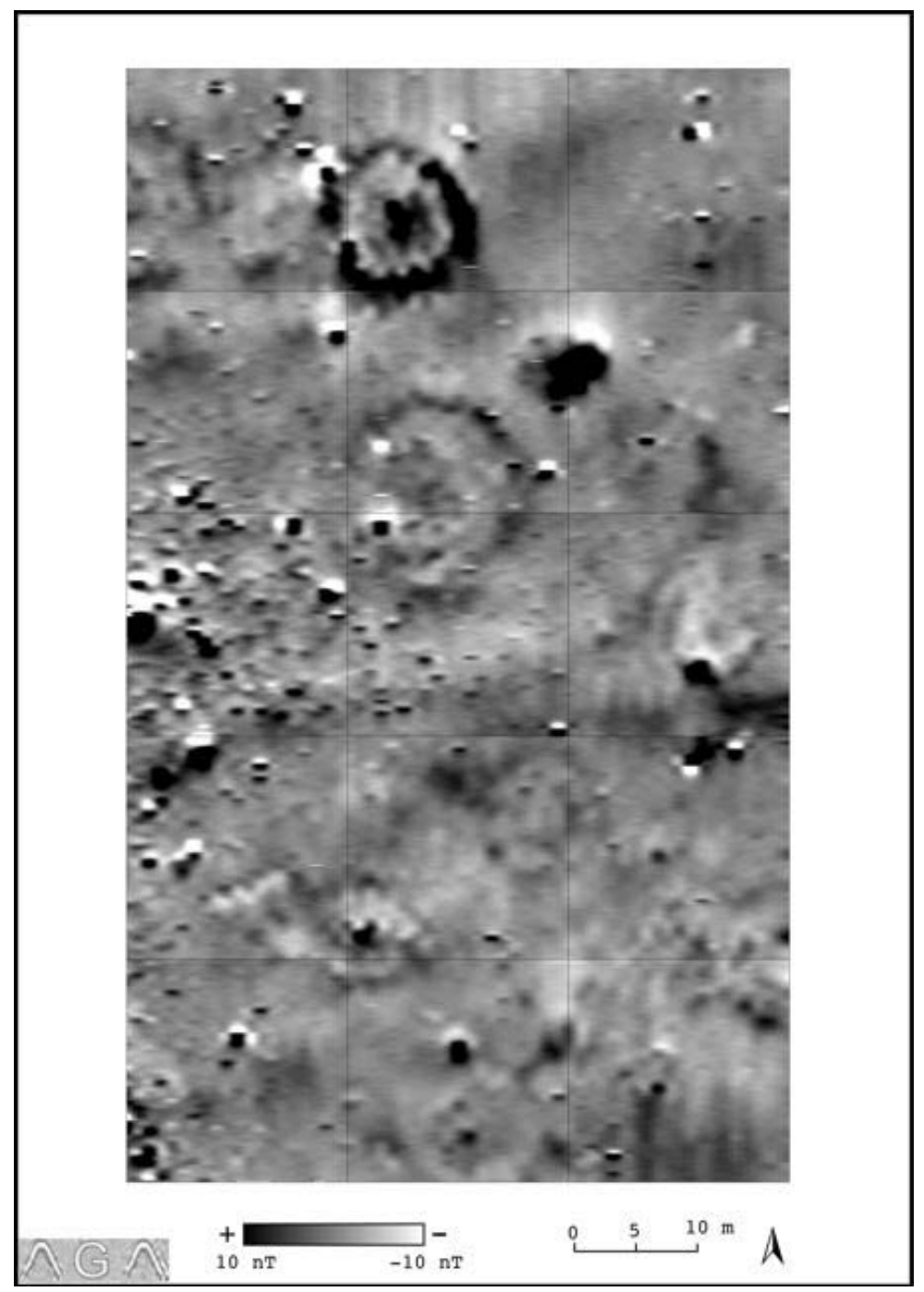

Figure 78. Plan of Area A collection blocks (Walker 2009:Figure 5-4). 


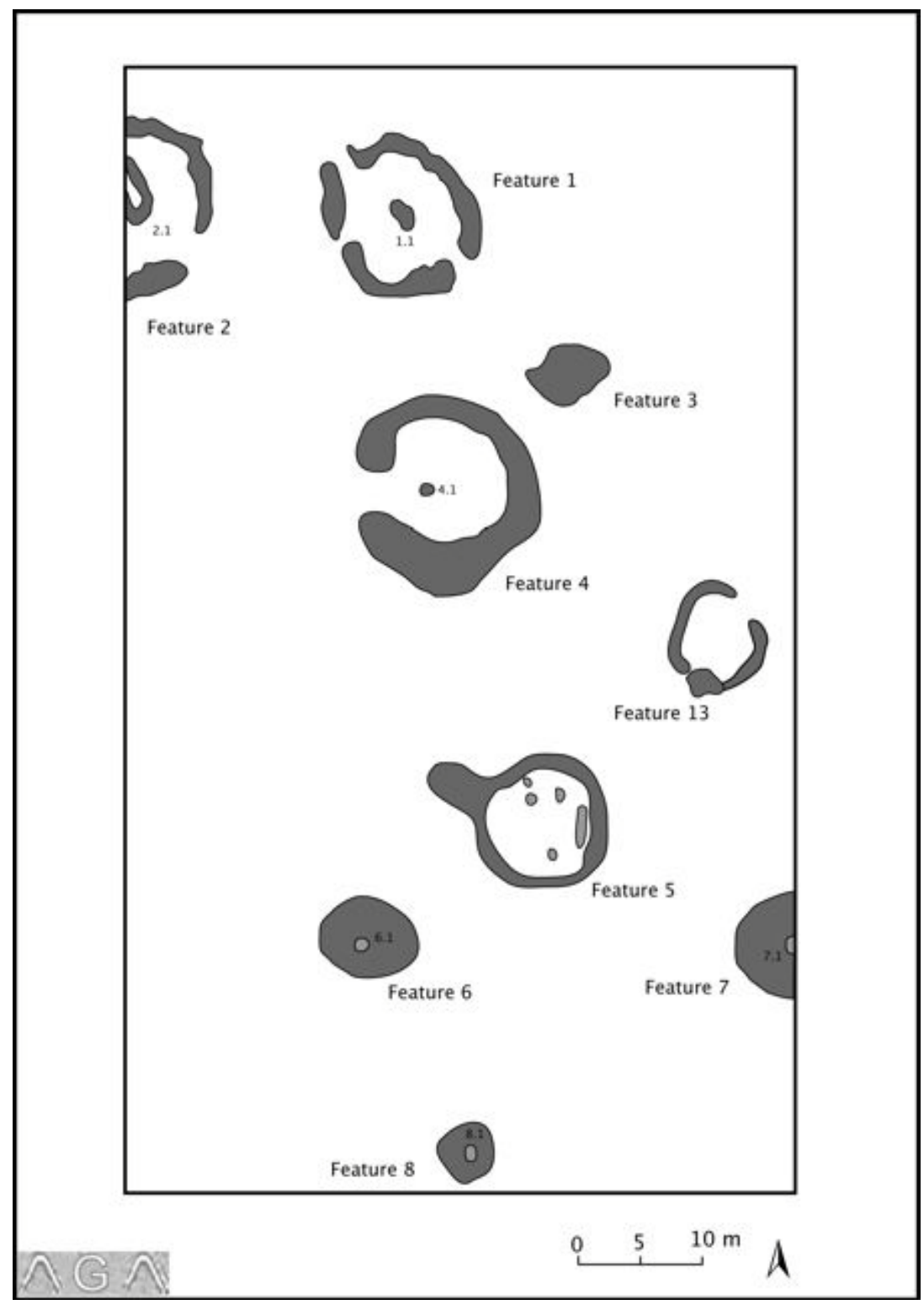

Figure 79. Interpretations of Area A features in the remote sensing data (Walker 2009:Figure 5-5; see also Perttula et al. 2008).

The Area B structures include Features 9 and 11. These structures are both approximately $10 \mathrm{~m}$ in diameter with interior areas of approximately $78.5 \mathrm{~m}^{2}$. They have 
interior magnetic anomalies interpreted as central hearths. In addition, both Features 9 and 11 appear to have been burned (Perttula et al. 2008; Walker 2009; Walker and Schultz 2008). Feature 9 has a southeast-facing extended entrance that, as Perttula et al. (2008) and Walker (2009) note, may have been oriented to face towards Area A. Figure 80 provides an image of the magnetometer results from Area B while Figure 81 shows the interpretation of the features.

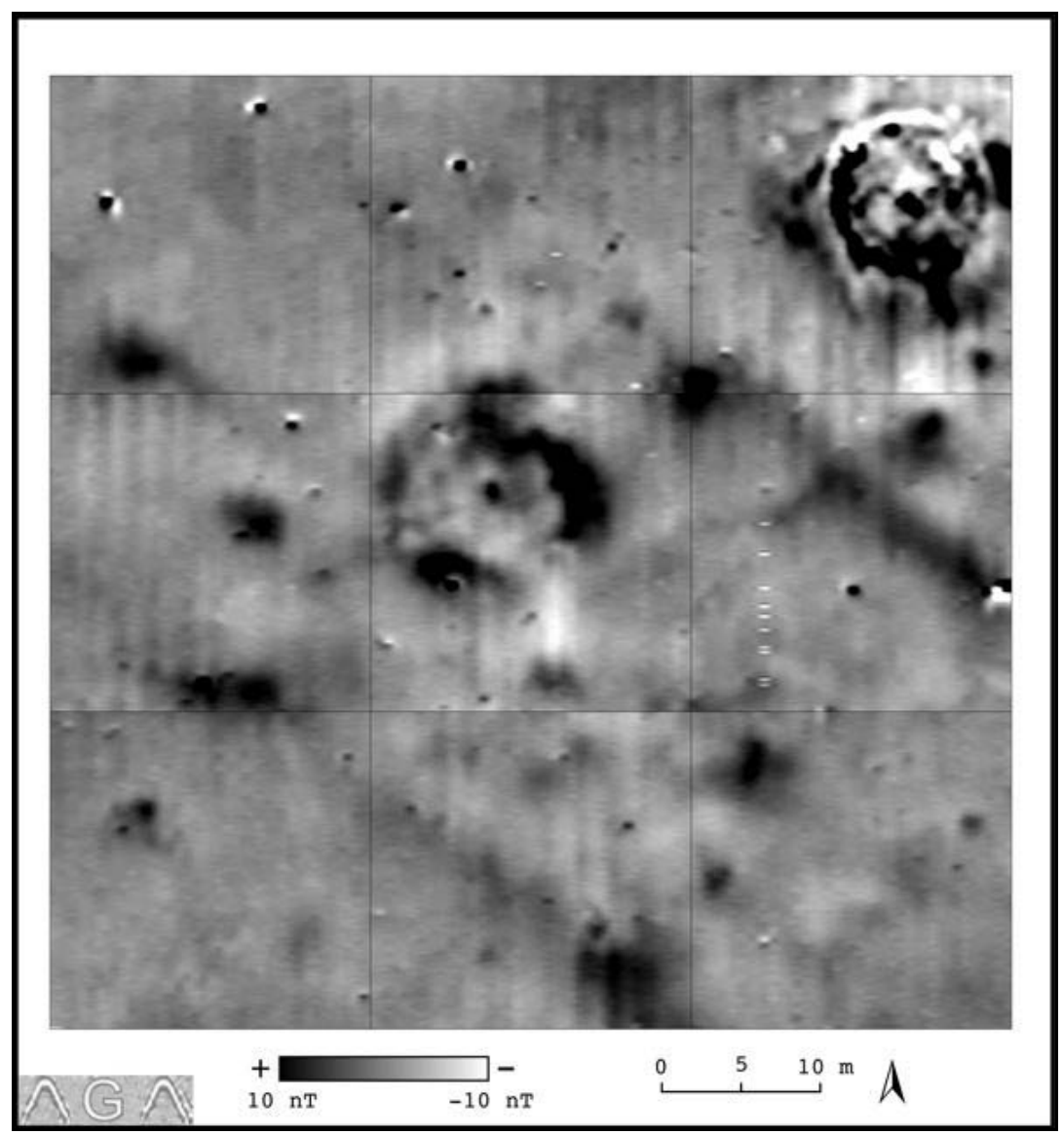

Figure 80. Plan of Area B collection blocks (Walker 2009:Figure 5-6). 
In addition to the two structures, two linear patterns of magnetic returns, Features 10 and 12, were recorded in Area B (Perttula et al. 2008; Walker 2009). Given their locations on either side of Feature 11, Perttula et al. (2008) and Walker (2009) have interpreted these features as possibly representing compound dividers. These linear features can clearly be seen in Figures 80 and 81 . While such dividers are well represented in the 1691 Terán map, linear features such as these associated with Caddo structures are also not unheard of in the East Texas archaeological record. Goldschmidt (1935a) uncovered a north-south linear pattern of post holes immediately to the east of a circular structure associated with the Keith mound. Perhaps the linear pattern of post holes at the Keith site represents a fence or other type of divider. Circular and straight dividers have been identified at other sites in and around the study area including Village Plot 2 at the Hatchel site (Perttula 2005), and the Battle (McKinnon 2008), Crenshaw, and Hardman (Early 1993) sites in southwest Arkansas.

Walker (2009) divides the Hill Farm structures into two architectural forms: circular structures (Features 1-2, 4, 6-8, 11 and 13) and circular structures with extended entrances (Features 5 and 9) (Figure 82). The circular structures range in size from $8 \mathrm{~m}$ to $17.5 \mathrm{~m}(\mathrm{n}=8, \bar{x}=11.25 \mathrm{~m}, \mathrm{~s}=3.3594)$, with areas ranging from $50.24 \mathrm{~m}^{2}$ to $240.41 \mathrm{~m}^{2}$ $\left(\mathrm{n}=8, \bar{x}=107.11 \mathrm{~m}^{2}, \mathrm{~s}=67.1211\right)$. The circular structures with extended entrances are $12 \mathrm{~m}$ (Feature 5) and $10 \mathrm{~m}$ (Feature 9), with areas of $113.04 \mathrm{~m}^{2}$ and $78.5 \mathrm{~m}^{2}$, respectively (Walker 2009). 


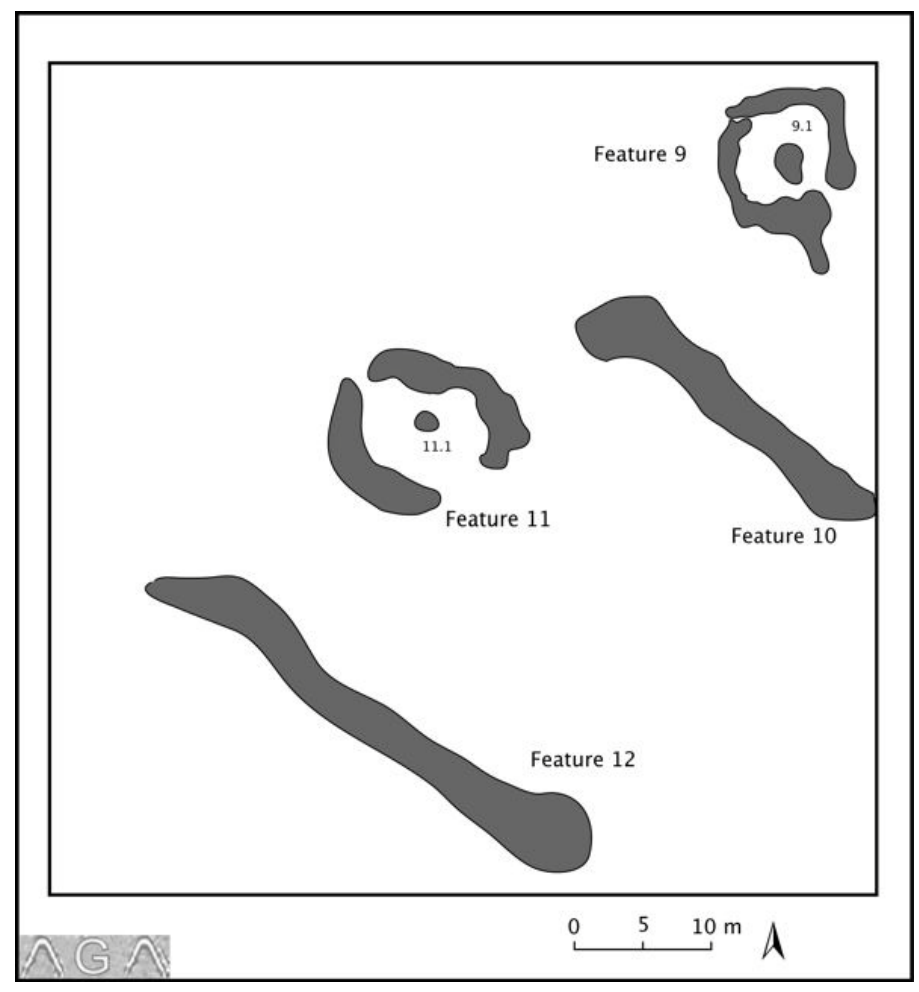

Figure 81. Interpretations of Area $\mathrm{B}$ features in the remote sensing data (Walker 2009:Figure 5-7; see also Perttula et al. 2008).

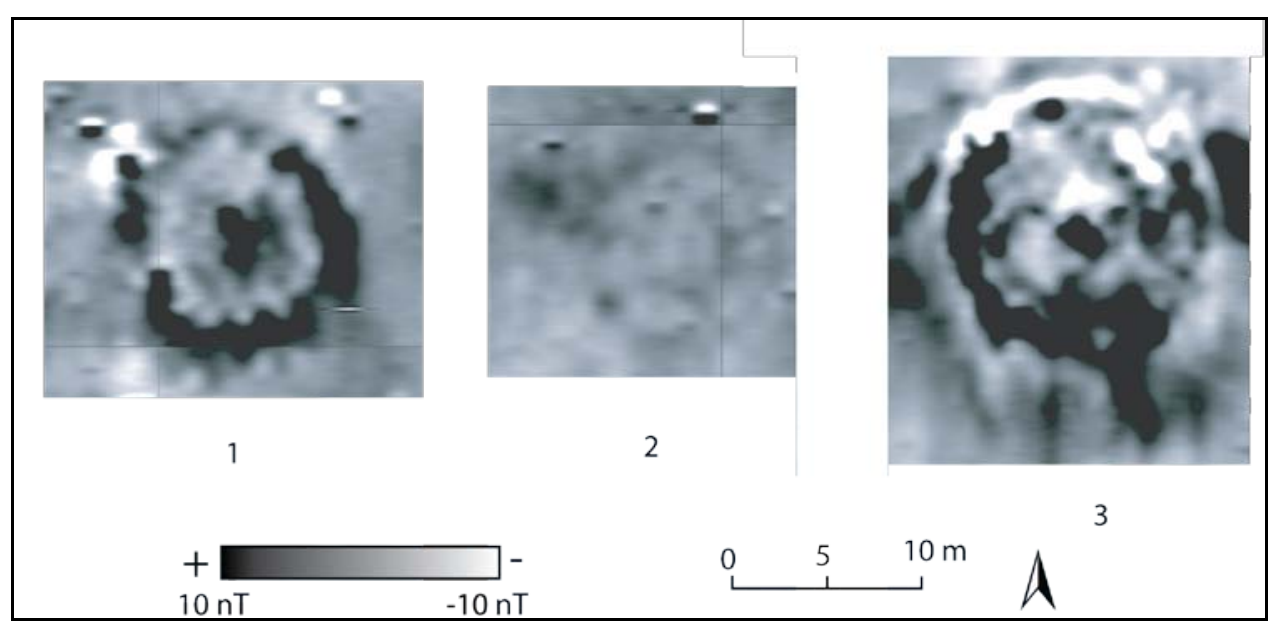

Figure 82. Geophysical signatures of various types of houses at the Hill Farm site (Walker 2009:Figure 5-3). 
The research conducted at the Hill Farm Site is an excellent example of the potential contribution to Caddo archaeology, and archaeology as a whole, that can occur when archaeogeophysical data can be used as primary data (Perttula et al. 2008; Walker 2009). The domestic deposits at the Hill Farm site appear to date to the seventeenth century A.D. Caddo occupation in this part of the larger Hatchel village (Perttula et al. 2008). In fact, Perttula et al. (2008:102) suggest that the Hill Farm site appears to be contemporaneous with stages A-D of the Hatchel Mound "based on the engraved ceramics from the mound deposits." Through integrating these various datasets, Perttula et al. (2008) have shown that the Hill Farm site may represent two village compounds east of the Templo mound depicted in the 1691 Terán Map. Figure 83 depicts the possible locations of Areas A and B from the Hill Farm site on the Terán map.

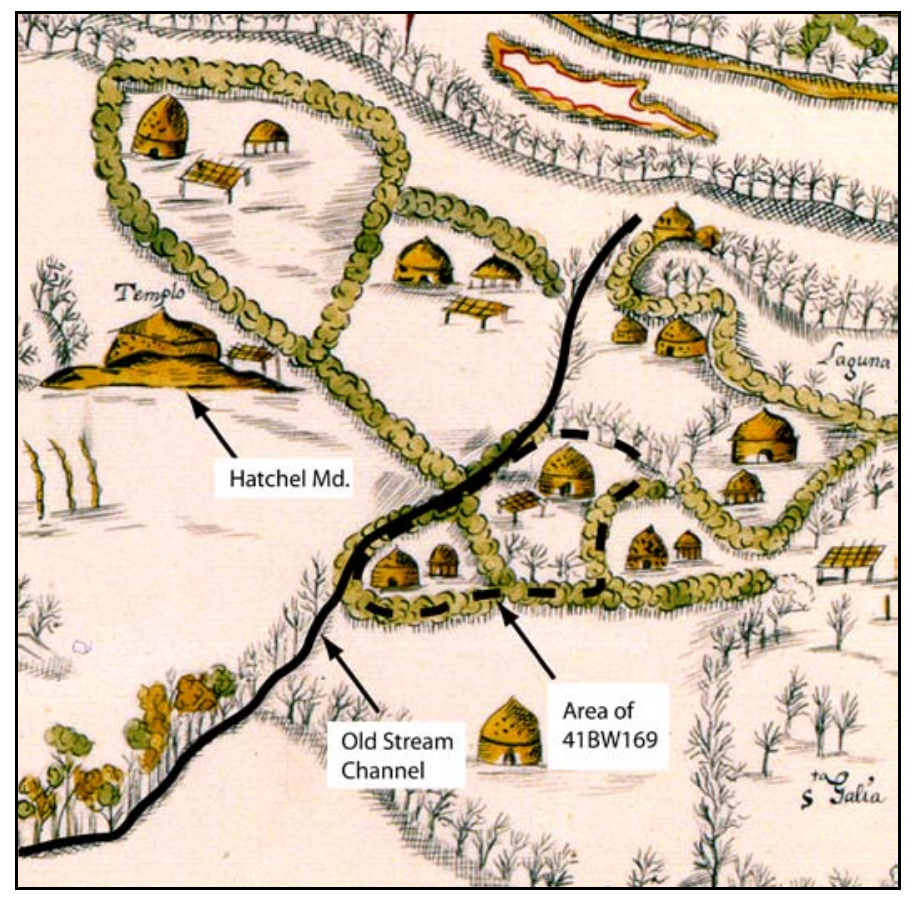

Figure 83. Detail of the 1691 Terán map showing the area interpreted by Perttula et al. (2008:Figure 14) as the approximate location of the Hill Farm site household compounds. 


\section{Foggy Fork (41NA235)}

In discussing house construction at five sites investigated as part of the Lake Naconiche project in the Attoyac Bayou basin, Perttula (2008) stated:

there is evidence for wood structures at all five Lake Naconiche sites, although because of poor preservation, the difficulty in identifying post hole stains in sandy soil, and structure rebuilding, the structure post hole patterns were not always clearly defined. The structures were built primarily with oak posts or poles well set in the ground (especially the center post and any main support posts), and were likely covered with thatch, sticks, and certain grasses; the general absence of daub suggests that the Lake Naconiche Caddo structures did not have a clay covering over the thatch. As best as can be discerned, the structures are circular in shape, with "the outer walls [following] very regular circles that must have been scribed before actual construction, perhaps by using a peg tethered by a rope to a pole" (Story 1995:239).

While there are clearly structure areas at the Tallow Grove (41NA231), Naconiche Creek (41NA236), Beech Ridge (41NA242), and Boyette (41NA285) sites, the most clearly defined post hole pattern was recorded at the Foggy Fork site.

Most of the cultural features recorded at the Foggy Fork site were related to a single Caddo structure (Figure 84 ). The $15^{\text {th }}$ century A.D. circular structure (Structure 1) was slightly more than $8 \mathrm{~m}$ in diameter and was marked by an arc of 14 wall post holes (Perttula 2008). The wall post holes had diameters ranging from $17 \mathrm{~cm}$ to $23 \mathrm{~cm}$, with a mean diameter of $18.45+-2.13 \mathrm{~cm}$. The wall post holes had depths ranging from approximately $50 \mathrm{~cm}$ to $72 \mathrm{~cm}$ with a mean depth of $59 \mathrm{~cm}$. Perttula (2008:134) notes that the similarity in size and depth of the post holes suggests "the use of wall post timbers about the same size and age." 
Structure 1 may have had an east-facing non-extended entrance. That is based at least partly on the presence of larger walls posts on the east side of the structure (Features 4 and 6), measuring $27-31 \mathrm{~cm}$ in diameter and extending to depths of approximately 65 and $72 \mathrm{~cm}$, that may have served as stronger supports for the entrance (Perttula 2008). The distance from the wall post holes to the approximate center of the structure ranges from approximately $3.6 \mathrm{~m}$ to $4.09 \mathrm{~m}(\mathrm{n}=13, \overline{\mathrm{x}}=3.91 \mathrm{~m}, \mathrm{~s}=0.1368)$. The distance between wall post holes was not measured because large gaps between post holes may have resulted from wall post holes that were not recorded.

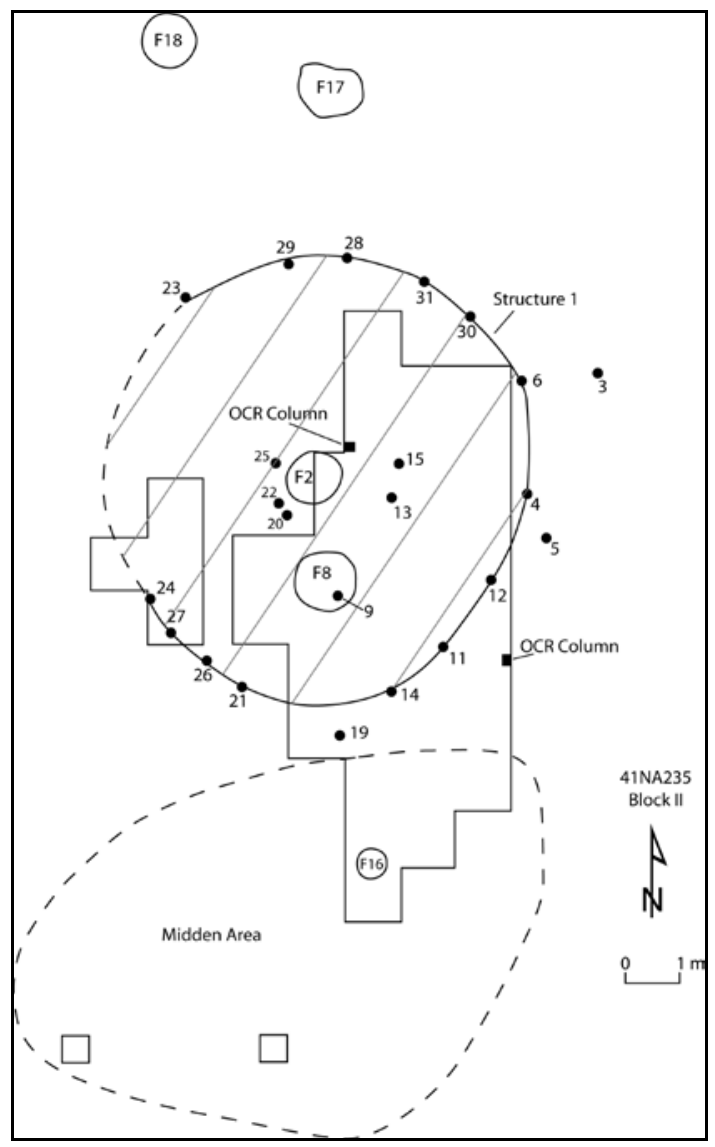

Figure 84. Structure 1 from the Foggy Fork site (41NA235) (Perttula 2008:133). 
Six interior post holes were recorded, three of which measured about $18.17 \pm 3.87$ $\mathrm{cm}$ in diameter (Perttula 2008). These interior post holes may represent either interior structure supports or possibly supports for small interior screens or dividers (Perttula 2008). Other interior features included a large, approximately $1 \mathrm{~m}$ diameter, $41 \mathrm{~cm}$ deep, basin-shaped pit in the approximate center of the structure (Feature 2) and an interior hearth (Feature 8). The basin-shaped hearth measured about $85 \times 96 \mathrm{~cm}$ and extended from where it was recorded, at about $50 \mathrm{~cm}$ bs, to $59 \mathrm{~cm}$ bs. Two post holes measuring about $20 \mathrm{~cm}$ in diameter were recorded underneath the hearth and may have served as roof supports at some time (Perttula 2008).

Three post holes, measuring $18 \pm 1.33 \mathrm{~cm}$ in diameter, found immediately to the south and east of Structure 1 were likely used for outdoor screens or racks (Perttula 2008). A $1 \mathrm{~m}$ diameter hearth and a basin-shaped pit measuring $1.1 \mathrm{~m}$ in diameter were recorded well outside of Structure 1 and a small midden deposit was recorded to the south of the structure (see Figure 84).

\section{SUMMARY}

This chapter has considered the architectural character of 128 previously excavated Caddo non-mound structures and another 87 non-mound structures recorded via magnetometer surveys. Data on these 215 structures come from 24 sites located throughout eastern Texas. The sites include major multi-mound centers such as the George C. Davis and Hatchel sites to small farmsteads such as New Hope or Bryan Hardy. Of these 215 structures, 186 are circular (86\%), four are sub-round (1.9\%), 10 are rectangular $(5 \%)$, and 15 are sub-square with rounded or diagonal corners $(7 \%)$. These structures include domiciles, granaries, and structures that were likely associated with the 
Caddo political or religious elite. The non-mound structures in this study span the range of the Caddo cultural tradition, dating from the Formative to Early Caddo periods into the Middle Caddo period as well as the Late Caddo and Historic Caddo phases, including the Frankston, Titus, and Allen phase. 


\section{CHAPTER 7}

\section{CADDO ARCHITECTURE IN EASTERN TEXAS}

\section{INTRODUCTION}

This chapter provides a comparison of the Caddo non-mound structures included in this study with the mound-related structures. I will examine construction techniques, associated features, and practices of building, use, reuse, rebuilding, and destruction of structures. Included in this chapter are 128 excavated non-mound structures and 48 excavated mound-related structures. In addition, this study includes another 87 nonmound structures and two mound-related structures recorded via magnetometer surveys. Data on these 265 structures come from 31 sites located throughout eastern Texas. The sites run the gamut from major multi-mound centers such as the George C. Davis, Whelan, and Hatchel sites to small farmsteads such as New Hope or Bryan Hardy.

\section{CONSTRUCTION TECHNIQUE}

\section{Size and Shape}

The majority of both non-mound and mound-related Caddo structures are circular; however, sub-round, sub-square, and rectangular structures occur in the area as well. While I have classified the structures in this study as falling into one of four general shapes, it should be noted that there is considerable variation within each of these shape categories. For instance, some of the sub-square structures are nearly rectangular in form, while others appear nearly sub-round. 
The circular structures consist of generally circular patterns of post holes and/or post molds along with their associated features (usually a central hearth). One-hundred eighty-six $(86 \%)$ of the non-mound structures are circular, while $38(76 \%)$ of the moundrelated structures are circular. Of the 185 circular non-mound structures, $78(42 \%)$ were recorded as part of magnetometer surveys at the George C. Davis and Hill Farm sites. Two of the mound-related structures were recorded as part of the magnetometer survey at the George C. Davis site. Figure 85 provides a distribution map of the circular structures.

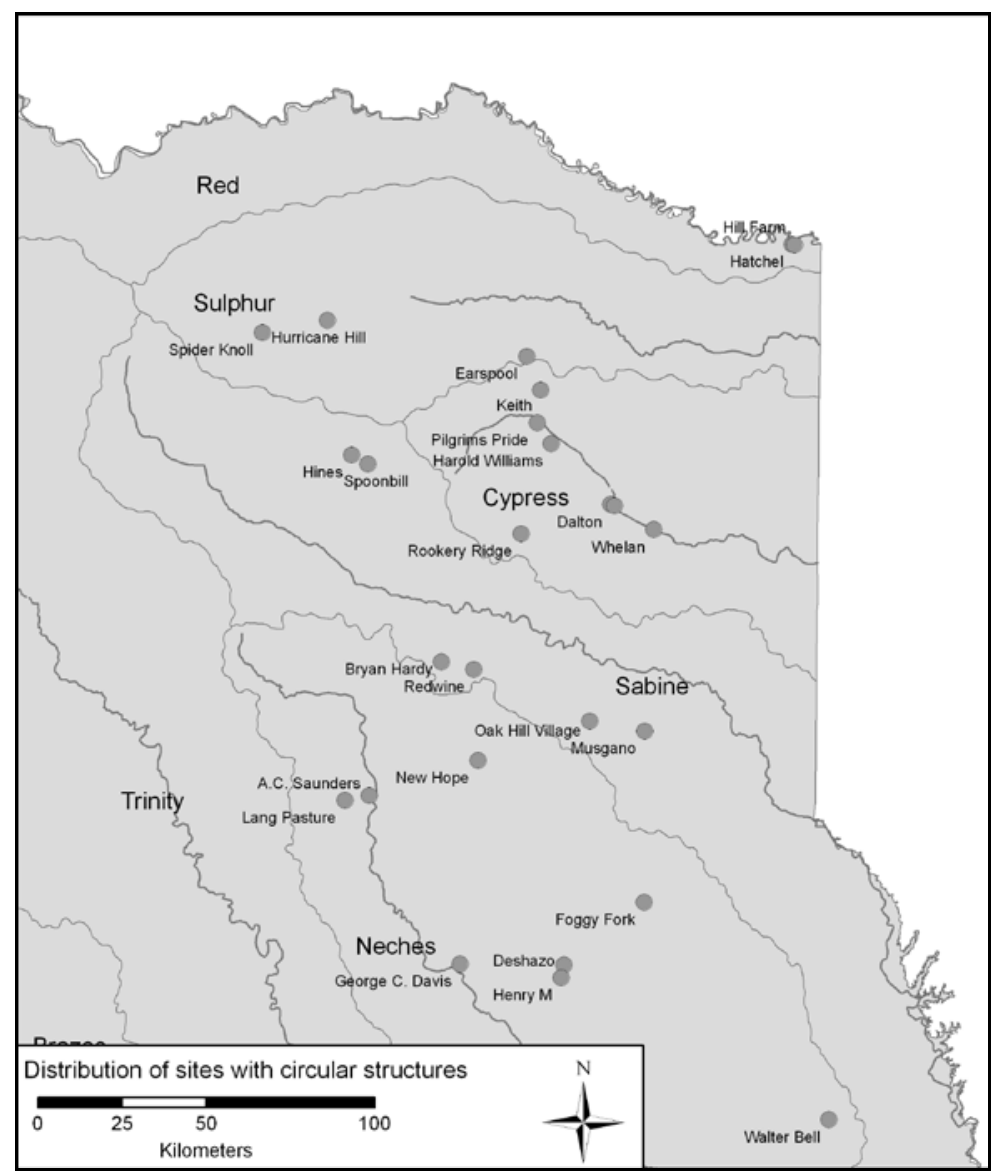

Figure 85: Distribution of circular structures. 
The circular non-mound structures have diameters ranging from $1.5 \mathrm{~m}$ to $21 \mathrm{~m}$ $(\mathrm{n}=185 ; \bar{x}=9.46 ; \mathrm{s}=4.0508)$, with areas ranging from $1.8 \mathrm{~m}^{2}$ to $346.36 \mathrm{~m}^{2}(\mathrm{n}=185 ; \bar{x}=$ 84.17; $\mathrm{s}=73.3187)$. The largest non-mound structure in the dataset is Feature 238 from the George C. Davis site, with the smallest being Feature 7 from Davis (Figure 86). Figure 87 is a histogram depicting the approximate interior area of the non-mound circular structures. Of the excavated non-mound circular structures, Feature 7 from the George C. Davis site is still the smallest in the dataset, while the largest is Feature 3 from the A. C. Saunders site with an interior area of approximately $149.5 \mathrm{~m}^{2}$.
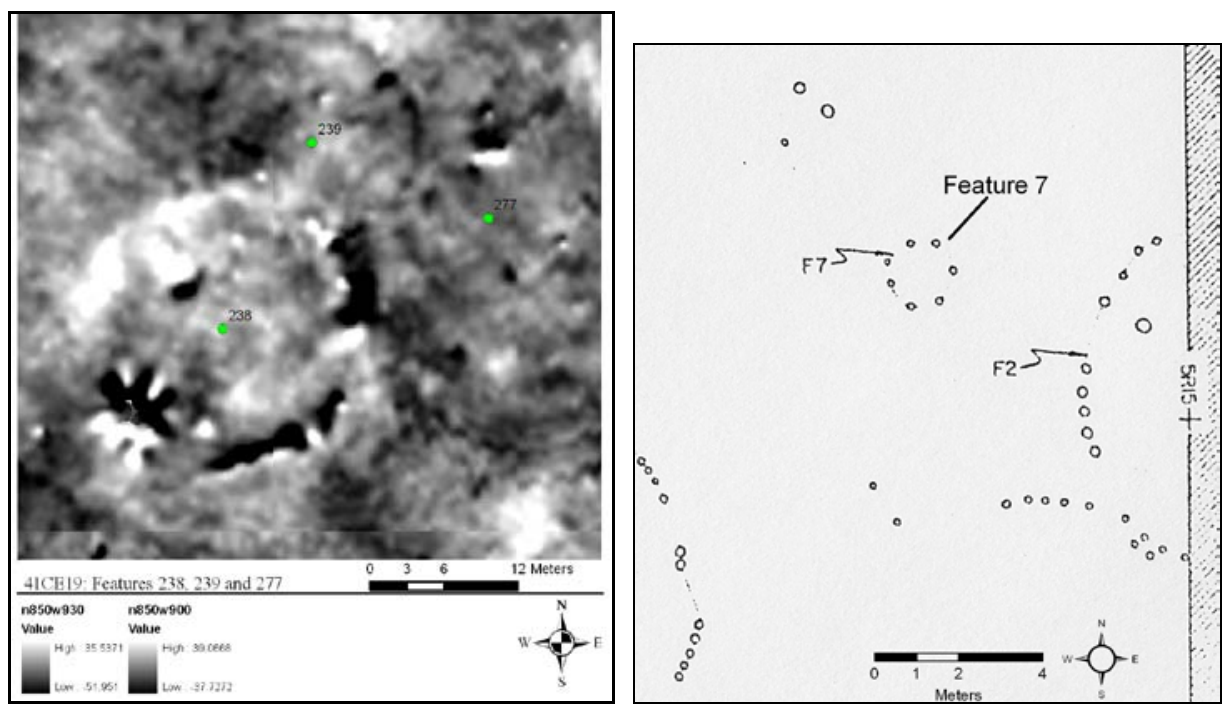

Figure 86. Features 238 and 7 from the George C. Davis Site.

The circular mound-related structures have diameters ranging from $3.66 \mathrm{~m}$ to 18 $\mathrm{m}(\mathrm{n}=38 ; \bar{x}=8.08 ; \mathrm{s}=3.27)$, with areas ranging from $10.51 \mathrm{~m}^{2}$ to $254.5 \mathrm{~m}^{2}(\mathrm{n}=38 ; \bar{x}=$ 59.40; $\mathrm{s}=52.46$ ) (Figure 88). By far, the largest mound structure in the dataset is Feature 111 from the George C. Davis site. This Mound B structure measures $18 \mathrm{~m}$ in diameter with an interior area of approximately $254.5 \mathrm{~m}^{2}$. This structure is approximately $3 \mathrm{~m}$ 
smaller than the largest non-mound structures recorded in the George C. Davis magnetometer survey and is considerably larger, approximately $105 \mathrm{~m}^{2}$, than the A. C. Saunders structure. The smallest circular mound-related structure is Structure 5 from the Hatchel site, with an approximate diameter of $3.66 \mathrm{~m}$ and an interior area of approximately $10.51 \mathrm{~m}^{2}$. This structure is over twice as large as Feature 7 from the George C. Davis site, the smallest non-mound structure. Structure 7 likely represents a granary or elevated storage platform. Perhaps Feature 5 from the Hatchel site, given its small size relative to the other structures associated with the Hatchel mound, may have been used in a similar manner as the smaller non-mound structures.

As noted previously, two of the mound-related structures were recorded as part of the George C. Davis magnetometer surveys (Features 321 and 322). These two features are interpreted to represent circular mound-related structures with diameters of approximately 5.8 and $5.9 \mathrm{~m}$. The size of these two possible structures fits within the size range of the previously excavated mound structures. In fact, the majority of moundrelated structures have diameters of $6 \mathrm{~m}$ or less, while most of the circular non-mound excavated structures at George C. Davis (58\%) have diameters of $8 \mathrm{~m}$ or less. 


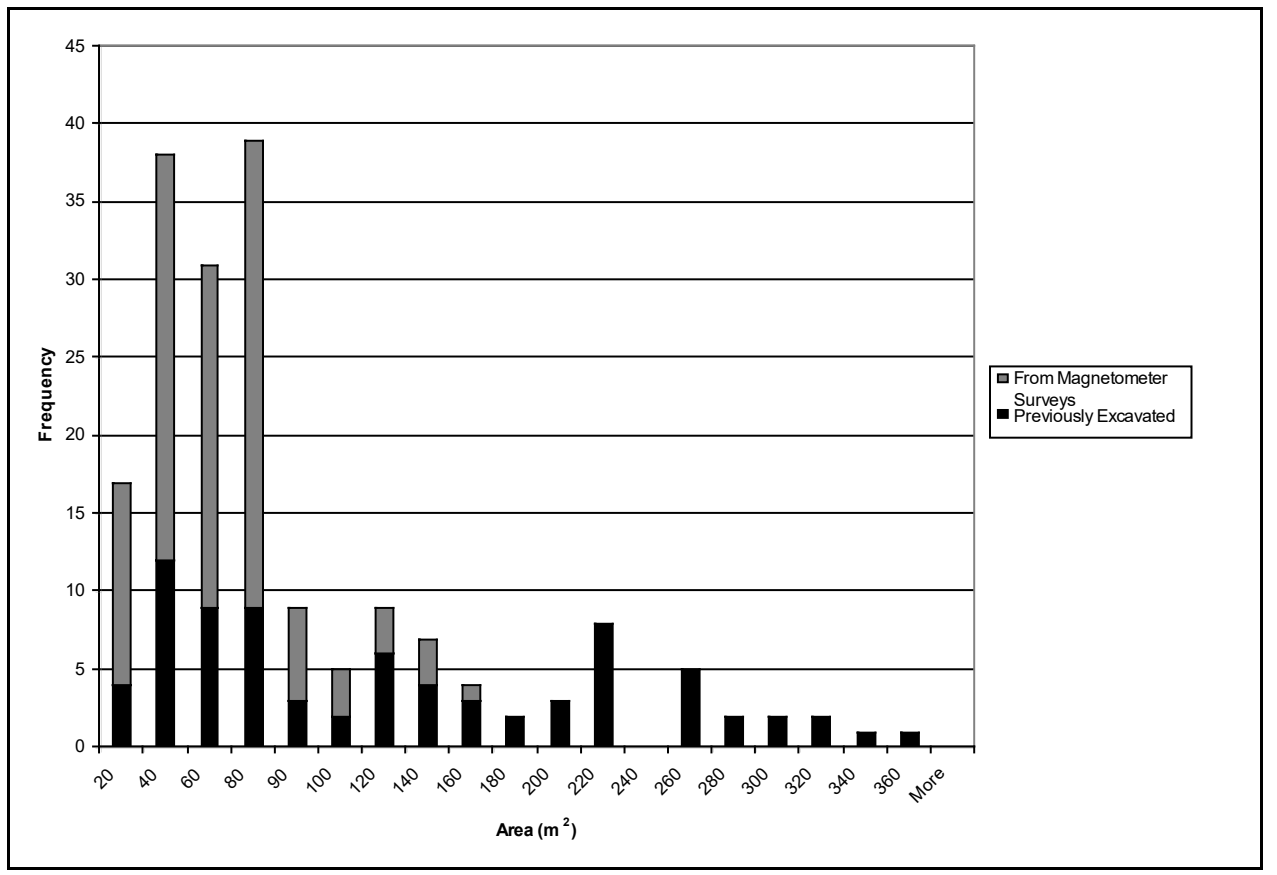

Figure 87. Histogram showing approximate interior area of the non-mound circular structures.

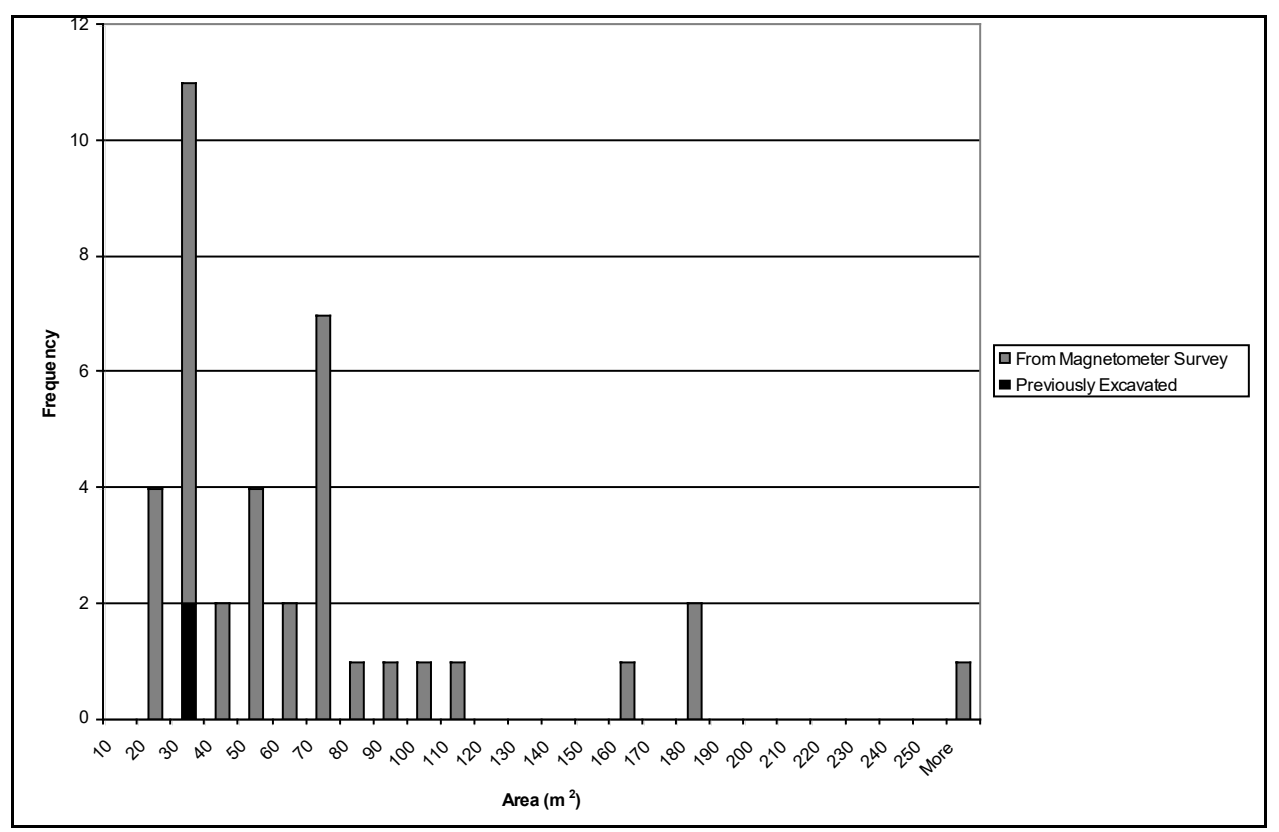

Figure 88. Histogram showing approximate interior area of the mound-related circular structures. 
The largest of the non-mound structures are those recorded through the magnetometer surveys at the George C. Davis and Hill Farm sites. These structures include several that exceed $14 \mathrm{~m}$ in diameter, with areas greater than $160 \mathrm{~m}^{2}$ (Figure 89). A greater number $(93 \%)$ of previously excavated non-mound structures have areas of less than $100 \mathrm{~m}^{2}$, compared to the magnetometer structures (51\%) (Figure 90). Forty-five percent of the George C. Davis magnetometer structures have areas exceeding $100 \mathrm{~m}^{2}$, and in fact only three of the excavated non-mound structures at the Davis site have areas exceeding $100 \mathrm{~m}^{2}$ (Features 49, 51, and 160), while 36\% of the Hill Farm structures have areas exceeding $100 \mathrm{~m}^{2}$. As discussed previously, rather than representing roofed buildings, it is possible that some of the largest of the non-mound structures recorded through the magnetometer surveys may represent open enclosures that were not covered by a roof, some possibly temporary, similar to those described by Espinosa for the September festival (Creel et al. 2008; Hatcher 1927; Walker 2009), or possibly fences similar to the large, $25 \mathrm{~m}$, fence found at the Hardman site encircling living areas (Early 1993). Alternatively these features could represent defined spaces such as dance-grounds or other types of ritual space. However, it is entirely possible that these large features recorded in the George C. Davis magnetometer data represent large domiciles, meeting or assembly houses, or other types of structures. 


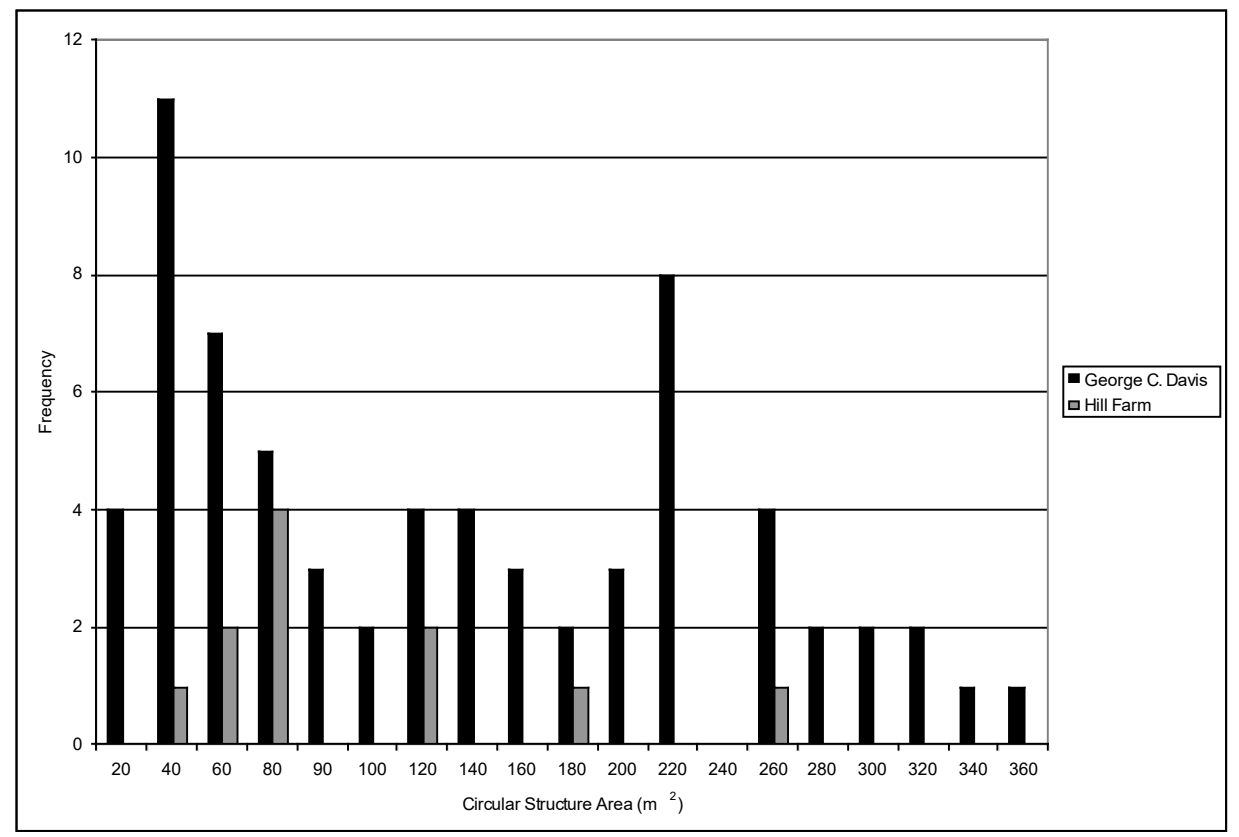

Figure 89. The interior area of magnetometer structures from the George C. Davis and Hill Farm sites.

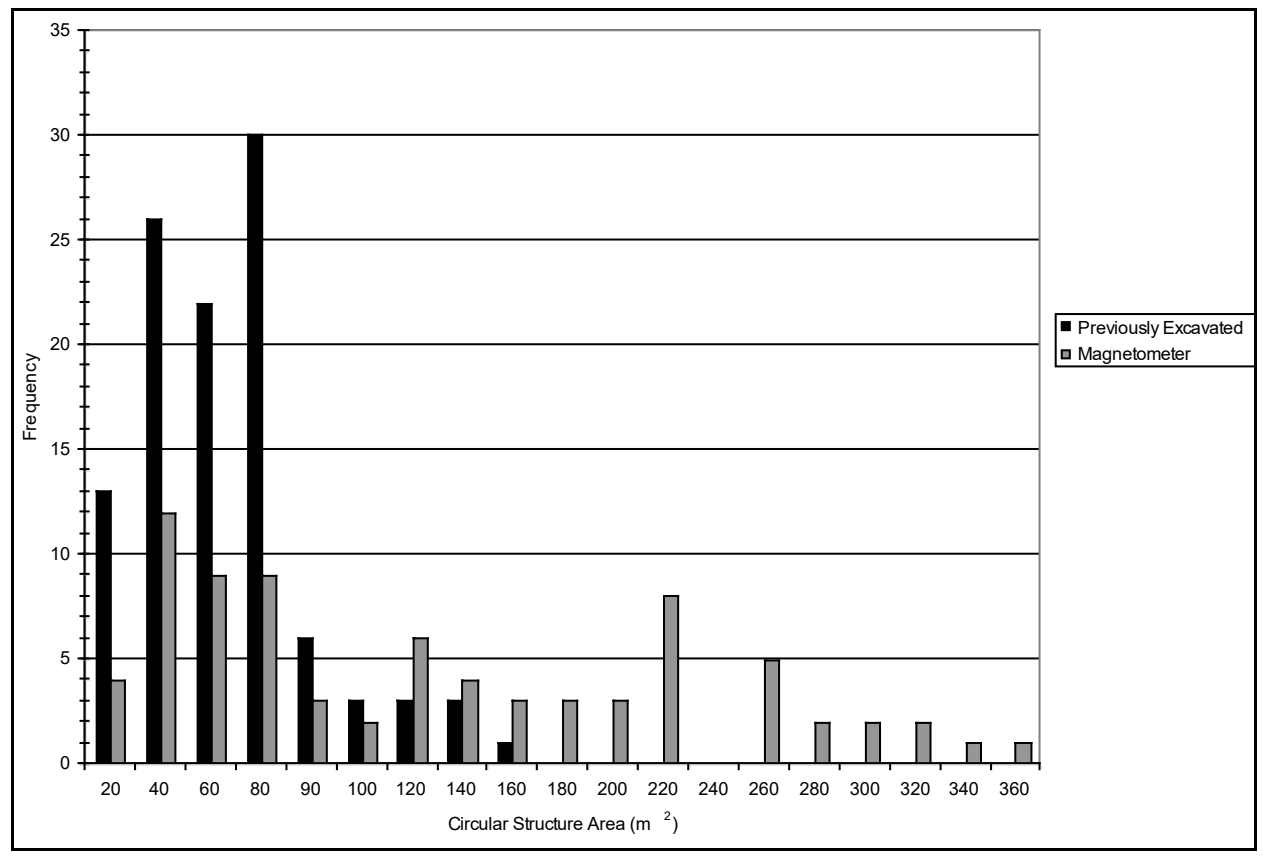

Figure 90. The interior area of circular non-mound magnetometer structures compared to previously excavated non-mound structures. 
Excluding the structures recorded through magnetometer surveys, the previously excavated structures have diameters ranging from approximately $1.5 \mathrm{~m}$ to $13.6 \mathrm{~m}(\mathrm{n}=$ $107 ; \bar{x}=7.80 ; \mathrm{s}=2.6108)$, with areas ranging from approximately $1.8 \mathrm{~m}^{2}$ to $149.5 \mathrm{~m}^{2}(\mathrm{n}$ $=107 ; \bar{x}=53.11 ; \mathrm{s}=30.8223)$. The magnetometer structures have diameters ranging from approximately $3.15 \mathrm{~m}$ to $21 \mathrm{~m}(\mathrm{n}=79 ; \bar{x}=11.78 ; \mathrm{s}=4.5369)$ with areas ranging from $7.79 \mathrm{~m}^{2}$ to $346.36 \mathrm{~m}^{2}(\mathrm{n}=79 ; \bar{x}=127.38 ; \mathrm{s}=90.9896)$. The larger non-mound structures evidenced in the magnetometer data are comparable in size to some of the large mound structures from the George C. Davis and Hatchel sites and to the large circular structure from the Werner site in Louisiana, which measured approximately $25 \mathrm{~m}$ in diameter, with an area of approximately $490.63 \mathrm{~m}^{2}$ (Webb 1983).

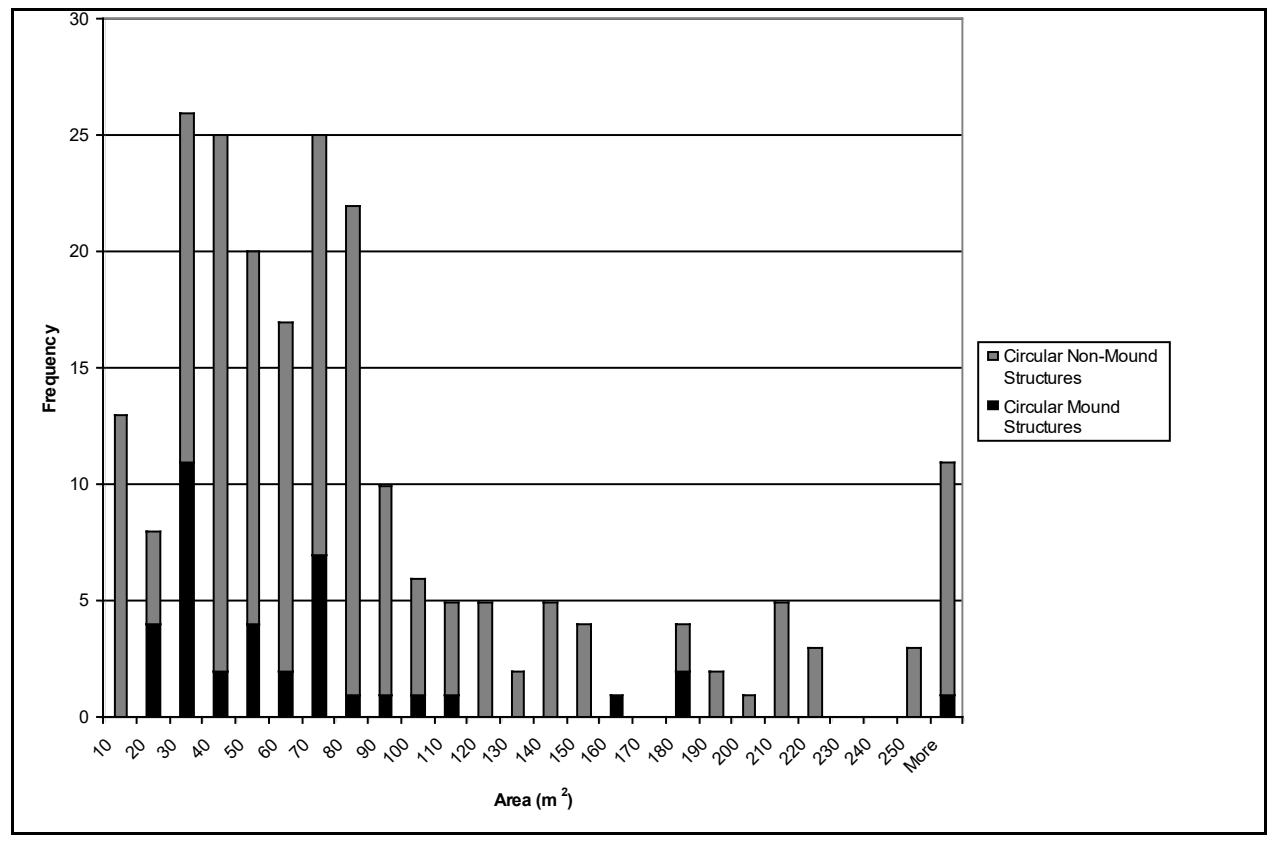

Figure 91. Comparison of mound and non-mound structure areas.

The majority of both mound and non-mound circular structures have interior areas falling between approximately 20 and $80 \mathrm{~m}^{2}$, with 108 of the non-mound structures and 282 
seven of the mound structures falling into this size range (Figure 91). Several more of the non-mound structures exceed $180 \mathrm{~m}^{2}$ in area, with most of the mound-related structures having interior areas of less than $180 \mathrm{~m}^{2}$. This is largely a result of the large features identified in the magnetometer surveys at the George C. Davis site, although as noted above, one of the largest structures in the dataset is Feature 111, the large excavated Mound B structure from the site.

Sub-square structures make up the next largest structure shape category with 15 non-mound structures $(7 \%)$ and four mound structures $(8 \%)$ comprising this category. With the exception of the Fasken structure, all of the sub-square structures are from the George C. Davis site. Most of the sub-square structures have what appear to be either rounded or diagonal corners, lacking post holes at the corners of the structures. Many of these structures were recorded as part of the magnetometer surveys at the George $\mathrm{C}$. Davis site, with some appearing to be nearly rectangular in shape. Figure 92 provides a distribution map of the sub-square structures.

The sub-square structures have areas ranging from $22.08 \mathrm{~m}^{2}$ to $326.69 \mathrm{~m}^{2}(\bar{x}=$ 97.51, $\mathrm{s}=71.6147)$. Nine of these structures were recorded as part of the magnetometer survey. The previously excavated sub-square structures have interior areas ranging from $44.1 \mathrm{~m}^{2}$ to $153.86 \mathrm{~m}^{2}(\bar{x}=93.89, \mathrm{~s}=34.7386)$, with the structures recorded as part of the magnetometer survey having areas ranging from $22.08 \mathrm{~m}^{2}$ to $326.69 \mathrm{~m}^{2}(\bar{x}=101.12, \mathrm{~s}=$ 98.2967). Only one of these structures exceeds $175 \mathrm{~m}^{2}$, House 2 (Feature B2), recorded by Osburn et al. (2008). If this $20.4 \mathrm{~m}$ diameter structure is excluded, given that it is considerably larger than the other non-mound structures, the areal range for the subsquare magnetometer structures is $22.08 \mathrm{~m}^{2}$ to $174.37 \mathrm{~m}^{2}(\bar{x}=72.93, \mathrm{~s}=53.5277)$. 


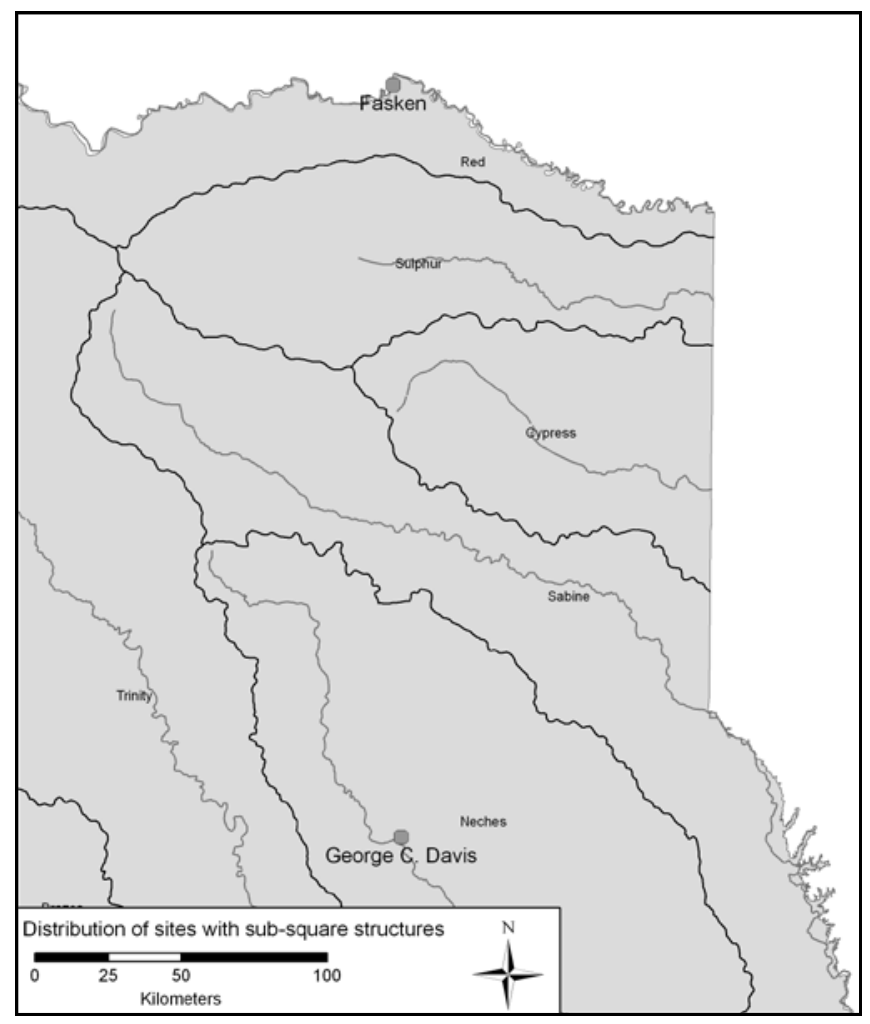

Figure 92: Distribution of sub-square structures.

Three of the subsquare structures recorded as part of the Davis magnetometer surveys (Features 260, 281, and 347) are nearly rectangular in form (Figure 93). The interpretation that all these features represent Caddo structures is not definitive. In fact, as discussed in Creel et al. (2008:186), Feature 260 may be a historic pit feature "perhaps similar to the horse burial found during the 1980 Unit 65 excavations." This interpretation is based on GPR data collected at the site. As discussed in Chapter 4, however, Feature 281 appears to most likely represent a sub-square structure with an extended entrance. 

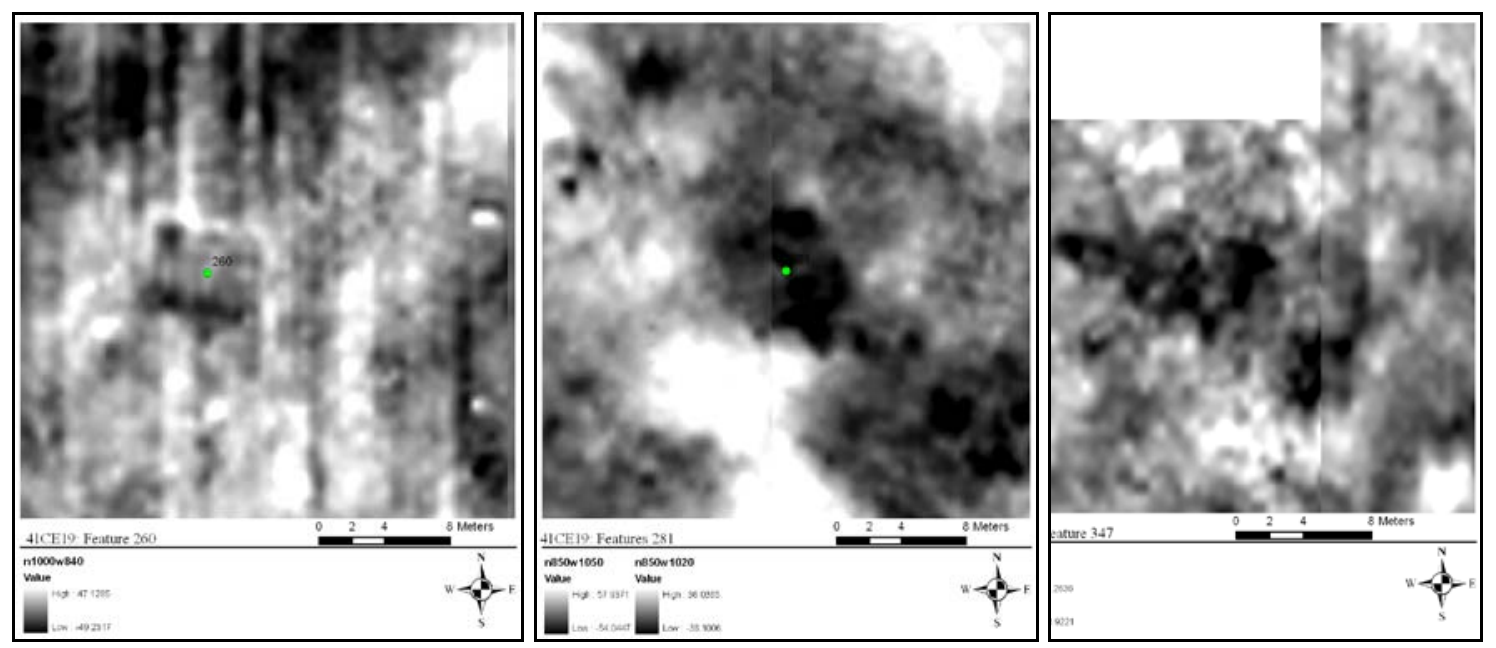

Figure 93. Possible sub square to rectangular non-mound structures in the George C. Davis site magnetometer data.

Four of the previously excavated sub-square structures are mound-related structures and have areas ranging from 44.1-66.3 $\mathrm{m}^{2}$, with a mean of $56.17 \mathrm{~m}^{2}$. Only three of the four sub-square mound structures could be measured given the incompleteness of the one Fasken site mound structure. Figure 94 provides a comparison of the mound and non-mound sub-square structures. 


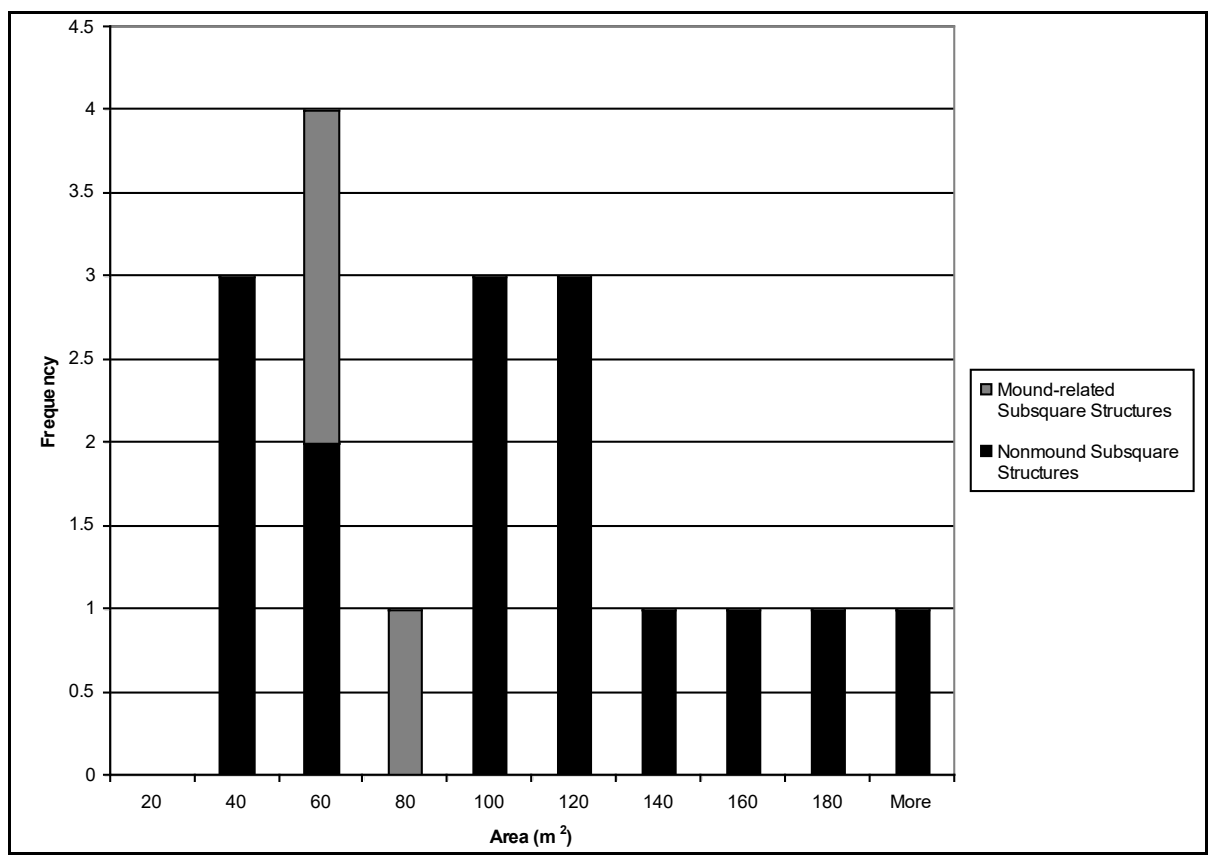

Figure 94. Comparison of internal area in mound and non-mound sub-square structures.

The East Texas Caddo architectural dataset also includes eight sub-round structures. With the exception of Structure 1 from the Blount site, all of the sub-round structures are from the George C. Davis site. These features are previously excavated structures, with half of them being directly associated with an earthen mound. ${ }^{7}$ The four non-mound sub-round structures have areas ranging from $17.35 \mathrm{~m}^{2}$ to $95.04 \mathrm{~m}^{2}$, with a mean of $56.50 \mathrm{~m}^{2}$. The mound-related sub-round structures have areas ranging from approximately $36.3 \mathrm{~m}^{2}$ to $61.5 \mathrm{~m}^{2}$, with a mean of $45.8 \mathrm{~m}^{2}$ (Table 47). Figure 95 provides a distribution map of the sub-round structures.

\footnotetext{
${ }^{7}$ Walker (2009) described Features 250-254 and 274 from the Davis site as sub-round structures. I have included these under the sub-square category with the exception of Feature 274, which I have classified as circular.
} 
Table 47: East Texas Caddo sub-round structures.

\begin{tabular}{|l|l|l|l|l|}
\hline \multicolumn{1}{|c|}{ Site } & Structure & \multicolumn{1}{|c|}{ Size (m) } & Area $\left(\mathbf{m}^{\mathbf{2}}\right)$ & \multicolumn{1}{c|}{ Mound-Related } \\
\hline Blount & 1 & $5.18 \times 3.35$ & 17.35 & No \\
\hline George C. Davis & 38 & $6.4 \times 7.2$ & 36.3 & Yes \\
\hline George C. Davis & 36 & 7.2 & 41.2 & Yes \\
\hline George C. Davis & 43 & $7.2 \times 7.8$ & 44.2 & Yes \\
\hline George C. Davis & 3 & 8.2 & 52.8 & No \\
\hline George C. Davis & 29 & 8.8 & 60.8 & No \\
\hline George C. Davis & 37 & $7.4 \times 10.3$ & 61.5 & Yes \\
\hline George C. Davis & 139 & $9.6 \times 9.9$ & 95.0 & No \\
\hline
\end{tabular}

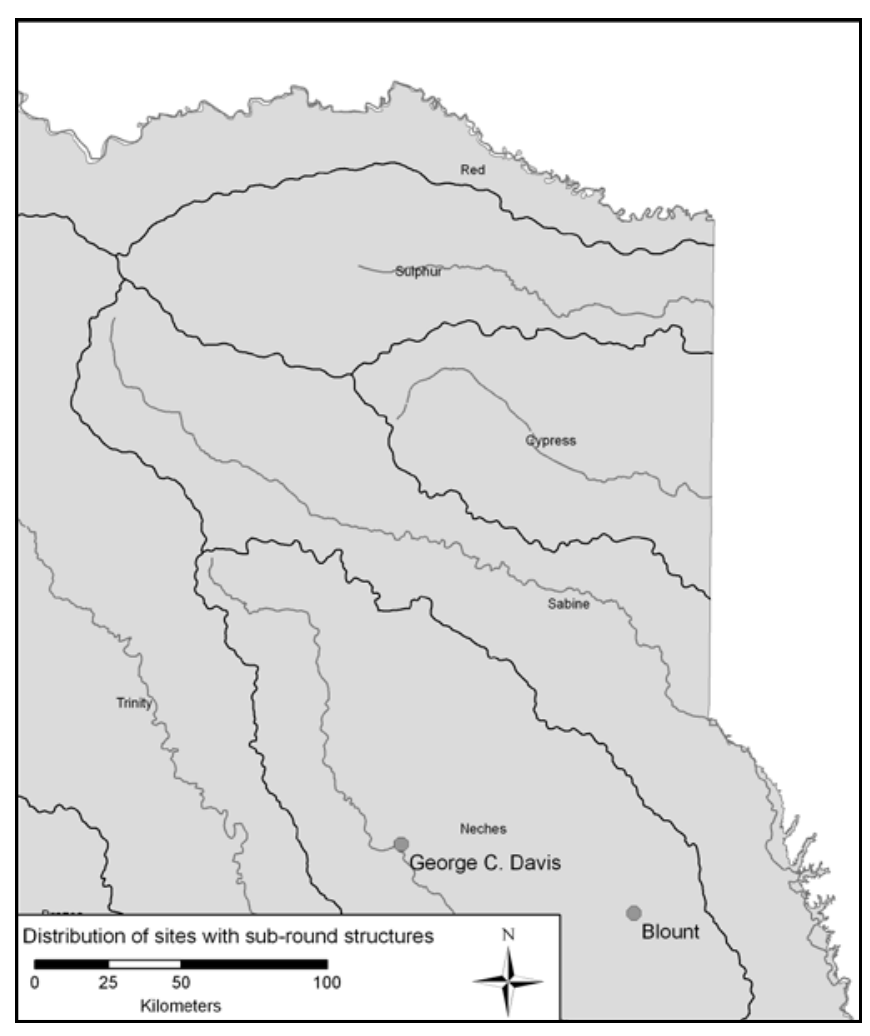

Figure 95: Distribution of sub-round structures.

The final shape category includes rectangular structures. There are 14 rectangular structures included in this study. Ten of these structures are not associated with an earthen mound. These structures have areas ranging from approximately $15.7 \mathrm{~m}^{2}$ to $96 \mathrm{~m}^{2}$ 
$(\bar{x}=53.87, \mathrm{~s}=34.6737)$. The four rectangular mound-related structures are from the Sanders, Holdeman, and Roitsch sites, all on the Red River. These structures have approximate areas ranging from $7.82 \mathrm{~m}^{2}$ to $42.75 \mathrm{~m}^{2}$, with a mean area of approximately $20.09 \mathrm{~m}^{2}$. These structures include those that were clearly four walled rectangular structures, namely those from Holdeman and Roitsch, as well as the less clearly defined Sanders structures. The former sites had rectangular structures with corners lacking posts, likely indicating rounded or diagonal corners, while the Sanders structures appeared to Jackson (2000) to represent a different type of structure all together, each having at least one open side, thus more similar to a lean-to than a typical Caddo structure. Table 48 provides size-related data on the 14 rectangular structures. Figure 96 provides a distribution map of the rectangular structures.

Table 48: Rectangular non-mound structures.

\begin{tabular}{|l|l|l|l|l|}
\hline Site & Structure & Size $(\mathbf{m})$ & Area $\left(\mathbf{m}^{2}\right)$ & $\begin{array}{l}\text { Mound } \\
\text { Related }\end{array}$ \\
\hline Sanders & 2 & $3.05 \times 2.59$ & 7.82 & Yes \\
\hline Sanders & 1 & $3.05 \times 3.66$ & 11.16 & Yes \\
\hline Hines & 2 & $4.8 \times 3.27$ & 15.7 & No \\
\hline Holdeman & 1 & $3.05 \times 6.10$ & 18.61 & Yes \\
\hline Roitsch & 3 & $5.6 \times 3.5$ & 19.6 & No \\
\hline Roitsch & 1 & $6 \times 4.1$ & 24.6 & No \\
\hline Hines & 3 & $6.65 \times 5.2$ & 34.58 & No \\
\hline Roitsch & 2 & $4.75 \times 9$ & 42.75 & Yes \\
\hline Oak Hill Village & 43 & $6.5 \times 9$ & 58.5 & No \\
\hline Oak Hill Village & 38 & $7.5 \times 12$ & 90 & No \\
\hline Oak Hill Village & 39 & $8 \times 11.5$ & 92 & No \\
\hline Oak Hill Village & 37 & $8 \times 12$ & 96 & No \\
\hline Hurricane Hill & $\mathrm{D}$ & $\mathrm{x}$ & $\mathrm{x}$ & No \\
\hline Hurricane Hill & $\mathrm{E}$ & $\mathrm{x}$ & $\mathrm{x}$ & No \\
\hline
\end{tabular}




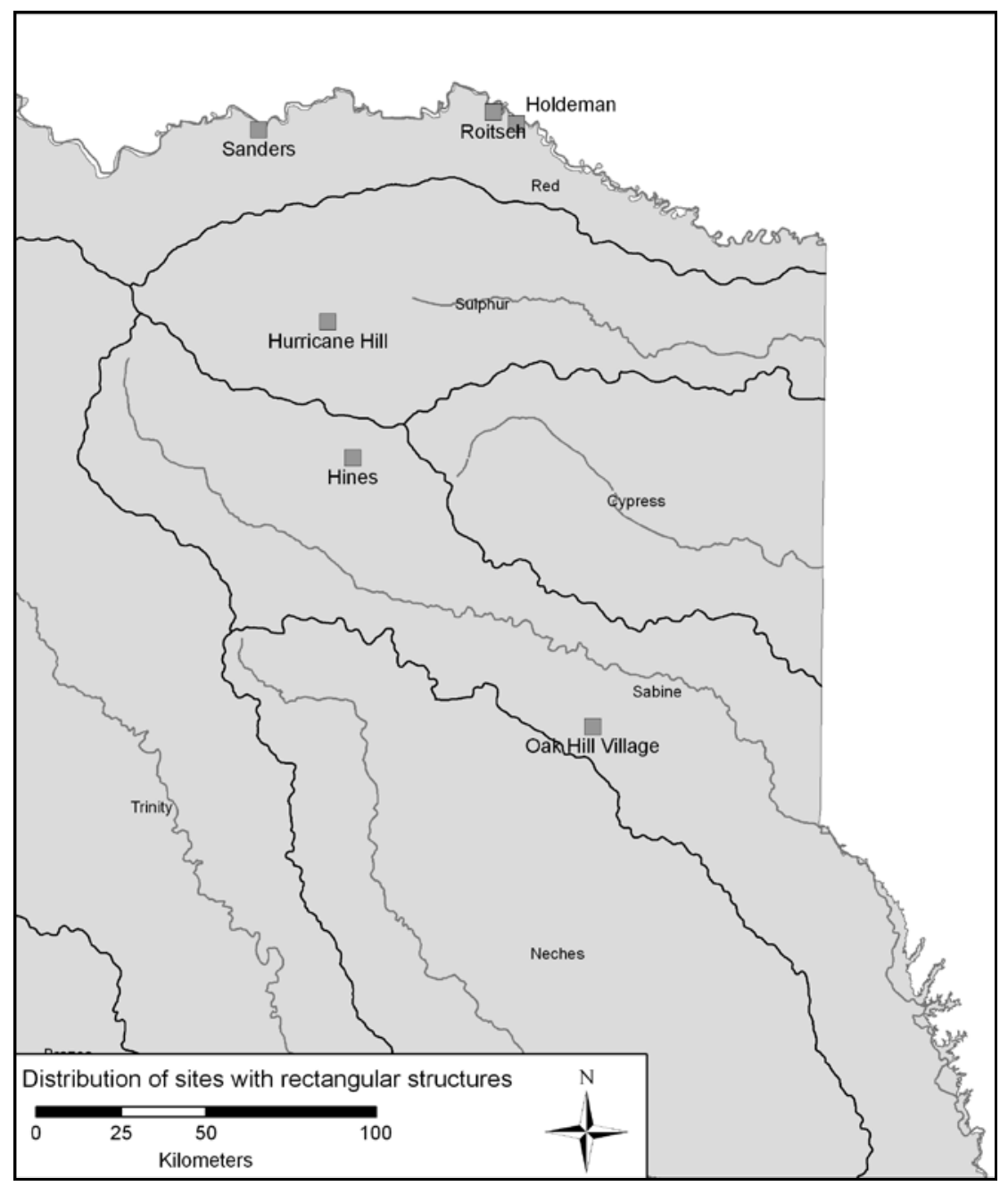

Figure 96: Distribution of rectangular structures.

Figure 97 provides a histogram comparing the approximate interior areas of the different shapes categories of both mound and non-mound related structures. Clearly there is considerable variation in size. The largest structures are circular, with only one non-circular structure having an interior area of more than $200 \mathrm{~m}^{2}$. The smallest overall class of structures is the rectangular structures, all of which have interior areas of less than $100 \mathrm{~m}^{2}$. The smallest buildings are the small circular structures that represent granaries or storage platforms. These buildings are considered to be fairly small, 
generally less than 3 m (Rogers and Perttula 2004; Spock 1977), and are associated with other buildings.

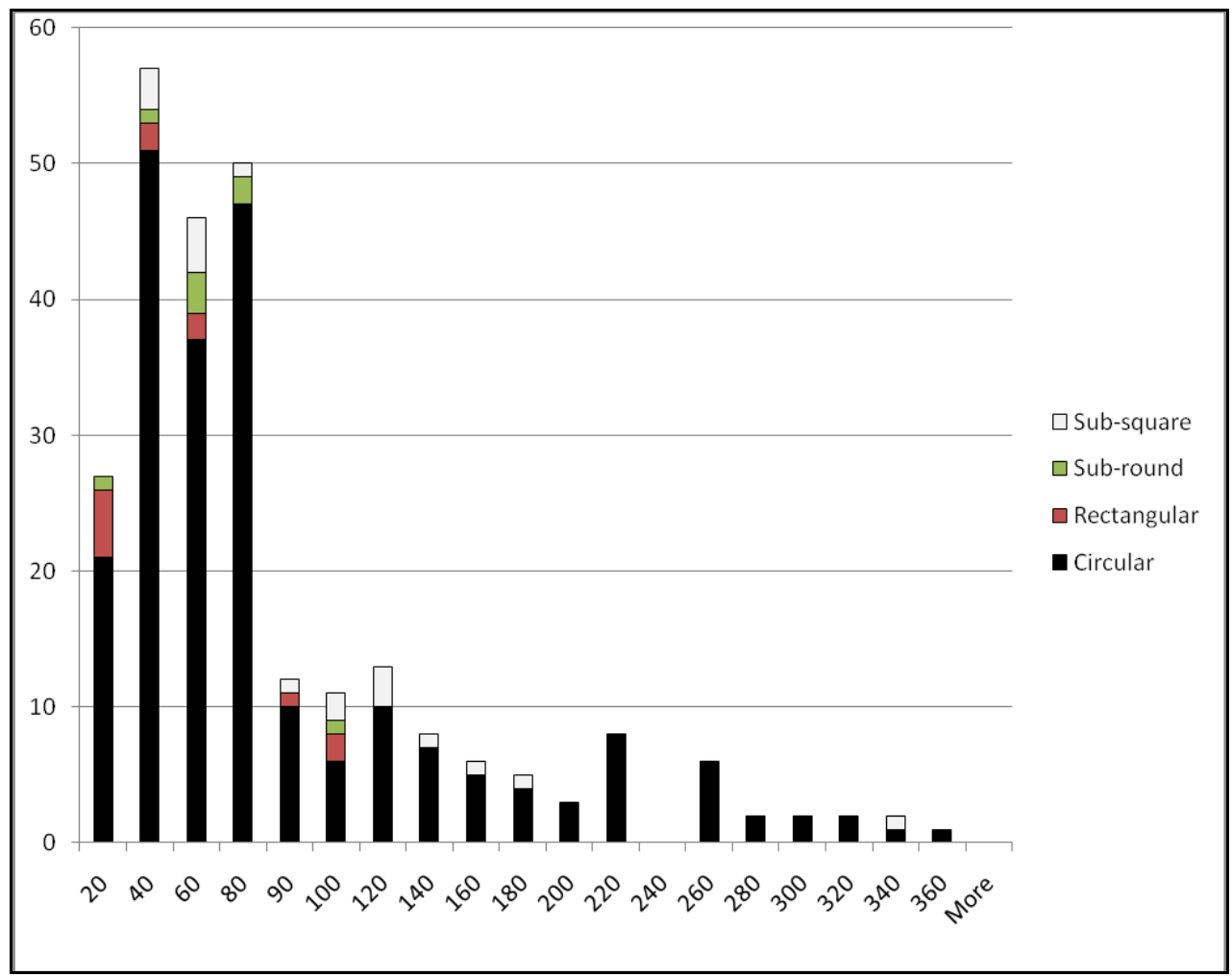

Figure 97: Histogram comparing interior areas of mound and non-mound related structures by shape.

\section{Summary}

The majority of Caddo structures in eastern Texas, whether associated with earthen mounds or not, are circular $(\mathrm{n}=223)$. These structures range in size from $1.5 \mathrm{~m}$ to $21 \mathrm{~m}$, with interior areas ranging from approximately $1.8 \mathrm{~m}^{2}$ to $346.36 \mathrm{~m}^{2}$. While there is considerable range in size, circular Caddo structures from eastern Texas tend to have interior areas falling between 20 to $80 \mathrm{~m}^{2}$, with $70 \%$ falling in this range. The largest of 
these structures were recorded through the magnetometer surveys at the George C. Davis and Hill Farm sites, with only 36 of the 80 magnetometer structures having interior areas less than $80 \mathrm{~m}^{2}$. Twenty-one of the magnetometer structures have interior areas exceeding than $200 \mathrm{~m}^{2}$. While the largest structures may represent large houses, assembly houses or other public buildings, or even open-aired structures, the smallest of the circular structures likely represent granaries or elevated storage platforms.

While circular Caddo structures are clearly the predominant architectural form in eastern Texas, there are also sub-square, rectangular, and sub-round structures. The subsquare and rectangular structures tend to have corners that lack posts, indicating diagonal or rounded corners. Sub-square structures $(n=19)$ have interior areas ranging from 22.08 $\mathrm{m}^{2}$ to $326.69 \mathrm{~m}^{2}$, sub-round structures have interior areas ranging from $17.35 \mathrm{~m}^{2}$ to 95.04 $\mathrm{m}^{2}$, and rectangular structures have interior areas ranging from $7.82 \mathrm{~m}^{2}$ to $96 \mathrm{~m}^{2}$.

Circular structures are prevalent throughout the Caddo tradition. There does not appear to be a distinct temporal shift from one construction form to another. One pattern that may relate to time is the construction of sub-square to rectangular buildings, all of which appear to date from Early to Middle Caddo periods, with the latest possibly being the rectangular mound structure from the Middle to Late Caddo Holdeman site. All of the other structures from Formative Caddo to Historic Caddo period sites are circular.

In general, there does not appear to be a correlation between structure size and time. Both large and small structures appear throughout the various Caddo periods. Most of the largest structures were recorded as part of the large-scale magnetometer survey of the Formative-Middle Caddo period (ca. A.D. 850-1300) George C. Davis site. Also, as discussed previously and suggested by Creel et al. (2008) and Walker (2009), some of these exceptionally large structures (relative to the average structure size for the area) 
may represent open enclosures rather than roofed buildings. Alternatively, these larger structures may have served as public buildings or assembly houses. The large circular structure from the Werner site measured approximately 24.4-27.4 $\mathrm{m}$ in diameter (Webb 1983), approximately 3.5 to $6.5 \mathrm{~m}$ in diameter larger than the largest of the George C. Davis magnetometer structures, and about 5.5 to $9.5 \mathrm{~m}$ larger than any of the previously excavated structures in this study. The Werner structure was interpreted by Webb (1983:221) as being "an immense lodge, presumably ceremonial; the destruction of which was memorialized (Caddoan fashion) by the covering mound." The smaller inner circle of the Werner structure was interpreted as being a ring of roof supports.

Including the magnetometer structures from the George C. Davis site, Early to Middle Caddo structures have interior areas ranging from $1.8 \mathrm{~m}^{2}$ to $346.36 \mathrm{~m}^{2}$, with a mean of $100.13 \pm 80.9 \mathrm{~m}^{2}$. Without the magnetometer structures, the range is from $1.8 \mathrm{~m}^{2}$ to $254.5 \mathrm{~m}^{2}$, with a mean of $70.49 \pm 44.26 \mathrm{~m}^{2}$. Middle to Late Caddo structures range in size from $2.01 \mathrm{~m}^{2}$ to $176.24 \mathrm{~m}^{2}$, with a mean of $43.60 \pm 29.34 \mathrm{~m}^{2}$. The largest of these is the pre-mound Feature 25 from the Hatchel site that Perttula (2005:183) has suggested may date to Middle Caddo times. This structure is considerably larger than the rest of the Middle to Late Caddo structures, measuring almost $4 \mathrm{~m}$ in diameter larger than the next smaller structure. Late Caddo to Historic structures range from $3 \mathrm{~m}$ to $17.5 \mathrm{~m}$ in diameter, with a mean of $8.26 \mathrm{~m}$, and a standard deviation of 2.78. Interior areas range from 7.16 $\mathrm{m}^{2}$ to $240.41 \mathrm{~m}^{2}$, with a mean of $59.74 \pm 41.11 \mathrm{~m}^{2}$. If the Hill Farm magnetometer structures are omitted, the sizes range from $3 \mathrm{~m}$ to $13.6 \mathrm{~m}$ in diameter, with a mean of 7.71 and a standard deviation of 2.38. Interior areas range from $7.16 \mathrm{~m}^{2}$ to $149.5 \mathrm{~m}^{2}$, with a mean of $51.15 \mathrm{~m}^{2}$, and a standard deviation of 30.16 . 


\section{Wall Trench, Single Set Posts, and Composite}

Only six of the $213(2.8 \%)$ non-mound structures have post trenches. Of these, two have wall trenches, while the others have extended entrances represented by post trenches. The two non-mound structures with wall trenches (Features 9 and 35) are both from the George C. Davis site. The four non-mound structures with entrance trenches are Structure 2 from Oak Hill Village, Structure 3 from Hines, House 1 from Rookery Ridge, and Structure B from Hurricane Hill. The non-mound structures with post trenches used in the entrances all have single set wall posts. There are no non-mound structures in this study that use composite wall trench and single set post construction for the exterior walls (excluding extended entrance trenches).

Ten percent of the 50 mound-related structures have post trenches. Of these, three have wall trenches and two have entrance trenches. The three mound-related structures with wall trenches (Features 43-45) are all from the George C. Davis site. Structures 43 and 45 are circular while Structure 44 is sub-round. The mean post hole diameter for wall trench post holes is $0.14 \mathrm{~m}$ and the mean post hole diameter for non-wall trench post holes is $0.15 \mathrm{~m}$. This similarity in size of the post holes is reflected in post hole depth as well, with the mean depth for wall trench post holes ranging from $0.50 \mathrm{~m}$ to $0.78 \mathrm{~m}$, and for single set posts the range is $0.50 \mathrm{~m}$ to $0.77 \mathrm{~m}$ deep.

The wall trenches associated with Features 43-45 are fairly short and spaced, at least in the case of Feature 45, somewhat evenly around the structure with gaps between each trench (Figure 98). Feature 45 has at least nine separate trenches, Feature 43 has four, and Feature 44 has only one identified trench. It is interesting to note that the post holes for Features 43 and 44 are grouped in rows of six to nine, separated by a small gap, similar to the clusters of post holes in Feature 45 that are grouped in wall trenches and as 
single-set posts. This grouping of wall post holes without the presence of wall trenches is present in other structures at the George C. Davis site as well.

The mound structures from the Bryan Hardy and Holdeman sites each have entrance trenches but no wall trenches, both having single-set wall posts (Figure 99). The Bryan Hardy entrance faced northeast and the Holdeman entrance faced southwest. Each of these entrances was defined by two roughly parallel wall trenches. The Bryan Hardy entrance trenches measured approximately $3.7 \mathrm{~m}$ long and were spaced approximately $0.75 \mathrm{~m}$ apart (center to center), allowing for a passage width of between $0.50 \mathrm{~m}$ and 0.60 $\mathrm{m}$, narrowing as one approached the structure. The Holdeman entrance was approximately $3.05 \mathrm{~m}$ long and 0.69 wide.
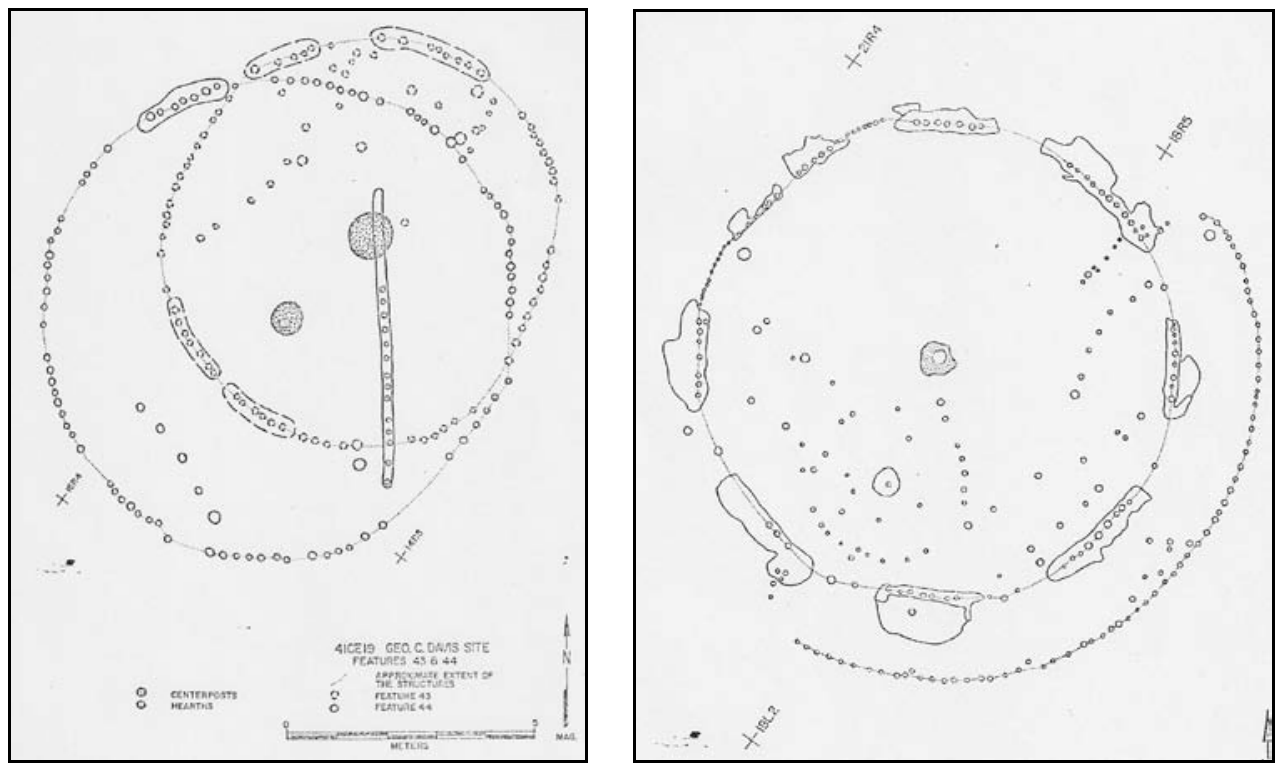

Figure 98. Composite wall trench and single-set post mound structures from the George C. Davis site, Feature 43, 44 and 45 (Spock 1977). 

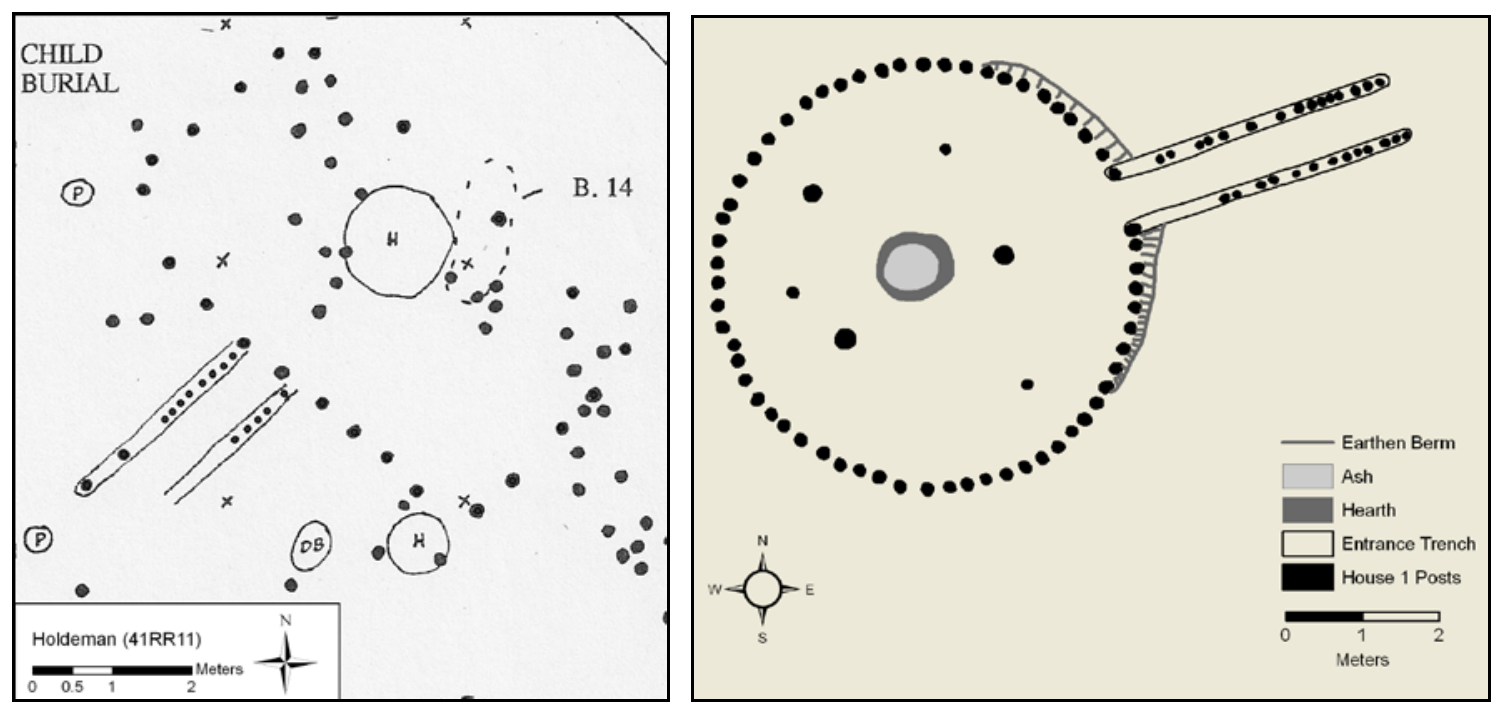

Figure 99: Entrance trenches from the Holdeman (Perino 1995) and Bryan Hardy (Walters and Haskins 2000) sites.

The Bryan Hardy entrance had 30 closely spaced post holes while the Holdeman entrance had a total of only 15 post holes; however, only a portion of the southern Holdeman entrance trench was recorded. The Bryan Hardy entrance posts were placed in individual holes in the entrance trench and then packed with clay. The Bryan Hardy entrance posts were slightly smaller than the wall post holes, ranging from $0.08 \mathrm{~m}$ to 0.14 $\mathrm{m}$ in diameter, with a mean of $0.11 \mathrm{~m}$, compared to the wall post holes with diameters ranging from $0.14 \mathrm{~m}$ to $0.21 \mathrm{~m}$, with a mean of $0.17 \mathrm{~m}$. At Bryan Hardy, two of the largest wall post holes are situated at each side of the entrance trench where the trench joins the structure wall, but at Holdeman, the largest posts were at the outer end of the extended entrance, furthest from the structure wall, likely providing added support for the long entrance. 


\section{Summary}

Figure 100 Shows the distribution of structures with wall or entrance trenches. The use of wall trenches is rare in eastern Texas Caddo structures, with only five structures having wall trench or composite wall trench and single-set post construction, all from the George C. Davis site. The use of trenches in extended entrances is more common than the use of wall trenches, but it is still quite rare. While most of the Caddo structures from eastern Texas either have non-extended entrances or entrances that were not clearly evident when the structure was excavated, at least 29 and possibly as many as 33 of the structures in this study had extended entrances. Only six of the structures with extended entrances used entrances trenches. The use of entrance trenches is not limited to a particular time period. Structures with entrance trenches include Early Caddo structures (Hines), Middle Caddo structures (Oak Hill Village, South Rise at Hurricane Hill, Holdeman, and Bryan Hardy), and one Late Caddo, Titus phase structure (Rookery Ridge). 


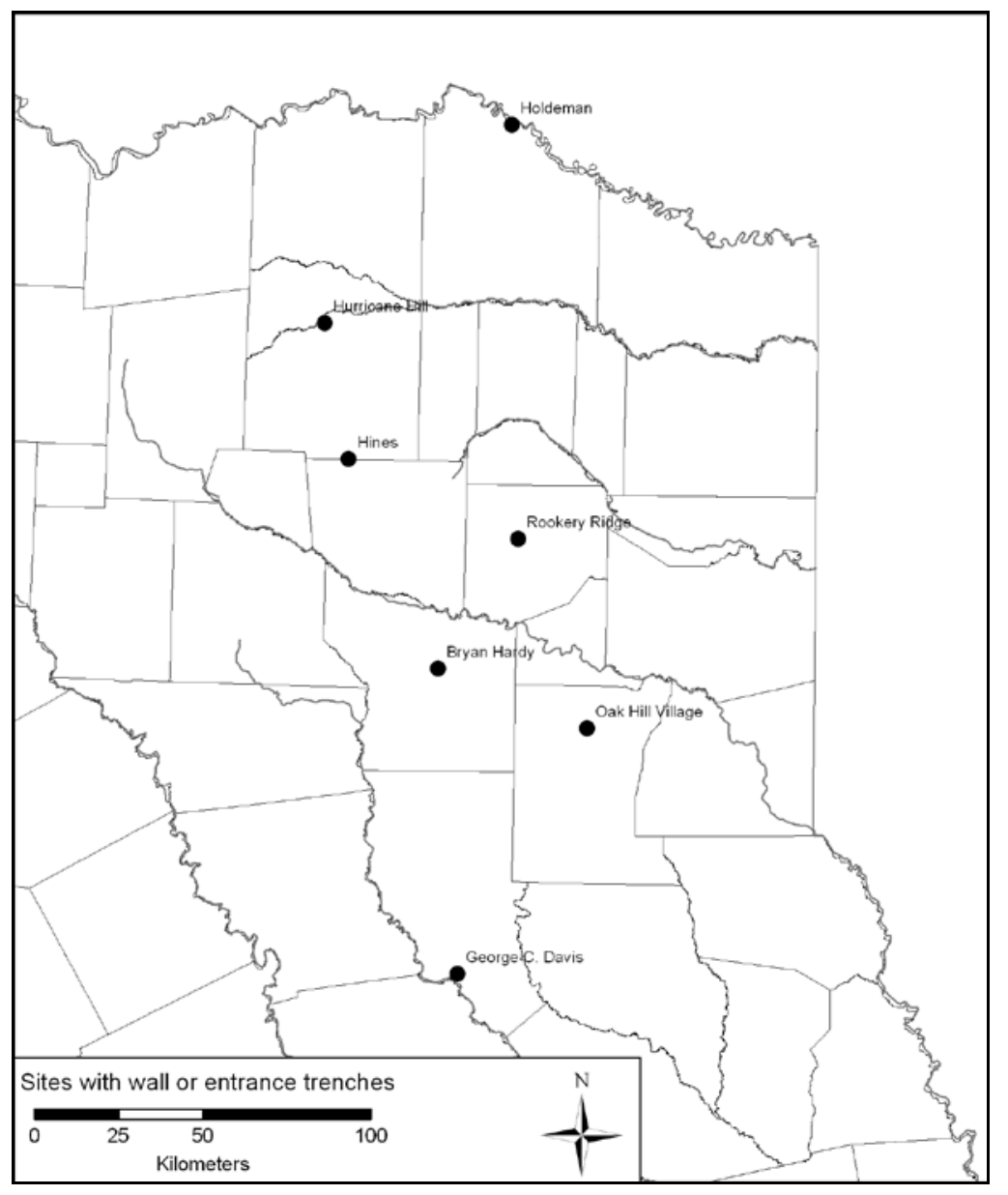

Figure 100: Distribution of sites with wall or entrance trenches.

\section{Entrances}

The majority of non-mound structures included in this study have non-extended entrances. Only 14 to 18 of the non-mound structures $(6.5-8.4 \%)$ have extended entrances. Four of the extended entrance structures were recorded in the magnetometer surveys at Hill Farm and the George C. Davis site (Table 49). 
Eleven of the non-mound circular structures included in this study $(6 \%)$ have extended entrances, while three (30\%) of the non-mound rectangular structures and three $(20 \%)$ of the sub-square structures have extended entrances. In addition, the "maze" (Feature 35) from the George C. Davis site has an extended entrance.

Table 49. Non-mound structures with extended entrances and entrance details.

\begin{tabular}{|l|l|l|l|l|l|l|l|l|}
\hline Site & Structure & \multicolumn{1}{|c|}{ Shape } & Size $(\mathbf{m})$ & $\begin{array}{c}\text { Area } \\
\left(\mathbf{m}^{2}\right)\end{array}$ & Facing & $\begin{array}{c}\text { Length } \\
(\mathbf{m})\end{array}$ & \multicolumn{1}{|c|}{$\begin{array}{c}\text { Width } \\
(\mathbf{m})\end{array}$} & $\begin{array}{c}\text { Trench } \\
(\mathbf{y e s} / \mathbf{n o})\end{array}$ \\
\hline Earspool & 1 & Circular & 4.56 & 16.27 & sw & 3.00 & 0.8 & No \\
\hline George C. Davis & 9 & Sub-square & $9.9 \times 9.9$ & 98.0 & sw & 1.90 & 0.7 & Yes \\
\hline George C. Davis & 35 & Maze & $6.9 \times 9.3$ & 51.5 & $\mathrm{n}$ & 1.50 & $0.50-0.60$ & Yes \\
\hline George C. Davis & 281 & Sub-square & $6.8 \times 6.8$ & 46.24 & s-se & 2.00 & 1.8 & N/A \\
\hline George C. Davis & 314 & Circular & 5.6 & 24.63 & sw & $1.7-3.5$ & 1.2 & N/A \\
\hline George C. Davis & 347 & Sub-square & $4.6 \times 4.8$ & 22.08 & s/w & $1.8 / 4$ & $1.8 / 2$ & N/A \\
\hline George C. Davis & 350 & Circular & 6 & 28.27 & se & 2.20 & 1.5 & N/A \\
\hline Hatchel & 1 & Circular & 7.14 & 40.02 & n-nw & 1.70 & $0.97-1.4$ & No \\
\hline Hill Farm & 5 & Circular & 12 & 113.04 & nw & 5.00 & 2.3 & N/A \\
\hline Hill Farm & 9 & Circular & 10 & 78.5 & se & 3.30 & 1.5 & N/A \\
\hline Hines & 2 & Rectangular & $4.8 \times 3.27$ & 15.70 & w & 3.50 & $0.70-1.26$ & No \\
\hline Hines & 3 & Rectangular & $6.65 \times 5.2$ & 34.58 & w & 3.27 & $0.59-0.92$ & Yes \\
\hline Hurricane Hill & $\mathrm{B}$ & Circular & 7.30 & 41.41 & sw & 1.10 & 1 & Yes \\
\hline Oak Hill Village & 2 & Circular & 6.5 & 33.18 & nw & 2.90 & $59-66$ & Yes \\
\hline Oak Hill Village & 18 & Circular & 8.7 & 59.45 & n & 4.00 & 1 & No \\
\hline Pilgrims Pride & 2 & Circular & $8.5-9$ & & s & x & x & No \\
\hline Roitsch & 3 & Rectangular & $5.6 \times 3.5$ & 19.60 & sw & 1.30 & 1.16 & No \\
\hline Rookery Ridge & 1 & Circular & 5.85 & 26.90 & n-ne & 4.00 & $0.75-1$ & Yes \\
\hline
\end{tabular}

The non-mound extended entrances have lengths ranging from $1.10 \mathrm{~m}$ to approximately $5.0 \mathrm{~m}$, with the longest from Feature 5 at the Hill Farm site. This seemingly long entrance is consistent with the fact that two previously excavated extended entrances extended to $4.0 \mathrm{~m}$ (see Table 49). Entrance width ranges from 0.5 to approximately 2.0 to $2.3 \mathrm{~m}$. The widest previously excavated extended entrance to a structure is the Hatchel Feature 1 entrance which, as Perttula (2005) notes, is not very 
compelling and measures $1.4 \mathrm{~m}$. The extended entrance associated with Roitsch Structure 3 is approximately $1.16 \mathrm{~m}$ wide. Non-mound entrances tend to become narrower as they approach the structure wall with, for example, the Hines Structure 2 and 3 entrances narrowing from $0.92 \mathrm{~m}$ (Structure 2) and $1.26 \mathrm{~m}$ (Structure 3) to $0.59 \mathrm{~m}$ (Structure 2) and $0.70 \mathrm{~m}$ (Structure 3).

In addition to the non-mound structures with extended entrances, at least 15 $(39 \%)$ of the mound structures have extended entrances. Fourteen of the circular mound structures $(37 \%)$ have extended entrances, while one of the four rectangular structures $(25 \%)$ has an extended entrance (Table 50).

Table 50. Mound structures with extended entrances and entrance details.

\begin{tabular}{|l|c|c|c|c|c|c|c|c|}
\hline \multicolumn{1}{|c|}{ Site } & Structure & Shape & Size (m) & $\begin{array}{c}\text { Area } \\
\left(\mathbf{m}^{2}\right)\end{array}$ & Facing & $\begin{array}{c}\text { Length } \\
(\mathbf{m})\end{array}$ & $\begin{array}{c}\text { Width } \\
(\mathbf{m})\end{array}$ & $\begin{array}{c}\text { Trench } \\
(\mathbf{y e s} / \mathbf{n o})\end{array}$ \\
\hline $\begin{array}{l}\text { Bryan } \\
\text { Hardy }\end{array}$ & 1 & circular & 5.48 & 23.59 & ne & 3.7 & 0.75 & Yes \\
\hline Dalton & A & circular & 4.6 & 16.62 & sw & 3.7 & 0.9 & No \\
\hline Dalton & B & circular & 5.5 & 23.76 & sw & 1.7 & 0.9 & No \\
\hline Harroun & 1 & circular & 5.48 & 23.59 & w & 2.4 & 0.8 & No \\
\hline Harroun & 2 & circular & 4.26 & 14.25 & w & 2.4 & 0.8 & No \\
\hline Harroun & 3 & circular & 5.18 & 21.07 & se & 1.5 & 0.9 & No \\
\hline Harroun & 4 & circular & 6.04 & 28.65 & w & 2.4 & 0.91 & No \\
\hline Hatchel & 5 & circular & 3.66 & 10.51 & sw & 1.03 & 1.15 & No \\
\hline Hatchel & 7 & circular & 9.14 & 65.61 & se & 1.85 & 1.3 & No \\
\hline Hatchel & 14 & circular & 8.84 & 61.36 & e & 2.07 & 1.9 & No \\
\hline Hatchel & 15 & circular & 9.75 & 74.72 & se & 1.65 & 1.11 & No \\
\hline Hatchel & 16 & circular & 7.32 & 42.03 & se & 2.61 & 1.06 & No \\
\hline Hatchel & 18 & circular & 8.6 & 58.03 & s & 1.95 & 1.1 & No \\
\hline Holdeman & 1 & rectangular & $3.05 \times 6.10$ & 18.61 & sw & 3.05 & 0.69 & Yes \\
\hline Redwine & 1 & circular & 5.5 & 23.74 & se & 1.2 & x & No \\
\hline
\end{tabular}

The mound-related extended entrances have lengths ranging from $1.03 \mathrm{~m}$ to approximately $3.7 \mathrm{~m}$, with a mean of $2.21 \mathrm{~m}$. Entrance widths range from 0.69 to 
approximately $1.9 \mathrm{~m}$, with a mean width of $1.02 \mathrm{~m}$. Of the 15 extended entrance mound structures, one faces northeast, one faces south, five face southeast, four face southwest, three face to the west, and one faces east.

As discussed in Chapter 3, Hidalgo (Hatcher 1927) and others noted that the Caddo in historic times placed entrances to their houses on the east or west. In the archaeological dataset, only $22 \%$ face either east or west (see Table 50) These data suggest that the direction these structure entrances faced was largely dependent upon other features on the landscape such as the village plaza, earthen mound, or possibly even a mound at another site (Perttula 2009), as well as varying beliefs about the significance of directions in the Caddo cosmos (Kay and Sabo 2006; Perttula 2009). For example, most of the Hatchel structures with extended entrances faced in the general direction of the village, rather than to the west or east.

Construction technique for non-mound entrances varies from single set posts to post trenches. Of the 18 non-mound entrances, $33 \%$ were constructed using post trenches, $33 \%$ were constructed without post trenches and the remainder (identified in the remote sensing) unknown given that they have not been excavated. Mean trench width for nonmound structures with entrance trenches is $1.12 \mathrm{~m}$, while the mean width for the singleset post entrances is $0.81 \mathrm{~m}$. Mean length for the two categories is similar as well, with post trench entrances extending to a mean length of $2.7 \mathrm{~m}$ and single set post entrances extending to a mean length of $2.45 \mathrm{~m}$. In addition, some of the non-mound entrances have special treatment, such as the Feature 9 entrance from the George C. Davis site, where the entrance was "paved with a layer of grayish-white, hard packed clay which measured $2.14 \mathrm{~m}$ long, $0.46 \mathrm{~m}$ to $0.61 \mathrm{~m}$ wide and was raised $0.31 \mathrm{~m}$ above the structure's rim. A second layer, $9 \mathrm{~cm}$ thick, and consisting of compact reddish clay, overlay most of the 
grayish-white clay" (Spock 1977:47). In addition, the Earspool Structure 1 entrance was slightly sloped, indicating that in order to enter the structure one would have walked downward from the ground surface into the structure (Perttula and Sherman 2009).

Construction techniques for the mound-related structure entrances include both single set posts and post trenches, although the former is the dominant construction method. Of the 15 extended entrances, $13 \%$ were constructed using post trenches, and the remaining $87 \%$ were constructed without post trenches. The narrowest entrances are those with entrance trenches. Mean entrance width for mound-related structures with entrance trenches is $0.72 \mathrm{~m}$, while the mean width for the single-set post entrances is 1.07 $\mathrm{m}$, a difference of $0.35 \mathrm{~m}$. Mean length for the different construction technique varied, with mound-related post trench entrances having a mean length of $3.38 \mathrm{~m}$ and single set post entrances having a mean length of $2.04 \mathrm{~m}$. In fact, only one of the mound-related single set post entrances extended to a length greater than $2.7 \mathrm{~m}$, that being the $3.7 \mathrm{~m}$ long Dalton Structure A entrance. The remaining single set post entrances have a mean length of $1.90 \mathrm{~m}$. Perhaps the use of entrance trenches allowed for greater support for longer entrances.

With the exception of structures with extended entrances it is difficult to determine with absolute certainty where a structure entrance is located in most cases. Non-extended entrances could be discerned from gaps in wall patterns or from locations of associated middens or activity areas. As Good (1982) noted at Deshazo, and as is evident in Soule's photo discussed in Chapter 3, non-extended entrances may not always be as easily identifiable as a gap in the structure wall. One of the structures in Soule's photo shows the entrance "raised off the ground, perhaps a foot, with the stepover silled. 
The stepover appears to consist of a row of short supports topped by the sill" (Good 1982:62).

\section{Summary}

Figure 101 shows the distribution of sites with extended entrances. As noted, most of the Caddo structures from eastern Texas either have non-extended entrances or entrances that were not clearly evident when the structure was excavated. Most of the extended entrance structures are from sites north of the Sabine River, with only the George C. Davis site and the Middle Caddo Bryan Hardy, Redwine, and Oak Hill Village sites having extended entrances south of the Sabine. Extended entrances include both single set posts and wall trenches and occur with both mound $(\mathrm{n}=15)$ and non-mound (n $=18)$ structures. The length of extended entrances ranges from $1.03 \mathrm{~m}$ to $5 \mathrm{~m}$ with a mean length of 2.47 and a standard deviation of 0.99 . Entrance width ranges from about $0.6 \mathrm{~m}$ to $2.3 \mathrm{~m}$, with a mean of $1.12 \mathrm{~m}$ and a standard deviation of 0.40 . Orientation varies with most facing southeast $(n=7)$ or southwest $(n=9)$. 


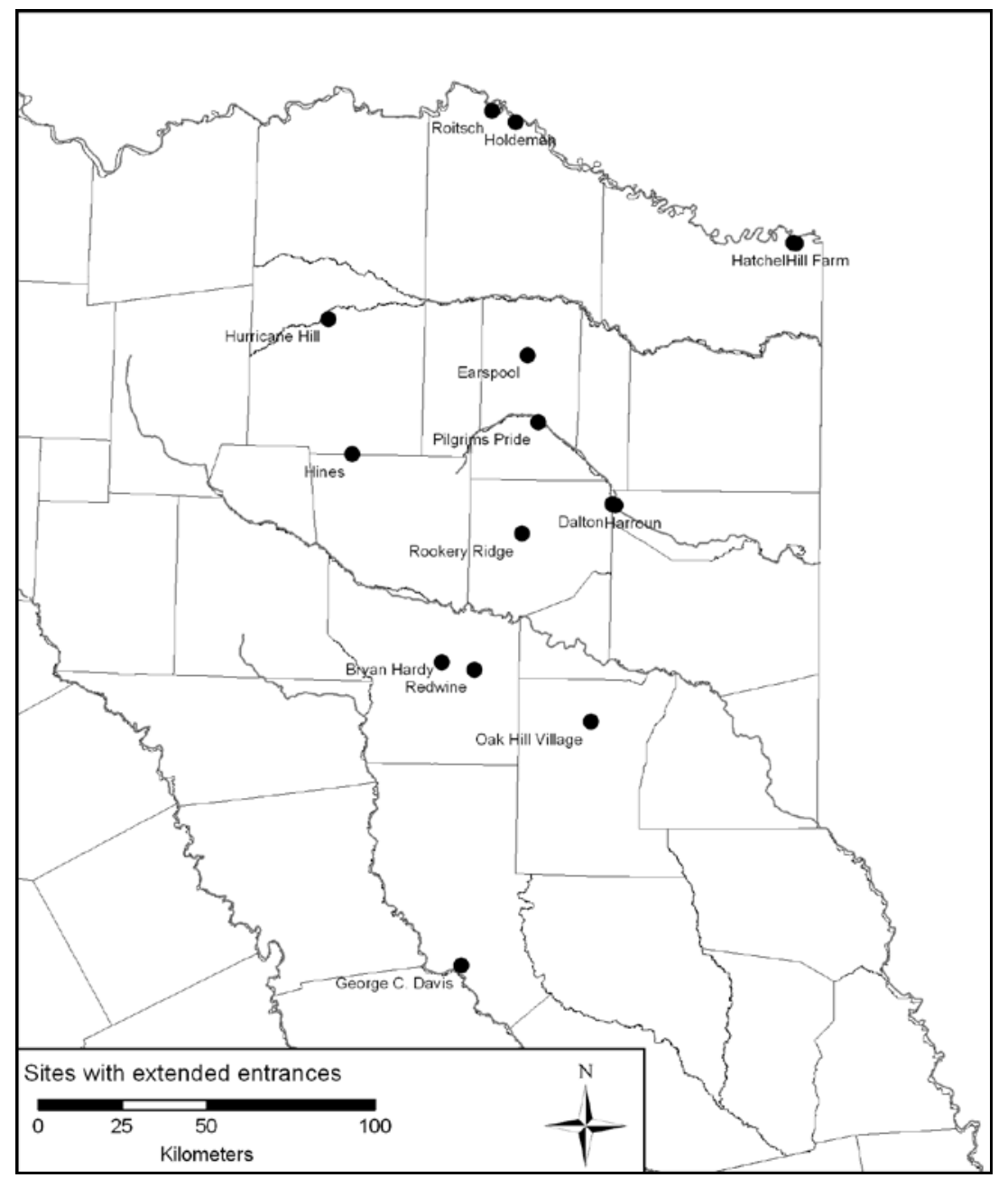

Figure 101: Distribution of sites with extended entrances.

\section{Post hole data}

One-hundred three of the 128 previously excavated non-mound structures were complete enough to allow measuring between wall post holes. In addition, 46 of the 50 mound-related structures were complete enough to allow measuring between wall postholes. Mean exterior wall post spacing for the non-mound structures ranges from $0.17 \mathrm{~m}$ (Feature 9 from the George C. Davis site) to $2.80 \mathrm{~m}$ (Structure 1 from Spider Knoll). However, at Spider Knoll, "the postholes do not form patterns that can be 303 
interpreted unquestionably as representing houses" (Fields et al. 1997:59), and they may actually represent open structures, arbors, or screens. Excluding the Spider Knoll structures, mean wall post hole spacing for the non-mound structures ranges from $0.17 \mathrm{~m}$ (George C. Davis Feature 9) to $1.71 \mathrm{~m}$ (Structure 6 from Deshazo). Also excluding Feature 9 at George C. Davis, one of only two non-mound structures with posts set in wall trenches, the spacing is broadly similar, ranging from $0.22 \mathrm{~m}$ (Structure 2 from Hines) to $1.71 \mathrm{~m}$.

Mean exterior wall post spacing for mound-related structures indicates a tendency for posts to be slightly more closely set. The mean ranges from $0.26 \mathrm{~m}$ (Structure 2 from the Keith site) to $0.90 \mathrm{~m}$ (Structure 1 from Sanders). As discussed above, however, the Sanders structure appears to be a different type than the other mound-related structures, referred to by Jackson (2000) as a lean-to, or an open-air structure, perhaps similar to the Spider Knoll structures described by Fields et al. (1997). The range for mean exterior wall spacing for mound-related structures excluding the Sanders structure is slightly smaller, ranging from approximately $0.26 \mathrm{~m}$ to $0.86 \mathrm{~m}$ (Hatchel Structure 5).

The majority of non-mound wall posts in the dataset tend to be spaced between $0.40 \mathrm{~m}$ and $0.70 \mathrm{~m}$, with $70(68 \%)$ of the 103 structures with these measurements having mean post spacing in this range (Table 51). Twenty-two $(21 \%)$ have mean post spacing greater than $0.70 \mathrm{~m}$ while $11(11 \%)$ have mean post spacing less than 0.40 . Other than one sub round non-mound structure with mean wall post spacing of $0.81 \mathrm{~m}$, the only nonmound structures with exterior post holes with mean spacing greater than $0.70 \mathrm{~cm}$ are the circular structures (Figure 102). Figure 103 provides a scatterplot of the spacing between wall posts plotted with structure area for non-mound structures. 
Post spacing for the majority of mound structures is similar to that for non-mound structures, with the majority of mound structure wall posts spaced between $0.40 \mathrm{~m}$ and $0.60 \mathrm{~m}$, with $30(65 \%)$ of the 46 mound-related structures having mean post spacing in this range (Figure 104). Seven (15\%) have mean post spacing greater than $0.60 \mathrm{~m}$ while nine $(20 \%)$ have mean post spacing less than 0.40 . A higher percentage of mound structures have mean post spacing of less than $0.40 \mathrm{~m}$ compared to a greater percentage of non-mound structures that have mean post spacing that exceeds $0.70 \mathrm{~m}$. Only two of the mound structures in this study have mean post spacing greater than $0.70 \mathrm{~m}$, Hatchel Structure 5 and Sanders Structure 1.

Table 51. Frequency of mean distance between wall posts by structure shape for nonmound structures.

\begin{tabular}{|r|r|r|r|r|}
\hline \multicolumn{5}{|c|}{ Mean Distance Between Wall Posts } \\
\hline \multicolumn{1}{|c|}{ Range } & Circular & Rectangular & \multicolumn{1}{l|}{ Sub-round } & Sub-square \\
\hline $0-0.1$ & 0 & 0 & 0 & 0 \\
\hline $0.11-0.2$ & 0 & 0 & 0 & 1 \\
\hline $0.21-0.3$ & 3 & 1 & 0 & 0 \\
\hline $0.31-0.4$ & 4 & 2 & 0 & 0 \\
\hline $0.41-0.5$ & 18 & 1 & 0 & 0 \\
\hline $0.51-0.6$ & 26 & 2 & 1 & 5 \\
\hline $0.61-0.7$ & 14 & 1 & 1 & 1 \\
\hline $0.71-0.8$ & 4 & 0 & 0 & 0 \\
\hline $0.81-0.9$ & 3 & 0 & 1 & 0 \\
\hline $0.91-1$ & 2 & 0 & 0 & 0 \\
\hline $1.01-1.1$ & 0 & 0 & 0 & 0 \\
\hline $1.11-1.2$ & 1 & 0 & 0 & 0 \\
\hline $1.21-1.3$ & 2 & 0 & 0 & 0 \\
\hline $1.31-1.4$ & 1 & 0 & 0 & 0 \\
\hline $1.41-1.5$ & 3 & 0 & 0 & 0 \\
\hline $1.51-1.6$ & 1 & 0 & 0 & 0 \\
\hline $1.61-1.7$ & 1 & 0 & 0 & 0 \\
\hline $1.71-1.8$ & 1 & 0 & 0 & 0 \\
\hline $1.81-1.9$ & 0 & 0 & 0 & 0 \\
\hline $1.91-2$ & 0 & 0 & 0 & 0 \\
\hline Over 2 & 2 & 0 & 0 & 0 \\
\hline
\end{tabular}




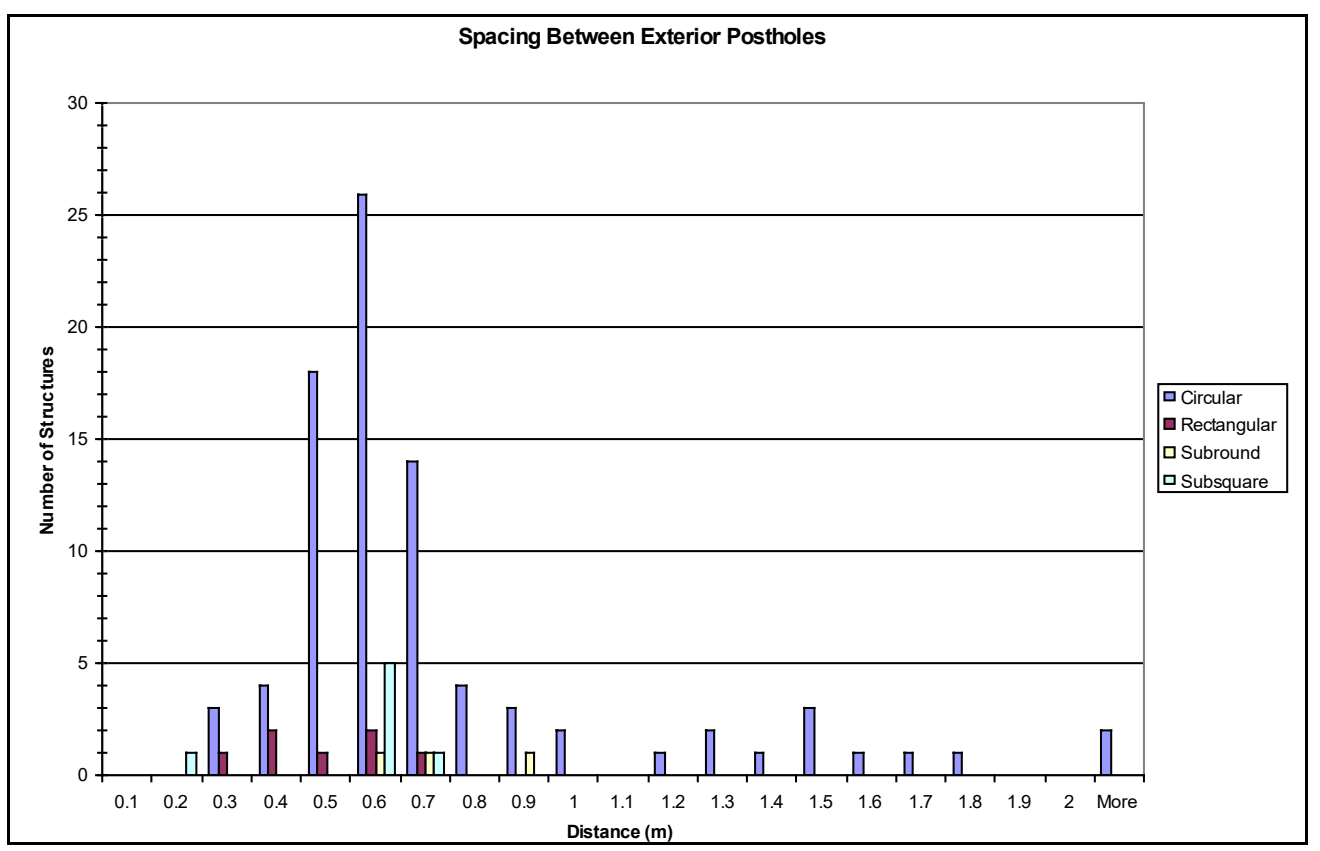

Figure 102. Comparison of spacing between exterior wall post holes by structure shape for non-mound structures.

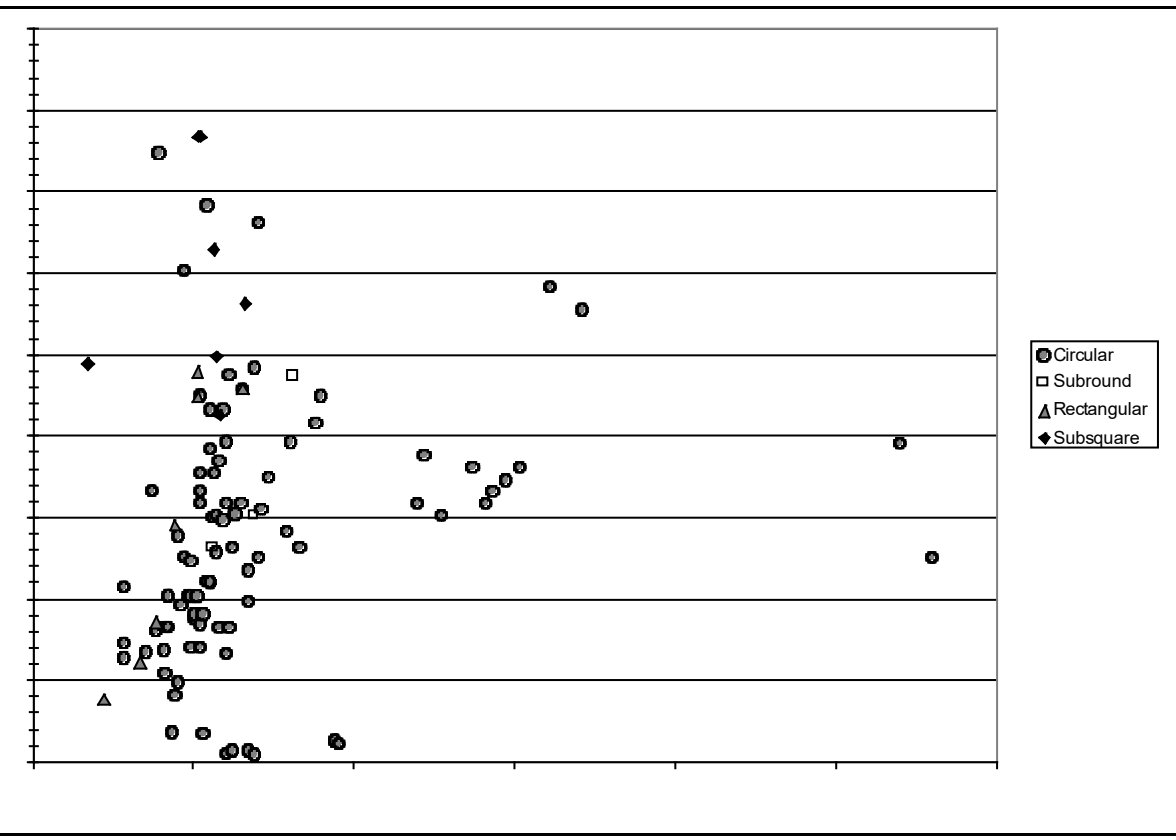

Figure 103. Scatterplot of wall post hole spacing and structure area for non-mound structures. 


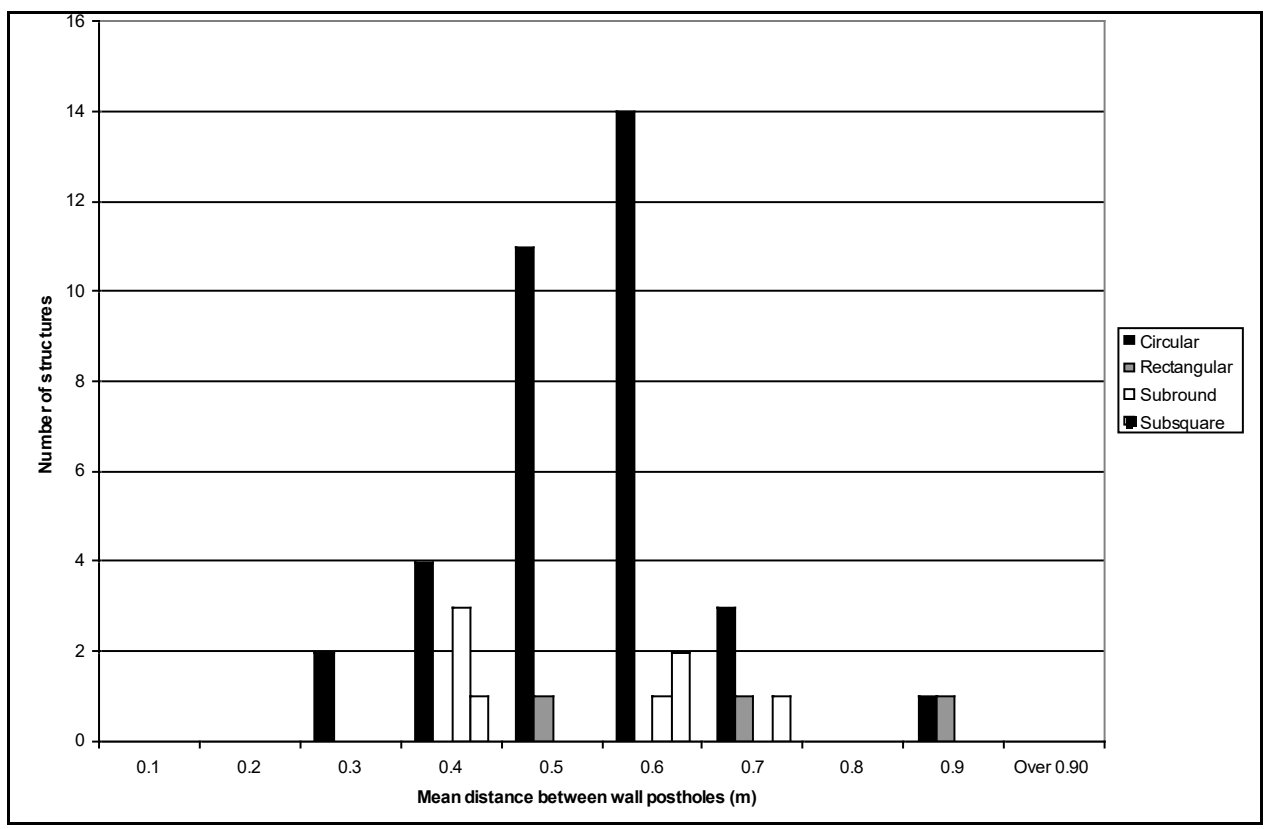

Figure 104. Comparison of spacing between exterior wall post holes by structure shape for mound-related structures.

Mean wall to center post hole spacing for the circular, sub-round, and sub-square non-mound structures ranges from $0.79 \mathrm{~m}$ (Feature 7 from the George C. Davis site) to $8.12 \mathrm{~m}$ (Feature 53 from the George C. Davis site) $(\mathrm{n}=87, \bar{x}=4.25, \mathrm{~s}=1.35)$ (Figure 105). The ratio of average distance between exterior post holes and from the exterior post holes to the center of the structure ranges from 1:1.14 (Feature 7 from the George $\mathrm{C}$. Davis site) to 1:33.12 (Feature 9 from the George C. Davis site) for non-mound structures (Table 52).

For the circular, sub-round, and sub-square mound-related structures, mean wall to center post hole spacing ranges from $1.76 \mathrm{~m}$ (Structure 5 from Hatchel) to $9.19 \mathrm{~m}$ (Feature 111 from the George C. Davis site) $(\mathrm{n}=42, \bar{x}=3.97, \mathrm{~s}=1.58)$ (Figure 106). The ratio of average distance between exterior post holes and from the exterior post holes to the center of the structure ranges from 1:2.05 (Hatchel Structure 5) to 1:18.15 (Feature 45 
from the George C. Davis site) for mound-related structures (Table 53). Figures 107 and 108 are graphical representations of this measurement by structure shape for the nonmound and mound structures. Figures 109 and 110 are scatterplots of post hole spacing plotted with distance from wall posts to structure center. In addition, Figure 111 is a figure of the ratio for all the structures in this study and Figure 112 is a comparison of the ratios for the mound and non-mound structures.

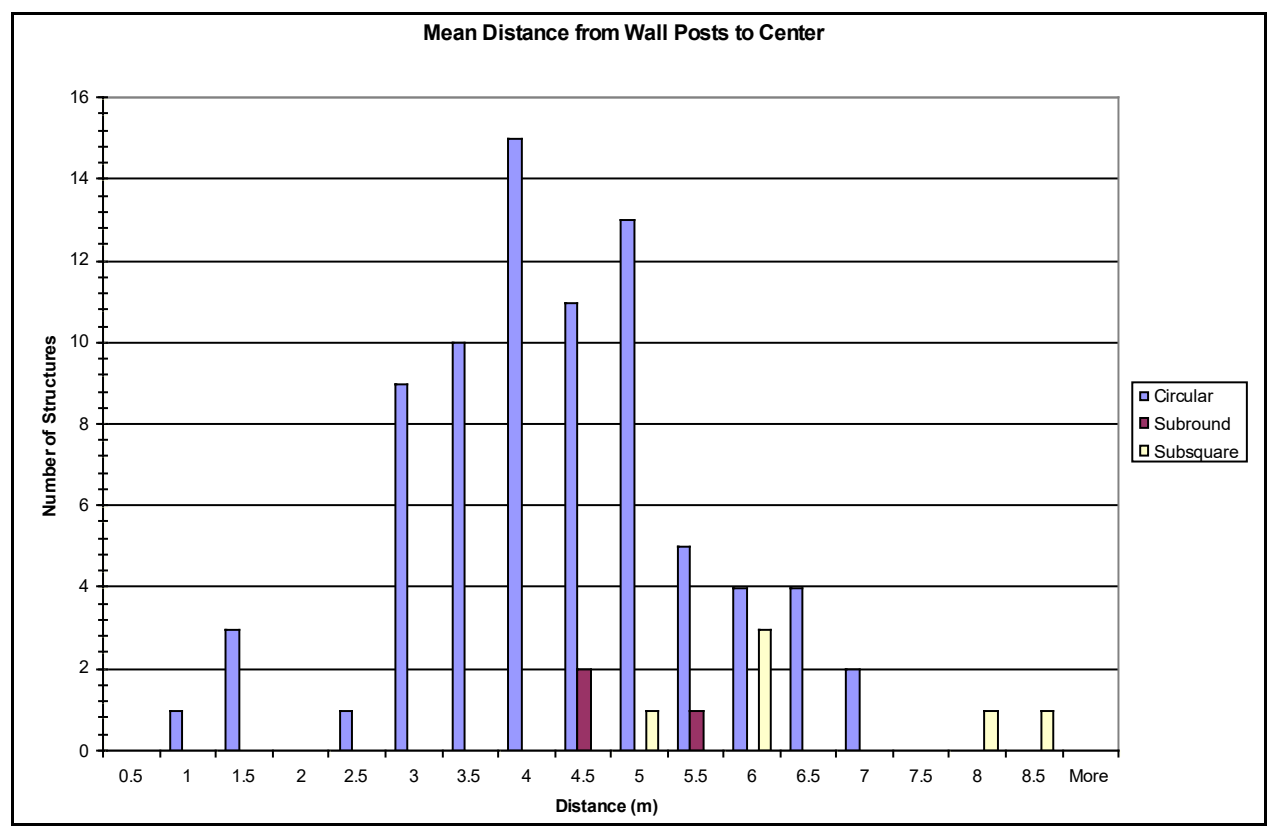

Figure 105. Comparison of mean distance from wall post holes to the center of the structure by structure shape for non-mound structures. 
Table 52. Ratio of the mean distance between wall post holes and from the wall post holes to the structure center for non-mound structures.

\begin{tabular}{|c|c|c|c|c|c|c|c|}
\hline Site & $\underset{\mathscr{D}}{\stackrel{0}{己}}$ & 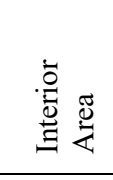 & $\begin{array}{c}\text { Ratio - Mean } \\
\text { Distance between } \\
\text { Wall Post holes and } \\
\text { Mean Distance to } \\
\text { Center }\end{array}$ & $\stackrel{0}{:}$ & $\stackrel{0}{\mathscr{Z}_{0}^{0}}$ & 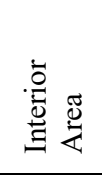 & $\begin{array}{c}\text { Ratio - Mean Distance } \\
\text { between Wall Post } \\
\text { holes and Mean } \\
\text { Distance to Center }\end{array}$ \\
\hline 41AN19 & 3 & 149.50 & 16.67 & 41NA27 & 7 & 63.62 & 3.80 \\
\hline 41AN38 & 1 & 36.32 & 6.60 & 41RK19 & 1 & 28.27 & 5.70 \\
\hline 41CE19 & 7 & 1.80 & 1.14 & 41RK214 & 41 & 52.81 & 4.40 \\
\hline 41CE19 & 52 & 2.80 & 1.55 & 41RK214 & 1 & 50.27 & 5.40 \\
\hline 41CE19 & 50 & 2.80 & 1.81 & 41RK214 & 13 & 56.75 & 5.40 \\
\hline 41CE19 & 33 & 89.90 & 6.23 & 41RK214 & 26 & 39.59 & 5.40 \\
\hline 41CE19 & 47 & 40.70 & 7.41 & 41RK214 & 17 & 33.18 & 5.50 \\
\hline 41CE19 & 19 & 40.70 & 7.69 & 41RK214 & 40 & 35.26 & 5.50 \\
\hline 41CE19 & 10 & 33.20 & 7.83 & 41RK214 & 36 & 83.32 & 5.60 \\
\hline 41CE19 & 41 & 60.80 & 7.93 & 41RK214 & 29 & 47.17 & 5.70 \\
\hline 41CE19 & 8 & 33.20 & 7.95 & 41RK214 & 6 & 21.65 & 6.10 \\
\hline 41CE19 & 55 & 96.80 & 8.01 & 41RK214 & 21 & 36.32 & 6.45 \\
\hline 41CE19 & 14 & 73.90 & 8.40 & 41RK214 & 31 & 70.88 & 6.50 \\
\hline 41CE19 & 12 & 50.30 & 8.55 & 41RK214 & 32 & 78.54 & 6.50 \\
\hline 41CE19 & 18 & 55.40 & 8.80 & 41RK214 & 20 & 33.18 & 6.60 \\
\hline 41CE19 & 11 & 70.90 & 9.02 & 41RK214 & 28 & 70.14 & 6.60 \\
\hline 41CE19 & 15 & 77.00 & 9.04 & 41RK214 & 42 & 40.72 & 6.80 \\
\hline 41CE19 & 51 & 132.70 & 9.50 & 41RK214 & 12 & 60.82 & 6.90 \\
\hline 41CE19 & 16 & 86.60 & 9.60 & 41RK214 & 14 & 44.18 & 6.90 \\
\hline 41CE19 & 17 & 25.50 & 10.11 & 41RK214 & 19 & 28.27 & 6.90 \\
\hline 41CE19 & 13 & 89.90 & 10.40 & 41RK214 & 7 & 51.53 & 7.02 \\
\hline 41CE19 & 30 & 29.20 & 10.57 & 41RK214 & 3 & 27.34 & 7.10 \\
\hline 41CE19 & 146 & 91.60 & 10.75 & 41RK214 & 30 & 63.62 & 7.40 \\
\hline 41CE19 & 49 & 136.80 & 11.35 & 41RK214 & 34 & 63.62 & 7.40 \\
\hline 41CE19 & 160 & 120.80 & 13.19 & 41RK214 & 18 & 59.45 & 7.50 \\
\hline 41CE19 & 125 & 43.00 & 13.96 & 41RK214 & 8 & 32.17 & 8.10 \\
\hline 41CP304 & 1 & 38.48 & 7.40 & 41RK214 & 35 & 78.54 & 8.50 \\
\hline 41FK107 & 1 & 60.79 & 3.40 & 41RK214 & 9 & 63.62 & 8.90 \\
\hline 41MR2 & 1 & 7.16 & 3.40 & 41RK214 & 33 & 95.03 & 9.10 \\
\hline 41MR2 & 2 & 49.39 & 8.40 & 41RK214 & 2 & 33.18 & 11.57 \\
\hline 41NA27 & 2 & 69.40 & 3.10 & 41TT653 & 3 & 26.57 & 4.90 \\
\hline 41NA27 & 5 & 72.38 & 3.20 & 41TT653 & 1 & 16.27 & 5.20 \\
\hline 41NA27 & 8 & 66.48 & 3.20 & 41TT653 & 2 & 33.83 & 6.40 \\
\hline 41NA27 & 9 & 63.59 & 3.20 & 41TT653 & 4 & 44.40 & 6.90 \\
\hline 41NA27 & 6 & 111.22 & 3.50 & 41UR133 & 2 & 60.10 & 7.00 \\
\hline 41NA27 & 4 & 72.38 & 3.60 & 41UR133 & 1 & 26.90 & 7.20 \\
\hline 41NA27 & 1 & 116.90 & 3.80 & 41WD109 & 1 & 86.55 & 8.90 \\
\hline 41NA27 & 3 & 75.43 & 3.80 & 41WD87 & 1 & 52.81 & 6.80 \\
\hline
\end{tabular}




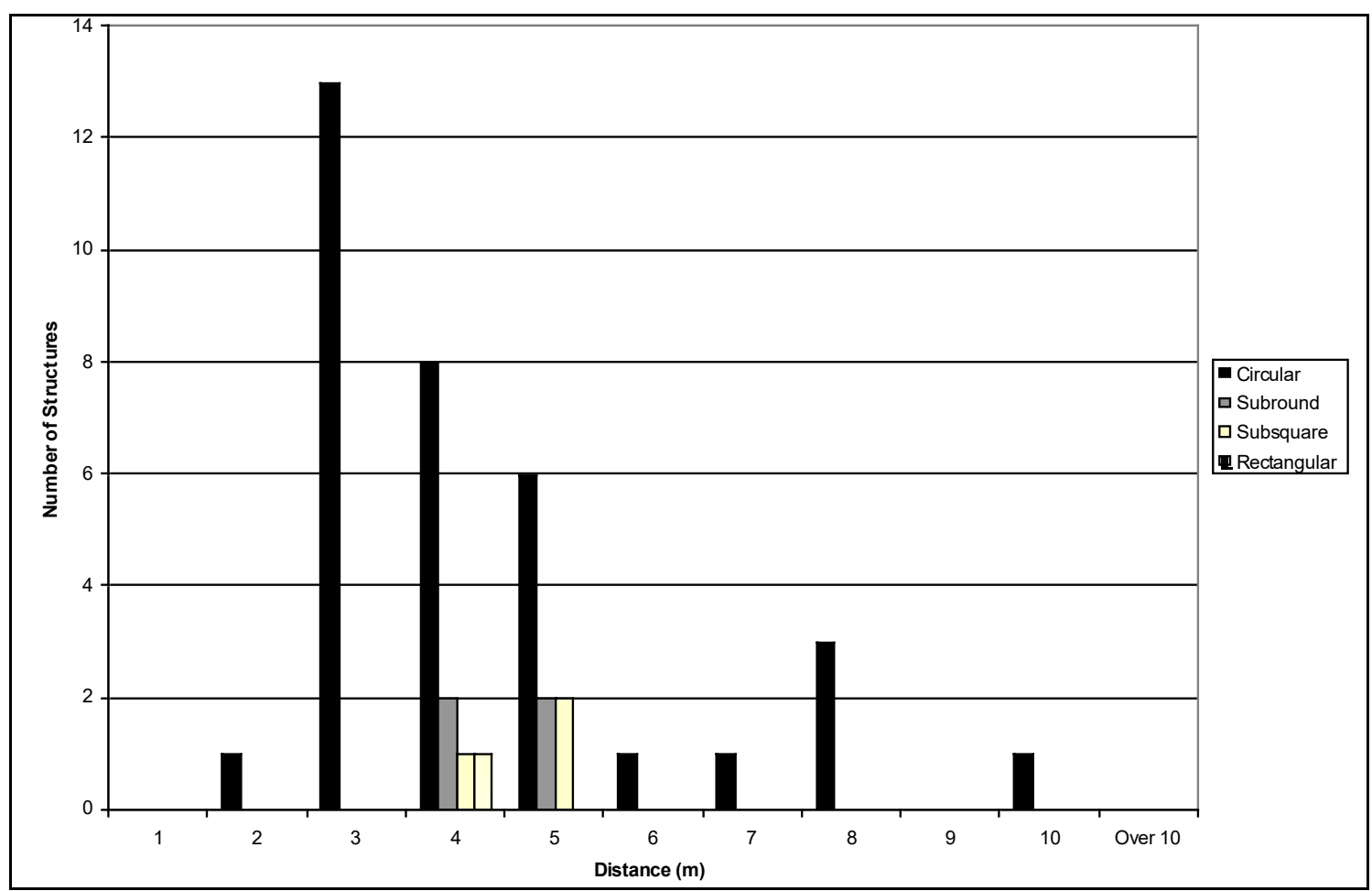

Figure 106. Comparison of mean distance from wall post holes to center of structure by structure shape for mound-related structures.

Table 53. Ratio of the mean distance between wall post holes and from the wall post holes to the structure center for mound-related structures. $\mathrm{c}=$ circular; $\mathrm{ss}=$ sub-square; $\mathrm{sr}=$ sub-round; $\mathrm{r}=$ rectangular.

\begin{tabular}{|l|c|c|c|c|}
\hline & & & & \\
Site & Structure & Shape & Area & Ratio \\
\hline Bryan Hardy & 1 & c & 23.59 & $1: 9.89$ \\
\hline George C. Davis & 31 & c & 174.4 & $1: 12.47$ \\
\hline George C. Davis & 34 & ss & 58.1 & $1: 7.36$ \\
\hline George C. Davis & 36 & sr & 41.2 & $1: 6.76$ \\
\hline George C. Davis & 37 & sr & 61.5 & $1: 14.22$ \\
\hline George C. Davis & 38 & sr & 36.3 & $1: 10.71$ \\
\hline George C. Davis & 39 & ss & 66.3 & $1: 7.62$ \\
\hline George C. Davis & 40 & ss & 44.1 & $1: 6.31$ \\
\hline George C. Davis & 42 & c & 109.4 & $1: 10.38$ \\
\hline George C. Davis & 43 & sr & 44.2 & $1: 13.43$ \\
\hline George C. Davis & 44 & c & 65 & $1: 11.5$ \\
\hline
\end{tabular}

\begin{tabular}{|l|c|c|c|c|} 
& & & & \\
Site & Structure & Shape & Area & Ratio \\
\hline Hatchel & 5 & c & 10.51 & $1: 2.05$ \\
\hline Hatchel & 7 & c & 65.61 & $1: 6.56$ \\
\hline Hatchel & 12 & c & 61.79 & $1: 8.65$ \\
\hline Hatchel & 13 & c & 64.47 & $1: 10.46$ \\
\hline Hatchel & 14 & c & 61.36 & $1: 6.86$ \\
\hline Hatchel & 15 & c & 74.72 & $1: 9.69$ \\
\hline Hatchel & 16 & c & 42.03 & $1: 7.48$ \\
\hline Hatchel & 17 & c & 32.18 & $1: 6.02$ \\
\hline Hatchel & 18 & c & 58.03 & $1: 9.19$ \\
\hline Hatchel & 25 & c & 176.2 & $1: 13.67$ \\
\hline Hatchel & 22 inner & c & 57.15 & $1: 7.15$ \\
\hline
\end{tabular}




\begin{tabular}{|c|c|c|c|c|c|c|c|c|c|}
\hline George C. Davis & 45 & $\mathrm{c}$ & 151.7 & $1: 18.15$ & Hatchel & 22outer & $\mathrm{c}$ & 82.03 & $1: 9.31$ \\
\hline George C. Davis & 111 & $\mathrm{c}$ & 254.5 & $1: 14.59$ & Redwine & 1 & $\mathrm{c}$ & 23.74 & $1: 6.4$ \\
\hline George C. Davis & $45 \mathrm{a}$ & $\mathrm{c}$ & 16.98 & $1: 4.85$ & Roitsch & 2 & $\mathrm{r}$ & 42.75 & $1: 7.56$ \\
\hline Harroun & 1 & $\mathrm{c}$ & 23.59 & $1: 5.79$ & Whelan & A & $\mathrm{c}$ & 21.07 & $1: 6.44$ \\
\hline Harroun & 2 & $\mathrm{c}$ & 14.25 & $1: 4.33$ & Whelan & $\mathrm{B}$ & $\mathrm{c}$ & 26.33 & $1: 7.13$ \\
\hline Harroun & 3 & $\mathrm{c}$ & 21.07 & $1: 4.69$ & Whelan & $\mathrm{C}$ & $\mathrm{c}$ & 27.34 & $1: 6.19$ \\
\hline Harroun & 4 & $\mathrm{c}$ & 28.65 & $1: 4.91$ & Whelan & $\mathrm{D}$ & $\mathrm{c}$ & 31.17 & $1: 7.93$ \\
\hline Oak Hill Village & 4 & $\mathrm{c}$ & 44.18 & $1: 8.72$ & Dalton & $\mathrm{A}$ & $\mathrm{c}$ & 16.62 & 1:6.08 \\
\hline Oak Hill Village & 24 & $\mathrm{c}$ & 46.57 & $1: 6.29$ & Dalton & $\mathrm{B}$ & $\mathrm{c}$ & 23.76 & $1: 5.31$ \\
\hline Oak Hill Village & 25 & $\mathrm{c}$ & 47.78 & $1: 7.24$ & & & & & \\
\hline
\end{tabular}

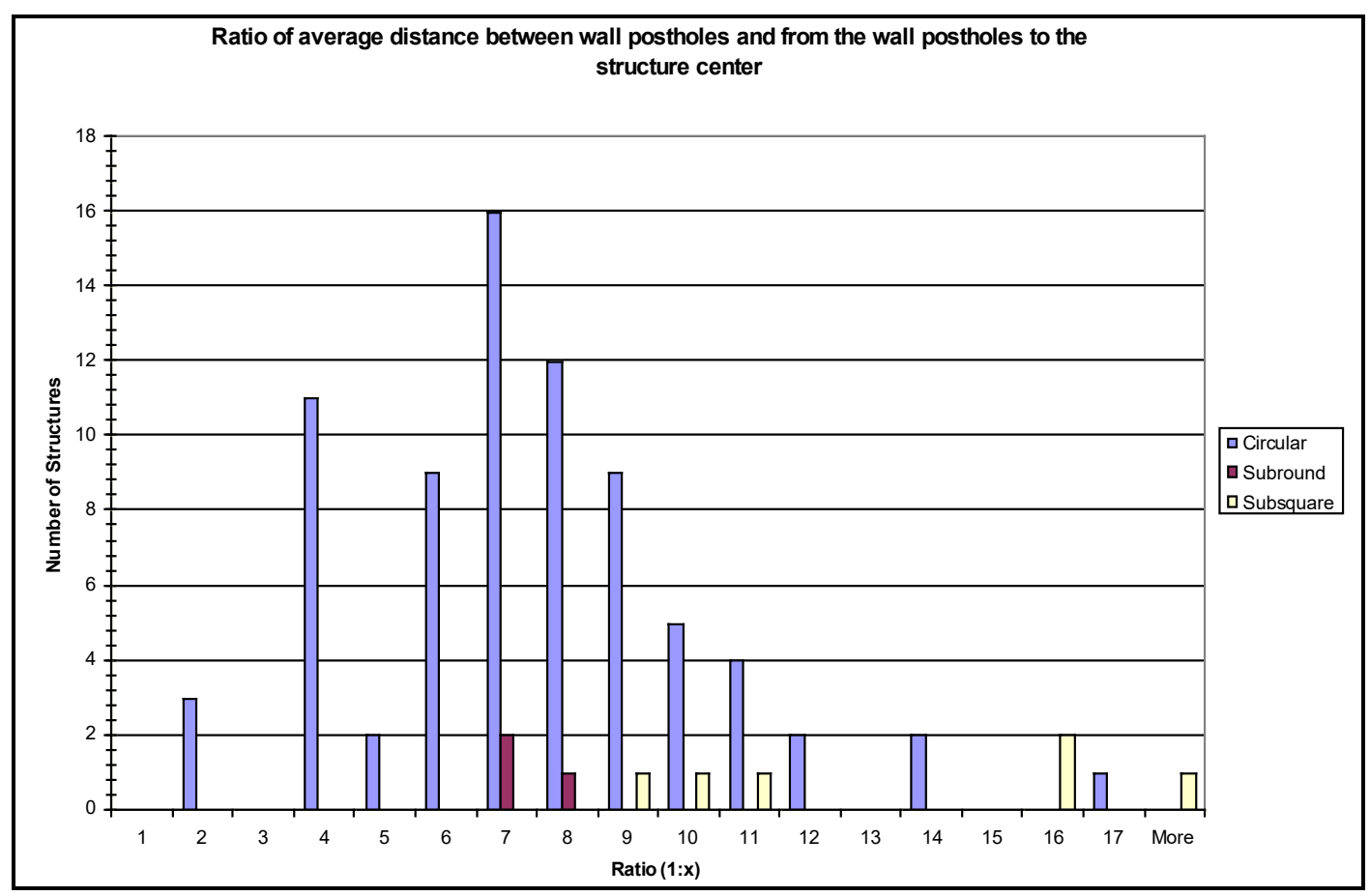

Figure 107. Ratio of average distance between wall post holes and from wall post holes to center of structure by structure shape for non-mound structures. 


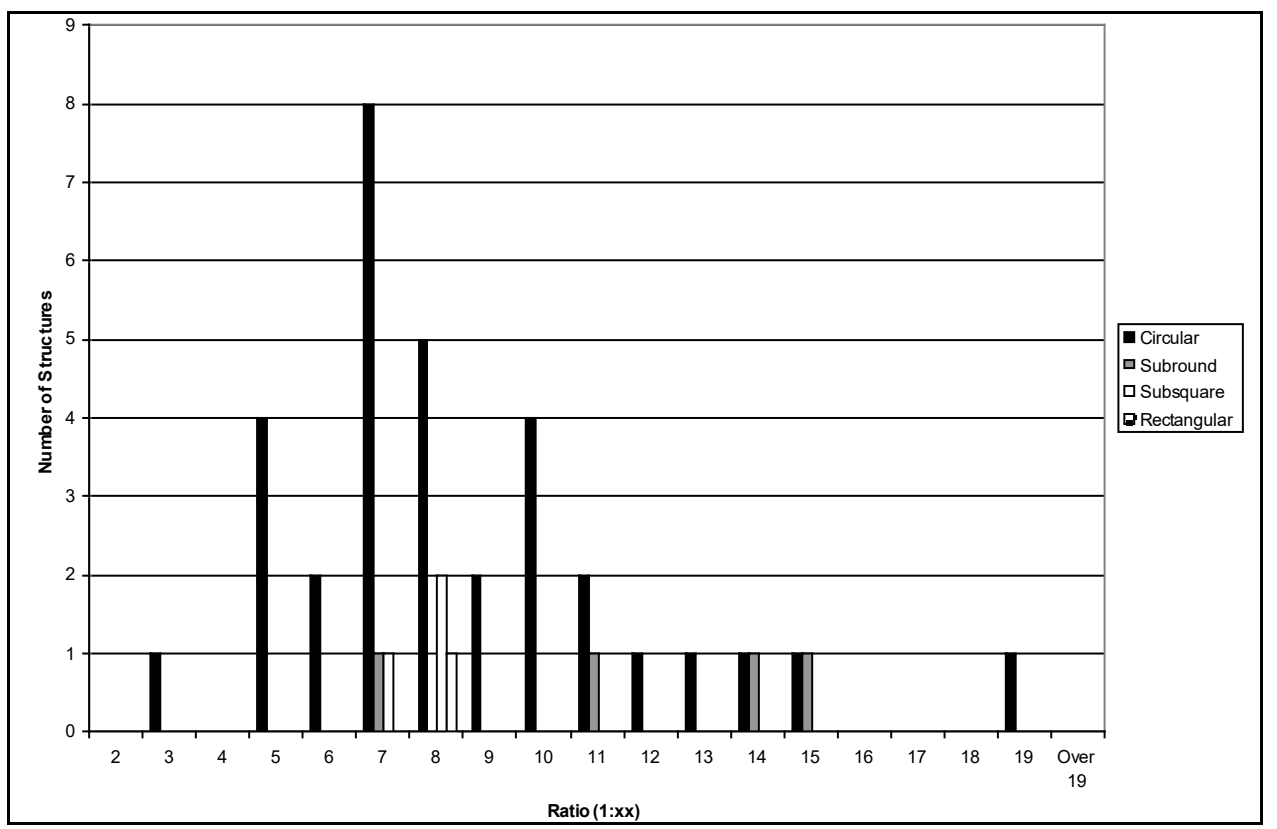

Figure 108. Ratio of average distance between wall post holes and from wall post holes to center of structure by structure shape for mound-related structures.

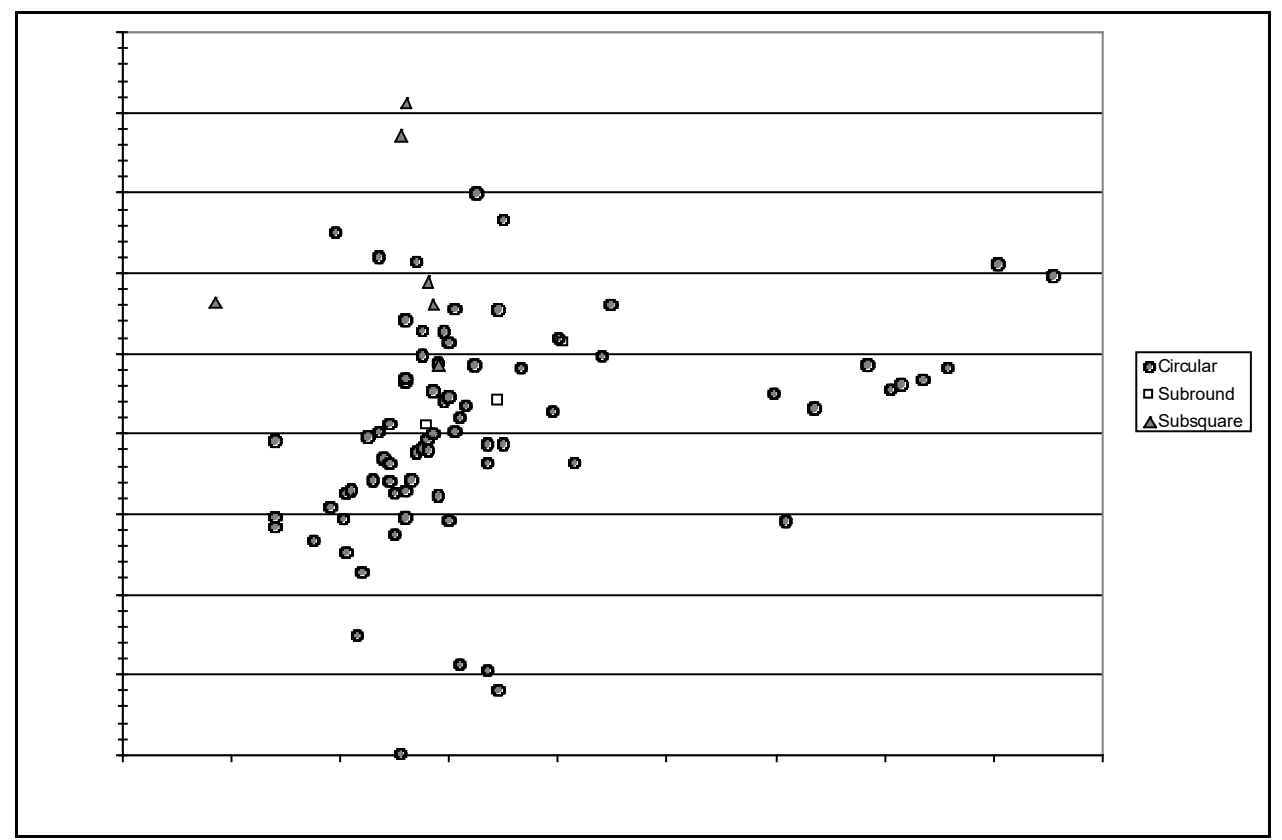

Figure 109. Scatterplot of wall post hole spacing and distance from wall to center of structure for non-mound structures. 


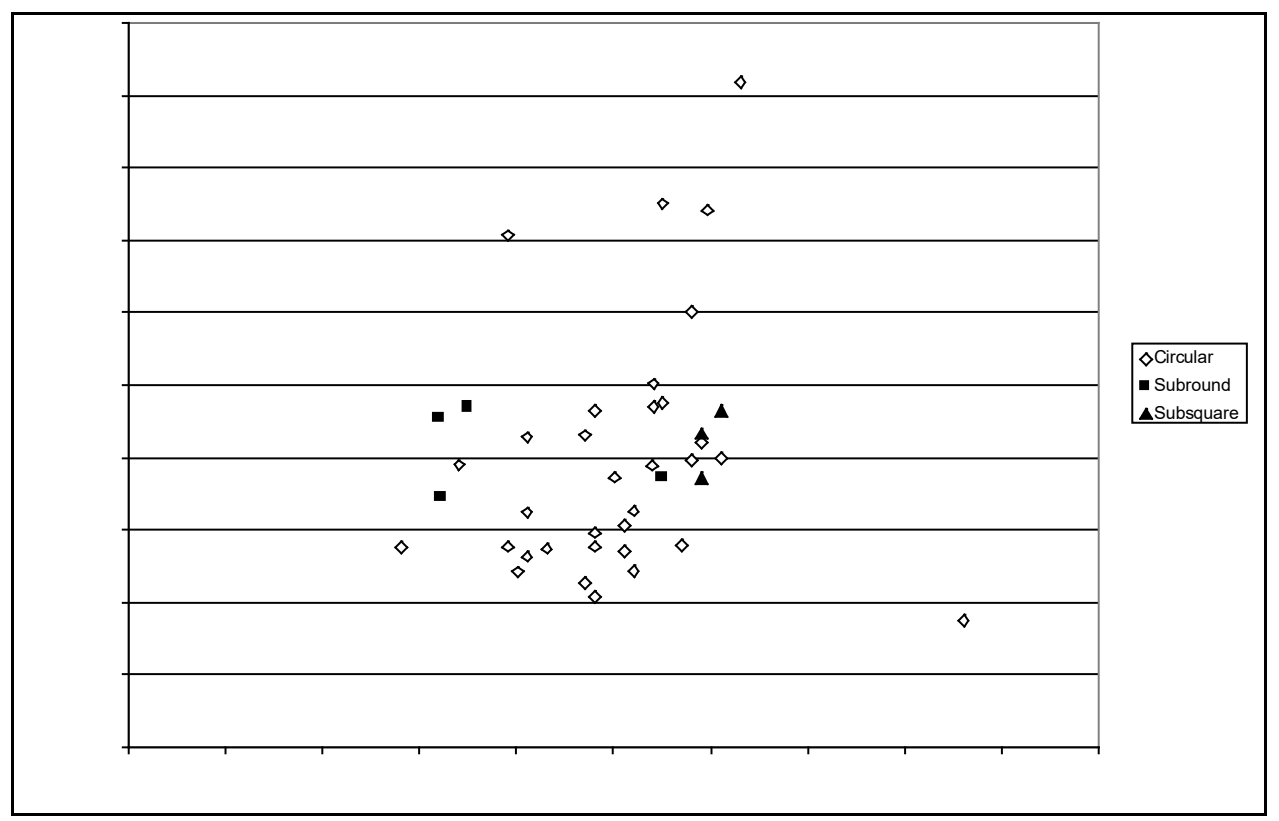

Figure 110. Scatterplot of wall post hole spacing and distance from wall to center of structure for mound-related structures.

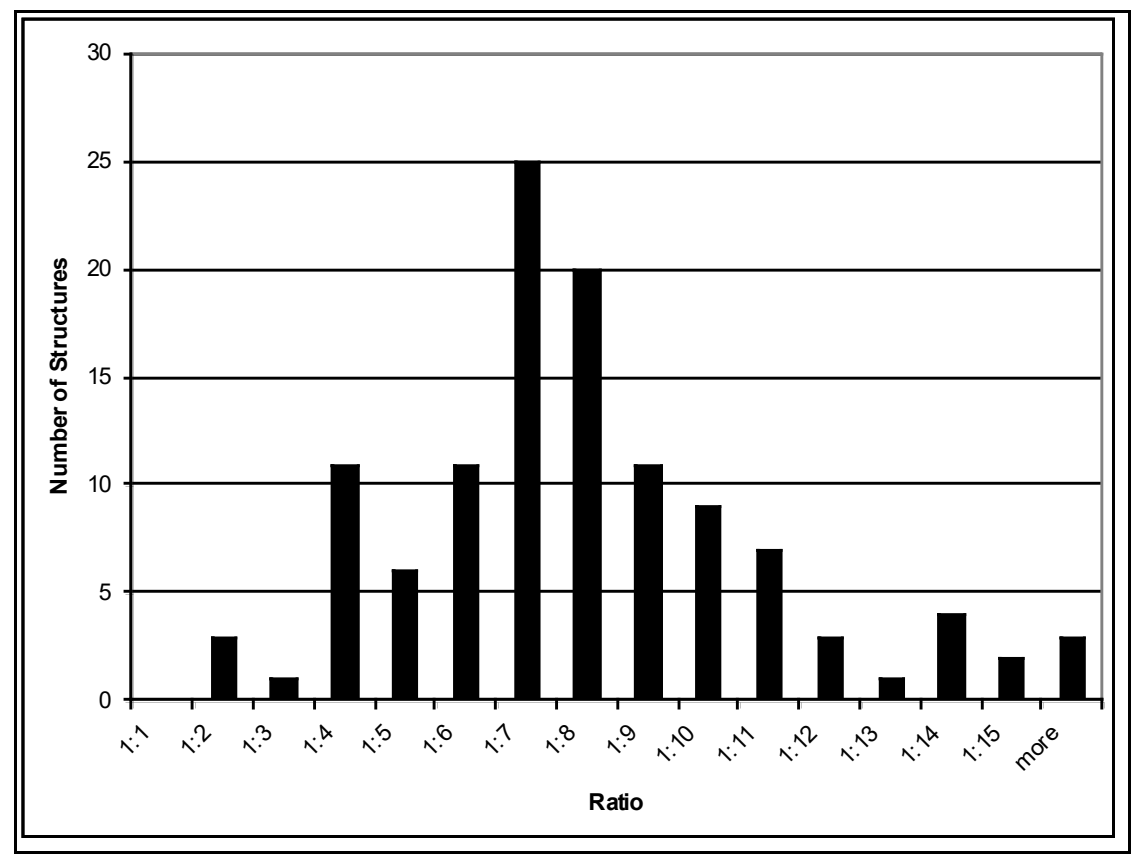

Figure 111. The ratio of average distance between exterior post holes and from the exterior post holes to the center of the structure for structures in this study. 


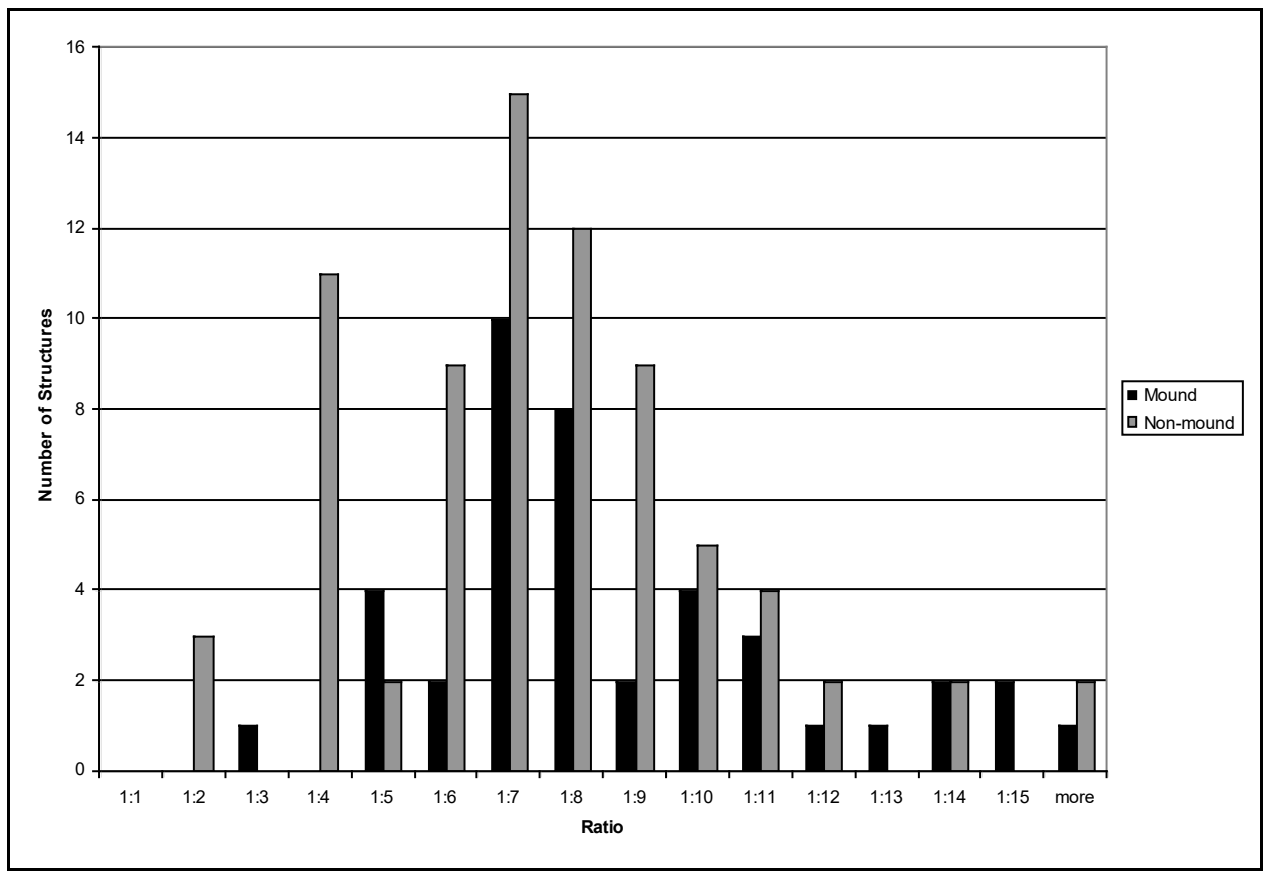

Figure 112. The ratio of average distance between exterior post holes and from the exterior post holes to the center of the structure - comparing mound and non-mound structures in this study.

Mean wall post hole diameter for the non-mound structures in this study ranges from $0.12 \mathrm{~m}$ to $0.35 \mathrm{~m}(\mathrm{n}=72$ structures, $\overline{\mathrm{x}}=0.19, \mathrm{~s}=0.0476)$. Mean wall post hole depth for non-mound structures ranges from $0.11 \mathrm{~m}$ to $0.98 \mathrm{~m}$ deep $(\mathrm{n}=60, \overline{\mathrm{x}}=0.36, \mathrm{~s}=$ 0.1640). As Figure 113 shows, the majority, 67\% of the non-mound structures have wall post holes with a mean diameter ranging from $0.15 \mathrm{~m}$ to $0.20 \mathrm{~m}$, with $65 \%$ having ranges from 0.17 to $0.20 \mathrm{~m}$. This is consistent with what has been suggested as the typical post hole diameter range for domestic Caddo structures from Northeast Texas (Perttula 2008). In addition, $78 \%$ of the non-mound structures have mean wall post hole depths ranging from $0.15 \mathrm{~m}$ to $0.50 \mathrm{~m}$, with $57 \%$ having ranges from $0.30 \mathrm{~m}$ to $0.50 \mathrm{~m}$ deep. Figure 114 depicts mean wall post hole diameter by structure shape. In addition, Figures 115 and 116 
provide scatterplots showing the relationship of post hole diameter and depth to mean wall post hole spacing.

Mean wall post hole diameter for the mound-related structures ranges from 0.11 $\mathrm{m}$ to $0.32 \mathrm{~m}(\mathrm{n}=43$ structures, $\bar{x}=0.17, \mathrm{~s}=0.0435)$. The majority $(64 \%)$ have wall post holes with a mean diameter ranging from $0.15 \mathrm{~m}$ to $0.18 \mathrm{~m}$ (Figure 117). Mean wall post hole depth for the mound structures ranges from $0.13 \mathrm{~m}$ to $0.85 \mathrm{~m}$ deep $(\mathrm{n}=32, \bar{x}=0.48$, $\mathrm{s}=0.2517$ ), a slightly smaller range, but a greater mean depth than non-mound structures. Mean wall post hole depth varies, with half having mean depths of $0.50 \mathrm{~m}$ or less, and half having mean depths over $0.50 \mathrm{~m}$ (Figure 118). In addition, Figures 119 and 120 provide scatter plots showing the relationship of post hole diameter and depth to mean wall post hole spacing.

The vast majority (88\%) of mound-related structures with mean post hole diameter available ( $n=43$ structures), have wall post hole diameters averaging less than $20 \mathrm{~cm}$ and can be considered small pole buildings (Lacquement 2007:55). The remaining five have mean post hole diameters of $20 \mathrm{~cm}$ or greater and can be considered large post buildings (Lacquement 2007:55). Mean post hole diameter was available for 64 of the non-mound structures, and $72 \%$ could be considered small pole buildings while the remainder are large post buildings. 


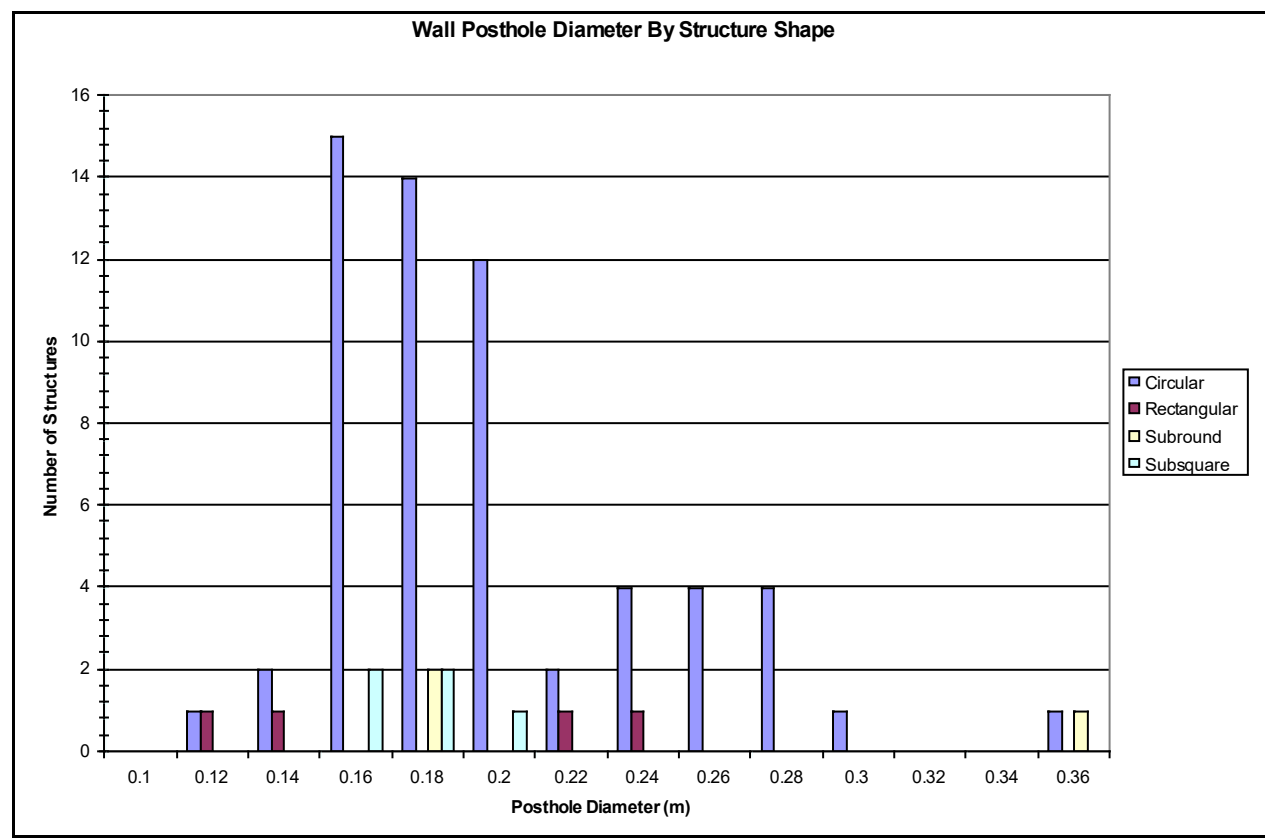

Figure 113. Mean wall post hole diameter by structure shape for non-mound structures.

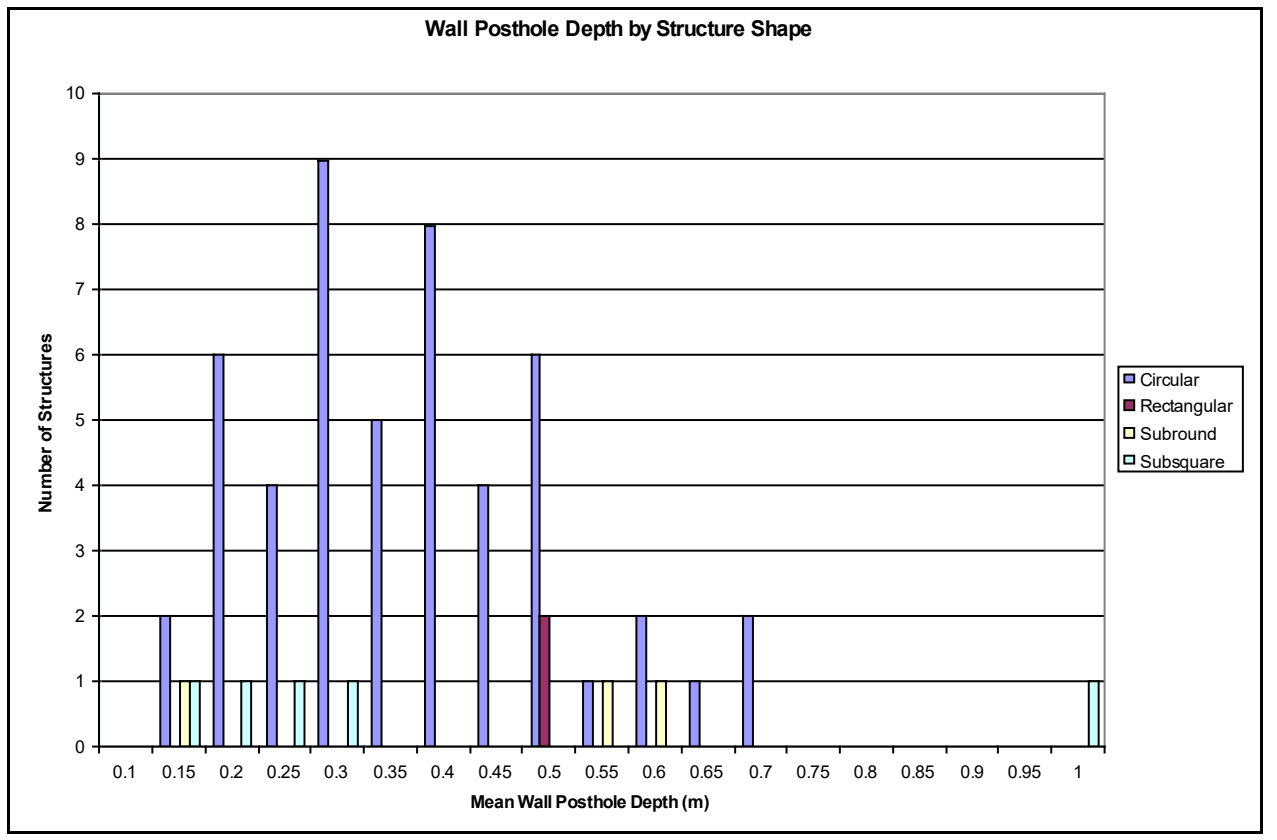

Figure 114. Mean wall post hole depth by structure shape for non-mound structures. 


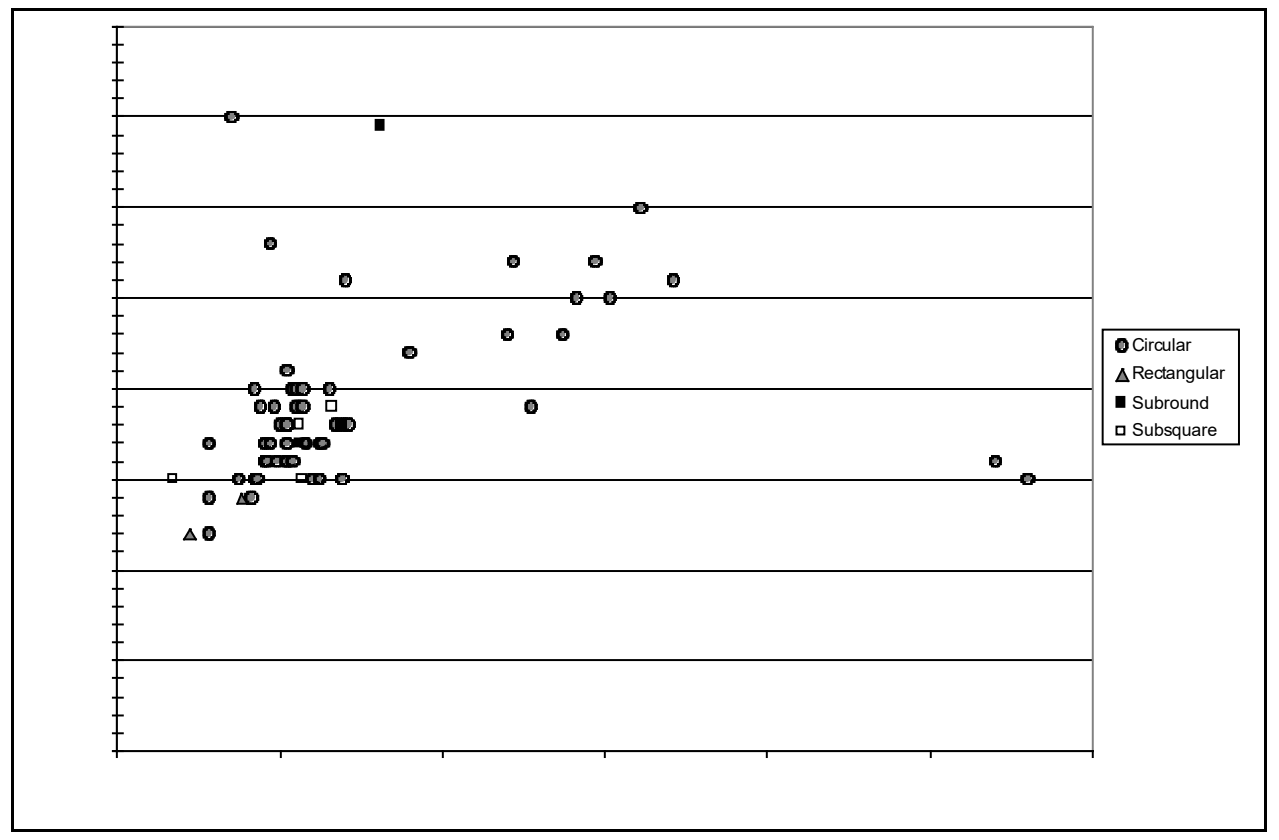

Figure 115. Scatterplot of wall post hole spacing and mean wall post hole diameter for non-mound structures.

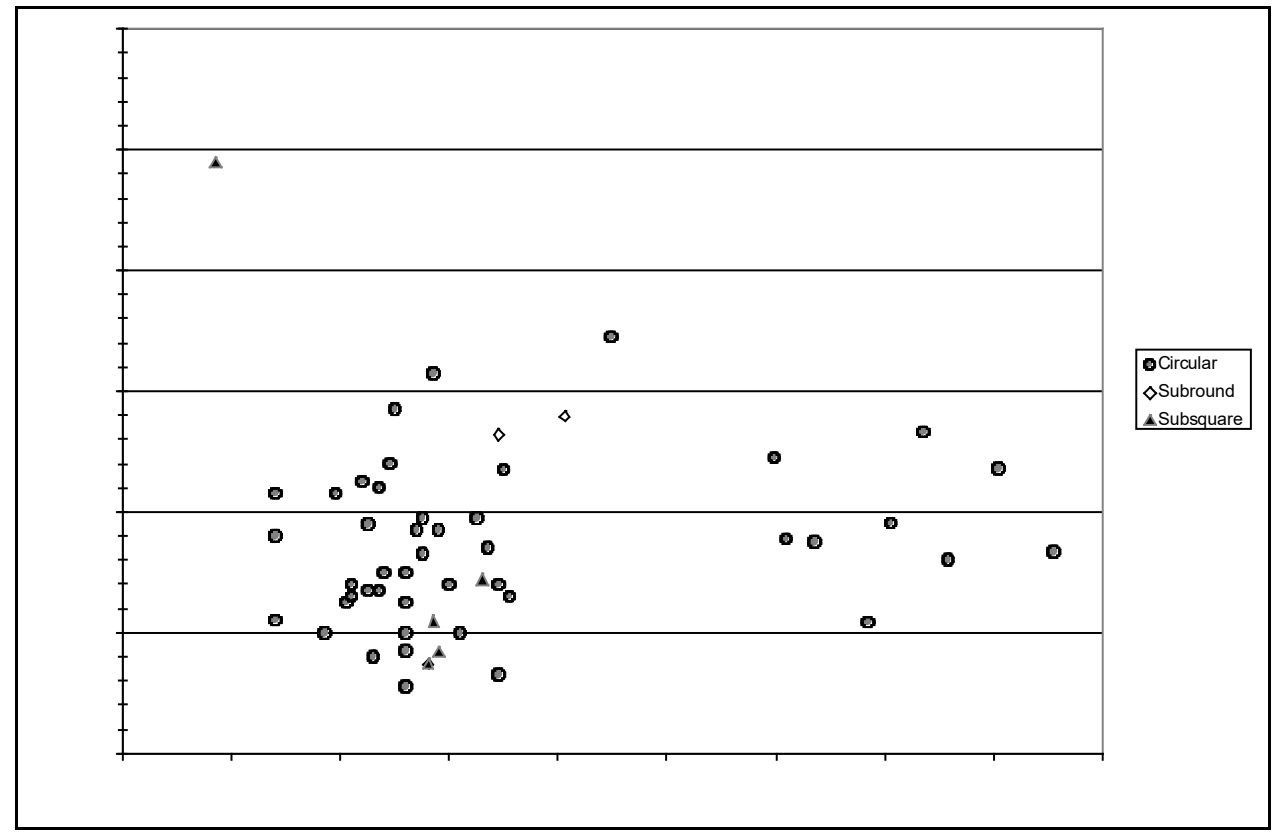

Figure 116. Scatterplot of wall post hole spacing and mean wall post hole depth for nonmound structures. 


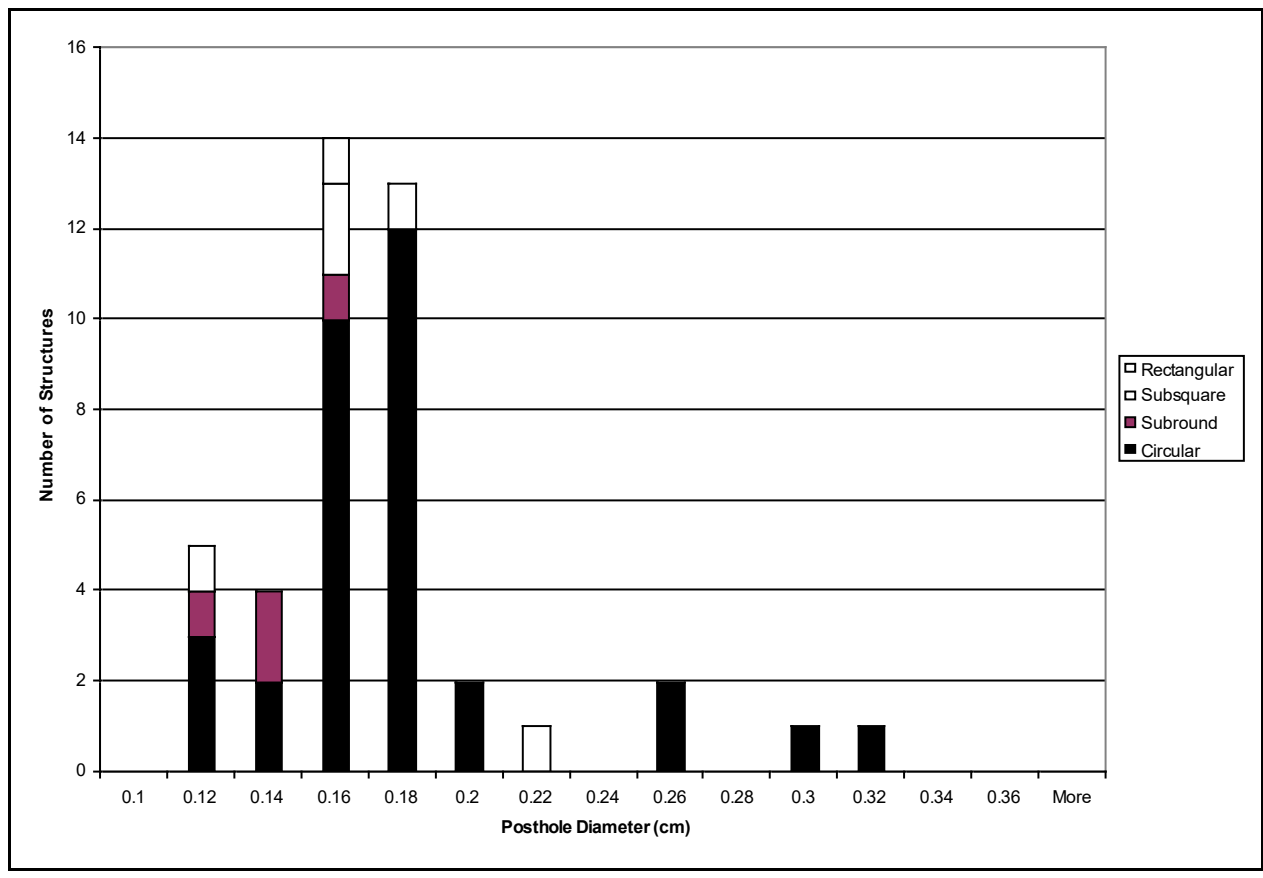

Figure 117. Mean wall post hole diameter by structure shape for mound-related structures.

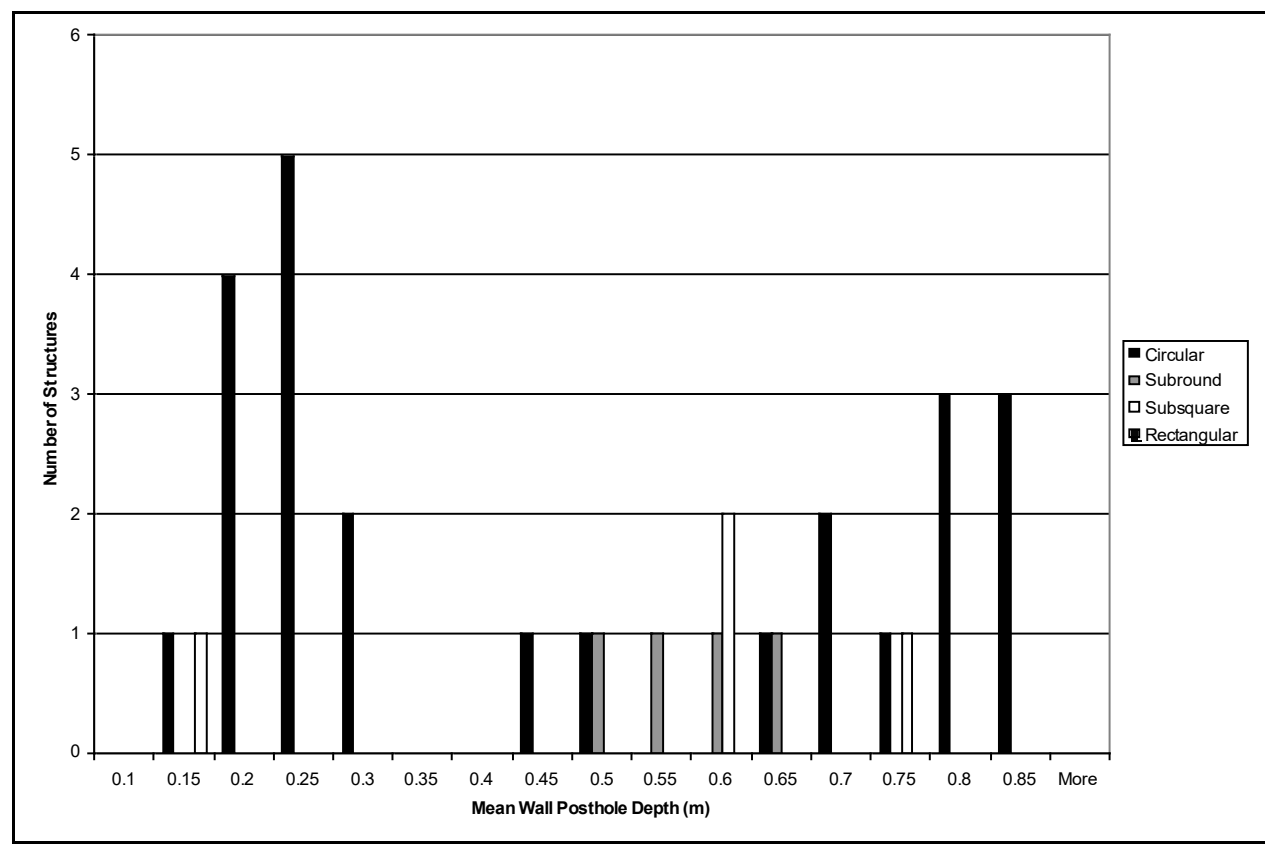

Figure 118. Mean wall post hole depth by structure shape for mound-related structures. 


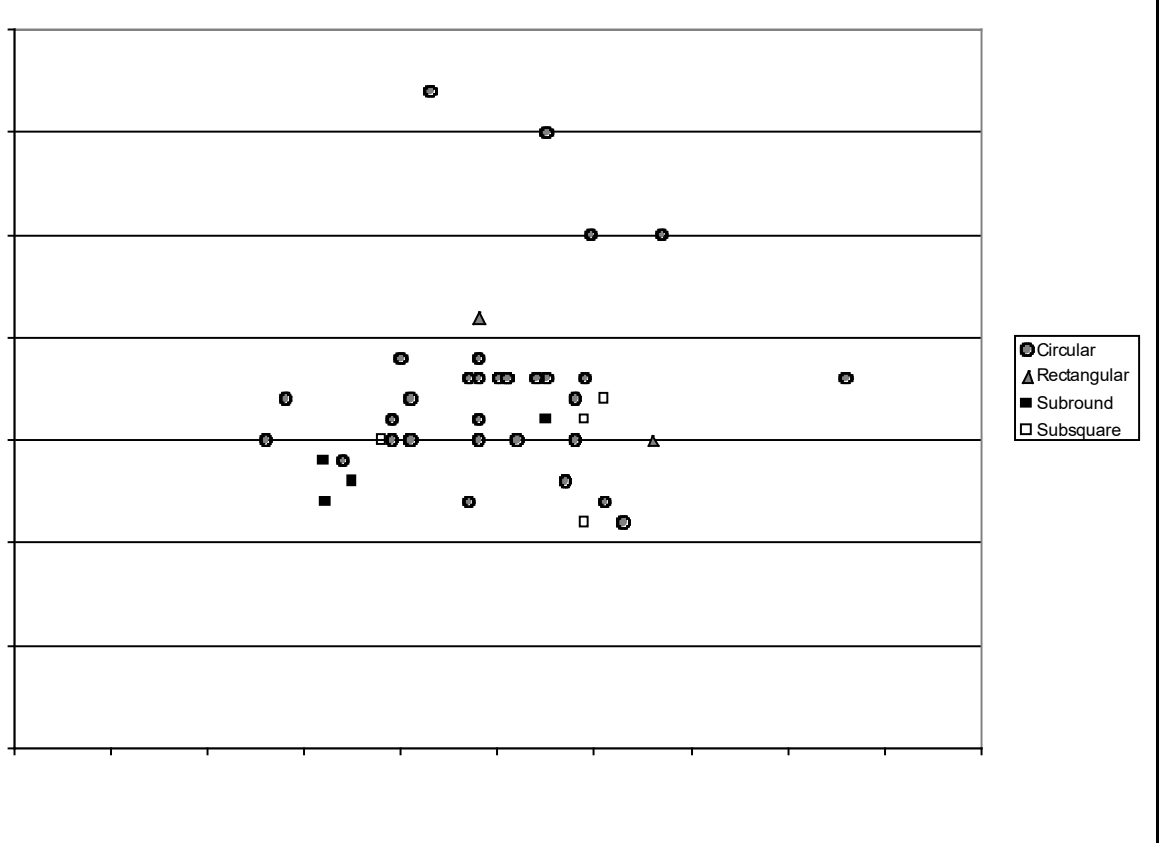

Figure 119. Scatterplot of wall post hole spacing and mean wall post hole diameter for mound structures.

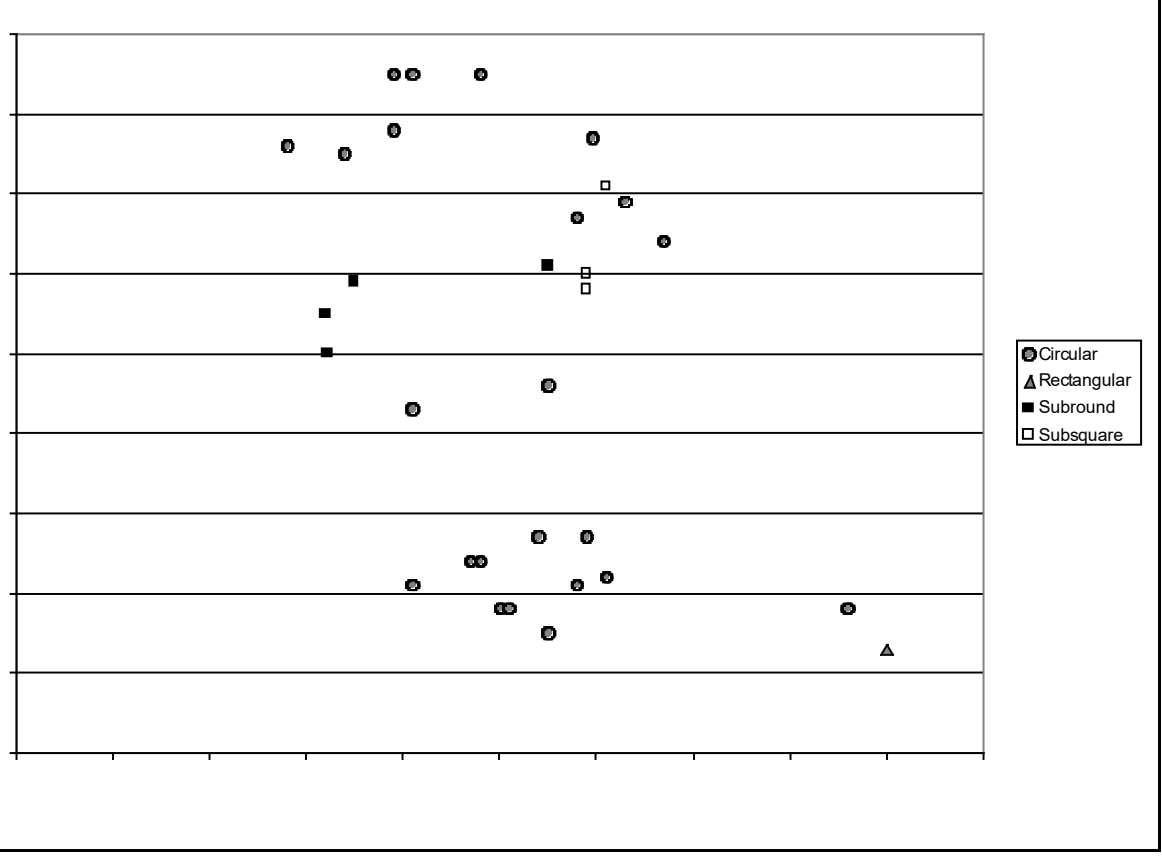

Figure 120. Scatterplot of wall post hole spacing and mean wall post hole depth for mound structures. 


\section{Summary}

Caddo structures from eastern Texas tend to be constructed of single set posts ranging in size from approximately $10 \mathrm{~cm}$ to $35 \mathrm{~cm}$. Most $(73 \%)$ have mean post diameters of less than $20 \mathrm{~cm}$, falling into the range of small pole buildings as discussed by Lacquement (2007) for structures from sites in Alabama. The rest fit into the category of large post buildings (Lacquement 2007). Sixty-five percent of the remaining structures have mean wall post hole diameters ranging from $20 \mathrm{~cm}$ to $25 \mathrm{~cm}$, with only 11 of the 115 structures with post hole diameter data having mean wall post hole diameters of 26 $\mathrm{cm}$ or greater.

Ninety-two of the structures in this study have data on mean post hole depth available. Mean post hole depth for these structures ranges from $11 \mathrm{~cm}$ to $98 \mathrm{~cm}$ with a mean of $40 \mathrm{~cm}$. Most of the structures have mean post hole depth of less than $50 \mathrm{~cm}$, with most of those falling below $30 \mathrm{~cm}$ (Figure 121). Caddo structures from eastern Texas tend to have wall post holes extending to depths of less than $50 \mathrm{~cm}$, with some exceptionally deep wall post holes occurring in some of the structures in the area.

Post hole spacing for 149 of the structures that were complete enough to allow measuring between wall post holes ranges from $17 \mathrm{~cm}$ to $2.8 \mathrm{~m}$, with a mean of $63 \mathrm{~cm}$. Excluding the Spider Knoll structures, which likely represent open-aired buildings, mean wall post hole spacing for all 149 structures ranges from $17 \mathrm{~cm}$ to $1.71 \mathrm{~m}$, with a mean of $59 \mathrm{~cm}$. Most Caddo structures from eastern Texas (91\%) have wall post holes spaced less than $1 \mathrm{~m}$. Most of these (69\%) have wall post holes spaced from approximately 15 to 60 $\mathrm{cm}$. 


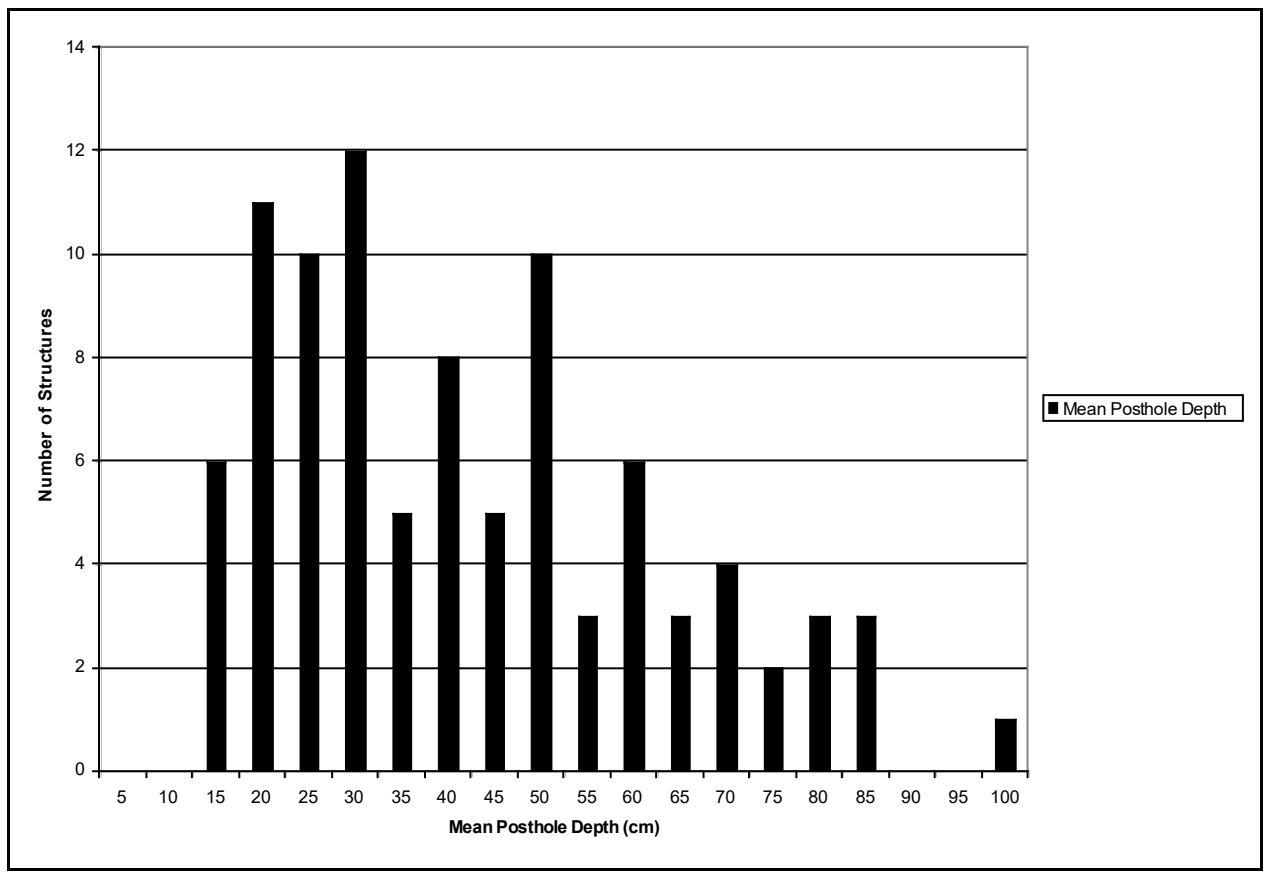

Figure 121. Mean post hole depth.

The ratio of average distance between exterior post holes and from the exterior post holes to the center of the structure was obtained for 117 structures. These structures are all circular, sub-round, or sub-square. The ratio ranges from 1:1.14 to 1:33.12, although the large ratio is from Structure 9 at the George C. Davis site and is considerably larger than the ratio for the remaining structures. For Early to Middle Caddo period structures, the ratio ranges from $1: 1.14$ to $1: 33.12$, or $1: 18.15$ without Feature 9 from Davis. For Middle to Late Caddo period structures, the ratio ranges from 1:3.4 to 1:13.67, with only two, Feature 2 from Oak Hill Village and Feature 25 from Hatchel, exceeding 1:10. For Late to Historic Caddo period structures, the range is from 1:2.05 to 1:16.67, with most falling between $1: 3$ and 1:8. Although there does not appear to be any specific temporal pattern related to the ratio of average distance between exterior post holes and from the exterior post holes to the center of the structure in eastern Texas, this 
measurement has been used to suggest the existence of different architectural traditions at specific sites (Perttula and Sherman 2009), and may be a useful tool for examining architecture within a specific community.

\section{Pits and Berms}

Three non-mound structures were built within pits and at least one had evidence of a berm surrounding part of the structure. Earspool Structure 1 was built within a 40-45 $\mathrm{cm}$ deep pit while Earspool Structure 3 was built within a 25-35 $\mathrm{cm}$ deep pit (Perttula and Sherman 2009). Feature 9 from the George C. Davis site was the only known non-mound structure there that was built within a pit. The structure was built within an approximately $0.37 \mathrm{~cm}$ deep pit. While no mention of a structure pit was made at the Rookery Ridge site, Structure 1 from Rookery Ridge had evidence suggesting the presence of a berm around a portion of the structure. This possible berm was approximately $0.40-0.50 \mathrm{~m}$ high (Parsons, personal communication 2009). These three and possibly four semisubterranean structures are unique among the structures included in this study.

Three mound-related structures were built within pits and at least seven to possibly nine others had evidence of a berm or earthen embankment surrounding part of the structure. Dalton Structures A and B as well as Harroun Structure 4 were all built within pits. Harroun Structure 4 was built within a $0.45 \mathrm{~m}$ deep pit, while the Dalton structures were each built in the same $5.5 \mathrm{~m}$ diameter by $0.09-0.12 \mathrm{~m}$ deep pit, with the debris from Structure A removed prior to the construction of Structure B (Davis and Gipson 1960). Each of these structures also had an extended entrance. These entrances, as noted by Jelks and Tunnell (1959) for the Harroun structure, likely would have sloped downward into the structure pit. 
The seven mound-related structures with earthen embankments or berms around a portion of their exterior are from Bryan Hardy, Harroun, and Dalton. The Redwine structure may have had an embankment, as represented by an exterior clay deposit Walters and Haskins 2000). Perino (1995:7) suggested that Holdeman Structure 1 was built on the original ground level with soil berms surrounding it. Although evidence of soil berms is far from conclusive, if the Holdeman structure did have an earthen embankment surrounding a portion of it, it would be the only non-circular structure in the study area to have such a feature.

Those mound-related structures for which there is clear evidence of an earthen berm include all four Harroun structures, both Dalton structures, and the Bryan Hardy mound structure. Such a feature could have helped insulate the outer walls of the structure and/or could have provided structural support. In discussing semi-subterranean house basins, Brennan (2007:77) suggested "the excavated fill is then piled against the walls, functioning structurally to strengthen them in a manner similar to daub." Either way, a sand embankment around the structure would have served to give the structure a semi-subterranean appearance, thus further separating these specialized structures from the domiciles and other non-mound structures in a village or mound center. Parsons (2009 personal communication) has also suggested that a berm placed around a structure may be seen as an incipient mound. As such, berms may be symbolically related to mounds and the structures associated with them may have been afforded the same symbolic significance as mound structures. If berms can be considered incipient mounds, then upon entering a structure surrounded by an earthen berm, one would have been entering the mound itself. 


\section{Summary}

Structures built within pits or surrounded by earthen berms are rare in eastern Texas, with only $8 \%$ of the 176 previously excavated structures in this study apparently having either of these characteristics. Only three non-mound and three mound-related structures were built within pits and only one non-mound structure and possibly as many as nine mound-related structures had berms or earthen embankments. With the possible exception of the Holdeman structure, all of these structures are circular. Being built in a pit and being surrounded by an earthen berm would have given these specialized structures a semi-subterranean appearance and would have afforded the non-mound structures similar symbolic significance given their association with what Parsons (personal communication 2009) suggests may have been incipient mounds

\section{Prepared Floors}

Prepared clay floors were recorded at only four of the non-mound structures included in this study (Table 54). Three of these structures were also built within pits. Features 9 and 35 from the George C. Davis site and Structures 1 and 3 from the Earspool site all had evidence for clay floors. In addition to a clay floor, Earspool Structure 3 also had an original sandy loam floor while Structure 1 had a later sandy loam floor (Perttula and Sherman 2009). It is possible that prepared floors were once present at some of the other structures, but they have been disturbed or destroyed to the extent that they were not recorded (e.g., Jelks 1965). 
Table 54. Non-mound structures with clay floors.

\begin{tabular}{|l|r|l|l|}
\hline & & \multicolumn{2}{|c|}{ Floor thickness (cm) } \\
\hline Site & Structure & Clay & Sandy Loam \\
\hline George C. Davis & 9 & $2-3$ & \\
\hline George C. Davis & 35 & poorly preserved & \\
\hline Earspool & 1 & $2-10$ & 4 \\
\hline Earspool & 3 & $\begin{array}{l}1-4 \text { (with } 13 \mathrm{~cm} \\
\text { thick filled in hearth) }\end{array}$ & $1-4$ \\
\hline
\end{tabular}

Prepared floors were recorded in least seven (14\%) of the mound-related structures. Features 111 and 43 from the George C. Davis site as well as Features A and B from Dalton, and Structure 2 from Roitsch all had what was described as hard packed clay floors, usually packed red clay. Hatchel Feature 14 was situated on a red clay deposit that may have represented a prepared clay floor. Harroun Structure 4 had a $6 \mathrm{~cm}$ thick layer of hard-packed sandy clay on the floor, possibly representing a prepared floor. Walters and Haskins (2000) note that the floor of the Bryan Hardy structure was compacted, possibly representing a prepared floor.

\section{Summary}

Prepared floors were noted at only $11(6 \%)$ of the previously excavated structures in this study. Three of the four non-mound structures with prepared floors were built within pits, suggesting a specialized function for these structures. Most of the prepared floors were hard-packed clay and measured between 1-4 cm thick. It is possible that other structures may have once had prepared floors that were too heavily disturbed to be recorded at the time of excavation. 


\section{REBUILDING AND REUSE}

Rebuilding and reuse of structures are seen at Caddo mound sites as well as small hamlets and farmsteads. Structures in some areas of sites appear to have been used for decades with structures being repaired and rebuilt as needed. The practice of rebuilding in the same general location indicates that the Caddo took an active role in creating a longterm sense of place and community. This connectedness with a specific location in a village or community applied to both mound and non-mound structures with sites such as Oak Hill Village, Deshazo, and George C. Davis showing intensive rebuilding of nonmound structures in the same general location as previous structures.

In discussing mound-related structures, Story (1990:341) notes "the most ubiquitous, thus single best attribute for defining this type structure, is their apparent deliberate destruction - by dismantling and/or burning - capping with earth, and, often subsequent rebuilding on the resultant earthen platform." Story (1990:341) continues: "these structural mounds are the tangible remains of a predetermined ritual cycle. Minimally, this cycle consisted of the following sequence: construction, use, destruction, and final capping (sealing off) with earth.” By following such a cycle, the Caddo political elite or ritual practitioners were apparently taping into the power and authority of the past, as well as integrating the power of the ancestors into their own time and place by appropriating and reusing sacred spaces or other spaces of power. The continued construction and use of specialized buildings atop the floors of earthen mounds, as well as the close vertical alignment of many of those structures with ones that came before, suggests a continuity of traditions related to the construction, use, and destruction of sacred spaces. 
At least 17 and possibly as many as 34 or more of the 215 non-mound structures (7.8-15.8\%) show evidence of being destroyed by burning. In addition, at least 14 and possibly 24 of the 50 mound-related structures (28-48\%) included in this study were burned and subsequently capped by an earthen mound. In some instances, however, such as that of Dalton Structures A and B, the burned debris of the preceding structure was cleared away and the subsequent structure was built directly on the floor area of the previous building. At Whelan, subsequent structures in Mound A were built on an accumulation of soil and ash, rather than on intentionally placed mound "floor" or caps (Thurmond 1990; Davis 1958). Following the destruction of the last structure, Structure A, the mound at the Whelan site was capped, sealing the sacred spaces within and creating a landmark that, in some instances may later be marked by marker posts (e.g., Perttula and Sherman 2009).

On the more practical side, there is abundant evidence that structures were repaired and wall posts were replaced as needed. Generally, repair is evident by closely spaced wall posts or wall posts placed adjacent to earlier wall posts, such as those at Oak Hill Village, Hatchel, Lang Pasture, Earspool, and others, as well as overlapping posts such as that seen at the Henry M. site, Oak Hill Village, and others.

In addition to the repair of damaged or rotting members, structures were clearly often replaced or rebuilt in the same general location as a preceding structure and it appears in many cases that recycled materials were used where possible. This practice, as seen at Oak Hill Village, Deshazo, Hines, as well as other sites, results, at least in some instances, in subsequent structures being smaller than the earlier buildings. As Rogers and Perttula (2004:49) suggested for many of the overlapping structures at the Oak Hill Village site, "in many instances the newer dwelling was placed adjacent to the first and 
closely paralleled it in the number, spacing, and size of the wall posts used, suggesting the reuse of existing materials. Often the two houses differed in size, further suggesting that the rebuilt house contained the recycled wall posts of the former, which may have rotted at ground level. As a consequence of using shorter posts, the second structure became smaller in diameter."

The village structures at the Hatchel site follow this rebuilding pattern, and Perttula (2005:186) pointed out that the later smaller Feature 1 "probably represents a rebuilding of the larger structure in approximately the same place," suggesting also that recycled materials may have been used. In addition to the benefits of reusing wall posts, the Caddo builders would have the added benefit of possibly being able to reuse existing post holes or other features.

In her analysis of the Deshazo structures, Good (1982:69) noted that the frequency of rebuilding structures was largely determined by the need to replace rotting supports or other structure materials. Based on her analysis, Good (1982) determined that the average lifespan of a Caddo structure at Deshazo was approximately 20 years. This figure has been used elsewhere in the Caddo area for estimating occupation spans of sites, where, for example, Bruseth and Perttula (1981:24) projected a 60 year occupation for the Early Caddo component with three structures at the Hines site.

Non-mound structure rebuilding and replacement is clearly seen by the evidence of overlapping structures in the archaeological record. The pattern of reuse of space is evident at the larger villages such as Oak Hill Village site, George C. Davis, and Deshazo, as well as smaller sites such as Bryan Hardy. The practice of rebuilding indicates a preference of place. This preference may be in proximity to places of power such as the inner precincts at George C. Davis (Story 1997, 1998), proximity to 
communal spaces such as the plaza at Oak Hill Village (Rogers and Perttula 2004) or those identified at the George C. Davis site by Walker (2009). In addition, this practice links a village to its past and solidifies the place of a structure's inhabitants as members of the community and as one of "Us", as opposed to those whose structures lack that link to the village's shared past who may be seen as "Not Us" or even "Other" (Helms 1998).

One method of perpetuating this shared identity and linking a community or village to the past is through the practice of marker posts, as seen at the Pilgrims Pride site and the Earspool site (Perttula 2005; Perttula and Sherman 2009). The marker posts placed directly through the burned structural remains and central hearth of Earspool Structure 1, an earlier Titus phase structure, marked the earlier structure and its hearth, a significant feature that housed the structure's fire that was traditionally lit from a shared source. Perttula and Sherman (2009) note that the marker post was probably placed during the later Titus phase occupation at the site, an action that would have then linked that post and activities related to it directly with the ancestors. The marker post through the Titus phase mound and mound structures at the Pilgrim's Pride site provides a "clear and intimate association with the large ash-filled hearth on the floor of the structure that was burned and covered by an earthen mound indicates that the excavation of the post hole and the erection of the pole in it was part and parcel of the sacred mound construction rituals employed by the Titus phase Caddo peoples at the Pilgrim's Pride site" (Perttula 2005:313).

The practice of rebuilding indicates a preference of place as well as a continuity of traditions. This practice links a village to its past. In much the same way that the communal nature of house building helped to bind the community, building special purpose structures atop earthen mounds over the remains of earlier special purpose 
buildings further illustrates how these mound-related structures and the organized spaces they created are themselves "objects of sacred display," much like the earthen mounds themselves or other ritual paraphernalia used in those special structures (Knight 1986; Sabo 1998; Story 1990).

The creation of sacred spaces through the burial or rebuilding of certain specialized structures (whether or not they were on mounds) seems to have become prevalent after A.D. 1250 to A.D. 1300. Schambach (1996:40) has noted that at that time Caddo ceremonialism appears to have shifted from "individual-oriented ceremonialism to public building-oriented ceremonialism." Conversely, Perttula (1997, 2004:403) notes "the Titus phase community cemeteries appear to have replaced the use of mounds for community ceremonial and religious functions by about the 1550s." This would seem to suggest that the period of "public-building oriented ceremonialism" suggested by Schambach (1996) may have had its heyday between around A.D. 1300 to the early to mid-sixteenth century, at least in parts of Caddo East Texas.

\section{STRUCTURE FORMS/TYPES}

This chapter has looked at attributes from 215 non-mound structures, including 128 excavated structures and 87 structures identified through magnetometer surveys. In addition, I have examined attributes from 50 mound structures, including 48 previously excavated structures and two additional structures identified through a magnetometer survey. These data have come from 31 sites in eastern Texas. This section categorizes

these 265 structures into groups or types of structures based on structure form, construction technique, or other structural attributes. 
A few architectural typologies have been proposed within the study area. At the George C. Davis site, Spock (1977) divided the excavated structures into special function structure or domiciles. Spock (1977:169) further divided the special function structure category into four subclasses: unusually small structures, structures on mound platforms, pre-mound structures, and non-mound structures with unusual architecture or interior features. Spock's unusually small structure category included three features $(7,50$, and 52) all measuring less than $2.0 \mathrm{~m}$ in diameter. Walker (2009) later identified three different types of structures at the George C. Davis site: Type 1, circular structures with four large interior pits or supports and a central hearth; Type 2, circular structures; and, Type 3, sub-round structures (Figure 122).

At the Hill Farm site, Walker (2009) places the structures into two architectural forms, circular structures with extended entrances and those without (Figure 123). Finally, at the Oak Hill Village site, Perttula and Rogers (2007:76) group the structures into at least four different categories: large rectangular structures, circular structures, circular structures with extended entrances, and small structures $(<3 \mathrm{~m})$.

Both non-mound and mound structures discussed in this dissertation tend to fit into one of four general structure forms: circular, sub-round, sub-square, or rectangular. Within these forms there are additional styles such as circular structures with extended entrances, circular structures with a center post or central hearth, circular structures with a central hearth and four large interior support posts, and small circular structures generally less than $3 \mathrm{~m}$ in diameter. Relying on this recognizable architectural diversity, I have divided the East Texas Caddo structures in this study into eight structure types (Table 55), irrespective of whether these structures are from non-mound or mound contexts. 


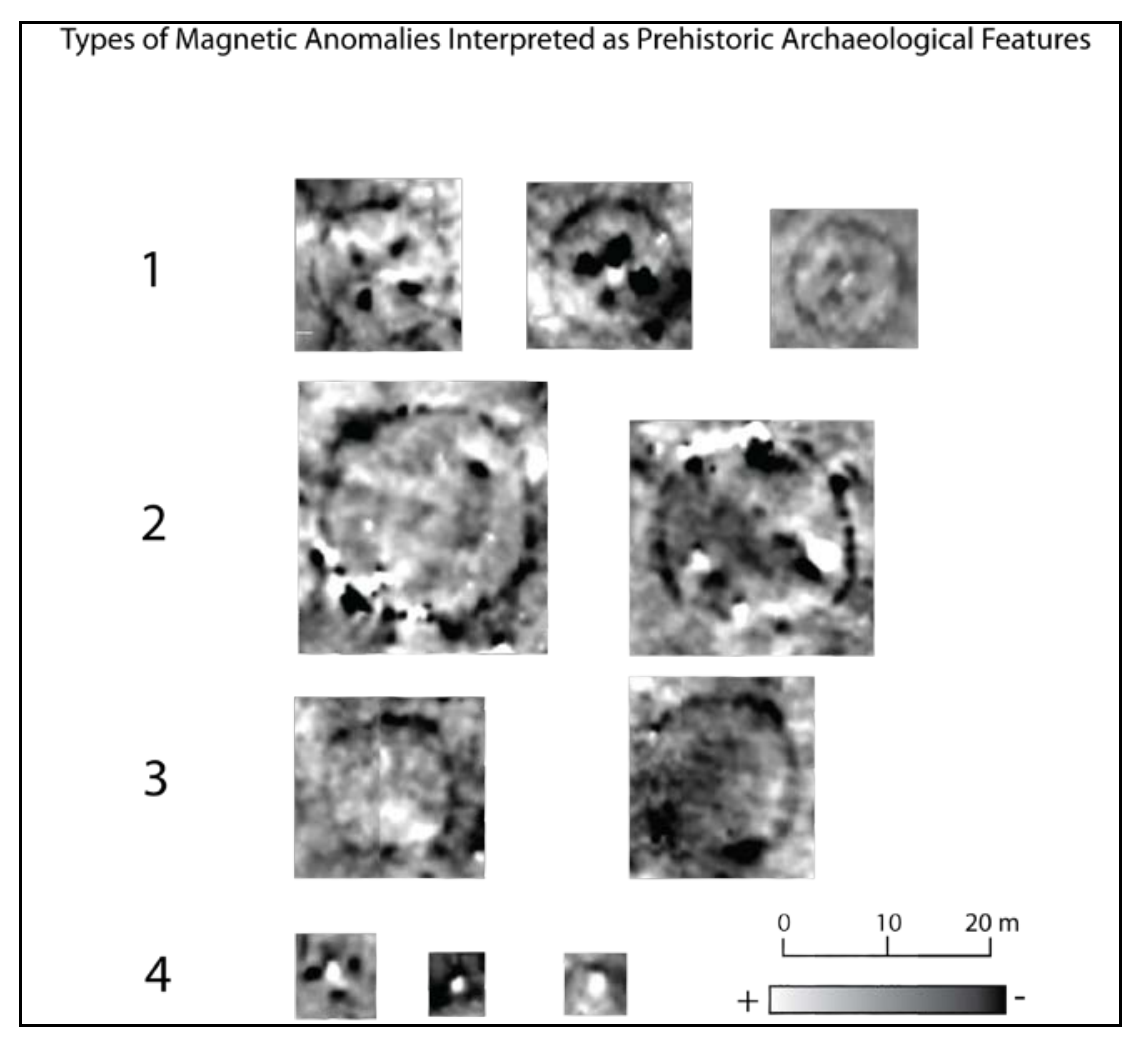

Figure 122. Walker's (2009:Figure 4.8) structure types from the Davis site magnetometer data. 1, Walker's Type 1 structures, 2, Type 2 structures, 3, Type 3 structures, and 4, fire hearths.

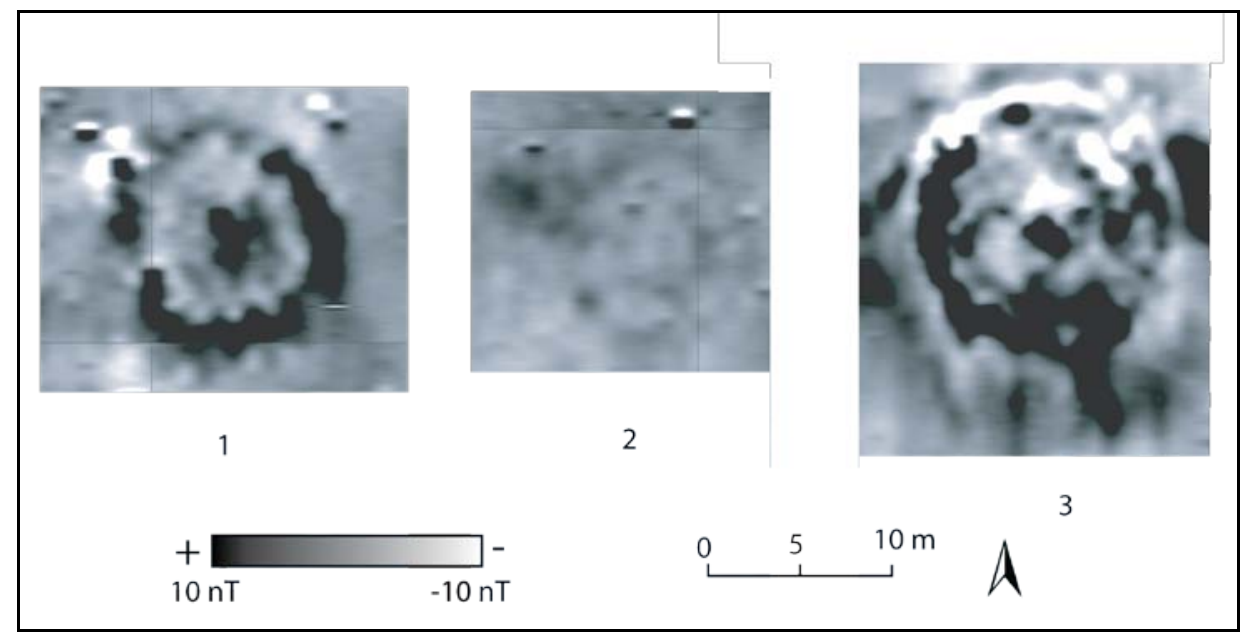

Figure 123. Walker's structure types from the Hill Farm site magnetometer data (Walker 2009:Figure 5-3) 
Table 55: Non-mound structures types.

\begin{tabular}{|c|l|}
\hline Type & \multicolumn{1}{c|}{ Description } \\
\hline 1 & Circular structures with a central hearth or post and four support posts \\
\hline 2 & Circular structures with non-extended entrances \\
\hline 3 & Circular structures with extended entrances \\
\hline 4 & Small circular structures \\
\hline 5 & Sub-round structures \\
\hline 6 & Sub-square structures \\
\hline 7 & Rectangular structures with non-extended entrances \\
\hline 8 & Rectangular structures with extended entrances \\
\hline
\end{tabular}

\section{Type 1}

Type 1 structures are circular structures with a central hearth or post hole and four interior support posts or large pits arranged in a square-like pattern around the central post or hearth. This is the same as Walker's (2009) Type 1 structures recorded in the magnetometer data at the George C. Davis site. As discussed in Chapter 4 and Walker (2009), there have been at least 10 complete or partial Type 1 non-mound structures identified in the magnetometer data from the Davis site (Table 56) (Figure 124). These structures correspond in form with at least three excavated structures from the site, Features 31, 42, and 125 (Figure 125) (Newell and Krieger 1949; Spock 1977).

While the Davis site certainly has the largest number of non-mound Type 1 structures, this distinct form shows up at other East Texas Caddo sites. Type 1 nonmound structures occur at Hurricane Hill, Earspool, Hines, and Oak Hill Village (Figure 126). Type 1 structures may occur at other sites such as Lang Pasture where possible interior support posts were recorded but less than half of a structure had been excavated. 
Table 56: Type 1 non-mound structures.

\begin{tabular}{|l|c|c|c|l|}
\hline Site & Feature & Diameter $(\mathbf{m})$ & Area $\mathbf{( m}^{\mathbf{2}} \mathbf{)}$ & Comments \\
\hline \multirow{5}{*}{ George C. Davis } & 31 & 14.90 & 174.40 & Under Mound A \\
\cline { 2 - 5 } & 42 & 11.80 & 109.40 & Under Mound A \\
\cline { 2 - 5 } & 125 & 7.4 & 43.0 & \\
\cline { 2 - 5 } & 237 & 10.60 & 88.25 & Partially excavated \\
\cline { 2 - 5 } & 241 & 13.50 & 143.14 & Partially excavated \\
\cline { 2 - 5 } & 242 & 13.00 & 132.73 & Partially excavated \\
\cline { 2 - 5 } & 243 & 13.6 & 145.27 & Circular; faint interior features \\
\cline { 2 - 5 } & 244 & 12.30 & 118.82 & \\
\cline { 2 - 5 } & 245 & 11.50 & 103.87 & \\
\cline { 2 - 5 } & 246 & 10.00 & 78.54 & \\
\cline { 2 - 5 } & 247 & 15.40 & 186.27 & \\
\cline { 2 - 5 } & 335 & 9.5 & 70.88 & Probably burned \\
\hline \multirow{4}{*}{ Earspool } & 238 & 10.40 & 84.95 & Probably burned \\
\hline Hines & 4 & 6.56 & 33.83 & Possibly Type 1 \\
\hline Oak Hill Village & 5 & 7.52 & 44.40 & \\
\hline \multirow{4}{*}{ Hurricane Hill } & $\mathrm{A}$ & 6.2 & 52.81 & Possibly Type 1 \\
\cline { 2 - 5 } & $\mathrm{B}$ & $7.1 \times 7.6$ & 41.41 & Overlapping structure \\
\hline
\end{tabular}



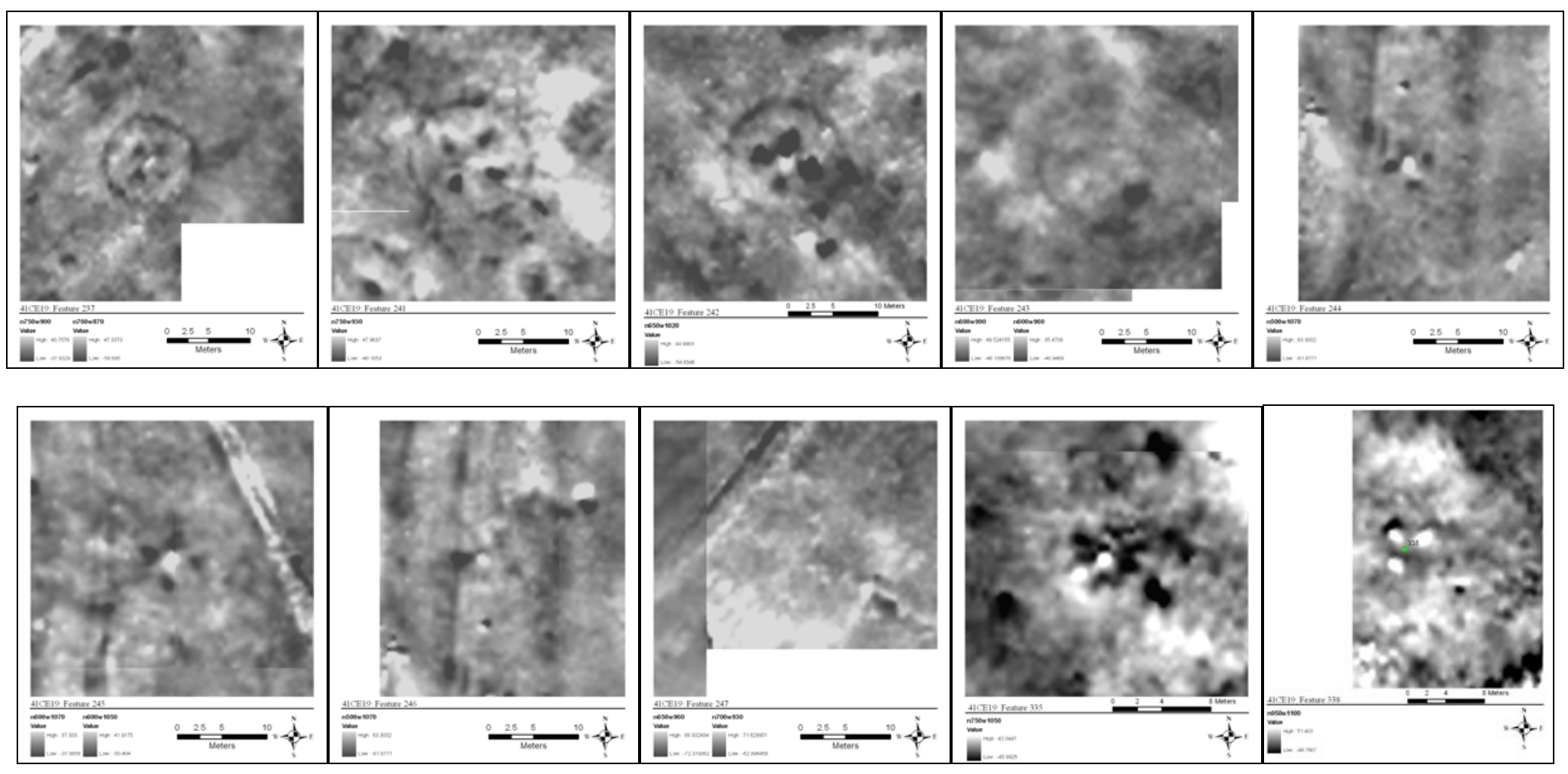

Figure 124: Features 237, 241, 242-247, 335, and 338 from the George C. Davis site. 


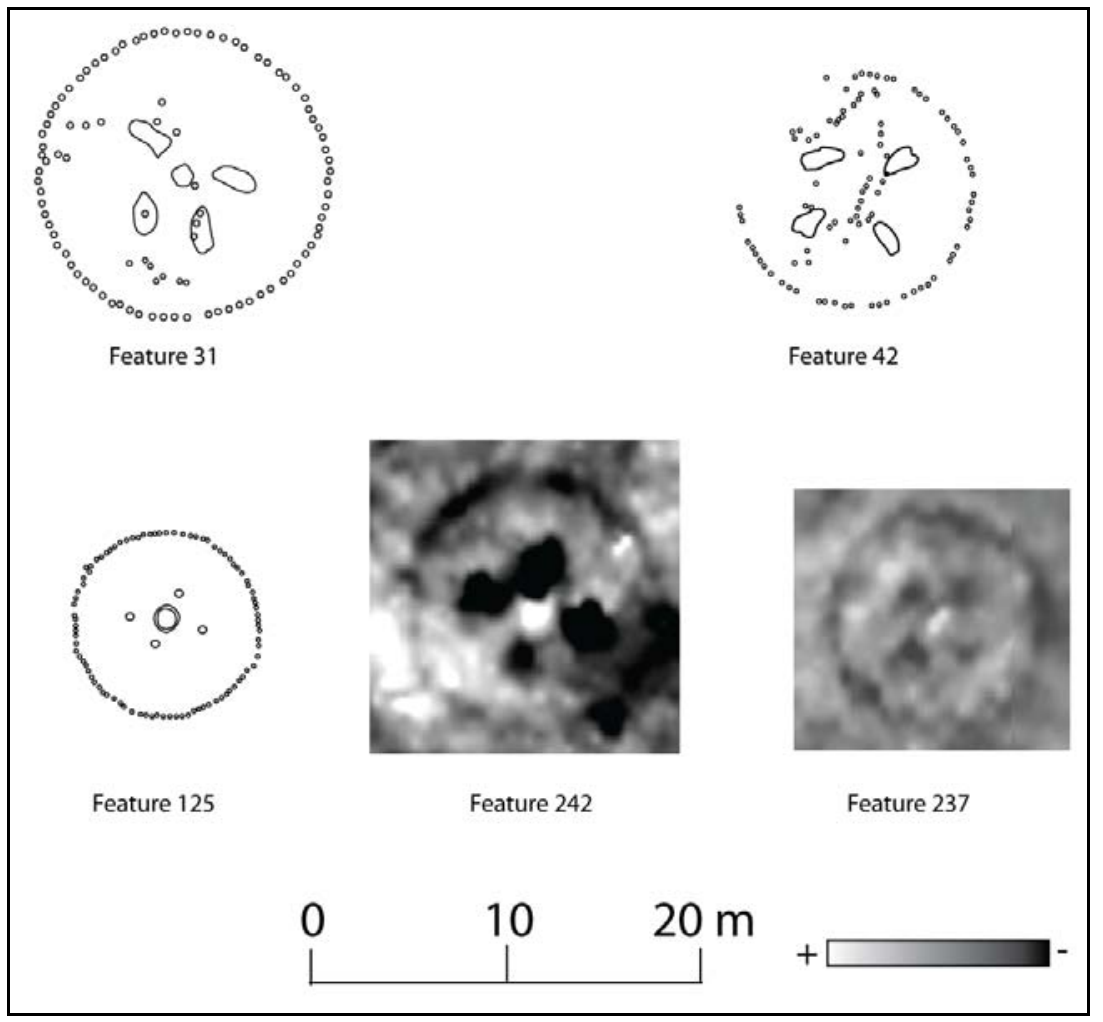

Figure 125: Comparison of Type 1 Structures from the George C. Davis site (Walker 2009:Figure 4.10).

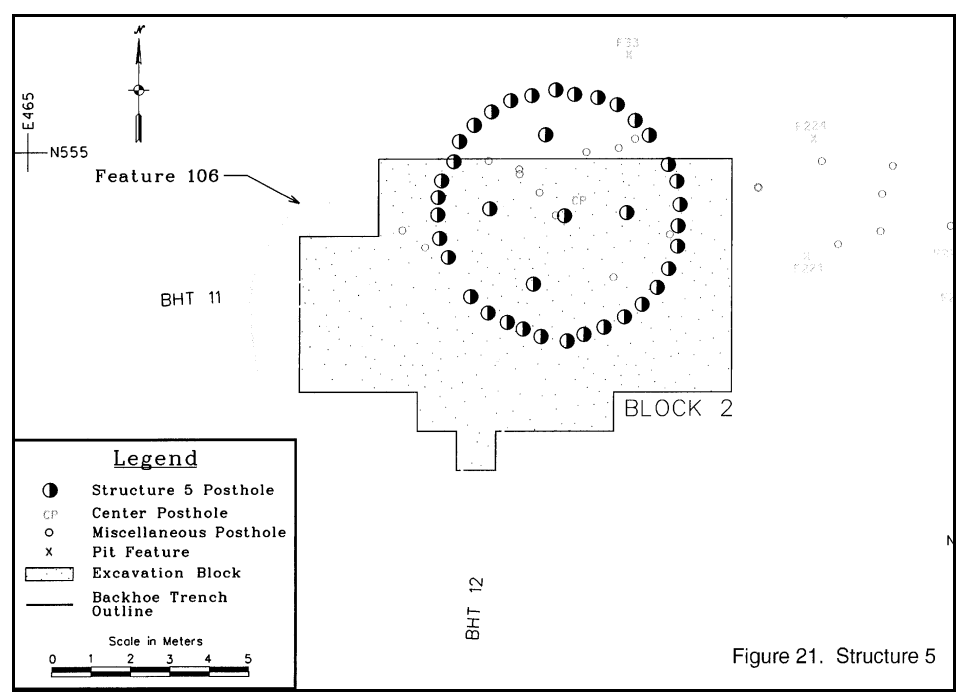

Figure 126: Type 1 structure from the Oak Hill Village site. 
In addition to the Type 1 non-mound structures, there are at least three and possibly four Type 1 mound structures in this study (Figure 127). Type 1 structures occur at the George C. Davis site (Features 31 and 42), Harroun (Structure 3), and at the Bryan Hardy site.

Most of the Type 1 structures have non-extended entrances. Hurricane Hill Structure B is the only non-mound Type 1 structure with a possible extended entrance. The Harroun and Bryan Hardy structures are the only Type 1 mound structures with extended entrances, a feature possibly more significant in terms of structure use than the interior posts and hearth, more defining characteristics of the Type.

In addition to entrance type, the Type 1 structures are variable in size. The diameter of the Type 1 mound structures ranges from $5.18 \mathrm{~m}$ to $14.9 \mathrm{~m}$, with a mean of $9.34 \mathrm{~m}$. The two George C. Davis structures are the largest, with diameters of $14.9 \mathrm{~m}$ and $11.8 \mathrm{~m}$, and areas of $174.4 \mathrm{~m}^{2}$ and $109.4 \mathrm{~m}^{2}$. These are considerably larger than the Harroun and Bryan Hardy structures that have diameters or $5.18 \mathrm{~m}$ and $5.48 \mathrm{~m}$, and areas of $21.07 \mathrm{~m}^{2}$ and $23.59 \mathrm{~m}^{2}$, respectively. This difference in size could be diachronic, with the George C. Davis structures both being situated under Mound A, which was built during the Formative to Early Caddo periods (ca. A.D. 850-1200), the Bryan Hardy site dating to the Middle Caddo period, and the Harroun site dating to the Late Caddo Titus phase. Alternatively, the variation in size could be related to different uses of these structures, whether for larger gatherings or smaller, more restricted groups.

The non-mound Type 1 structures are similar in size, although tending to be slightly larger, with the structures ranging in size from approximately $6.5 \mathrm{~m}$ to $15.4 \mathrm{~m}$ (n $=19, \bar{x}=10.35 \mathrm{~m}, \mathrm{~s}=2.9281$ ), with interior areas ranging from approximately $33.18 \mathrm{~m}^{2}$ to $186.27 \mathrm{~m}^{2}$ ( $\left.\mathrm{n}=19, \bar{x}=90.58 \mathrm{~m}, \mathrm{~s}=49.0806\right)$. The variation in size between the mound 
and non-mound Type 1 structures may be due to the estimation of size for the 10 nonmound structures identified through the George C. Davis magnetometer survey. Removing those 10 structures leaves a size range that more closely matches that of the Type 1 mound structures, with diameters ranging from $6.5 \mathrm{~m}$ to $14.9 \mathrm{~m}(\mathrm{n}=9, \bar{x}=8.55$ $\mathrm{m}, \mathrm{s}=2.88)$, and interior areas ranging from approximately $33.18 \mathrm{~m}^{2}$ to $174.4 \mathrm{~m}^{2}(\mathrm{n}=9$, $\bar{x}=63.14 \mathrm{~m}, \mathrm{~s}=47.8994)$.

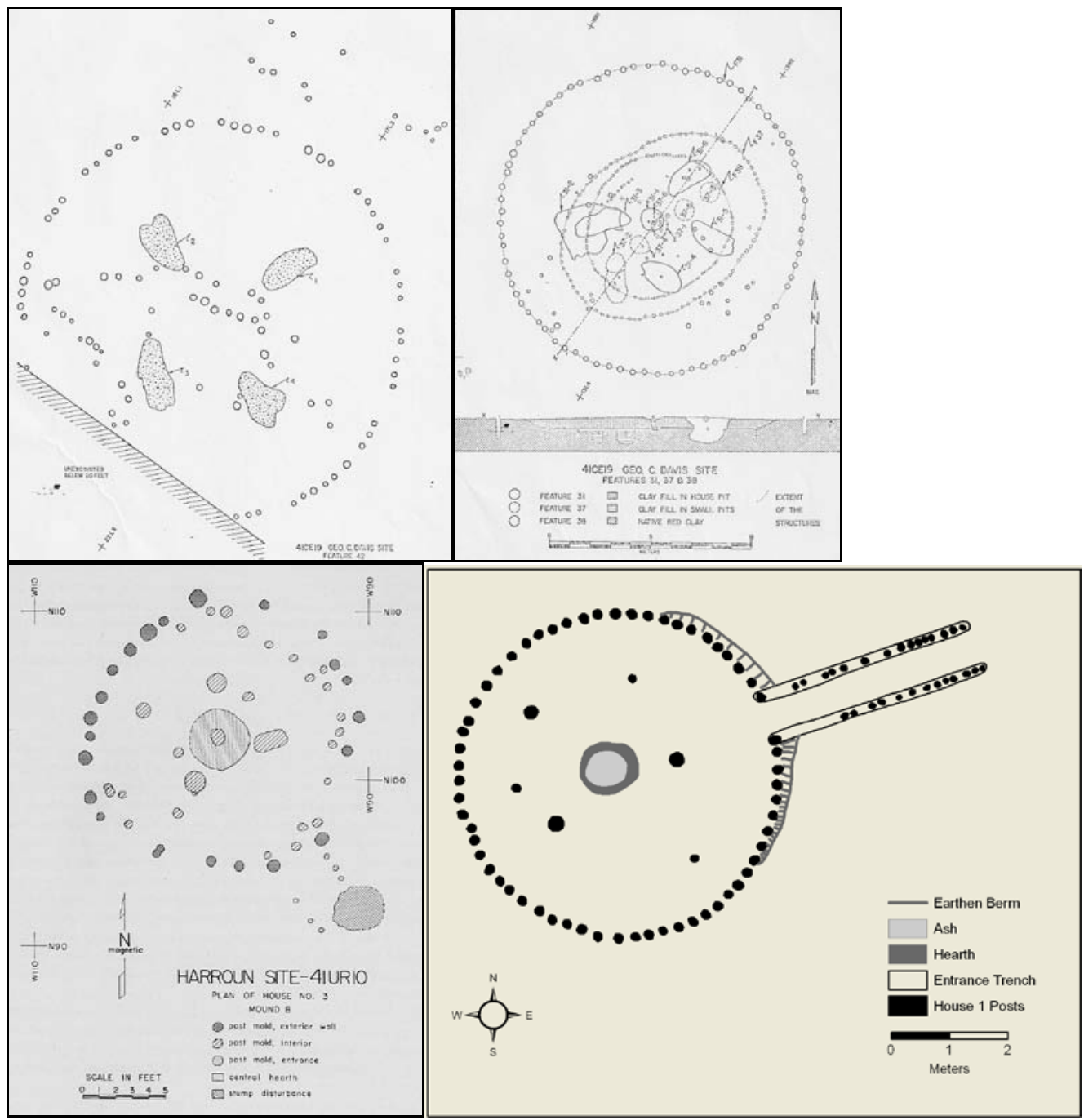

Figure 127. Type 1 mound structures: a, George G. Davis, Feature 42; b, George C. Davis, Features 31, 37-38; c, Harroun, Mound B, House No. 3; d, Bryan Hardy. 


\section{Type 2}

Type 2 structures include circular structures with non-extended entrances. This category of structures is by far the largest and most inclusive of the East Texas Caddo structures. There are at least 108 previously excavated Type 2 structures in the architectural database and as many as an additional 78 Type 2 structures recorded through the magnetometer surveys of the George C. Davis and Hill Farm sites. These structures range in size from $3.15 \mathrm{~m}$ to $21 \mathrm{~m}$ in diameter, with areas ranging from $7.79 \mathrm{~m}^{2}$ to $346.36 \mathrm{~m}^{2}$. The mean area for the Type 2 structures is $88.44 \mathrm{~m}^{2}$, with a standard deviation of 72.45. Excluding those structures recorded through magnetometer surveys, some of which represent the largest structures in this study, areas range from approximately $16.27-254.5 \mathrm{~m}^{2}$, with a mean area of $62.27 \mathrm{~m}^{2}$ and a standard deviation of 35.56.

There are at least 91 previously excavated Type 2 non-mound structures and as many as an additional 73 Type 2 non-mound structures recorded through the magnetometer surveys of the George C. Davis and Hill Farm sites. The Type 2 nonmound structures range in size from $4.56 \mathrm{~m}$ to $21 \mathrm{~m}$ in diameter, with areas ranging from $7.79 \mathrm{~m}^{2}$ to $346.36 \mathrm{~m}^{2}$. The mean area for the Type 2 structures is $91.16 \mathrm{~m}^{2}$, with a standard deviation of 73.35. Excluding those structures recorded through magnetometer surveys, sizes range from $4.56 \mathrm{~m}$ to $13.6 \mathrm{~m}$ in diameter with a mean diameter of $8.54 \mathrm{~m}$ and a standard deviation of 1.97. Interior areas of these structures range from $16.27 \mathrm{~m}^{2}$ to $149.5 \mathrm{~m}^{2}$, with a mean area of $59.69 \mathrm{~m}^{2}$ and a standard deviation of 27.98 .

Type 2 non-mound structures have a range of associated features including interior hearths, center post holes, pits, smudge pits, burials, and interior post holes that likely represent interior structure supports as well as supports for benches, racks, 
partitions, etc. Many of these structures likely represent domiciles, but some may be special purpose structures; the larger structures discussed above may be considered specialized structures. Most (73\%) Type 2 structures have interior areas of $100 \mathrm{~m}^{2}$ or less. In fact, all of the excavated Type 2 structures have interior areas less than $200 \mathrm{~m}^{2}$. Only $20(30 \%)$ of the magnetometer-identified structures from the George C. Davis site have interior areas exceeding $200 \mathrm{~m}^{2}$, with only one of the Hill Farm structures having an interior area that may exceed $200 \mathrm{~m}^{2}$. Of the larger structures, only four of the George C. Davis magnetometer structures have areas exceeding $300 \mathrm{~m}^{2}$. Some of the largest Type 2 structures may actually represent open enclosures rather than roofed buildings (Creel et al. 2008:188; Walker 2009). Figure 128 provides a histogram of non-mound Type 2 structures by area.

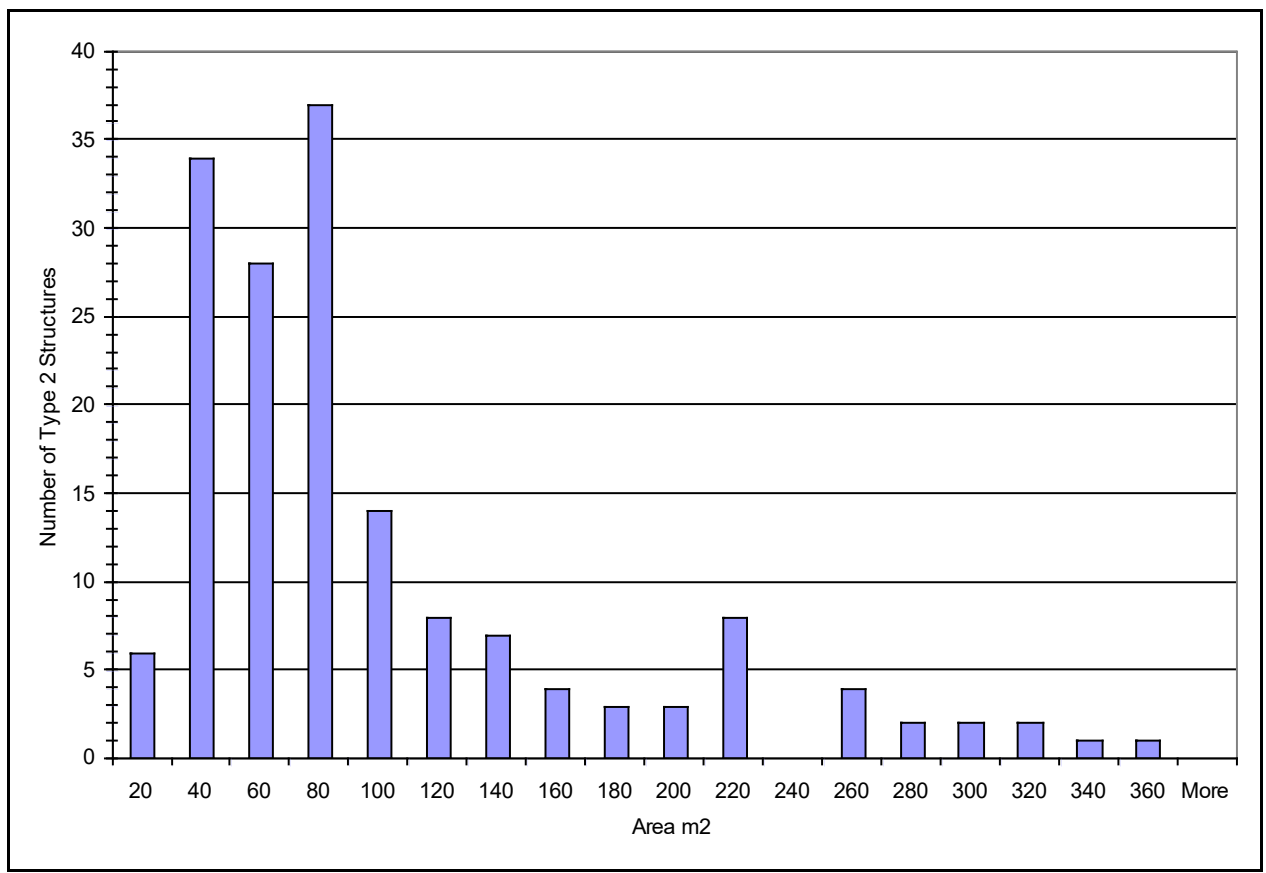

Figure 128. Distribution of Type 2 structures by interior area. 
There are at least 20 previously excavated Type 2 mound structures, and at least two possible Type 2 mound structures recorded through the magnetometer survey at the George C. Davis site (Table 57). These circular structures with non-extended entrances range in size from $4.65 \mathrm{~m}$ to $18 \mathrm{~m}$ in diameter, with areas ranging from $16.98 \mathrm{~m}^{2}$ to 254.5 $\mathrm{m}^{2}$. The mean area for the Type 2 structures is $67.54 \mathrm{~m}^{2}$, with a standard deviation of 57.85. Most of the Type 2 mound structures (77\%) are less than $10 \mathrm{~m}$ in diameter, and only one, Feature 111 from the George C. Davis site, is over $15 \mathrm{~m}$ in diameter. Whereas all of the previously excavated Type 2 non-mound structures had interior areas of less than $200 \mathrm{~m}^{2}$, with $70 \%$ of the geophysical features from George C. Davis having approximate interior areas of $200 \mathrm{~m}^{2}$ or less, Feature 111 exceeds the $200 \mathrm{~m}^{2}$ threshold, with an interior area of approximately $254.5 \mathrm{~m}^{2}$, the largest previously excavated structure in this study. It is clear that there are more non-mound structures exceeding the $200 \mathrm{~m}^{2}$ mark than mound structures (Figure 129). Again, some of these larger structures identified via the magnetometer survey at George C. Davis may represent open enclosures or other types of enclosed spaces that likely differ in use from the smaller structures seen throughout East Texas. Excluding those from the analysis reveals that all of the previously excavated non-mound structures have interior areas of less than $160 \mathrm{~m}^{2}$ (Figure 130), considerably smaller than some of those recorded as part of the George C. Davis magnetometer surveys. 
Table 57. Type 2 mound structures. $\mathrm{c}=$ circular

\begin{tabular}{|l|c|c|c|c|c|l|c|c|c|c|}
\hline Site & Structure & Shape & $\begin{array}{c}\text { Size } \\
(\mathrm{m})\end{array}$ & $\begin{array}{l}\text { Area } \\
\left(\mathrm{m}^{2}\right)\end{array}$ & Site & Structure & Shape & $\begin{array}{c}\text { Size } \\
(\mathrm{m})\end{array}$ & $\begin{array}{c}\text { Area } \\
\left(\mathrm{m}^{2}\right)\end{array}$ \\
\hline George C. Davis & 111 & $\mathrm{c}$ & 18 & 255 & $\begin{array}{l}\text { Oak Hill } \\
\text { Village }\end{array}$ & 4 & $\mathrm{c}$ & 7.5 & 44.18 \\
\hline George C. Davis & 112 & $\mathrm{c}$ & 11 & 95 & $\begin{array}{l}\text { Oak Hill } \\
\text { Village }\end{array}$ & 24 & $\mathrm{c}$ & 7.7 & 46.57 \\
\hline George C. Davis & $45 \mathrm{a}$ & $\mathrm{c}$ & 4.65 & 17 & $\begin{array}{l}\text { Oak Hill } \\
\text { Village }\end{array}$ & 25 & $\mathrm{c}$ & 7.8 & 47.78 \\
\hline George C. Davis & 322 & $\mathrm{c}$ & 5.8 & 26.4 & Whelan & A & $\mathrm{c}$ & 5.18 & 21.07 \\
\hline George C. Davis & 321 & $\mathrm{c}$ & 5.9 & 27.3 & & Whelan & $\mathrm{B}$ & $\mathrm{c}$ & 5.79 & 26.33 \\
\hline Hatchel & 1 & $\mathrm{c}$ & 9.14 & 65.7 & & Whelan & $\mathrm{C}$ & $\mathrm{c}$ & 5.9 & 27.34 \\
\hline Hatchel & 12 & $\mathrm{c}$ & 8.87 & 61.8 & & Whelan & $\mathrm{D}$ & $\mathrm{c}$ & 6.3 & 31.17 \\
\hline Hatchel & 13 & $\mathrm{c}$ & 9.06 & 64.5 & & Keith & 2 & $\mathrm{c}$ & 9.1 & 65.04 \\
\hline Hatchel & 17 & $\mathrm{c}$ & 6.4 & 32.2 & & Hatchel & 25 & $\mathrm{c}$ & 15 & 176.2 \\
\hline Hatchel & 22 inner & $\mathrm{c}$ & 8.53 & 57.2 & $\begin{array}{l}\text { George } \\
\text { C. Davis }\end{array}$ & 44 & $\mathrm{c}$ & 9.1 & 65 \\
\hline Hatchel & $220 u t e r$ & $\mathrm{c}$ & 10.2 & 82 & $\begin{array}{l}\text { George } \\
\text { C. Davis }\end{array}$ & 45 & $\mathrm{c}$ & 13.9 & 151.7 \\
\hline
\end{tabular}

The Type 2 mound-related structures have a range of associated features, including interior hearths, center post holes, pits, smudge pits, burials, and interior post holes that likely represent interior structure supports as well as supports for benches, racks, partitions, etc. Two of these structures (Features 44 and 45 from George C. Davis) were constructed using both wall trenches and single set posts. In addition, at least two Type 2 structures are associated with clearly defined partitions. Feature 45 from George C. Davis has an exterior wall or partition encircling a portion of the structure, likely limiting access to the structure. Feature 25 from Hatchel has a similar wall on the interior of the structure, clearly dividing the structure into separate rooms (Figure 131). 


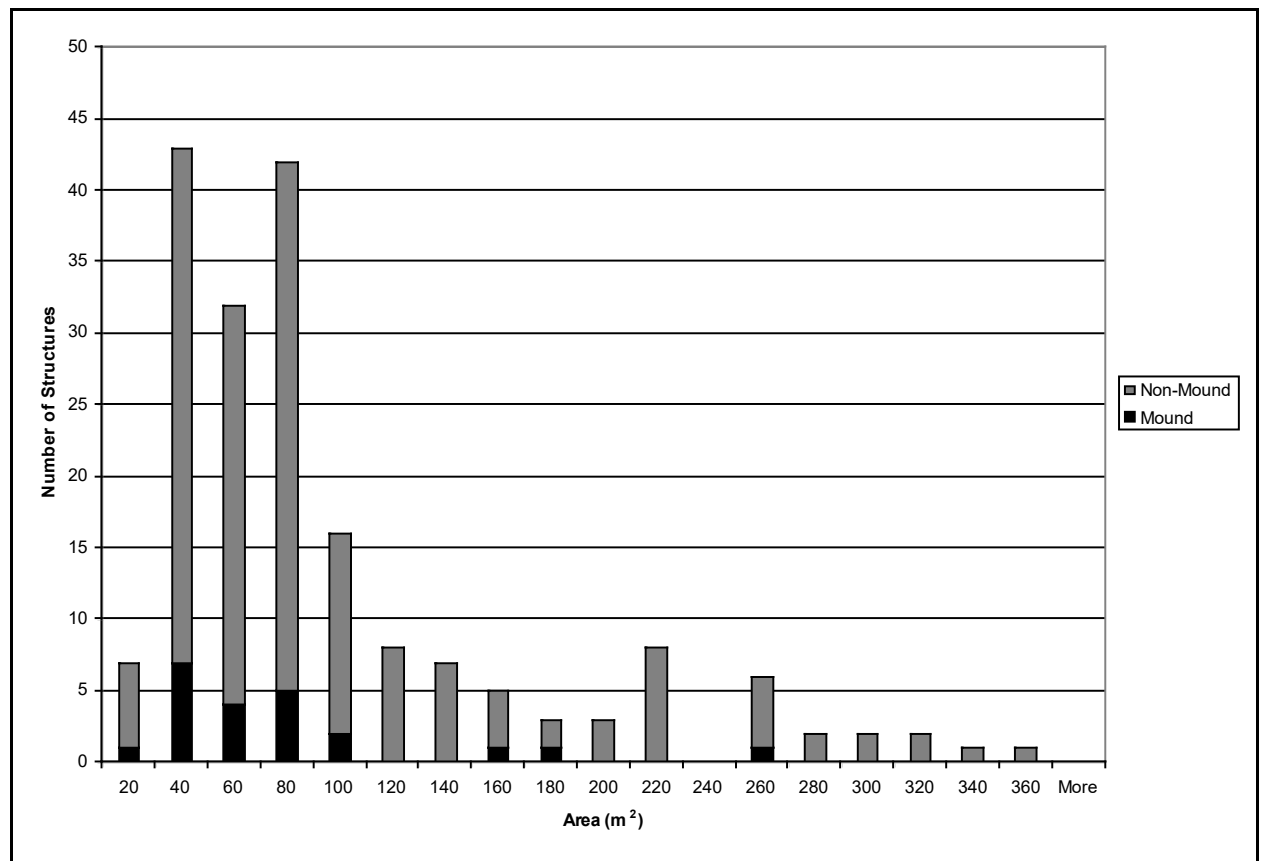

Figure 129. Distribution of Type 2 mound and non-mound structures by interior area.

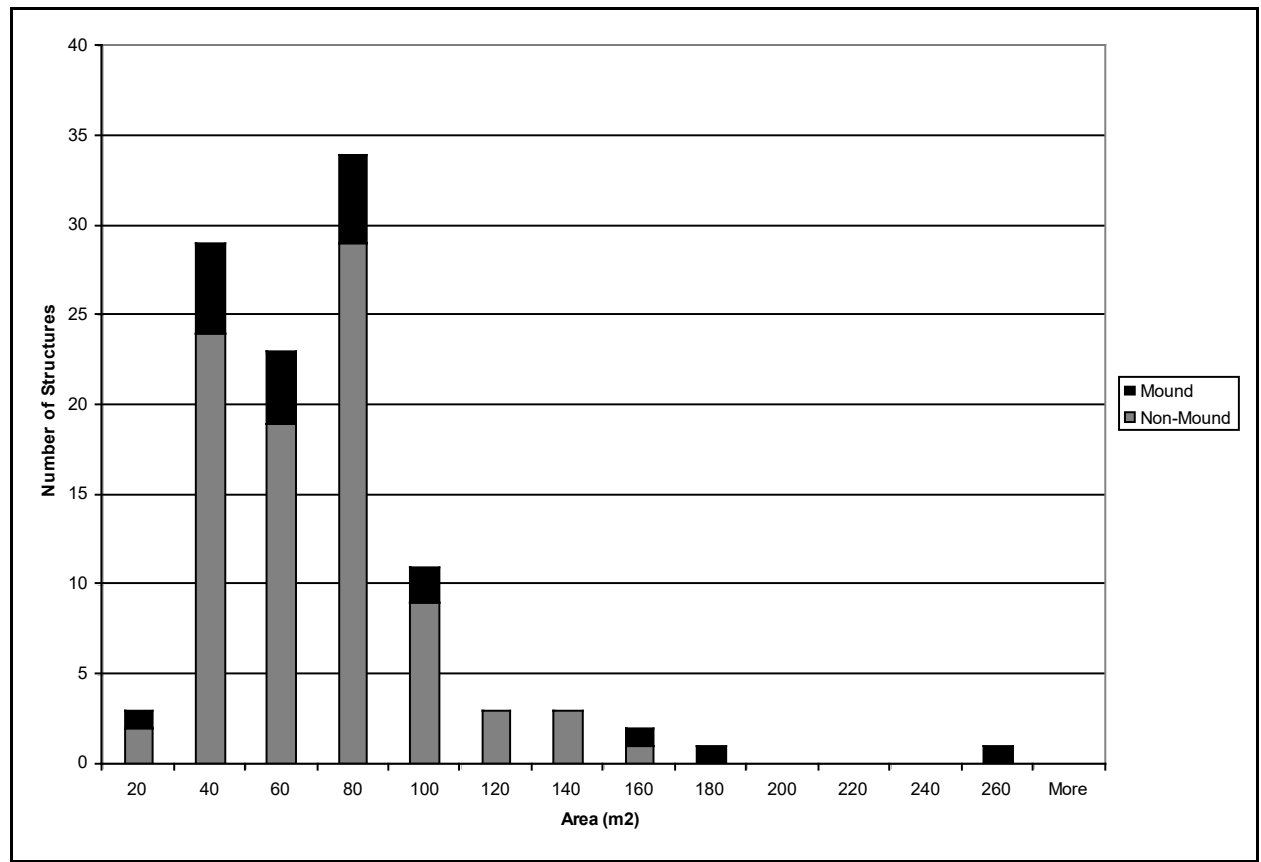

Figure 130. Distribution of Type 2 mound and non-mound structures by interior area, without those structures recorded through magnetometer surveys at George C. Davis and Hill Farm. 

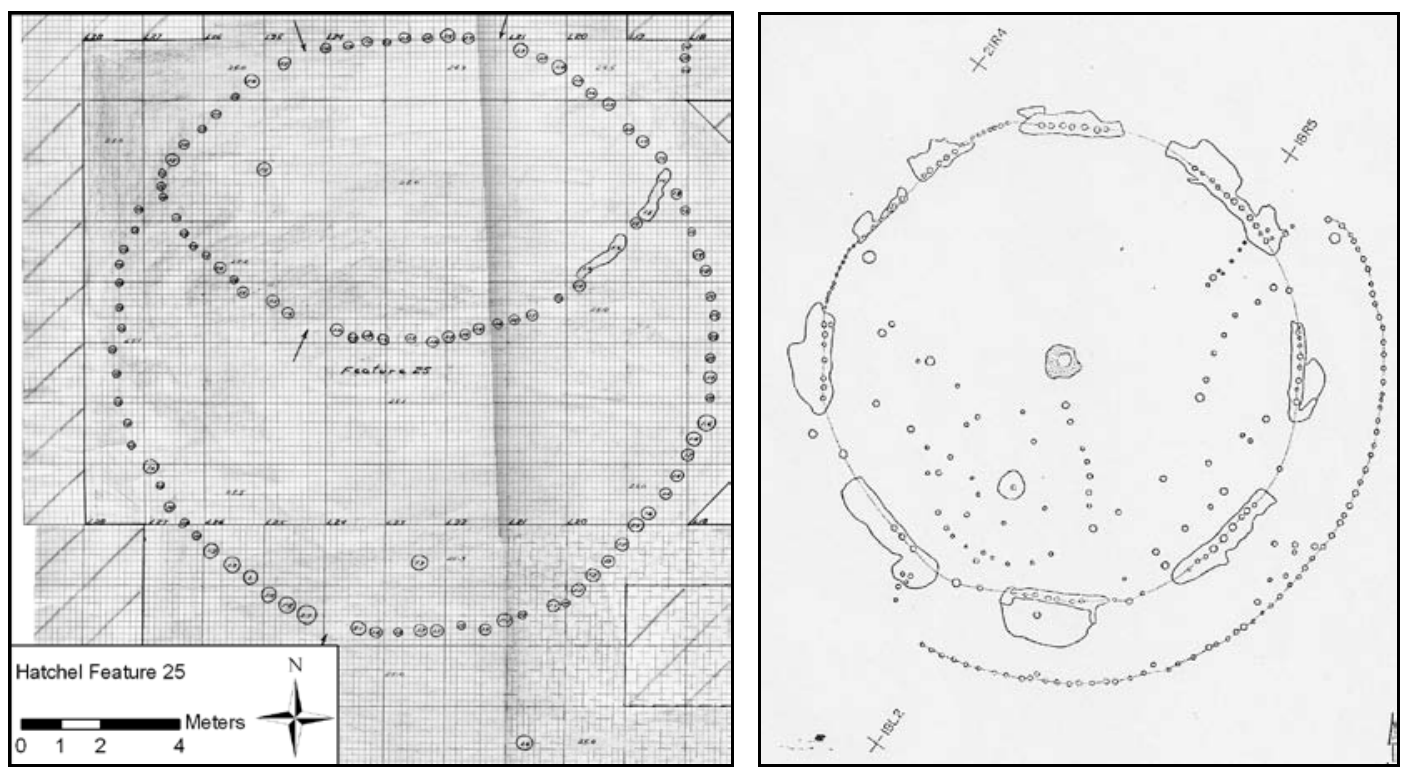

Figure 131. Type 2 mound structures associated with partitions.

\section{Type 3}

Type 3 structures are circular in plan with extended entrances. There are 10 Type 3 non-mound structures from seven different sites (Table 58). These structures have diameters ranging from $5.6 \mathrm{~m}$ to $12.0 \mathrm{~m}$, with areas ranging from $24.63 \mathrm{~m}^{2}$ to $113.04 \mathrm{~m}^{2}$. The difference between the Type 2 and Type 3 structures is the presence of the extended entrance, as the latter is often interpreted to indicate a special purpose structure (Kay and Sabo 2006; Perttula 2009; Rogers 1982a, 1982b; Spock 1977). Four of the Type 3 structures are from the George C. Davis and Hill Farm sites, and were recorded through magnetometer surveys; out of the more than 110 non-mound structures recorded at the George C. Davis site, only two (1.8\%) fall into the Type 3 category.

Type 3 structures tend to be associated with mounds. Twelve $(24 \%)$ of the 50 mound structures included in this study fit into this category of structure (Table 59). The 
Type 3 mound structures have diameters ranging from $3.66 \mathrm{~m}$ to $9.75 \mathrm{~m}$, with areas ranging from $10.51 \mathrm{~m}^{2}$ to $74.72 \mathrm{~m}^{2}$. While extended entrances are often thought of as a feature typically associated with mound structures (Kay and Sabo 2006; Perttula 2009; Rogers 1982a, 1982b; Spock 1977), they only occur in $26 \%$ of the mound structures in this study.

Table 58: Type 3 non-mound structures.

\begin{tabular}{|l|c|c|c|c|c|c|}
\hline \multicolumn{1}{|c|}{ Site } & Structure & Size (m) & Area $\left.\mathbf{( m}^{\mathbf{2}}\right)$ & $\begin{array}{c}\text { Entrance } \\
\text { Facing }\end{array}$ & $\begin{array}{c}\text { Entrance } \\
\text { Length (m) }\end{array}$ & $\begin{array}{c}\text { Entrance } \\
\text { Width (m) }\end{array}$ \\
\hline George C. Davis & 314 & 5.6 & 24.63 & $\mathrm{sw}$ & $1.7-3.5$ & 1.2 \\
\hline George C. Davis & 350 & 6 & 28.27 & $\mathrm{se}$ & 2.2 & 1.5 \\
\hline Hatchel & 1 & 7.14 & 40.02 & $\mathrm{n}-\mathrm{nw}$ & 1.7 & $0.97-1.4$ \\
\hline Hill Farm & 5 & 12 & 113.04 & $\mathrm{nw}$ & 5 & 2.3 \\
\hline Hill Farm & 9 & 10 & 78.5 & $\mathrm{se}$ & 3.3 & 1.5 \\
\hline Hurricane Hill & $\mathrm{B}$ & 7.3 & 41.41 & $\mathrm{sw}$ & 1.1 & 1 \\
\hline Oak Hill Village & 2 & 6.5 & 33.18 & $\mathrm{nw}$ & 2.9 & $59-66$ \\
\hline Oak Hill Village & 18 & 8.7 & 59.45 & $\mathrm{n}$ & 4 & 1 \\
\hline Pilgrims Pride & 2 & $8.5-9$ & $56.72-63.59$ & $\mathrm{~s}$ & $\mathrm{n} / \mathrm{a}$ & $\mathrm{n} / \mathrm{a}$ \\
\hline Rookery Ridge & 1 & 5.85 & 26.9 & $\mathrm{n}-\mathrm{ne}$ & 4 & $0.75-1$ \\
\hline
\end{tabular}

Table 59: Type 3 mound structures. $\mathrm{c}=$ circular

\begin{tabular}{|l|c|c|c|c|}
\hline Site & Structure & Shape & Size (m) & Area $\left.\mathbf{( m}^{\mathbf{2}}\right)$ \\
\hline Dalton & A & c & 4.6 & 16.62 \\
\hline Dalton & B & c & 5.5 & 23.76 \\
\hline Harroun & 1 & c & 5.48 & 23.59 \\
\hline Harroun & 2 & c & 4.26 & 14.25 \\
\hline Harroun & 4 & c & 6.04 & 28.65 \\
\hline Hatchel & 5 & c & 3.66 & 10.51 \\
\hline Hatchel & 7 & c & 9.14 & 65.61 \\
\hline Hatchel & 14 & c & 8.84 & 61.36 \\
\hline Hatchel & 15 & c & 9.75 & 74.72 \\
\hline Hatchel & 16 & c & 7.32 & 42.03 \\
\hline Hatchel & 18 & c & 8.6 & 58.03 \\
\hline Redwine & 1 & c & 5.5 & 23.74 \\
\hline
\end{tabular}




\section{Type 4}

Type 4 structures are small circular structures with diameters of approximately 3 m or less. Approximately 3 meters was chosen for the cutoff based on work from other Caddo sites that has identified smaller structures, those measuring approximately $3 \mathrm{~m}$ or less, as granaries or elevated storage platforms (Rogers and Perttula 2004; Perttula 2005; Spock 1977). There are 11 Type 4 non-mound structures included in this study from four sites (Table 60). The Type 4 structures range in size from 1.5-3.45 $\mathrm{m}$ in diameter with interior areas ranging from $1.8 \mathrm{~m}^{2}$ to $9.35 \mathrm{~m}^{2}$. In discussing what are interpreted as above-ground granaries from the Oak Hill Village site, Perttula and Rogers (2007:78) noted that these structures have no identifiable entrance, "instead, entrance to the structures was probably by a ladder to an elevated platform."

Table 60. Type 4 non-mound structures.

\begin{tabular}{|l|l|l|l|l|l|}
\hline Site & Structure & Shape & Size $(\mathbf{m})$ & $\begin{array}{l}\text { Structure } \\
\left.\text { Area } \mathbf{( m}^{2}\right)\end{array}$ & Comments \\
\hline 41BW3 & 2 & circular & 3.05 & 7.35 & \multicolumn{1}{|c|}{} \\
\hline 41CE19 & 7 & circular & 1.5 & 1.80 & \\
\hline 41CE19 & 50 & circular & 1.9 & 2.80 & \\
\hline 41CE19 & 52 & circular & 1.9 & 2.80 & \\
\hline 41CE19 & 302 & circular & 3.15 & 7.79 & \\
\hline 41CE19 & 301 & circular & 3.45 & 9.35 & \\
\hline 41MR2 & 1 & circular & 3 & 7.16 & \\
\hline 41RK214 & 11 & circular & 3 & 7.07 & \\
\hline 41RK214 & 15 & circular & 2.4 & 4.52 & \\
\hline 41RK214 & 16 & circular & 2.6 & 5.31 & \\
\hline 41RK214 & 27 & circular & 1.6 & 2.01 & \\
\hline
\end{tabular}

In addition to the possible use of small circular structures as granaries, Spock (1977:169) provided additional possible functions for small structures, and noted that 
"the ceremonial or community nature of small structures were described by Espinosa (Hatcher 1927:160) as homes for the cononicis; by Hidalgo (Hatcher 1927:52) as huts for dancers during feasts; and by Massanet (in Swanton 1942:149) as lodging for the pages of the captains."

\section{Type 5}

There are four Type 5 non-mound structures. These structures are all sub-round in shape, have no extended entrance, and have interior areas ranging from approximately $17.35 \mathrm{~m}^{2}$ to $95 \mathrm{~m}^{2}$ (Table 61). Walker (2009:107; see also Spock 1977) describes subround structures as those that have truncated or rounded corners. All but one of the Type 5 structures come from the George C. Davis site. The remaining sub-round structure is from the Blount site. All of the Type 5 non-mound structures have non-extended entrances.

There are four Type 5 mound structures, all from the George C. Davis site. These structures have interior areas ranging from approximately $36.3 \mathrm{~m}^{2}$ to $61.5 \mathrm{~m}^{2}$ (Table 62). One of the Type 5 structures has wall trenches.

Table 61: Type 5 non-mound structures.

\begin{tabular}{|l|l|l|l|l|}
\hline Site & Structure & \multicolumn{1}{|c|}{ Shape } & \multicolumn{1}{|c|}{ Size (m) } & \multicolumn{1}{c|}{ Area $\left.\mathbf{( m}^{\mathbf{2}}\right)$} \\
\hline George C. Davis & 3 & Sub-round & 8.2 & 52.80 \\
\hline George C. Davis & 29 & Sub-round & 8.8 & 60.80 \\
\hline George C. Davis & 139 & Sub-round & $9.6 \times 9.9$ & 95.00 \\
\hline Blount & 1 & Sub-round & $5.18 \times 3.35$ & 17.35 \\
\hline
\end{tabular}


Table 62: Type 5 mound structures.

\begin{tabular}{|l|l|l|l|l|}
\hline Site & Structure & \multicolumn{1}{|c|}{ Shape } & Size (m) & $\begin{array}{c}\text { Area } \\
\left(\mathbf{( m}^{2}\right)\end{array}$ \\
\hline George C. Davis & 36 & Sub-round & 7.2 & 41.2 \\
\hline George C. Davis & 37 & Sub-round & $7.4 \times 10.3$ & 61.5 \\
\hline George C. Davis & 38 & Sub-round & $6.4 \times 7.2$ & 36.3 \\
\hline George C. Davis & 43 & Sub-round & $7.2 \times 7.8$ & 44.2 \\
\hline
\end{tabular}

\section{Type 6}

Type 6 structures are sub-square in shape, with most of them having rounded or diagonal corners. The main difference between the Type 6 and Type 5 structures is that Type 6 structures tend to have relatively flattened sides with several appearing almost rectangular in form (Features 260, 281, and 347 from the George C. Davis site). All of the Type 6 structures are from the George C Davis site. The Type 6 non-mound structures (Table 63) have interior areas ranging from approximately $22.08 \mathrm{~m}^{2}$ to $414.1 \mathrm{~m}^{2}(\mathrm{n}=15$, $\bar{x}=111.61 \mathrm{~m}^{2}, \mathrm{~s}=95.0711$ ). The Type 6 mound structures (Table 64) have interior areas ranging from $44.1 \mathrm{~m}^{2}$ to $66.3 \mathrm{~m}^{2}$, with a mean area of $56.17 \mathrm{~m}^{2}$. One Type 6 non-mound structure, Feature 9, has a southeast-facing extended entrance. Two of the Type 6 mound structures, Features 281 and 347, both of which are almost rectangular in form, have extended entrances facing south-southeast and southwest respectively. All of the other Type 6 structures have non-extended entrances. 
Table 63. Type 6 non-mound structures.

\begin{tabular}{|c|c|c|}
\hline Structure & Size (m) & Area $\left.\mathbf{( m}^{\mathbf{2}}\right)$ \\
\hline 4 & $10.7 \times 11.8$ & 126.3 \\
\hline 6 & $9.7 \times 10.3$ & 99.9 \\
\hline 9 & $9.9 \times 9.9$ & 98 \\
\hline 53 & 14 & 153.9 \\
\hline 54 & $9.0 \times 9.5$ & 85.5 \\
\hline 185 & 12 & 113 \\
\hline 250 & 8 & 50.24 \\
\hline 251 & 7 & 38.47 \\
\hline 252 & 11.7 & 107.51 \\
\hline 253 & 14.9 & 174.37 \\
\hline 254 & $10.7 \times 10.7$ & 114.49 \\
\hline 260 & $5 \times 6$ & 30 \\
\hline 281 & $6.8 \times 6.8$ & 46.24 \\
\hline 347 & $4.6 \times 4.8$ & 22.08 \\
\hline Osburn et al. (2008), Structure 2 & $20.2 \times 20.5$ & 414.1 \\
\hline
\end{tabular}

Table 64. Type 6 mound structures.

\begin{tabular}{|l|c|c|c|c|}
\hline Site & Structure & Shape & Size (m) & Area $\left.\mathbf{( m}^{\mathbf{2}}\right)$ \\
\hline George C. Davis & 34 & Sub-square & $7.9 \times 7.9$ & 58.1 \\
\hline George C. Davis & 39 & Sub-square & $8.7 \times 8.7$ & 66.3 \\
\hline George C. Davis & 40 & Sub-square & $7 \times 7$ & 44.1 \\
\hline
\end{tabular}

\section{Type 7}

Rectangular structures on East Texas Caddo sites are divided into two types, Types 7 and 8 . Type 7 structures are rectangular with non-extended entrances while Type 8 rectangular structures have extended entrances. There are seven Type 7 non-mound structures (Table 65), with interior areas ranging from approximately $24.60 \mathrm{~m}^{2}$ to $96 \mathrm{~m}^{2}$ $\left(\mathrm{n}=5, \bar{x}=72.22 \mathrm{~m}^{2}, \mathrm{~s}=30.5318\right)$. Four of these structures are from the Oak Hill Village site and were determined to be the earliest structures built at the site, probably dating to before A.D. 1250 (Perttula and Rogers 207). Perttula and Rogers (2007:75-76) further 
noted that the rectangular structures from the Oak Hill Village site "lacked postholes at the corners, suggesting they had rounded rather than square corners." This is also true of the Type 8 structures from Roitsch and Hines. All of the Type 7 and 8 structures from the George C. Davis site were recorded through magnetometer surveys and have not been ground-truthed to establish what kinds of corners the buildings had.

There are four Type 7 mound structures with interior areas ranging from approximately $7.82 \mathrm{~m}^{2}$ to $42.75 \mathrm{~m}^{2}$. Two of these structures are from the Sanders site and may be a subtype since they may be a different architectural style (or were incompletely exposed) than the others since they were described by Jackson (2000) as open-sided structures, resembling a lean-to. The other two Type 7 structures are from the Fasken and Roitsch-Sam Kaufman sites. Extended entrances were not recorded for either of these structures, but they are both so incomplete that one cannot say confidently that they did not have extended entrances.

Table 65. Excavated Type 7 structures.

\begin{tabular}{|l|c|c|c|c|}
\hline \multicolumn{1}{|c|}{ Site } & Structure & Size (m) & Area ( $\left.\mathbf{m}^{\mathbf{2}}\right)$ & Mound \\
\hline Hurricane Hill & $\mathrm{D}$ & $\mathrm{x}$ & $\mathrm{N} / \mathrm{A}$ & No \\
\hline Hurricane Hill & $\mathrm{E}$ & $\mathrm{x}$ & $\mathrm{N} / \mathrm{A}$ & No \\
\hline Oak Hill Village & 37 & $8 \times 12$ & 96.00 & No \\
\hline Oak Hill Village & 38 & $7.5 \times 12$ & 90.00 & No \\
\hline Oak Hill Village & 39 & $8 \times 11.5$ & 92.00 & No \\
\hline Oak Hill Village & 43 & $6.5 \times 9$ & 58.50 & No \\
\hline Roitsch (Sam Kaufman) & 1 & $6 \times 4.1$ & 24.60 & No \\
\hline Sanders & 1 & $3.05 \times 3.66$ & 11.16 & Yes \\
\hline Sanders & 2 & $3.05 \times 2.59$ & 7.90 & Yes \\
\hline Holdeman & 1 & $3.05 \times 6.10$ & 18.61 & Yes \\
\hline Roitsch (Sam Kaufman) & 2 & $4.75 \times 9$ & 42.75 & Yes \\
\hline
\end{tabular}


Table 66. Excavated Type 8 structures.

\begin{tabular}{|l|r|l|r|r|}
\hline Site & Feature/Structure & Size $(\mathrm{m})$ & Area $\left(\mathrm{m}^{2}\right)$ & Mound \\
\hline Roitsch & 3 & $5.6 \times 3.5$ & 19.60 & No \\
\hline Hines & 2 & $4.8 \times 3.27$ & 15.70 & No \\
\hline Hines & 3 & $6.65 \times 5.2$ & 34.58 & No \\
\hline Holdeman & 1 & $3.05 \times 6.10$ & 18.61 & Yes \\
\hline
\end{tabular}

\section{Type 8}

There are three Type 8 non-mound structures and one Type 8 mound structure in this study (Table 66). The Type 8 non-mound structures tend to be smaller with interior areas ranging from approximately $15.70 \mathrm{~m}^{2}$ to $34.58 \mathrm{~m}^{2}$. These structures have extended entrances facing to the southwest or west. The Type 8 mound structure is from the Holdeman site and has an interior area of approximately $18.61 \mathrm{~m}^{2}$ and an extended entrance facing southwest.

Type 7 and 8 structures tend to have at least one center support post, but some have two or more. Perttula and Rogers (2007) noted, for example, at the Oak Hill Village site that interior support posts were not recorded for all of the rectangular structures. This is also true for other Type 7 or 8 structures. However, I would agree with their assessment that on architectural grounds, it is likely that "they all had a center post to support corner rafters and the roof" (Perttula and Rogers 2007:75-76). This architectural assessment can likely be extended to all Type 7 and 8 structures as well. 


\section{CHAPTER 8}

\section{CADDO ARCHITECTURE IN EASTERN TEXAS}

Circular, sub-square, sub-round, and rectangular structures on East Texas Caddo sites include daily use, communal, and family spaces such as domiciles and granaries, as well as special purpose spaces that may have been reserved for particular activities or specific peoples (i.e., the religious and political elite). Such special purpose structures may have been directly associated with religious, political, or ceremonial uses. Based on form, construction attributes, association with earthen mounds, or previous interpretations based on artifact associations and associated features, at least 209 of the structures included in this study are classified as daily use, communal, or family spaces, those allowing greater access to people in the farmstead, hamlet, village, or mound center, with the remaining 56 being special purpose spaces, those with limited access to people in the larger community.

\section{NATURe OF CAdDo ARChitectural SPACE}

In this concluding chapter of the dissertation, I discuss the classification of structures as either specialized/special purpose or non-specialized/non-special purpose structures, architectural categories often used in the Caddo area (Rogers 1982a, 1982b; Lisk 1984:74-75; Early 1988, 2000; Kay and Sabo 2006; Perttula 2009; Perttula and Rogers 2007; Sabo 1998; Spock 1977; Story 1990; Trubitt 2010) and the nature of Caddo architectural spaces. The categories of specialized or special purpose and non-specialized structures are based partly on architectural form and partly on location and mound association. In Chapter 3, I discussed three broad categories of architectural space, daily 
use, communal, and family spaces (including houses, arbors, granaries, etc), spaces reserved for particular activities and/or people (i.e. assembly houses and the reserved seats for the xinesi), and religious, ceremonial, and symbolic structures or spaces (i.e the temple, the houses of the coninisi, etc). The first category of structures are nonspecialized or non-special purpose spaces while the last two, particularly the third category, can be considered specialized or special purpose spaces.

In archaeological terms, Spock (1977) had classified structures from the George C. Davis site as either domiciles or special function structures. Spock's (1977:169) special function structures included those structures directly associated with mounds, structures that were exceptionally large or small in size, those with unusual shapes, and/or those characterized by unusual or distinctive interior features. Rogers (1982b:49) classified specialized structures as "any of the variety of structures that provided a physical context for the integration of social organization beyond that of the household unit.” Rogers (1982:105, 1982b:89) further included a range of architectural spaces, including mortuaries, meeting halls, temples, elite residences, or other public buildings, as specialized structures. These architectural spaces would include those directly associated with earthen mounds, those that are larger than typical structures, those "that are markedly different from contemporaneous domestic dwellings" (Rogers 1982b:49), and those associated with atypical artifact assemblages or features (Rogers 1982a:105). Extended entranceway structures are also generally considered to be specialized structures (Kay and Sabo 2006; Perttula 2009; Walker 2009), possibly representing buildings associated with ritual practitioners or the elite.

Given these considerations, all of the Type 3 and Type 8 structures on East Texas Caddo sites can be categorized as specialized structures, as would Feature 9 from Davis, 
which is a Type 6 structure. In addition, based on size, Type 4 structures can also be considered specialized structures, as they likely represent raised platforms or granaries. The unusually large structures, those with interior areas exceeding $150 \mathrm{~m}^{2}$ can be classified as specialized structures. These structures may represent open enclosures, assembly houses, community spaces, or other buildings that could have accommodated large numbers of people or certain kinds of activities requiring considerable amounts of space, such as dances or feasting. Structures 6 (Type 6) and 125 (Type 1) from the George C. Davis site were classified as specialized structures by Spock (1977:177-179) due to their architecture or associated features and are so classified here. Specialized structures (Structures 1 and 3) from Earspool, both Type 2 structures, were each built in pits. Table 67 provides a list of the 56 non-mound specialized structures identified in this study.

Structures associated with mounds in the Caddo area have been thought of as special purpose structures (e.g., Perttula 2009; Rogers 1982a, 1982b; Schambach 1996; Spock 1977; Story 1990). Accordingly, all of those structures (of whatever structure type) associated with either platform mounds or sub-structural mounds in this study are considered special purpose structures. In reference to Caddo platform and structural mounds, Story (1990:340) noted that "while it is the earthen mound that today stands out, it surely is the associated structures (as well as possibly related features such as plazas) and the activities/events that took place in them that are important." Furthermore, Schambach's (1996:40) assertion of the shift from "individual-oriented ceremonialism to public-building ceremonialism" in the area indicates the importance placed on these kinds of architectural spaces. 
Table 67: Special purpose structures not built on mounds.

\begin{tabular}{|c|c|c|c|}
\hline Site & Structure & Size (m) & $\operatorname{Area}\left(\mathbf{m}^{2}\right)$ \\
\hline Hill Farm & 2 & 15 & 176.63 \\
\hline Hill Farm & 4 & $14.5-17.5$ & $\begin{array}{l}165.05- \\
240.41\end{array}$ \\
\hline Hill Farm & 5 & 12 & 113.04 \\
\hline Hill Farm & 9 & 10 & 78.5 \\
\hline Hatchel & 1 & 7.14 & 40.02 \\
\hline Hatchel & 2 & 3.05 & 7.35 \\
\hline $\begin{array}{l}\text { George C. } \\
\text { Davis }\end{array}$ & 6 & $9.7 \times 10.3$ & 99.9 \\
\hline $\begin{array}{l}\text { George C. } \\
\text { Davis }\end{array}$ & 7 & 1.5 & 1.8 \\
\hline $\begin{array}{l}\text { George C. } \\
\text { Davis }\end{array}$ & 9 & $9.9 \times 9.9$ & 98 \\
\hline $\begin{array}{l}\text { George C. } \\
\text { Davis }\end{array}$ & 50 & 1.9 & 2.8 \\
\hline $\begin{array}{l}\text { George C. } \\
\text { Davis }\end{array}$ & 52 & 1.9 & 2.8 \\
\hline $\begin{array}{l}\text { George C. } \\
\text { Davis }\end{array}$ & 125 & 7.4 & 43 \\
\hline $\begin{array}{l}\text { George C. } \\
\text { Davis }\end{array}$ & 179 & 20.3 & 323.65 \\
\hline $\begin{array}{l}\text { George C. } \\
\text { Davis }\end{array}$ & 238 & 21 & 346.36 \\
\hline $\begin{array}{l}\text { George C. } \\
\text { Davis }\end{array}$ & 239 & 17.5 & 240.53 \\
\hline $\begin{array}{l}\text { George C. } \\
\text { Davis }\end{array}$ & 247 & 15.4 & 186.27 \\
\hline $\begin{array}{l}\text { George C. } \\
\text { Davis }\end{array}$ & 253 & 14.9 & 174.37 \\
\hline $\begin{array}{l}\text { George C. } \\
\text { Davis }\end{array}$ & 255 & 18.4 & 265.9 \\
\hline $\begin{array}{l}\text { George C. } \\
\text { Davis }\end{array}$ & 256 & 16.1 & 203.58 \\
\hline $\begin{array}{l}\text { George C. } \\
\text { Davis }\end{array}$ & 257 & 16.7 & 219.04 \\
\hline $\begin{array}{l}\text { George C. } \\
\text { Davis }\end{array}$ & 258 & 17.7 & 246.06 \\
\hline $\begin{array}{l}\text { George C. } \\
\text { Davis }\end{array}$ & 259 & 20.1 & 317.31 \\
\hline $\begin{array}{l}\text { George C. } \\
\text { Davis }\end{array}$ & 264 & 15 & 176.71 \\
\hline $\begin{array}{l}\text { George C. } \\
\text { Davis }\end{array}$ & 265 & 16.2 & 206.12 \\
\hline $\begin{array}{l}\text { George C. } \\
\text { Davis }\end{array}$ & 267 & 16.2 & 206.12 \\
\hline $\begin{array}{l}\text { George C. } \\
\text { Davis }\end{array}$ & 269 & 18.1 & 257.3 \\
\hline $\begin{array}{l}\text { George C. } \\
\text { Davis }\end{array}$ & 281 & $6.8 \times 6.8$ & 46.24 \\
\hline $\begin{array}{l}\text { George C. } \\
\text { Davis }\end{array}$ & 284 & 16.1 & 203.58 \\
\hline
\end{tabular}

\begin{tabular}{|c|c|c|c|}
\hline Site & Structure & Size (m) & $\operatorname{Area}\left(\mathrm{m}^{2}\right)$ \\
\hline $\begin{array}{l}\text { George C. } \\
\text { Davis }\end{array}$ & 305 & 18.25 & 261.59 \\
\hline $\begin{array}{l}\text { George C. } \\
\text { Davis }\end{array}$ & 314 & 5.6 & 24.63 \\
\hline $\begin{array}{l}\text { George C. } \\
\text { Davis }\end{array}$ & 340 & 15.5 & 188.69 \\
\hline $\begin{array}{l}\text { George C. } \\
\text { Davis }\end{array}$ & 347 & $4.6 \times 4.8$ & 22.08 \\
\hline $\begin{array}{l}\text { George C. } \\
\text { Davis }\end{array}$ & 350 & 6 & 28.27 \\
\hline $\begin{array}{l}\text { George C. } \\
\text { Davis }\end{array}$ & $\begin{array}{l}\text { Osburn et al. } \\
(2008), 10\end{array}$ & 15.9 & 198.46 \\
\hline $\begin{array}{l}\text { George C. } \\
\text { Davis }\end{array}$ & $\begin{array}{l}\text { Osburn et al. } \\
(2008), 3\end{array}$ & $18 \times 17.5$ & 315 \\
\hline $\begin{array}{l}\text { George C. } \\
\text { Davis }\end{array}$ & $\begin{array}{l}\text { Osburn et al. } \\
(2008), 4\end{array}$ & 16.4 & 211.13 \\
\hline $\begin{array}{l}\text { George C. } \\
\text { Davis }\end{array}$ & $\begin{array}{l}\text { Osburn et al. } \\
(2008), 5\end{array}$ & $16.8 \times 17.5$ & 294 \\
\hline $\begin{array}{l}\text { George C. } \\
\text { Davis }\end{array}$ & $\begin{array}{l}\text { Osburn et al. } \\
(2008), 6\end{array}$ & 16.5 & 213.72 \\
\hline $\begin{array}{l}\text { George C. } \\
\text { Davis }\end{array}$ & $\begin{array}{l}\text { Osburn et al. } \\
(2008), 7\end{array}$ & $17.0 \times 17.3$ & 294.1 \\
\hline $\begin{array}{l}\text { George C. } \\
\text { Davis }\end{array}$ & $\begin{array}{l}\text { Osburn et al. } \\
\text { (2008), } 8\end{array}$ & 16.3 & 208.57 \\
\hline $\begin{array}{l}\text { George C. } \\
\text { Davis }\end{array}$ & $\begin{array}{l}\text { Osburn et al. } \\
(2008), 9\end{array}$ & 18 & 254.34 \\
\hline $\begin{array}{l}\text { Pilgrims } \\
\text { Pride }\end{array}$ & 2 & $8.5-9$ & $\begin{array}{l}56.72- \\
63.59 \\
\end{array}$ \\
\hline $\begin{array}{l}\text { Hurricane } \\
\text { Hill }\end{array}$ & $\mathrm{B}$ & 7.3 & 41.41 \\
\hline Whelan & 1 & 3 & 7.16 \\
\hline $\begin{array}{l}\text { Oak Hill } \\
\text { Village }\end{array}$ & 2 & 6.5 & 33.18 \\
\hline $\begin{array}{l}\text { Oak Hill } \\
\text { Village }\end{array}$ & 11 & 3 & 7.07 \\
\hline $\begin{array}{l}\text { Oak Hill } \\
\text { Village }\end{array}$ & 15 & 2.4 & 4.52 \\
\hline $\begin{array}{l}\text { Oak Hill } \\
\text { Village }\end{array}$ & 16 & 2.6 & 5.31 \\
\hline $\begin{array}{l}\text { Oak Hill } \\
\text { Village }\end{array}$ & 18 & 8.7 & 59.45 \\
\hline $\begin{array}{l}\text { Oak Hill } \\
\text { Village }\end{array}$ & 27 & 1.6 & 2.01 \\
\hline Roitsch & 3 & $5.6 \times 3.5$ & 19.6 \\
\hline Earspool & 1 & 4.56 & 16.27 \\
\hline Earspool & 3 & 5 & 15.81 \\
\hline $\begin{array}{l}\text { Rookery } \\
\text { Ridge }\end{array}$ & 1 & 5.85 & 26.9 \\
\hline Hines & 2 & $4.8 \times 3.27$ & 15.7 \\
\hline Hines & 3 & $6.65 \times 5.2$ & 34.58 \\
\hline
\end{tabular}


Caddo mounds have been examined as expressions of political ideology and, as Sabo (1998) has argued, mound construction expressed material symbolism through a number of ways. Sabo (cited in Story 1998) noted that certain aspects of mound construction and use are "physical expressions of underlying principles that guided Caddoan religious and social symbolism.” Similarly, Rogers (1982b:105) has pointed out that the "concept of cultural space relates to a variety of contexts, not the least of which is the interplay between the world of humans and the realm of the supernatural. In this context cultural space is physically represented by the buildings, grounds, and other enclosures that religious practitioners use." The socio-political/ideological significance of earthen mounds is bolstered by Knight's (1986:678) argument that platform mounds associated with Mississippian traditions should themselves be included in the triad of iconic families of sacra. This recognition of earthen mounds as symbolically significant "objects of sacred display" (Knight 1986:678) places the specialized structures associated with mounds and those that apparently were used for political or religious purposes within the realm of social, political, or ideological symbolism as well. Furthermore, the superposition of structures often documented on earthen mounds is a clear expression of the significance of location and place in the construction of these important or "specialized" spaces. Such superposition would act as a means of harkening back and tying into the past and previous use of space, possibly offering a means of legitimizing power.

Parsons (personal communication 2009) notes that extended entrances (an architectural attribute that limits access), the act of ritually destroying and rebuilding (signifying a pattern of death and renewal of ritual or otherwise specialized spaces), and the act of covering with an earthen mound or incorporating an earthen berm around a 
structure may be seen as an interlocking complex. Although not all of these attributes are associated with each of the specialized structures in Caddo East Texas, such a complex would identify special purpose structures on the landscape, setting such structures apart, and setting the rules for how such structures are to be treated.

The European accounts provide ample evidence for the symbolic significance of Caddo architecture, primarily in the role played by domiciles themselves. While those structures categorized as "non-specialized" structures may not play what is traditionally thought of as "specialized" role, such as those buildings used or lived in by the elite or ritual practitioners, Caddo domiciles played a significant role in maintaining the cohesiveness of the community and grounding individuals and families within the larger group. Cus and Raharijaona (2000:101) have noted that "while there exists a "plurality of meaning' to a house within a given culture, one recurrent symbolic theme that has been noted cross-culturally is that the arrangement of the domestic structure often reproduces the map of the cosmos, the order of the world." This practice is clear among the Caddo where concepts such as who was considered "Us," "Not Us," and "Other" (Helms 1998) (i.e., "member of a specific community or village", "not a member of a specific community or village", and "supernatural, ancestral, otherworldly") as well as distinctions or categories centered on such things as status, access, kinship, or group membership are surely manifest in the cultural landscape and structured environment (Helms 1998; Locock 1994; Tilley 1994; Sullivan and Rodning 2001; Yeager and Canuto 2000). The symbolism inherent in house construction illustrates concepts and actions promoting group membership as well as the role of house as metaphor for the social group, and also illustrates the symbolism inherent in Caddo architectural space and the practices associated with its creation, use, and destruction (Cus and Raharijaona 2000; 
Donley 1987; Sabo 1998; Schultz 2004). As Sabo (1998:168) has argued, "it seems clear enough that houses (or, more specifically, the households represented by the houses) were regarded as constituent elements of matrilineally organized communities."

The similarity between common domestic structures and the residences of the elite as well as the control of the structuring of space (e.g., scheduling construction, structure size, and layout organized by political and religious figures) may be reflective of what Cus and Raharijaona (2000:101) note as a desirable action by political or ritual elites "to gain an ideological foothold in local knowledge and symbols to guarantee intelligibility, to facilitate the assimilation of its order by average citizens, and to argue for its legitimacy." Furthermore, as discussed by Tilley (1994:17), "features of the settings of social interaction may constitute 'disciplinary' spaces through which knowledge is controlled or acquired in a highly structured manner. The ability to control access to and manipulate particular settings for action is a fundamental feature of the operation of power as domination."

These points are illustrated in the accounts of specialized structures situated near the house of a Caddo chief. These structures were limited to use by particular individuals, some for ritual practitioners, some for visiting dignitaries. By limiting access to, or the use of certain spaces to, ritual practitioners, for instance, those spaces, such as the temple, and the activities associated with them, can be instilled with ideological or supernatural significance. Additionally, these specialized spaces were limited to use at specific times and for specific occasions. The temple and related houses of the cononices are evidence for specialized, disciplinary spaces with limited access, specialized functions, and symbolic significance, through which the rules of society are brought 
forth, and in which interactions between this world and the otherworld take place (Sabo 1998; Schultz 2004).

Architectural spaces may become significant as social, political, or ideological symbols signifying meanings not intrinsic to or identifiable in a structure itself. Once the cultural association of architectural spaces transcends the ordinary and takes on the role of signifier, such spaces can act to mediate the interactions and the relationships between the individual and the broader social realm, reflecting broader cultural beliefs or practices. Symbolic meanings can be assigned to architectural spaces through several means, including practices associated with given structures, such as the use of spaces by individuals or groups to which significance has been assigned, through associations with supernatural or religious spaces, or through the locations of structures. Sabo (1998:171) has argued "since kinship was traced through the mother's line, the house-as-icon may be regarded as a symbolic representation of the matrilineage," while "since leadership offices were inherited through the male line, temples and ceremonial centers-as-icons symbolically represented patrilineal jural descent.”

The emphasis on an otherworldly house of the dead to which all will go as well as the supernatural origin for patterns of spatial organization, and the construction of heaven in the manner and shape of earthly structures, provides a sound foundation for the examination of sacred and symbolic spaces. In addition, the European accounts of the Caddo suggest the symbolism inherent in the temple as icon (Sabo 1998) in its representation of the heavens in the form of the house of the great captain; in housing the sacred and perpetual fire and the accouterments necessary for, and associated with, communication between this and the otherworld; and in serving as a sort of vessel in which the xinesi transcends that gap and communicates with the caninisi (Sabo 1998; 
Schultz 2004). The iconic significance of this architectural space is further stressed in the accounts of the caddi's residence, within which was kept a small replica of the temple itself. This recreation of sacred and symbolic space within the home of the caddices associated these officials and their compounds with the power inherent in the temple space, thus bringing that power into their compounds and providing these officials with a direct association with the otherworld.

The function played by the fire temple in providing the fire for each house in a community or village further illustrates the notion that a community is embodied in the cultural landscape and architecture of the Caddo. Sabo (1998:169) has suggested that "the lighting of house fires with embers from the fire temple can be interpreted as a symbolic representation of sacred connections that subsumed individual households within a large community." The spiritual capital gained by elites, specifically the Gran Xinesi, through their ability to access spaces of power, such as the temple and the houses of the caninisi, necessitated a strong symbolic association with these architectural spaces. The recreation of this sacred and symbolic space within the homes of the caddices further illustrates the significance of architectural spaces as icons and the symbolic significance associated with specialized or iconic spaces such as a temple structure, itself possibly a metaphor for otherworldly space.

The broader social and symbolic roles played by Caddo architecture suggest that physical structures themselves and the organized spaces they create played active roles as “objects of sacred display" (Knight 1986:678). In addition, by being a correlate to the house structure in the otherworld, a Caddo house may be seen as having a close relationship with the cosmos, functioning to locate the Caddo occupants at the focal point of cosmic power and linking together every Caddo household (Sabo 1998). 
These conclusions suggest that the broad range of architectural spaces used by the Caddo in prehistoric and early historic times, including daily use, communal, and family spaces; spaces reserved for particular activities and/or people; and religious, ceremonial, and symbolic structures/spaces; all played significant roles in those Caddo societies. Among the Caddo of eastern Texas, there was a direct relationship between cultural identity, power and ideological authority, and architecture. These spaces all worked together to provide the Caddo with reflections of their cultural identity as well as physical links to the past and the otherworld. For the Caddo, identity and community cohesiveness appears to have been encoded in architecture (Sabo 1998), which acted to reify ideas of community and otherness.

\section{Regional Perspective}

This dissertation has shown that, while Caddo architecture includes various forms, the dominant structure form throughout the range of Caddo time periods in eastern Texas is circular. This is true for both mound and non-mound contexts. Trubitt (2010) recently noted that, while straight-sided structures are found in southwest Arkansas, the norm, particularly for non-mound structures, is circular. For Webb (1940), the dominant structure shape appeared to be circular with the rectangular structures at the Belcher site being built by an earlier Caddo group. In addition, Webb (1940:73) noted that the predominant structure form for the southern Caddo was "grass lodges and lodges with wattle and daub walls and grass thatched roofs." Structures from other sites in northwest Louisiana such as the McLelland, Joe Clark, Hanna, and Werner sites are consistent with Webb's assessment. This suggests that in non-mound contexts at least, circular structures 
are the norm for the southern Caddo area, with square to rectangular structures being the anomaly in many instances or primarily being associated with mounds.

Many of the mound-related "specialized" structures in portions of southwest Arkansas are square or rectangular (Early 2000). For the Ouachita River Basin, at the northern reaches of the southern Caddo area, Early (2000:130) noted that "straight-walled structures are well-documented phenomena at Caddo mound sites in the greater Ouachita River basin." At the Winding Stair site, Early (2000) excavated a rectangular structure measuring approximately $6.2 \times 4.5 \mathrm{~m}$. Early (2000:129) noted "in looking at how the Winding Stair structure, both its general form and the fragmentary superstructure remains, compares with architecture at other sites in the Little Missouri River valley and elsewhere in the Ouachita drainage basin, it seems that rather than being a regional anomaly, it is consistent with general trends in "special" architecture throughout this portion of the greater Caddo area."

Many of the mounds excavated by Harrington (1920) in southwest Arkansas had square to rectangular structures as did Mound A excavated by Schambach at the Ferguson site in the Little Missouri drainage. Rectangular structures were also recorded at the Standridge and Adair sites in the Ouachita Mountains (Early 1988, 2000). At the Caddo Valley site on the Caddo River, Trubitt (2010) noted a sequence of buildings including circular pre-mound structures, a rectangular building built on a layer of fill covering the area where the circular buildings had once stood, and then a later circular building atop the mound fill covering the burned rectangular building. For the middle Ouachita River and the Little Missouri River regions, Trubitt (2010:240) noted that archaeologists have recorded "both circular and square/rectangular post structures in mound contexts." In addition, square to rectangular structures have been found via 
geophysical surveys. At the Tom Jones site, a large Caddo mound site in southwest Arkansas dating from about A.D. 1200 to 1500, surveys recorded eight rectangular structures at the base of one of the mounds (Lockhart 2007). McKinnon (2008) recorded both circular and square to rectangular structures at the Battle Mound site located along the Red River in southwest Arkansas.

For eastern Oklahoma and the northern Caddo area, the common structure form appears to be square to rectangular, many with two to four interior support posts, similar to the pattern of posts seen in the Type 1 structures from eastern Texas. There is an apparent shift in architectural practices in the Arkansas Basin during the Harlan to Spiro phases. Structures during the Harlan Phase were generally square with four large interior support posts while the later Spiro Phase structures are small and are rectangular with two interior support posts (Rogers 1982a). There is another possible shift during the Fort Coffee phase (A.D. 1450-1650) from predominantly rectangular structures to circular buildings. In fact, Rogers (1982a:107) noted that "round structures are unusual in the Arkansas Basin and it is possible that they represent a very late component rather than specialized buildings in a Fort Coffee Phase context."

As is clear from research throughout the Caddoan archaeological area, there is considerable architectural variation and apparent regional architectural traditions. Future studies should explore this variation and look into regional practices and variations in the architectural traditions of the different Caddo groups.

\section{AVENUES FOR FURTHER RESEARCH}

This dissertation has provided a detailed look at 265 Caddo structures from 31 sites throughout eastern Texas. One-hundred seventy six of these have been at least 
partially excavated with the rest $(n=89)$ recorded as part of the magnetometer surveys at the George C. Davis and Hill Farm sites.

As noted, this dissertation has focused on a portion of the broader Caddoan archaeological area. Future studies of Caddo architecture should broaden the scope to include data from Caddo sites in Louisiana, Arkansas, and Oklahoma. Including research on Caddo architecture from archaeological sites from throughout the Caddoan archaeological area will provide a large-scale perspective on architectural variability and practices. In discussing the variety of architectural styles throughout the Caddo area, Early (2000:129) noted "an important future avenue to explore is the development trajectories and regional variation within this far-flung tradition."

Future research guided by exploring the different architectural traditions from the Caddoan archaeological area will provide a range of possibilities for future research. For instance, are there architectural practices that are distinct to a particular Caddo group or community? Given that architecture appears to have had such a strong association with the broader community and played such a significant role in group identity, could the architectural diversity seen at sites such as Oak Hill Village and George C. Davis, be indicative of co-residence of different Caddo or even non-Caddo individuals or groups? Can traits associated with the different architectural traditions in the Caddo area be used to help identify different Caddo or non-Caddo groups? Could these different forms at the same site, rather than simply being related to different functions, be related to different cultural identities of the inhabitants? Are the architectural anomalies at specific sites or in specific areas due to different Caddo or non-Caddo peoples moving into the area or taking up residence among another group and bringing their own, very different architectural traditions with them? 
The use of daub versus thatch is another potential research issue yet to be addressed. Is the practice of plastering structure walls a trait that is specific to certain Caddo groups and not others? After all, Casañas (Hatcher 1927) and others (Cox 1904; Swanton 1942) noted that some Caddo groups, those to the north of the Hasinai for example, particularly the Red River Caddo groups, had the tradition of plastering their buildings. If plastered structures are found in the Hasinai area, for example, could they possibly represent settlers or other inhabitants from northern Caddo groups?

This dissertation includes only a small portion of the architectural data that is available from throughout the larger Caddoan archaeological area. Additional avenues for research include looking at the archaeological evidence related to the use of space within structures (i.e., how the interiors of different types of structures were laid out and what that evidence may reveal about use of space, or how the archaeological evidence corresponds to the European account of structure interiors). An additional avenue for research is to construct and examine architectural models and reconstructions of Caddo structures. Such a study could provide evidence that could be used to address the function, layout, design, purpose, etc., of structures seen archaeologically.

In addition to the structures recorded via magnetometer surveys, this dissertation included a detailed look at only those previously excavated structures with well-defined posthole patterns. Future studies should include less well defined structures and structure areas that were excluded from this study. Doing so would expand the corpus of possible buildings considerably and will undoubtedly provide additional data pertaining to the construction, use, and destruction of architectural spaces in the Caddo world.

Finally, Chapter 3 briefly touched on modern Caddo perspectives on traditional architecture. An additional avenue for future research is to explore modern Caddo 
perspectives on traditional architecture and how Caddo architecture, including its design, meaning, and function, has changed over the course of the last one to two centuries.

These are but a few potential research questions that may be explored as we gain a better understanding of the role of architecture in the Caddo world and the architectural traditions that were active in the region from pre-Columbian into historic times. 


\section{APPENDIX A}

\section{STRUCTURES FROM THE 2003 MAGNETOMETER SURVEY OF THE GEORGE C. DAVIS SITE}

\section{INTRODUCTION}

This appendix presents the results of the analysis of the George C. Davis site (41CE19) magnetometer data. The data processing and analysis of the magnetometer data were both collaborative efforts. Most of the data processing was conducted by Dale Hudler. Data analysis and feature identification was primarily conducted by Darrell Creel, Dale Hudler, Samuel M. Wilson, Matthew Taliaferro, Chester Walker, and the author. This study examines in detail only those measurable features that can confidently be identified as structures or architectural features (Table 68). Figure 132 provides a figure of the distribution of the structures recorded as part of the TARL/UT magnetometer survey of the George C. Davis site. The remainder of the appendix includes a figure of each separate feature (Figures 133-187) as seen in the magnetometer data as well as a summary table for each defined feature. 
Table 68. George C. Davis site (41CE19) Magnetometer features included in this dissertation.

\begin{tabular}{|c|c|c|c|c|c|c|c|}
\hline $\begin{array}{l}\text { Feat } \\
\text { No. }\end{array}$ & $\begin{array}{l}\text { Dimensions/ } \\
\text { Diameter (m) }\end{array}$ & $\begin{array}{l}\text { Area } \\
\left(\mathbf{m}^{2}\right)\end{array}$ & Type & $\begin{array}{l}\text { Feat } \\
\text { No. }\end{array}$ & $\begin{array}{l}\text { Dimensions/ } \\
\text { Diameter (m) }\end{array}$ & $\operatorname{Area}\left(m^{2}\right)$ & Type \\
\hline & & & & 280 & 11.1 & 96.77 & circular \\
\hline 179 & 20.3 & 323.65 & circular & 281 & $6.8 \times 6.8$ & 46.24 & rectangular \\
\hline 220 & 5.6 & 24.63 & circular & 284 & 16.1 & 203.58 & circular \\
\hline 237 & 10.6 & 88.25 & circular & 285 & 11.69 & 107.33 & circular \\
\hline 238 & 21 & 346.36 & circular & 290 & 7.3 & 41.85 & circular \\
\hline 239 & 17.5 & 240.53 & circular & 291 & 6.7 & 35.26 & circular \\
\hline 241 & 13.5 & 143.14 & circular & 292 & 7.2 & 40.72 & circular \\
\hline 242 & 13 & 132.73 & circular & 301 & 3.45 & 9.35 & circular \\
\hline 243 & 13.6 & 145.27 & circular & 302 & 3.15 & 7.79 & circular \\
\hline 244 & 12.3 & 118.82 & circular & 305 & 18.25 & 261.59 & circular \\
\hline 245 & 11.5 & 103.87 & circular & 306 & 7.9 & 49.02 & circular \\
\hline 246 & 10 & 78.54 & circular & 307 & 7.6 & 45.36 & circular \\
\hline 247 & 15.4 & 186.27 & circular & 308 & 6.9 & 37.39 & circular \\
\hline 252 & 11.7 & 107.51 & sub-rectangular & 310 & 6.17 & 29.9 & circular \\
\hline 253 & 14.9 & 174.37 & $\begin{array}{l}\text { circular to sub- } \\
\text { rectangular }\end{array}$ & 312 & 11.5 & 103.87 & circular \\
\hline 254 & $10.7 \times 10.7$ & 114.49 & rectangular & 313 & 13.8 & 149.57 & circular \\
\hline 255 & 18.4 & 265.9 & circular & 314 & 5.6 & 24.63 & circular \\
\hline 256 & 16.1 & 203.58 & circular & 315 & 8.3 & 54.11 & circular \\
\hline 257 & 16.7 & 219.04 & circular & 318 & 10.9 & 93.31 & circular \\
\hline 258 & 17.7 & 246.06 & circular & 320 & 7.1 & 39.59 & circular \\
\hline 259 & 20.1 & 317.31 & circular & 321 & 5.9 & 27.34 & circular \\
\hline 260 & $5 \times 6$ & 30 & rectangular & 322 & 5.8 & 26.42 & circular \\
\hline 263 & 6.6 & 34.21 & circular & 327 & 6.75 & 35.78 & circular \\
\hline 264 & 15 & 176.71 & circular & 328 & 6.4 & 32.17 & circular \\
\hline 265 & 16.2 & 206.12 & circular & 334 & 6.7 & 35.26 & circular \\
\hline 266 & 9.5 & 70.88 & circular & 335 & 9.5 & 70.88 & circular \\
\hline 267 & 16.2 & 206.12 & circular & 338 & 10.4 & 84.95 & circular \\
\hline 269 & 18.1 & 257.3 & circular & 339 & 12.5 & 122.72 & circular \\
\hline 274 & 13 & 132.73 & circular & 340 & 15.5 & 188.69 & circular \\
\hline 275 & 4.6 & 16.62 & circular & 343 & 4.7 & 17.35 & circular \\
\hline 276 & 8.7 & 59.45 & circular & 346 & 10 & 78.54 & circular \\
\hline 277 & 13.2 & 136.85 & circular & 347 & $4.6 \times 4.8$ & 22.08 & rectangular \\
\hline \multirow[t]{2}{*}{278} & 10.3 & 83.32 & circular & 348 & 9 & 63.62 & circular \\
\hline & & & & 350 & 6 & 28.27 & circular \\
\hline
\end{tabular}




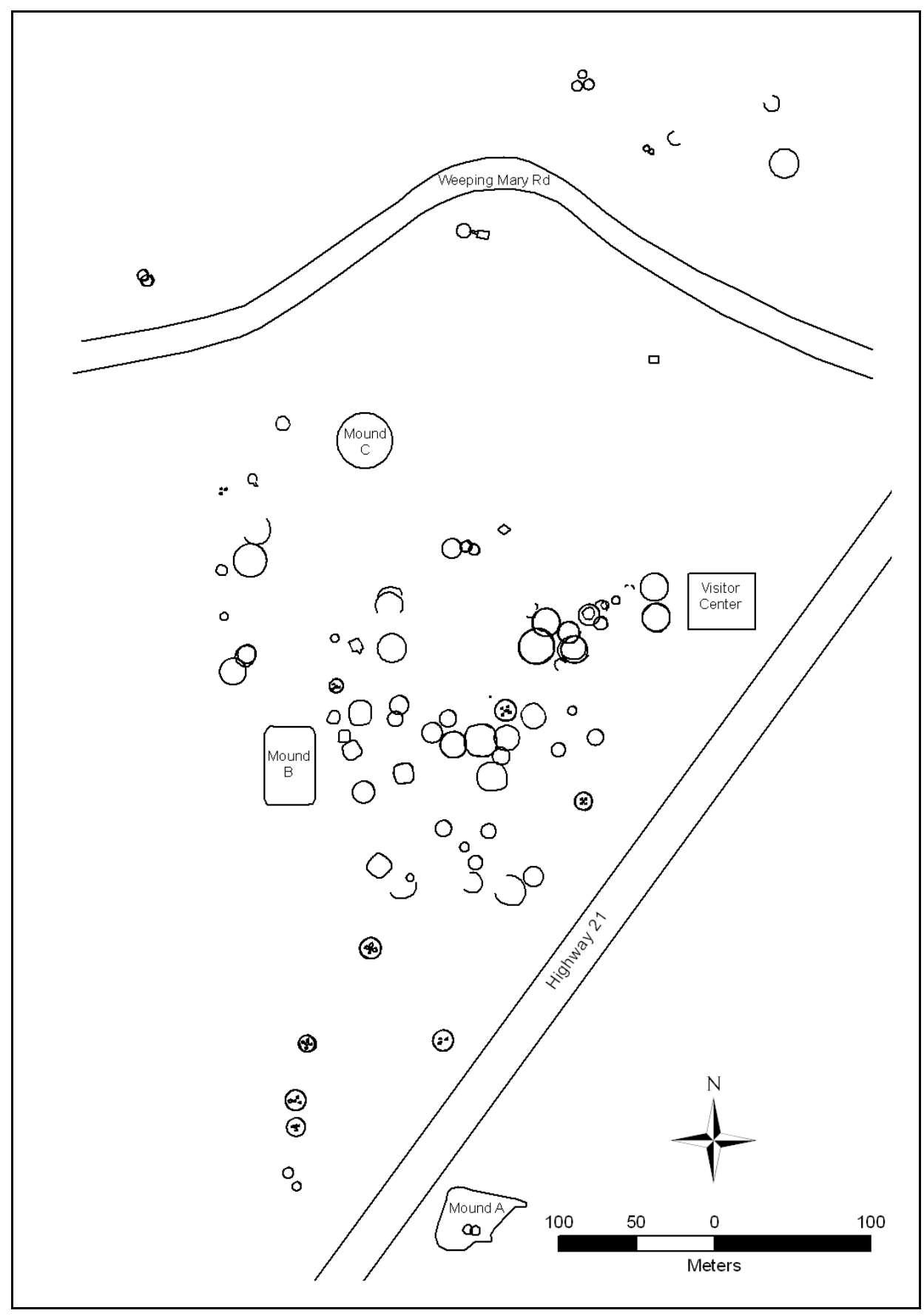

Figure 132: Structures recorded as part of the TARL/UT magnetometer survey of the George C. Davis site. 


\section{STRUCTURES RECORDED IN MAGNETOMETER DATA}

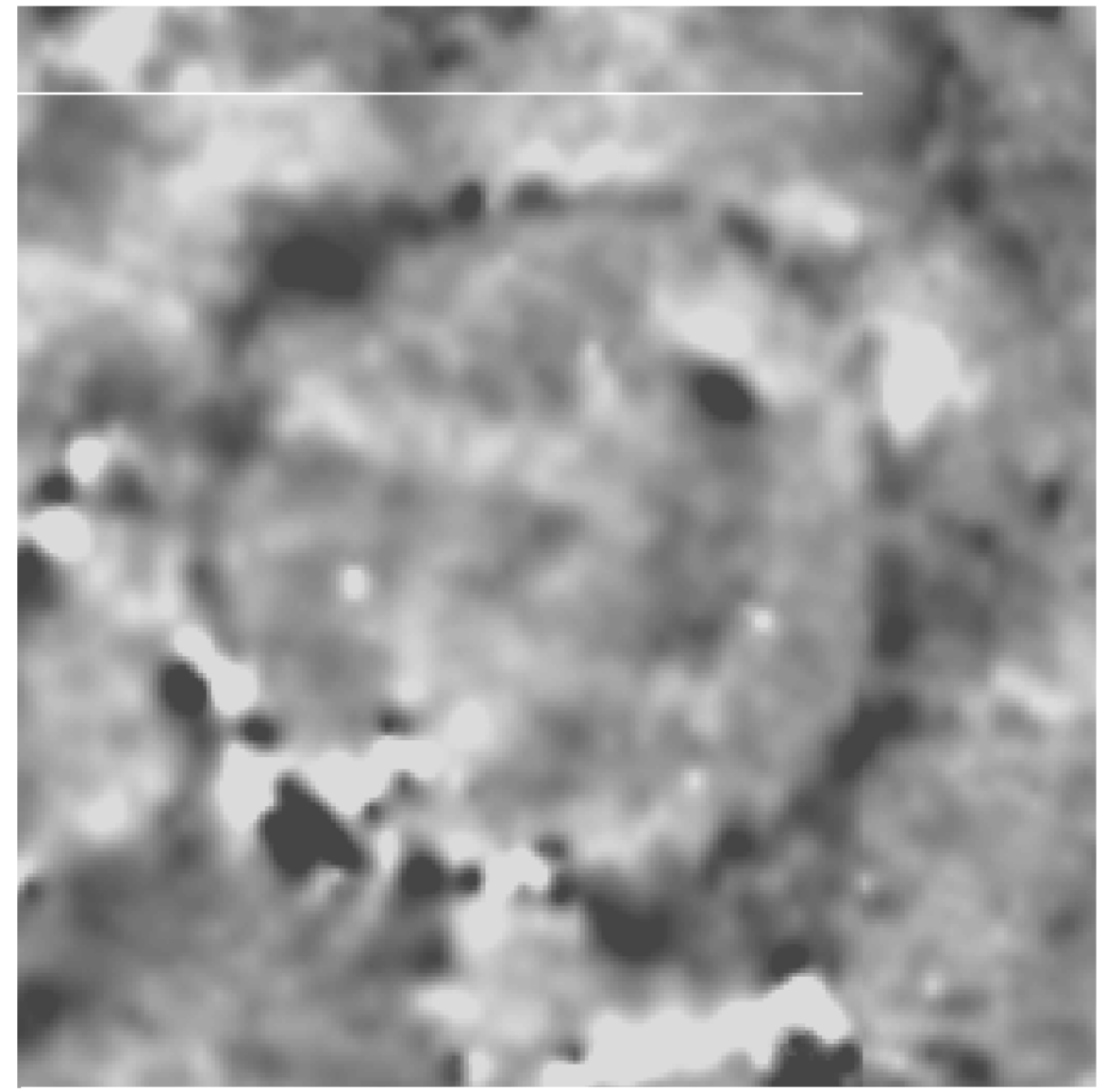

41CE19: Feature 179

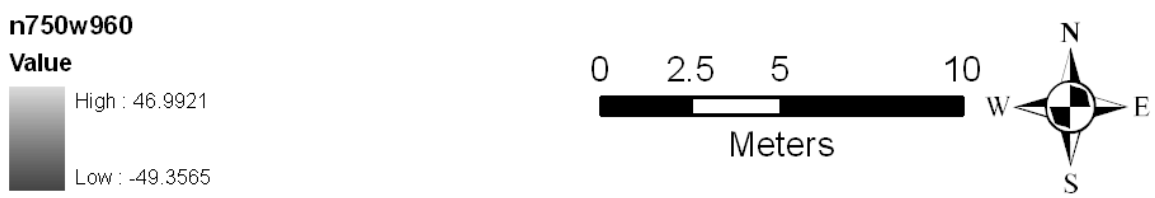

Figure 133: Feature 179

\begin{tabular}{|c|l|l|l|l|}
\hline Feat & $\begin{array}{l}\text { Dimensions/ } \\
\text { Diameter }(\mathbf{m})\end{array}$ & $\begin{array}{l}\text { Area } \\
\mathbf{( m}^{\mathbf{2}} \mathbf{)}\end{array}$ & Type & Comments \\
\hline 179 & 20.30 & 323.65 & circular & $\begin{array}{l}\text { Possibly burned; possible interior feature in } \\
\text { data - pit or hearth? }\end{array}$ \\
\hline
\end{tabular}




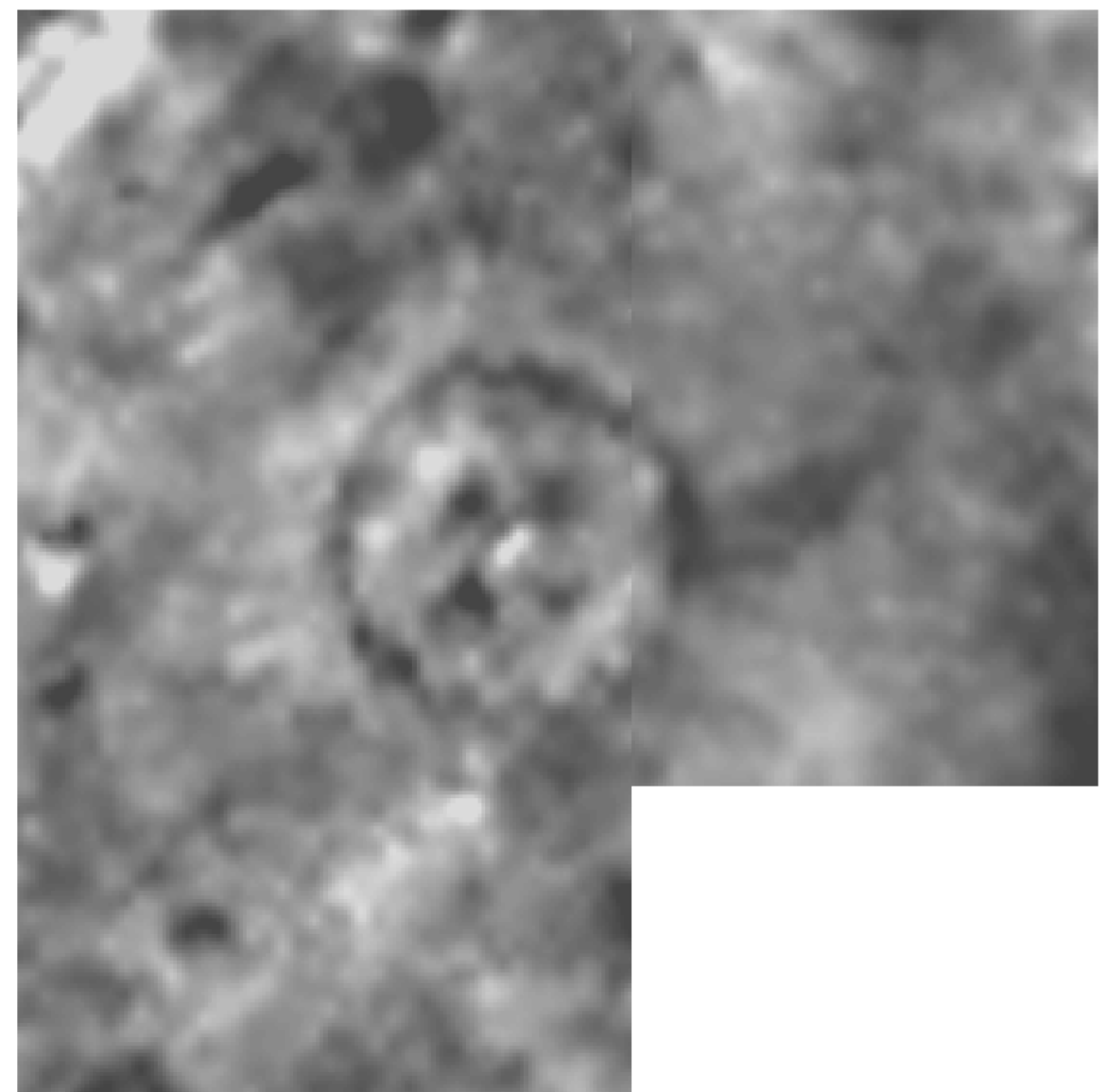

41CE19: Feature 237

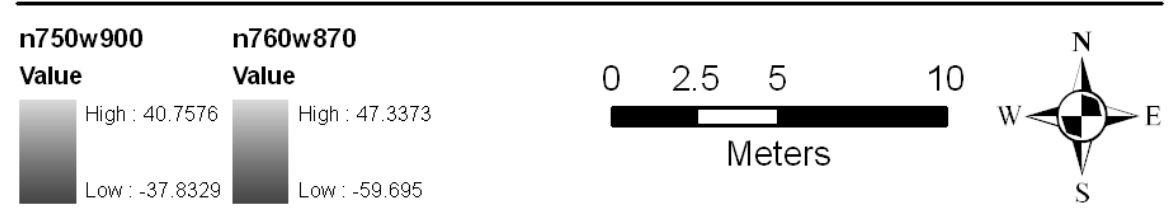

Figure 134: Feature 237

\begin{tabular}{|r|r|l|l|l|}
\hline Feat & $\begin{array}{l}\text { Dimensions/ } \\
\text { Diameter }(\mathbf{m})\end{array}$ & $\begin{array}{l}\text { Area } \\
\left(\mathbf{m}^{2}\right)\end{array}$ & Type & Comments \\
\hline 237 & 10.60 & 88.25 & Circular & $\begin{array}{l}\text { Button house; four large interior posts, } \\
\text { central hearth }\end{array}$ \\
\hline
\end{tabular}



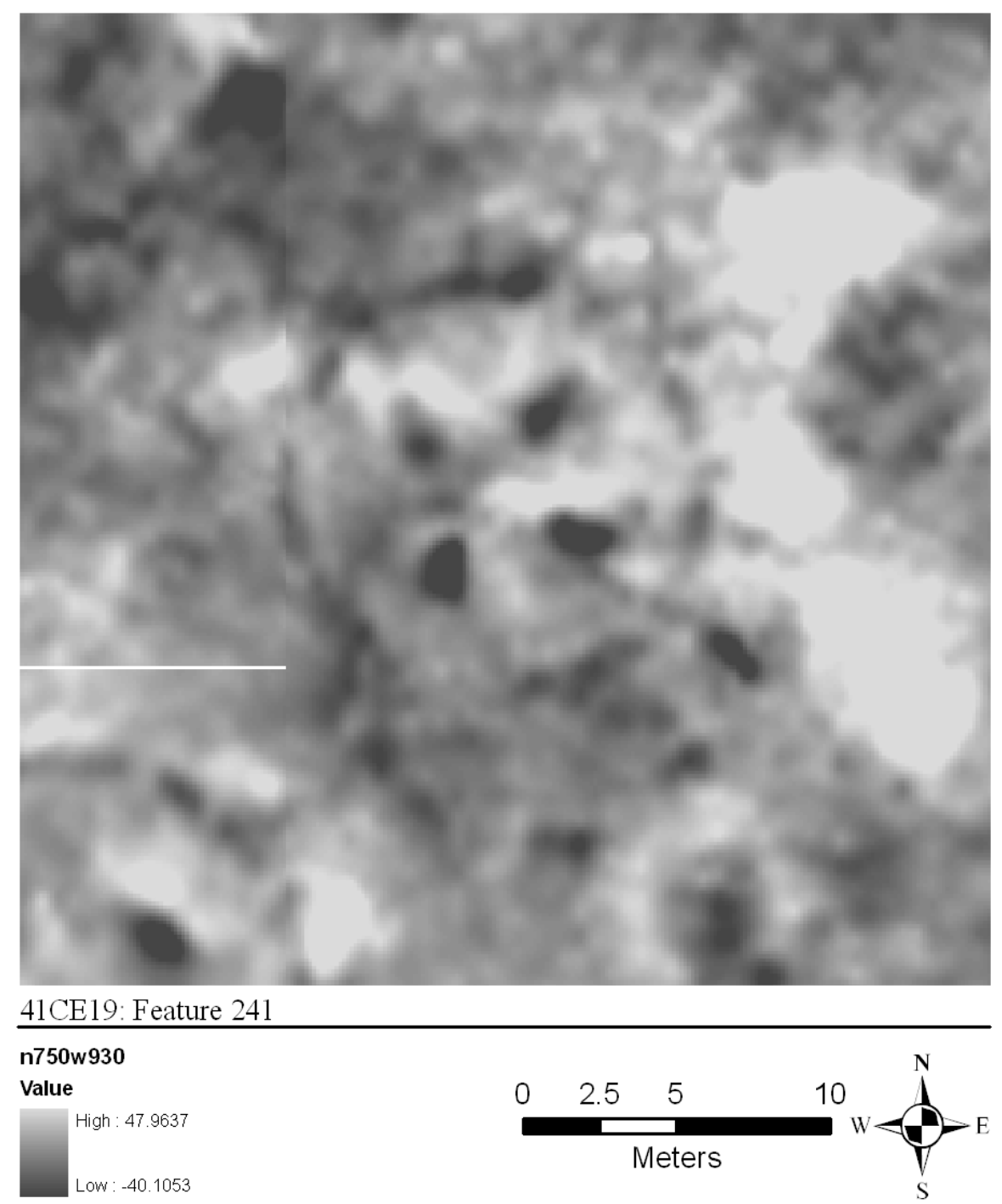

Figure 135: Feature 241

\begin{tabular}{|c|r|l|l|l|}
\hline Feat & $\begin{array}{l}\text { Dimensions/ } \\
\text { Diameter }(\mathbf{m})\end{array}$ & $\begin{array}{l}\text { Area } \\
\left(\mathbf{m}^{2}\right)\end{array}$ & Type & Comments \\
\hline 241 & 13.50 & 143.14 & circular & $\begin{array}{l}\text { Button house; four large interior posts, } \\
\text { central hearth }\end{array}$ \\
\hline
\end{tabular}




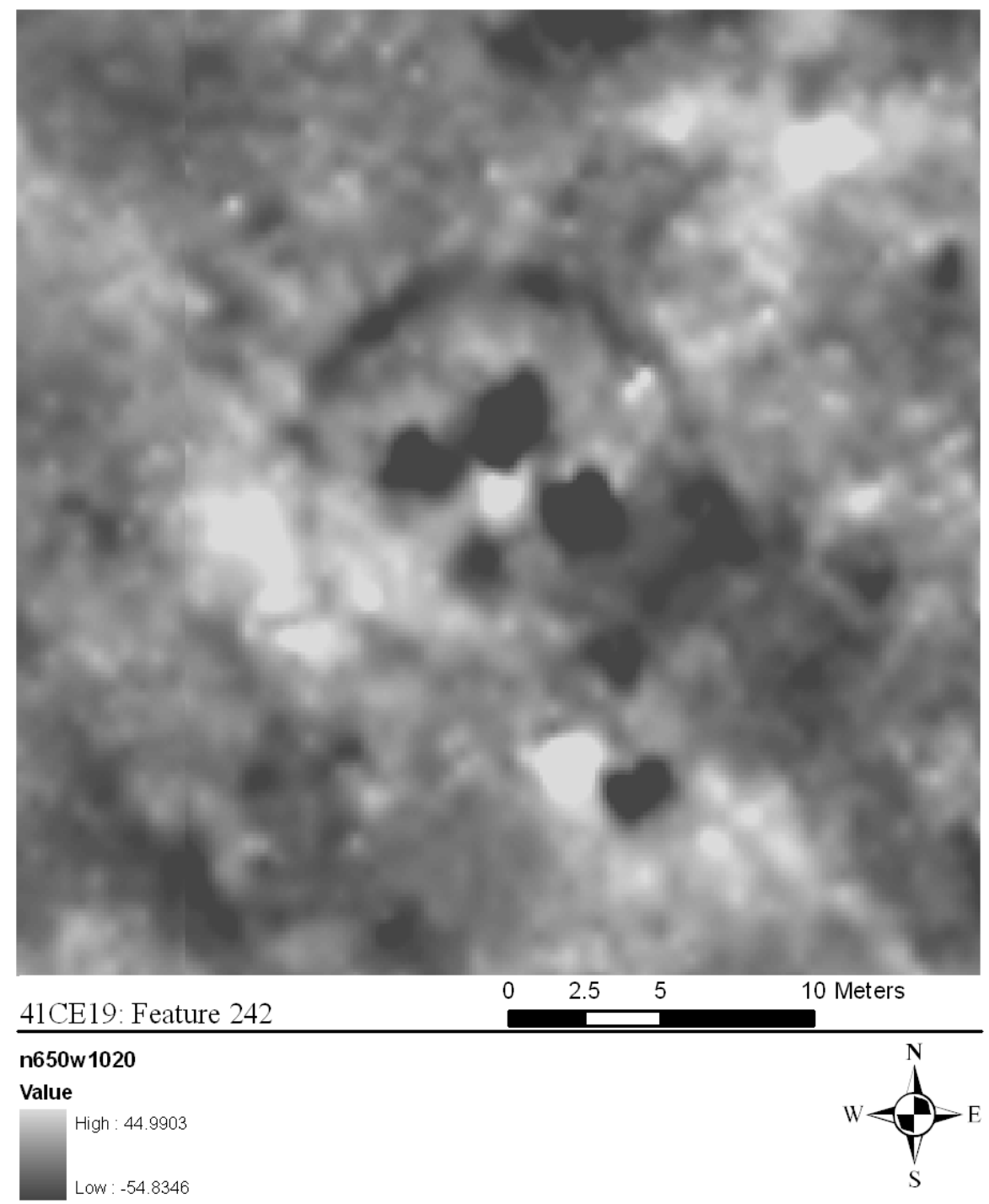

Figure 136: Feature 242

\begin{tabular}{|r|r|l|l|l|}
\hline Feat & $\begin{array}{l}\text { Dimensions/ } \\
\text { Diameter }(\mathbf{m})\end{array}$ & $\begin{array}{l}\text { Area } \\
\left(\mathbf{m}^{2}\right)\end{array}$ & Type & Comments \\
\hline 242 & 13.00 & 132.73 & Circular & $\begin{array}{l}\text { Button house; four large interior posts, and } \\
\text { a central hearth }\end{array}$ \\
\hline
\end{tabular}




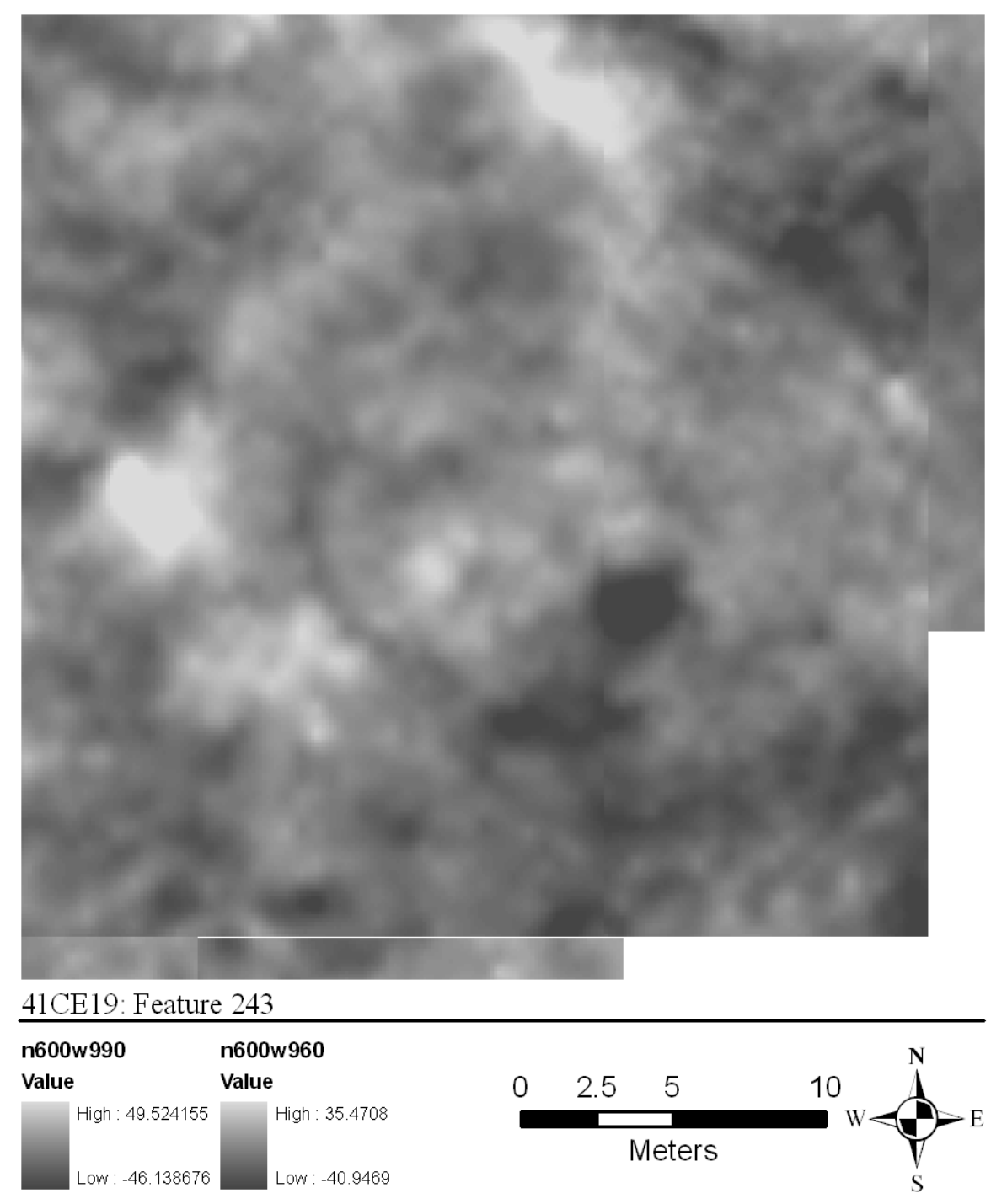

Figure 137: Feature 243

\begin{tabular}{|r|r|l|l|l|}
\hline Feat & $\begin{array}{l}\text { Dimensions/ } \\
\text { Diameter }(\mathbf{m})\end{array}$ & $\begin{array}{l}\text { Area } \\
\left(\mathbf{m}^{2}\right)\end{array}$ & Type & Comments \\
\hline 243 & 13.60 & 145.27 & circular & $\begin{array}{l}\text { Faint partial circular arc; possibly an area } \\
\text { of superimposed structures }\end{array}$ \\
\hline
\end{tabular}




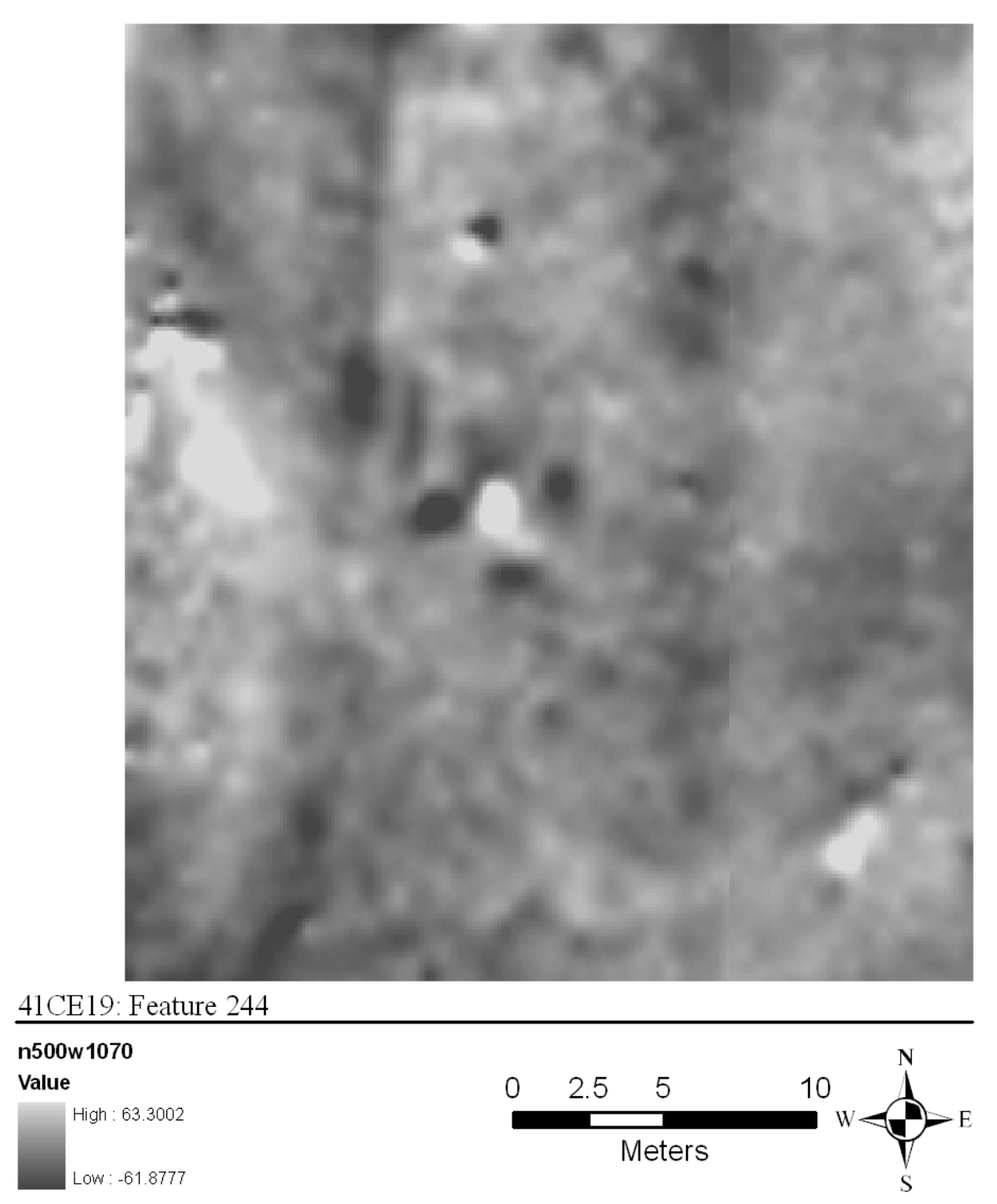

Figure 138: Feature 244

\begin{tabular}{|r|r|l|l|l|}
\hline Feat & $\begin{array}{l}\text { Dimensions/ } \\
\text { Diameter }(\mathbf{m})\end{array}$ & $\begin{array}{l}\text { Area } \\
\left(\mathbf{m}^{2}\right)\end{array}$ & Type & Comments \\
\hline & 12.30 & 118.82 & Circular & $\begin{array}{l}\text { Button house; four large interior posts, } \\
\text { central hearth; one interior post is } \\
\text { magnetically faint }\end{array}$ \\
\hline 244 & 12.0 \\
\hline
\end{tabular}




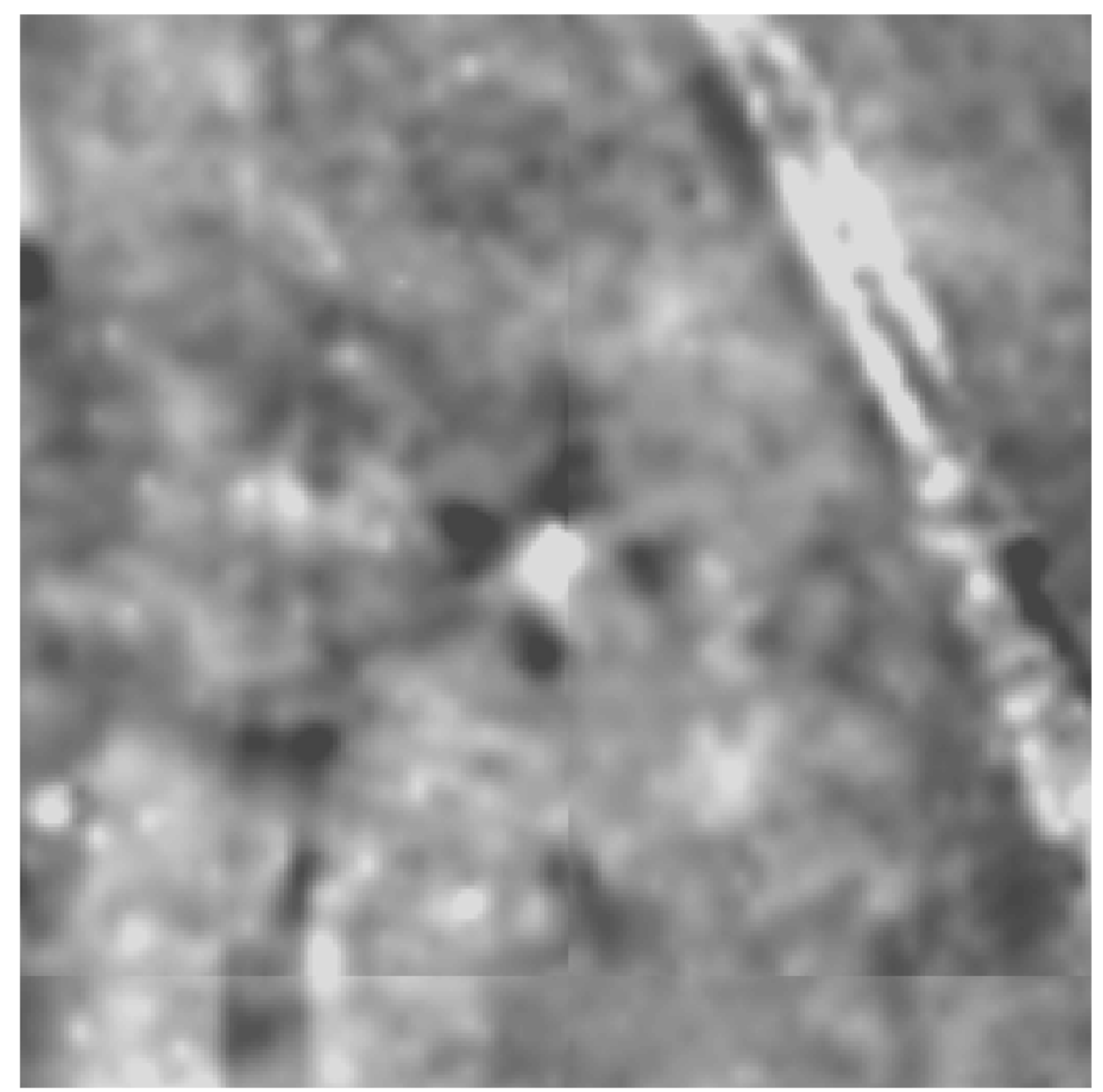

41CE19: Feature 245

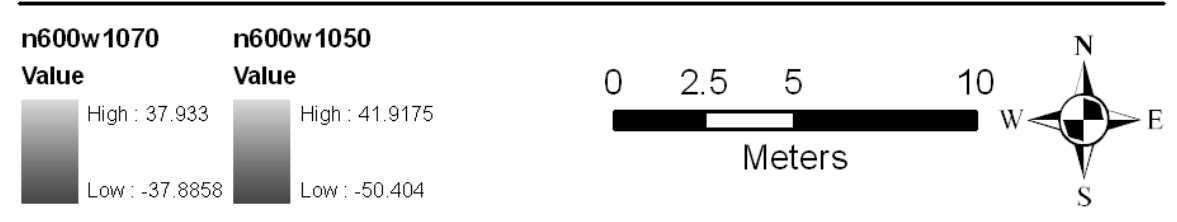

Figure 139: Feature 245

\begin{tabular}{|c|c|l|l|l|}
\hline Feat & $\begin{array}{l}\text { Dimensions/ } \\
\text { Diameter }(\mathbf{m})\end{array}$ & $\begin{array}{l}\text { Area } \\
\left(\mathbf{m}^{2}\right)\end{array}$ & Type & Comments \\
\hline 245 & 11.50 & 103.87 & circular & $\begin{array}{l}\text { Button house; four large interior posts, } \\
\text { central hearth }\end{array}$ \\
\hline
\end{tabular}




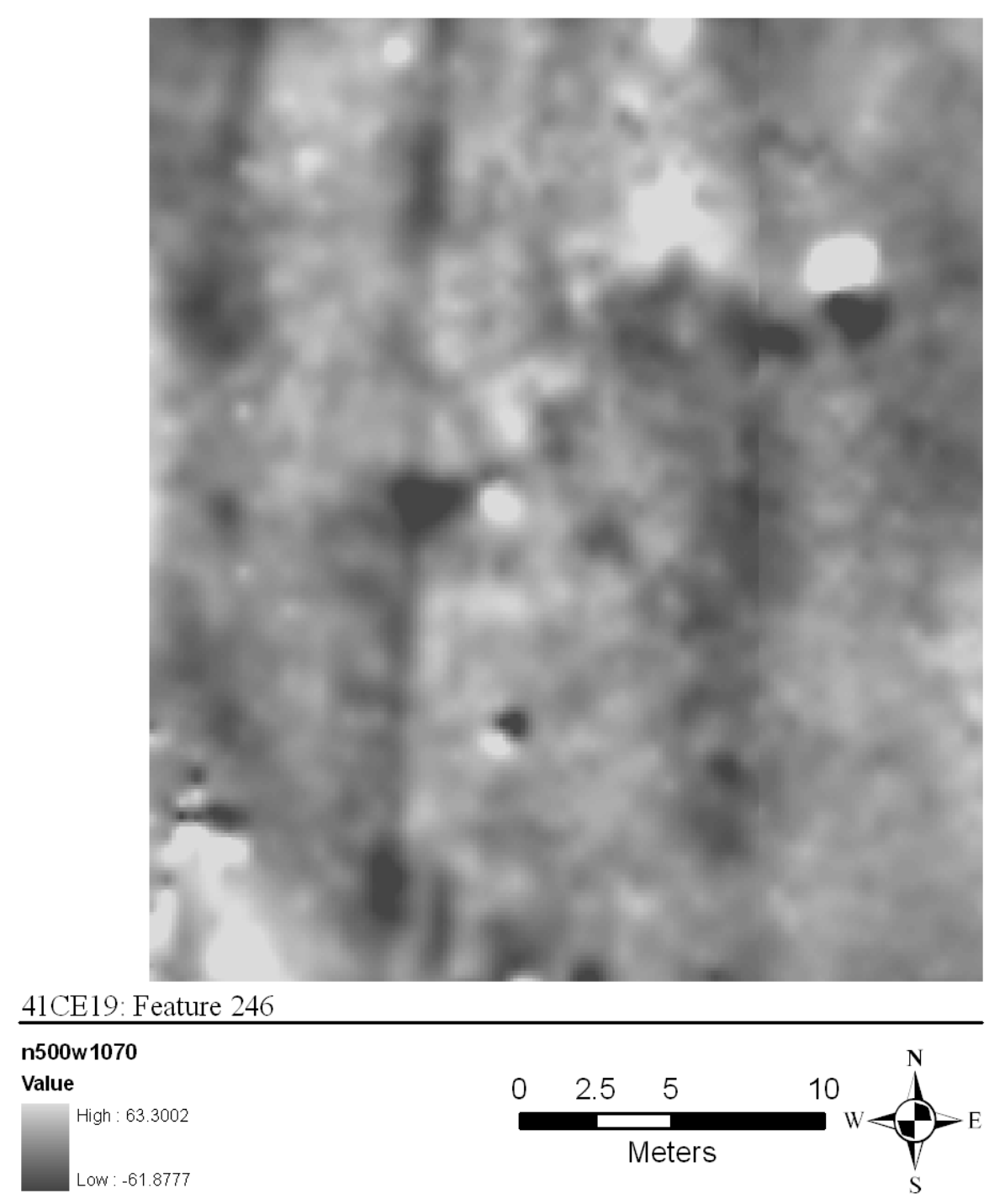

Figure 140: Feature 246

\begin{tabular}{|c|l|l|l|l|}
\hline Feat & $\begin{array}{l}\text { Dimensions } / \\
\text { Diameter }(\mathbf{m})\end{array}$ & $\begin{array}{l}\text { Area } \\
\left(\mathbf{m}^{2}\right)\end{array}$ & Type & Comments \\
\hline 246 & & & & $\begin{array}{l}\text { Likely button house; four large interior } \\
\text { posts, three are magnetically faint; central } \\
\text { hearth; faint structure outline }\end{array}$ \\
\hline
\end{tabular}




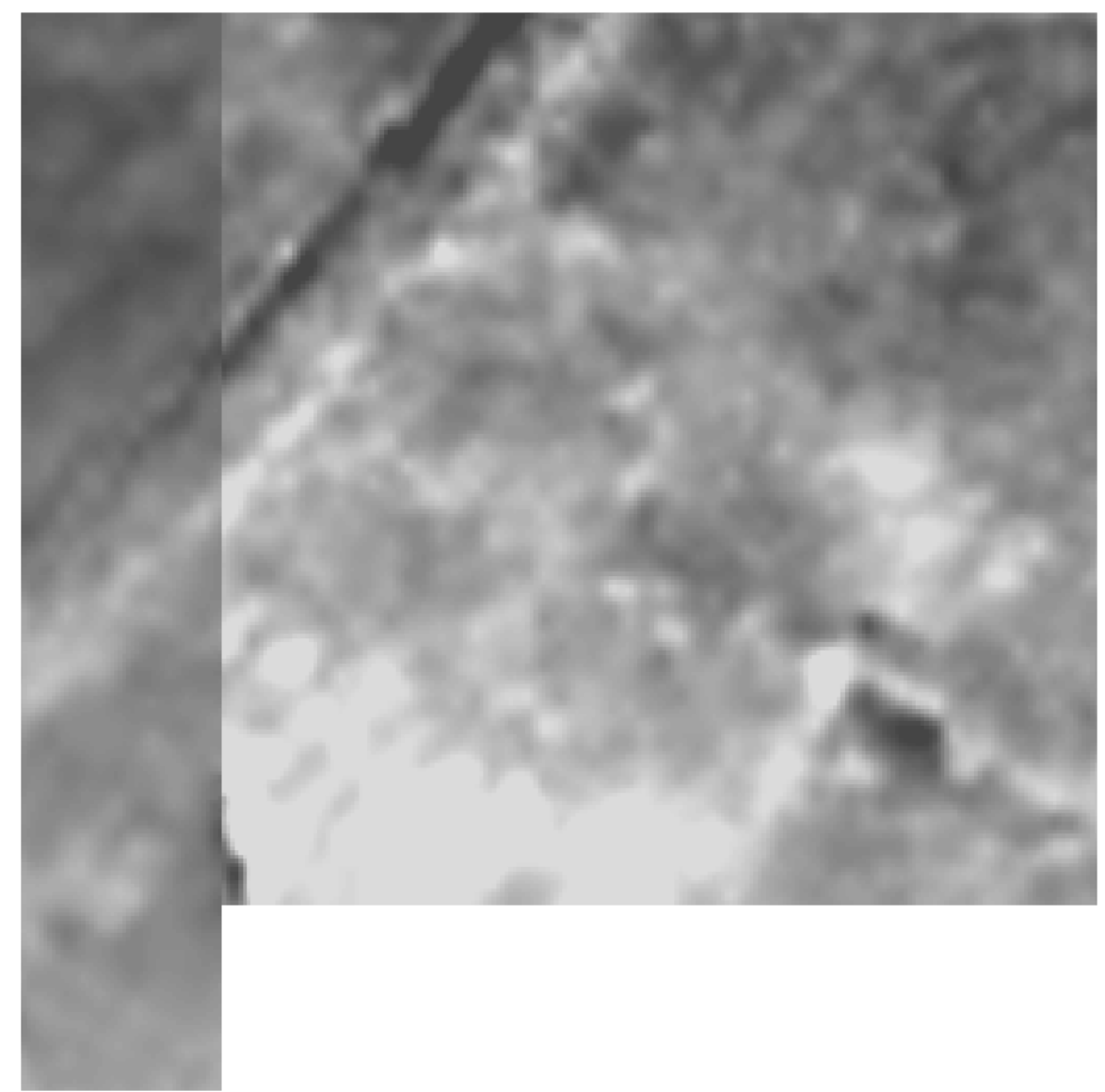

41CE19: Feature 247

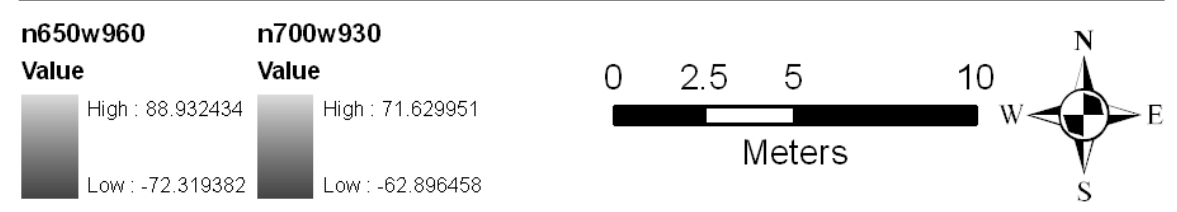

Figure 141: Feature 247

\begin{tabular}{|r|r|l|l|l|}
\hline Feat & $\begin{array}{l}\text { Dimensions } / \\
\text { Diameter }(\mathbf{m})\end{array}$ & $\begin{array}{l}\text { Area } \\
\left(\mathbf{m}^{2}\right)\end{array}$ & Type & Comments \\
\hline 247 & 15.40 & 186.27 & circular & $\begin{array}{l}\text { Burned; possible button house, four large } \\
\text { but faint interior posts and likely burned; } \\
\text { hearth not visible }\end{array}$ \\
\hline
\end{tabular}




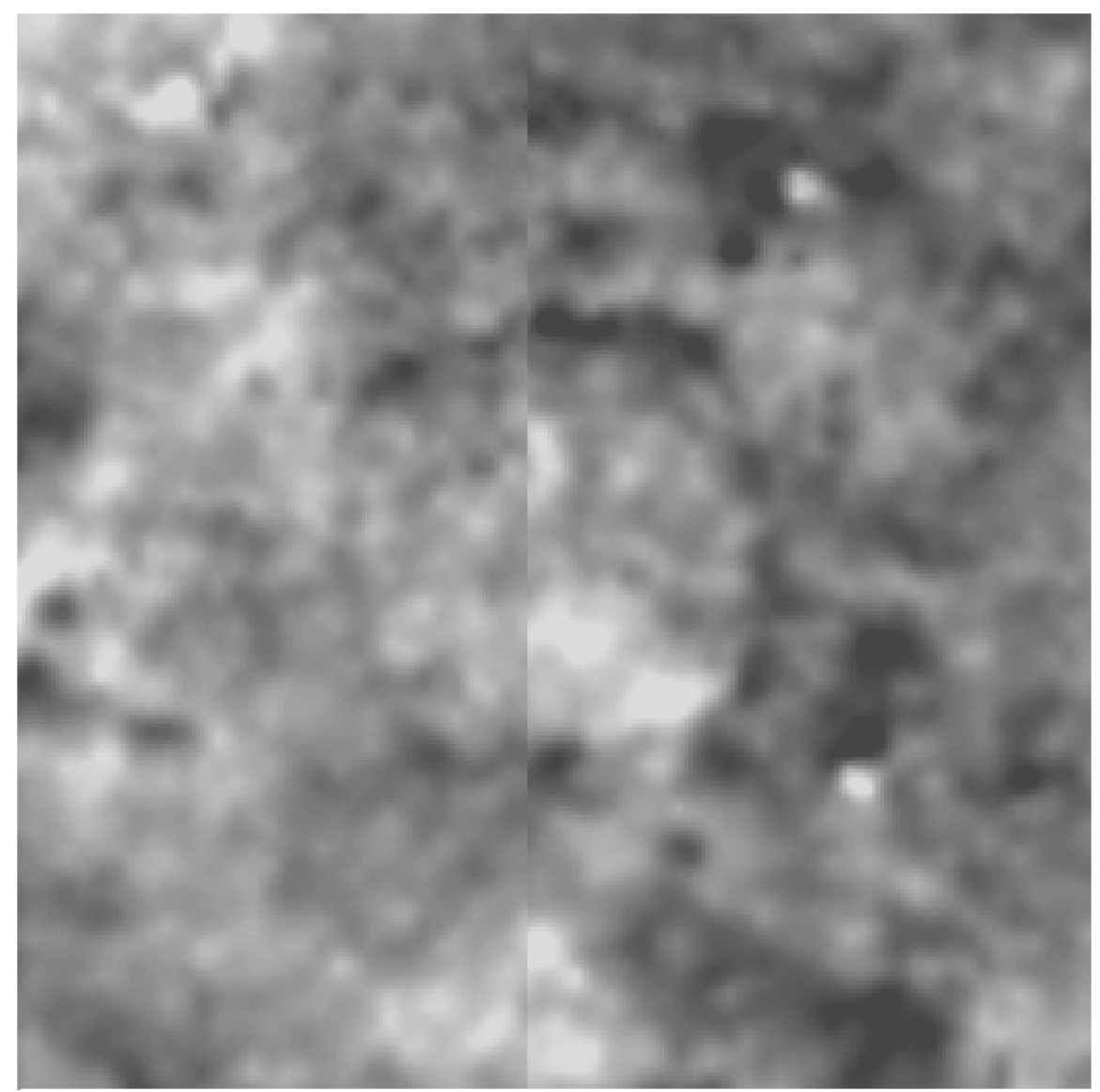

41CE19: Feature 252

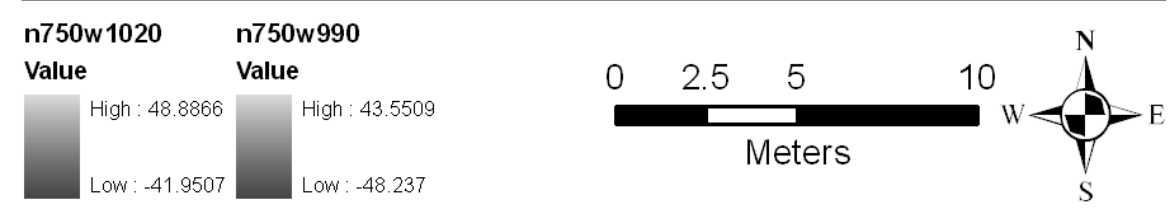

Figure 142: Feature 252

\begin{tabular}{|c|l|l|l|l|}
\hline Feat & $\begin{array}{l}\text { Dimensions } / \\
\text { Diameter }(\mathbf{m})\end{array}$ & $\begin{array}{l}\text { Area } \\
\left(\mathbf{m}^{2}\right)\end{array}$ & Type & Comments \\
\hline 252 & 11.70 & 107.51 & subrectangular & $\begin{array}{l}\text { Possible interior burned feature, not } \\
\text { centrally located within structure }\end{array}$ \\
\hline
\end{tabular}



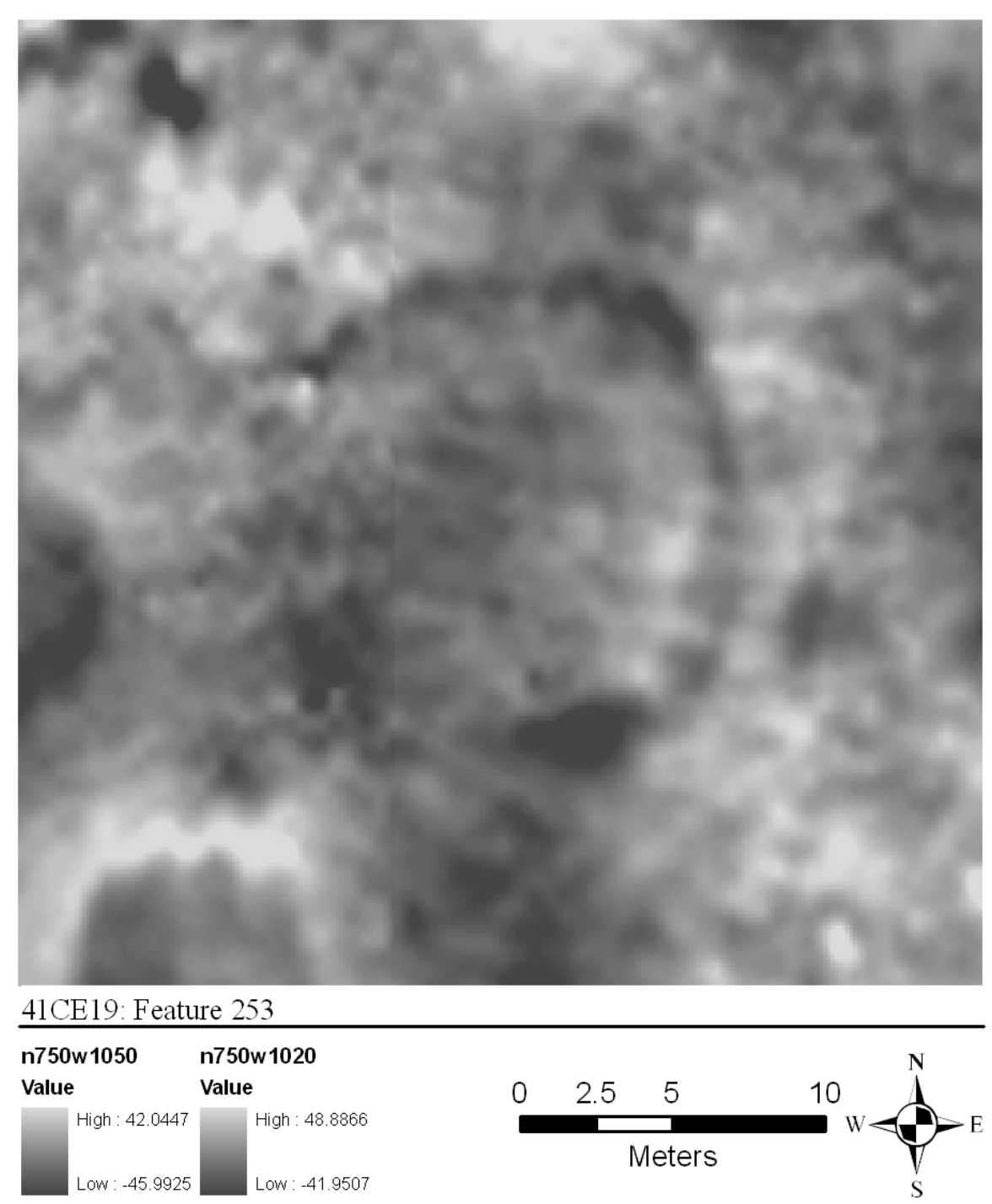

Figure 143: Feature 253

\begin{tabular}{|c|r|l|l|l|} 
Feat & $\begin{array}{l}\text { Dimensions/ } \\
\text { Diameter }(\mathbf{m})\end{array}$ & $\begin{array}{l}\text { Area } \\
\left(\mathbf{m}^{2}\right)\end{array}$ & Type & Comments \\
\hline 253 & 14.90 & 174.37 & $\begin{array}{l}\text { Circular to sub- } \\
\text { rectangular }\end{array}$ & No interior features visible \\
\hline
\end{tabular}




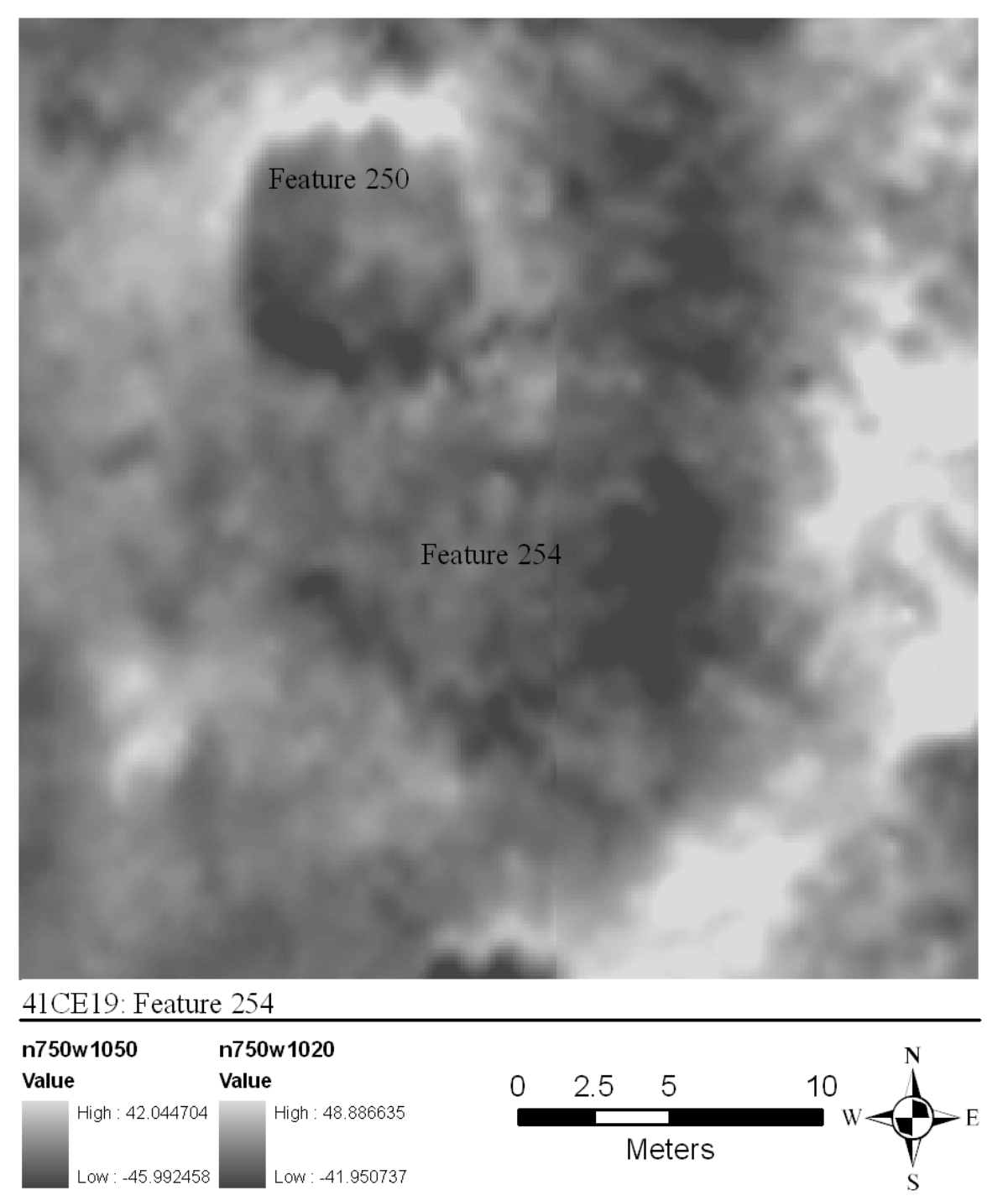

Figure 144: Feature 254

\begin{tabular}{|r|r|r|l|l|} 
Feat & $\begin{array}{l}\text { Dimensions/ } \\
\text { Diameter }(\mathrm{m})\end{array}$ & $\begin{array}{l}\text { Area } \\
\left(\mathbf{m}^{2}\right)\end{array}$ & Type & Comments \\
\hline 254 & 10.70 & 89.92 & rectangular & Structural anomaly \\
\hline
\end{tabular}



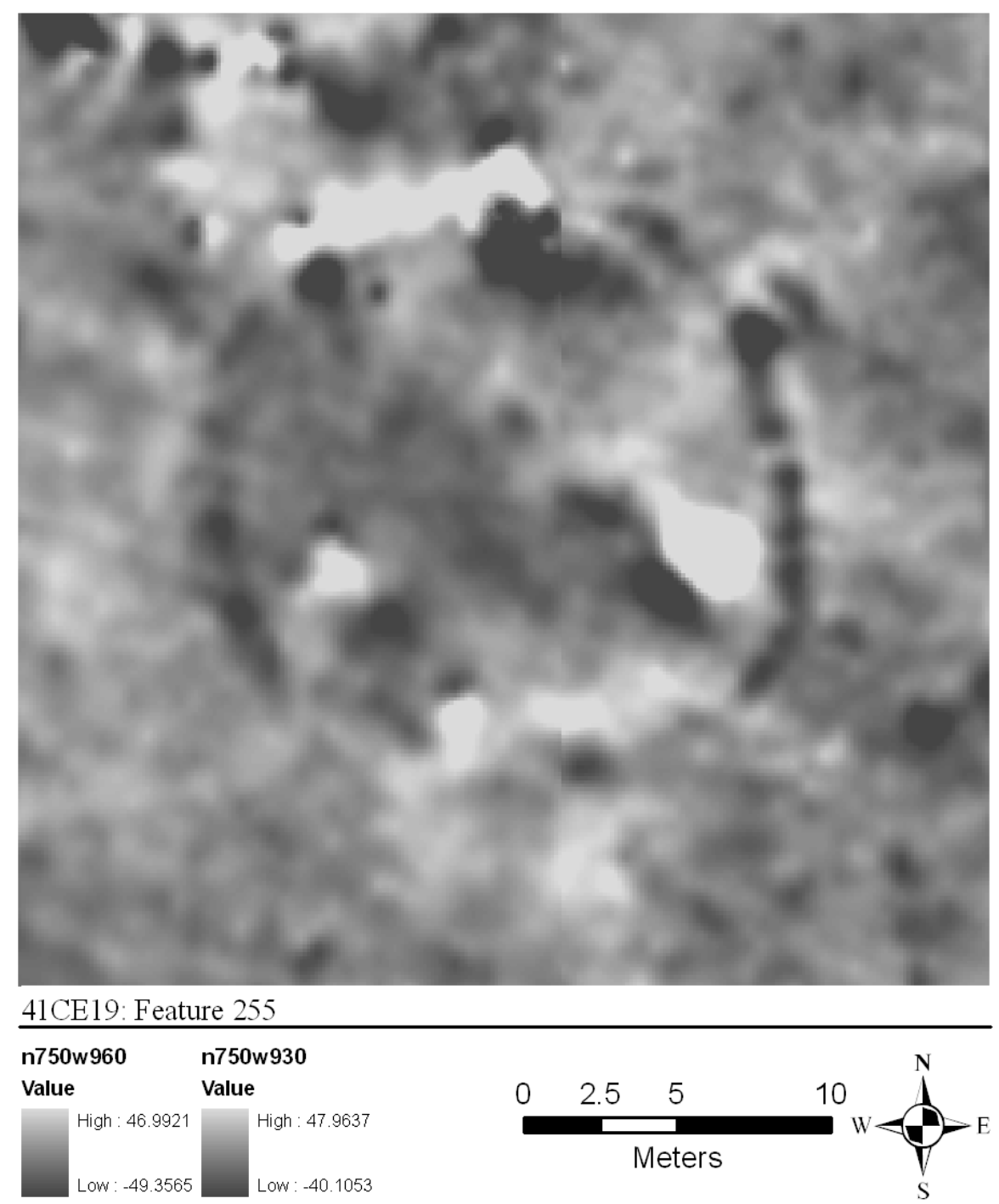

Figure 145: Feature 255

\begin{tabular}{|r|r|l|l|l|} 
Feat & $\begin{array}{l}\text { Dimensions/ } \\
\text { Diameter }(\mathbf{m})\end{array}$ & $\begin{array}{l}\text { Area } \\
\left(\mathbf{m}^{2}\right)\end{array}$ & Type & Comments \\
\hline 255 & 18.40 & 265.90 & circular & $\begin{array}{l}\text { Possibly burned; at least two interior posts } \\
\text { or hearths }\end{array}$ \\
\hline
\end{tabular}



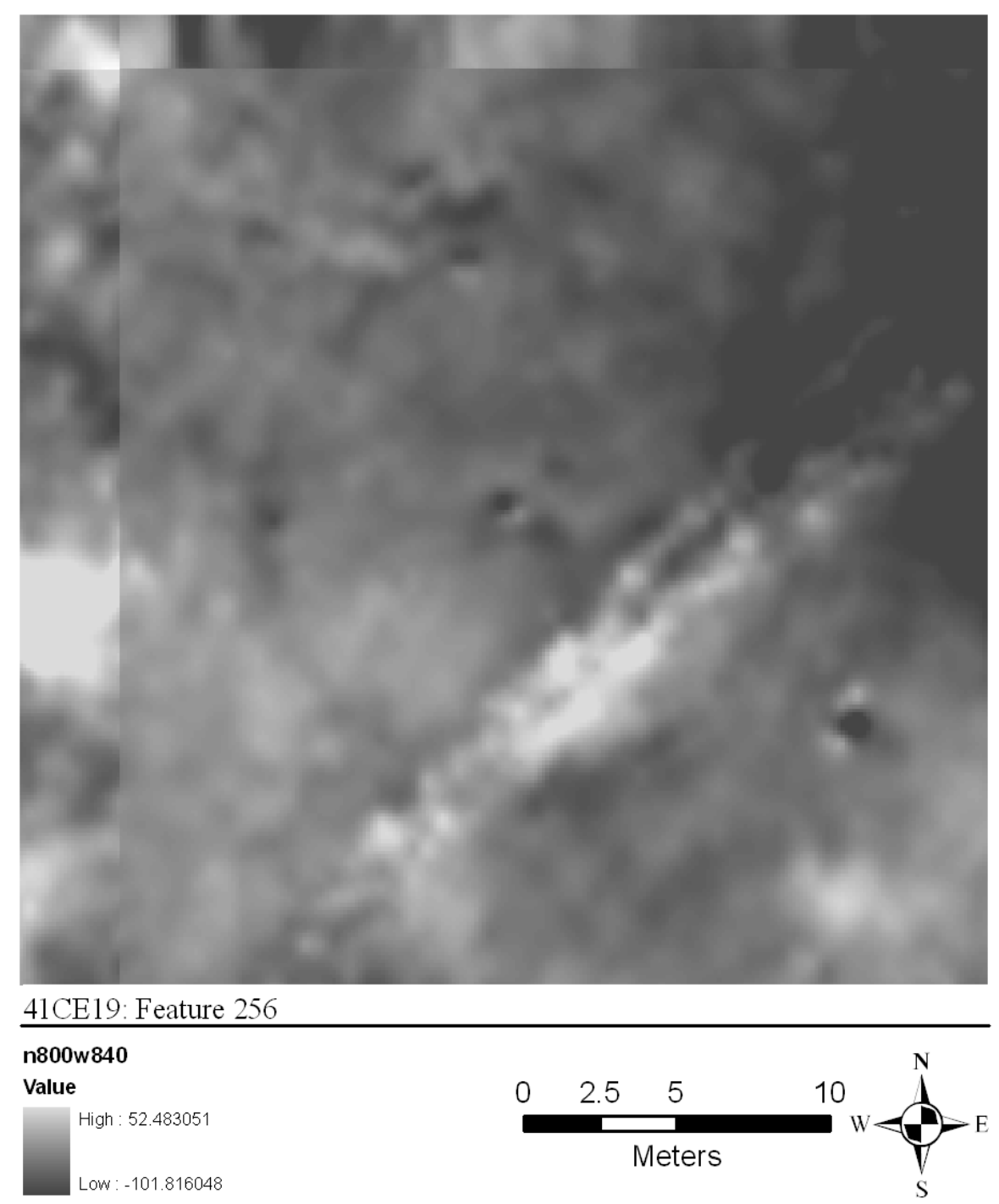

Figure 146: Feature 256

\begin{tabular}{|r|r|l|l|l|} 
Feat & $\begin{array}{l}\text { Dimensions/ } \\
\text { Diameter }(\mathbf{m})\end{array}$ & $\begin{array}{l}\text { Area } \\
\left(\mathbf{m}^{2}\right)\end{array}$ & Type & Comments \\
\hline 256 & 16.10 & 203.58 & circular & Central post or hearth \\
\hline
\end{tabular}




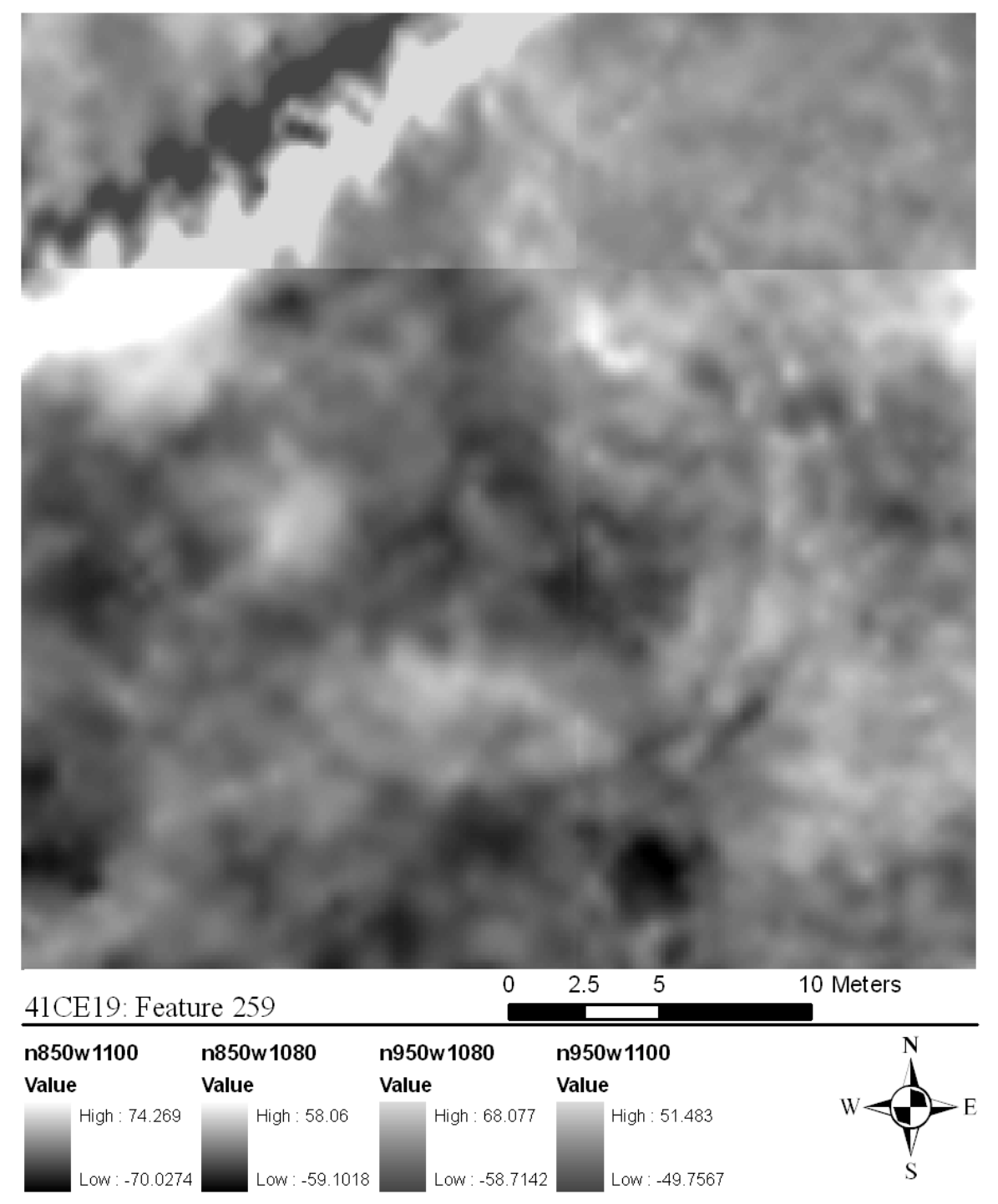

Figure 147: Feature 259

\begin{tabular}{|r|r|l|l|l|} 
Feat & $\begin{array}{l}\text { Dimensions/ } \\
\text { Diameter }(\mathbf{m})\end{array}$ & $\begin{array}{l}\text { Area } \\
\left(\mathbf{m}^{2}\right)\end{array}$ & Type & Comments \\
\hline 259 & 20.10 & 317.31 & circular & $\begin{array}{l}\text { No definite interior features visible; } \\
\text { possible multiple structure arcs. }\end{array}$ \\
\hline
\end{tabular}




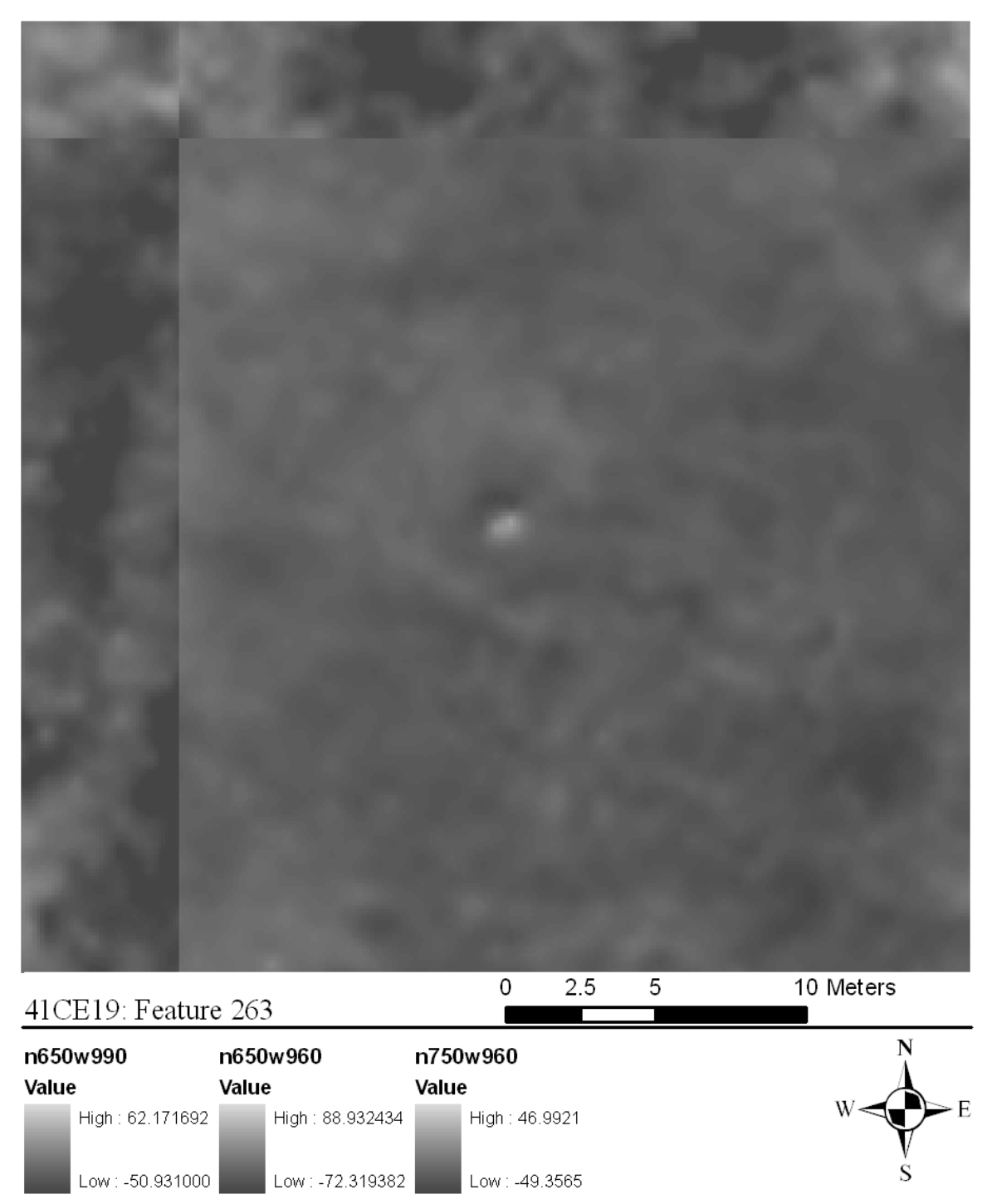

Figure 148: Feature 263

\begin{tabular}{|r|r|r|l|l|} 
Feat & $\begin{array}{l}\text { Dimensions/ } \\
\text { Diameter }(\mathbf{m})\end{array}$ & $\begin{array}{l}\text { Area } \\
\left(\mathbf{m}^{2}\right)\end{array}$ & Type & Comments \\
\hline 263 & 6.60 & 34.21 & circular & $\begin{array}{l}\text { Central post or hearth; faint structure } \\
\text { outline }\end{array}$ \\
\hline
\end{tabular}




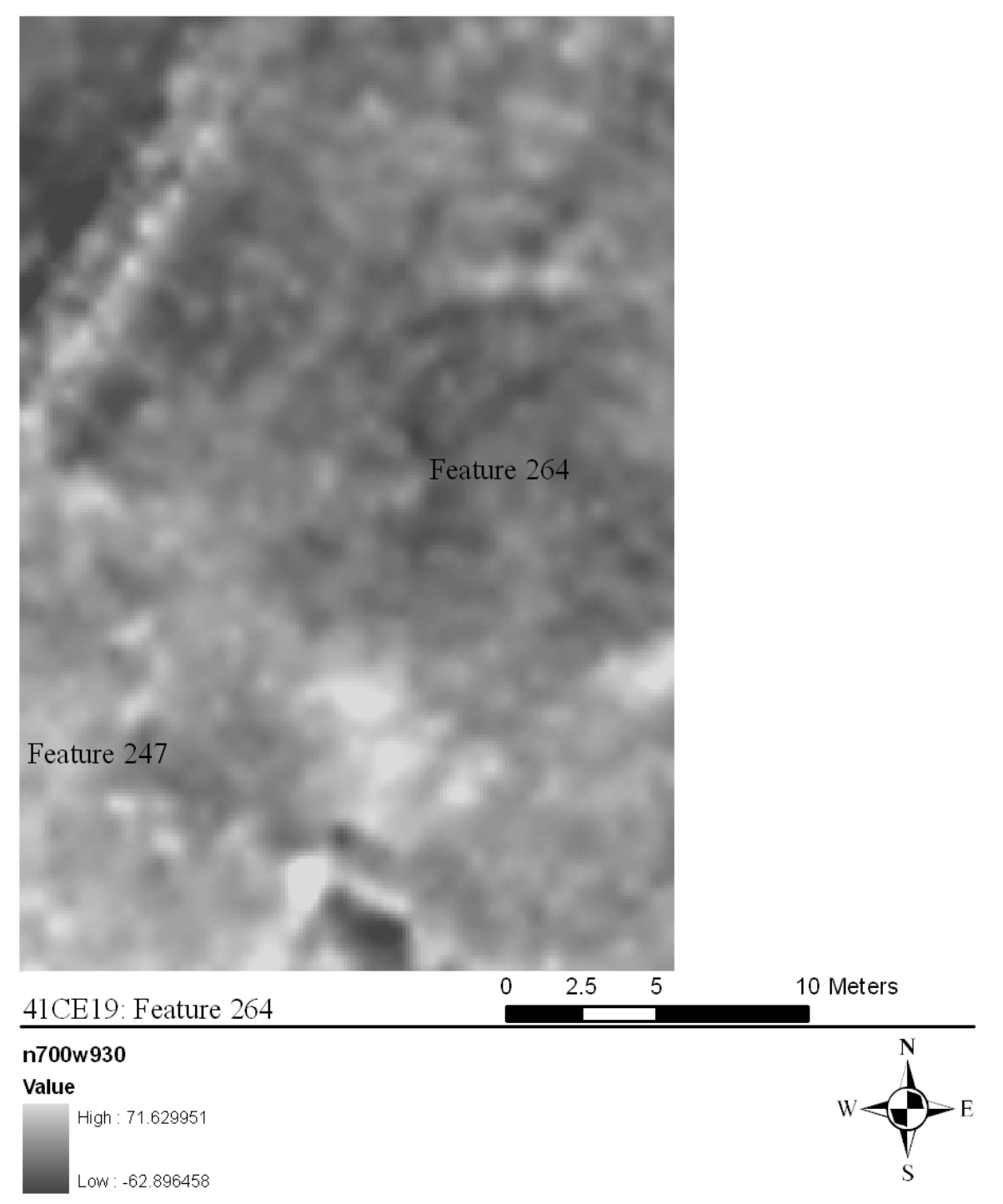

Figure 149: Feature 264

\begin{tabular}{|r|r|l|l|l|} 
Feat & $\begin{array}{l}\text { Dimensions/ } \\
\text { Diameter }(\mathbf{m})\end{array}$ & $\begin{array}{l}\text { Area } \\
\left(\mathbf{m}^{\mathbf{2}}\right)\end{array}$ & Type & Comments \\
\hline 264 & 15.00 & 176.71 & circular & $\begin{array}{l}\text { Faint outline; no definite interior features } \\
\text { visible }\end{array}$ \\
\hline
\end{tabular}




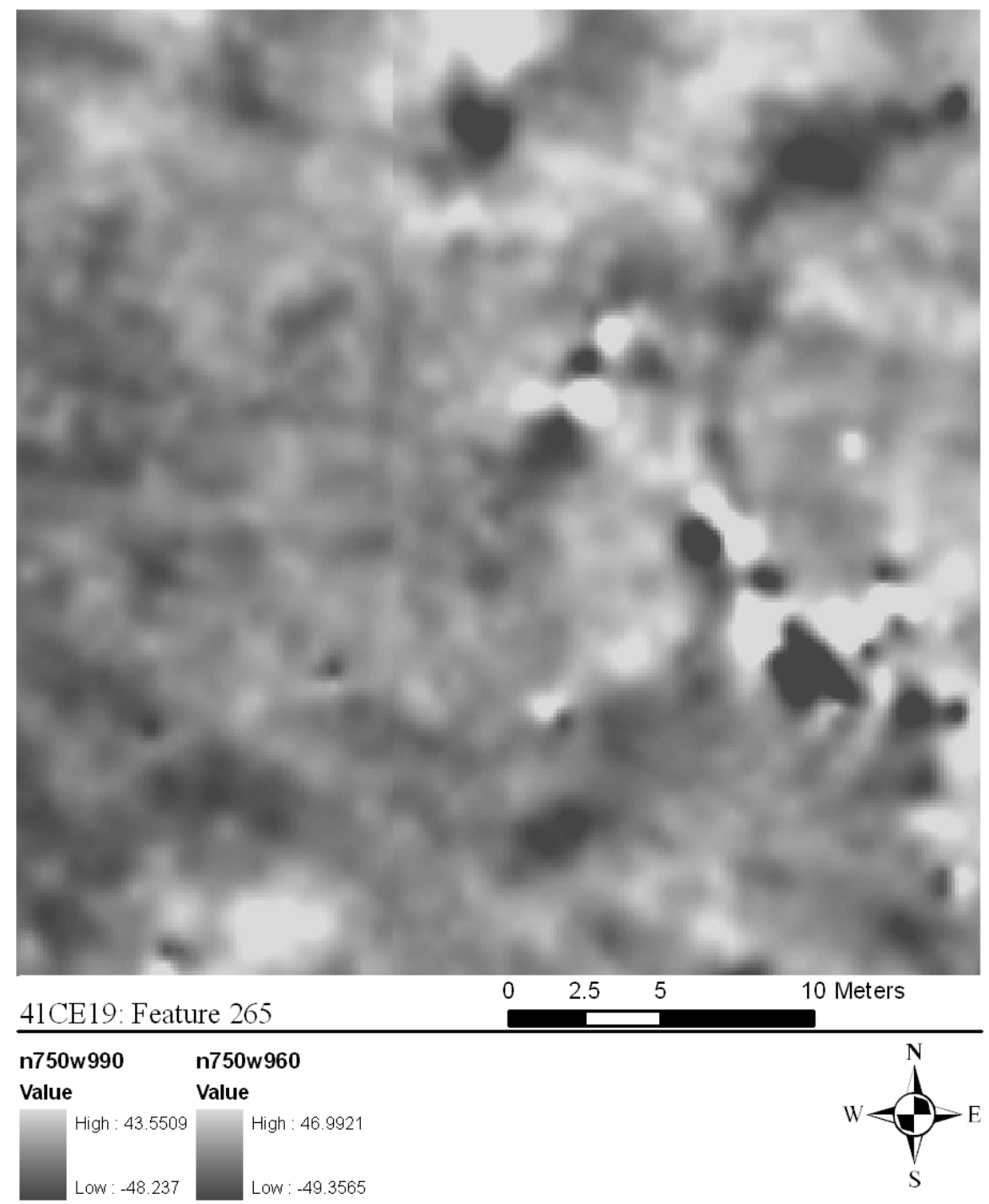

Figure 150: Feature 265

\begin{tabular}{|r|r|l|l|l|} 
Feat & $\begin{array}{l}\text { Dimensions/ } \\
\text { Diameter }(\mathbf{m})\end{array}$ & $\begin{array}{l}\text { Area } \\
\left(\mathbf{m}^{2}\right)\end{array}$ & Type & Comments \\
\hline 265 & 16.20 & 206.12 & circular & $\begin{array}{l}\text { Possible interior posts or hearths; structure } \\
\text { possibly burned }\end{array}$ \\
\hline
\end{tabular}




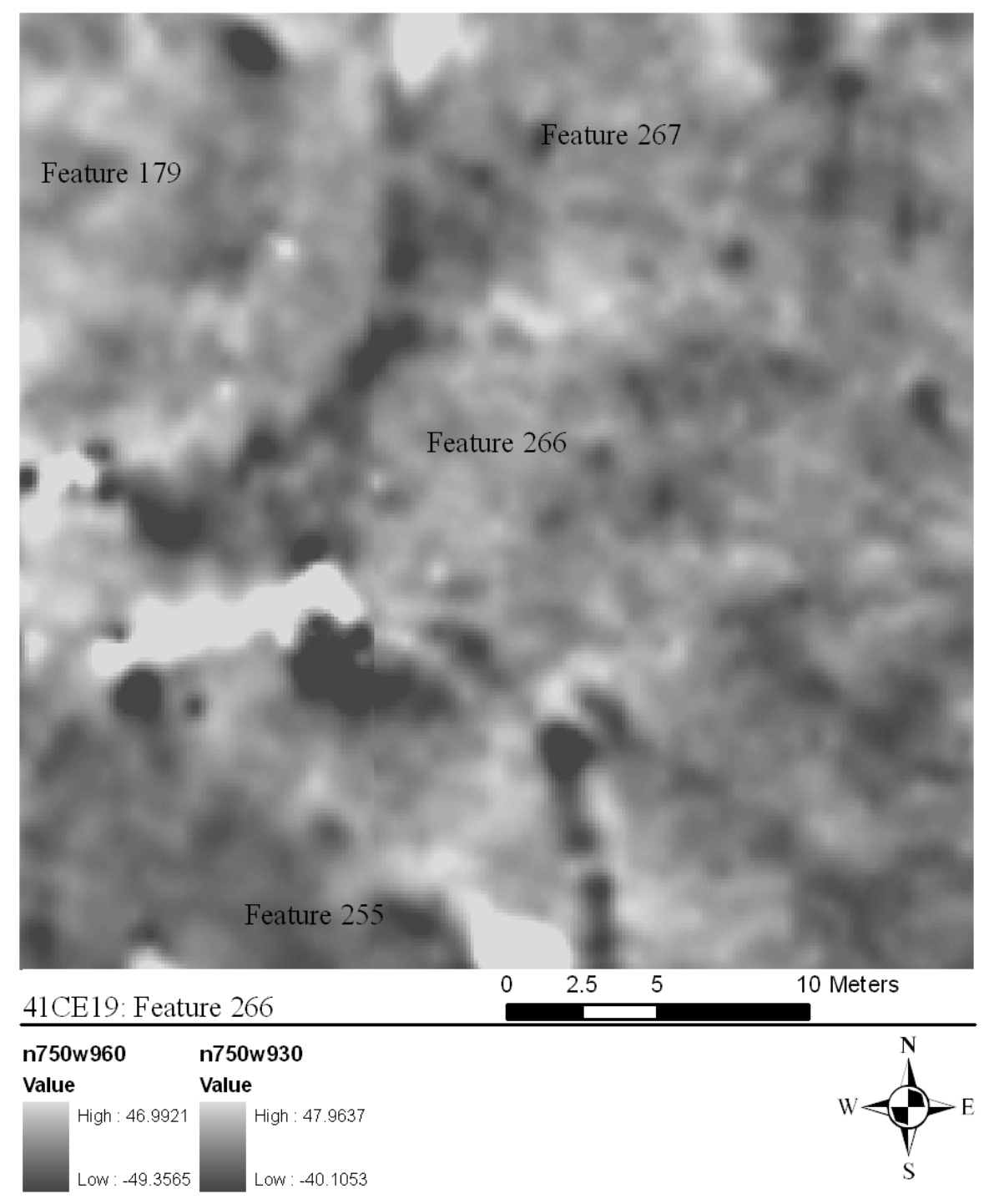

Figure 151: Feature 266

\begin{tabular}{|r|r|l|l|l|} 
Feat & $\begin{array}{l}\text { Dimensions/ } \\
\text { Diameter }(\mathbf{m})\end{array}$ & $\begin{array}{l}\text { Area } \\
\left(\mathbf{m}^{2}\right)\end{array}$ & Type & Comments \\
\hline 266 & 9.50 & 70.88 & circular & $\begin{array}{l}\text { Area of overlapping structures; no definite } \\
\text { interior features visible }\end{array}$ \\
\hline
\end{tabular}




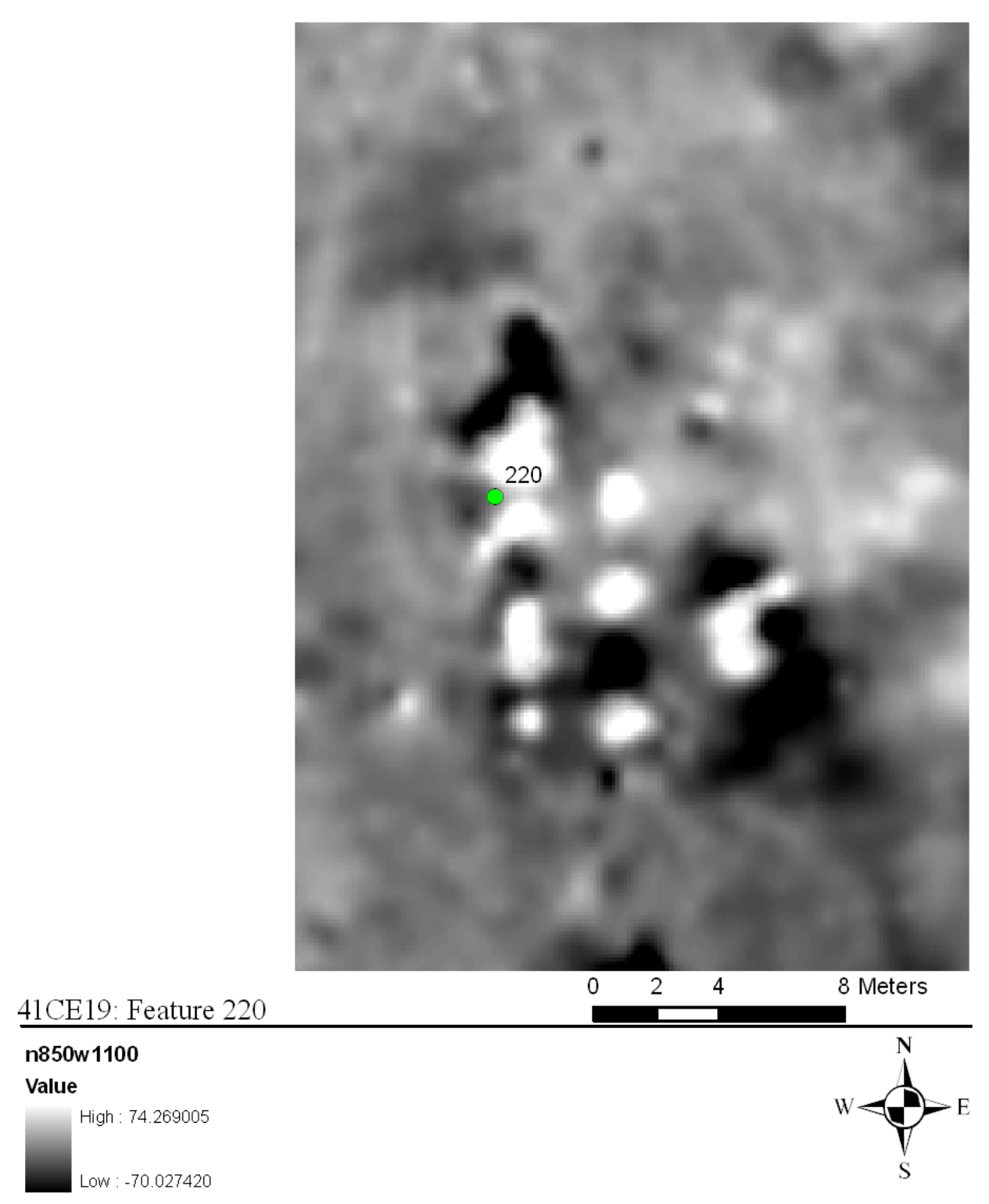

Figure 152: Feature 220

\begin{tabular}{|r|r|r|l|l|}
\hline Feat & $\begin{array}{l}\text { Dimensions/ } \\
\text { Diameter }(\mathbf{m})\end{array}$ & $\begin{array}{l}\text { Area } \\
\left(\mathbf{m}^{2}\right)\end{array}$ & Type & Comments \\
\hline 220 & 5.60 & 24.63 & circular & Burned interior features \\
\hline
\end{tabular}




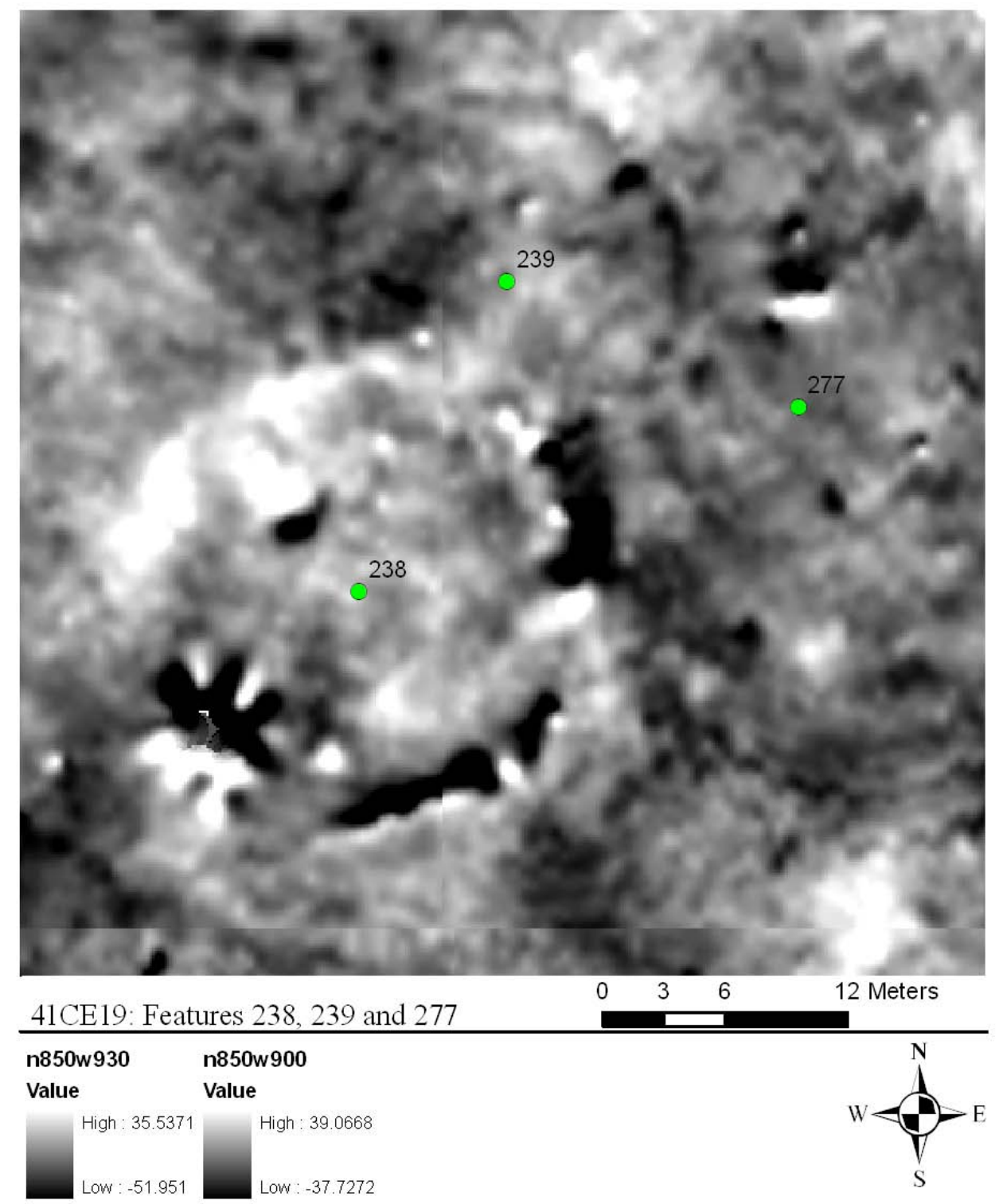

Figure 153: Feature 238, 239 and 277

\begin{tabular}{|r|r|l|l|l|} 
Feat & $\begin{array}{l}\text { Dimensions/ } \\
\text { Diameter }(\mathbf{m})\end{array}$ & $\begin{array}{l}\text { Area } \\
\left(\mathbf{m}^{2}\right)\end{array}$ & Type & Comments \\
\hline 238 & 21.00 & 346.36 & circular & $\begin{array}{l}\text { Burned; possible interior post/hearth-not } \\
\text { centrally placed; area of overlapping } \\
\text { structures }\end{array}$ \\
\hline & 17.50 & 240.53 & circular & $\begin{array}{l}\text { Possible interior post or hearth-not } \\
\text { centrally placed; area of overlapping } \\
\text { structures }\end{array}$ \\
\hline
\end{tabular}




\begin{tabular}{|l|l|l|l|l|}
277 & 13.20 & 136.85 & circular & $\begin{array}{l}\text { At least two possible interior pits; area of } \\
\text { overlapping structures }\end{array}$ \\
\hline
\end{tabular}

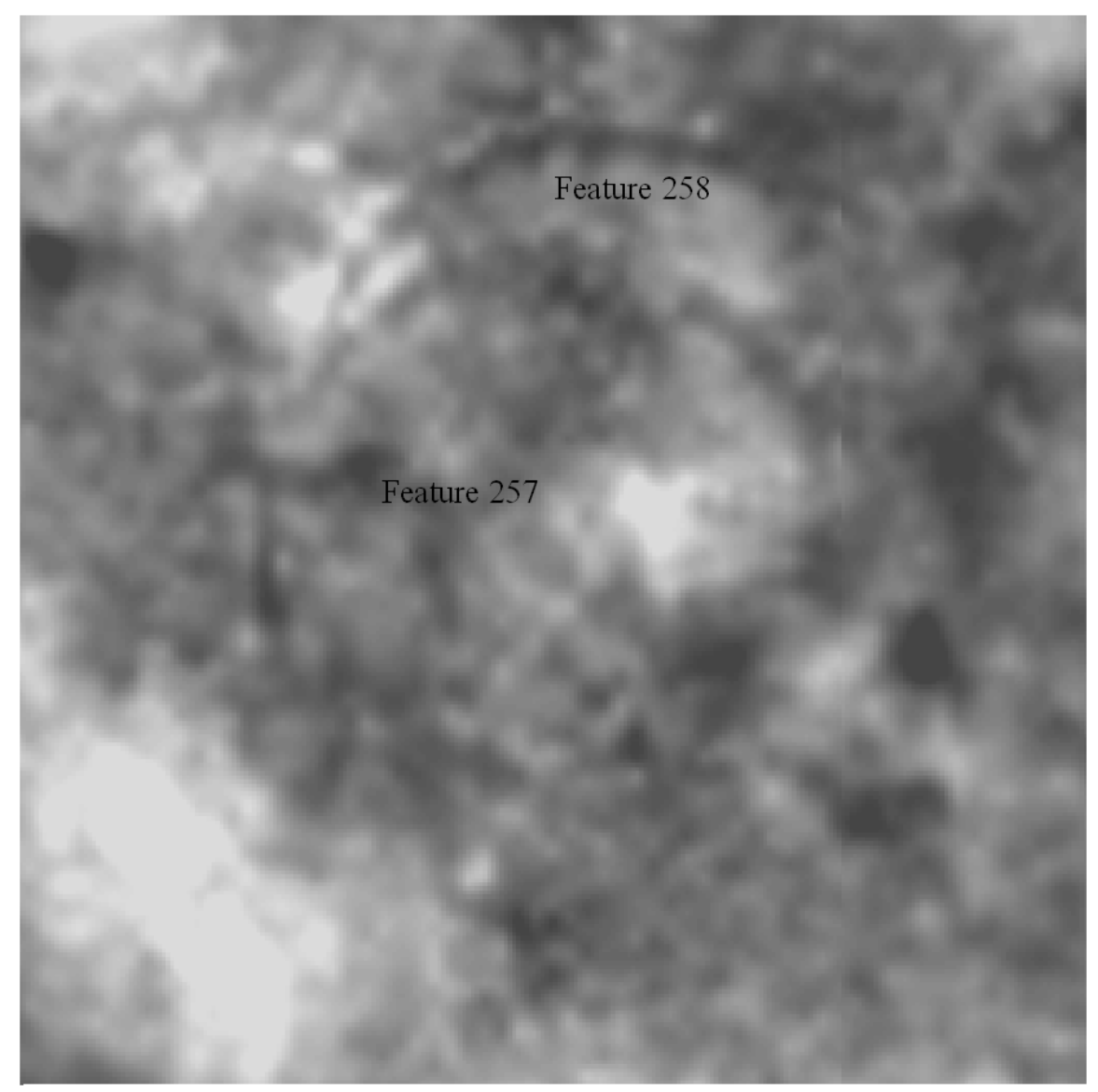

41CE19: Features 257 and 258

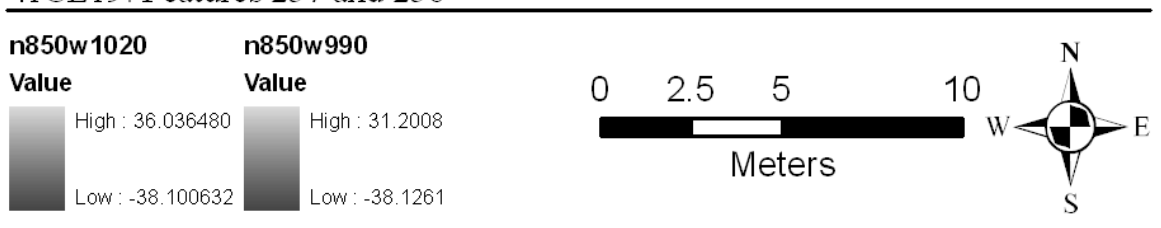

Figure 154: Feature 257 and 258

\begin{tabular}{|c|c|c|c|c|}
\hline Feat & $\begin{array}{l}\text { Dimensions/ } \\
\text { Diameter (m) }\end{array}$ & $\begin{array}{l}\text { Area } \\
\left(\mathrm{m}^{2}\right)\end{array}$ & Type & Comments \\
\hline 257 & 16.70 & 219.04 & circular & $\begin{array}{l}\text { Partial outline; area of overlapping } \\
\text { structures; possible interior feature }\end{array}$ \\
\hline 258 & 17.70 & 246.06 & circular & $\begin{array}{l}\text { Partial outline; area of overlapping } \\
\text { structures; possible interior feature }\end{array}$ \\
\hline
\end{tabular}




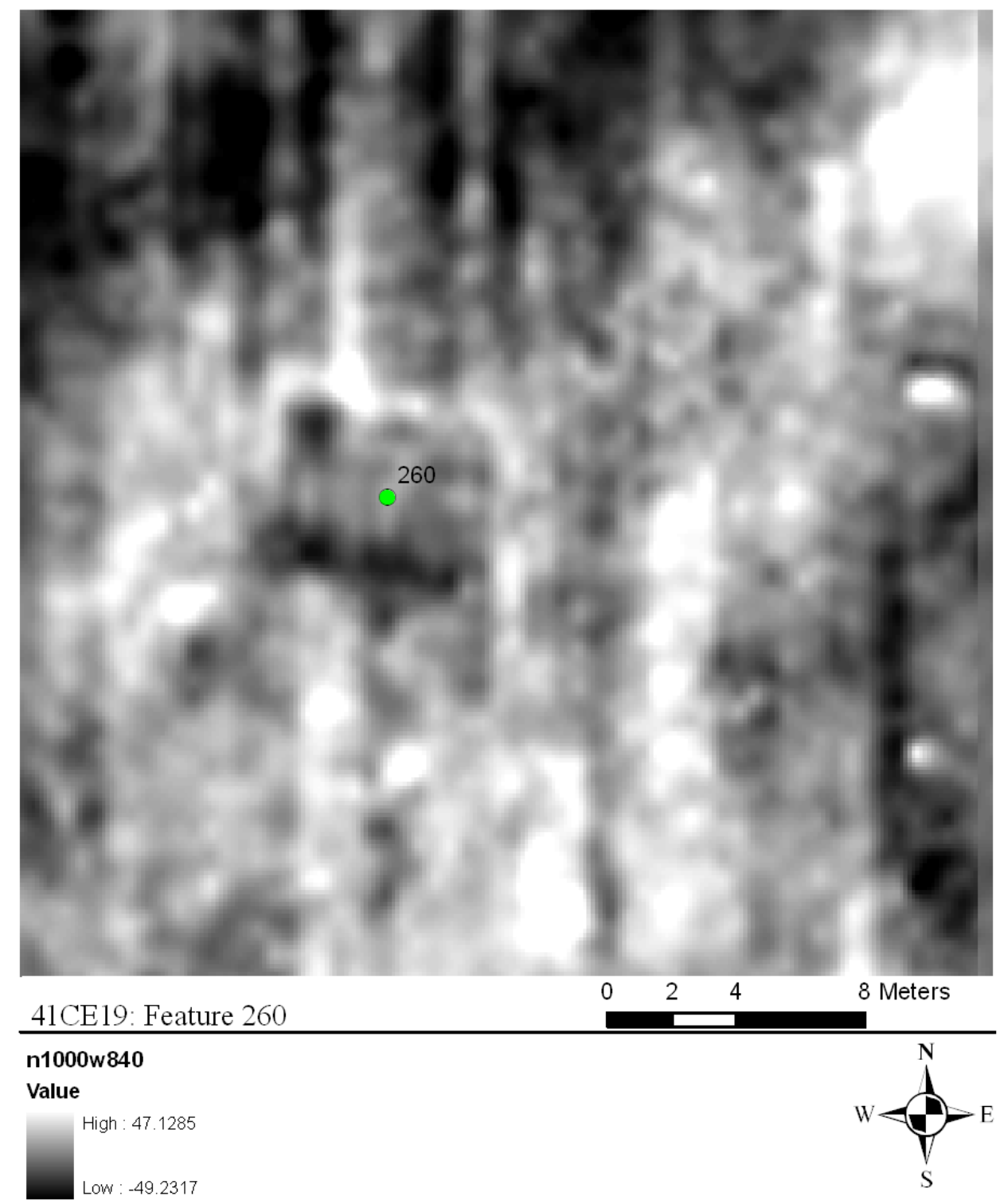

Figure 155: Feature 260

\begin{tabular}{|r|l|l|l|l|} 
Feat & $\begin{array}{l}\text { Dimensions/ } \\
\text { Diameter }(\mathbf{m})\end{array}$ & $\begin{array}{l}\text { Area } \\
\left(\mathbf{m}^{2}\right)\end{array}$ & Type & Comments \\
\hline 260 & $5 \times 6$ & 30 & rectangular & Structural feature? \\
\hline
\end{tabular}




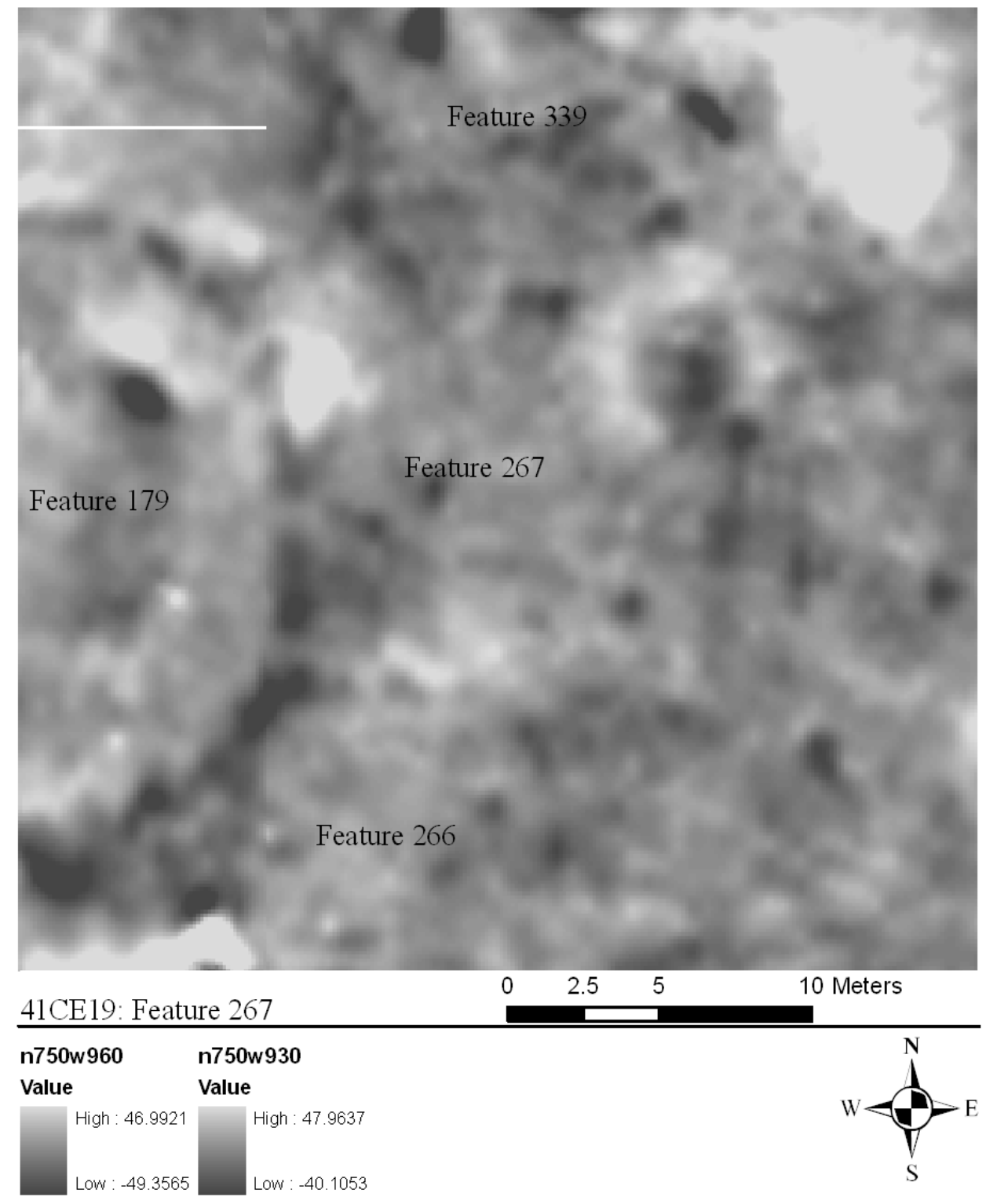

Figure 156: Feature 267

\begin{tabular}{|r|r|l|l|l|} 
Feat & $\begin{array}{l}\text { Dimensions/ } \\
\text { Diameter }(\mathbf{m})\end{array}$ & $\begin{array}{l}\text { Area } \\
\left(\mathbf{m}^{2}\right)\end{array}$ & Type & Comments \\
\hline 267 & 16.20 & 206.12 & circular & Faint outline; possible interior features \\
\hline
\end{tabular}




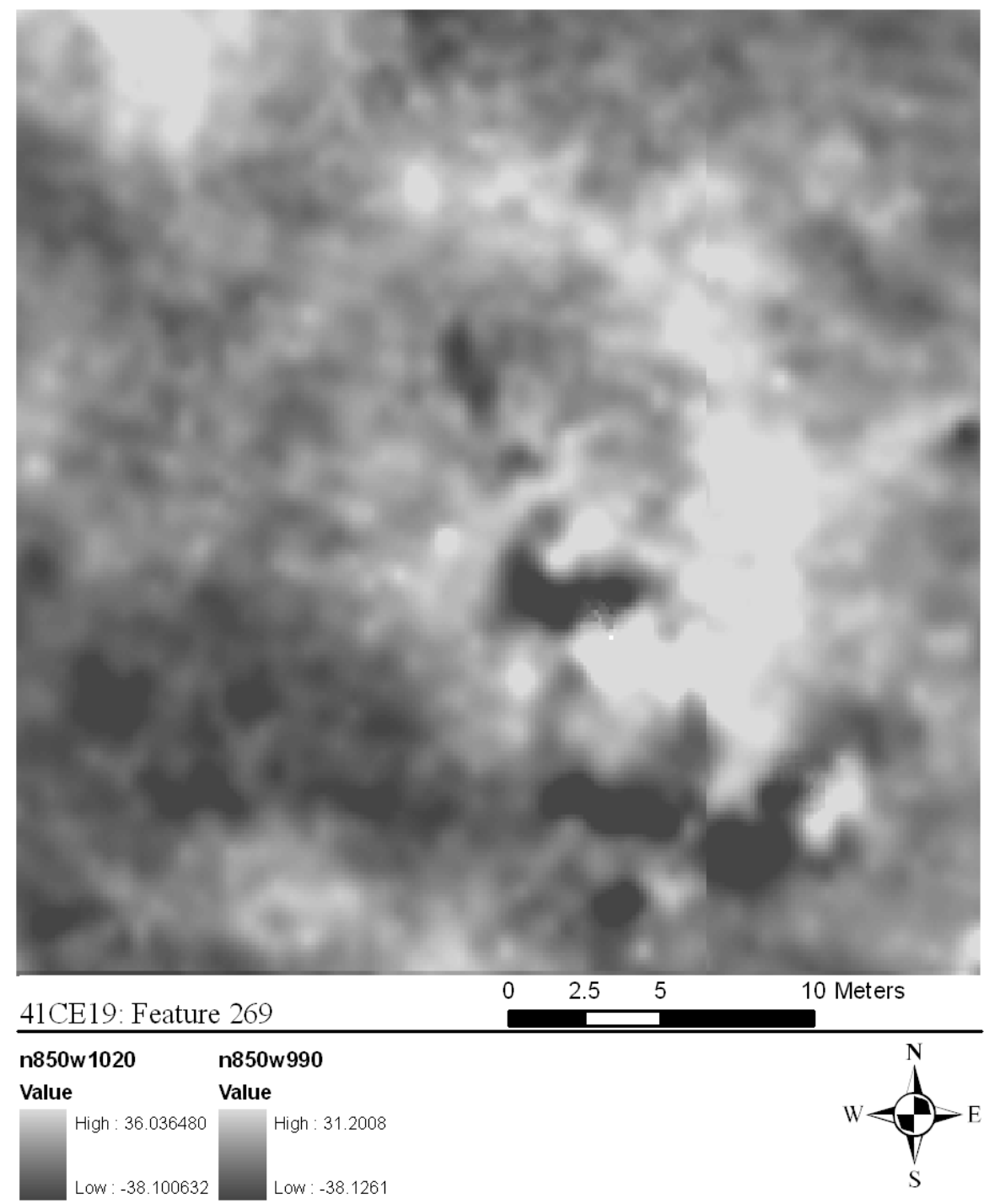

Figure 157: Feature 269

\begin{tabular}{|r|r|l|l|l|} 
Feat & $\begin{array}{l}\text { Dimensions/ } \\
\text { Diameter }(\mathbf{m})\end{array}$ & $\begin{array}{l}\text { Area } \\
\left(\mathbf{m}^{2}\right)\end{array}$ & Type & Comments \\
\hline 269 & 18.10 & 257.30 & circular & Burned; faint structure outline \\
\hline
\end{tabular}



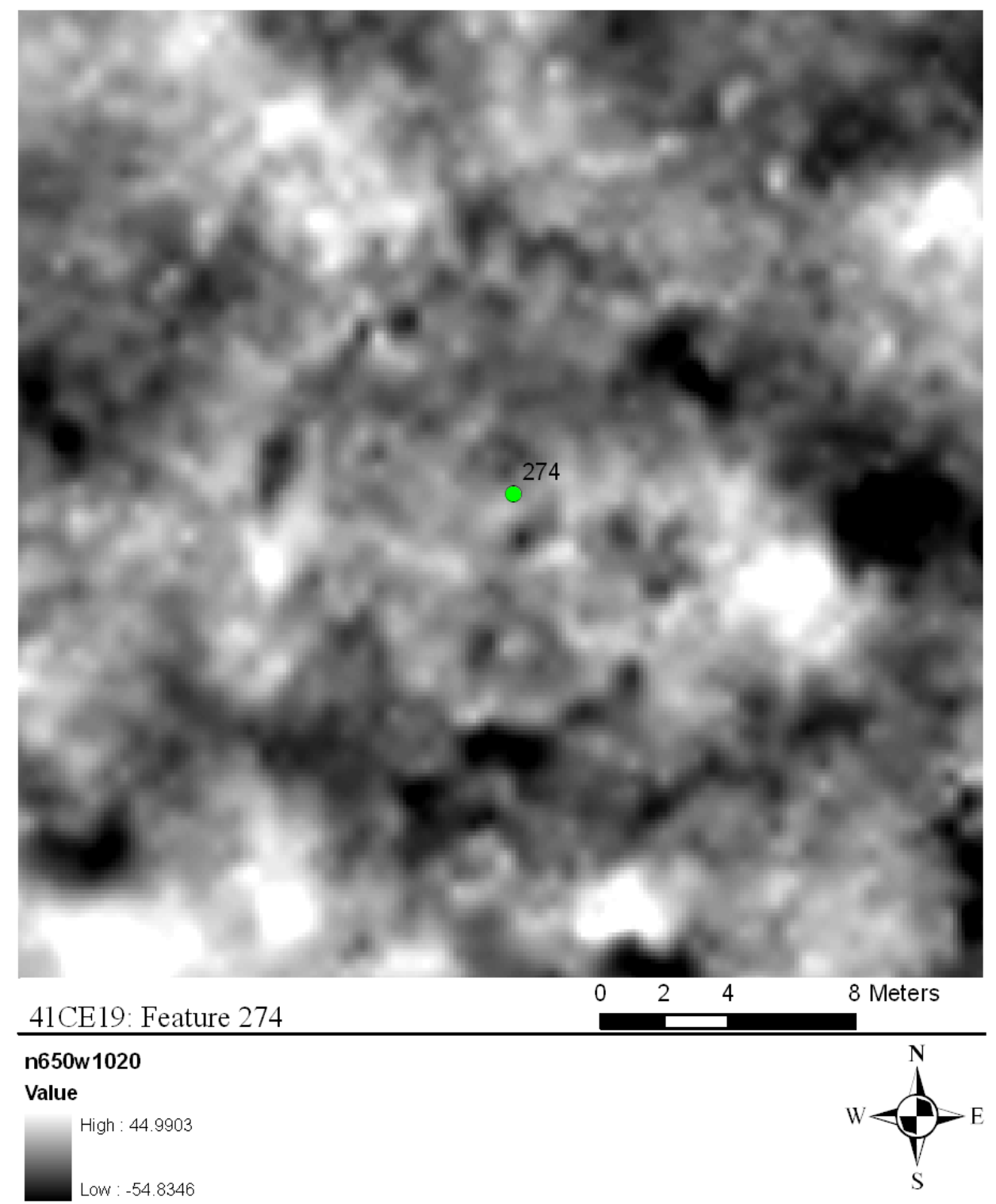

Figure 158: Feature 274

\begin{tabular}{|r|l|l|l|l|} 
Feat & $\begin{array}{l}\text { Dimensions } \\
\text { Diameter }(\mathbf{m})\end{array}$ & $\begin{array}{l}\text { Area } \\
\left(\mathbf{m}^{\mathbf{2}} \mathbf{)}\right.\end{array}$ & Type & Comments \\
\hline 274 & 13 & 132.73 & Circular & Possibly burned; possible interior features \\
\hline
\end{tabular}




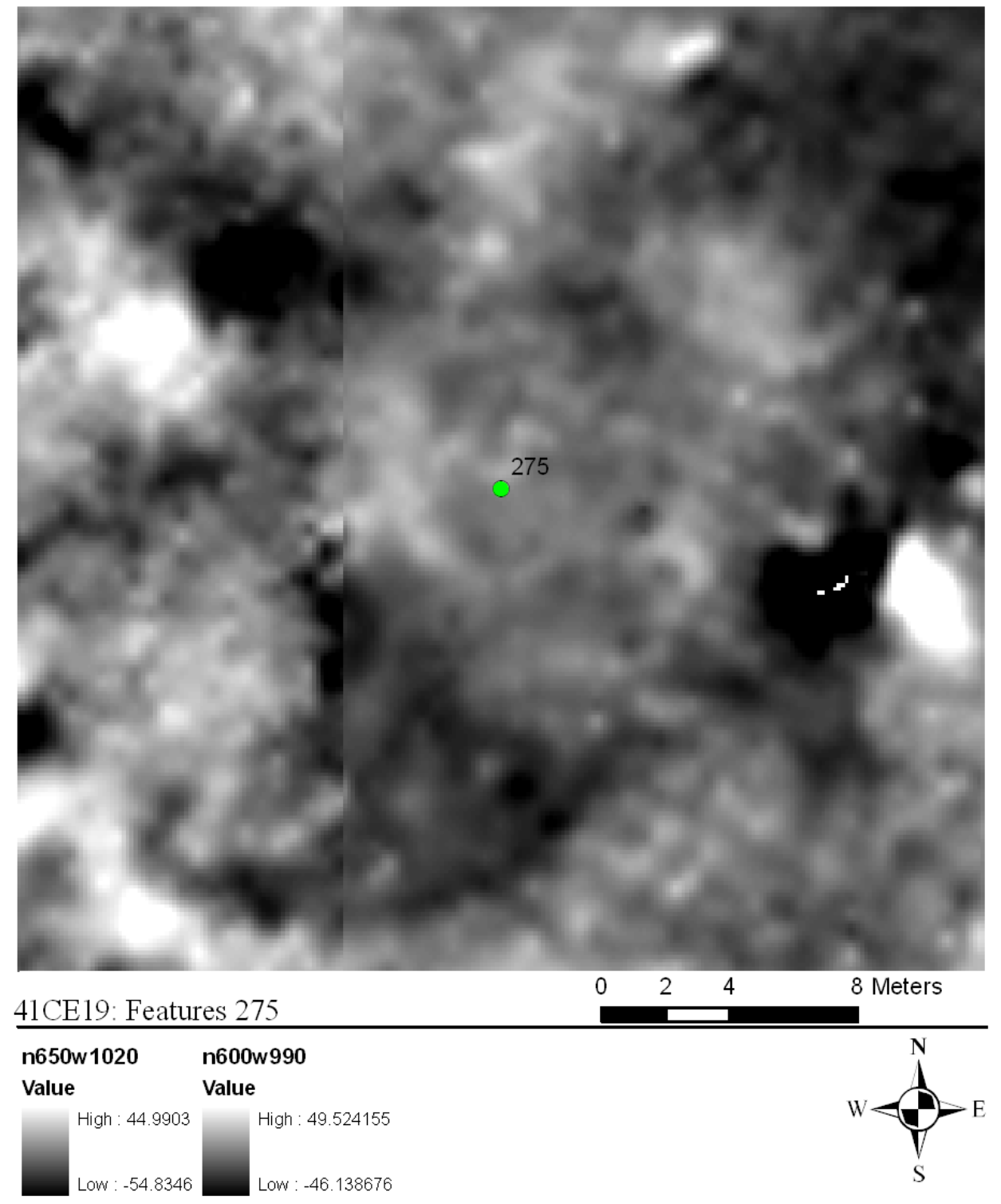

Figure 159: Feature 275

\begin{tabular}{|r|r|l|l|l|} 
Feat & $\begin{array}{l}\text { Dimensions/ } \\
\text { Diameter }(\mathbf{m})\end{array}$ & $\begin{array}{l}\text { Area } \\
\left(\mathbf{m}^{2}\right)\end{array}$ & Type & Comments \\
\hline 275 & 4.60 & 16.62 & circular & $\begin{array}{l}\text { Small structure; granary or storage } \\
\text { platform? }\end{array}$ \\
\hline
\end{tabular}




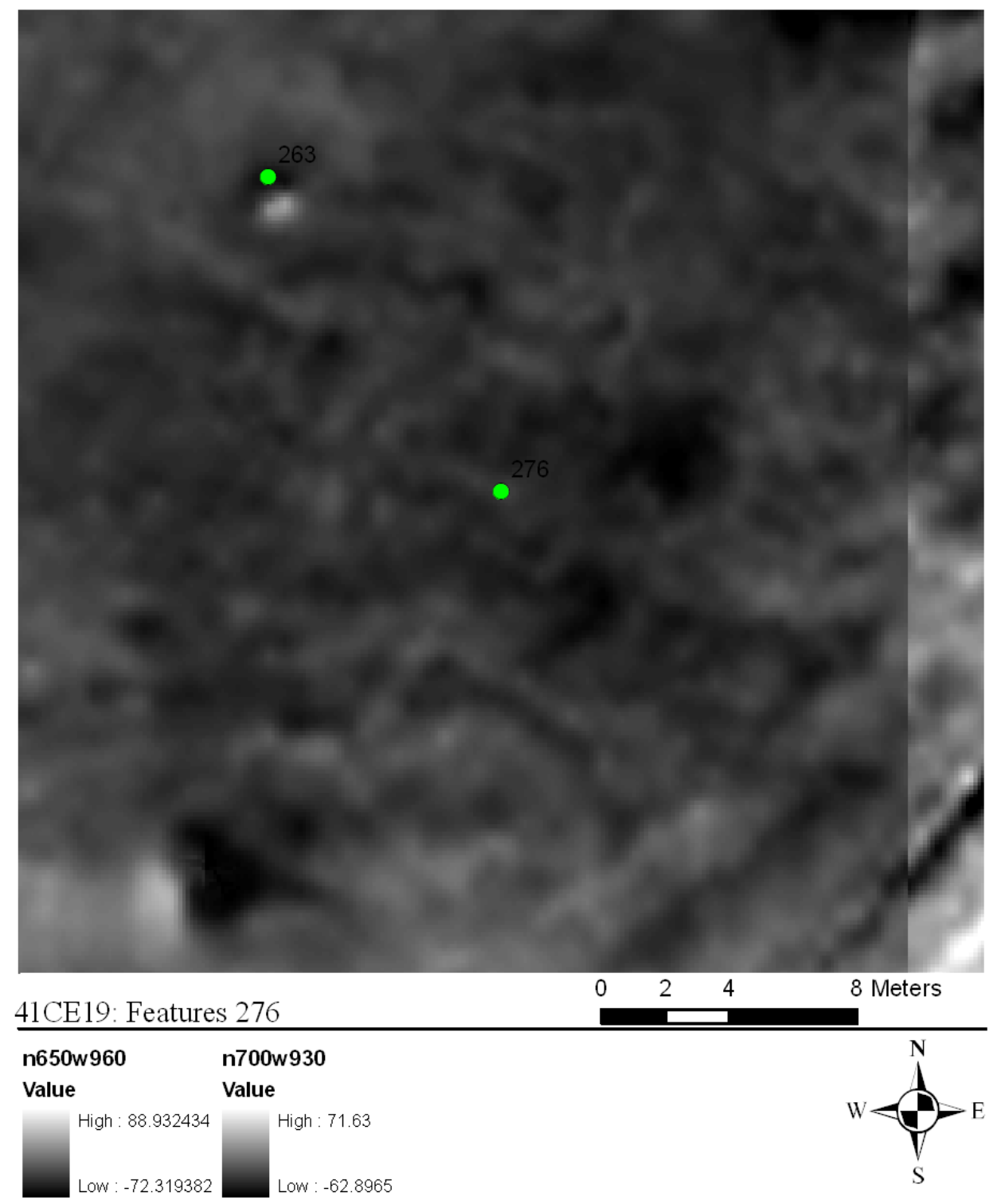

Figure 160: Feature 276

\begin{tabular}{|r|r|l|l|l|} 
Feat & $\begin{array}{l}\text { Dimensions/ } \\
\text { Diameter }(\mathbf{m})\end{array}$ & $\begin{array}{l}\text { Area } \\
\left(\mathbf{m}^{2}\right)\end{array}$ & Type & Comments \\
\hline 276 & 8.70 & 59.45 & circular & $\begin{array}{l}\text { Possible button house, although interior } \\
\text { features are faint }\end{array}$ \\
\hline
\end{tabular}




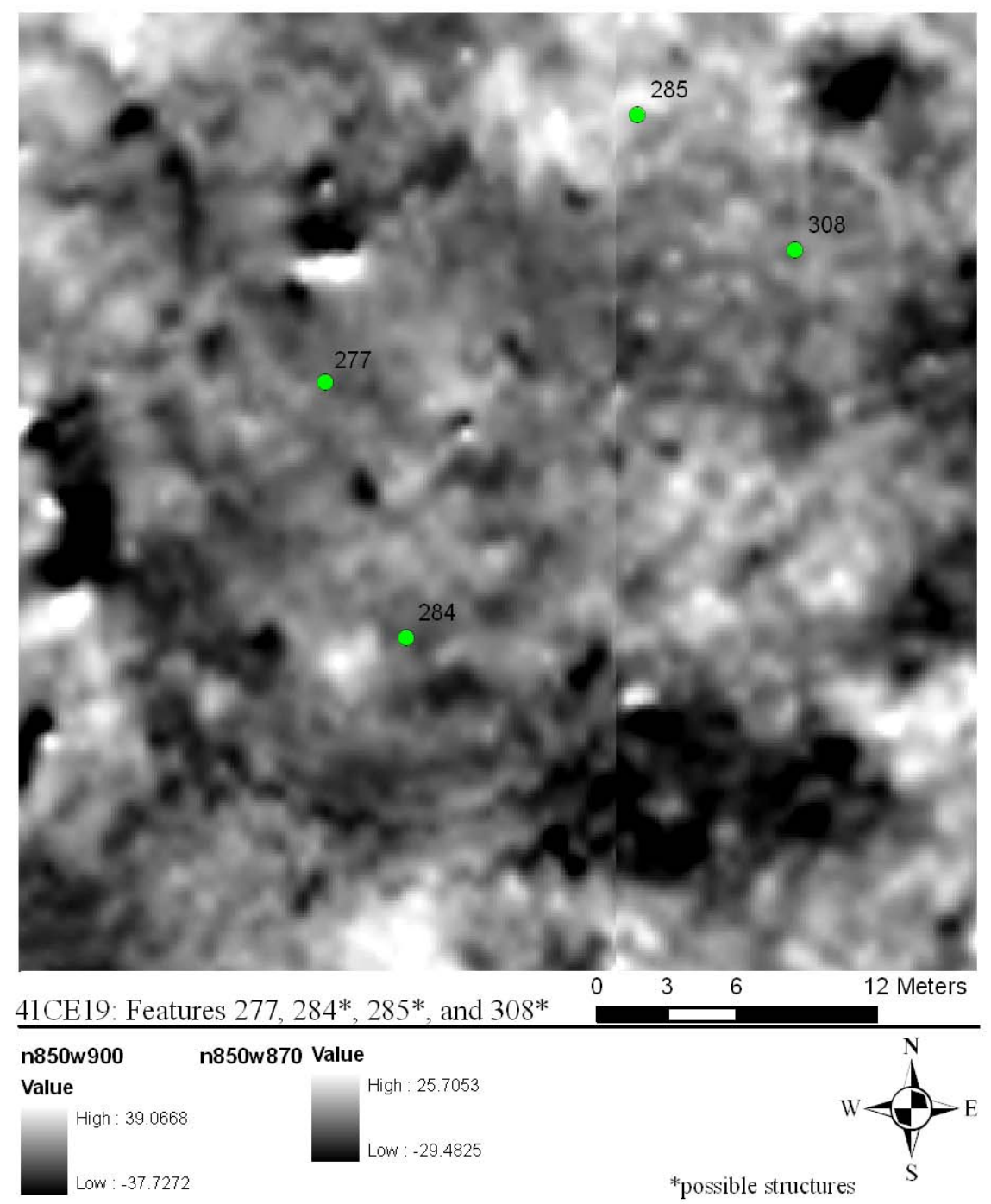

Figure 161: Feature 277, 284, 285, and 308

\begin{tabular}{|r|r|l|l|l|}
\hline Feat & $\begin{array}{l}\text { Dimensions } / \\
\text { Diameter }(\mathbf{m})\end{array}$ & $\begin{array}{l}\text { Area } \\
\left(\mathbf{m}^{2}\right)\end{array}$ & Type & Comments \\
\hline 277 & 13.20 & 136.85 & circular & $\begin{array}{l}\text { Possible interior features; area of } \\
\text { superimposed structures }\end{array}$ \\
\hline 284 & 16.10 & 203.58 & circular & $\begin{array}{l}\text { Possible interior features; area of } \\
\text { superimposed structures }\end{array}$ \\
\hline 285 & 11.69 & 107.33 & circular & $\begin{array}{l}\text { area of superimposed structures; burned } \\
\text { area? }\end{array}$ \\
\hline 308 & 6.90 & 37.39 & circular & $\begin{array}{l}\text { Possible faint interior features; area of } \\
\text { superimposed structures }\end{array}$ \\
\hline
\end{tabular}




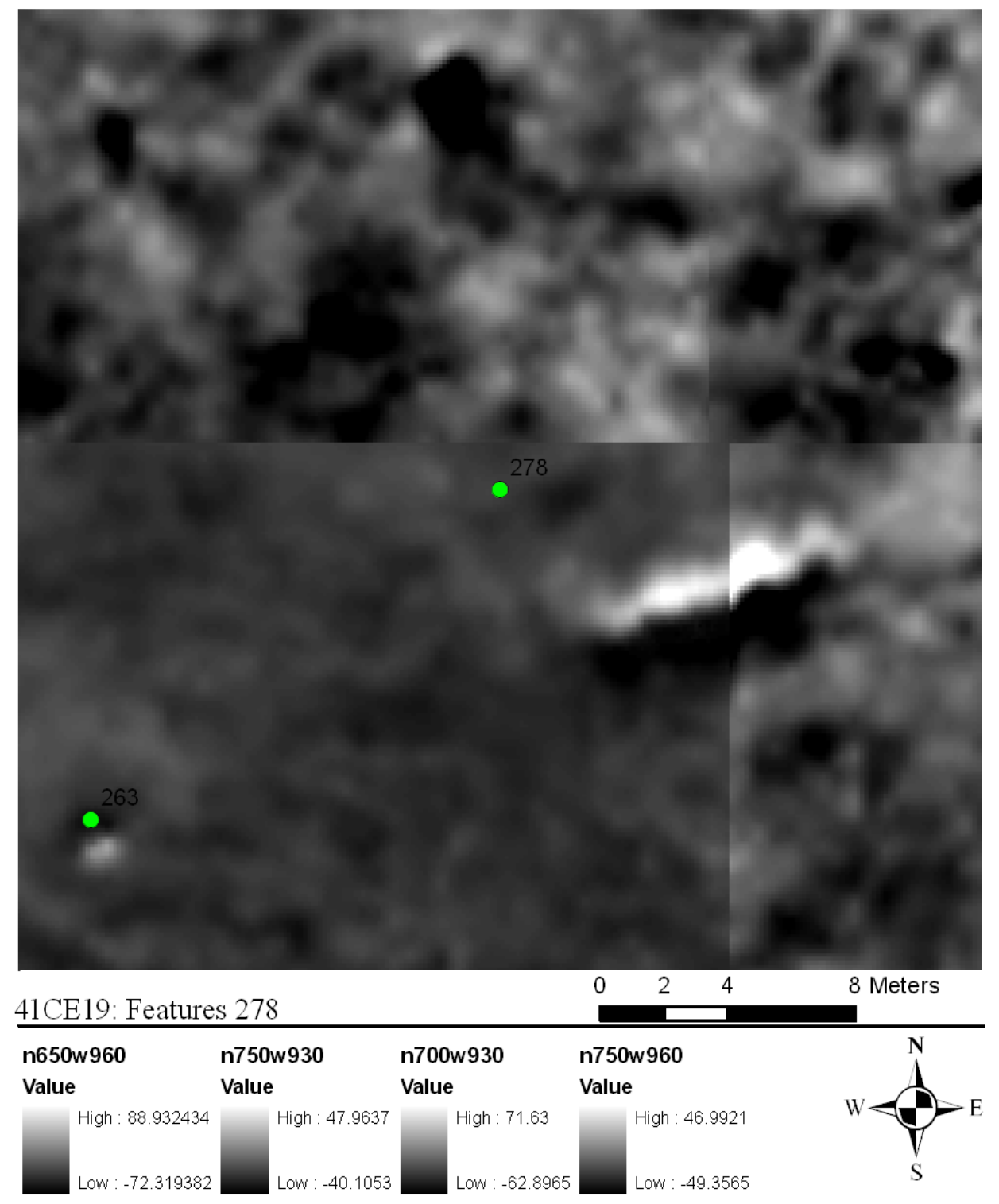

Figure 162: Feature 278

\begin{tabular}{|r|r|r|l|l|}
\hline Feat & $\begin{array}{l}\text { Dimensions } / \\
\text { Diameter }(\mathbf{m})\end{array}$ & $\begin{array}{l}\text { Area } \\
\left(\mathbf{m}^{2}\right)\end{array}$ & Type & Comments \\
\hline 278 & 10.30 & 83.32 & circular & Half-circle arc; possible interior features \\
\hline
\end{tabular}




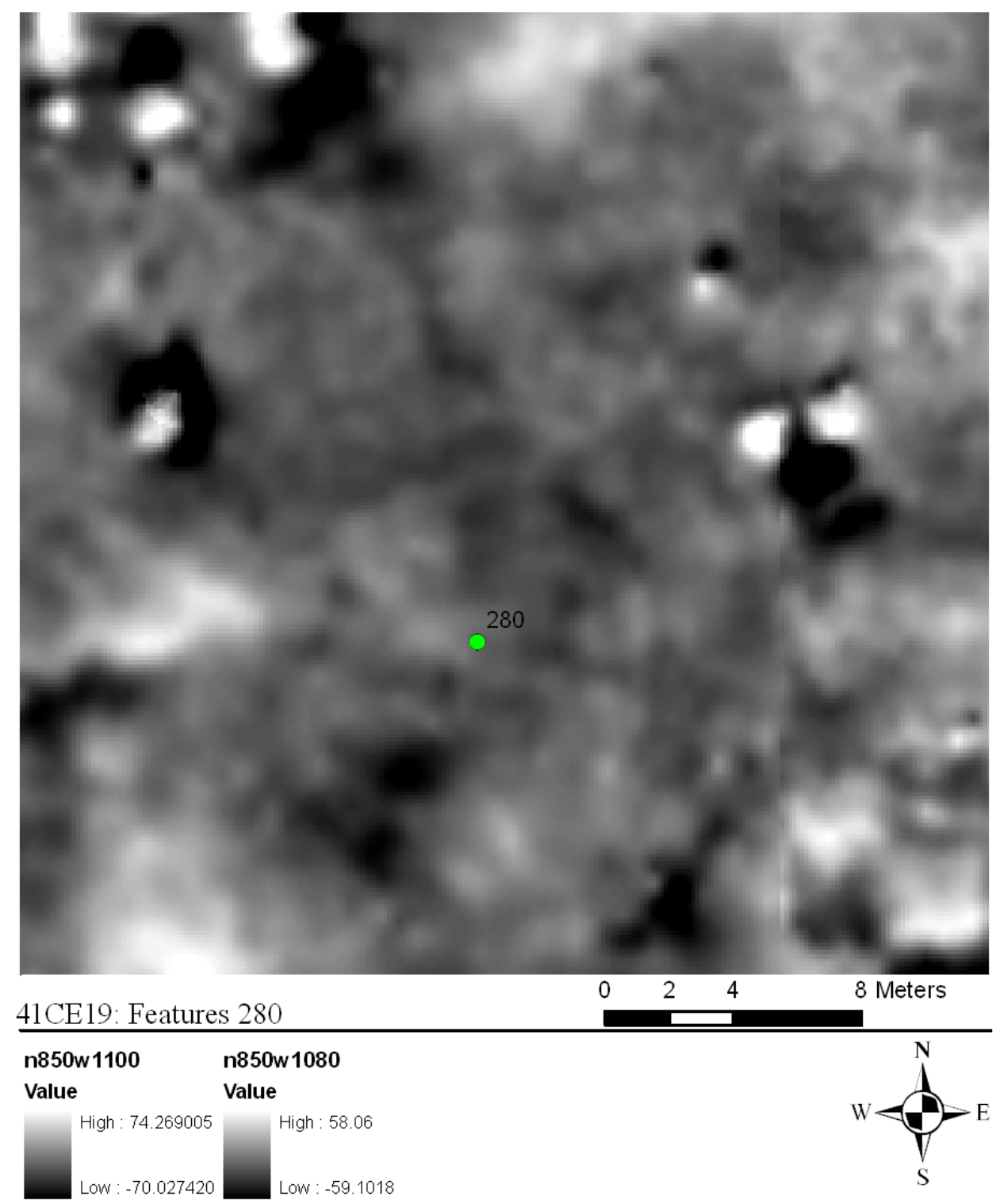

Figure 163: Feature 280

\begin{tabular}{|r|r|r|l|l|}
\hline Feat & $\begin{array}{l}\text { Dimensions/ } \\
\text { Diameter }(\mathbf{m})\end{array}$ & $\begin{array}{l}\text { Area } \\
\left(\mathbf{m}^{2}\right)\end{array}$ & Type & Comments \\
\hline 280 & 11.10 & 96.77 & circular & $\begin{array}{l}\text { Possible interior features; possible } \\
\text { overlapping faint structure wall arcs }\end{array}$ \\
\hline
\end{tabular}




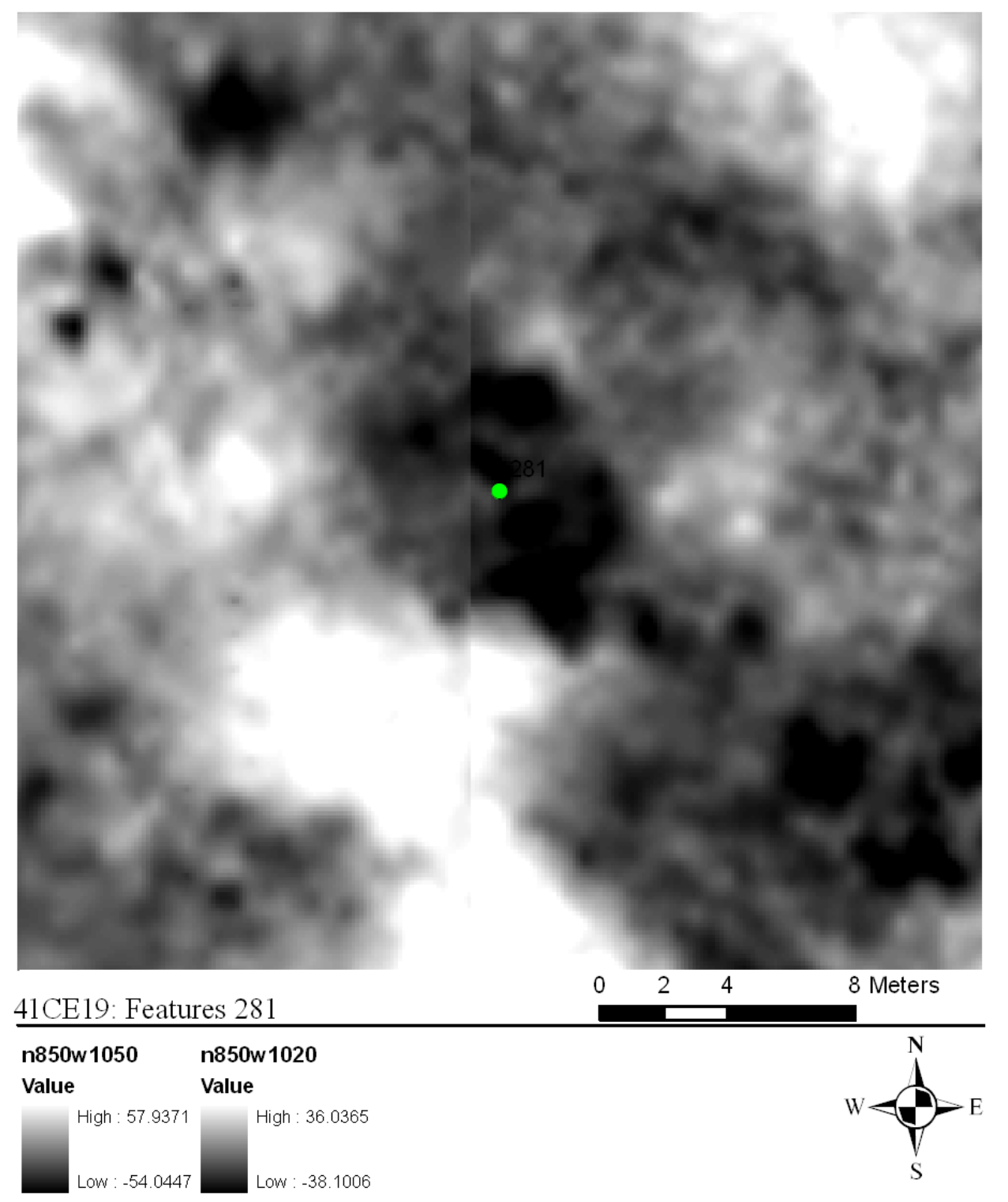

Figure 164: Feature 281

\begin{tabular}{|r|l|l|l|l|}
\hline Feat & $\begin{array}{l}\text { Dimensions/ } \\
\text { Diameter }(\mathbf{m})\end{array}$ & $\begin{array}{l}\text { Area } \\
\left(\mathbf{m}^{2}\right)\end{array}$ & Type & Comments \\
\hline 281 & $6.8 \times 6.8$ & 46.24 & rectangular & Southeast facing extended entrance \\
\hline
\end{tabular}




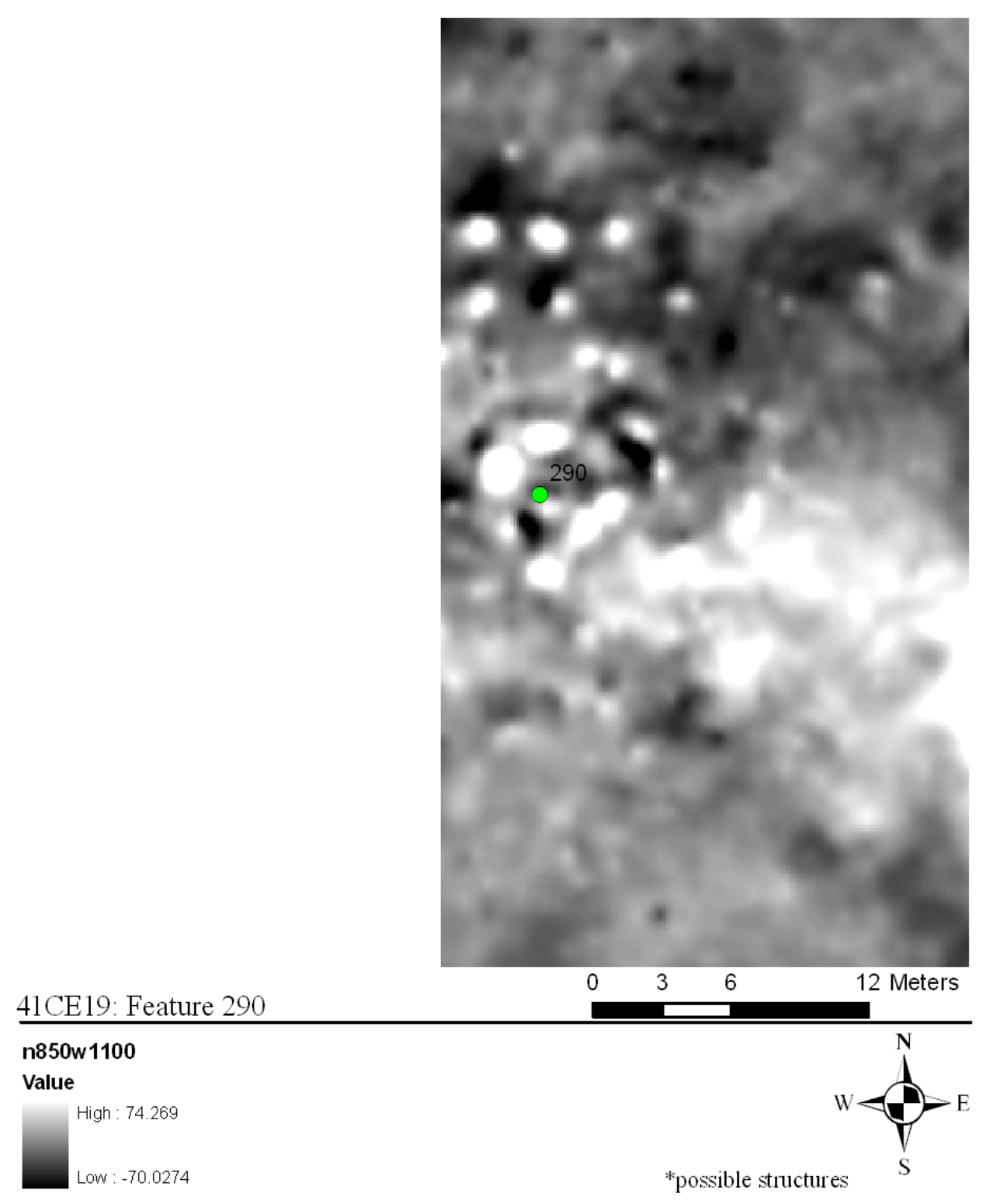

Figure 165: Feature 290

\begin{tabular}{|r|r|r|l|l|}
\hline Feat & $\begin{array}{l}\text { Dimensions/ } \\
\text { Diameter }(\mathbf{m})\end{array}$ & $\begin{array}{l}\text { Area } \\
\left(\mathbf{m}^{2}\right)\end{array}$ & Type & Comments \\
\hline 290 & 7.30 & 41.85 & circular & Likely burned; possible interior features \\
\hline
\end{tabular}



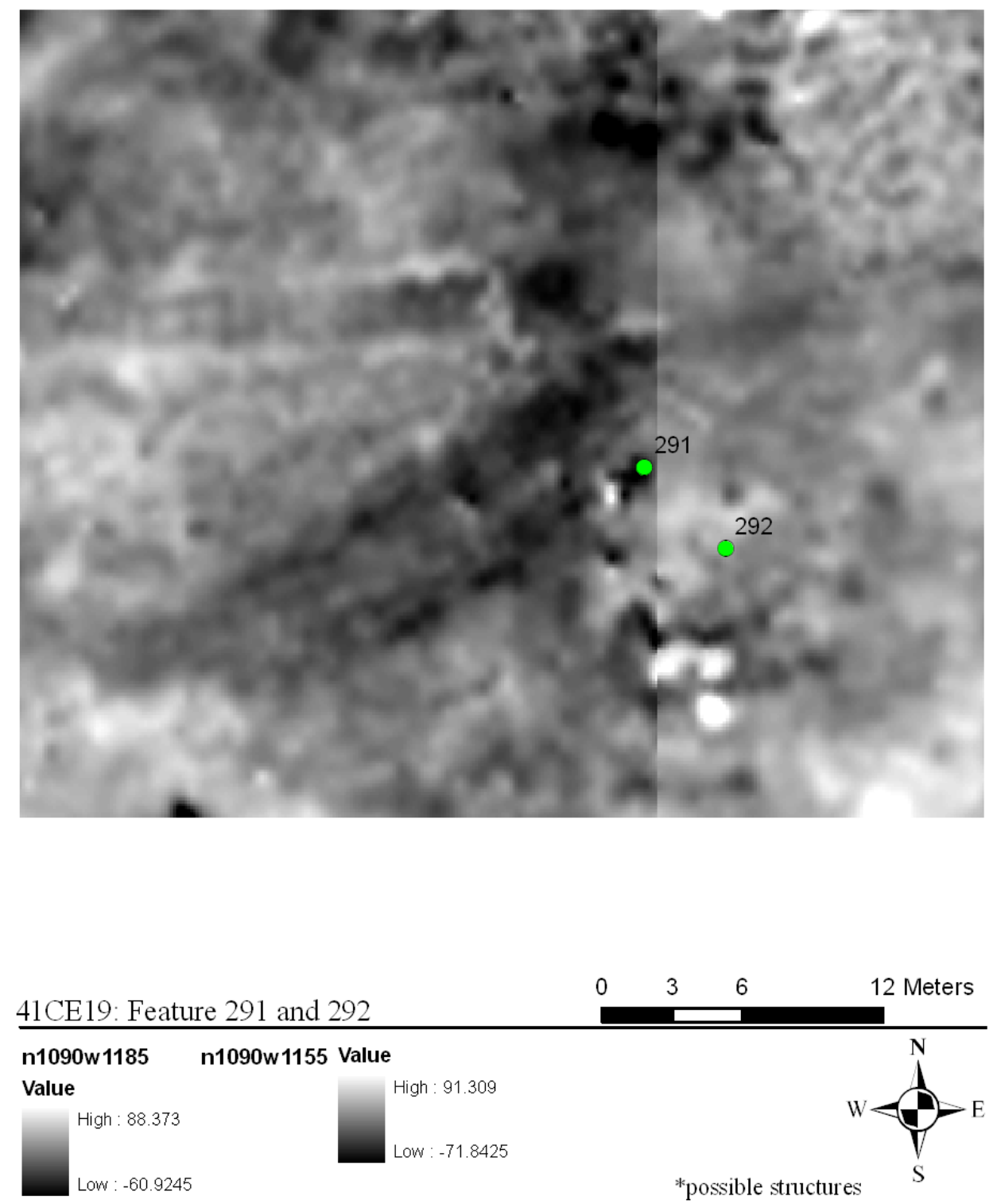

Figure 166: Features 291 and 292

\begin{tabular}{|r|r|r|l|l|}
\hline Feat & $\begin{array}{l}\text { Dimensions } / \\
\text { Diameter }(\mathbf{m})\end{array}$ & $\begin{array}{l}\text { Area } \\
\left(\mathbf{m}^{2}\right)\end{array}$ & Type & Comments \\
\hline 291 & 6.70 & 35.26 & circular & $\begin{array}{l}\text { Possible interior features; one of two } \\
\text { superimposed structures }\end{array}$ \\
\hline 292 & 7.20 & 40.72 & circular & $\begin{array}{l}\text { Possible interior features; one of two } \\
\text { superimposed structures }\end{array}$ \\
\hline
\end{tabular}




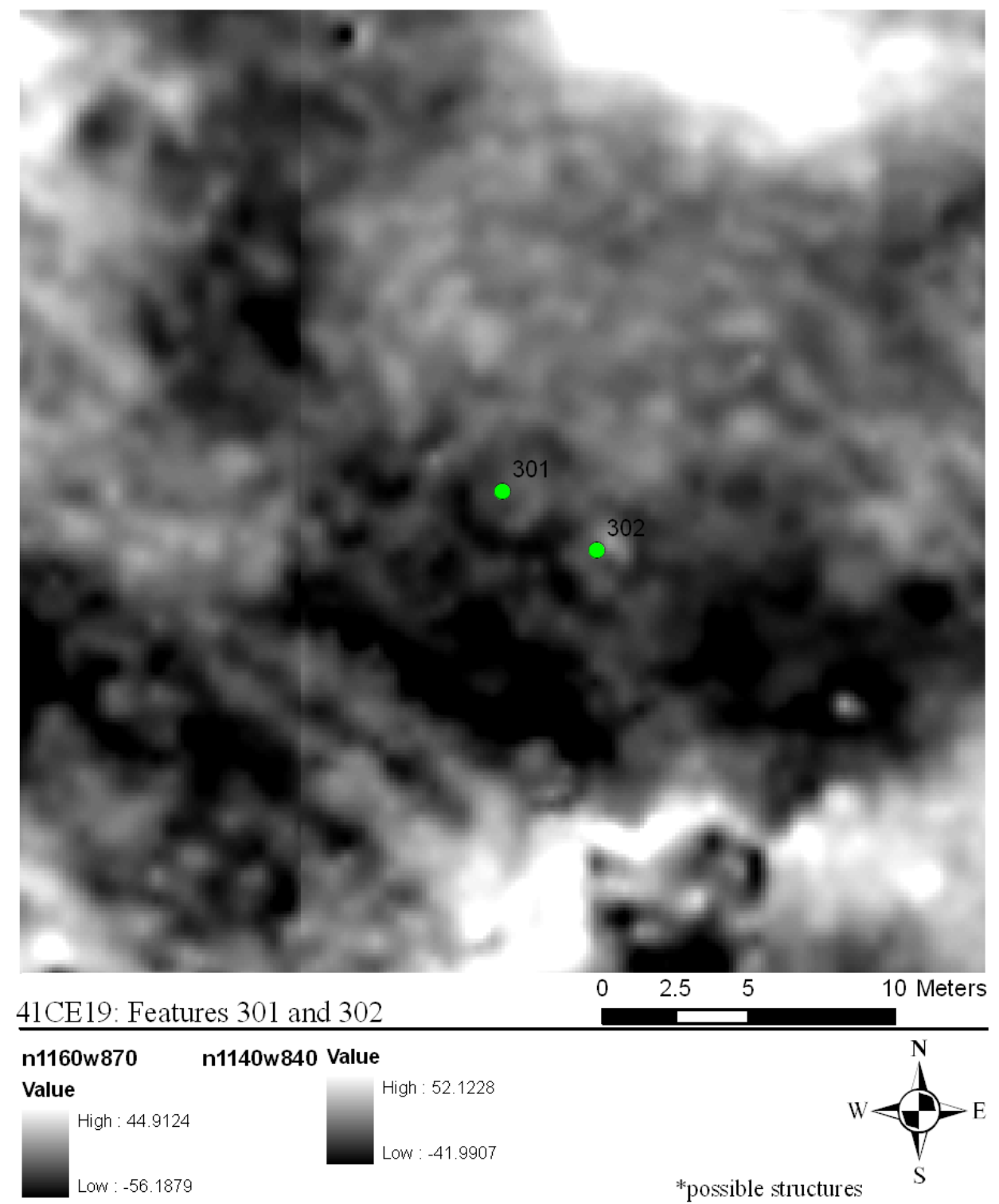

Figure 167: Features 301 and 302

\begin{tabular}{|r|r|r|l|l|}
\hline Feat & $\begin{array}{l}\text { Dimensions/ } \\
\text { Diameter }(\mathbf{m})\end{array}$ & $\begin{array}{l}\text { Area } \\
\left(\mathbf{m}^{2}\right)\end{array}$ & Type & Comments \\
\hline 301 & 3.45 & 9.35 & circular & Possible granary/storage facility \\
\hline 302 & 3.15 & 7.79 & circular & Possible granary/storage facility \\
\hline
\end{tabular}




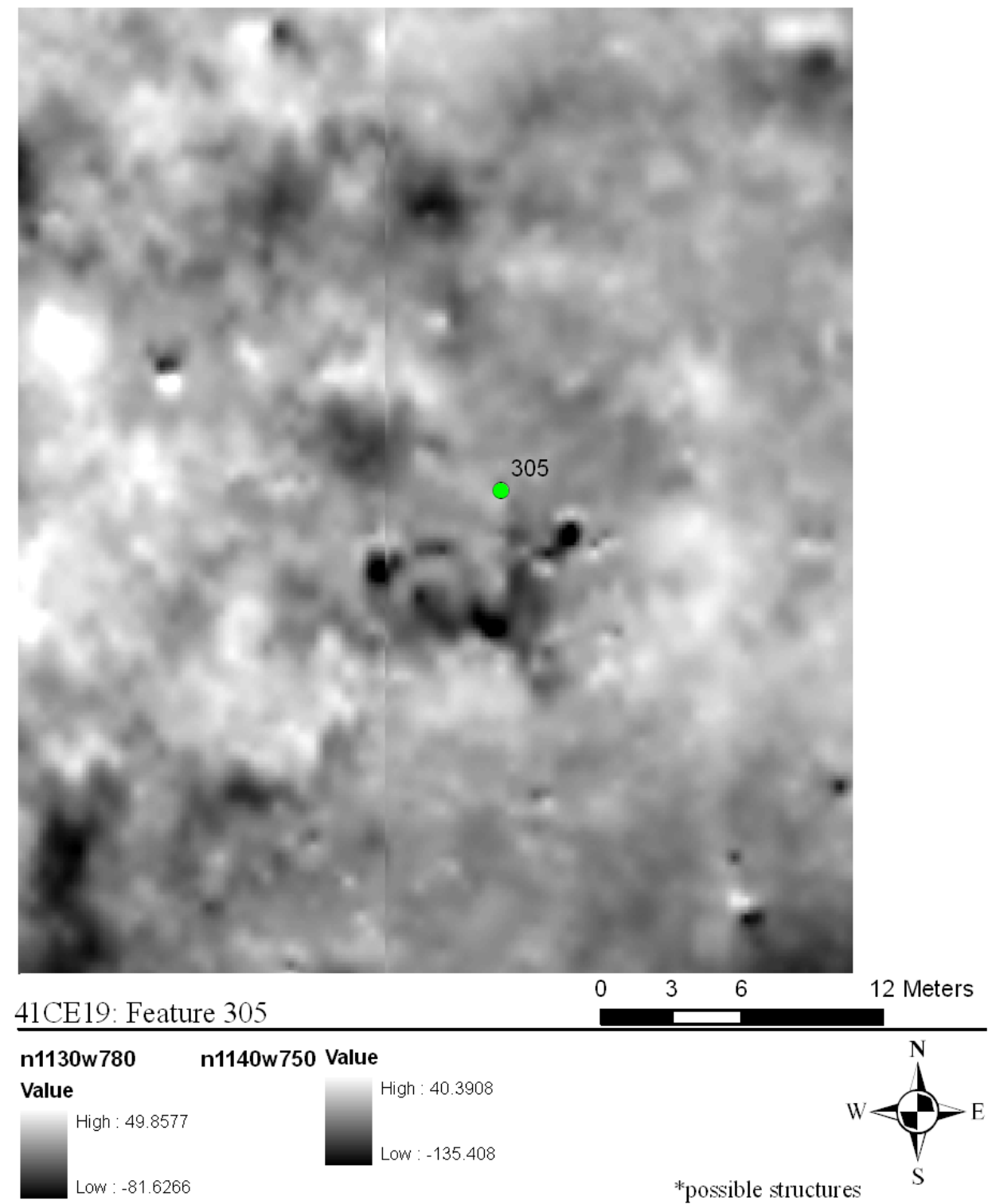

Figure 168: Feature 305

\begin{tabular}{|r|r|l|l|l|}
\hline Feat & $\begin{array}{l}\text { Dimensions/ } \\
\text { Diameter }(\mathbf{m})\end{array}$ & $\begin{array}{l}\text { Area } \\
\left(\mathbf{m}^{2} \mathbf{)}\right.\end{array}$ & Type & Comments \\
\hline 305 & 18.25 & 261.59 & circular & Possible interior features; possibly burned \\
\hline
\end{tabular}




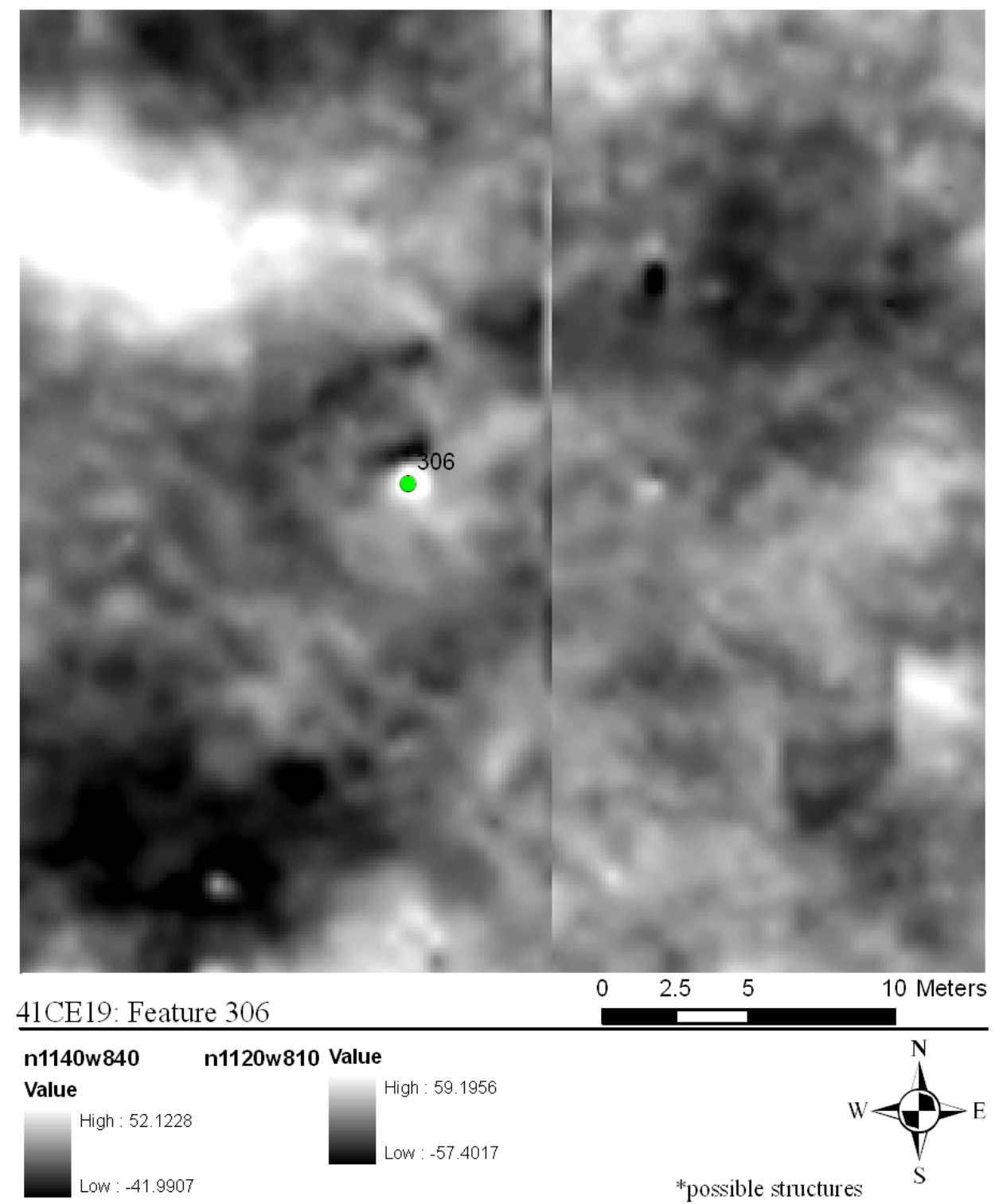

Figure 169: Feature 306

\begin{tabular}{|r|r|r|l|l|}
\hline Feat & $\begin{array}{l}\text { Dimensions } / \\
\text { Diameter }(\mathbf{m})\end{array}$ & $\begin{array}{l}\text { Area } \\
\left(\mathbf{m}^{2}\right)\end{array}$ & Type & Comments \\
\hline 306 & 7.90 & 49.02 & circular & Central hearth \\
\hline
\end{tabular}




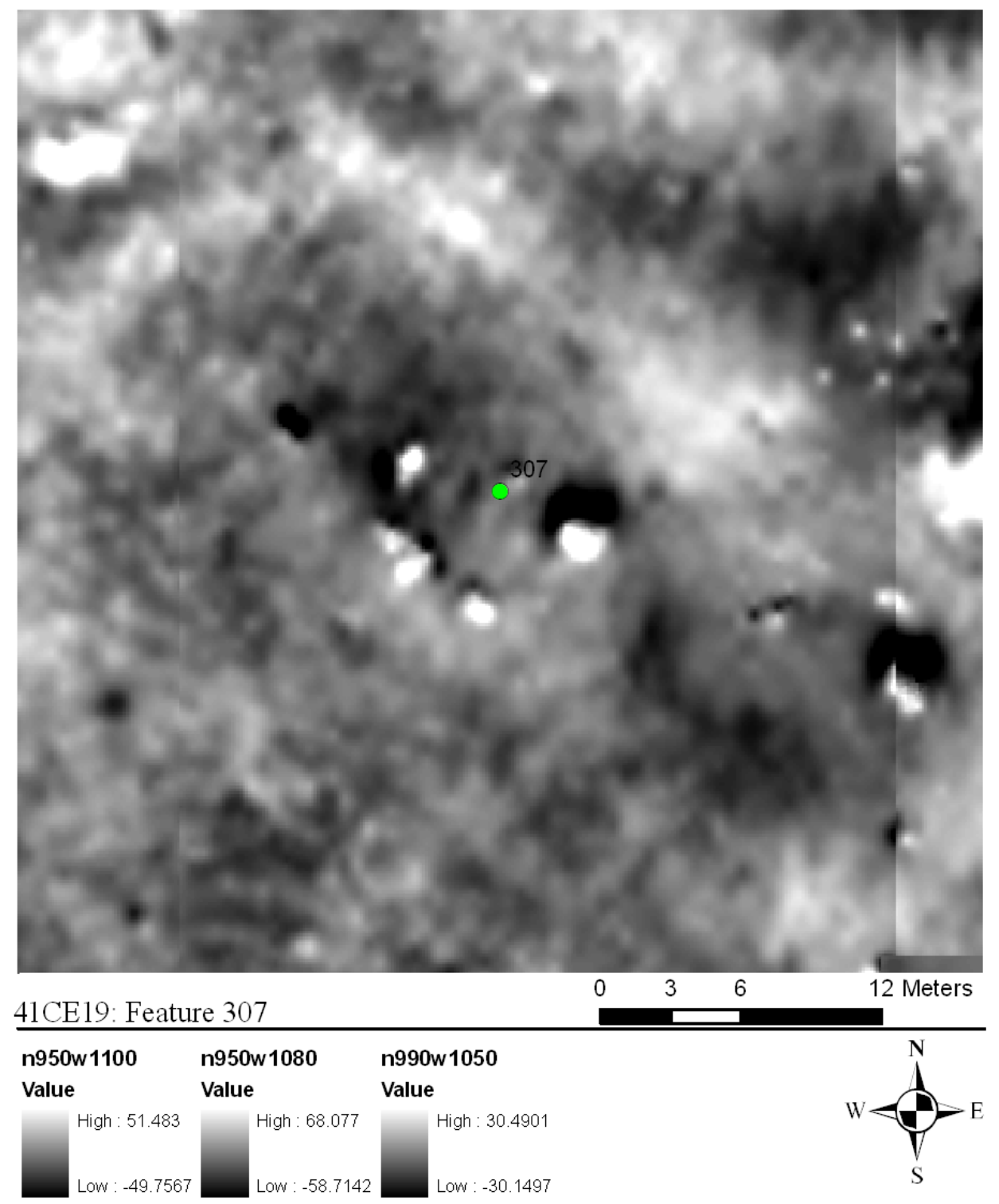

Figure 170: Feature 307

\begin{tabular}{|r|r|r|l|l|}
\hline Feat & $\begin{array}{l}\text { Dimensions } / \\
\text { Diameter }(\mathbf{m})\end{array}$ & $\begin{array}{l}\text { Area } \\
\left(\mathbf{m}^{2}\right)\end{array}$ & Type & Comments \\
\hline 307 & 7.60 & 45.36 & circular & possibly burned; possible interior features \\
\hline
\end{tabular}




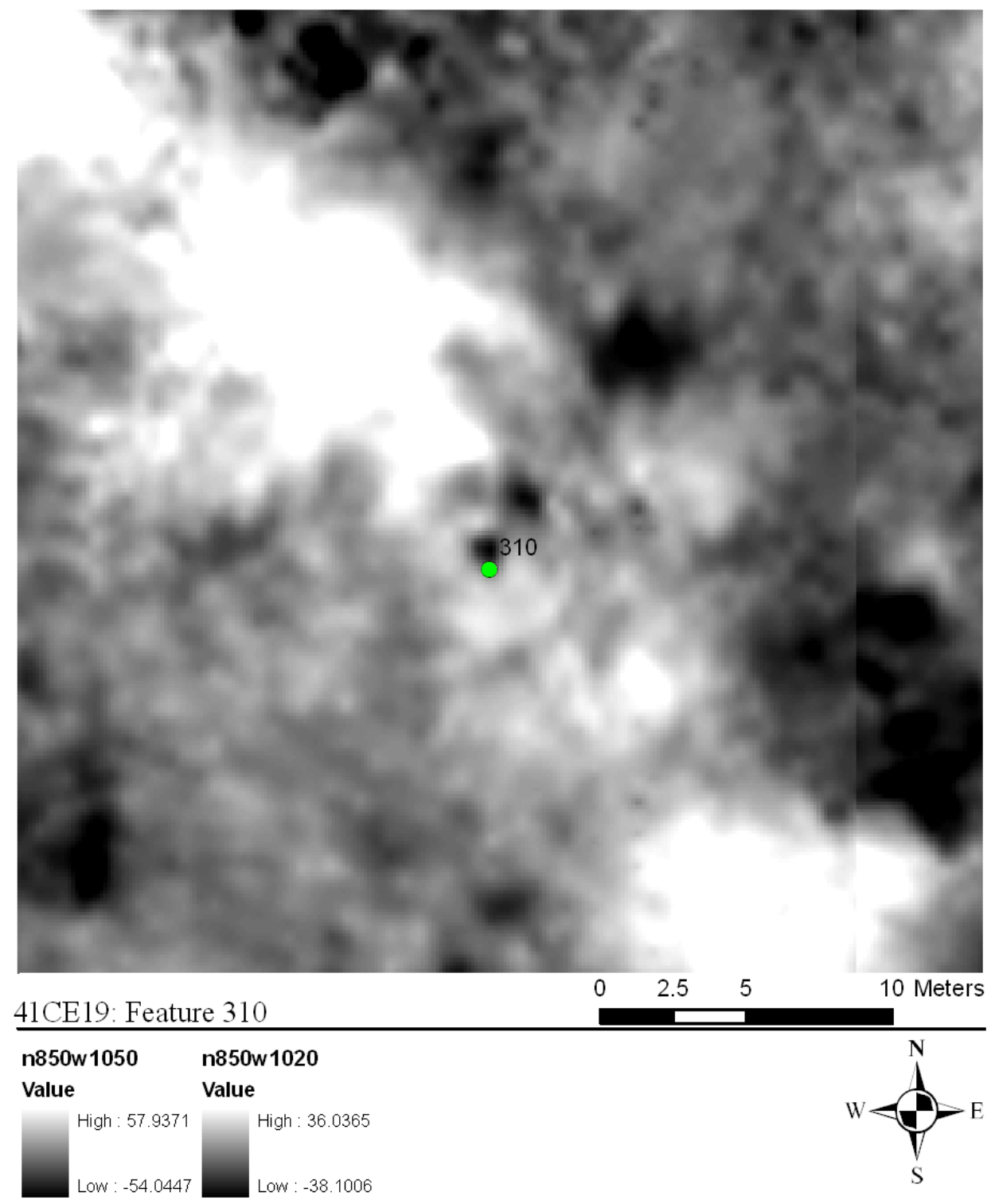

Figure 171: Feature 310

\begin{tabular}{|r|r|r|l|l|}
\hline Feat & $\begin{array}{l}\text { Dimensions/ } \\
\text { Diameter }(\mathbf{m})\end{array}$ & $\begin{array}{l}\text { Area } \\
\left(\mathbf{m}^{2}\right)\end{array}$ & Type & Comments \\
\hline 310 & 6.17 & 29.90 & circular & Possible central hearth; possibly burned \\
\hline
\end{tabular}




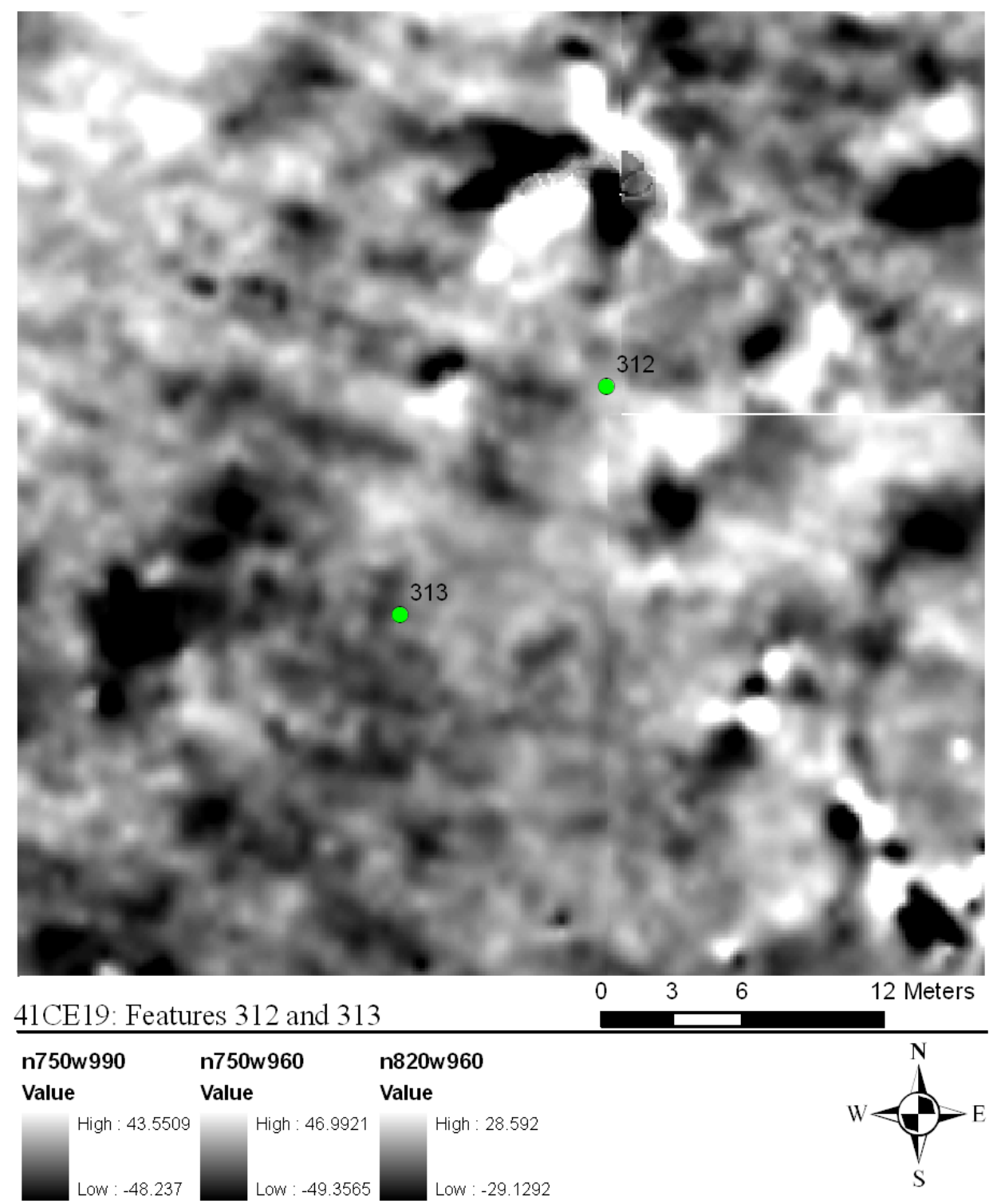

Figure 172: Features 312 and 313

\begin{tabular}{|r|r|l|l|l|}
\hline Feat & $\begin{array}{l}\text { Dimensions } \mathbf{~} \\
\text { Diameter } \mathbf{( m )}\end{array}$ & $\begin{array}{l}\text { Area } \\
\left(\mathbf{m}^{\mathbf{2}}\right)\end{array}$ & Type & Comments \\
\hline 312 & 11.50 & 103.87 & circular & $\begin{array}{l}\text { Burned; at least four possible large interior } \\
\text { features - hearths, pits or posts; likely } \\
\text { burned button house }\end{array}$ \\
\hline 313 & 13.80 & 149.57 & circular & Possible interior features \\
\hline
\end{tabular}




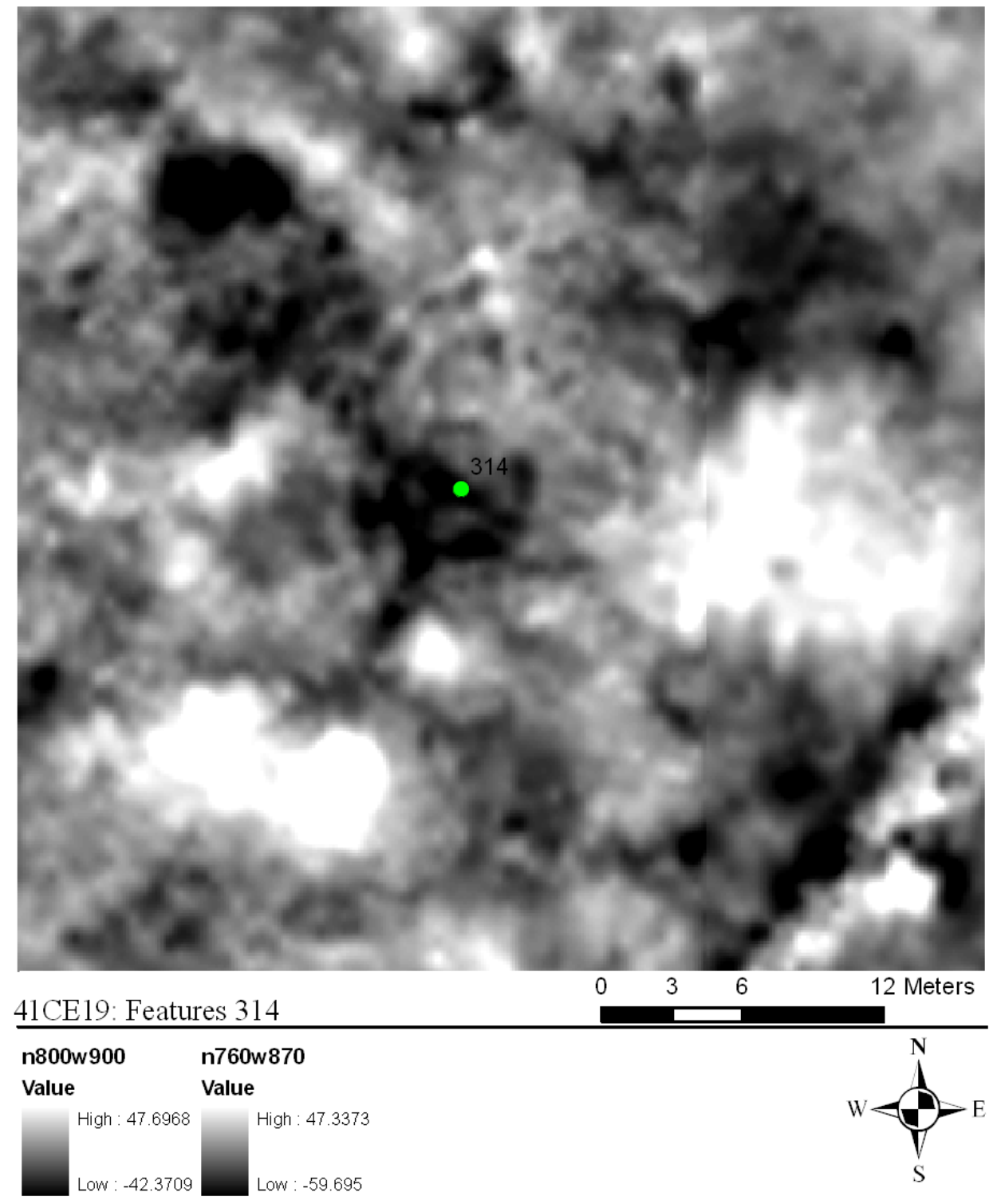

Figure 173: Feature 314

\begin{tabular}{|r|r|r|l|l|}
\hline Feat & $\begin{array}{l}\text { Dimensions } / \\
\text { Diameter }(\mathbf{m})\end{array}$ & $\begin{array}{l}\text { Area } \\
\left(\mathbf{m}^{2}\right)\end{array}$ & Type & Comments \\
\hline 314 & 5.60 & 24.63 & circular & Southwestern-facing extended entrance \\
\hline
\end{tabular}




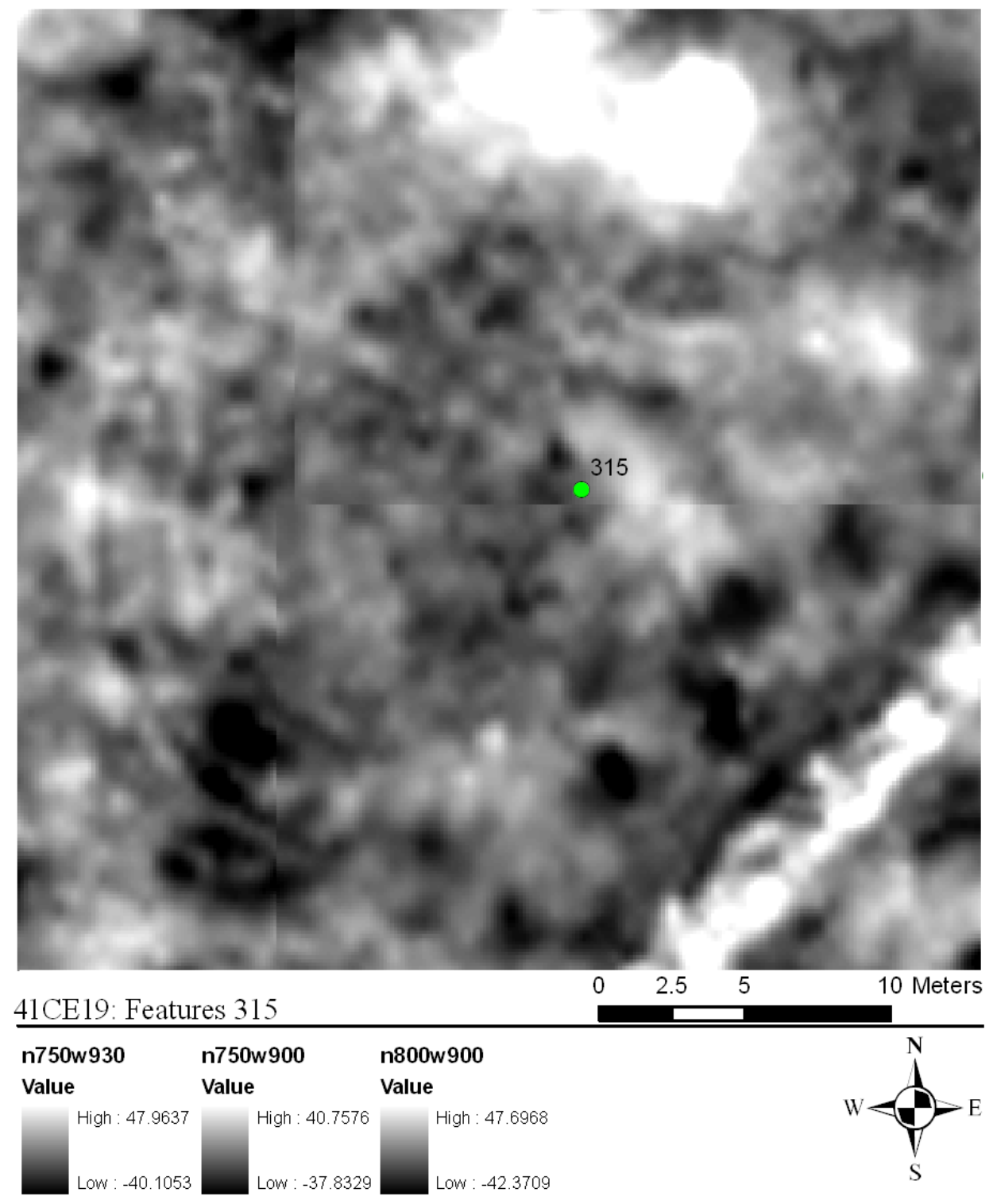

Figure 174: Feature 315

\begin{tabular}{|r|r|r|l|l|}
\hline Feat & $\begin{array}{l}\text { Dimensions } / \\
\text { Diameter }(\mathbf{m})\end{array}$ & $\begin{array}{l}\text { Area } \\
\left(\mathbf{m}^{2}\right)\end{array}$ & Type & Comments \\
\hline 315 & 8.30 & 54.11 & circular & Interior features \\
\hline
\end{tabular}




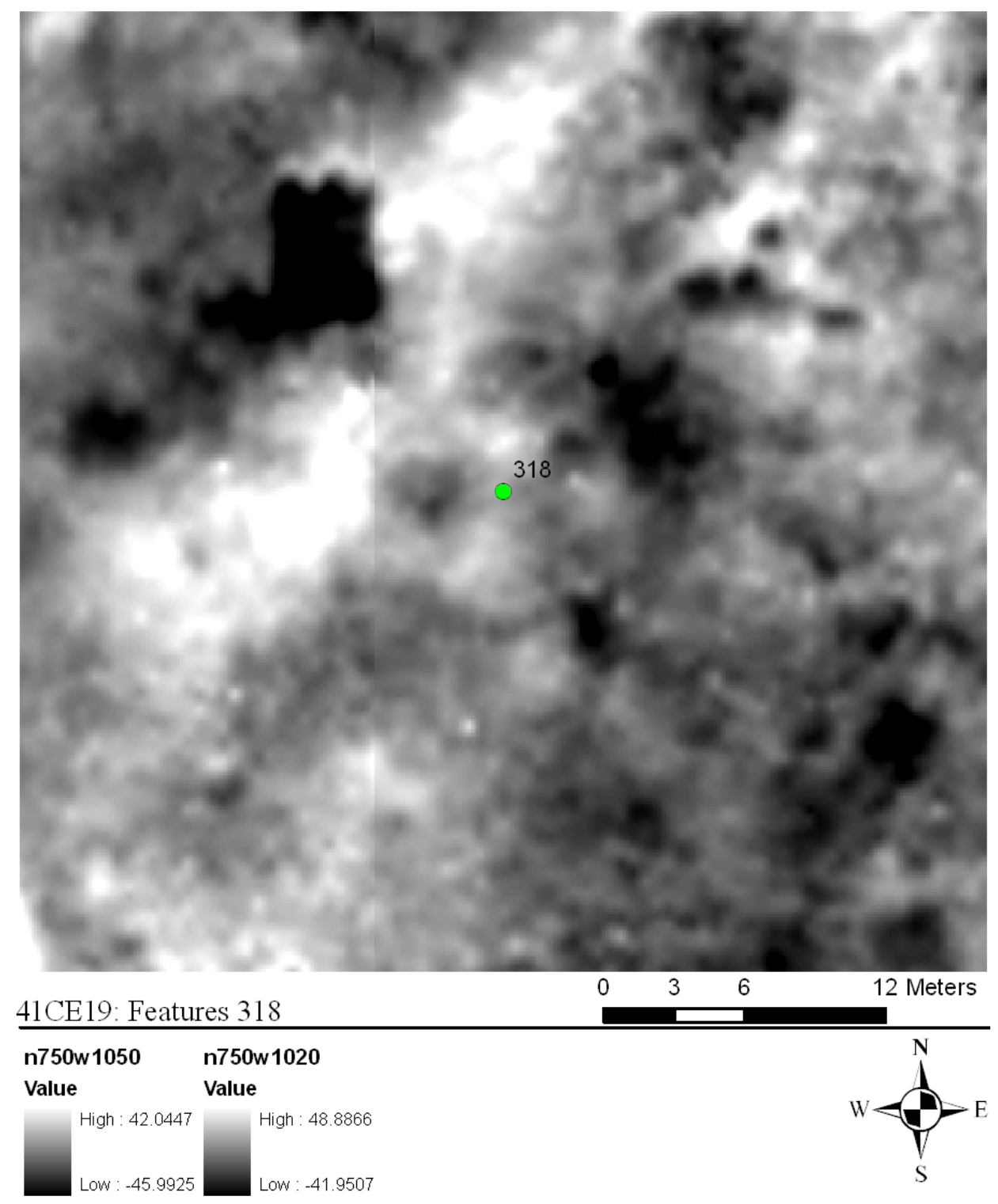

Figure 175: Feature 318

\begin{tabular}{|r|r|r|l|l|}
\hline Feat & $\begin{array}{l}\text { Dimensions/ } \\
\text { Diameter }(\mathbf{m})\end{array}$ & $\begin{array}{l}\text { Area } \\
\left(\mathbf{m}^{2}\right)\end{array}$ & Type & Comments \\
\hline 318 & 10.90 & 93.31 & circular & $\begin{array}{l}\text { possibly burned; interior features - likely } \\
\text { interior support posts }\end{array}$ \\
\hline
\end{tabular}




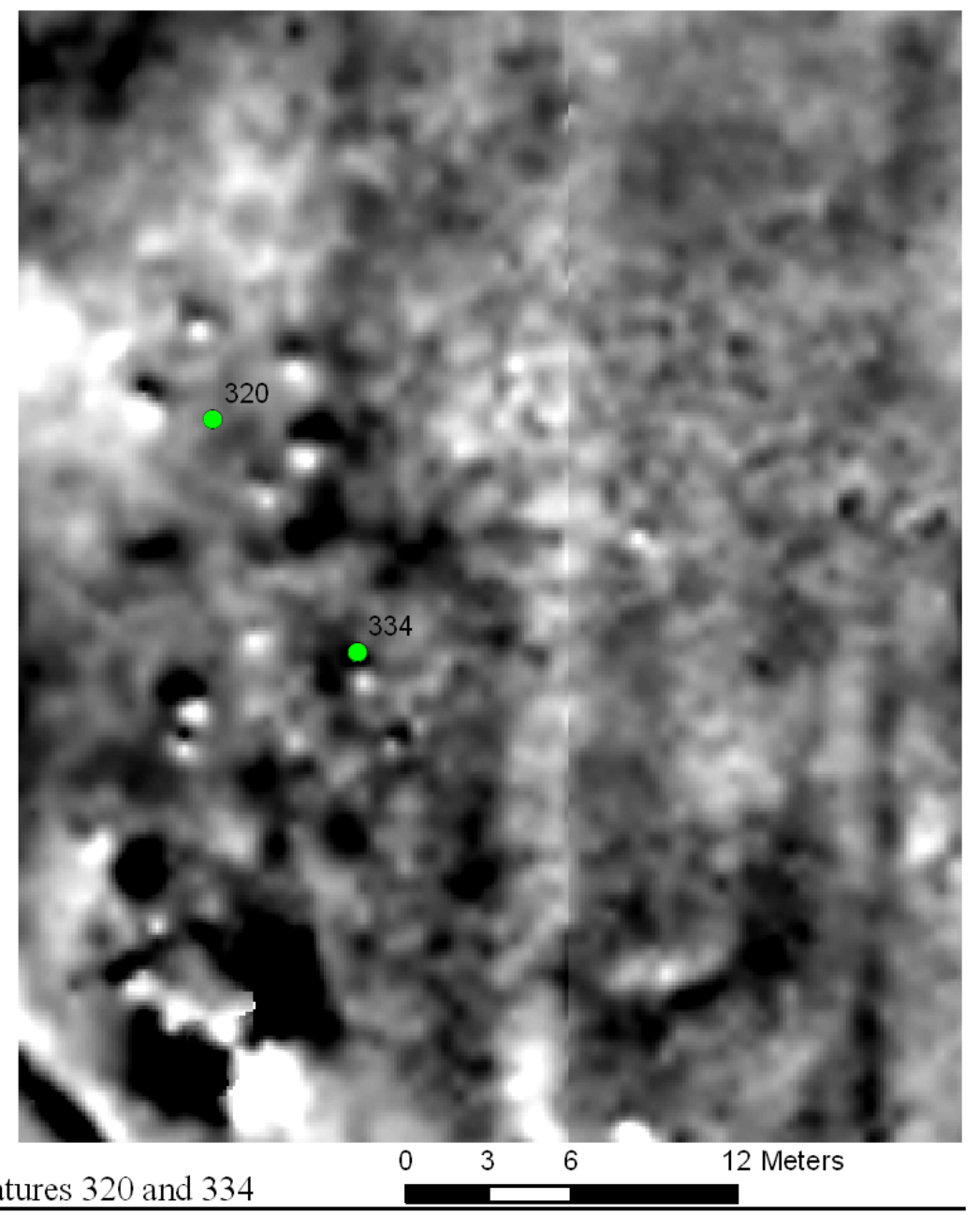

41CE19: Features 320 and 334

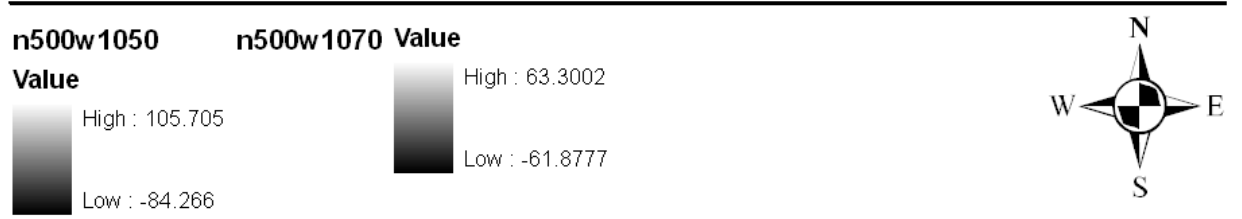

Figure 176: Features 320 and 334

\begin{tabular}{|r|r|r|l|l|}
\hline Feat & $\begin{array}{l}\text { Dimensions } / \\
\text { Diameter }(\mathbf{m})\end{array}$ & $\begin{array}{l}\text { Area } \\
\left(\mathbf{m}^{2}\right)\end{array}$ & Type & Comments \\
\hline 320 & 7.10 & 39.59 & circular & Probably burned \\
\hline 334 & 6.70 & 35.26 & circular & Interior features \\
\hline
\end{tabular}



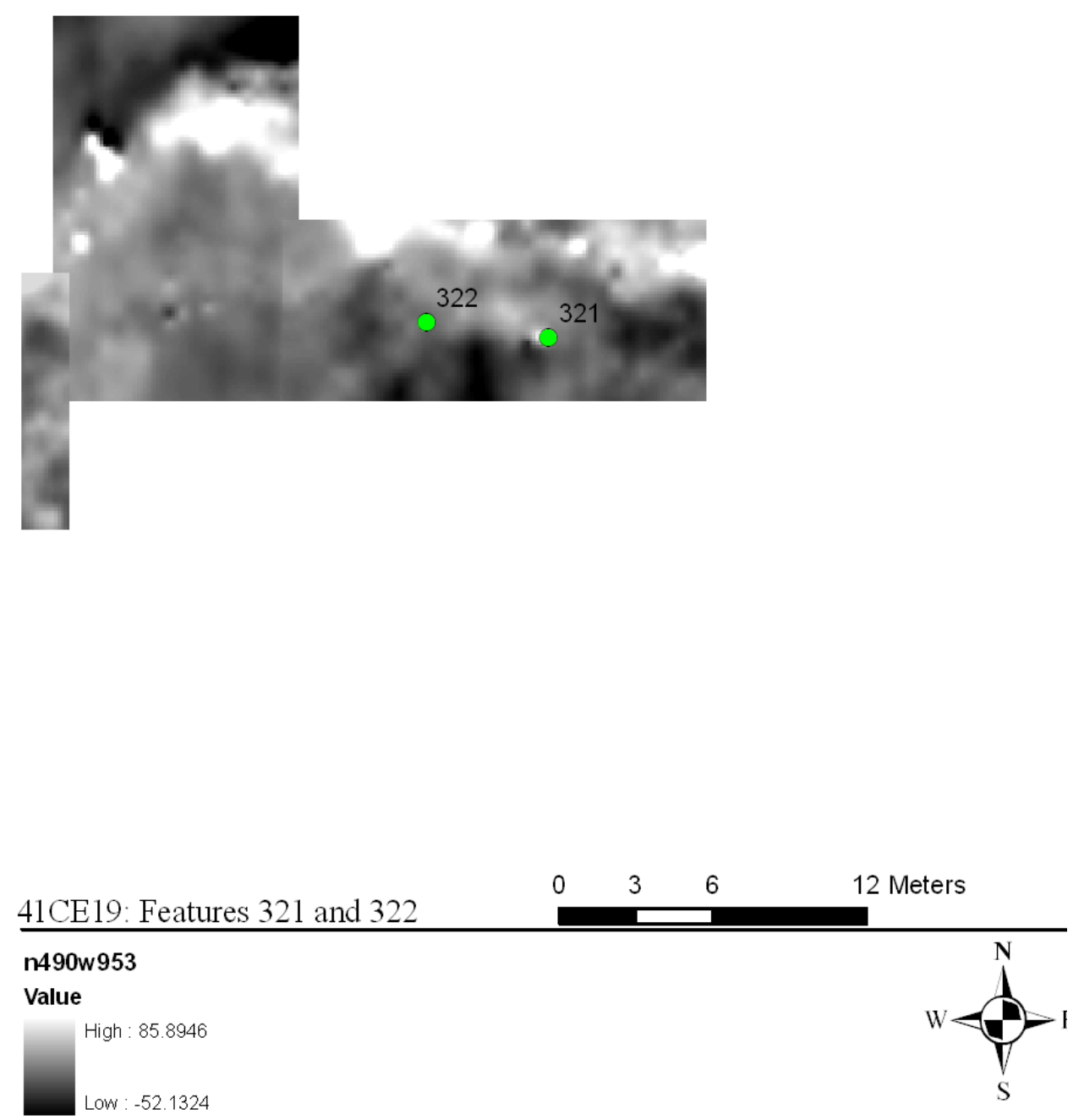

Figure 177: Features 321 and 322

\begin{tabular}{|r|r|l|l|l|}
\hline Feat & $\begin{array}{l}\text { Dimensions } \\
\text { Diameter } \mathbf{( m )}\end{array}$ & $\begin{array}{l}\text { Area } \\
\left(\mathbf{m}^{\mathbf{2}} \mathbf{)}\right.\end{array}$ & $\begin{array}{l}\text { Type } \\
\text { Diaments }\end{array}$ \\
\hline 321 & 5.90 & 27.34 & circular & $\begin{array}{l}\text { One of two superimposed structures on } \\
\text { Mound A }\end{array}$ \\
\hline 322 & 5.80 & 26.42 & circular & $\begin{array}{l}\text { one of two superimposed structures on } \\
\text { Mound A; possible central hearth }\end{array}$ \\
\hline
\end{tabular}




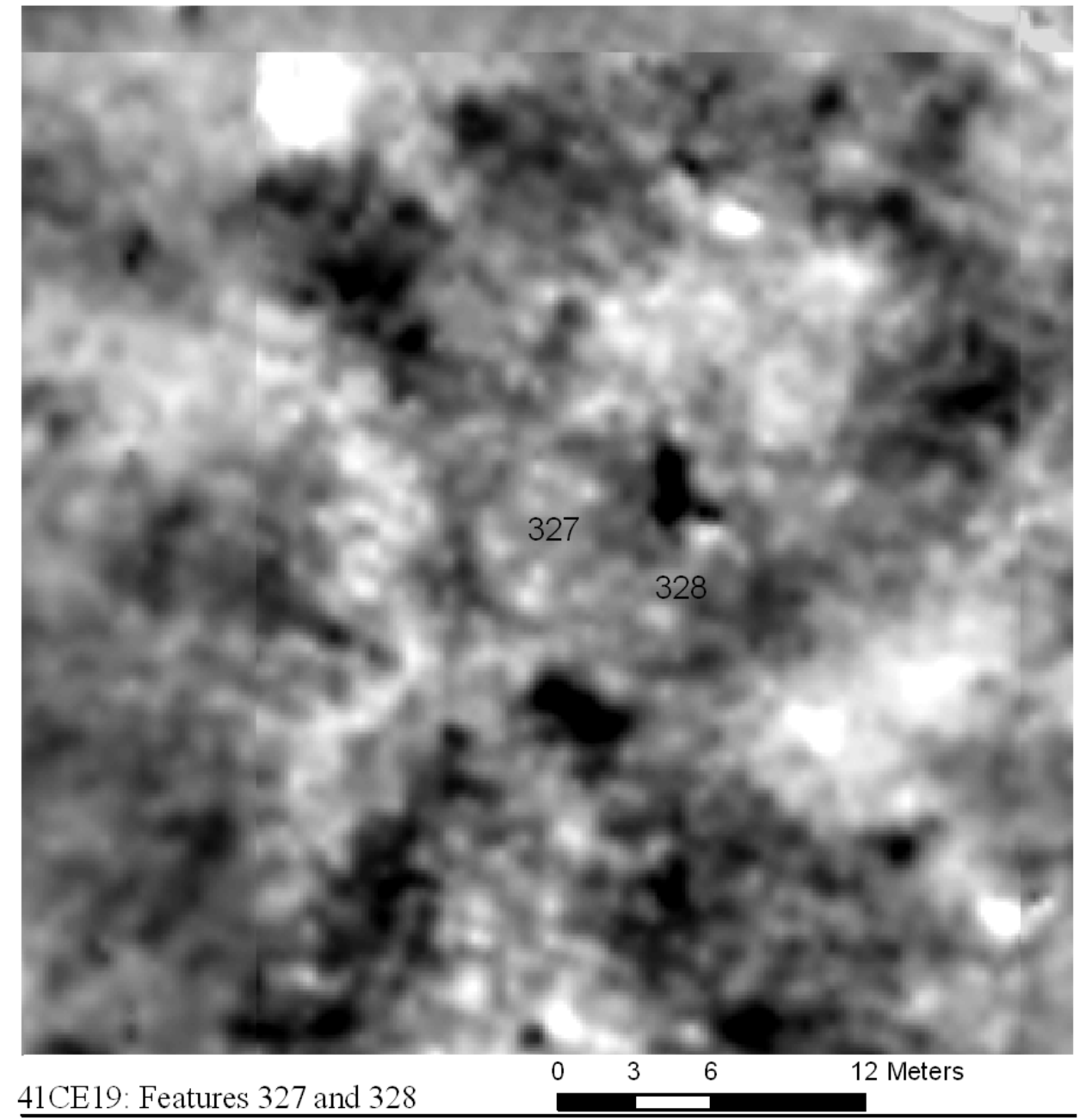

41CE19: Features 327 and 328

n850w960

Value

High : 30.8032
Low : -29.8336

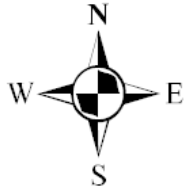

Figure 178: Features 327 and 328

\begin{tabular}{|c|r|r|l|l|}
\hline Feat & $\begin{array}{l}\text { Dimensions/ } \\
\text { Diameter }(\mathbf{m})\end{array}$ & $\begin{array}{l}\text { Area } \\
\left(\mathbf{m}^{2}\right)\end{array}$ & Type & Comments \\
\hline 327 & 6.75 & 35.78 & circular & $\begin{array}{l}\text { one of two superimposed structures; } \\
\text { possible interior features }\end{array}$ \\
\hline 328 & 6.40 & 32.17 & circular & $\begin{array}{l}\text { one of two superimposed structures; } \\
\text { possible interior features }\end{array}$ \\
\hline
\end{tabular}




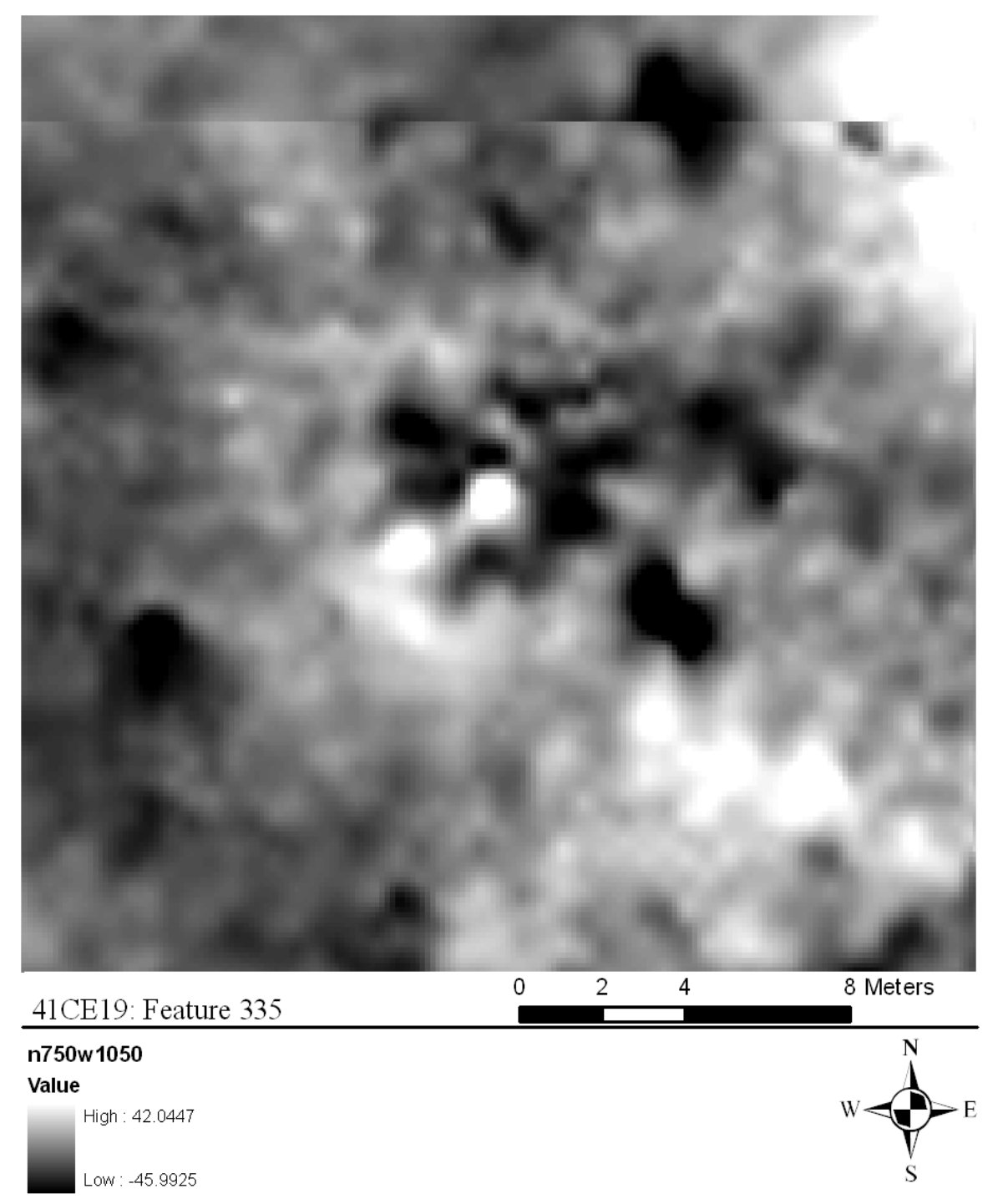

Figure 179: Feature 335

\begin{tabular}{|r|r|r|l|l|}
\hline Feat & $\begin{array}{l}\text { Dimensions/ } \\
\text { Diameter }(\mathbf{m})\end{array}$ & $\begin{array}{l}\text { Area } \\
\left(\mathbf{m}^{2}\right)\end{array}$ & Type & Comments \\
\hline 335 & 9.5 & 70.88 & circular & Burned interior features \\
\hline
\end{tabular}




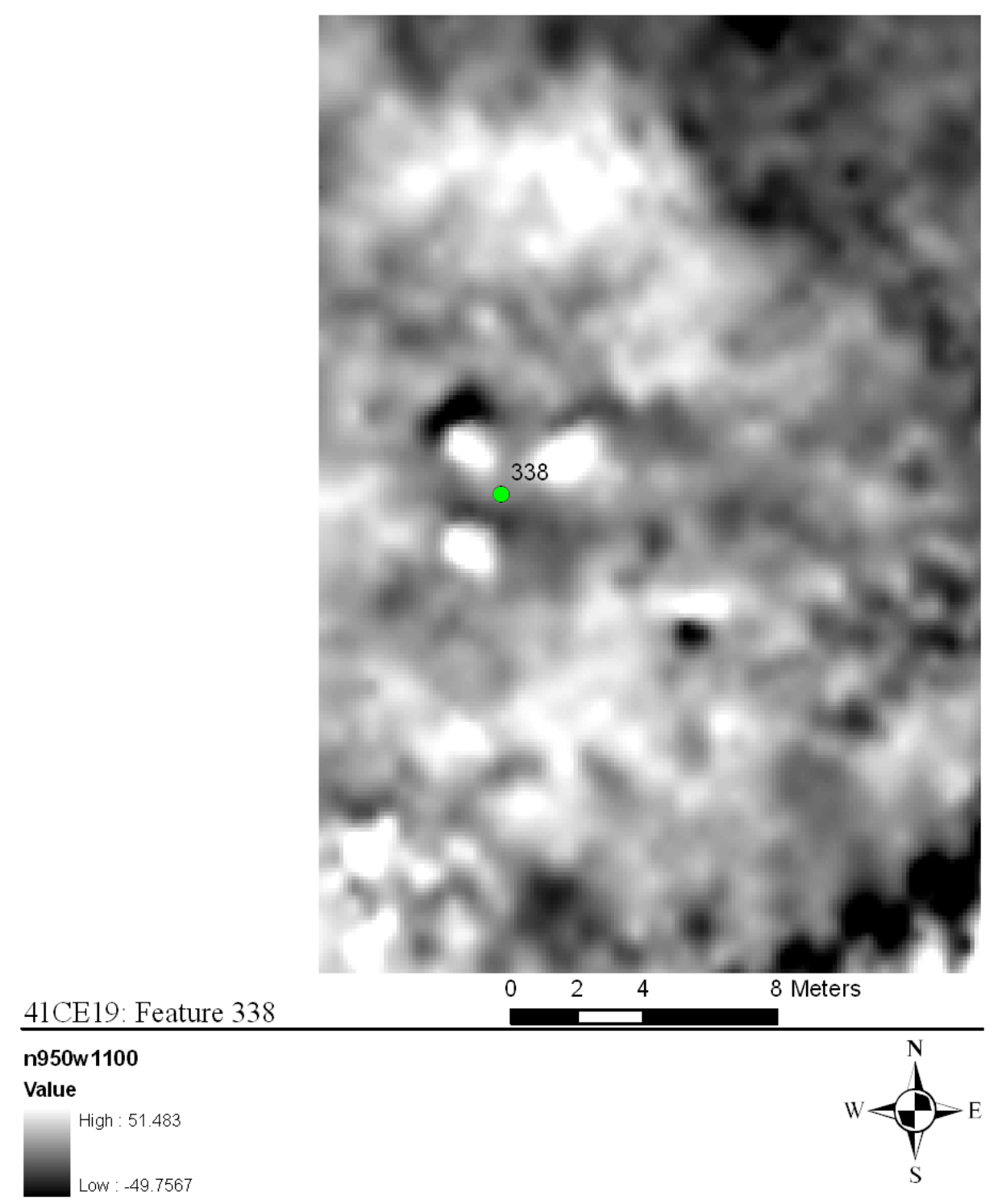

Figure 180: Feature 338

\begin{tabular}{|r|r|r|l|l|}
\hline Feat & $\begin{array}{l}\text { Dimensions } / \\
\text { Diameter }(\mathbf{m})\end{array}$ & $\begin{array}{l}\text { Area } \\
\left(\mathbf{m}^{2}\right)\end{array}$ & Type & Comments \\
\hline 338 & 10.40 & 84.95 & circular & Burned button house with interior features \\
\hline
\end{tabular}




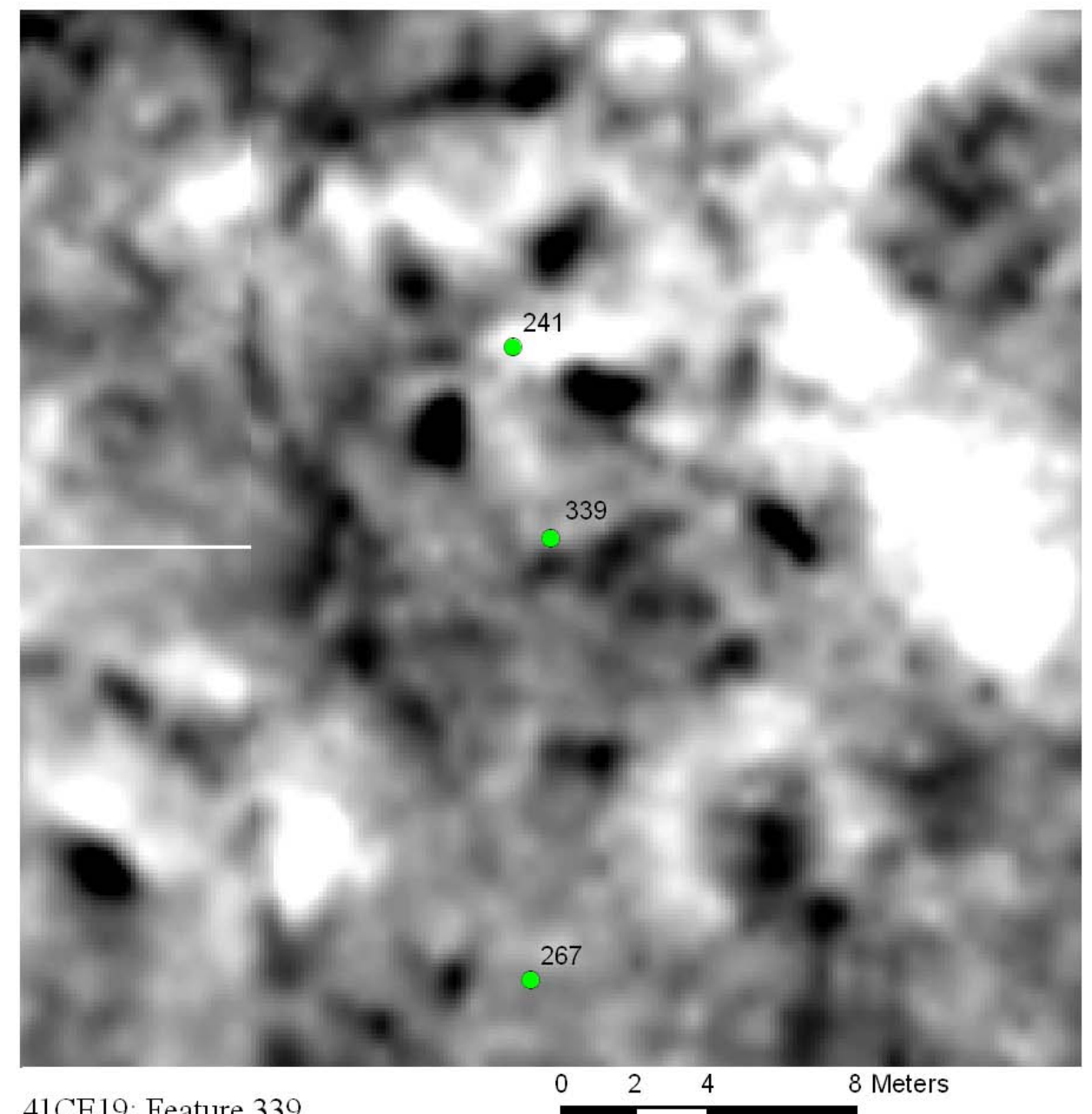

41CE19: Feature 339

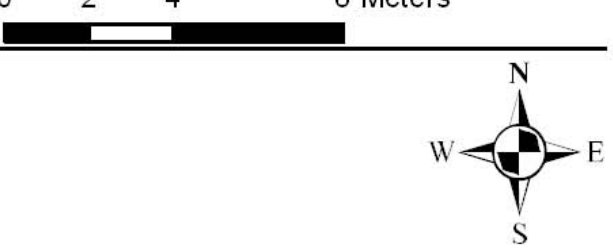

Figure 181: Feature 339

\begin{tabular}{|r|r|l|l|l|}
\hline Feat & $\begin{array}{l}\text { Dimensions/ } \\
\text { Diameter } \mathbf{( m )}\end{array}$ & $\begin{array}{l}\text { Area } \\
\left(\mathbf{m}^{2} \mathbf{)}\right.\end{array}$ & Type & Comments \\
\hline 339 & 12.50 & 122.72 & circular & $\begin{array}{l}\text { Possibly burned structure; possible interior } \\
\text { features }\end{array}$ \\
\hline
\end{tabular}



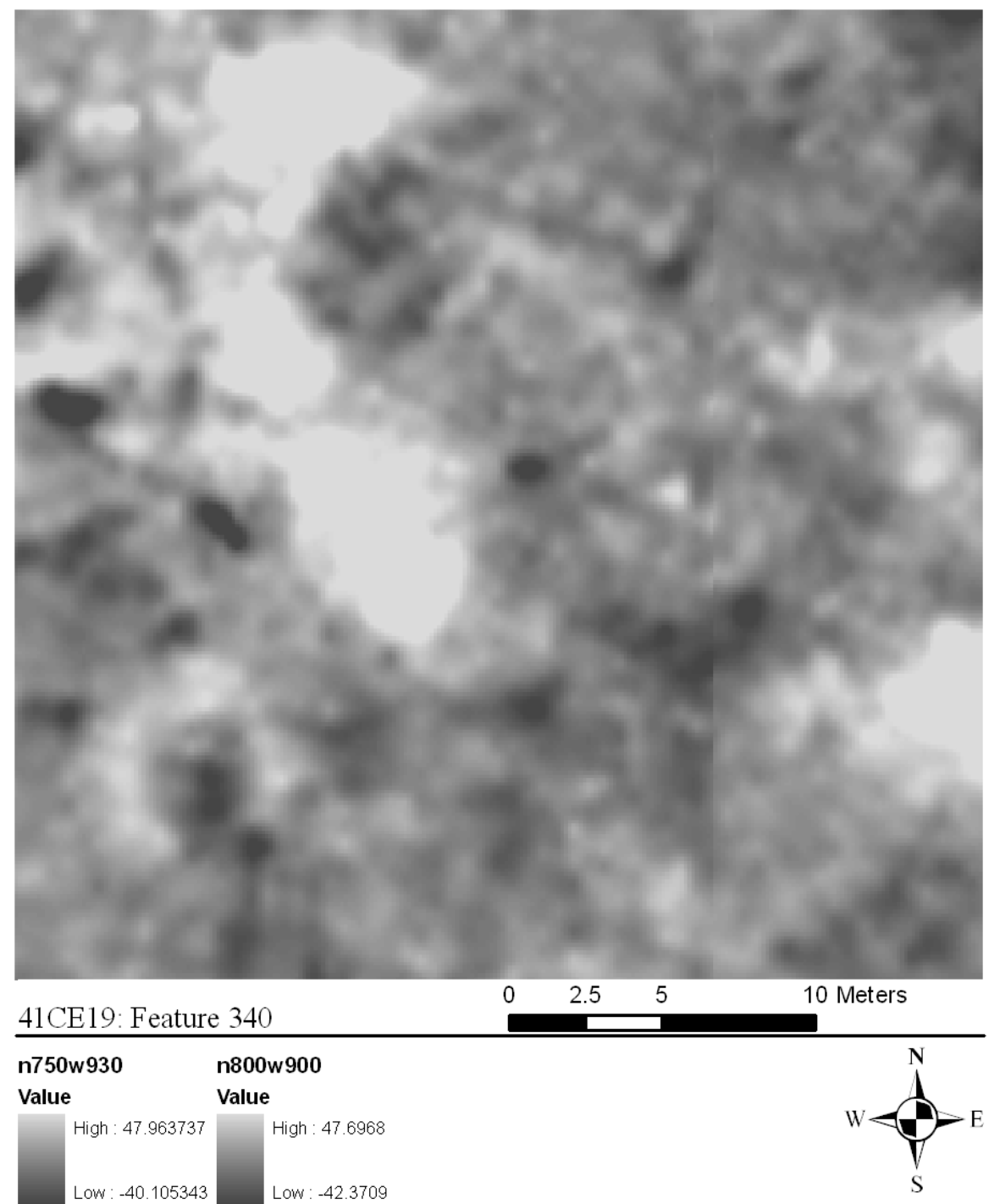

Figure 182: Feature 340

\begin{tabular}{|r|r|l|l|l|}
\hline Feat & $\begin{array}{l}\text { Dimensions/ } \\
\text { Diameter } \mathbf{( m )}\end{array}$ & $\begin{array}{l}\text { Area } \\
\left(\mathbf{m}^{2} \mathbf{)}\right.\end{array}$ & Type & Comments \\
\hline 340 & 15.50 & 188.69 & circular & Possibly burned; possible interior features \\
\hline
\end{tabular}




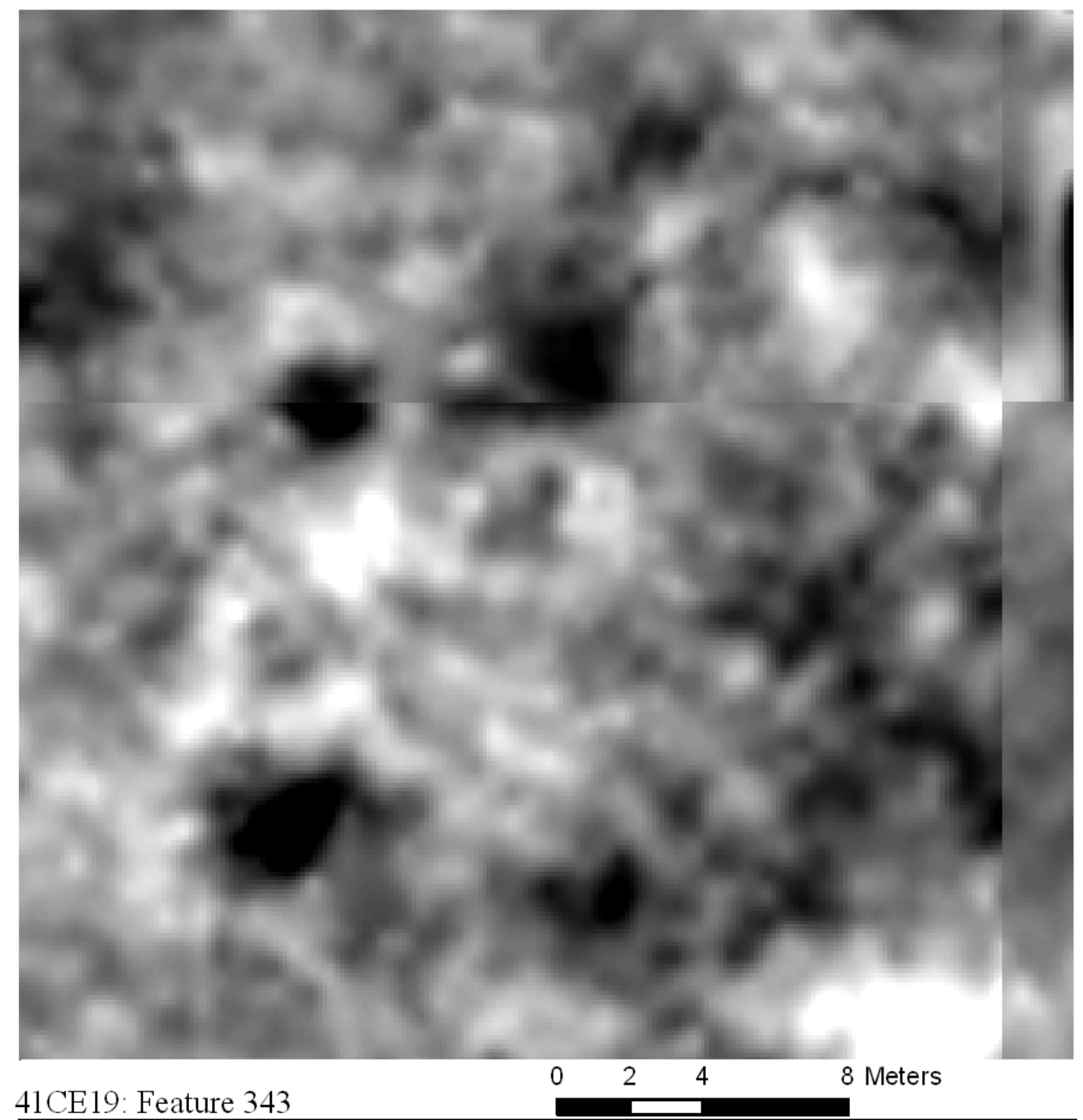

41CE19: Feature 343

8 Meters

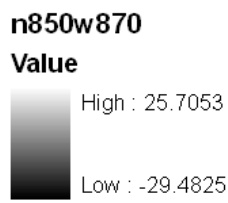

Value

High : 25.7053

Low : -29.4825

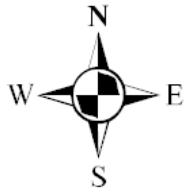

Figure 183: Feature 343

\begin{tabular}{|c|c|c|l|l|} 
Feat & $\begin{array}{l}\text { Dimensions/ } \\
\text { Diameter }(\mathbf{m})\end{array}$ & $\begin{array}{l}\text { Area } \\
\left(\mathbf{m}^{2}\right)\end{array}$ & Type & Comments \\
\hline 343 & 4.70 & 17.35 & circular & Possibly burned \\
\hline
\end{tabular}




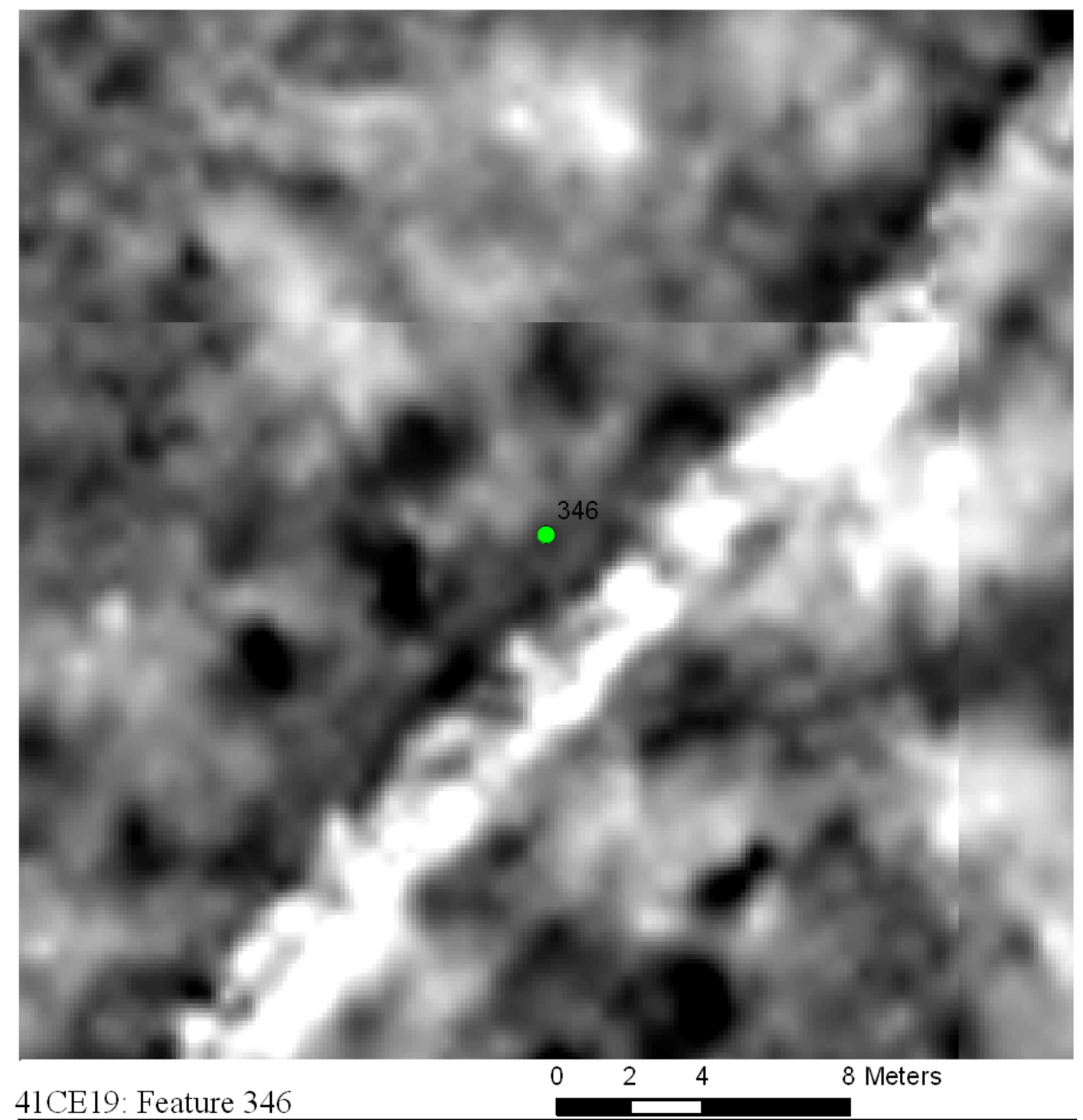

41CE19: Feature 346
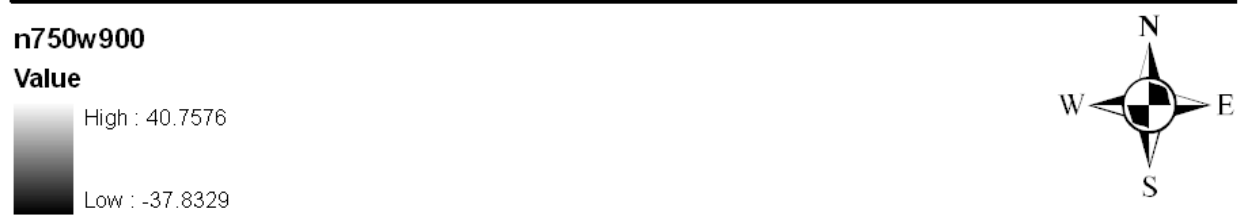

Figure 184: Feature 346

\begin{tabular}{|r|r|r|l|l|} 
Feat & $\begin{array}{l}\text { Dimensions/ } \\
\text { Diameter }(\mathbf{m})\end{array}$ & $\begin{array}{l}\text { Area } \\
\left(\mathbf{m}^{2}\right)\end{array}$ & Type & Comments \\
\hline 346 & 10.00 & 78.54 & circular & May have large perimeter posts \\
\hline
\end{tabular}




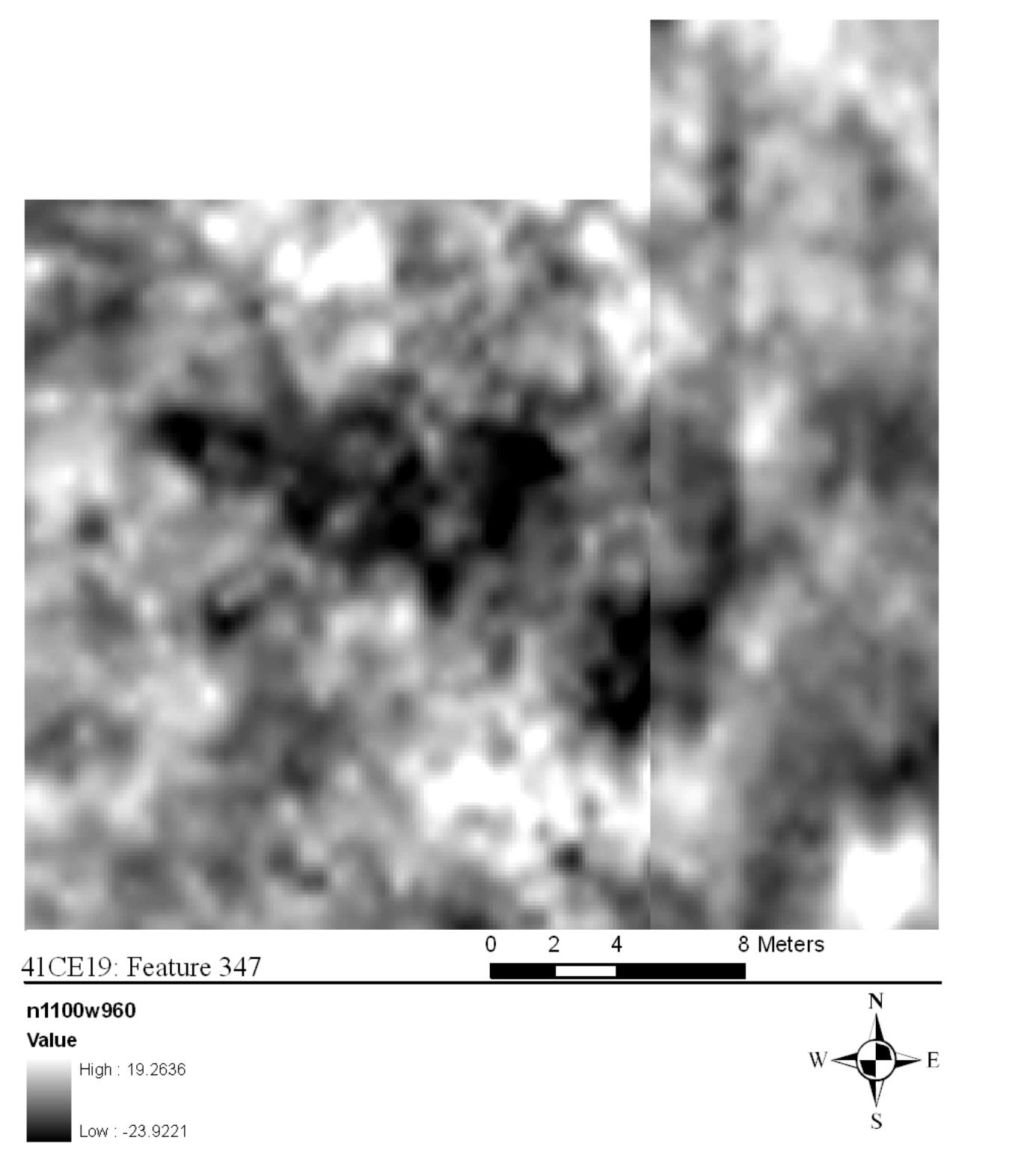

Figure 185: Feature 347

\begin{tabular}{|c|l|l|l|l|}
\hline Feat & $\begin{array}{l}\text { Dimensions/ } \\
\text { Diameter }(\mathbf{m})\end{array}$ & $\begin{array}{l}\text { Area } \\
\left(\mathbf{m}^{2}\right)\end{array}$ & Type & Comments \\
\hline 347 & $4.6 \times 4.8$ & 22.08 & rectangular & $\begin{array}{l}\text { Possible south or west-facing extended } \\
\text { entrance; possible interior features }\end{array}$ \\
\hline
\end{tabular}



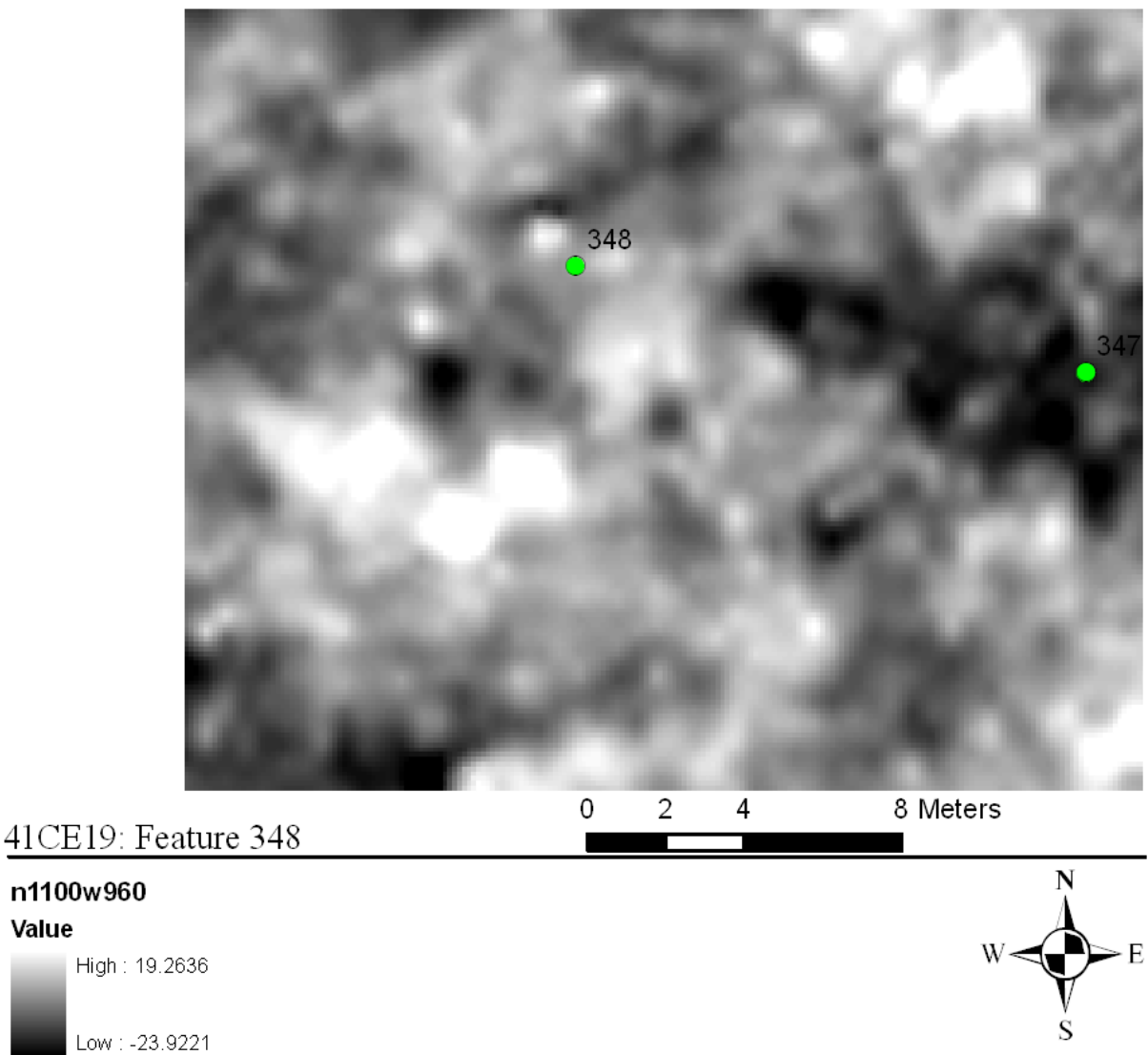

Figure 186: Feature 348

\begin{tabular}{|r|r|r|l|l|}
\hline Feat & $\begin{array}{l}\text { Dimensions/ } \\
\text { Diameter }(\mathbf{m})\end{array}$ & $\begin{array}{l}\text { Area } \\
\left(\mathbf{m}^{2}\right)\end{array}$ & Type & Comments \\
\hline 348 & 9.00 & 63.62 & circular & Possibly burned; possible interior features \\
\hline
\end{tabular}




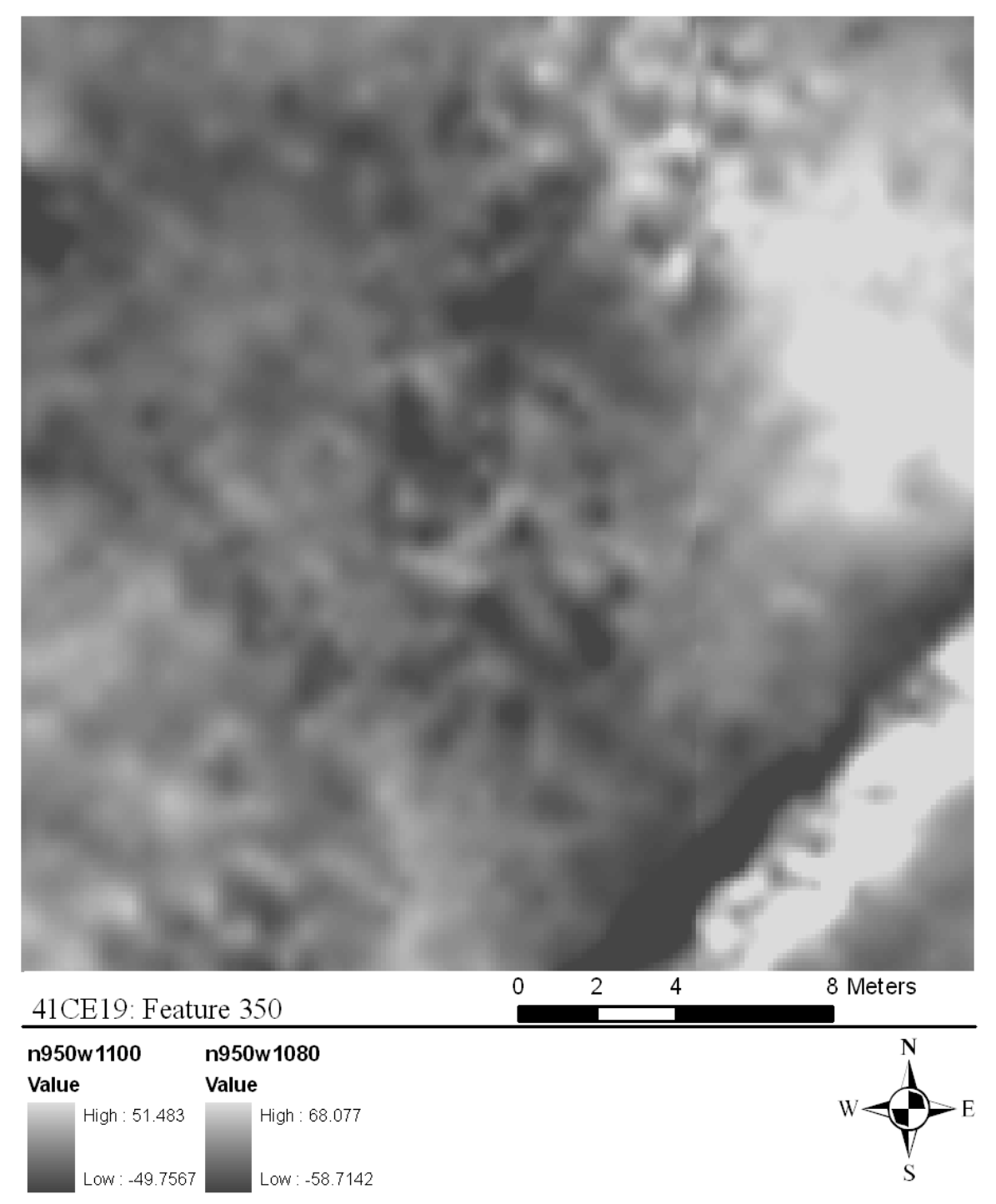

Figure 187: Feature 350

\begin{tabular}{|l|l|l|l|l|}
\hline Feat & $\begin{array}{l}\text { Dimensions/ } \\
\text { Diameter }(\mathbf{m})\end{array}$ & $\begin{array}{l}\text { Area } \\
\left(\mathbf{m}^{2}\right)\end{array}$ & Type & Comments \\
\hline 350 & & & & $\begin{array}{l}\text { Extended entrance facing Southeast; several } \\
\text { possible pits/posts }\end{array}$ \\
\hline
\end{tabular}




\section{REFERENCES CITED}

Alt, Susan M.

2001 Cahokian Change and the Authority of Traditions in The Archaeology of Traditions: Agency and History Before and After Columbus edited by Timothy R. Pauketat, pages 141-156. University of Florida Press, Gainesville.

Baugh, T. G.

1998 Regional Polities and Socioeconomic Exchange: Caddoan and Puebloan Interaction. In The Native History of the Caddo: Their Place in Southeastern Archeology and Ethnohistory, edited by T K. Perttula and J. E. Bruseth, pages 145-158. Studies in Archeology 30. Texas Archeological Research Laboratory, The University of Texas at Austin.

Bell, Robert

1972 The Harlan Site, Ck-6, A Prehistoric Mound Center in Cherokee County Eastern Oklahoma. Memoir 2. Oklahoma Anthropological Society, Norman.

Bolton, Herbert E.

1908 The Native Tribes about the East Texas Missions. Texas State Historical Association Quarterly 11:249-276.

1916 Spanish Exploration in the Southwest, 1542-1706 Charles Scribner's Sons, New York.

1987 The Hasinais. Southern Caddoans as seen by the Earliest Europeans. University of Oklahoma Press,

Bourdieu, P.

1977 Outline of a Theory of Practice. Cambridge: Cambridge University Press.

Brennan, Tamira K.

2007 In-Ground Evidence of Above-Ground Architecture at Kincaid Mounds in Architectural Variability in the Southeast edited by Cameron H. Lacquement, pages 73-100. The University of Alabama Press: Tuscalossa.

Brown, James A.

1983 Spiro Exchange Connections Revealed by Sources of Imported Raw Materials. In Southeastern Natives and Their Pasts, edited by D. G. Wyckoff and J. L. Hofman, pages 129-162. Studies in Oklahomas Past No. 11. Oklahoma Archeological Survey, Norman. 
Brown, J. A, R E. Bell, and D. G. Wyckoff

1978 Caddoan Settlement Patterns in the Arkansas River Drainage. In Mississippian Settlement Patterns, edited by B. D. Smith, pages 169-200. Academic Press, New York.

Bruseth, James E.

1991 Hudnall-Pirtle Site: An Early Caddoan Mound Complex in Northeast Texas. Caddoan Archeology Newsletter II(3):9-15.

Bruseth, James E. and Timothy K. Perttula

1981 Prehistoric Settlement Patterns at Lake Fork Reservoir. Texas Antiquities Permit Series, Report No. 2. Texas Antiquities Committee and Southern Methodist University, Austin and Dallas.

2006 Archeological Investigations at the Hudnall-Pirtle Site (41RK4): An Early Caddo Mound Center in Northeast Texas. In Caddo Archeology Journal 15:59-158.

Bruseth, James E. and Bill Pierson

2004 Magnetometer Survey at the George C. Davis Site (41CE19). Current Archeology in Texas 6(1):7-9.

Carter, Cecile

1995 Caddo Indians: Where We Come From. University of Oklahoma Press, Norman.

Clark, John W and James Ivey 1974 Archeological and Historical Investigations at Martin Lake Rusk and Panola Counties, Texas. Research Report No. 32. Texas Archeological Survey, The University of Texas at Austin.

Cox, I. J.

1904 The Explorations of the Louisiana Frontier, 1803 - 1806. American Historical Association Annual Report, pages 151-174 and pages 274-284.

Creel, Darrell G.

1979 Archeological Investigations at the George C. Davis Site, Cherokee County, Texas, Summer 1978. Antiquities Permit Series 1. Texas A\&M University and Texas Antiquities Committee, College Station and Austin.

1996 Hatchel-Mitchell Site. In The New Handbook of Texas, Vol. 3, edited by R Tyler, pages 504-505. Texas State Historical Association, Austin. 
Creel, Darrell G., Dale Hudler, Samuel M. Wilson, T. Clay Schultz, and Chester P. Walker

2005 A Magnetometer Survey of Caddo Mounds State Historic Site. Technical Report 51. Texas Archeological Research Laboratory, The University of Texas at Austin.

2008 Geophysical Survey of the Mound B Area at the George C. Davis Site. Bulletin of the Texas Archaeological Society 79:177-190.

Cruse, J. Brett and Timothy K. Perttula

1996 The Caddoan Oak Hill Village Site. Caddoan Archeology Newsletter 6(4):2325.

Cus, Susan and Victor Raharijaona

2000 House to Palace, Village to State: Scaling up Architecture and Ideology in American Anthropologist 102(1):98-113.

Davis, E. Mott

1958 The Whelan Site, A Late Caddoan Component in the Ferrell's Bridge Reservoir, Northeastern Texas. Division of Research in Anthropology, The University of Texas at Austin.

Davis, E. Mott and Jules R. Gipson

1960 The Dalton Site: A Late Caddoan Mound Site in the Ferrell's Bridge Reservoir Area, Northeastern Texas. Report Submitted to the National Park Service. Division of Research in Anthropology, The University of Texas at Austin. Contract 14-10-333-242.

Early, Ann M.

1988 Standridge: Caddoan Settlement in a Mountain Environment. Research Series No. 29. Arkansas Archeological Survey, Fayetteville.

1993 Caddoan Saltmakers in the Ouachita Valley: The Hardman Site, edited by A. M. Early, pages 223-234. Research Series No. 43. Arkansas Archeological Survey, Fayetteville.

Early, Ann M. (editor)

2000 Forest Farmsteads: A Millennium of Human Occupation at Winding Stair in the Ouachita Mountains. Research Series 57. Arkansas Archeological Survey, Fayetteville.

Fenneman, Nevin M.

1938 Physiography of Eastern United States. McGraw-Hill, New York. 
Fields, R C. and J. P Thurmond

1980 The George C. Davis Site, Cherokee County, Texas. Spring 1980 Archeological Investigations. Report of Investigations No. 8. Prewitt and Associates, Inc., Austin.

Fields, Ross C., M. E. Blake, and K. W. Kibler

1997 Synthesis of the Prehistoric and Historic Archaeology of Cooper Lake, Delta and Hopkins Counties, Texas. Reports of Investigations No. 104. Prewitt and Associates, Inc., Austin.

Fields, Ross C., E. F. Gadus, L. W. Klement, and K. M. Gardner 1994 Excavations at the Spider Knoll Site, Cooper Lake Project, Delta County, Texas. Reports of Investigations No. 96. Prewitt and Associates, Inc., Austin.

Forrestal, P P

1931 The Solis Diary of 1767. Preliminary Studies of the Texas Catholic Historical Society 1(6):18-66.

Foster, William

1998 The La Salle Expedition to Texas: The Journal of Henri Joutel, 1684-1687. Texas State Historical Association, Austin.

Galan, Victor

1998 Excavations at 41TT653, The Ear Spool Site. CRM News \& Views, September 1998:21-25.

Goldschmidt, W. R.

1935a A Report on the Archeology of Titus County in East Texas. Bulletin of the Texas Archeological and Paleontological Society 7:89-99.

1935b Some Archeological Sites in Titus County and Their Relation to East Texas Prehistory. Master's Thesis, Department of Anthropology, The University of Texas at Austin.

Good, Carolyn E.

1982 Analysis of Structures, Burials, and Other Cultural Features in The Deshazo Site, Nacogdoches County, Texas, edited by Dee Ann Story, pages 51-112. Texas Antiquities Permit Series No. 7. Texas Antiquities Committee, Austin.

Gould, F. W.

1962 Texas Plants - A Checklist and Ecological Summary. MP-585. Texas Agricultural Experiment Station, College Station. 
Grealy, M. and L. B. Conyers

2008 EM31 Geophysical Survey Methods, Results, and Recommendations. In An Intensive Cultural Resources Survey and Remote Sensing and Geomorphological Investigations for the Bowie County Levee Realignment Project, Bowie County, Texas and Little River County, Arkansas, by S. A. Sundermeyer, J. T. Penman, and T. K. Perttula, pages 89-103. Miscellaneous Reports, Report of Investigations No. 29. Lopez Garcia Group, Dallas, Texas.

Griffith, W J.

1954 The Hasinai Indians of East Texas as Seen by Europeans, 1687-1772. Philological and Documentary Studies, Vol. 2, No. 3. Middle American Research Institute, Tulane University, New Orleans.

Harrington, Mark R.

1920 Certain Caddo Sites in Arkansas. Indian Notes and Monographs, Miscellaneous Series No. 10. Museum of the American Indian, Heye Foundation, New York.

Hatcher, M. A.

1927 Descriptions of the Tejas or Asinai Indians, 1691-1722. Southwestern Historical Quarterly 30-31.

Helms, Mary

1998 Access to Origins: Affines, Ancestors, and Aristocrats. The University of Texas Press, Austin.

Jackson, A.T

1936 A "Perpetual Fire" Site. Bulletin of the Texas Archeological and Paleontological Society 8:134-173.

Jackson, A. T., M. Goldstein, and A. Krieger

2000 The 1931 Excavations at the Sanders Site Lamar County, Texas. Archival Series 2, Texas Archaeological Research Laboratory, The University of Texas at Austin.

Jackson and Foster

1995 Imaginary Kingdom: Texas as Seen by the Rivera and Rubi Military Expeditions, 1727 and 1767. Texas State Historical Association, Austin, Texas. 
Jelks, Edward B.

1963 The Blount Site at McGee Bend Reservoir, San Augustine County, Texas. Report Submitted to the National Park Service by the Texas Archeological Salvage Project, the University of Texas.

1965 The Archeology of the McGee Bend Reservoir, Texas. Ph.D. dissertation, Department of Anthropology, The University of Texas at Austin.

Jelks, Edward B. and Curtis D. Tunnell

1959 The Harroun Site: A Fulton Aspect Component of the Caddoan Area, Upshur County, Texas. Archaeology Series No. 2. Department of Anthropology, The University of Texas at Austin.

Kay, Marvin and George Sabo III

2006 Mortuary Ritual and Winter Solstice Imagery of the Harlan-Style Charnel House. Southeastern Archaeology 25(1):29-47.

Kelley, D.B. (editor)

1997 Two Caddoan Farmsteads in the Red River Valley Research Series No. 51. Arkansas Archeological Survey, Fayetteville.

Kleinschmidt, Ulrich K. W.

1982 Review and Analysis of the A. C. Saunders Site, 41AN19, Anderson County, Texas. Master's thesis, Department of Anthropology, The University of Texas at Austin.

1984 The A. C. Saunders Site Revisited: A Hasinai Fire Temple? Paper presented at the 26th Annual Caddo Conference. On file in the 41AN19 file at the Texas Archeological Research Laboratory.

Knight, Vernon James

1986 The Institutional Organization of Mississippian Religion. American Antiquity 51(4):675-687.

Lacquement, Cameron $\mathrm{H}$.

2007 Typology, Chronology, and Technological Changes of Mississippian Domestic Architecture in West-Central Alabama in Architectural Variability in the Southeast edited by Cameron H. Lacquement, pages 49-72. The University of Alabama Press: Tuscalossa.

Lewis, R. B. and C. Stout

1998 The Town as Metaphor in Mississippian Towns and Sacred Spaces: Searching for an Architectural Grammar edited by R. B. Lewis and C. Stout, pages 227242. University of Alabama Press:Tuscaloosa. 
Lisk, S. V.

1984 Ceramics from the Whelan Site: A Temporal and Functional Analysis of a Late Caddoan Mound Site Assemblage. Master's Thesis, Department of Anthropology, The University of Texas at Austin.

Locock, Martin

1994 Meaningful Architecture: Social Interpretations of Buildings, edited by Martin Locock.

Lockhart, Jami J.

2007 Prehistoric Caddo of Arkansas: A Multiscalar Examination of Past Cultural Landscapes. Ph.D. dissertation, Department of Geosciences, University of Arkansas, Fayetteville, Arkansas.

McKinnon, Duncan P.

2008 An Archaeogeophysical Analysis of Central Caddo Settlement Patterning at Battle Mound (3LA1). Masters thesis, Department of Anthropology, University of Arkansas, Fayetteville.

Middlebrook, T and R Middlebrook

1996 Of Hearths and Houses. Caddoan Archeology Newsletter 6(4):11-22.

Nelson, Bo and Timothy K. Perttula

2006 Archaeological Investigations at the New Hope Site (41FK107) at Lake Bob Sandlin, Franklin County, Texas. Journal of Northeast Texas Archaeology 25:26-37.

Newell, H. P and A D. Krieger

1949 The George C. Davis Site, Cherokee County Texas. Memoir No. 5. Society for American Archaeology, Menasha, Wisconsin.

2000 The George C. Davis Site, Cherokee County Texas. Society for American Archaeology.

Newkumet, V.B., and H.L. Meredith

1988 Hasinai: A Traditional History of the Caddo Confederacy. Texas A\&M University Press, College Station.

Osburn, Tiffany, James Bruseth, and William Pierson

2008 Magnetometer Investigations at the George C. Davis site, a Prehistoric Caddo Village. Bulletin of the Texas Archaeological Society 79:191-200.

Padilla, J. A

1919 Texas in 1820: Report on the Barbarous Indians of the Province of Texas. Translated by M. A. Hatcher. Southwestern Historical Quarterly 23:47-68. 
Parsons, E. C.

1941 Notes on the Caddo. Memoir 57. American Anthropological Association, Washington, D.C.

Parsons, Mark

1998 41UR133: A Late Caddo hamlet at Lake Gilmer. CRM News and Views February 1998:16-19.

Perino, Gregory

1995 The Dan Holdeman Site (41RR11), Red River County, Texas. Journal of Northeast Texas Archaeology 6:3-65.

Perttula, Timothy K.

1995a Archeology of the Pineywoods and Post Oak Savanna of Northeast Texas. Bulletin of the Texas Archeological Society 66:331-359.

1995b A Reconsideration of the Chronological and Cultural Placement of the Mortuary Remains and Grave Goods from the Dan Holdeman Site. Journal of Northeast Texas Archaeology 6:67-87.

1996 Caddoan Area Archaeology Since 1990. In Journal of Archaeological Research 4(4):295-348.

1997 "The Caddo Nation": Archaeological and Ethnohistoric Perspectives. The University of Texas Press, Austin.

1997 A Compendium of Radiocarbon and Oxidizable Carbon Ratio Dates from Archaeological Sites in East Texas, With a Discussion of the Age and Dating of Select Components and Phases in Radiocarbon 39(3):305-341.

1998 Late Caddoan Societies in the Northeast Texas Pineywoods. In The Native History of the Caddv: Their Place in Southeastern Archeology and Ethnohistory, edited by T K Perttula and J. E. Bruseth, pages 69-90. Studies in Archeology 30. Texas Archeological Research Laboratory, The University of Texas at Austin.

2004a The Prehistoric and Caddoan Archeology of the Northeast Texas Pineywoods. In The Prehistory of Texas, edited by Timothy K. Perttula, pages 370-407. Texas A\&M University, College Station.

2004b The Oak Hill Village Site in its Regional Context: The Middle Caddoan Period, ca. A.D. 1150-1400. In The Oak Hill Village (41RK214), Rusk County, Texas by Robert Rogers and Timothy K. Perttula, pages 23-42. Document No. 030083. PBS\&J, Austin.

2005 1938-1939 WPA Excavations at the Hatchel Site (41BW2) on the Red River in Bowie County, Texas. Southeastern Archaeology 24(2):180-198.

2009 Extended Entranceway Structures in the Caddo Archaeological Area. Southeastern Archaeology 28(1):27-42. 
Perttula, Timothy K. (editor)

1999 The Hurricane Hill Site (41HP106): The Archaeology of a Late Archaic/Early Ceramic and Early-Middle Caddoan Settlement in Northeast Texas. 2 Vols. Special Publication No. 4. Friends of Northeast Texas Archaeology, Pittsburg and Austin.

2005 Archeological Investigations at the Pilgrim's Pride Site (41CP304), a Titus Phase Community in the Big Cypress Creek Basin, Camp County, Texas. 2 Vols. Report of Investigations No. 30. Archeological \& Environmental Consultants, LLC, Austin.

2008 Lake Naconiche Archeology, Nacogdoches County, Texas: Results of the Data Recovery Excavations at Five Prehistoric Archeological Sites. 2 Vols. Report of Investigations No. 60. Archeological \& Environmental Consultants, LLC, Austin.

Perttula, Timothy K. and James E. Bruseth

1998 The Native History of the Caddo and Their Place in Southeastern Archeology and Ethnohistory in The Native History of the Caddo: Their Place in Southeastern Archeology and Ethnohistory, edited by T K. Perttula and J. E. Bruseth, pages 1-3. Studies in Archeology 30. Texas Archeological Research Laboratory, The University of Texas at Austin.

Perttula, Timothy K. and David B. Kelley (assemblers and editors)

2009 Archeological Investigations at the Lang Pasture Site (41AN38) in the Upper Neches River Basin of East Texas. Completed MS on file, Coastal Environments, Inc., Baton Rouge.

Perttula, Timothy K. and Robert Rogers

2007 The Evolution of a Caddo Community in Northeastern Texas: The Oak Hill Village Site (41RK214), Rusk County, Texas. American Antiquity 72(1):7194.

Perttula, Timothy K. and David L. Sherman

2009 Data Recovery Investigations at the Ear Spool Site (41TT653), Titus County, Texas. Document No. 070205. PBS\&J, Austin.

Perttula, Timothy K., Chester P. Walker, and T. Clay Schultz 2008 A Revolution in Caddo Archaeology: The Remote Sensing and Archaeological View from the Hill Farm Site (41BW169) in Bowie County, Texas. Southeastern Archaeology 27(1):93-107. 
Perttula, Timothy K. Mark Walters, and Bo Nelson

2010 Caddo Pottery Vessels and Pipes from Sites in the Big Cypress, Sulphur, Neches-Angelina, and Middle Sabine River Basins in the Turner and Johns Collections, Camp, Cass, Cherokee, Harrison, Morris, Titus, and Upshur Counties, Texas and Sabine Parish, Louisiana. Special Publication No. 10. Friends of Northeast Texas Archaeology, Austin and Pittsburg.

Perttula, Timothy K., Leslie L. Bush, LeeAnna Schniebs, Tom Middlebrook, and P. Shawn Marceaux

2010 An Early Historic Caddo Farmstead at the Henry M. Site (41NA60) in Nacogdoches County, Texas. Stephen F. Austin State University Press, Nacogdoches.

Perttula, Timothy K, James E. Bruseth, Nancy A. Kenmotsu, Daniel J. Prikryl, William

A. Martin, Larry Banks, Jimmy Smith, Nancy G. Reese, and Sergio A. Iruegas 2001 Archeological Investigations on the Red River and Tributaries: Summary of the Findings of the 1991 and 1992 Texas Archeological Society Field School in Red River and Lamar Counties, Texas. Bulletin of the Texas Archeological Society 72:165-250.

Rogers, J. Daniel

1982a Specialized Buildings in Northern Caddo Prehistory. In Southern Plains Archaeology, edited by Susan C. Vehik, pages 105-117. Papers in Anthropology 23(1). Department of Anthropology, University of Oklahoma, Norman.

1982b Spiro Archaeology. 1980 Research. Studies in Oklahomas Past No. 9. Oklahoma Archeological Survey, Norman.

Rogers, Robert and Timothy K. Perttula

2004 The Oak Hill Village (41RK214), Rusk County, Texas. Document No. 030083. PBS\&J, Austin.

Sabo, George

1995 Encounters and Images: European Contact and Caddo Indians. Historical Reflections/Reflexions Historiques 21(2):217242.

1998 The Structure of Caddo Leadership in the Colonial Era. In The Native History of the Caddo: Their Place in Southeastern Archeology and Ethnohistory, edited by Timothy K. Perttula and James E. Bruseth, pages 159-174. Studies in Archeology 30. Texas Archeological Research Laboratory The University of Texas at Austin. 
Schambach, Frank F.

1982 The Archeology of the Great Bend Region in Arkansas. In Contributions to the Archeology of the Great Bend Region, edited by Frank F. Schambach and Frank Rackerby, pages 1-11. Research Series No. 22. Arkansas Archeological Survey, Fayetteville.

1993 The End of the Trail: Reconstruction of the Route of Hernando de Soto's Army through Southwest Arkansas and East Texas. In The Expedition of Hernando de Soto West of the Mississippi, 1541-1543: Proceedings of the De Soto Symposia, 1988 and 1990, edited by G.A. Young and M.P. Hoffman, pages 78-105. University of Arkansas Press, Fayetteville.

1996 Mounds, Embankments, and Ceremonialism in the Trans-Mississippi South. In Mounds, Embankments, and Ceremonialism in the Midsouth, edited by Robert C. Mainfort and Richard Walling, pages 36-43. Research Series No. 46. Arkansas Archeological Survey, Fayetteville.

1998 Pre-Caddoan Cultures in the Trans-Mississippi South. Research Series No. 53. Arkansas Archeological Survey, Fayetteville.

Schambach, Frank F., and Jami J. Lockhart

2003 The 2001-2002 Investigations by the Arkansas Archeological Survey and the Arkansas Archeological Society at the Tom Jones Site (3HE40), a Late 14th, Early $15^{\text {th }}$ Century Caddo Mound Group in Southwest Arkansas, Paper presented at the 45th Annual Caddo Conference, Arkadelphia, AR.

Schambach, Frank F, Ann M. Early, E. Thomas Hemmings, David B. Kelley, and Michael Swanda

1983 Southwest Arkansas. In A State Plan for the Conservation of Archeological Resources in Arkansas, edited by Hester A. Davis. Research Series No. 21. Arkansas Archeological Survey, Fayetteville.

Schultz, T. Clay

2004 Space and Place: Architectural Space and Caddoan Cultural Practices. Paper presented at an invited session at the 2004 annual meetings of The American Society for Ethnohistory.

Schultz, T. Clay and Chester P. Walker

2006 Sensing Upper Nasoni: Archaeo-Geophysical Findings Near the Hatchel Site (41BW3). Paper presented at the $14^{\text {th }}$ annual East Texas Archeological Conference in Tyler, Texas.

Schultz, T. Clay, Chester P. Walker, Darrell Creel, Dale Hudler, and Samuel M. Wilson 2004 Magnetometer Survey and Intrasite Structure of an Early Caddo Site. Poster presented at the $69^{\text {th }}$ Annual Meeting of the Society for American Archaeology, Montreal, Quèbec, Canada. 
Skinner, S. A, R K Harris, and K. M. Anderson (editors)

1969 Archaeological Investigations at the Sam Kaufrnan Site, Red River County Texas. Contributions in Anthropology No. 5. Department of Anthropology, Southern Methodist University, Dallas.

Smith, F. Todd

1995 The Caddo Indians: Tribes at the Convergence of Empires 1542-1854. Texas A\&M University Press.

Spock, Carolyn

1977 An Analysis of the Architectural and Related Features at the George C. Davis Site. Master's thesis, Department of Anthropology, University of Texas, Austin.

Story, Dee Ann

1981 An Overview of the Archeology of East Texas. Plains Anthropologist 26(92):139-156.

1982 The Deshazo Site, Nacogdoches County Texas, Volume 1: The Site, Its Setting, Investigations, Cultural Features, Artifacts of Non-Native Manufacture, and Subsistence Remains. Texas Antiquities Permit Series No. 7. Texas Antiquities Committee, Austin.

1990 Cultural History of the Native Americans. In The Archeology and Bioarcheology of the Gulf Coastal Plain, by Dee Ann Story, Janice A. Guy, Barbara A. Burnett, Martha D. Freeman, Jerome C. Rose, D. Gentry Steele, Ben W. Olive, and Karl J. Reinhard, pages 163-366. Research Series No. 38. 2 Vols. Arkansas Archeological Survey, Fayetteville.

1995 The Deshazo Site, Nacogdoches Count; Texas, Volume 2: Artifacts of Native Manufacture. Studies in Archeology 21. Texas Archeological Research Laboratory, The University of Texas at Austin.

1998 1968-1970 Archeological Investigations at the George C. Davis Site, Cherokee County, Texas. Bulletin of the Texas Archeological Society 68:1103.

1998 The George C. Davis Site: Glimpses into Early Caddoan Symbolism and Ideology. In The Native History of the Caddo: Their Place in Southeastern Archeology and Ethnohistory, edited by Timothy K. Perttula and James E. Bruseth, pages 9-43. Studies in Archeology 30. Texas Archeological Research Laboratory The University of Texas at Austin.

1999 Introduction. In The George C. Davis Site, Cherokee County, Texas, by H. Perry Newell and Alex D. Krieger, pp. 1-31. $2^{\text {nd }}$ Edition. Society for American Archaeology, Washington, D. C. 
Sullivan, Lynne P. and Christopher B. Rodning

2001 Gender, Tradition, and the Negotiation of Power Relationships in Southern Appalachian Chiefdoms in The Archaeology of Traditions: Agency and History Before and After Columbus edited by Timothy R. Pauketat, pages 107-120. University of Florida Press, Gainesville.

Sundermeyer, Scott A., John T. Penman, and Timothy K. Perttula

2008 Integrated Cultural Resources Investigations for the Bowie County Levee Realignment Project, Bowie County, Texas and Little River County, Arkansas. Miscellaneous Reports, Report of Investigations No. 29. Lopez Garcia Group, Dallas, Texas.

Swanton, John R.

1942 Source Material on the History and Ethnology of the Caddo Indians. Bulletin 132. Bureau of American Ethnology, Smithsonian Institution, Washington, D.C..

Texas Archeological Research Laboratory

n.d. $\quad$ Binder No. 2: ET-30 Mound, Phases "A" to "F." Field Notes Site ET-30, A. J. Hatchel Place, 11 Miles Northwest of Texarkana, Bowie County, Texas, Excavated from November 1, 1938 to August 25, 1939. On file, Texas Archeological Research Laboratory, The University of Texas at Austin.

Thurmond, J. Peter

1990 Archeology of the Cypress Creek Drainage Basin, Northeastern Texas and Northwestern Louisiana. Studies in Archeology 5. Texas Archeological Research Laboratory, The University of Texas at Austin.

Tilley, C.

1994 A Phenomenology of Landscape: places, paths, and monuments. Oxford: Berg Publishers.

Trubitt, Mary Beth

2009 Burning and Burying Buildings: Exploring Variation in Caddo Architecture in Southwest Arkansas. Southeastern Archaeology 28(2):233-247.

Turner, Robert L. and James E. Smith II 2002 The Harold Williams Site (41CP10) and the Texas Archeological Society Field School of 1967. Bulletin of the Texas Archeological Society 73:1-68.

Vogel, Gregory

2005 Civic Ceremonial Centers and Landscape Relationships in the Northern Caddo Area. Ph.D. dissertation, Environmental Dynamics Program, University of Arkansas, Fayetteville. 
Walker, Chester P.

2009 Landscape Archaeogeophysics: A Study of Magnetometer Surveys from Etowah (9BW1), the George C. Davis Site (41CE19), and the Hill Farm Site (41BW169). Ph.D. Dissertation, Department of Anthropology, The University of Texas at Austin.

Walker, Chester P. and T. Clay Schultz

2008 Magnetometer Survey and Results. In Integrated Cultural Resources Investigations for the Bowie County Levee Realignment Project, Bowie County, Texas and Little River County, Arkansas, by Scott A. Sundermeyer, John T. Penman, and Timothy K. Perttula, pages 167-183. Miscellaneous Reports, Report of Investigations No. 29. Lopez Garcia Group, Dallas, Texas.

Walters, Mark and Patti Haskins

1998 Archaeological Investigations at the Redwine Site (41SM193), Smith County, Texas. Journal of Northeast Texas Archaeology 11:1-38.

2000 The Bryan Hardy Site (41SM55), Smith County, Texas. Journal of Northeast Texas Archaeology 12:1-26.

Webb, Clarence $\mathrm{H}$.

1940 House Types Among the Caddo Indians. Bulletin ofthe Texas Archeological and Paleontological Society 12:49-75.

1959 The Belcher Mound, a Stratified Caddoan Site in Caddo Parish, Louisiana. Memoirs No. 16. Society for American Archaeology, Salt Lake City.

1983 The Bossier Focus Revisited: Montgomery I, Werner, and Other Unicomponent Sites. In Southeastern Natives and Their Pasts, edited by Don G. Wyckoff and Jake L. Hofman, pages 183-240. Studies in Oklahoma's Past No. 11. Oklahoma Archeological Survey, Norman.

Wedel, Mildred

1978 La Harpe's 1719 Post on Red River and Nearby Caddo Settlements. Bulletin No. 30. Texas Memorial Museum, Austin.

Wesson, C.

1997 Households and Hegemony: An Analysis of Historic Creek Culture Change. $\mathrm{Ph}$.D. dissertation, University of Illinois at Urbana-Champaign, Department of Anthropology.

Wilmsen, E. N.

1961 A Suggested Developmental Sequence for House Forms in the Caddoan Area. Bulletin of the Texas Archeological Society 30:35-49. 
Wilson, Samuel M. and T. Clay Schultz

n.d. 2003 Investigations at Caddoan Mounds State Historic Site, The George . Davis Site (41CE19), Cherokee County, Texas. Draft Report in preparation.

Woodall, J. Ned

1967 The Harold Williams Site - A Preliminary Statement. Texas Archeology 11(4):7-10.

Wyckoff, Don G. and Timothy G. Baugh

1980 Early Historic Hasinai Elites: A Model for the Material Culture of Governing Elites. Midcontinental Journal of Archaeology 5:225-283.

Yaeger, J. and M. Canuto

2000 Introducing an Archaeology of Communities. In The Archaeology of Communities: A New World Perspective. New York: Routledge. 